\title{
Lucien Febvre (1878-1956)
}

historien français, fondateur de l'École des Annales qu'il a fondée avec Marc Bloch.

$(1912)$

\section{PHILIPPE II \\ ET LA FRANCHE-COMTÉ ÉTUDE D’HISTOIRE POLITIQUE, RELIGIEUSE ET SOCIALE}

Un document produit en version numérique par Réjeanne Toussaint, ouvrière bénévole, Chomedey, Ville Laval, Québec

Page web personnelle. Courriel: rtoussaint@aei.ca

Dans le cadre de la collection: "Les classiques des sciences sociales"

Site web: http://classiques.uqac.ca/

Une bibliothèque fondée et dirigée par Jean-Marie Tremblay, sociologue

Une collection développée en collaboration avec la Bibliothèque Paul-Émile-Boulet de l'Université du Québec à Chicoutimi Site web: http://bibliotheque.uqac.ca/ 


\section{Politique d'utilisation de la bibliothèque des Classiques}

Toute reproduction et rediffusion de nos fichiers est interdite, même avec la mention de leur provenance, sans l'autorisation formelle, écrite, du fondateur des Classiques des sciences sociales, Jean-Marie Tremblay, sociologue.

Les fichiers des Classiques des sciences sociales ne peuvent sans autorisation formelle:

- être hébergés (en fichier ou page web, en totalité ou en partie) sur un serveur autre que celui des Classiques.

- servir de base de travail à un autre fichier modifié ensuite par tout autre moyen (couleur, police, mise en page, extraits, support, etc...),

Les fichiers (.html, .doc, .pdf., .rtf, .jpg, .gif) disponibles sur le site Les Classiques des sciences sociales sont la propriété des Classiques des sciences sociales, un organisme à but non lucratif composé exclusivement de bénévoles.

Ils sont disponibles pour une utilisation intellectuelle et personnelle et, en aucun cas, commerciale. Toute utilisation à des fins commerciales des fichiers sur ce site est strictement interdite et toute rediffusion est également strictement interdite.

L'accès à notre travail est libre et gratuit à tous les utilisateurs. C'est notre mission.

Jean-Marie Tremblay, sociologue

Fondateur et Président-directeur général, LES CLASSIQUES DES SCIENCES SOCIALES. 
Cette édition électronique a été réalisée par Réjeanne Toussaint, bénévole, Courriel: rtoussaint@aei.ca

Lucien Febvre (1878-1956)

historien français, fondateur de l'École des Annales qu'il a fondée avec Marc Bloch.

PHILIPPE II ET LA FRANCHE-COMTÉ. Étude d'histoire politique, religieuse et sociale.

Texte intégral de la thèse de doctorat publiée originalement en 1912 par la Librairie ancienne Honoré Champion. Paris : Les Éditions Flammarion, 1970, 538 pp. Collection : Science de l'histoire.

Polices de caractères utilisée :

Pour le texte: Times New Roman, 12 points.

Pour les citations : Times New Roman, 12 points.

Pour les notes de bas de page : Times New Roman, 12 points.

Édition électronique réalisée avec le traitement de textes Microsoft Word 2004 pour Macintosh.

Mise en page sur papier format : LETTRE (US letter), 8.5’’ x 11’’)

Édition numérique réalisée le 16 août 2009 à Chicoutimi, Ville de Saguenay, province de Québec, Canada. 


\section{Lucien Febvre (1878-1956)}

historien français, fondateur de l'École des Annales qu'il a fondée avec Marc Bloch.

\section{PHILIPPE II ET LA FRANCHE-COMTÉ. Étude d'histoire politique, religieuse et sociale.}

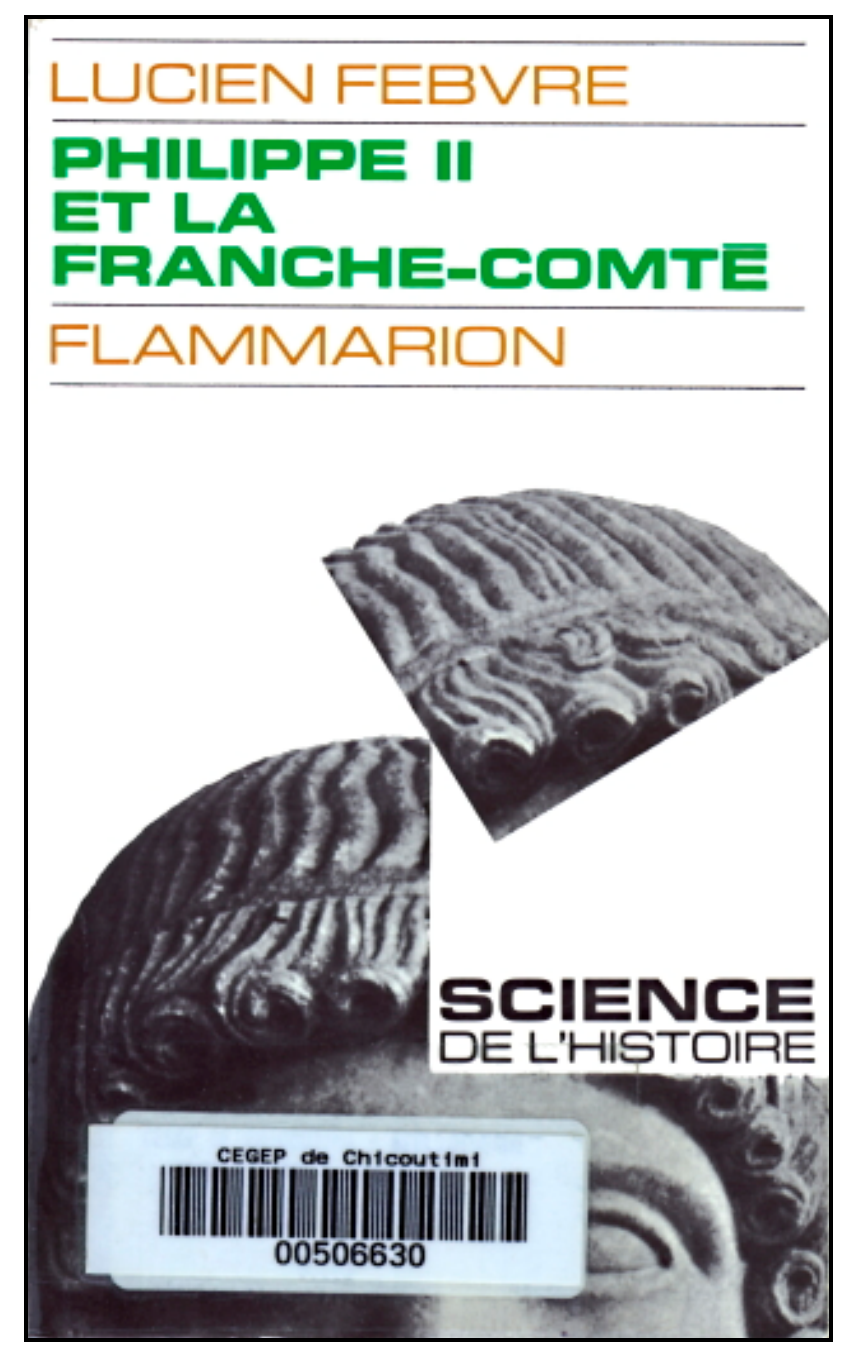

Texte intégral de la thèse de doctorat publiée originalement en 1912 par la Librairie ancienne Honoré Champion. Paris: Les Éditions Flammarion, 1970, 538 pp. Collection : Science de l'histoire. 


\section{Table des matières}

Quatrième de couverture

PRÉFACE

AVANT-PROPOS

\section{PREMIÈRE PARTIE \\ LA COMTÉ À LA VEILLE DU RÈGNE DE PHILIPPE II}

\section{Chapitre I. $\quad \underline{\text { LE PAYS }}$}

I. La Comté du Nord. Les plateaux et le haut val de Saône. Marches comtoises et terres de surséance, l'Ognon.

II. Entre Doubs et Ognon : l'isthme calcaire. La route du Rhône au Rhin. Dole et la forêt de Chaux

III. La Bourgogne de campagne : Bresse comtoise, Finage, Vignoble. Routes et marchés. Salins

$\underline{\text { IV. }} \quad$ Le Jura. Plateaux et vals. Défricheurs et colons. Les divisions naturelles. La Comté méridionale

$\underline{\text { V. }} \quad$ Variété du pays comtois. Le bon pays qui se suffit en tout

\section{Chapitre II. $\quad$ L'ÉTAT COMTOIS ET SES ORIGINES}

I. La Comté, province perdue, État sans souveraineté. - Les origines : la Séquanie ; la Comté du Moyen âge

II. La crise de 1477. Impériaux, Suisses ou Français ? L'idéal bourguignon. L'oeuvre de Marguerite et de Maximilien

III. Les conventions diplomatiques : Ligue héréditaire et neutralité

IV. Charles-Quint : le comte et l'Empereur ; la Comté et l'Empire. Les fortifications et la neutralité

V. $\quad$ Persistance de l'esprit bourguignon

\section{Chapitre III. $\quad$ LE GOVERNEMENT}

I. La Comté et le gouvernement des Pays-Bas. Éloignement des deux pays

II. Le gouvernement local. Gouverneurs en titre et lieutenantsgouverneurs. Les bons personnages 
III. Le Parlement. Fonctions judiciaires, fonctions politiques. Origines et composition

$\underline{\text { IV. }}$ Conseillers et gouverneurs. Le pouvoir aux mains des légistes bourgeois

$\underline{V}$. Les États. Le don gratuit. Droits politiques de l'assemblée

VI. Équilibre des institutions comtoises sous Charles-Quint - mais équilibre précaire

\section{Chapitre IV. PROSPÉRITÉ MATÉRIELLE ET NATIONALITÉ}

I. La Comté s'agrandit, consolide ses frontières sous Charles-Quint

II. $\quad$ Elle possède en elle toutes ses nécessités

III. La renaissance agricole et industrielle. Multiplication de la population

$\underline{\mathrm{IV}}$. Naissance et formation d'un sentiment national comtois

$\underline{\mathrm{V}}$. Conclusion : la Comté à la veille du règne de Philippe II

\section{DEUXIÈME PARTIE \\ LES DÉBUTS DU RÈGNE DE PHILIPPE II \\ NOBLESSE ET BOURGEOISIE}

\section{Chapitre V. $\quad$ L'AVÈNEMENT DE PHILIPPE Il}

L'abdication de Charles-Quint en Comté

I. Impopularité de Philippe II à ses débuts : les partisans de Maximilien

II. Les premiers actes du nouveau Comte : son avènement seul est une révolution

III. Les Granvelle. La question d'avenir pour l'évêque d'Arras

IV. Simon Renard ; sa rupture avec Antoine Perrenot

$\underline{\mathrm{V}}$. Les adversaires des Perrenot dans la noblesse comtoise. Les Rye et l'affaire Bonvalot

\section{Chapitre VI. GRAVELLE, SIMON RENARD ET LA NOBLESSE COMTOISE}

I. L'affaire Quiclet

II. Son importance politique : Renard mis en cause

III. Autres conséquences du nouveau règne : les nobles comtois renvoyés de la cour. Leur turbulence

$\underline{\text { IV. }} \quad$ En Comté, pas d'emploi pour eux : leur haine des robins

$\underline{\mathrm{V}}$. Importance politique de cet antagonisme : ses causes économiques 


\section{Chapitre VII. LA NOBLESSE ET LES SEIGNEURIES}

Que rapporte la terre noble au gentilhomme ?

I. $\quad$ Les alleux : leur petit nombre. - Les seigneuries : leur multiplicité et leur variété

II. Parties constitutives de la seigneurie : Le domaine proche : la réserve

III. Les granges ; leur rapport

$\underline{\text { IV. }}$ Les engins : moulins, foules, battoirs, etc.

$\underline{V}$. Droits du seigneur sur les tenures nobles (fiefs) et roturières (censives)

VI. Id., sur les tenures mainmortables. Lods et retenue

VII. Les droits domaniaux ; leur variété

VIII. Double assaut contre eux : du souverain, des tenanciers

$\underline{\underline{X}}$. La seigneurie, legs du passé, ne répond plus aux nouveaux besoins

$\underline{X}$. L'augmentation des revenus seigneuriaux, plus apparente que réelle. Exemples

Chapitre VIII. LES SOURCES DE LA FORTUNE BOURGEOISE : LE COMMERCE, L'USURE, LA CONQUÊTE DE LA TERRE PAYSANNE

I. Le commerce. Maîtres de métiers et marchands. L'accaparement

II. L'usure. Exploitation du paysan

III. La terre paysanne passe aux prêteurs. Mécanisme de l'opération

$\underline{\text { IV. }}$ Importance, extension de ce transfert

$\underline{\text { V. }} \quad$ Ce que le bourgeois fait de la terre paysanne. Reventes ou constitution de granges

VI. Les locations de bétail : la commandise

\section{Chapitre IX. LES OFFICES, LA ROBE, LA CONQUÊTE DE LA} TERRE NOBLE

I. $\quad$ Les petits robins : huissiers, receveurs, notaires

II. Docteurs et officiers : gages, cumuls, comparaison avec les gentilshommes

III. Multiplication des offices. La caste des robins. Mariages et dynasties

$\underline{\text { IV. }}$ Le bourgeois à l'attaque de la seigneurie. Il l'administre. Il la loue

$\underline{V}$. Créancier du noble, il la lui achète à rachat

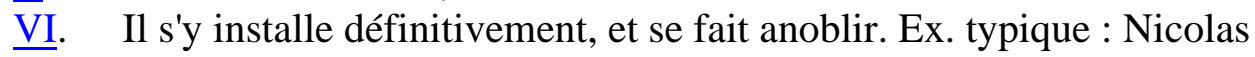
Perrenot

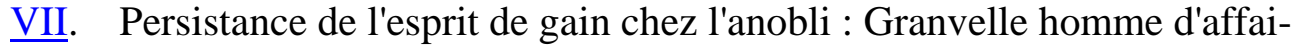
res 


\section{Chapitre X. LA VIE BOURGEOISE}

Diversité des conditions bourgeoises ; similitude des intérêts et des sentiments

I. Le bourgeois homme d'action. Ses voyages; ses campagnes

II. La recherche du profit

III. Le mariage ; le ménage bourgeois

$\underline{\mathrm{IV}}$. Le savoir, source de la puissance bourgeoise

$\underline{\mathrm{V}}$. Souci de l'instruction. Collèges et pédagogues. Le luxe et la culture des anoblis

\section{Chapitre XI. LA VIE NOBLE}

Le noble entendu aux affaires : rareté du type

I. Charges qui pèsent sur lui : le rang à soutenir. Dépenses des morts, dépenses des vivants

II. $\quad$ La guerre et ses dépenses

$\underline{\text { III. }} \quad$ L'instruction du noble : ce qu'elle représente pour lui

$\underline{\text { IV. }}$ Le mariage : les belles dots

$\underline{V}$. Concurrence du noble étranger

$\underline{\text { VI. }} \quad$ Les mariages mixtes ; leur rareté. Revanches d'amour-propre : l'étiquette. Nobles et anoblis

\section{TROISIÈME PARTIE \\ LA COMTÉ ET LA RÉVOLUTION DES PAYS-BAS}

\section{Chapitre XII. GUILLAUME D'ORANGE EN FRANCHE-COMTÉ}

I. Marguerite de Parme, Granvelle et la Consulta. Guillaume d'Orange gouverneur du Comté. Le domaine de Chalon

II. Importance de la nomination de Guillaume. Fr. de Vergy lieutenantgouverneur

III. Guillaume adversaire de Granvelle ; derrière lui, les Rye

$\underline{\mathrm{IV}}$. Campagne contre Granvelle en Comté. Renard. L'épée contre la robe

$\underline{\text { V. }} \quad$ Duel de Renard et de Granvelle. Disgrâce du cardinal

VI. Granvelle en Comté. Disgrâce de Renard 


\section{Chapitre XIII. LA MISSION DE MORON}

I. Moron, ses projets, sa mission

II. Débuts maladroits des enquêteurs

III. L'enquête à la Saunerie et les Perrenot

$\underline{\mathrm{IV}}$. L'enquête sur le domaine : les engagères

$\underline{V}$. Les États de décembre 1564 : succès des Granvellistes

VI. Fin de Moron. Échec politique de sa tentative

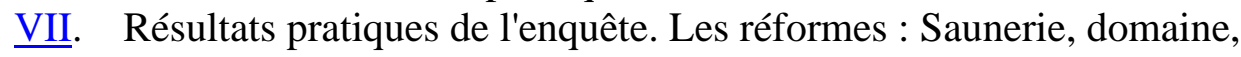
bailliages.

\section{Chapitre XIV. BESANCON, LA RÉFORME ET LA FRANCHE-COMTÉ}

I. Conditions favorables à la Réforme : la population bisontine, sa variété

II. Les conditions politiques et municipales

III. La Réforme bisontine, les Suisses et la Comté

IV. L'avènement de Philippe II et ses conséquences à Besançon. Les évènements de 1560

$\underline{\text { V. }} \quad$ Progrès de la Réforme dans la ville : leur importance pour le Comté

\section{Chapitre XV. LA RÉFORME EN COMTÉ}

Difficultés de la propagande réformée en Comté

I. Les débuts. Les premières crises

II. Progrès de la Réforme au début du règne de Philippe

III. Petit nombre des poursuites contre les Comtois

$\underline{\mathrm{IV}}$. Soupçons de partialité chez les conseillers

$\underline{\text { V. }} \quad$ L'Église comtoise. Impuissance de ses chefs

VI. Chanoines, religieux et prêtres : besoins urgents de réforme

VII. L'archevêque de la Baume et les nobles anti-ranvellistes

\section{Chapitre XVI. LES GUEUX ET LA COMTÉ. LA CONFRÉRIE DE SAINTE-BARBE}

Divisions profondes en Comté. Seconde disgrâce de Granvelle

I. La succession du président Desbarres. Claude Belin candidat de Granvelle

II. Les nobles comtois et les Gueux. Andelot. Les Rye. Confrérie de Sainte-Barbe

III. Troubles de Salins : leurs origines municipales, sociales et religieuses

$\underline{\mathrm{IV}}$. Inaction relative des conseillers ; leurs ambitions, leurs incertitudes

$\underline{\mathrm{V}}$. On espère la venue du roi 


\section{Chapitre XVII. LE PASSAGE DU DUC D'ALBE}

I. Récit du passage. Conséquences matérielles et politiques

II. Les nobles comtois reprennent du service et relèvent la tête

III. Le Parlement se réveille. Interventions du roi et de Pie V

$\underline{\text { IV. }}$ Belin aux Pays-Bas. Ses partialités. Enquête sur les Rye

V. Confiscation du domaine de Chalon ; ruine de Renard

VI. F. de Lannoy et les arrestations de Salins : le Parlement dessaisi

VII. Retour de Belin en Comté

\section{Chapitre XVIII. LE PASSAGE DU DUC DE DEUX-PONTS}

I. Activité militaire des nobles comtois en 1567 et 1568 . Leur présomption

II. Les États de 1569

III. Invasion de Wolfgang. Trahison de Citey

$\underline{\underline{I V}}$. Le bailliage d'Amont ravagé par les reîtres. Impuissance des Comtois

$\underline{\mathrm{V}}$. Fureur des bourgeois après l'invasion; leurs attaques contre les nobles

VI. Réponse des gentilshommes : l'affaire Demongenet

\section{QUATRIÈME PARTIE}

\section{LES PROGRÈS DE L'ABSOLUTISME; LA COMTÉ NOUVELLE}

\section{Chapitre XIX. LES RÉFORMES : L'ÉGLISE}

I. $\quad$ Pie V et Claude de la Baume

II. L'inquisition diocésaine en Comté

III. Tentative d'installation de l'Inquisition romaine

IV. Publication du Concile de Trente

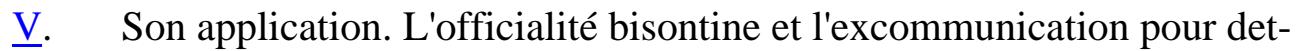
tes

\section{Chapitre XX. LES RÉFORMES : L'UNIVERSITÉ DE DOLE}

I. $\quad$ L'interdiction d'étudier de 1570

II. L'Université de Dole. Prospérité des études juridiques

III. L'ordonnance réformatrice du duc d'Albe

IV. Ses conséquences : recrutement de l'Université 


\section{Chapitre XXI. LES RÉFORMES : LE PARLEMENT}

I. Intentions réformatrices du duc d'Albe : Saunerie, domaine

II. Il s'attaque à la cour. Nécessité d'une réforme

III. Blasere et Mesabarba en Comté. Les suspensions

$\underline{\text { IV. }} \quad$ Trouble profond en Comté. L'affaire Roussel, la Réforme à Ornans

V. Conséquences de la mission Blasere : Pierre Froissard président de Bourgogne

VI. Publication des Ordonnances de 1573 : leur analyse

VII. Les articles secrets

\section{Chapitre XXII. L'AFFAIRE DES ORDONNANCES ET LES ÉTATS DE} $\underline{1514}$

I. Difficulté de la situation. Requesens successeur d'Albe

II. Convocation des États : gravité de cette mesure

III. Les délibérations. La commission des Neuf

IV. La mort de Froissard

\section{Chapitre XXIII. LE GOUVERNEMENT DE DON JUAN}

I. Délégation aux Pays-Bas. Concessions de Requesens. Mission de Boisset

II. Délégation en Espagne. Négociations avec les États-Généraux des Pays-Bas

III. Don Juan ; son caractère, son entourage ; discrédit de la robe

$\underline{\text { IV. }}$ Faveur de Vergy et des corne-guerre

$\underline{V}$. Armements et pillages en Comté

VI. Impuissance et division du Parlement

\section{Chapitre XXIV. LA RENTRÉE DE GRANVELLE}

I. Alternatives de faveur et de disgrâce pour le cardinal. Son programme

II. Les États de 1579

III. Le Parlement reste en défaveur

IV. La Réforme en Comté. Voyage de Marguerite. Granvelle, Froissard et Fonck

V. Les ordonnances de 1586. Consécration des efforts antérieurs. La fin d'une génération 
Chapitre XXV. CONCLUSION : LA COMTÉ EXPLOITÉE ET SACRIFIÉE

I. Ce qu'est la Comté : une route militaire. Passages de troupes

II. Les exploits des munitionnaires

III. La Comté dépouillée de ses soldats et de ses deniers

IV. Accroissement des charges, diminution des revenus

$\underline{\mathrm{V}}$. Les mauvaises années, la misère

$\underline{\text { VI. }} \quad$ Les institutions faussées : Résultats de la politique d'absolutisme

\section{INDEX}

DOCUMENTS ET OUVRAGES UTILISÉS 


\section{L’ÂGE DES FOULES.}

Un traité historique de psychologie des masses.

\section{QUATRIÈME DE COUVERTURE}

Retour à la table des matières

«Ce qui nous intéresse, c'est moins une certaine région à une certaine date qu'à un moment déterminé de son évolution une personne historique collective, trouvant dans un état son expression politique... Ce que nous allons essayer de décrire, ce n'est pas seulement un épisode local du grand conflit qui, partout alors, mettait aux prises avec la Réforme et les libertés provinciales l'absolutisme catholique et monarchique. C'est la lutte, c'est la combat acharné de deux classes rivales : noblesse et bourgeoisie. Lutte pour le pouvoir, pour l'influence, pour la domination politique: sans doute, mais les causes profondes de l'antagonisme, ne sont-elles pas ailleurs? C'est dans l'analyse, aussi poussée que possible, des conditions d'existence contemporaines que nous chercherons du moins à les trouver. »

L. F. 


\section{À mon ami Henri Wallon}




\section{PHILIPPE II ET LA FRANCHE-COMTÉ \\ Étude d'histoire politique, religieuse et sociale. \\ PRÉFACE}

$\underline{\text { Retour à la table des matières }}$

Je suis heureux de présenter à un large public le premier livre, le premier chefd'oeuvre de Lucien Febvre - Philippe II et la Franche-Comté - soumis comme thèse de doctorat ès lettres à la Sorbonne, en 1911. Lucien Febvre a alors trentetrois ans, mais tel Michelet, au seuil d'une longue vie de travail, il se trouve déjà en pleine possession de son multiple talent. Les années d'apprentissage sont derrière lui, toutes les formes de l'histoire lui sont accessibles, toutes le séduisent, et son style a déjà son éclat, sa vraie couleur.

Inutile évidemment d'analyser cet ouvrage classique qui s'affirme de lui-même dans sa richesse et son étonnante précocité. Notez qu'il prend aujourd'hui sa place, sans signaler le moins du monde son âge, auprès des plus belles thèses d'histoire régionale, soutenues hier: Beauvais et le Beauvaisis, de Pierre Goubert, la Basse Provence de René Baehrel, les éblouissants Paysans de Languedoc d'Emmanuel Le Roy Ladurie. Il est leur compagnon, tout en ayant été leur prédécesseur.

Que Lucien Febvre ait été le plus grand historien de langue française de notre époque, chacun le sait. Mais à mesure que les années passent, son rôle éminent s'estompe, se perd de vue, ce qui est triste, assez logique pourtant. Car Lucien Febvre aura été victime de sa générosité même, il a beaucoup donné, sans compter, sans réclamer ensuite son propre bien. Il a mis une sorte d'acharnement à pousser ses élèves, ses disciples, ses amis jusqu'au plan de leur propre perfection. 
Marc Bloch, plus jeune que lui, lui a dû de franchir bien des difficultés. Moimême, il m'a sorti de mes doutes et de mes hésitations. Le vrai rôle de Lucien Febvre dans la vie intellectuelle de la France ne s'affirmerait que si sa volumineuse correspondance était publiée un jour. Il le souhaitait lui-même. Le sera-t-elle ? Un sort malin s'acharne à la fois contre elle et contre son oeuvre inédite. A la veille de sa mort, en septembre 1956, Lucien Febvre avait achevé la mise au point de son dernier livre, Honneur et Patrie. Le manuscrit en a bizarrement disparu. Je désespère qu'il puisse paraître un jour sous la signature de son auteur. Quant aux nombreux cours qu'il a professés au Collège de France ou à Strasbourg, à l'inverse de ceux de Marc Bloch entièrement rédigés, ils ne sont représentés que par des notes incomplètes, abondantes mais impubliables telles quelles. Pour aboutir à un texte, il faudrait compléter, réécrire, faire ce que Camille Jullian aura fait pour les manuscrits de Fustel de Coulanges. D'aucuns ont pensé que ce serait un service discutable à rendre à la mémoire de Lucien Febvre que de retraduire en quelque sorte sa pensée, dans un style qui ne serait plus tout à fait le sien.

Tout ceci explique que je me sois employé à la réédition de son premier grand livre. Au moment où viennent de sortir de nouvelles éditions de la Terre et l'Évolution humaine, de la Religion de Rabelais, du Luther, je me réjouis particulièrement que la collection Science, ouverte à un très large public, mette àla disposition des étudiants et des amateurs d'histoire, le moins connu, le plus divers de ses ouvrages.

Fernand Braudel. 


\author{
PHILIPPE II ET LA FRANCHE-COMTÉ \\ Étude d’histoire politique, religieuse et sociale.
}

\title{
AVANT-PROPOS
}

$\underline{\text { Retour à la table des matières }}$

Nous nous sommes proposé, dans le travail qui va suivre, d'étudier la vie intérieure d'une individualité politique : la Franche-Comté, pendant une des périodes les plus vivantes de son histoire : la seconde moitié du XVIe siècle.

Ce qu'implique ce dessein, ce qu'il exclut aussi, on le voit nettement. Il ne s'agit point pour nous d'inventorier successivement, dans une série de chapitres méthodiquement juxtaposés, tous les faits intéressants de tous les ordres - politiques, administratifs, religieux, économiques - qui se sont manifestés, un demisiècle durant, dans les limites d'une circonscription territoriale donnée. Ce qui nous intéresse, c'est moins une certaine région à une certaine date qu'à un moment déterminé de son évolution une personne historique collective, trouvant dans un État son expression politique. - Mais d'autre part, comment se borner à décrire cette évolution, pendant quelques années, de formes politiques et d'institutions particulières ? Ces institutions et ces formes, leurs changements, leurs variations s'expliquent par l'action multiple de causes profondes, par le conflit, la collaboration de toute une série d'influences, de passions, d'intérêts, - et c'est le jeu de tels éléments qui, précisément, constitue cette vie intérieure dont nous voudrions rendre la richesse complexe.

La petite Comté, parmi les États secondaires de l'Europe, présente au milieu du XVIe siècle un aspect original. De son passé tourmenté, elle retient encore les 
deux traits les plus caractéristiques. D'une part, vis-à-vis des grandes nationalités, elle garde, elle réserve son indépendance. Française de langue, de coutumes, d'esprit, elle ne s'est point fondue comme le Dauphiné, la Provence ou la Bourgogne proche, dans l'unité du grand royaume voisin. D'autre part, elle ne s'incarne pas, ne se résume pas tout entière dans une dynastie née de son sol et vivant sur son sol dans un « seigneur naturel ». Elle a pour maître, une fois de plus, un étranger ; et les grands intérêts de Charles-Quint ne résident pas, sans doute, dans ce coin de terre médiocre et fidèle... Ainsi, libre de ses frontières, mais associée par son chef du dehors aux destinées souvent contradictoires d'une somme d'États disparates, la Comté ignore la véritable autonomie ; elle oscille, elle hésite entre deux types distincts de formations politiques : le type féodal du petit État provincial indépendant, et le type plus moderne de la province, fondue avec d'autres dans l'unité supérieure d'un grand État - sacrifiant aux avantages de la centralisation monarchique le trésor hérité de son particularisme.

Cette situation complexe et délicate fait l'intérêt profond de l'histoire comtoise vers le milieu du XVIe siècle. Pour continuer à vivre, dans l'Europe des Henri et des Philippe II, l'existence à demi solitaire dont elle goûtait depuis le début du siècle le tranquille archaïsme, la province ne devait pas veiller seulement aux périls d'une brusque agression, d'un rapt toujours possible. Il fallait également, il aurait fallu, que sa vitalité propre ne fût point amoindrie ; il aurait fallu, miracle impossible, qu'entendant résister à cette force d'unification qui, un peu partout, groupait en nations les provinces éparses, la Comté pût résister aussi à ces forces de centralisation, de concentration intérieure, à ces forces d'absolutisme qui, chez elle et pour elle, ne pouvaient être que des forces de ruine. Mais de cela précisément, moins que toute autre, elle était maîtresse. C'était la fatalité de sa situation qu'elle dépendît d'autrui - que ses destinées extérieures comme sa vie intérieure fussent à la merci d'un événement lointain, d'un épisode dynastique, d'un changement de souverain.

L'étude d'un événement de ce genre, l'analyse détaillée de ses conséquences, tel va être l'objet de nos efforts. Jouissant d'une organisation politique qui mettait en jeu ses forces vives; maintenue hors des conflits européens par des conventions de neutralité ; rattachée à d'autres domaines de son maître par un réseau de fils diplomatiques très souples - la Comté, vers 1550, laissant autour d'elle le temps couler plus rapide, poursuivait dans la confiance d'un avenir sans surprise 
toute une oeuvre obscure et patiente de réparation lente et d'enrichissement. L'avènement de Philippe II bouleversa tout pour elle.

Changement de personnes, certes ; changement de système, changement de milieu surtout - de ce milieu politique européen auquel la Comté, pour vivre, se devait adapter. Ce fut ainsi, avant même que le nouveau souverain parlât ou agît, tout l'équilibre intérieur de la province compromis et, pour de longues années, une crise ouverte de l'État comtois. Mais ce fut aussi, dans ce pays tranquille et comme assoupi, le brusque jaillissement d'un feu qui couvait un choc de passions violentes et d'appétits longtemps contenus.

La Comté avait bien pu, pendant des années, se replier toute dans son presque isolement : la vie profonde de ses habitants n'avait pas cessé d'être en harmonie avec celle de leurs contemporains. Ils avaient éprouvé les mêmes besoins intellectuels et moraux, subi le contrecoup des mêmes crises économiques, ressenti pleinement les mêmes malaises sociaux. Sous la paix apparente, les événements révélèrent bientôt des désaccords profonds d'idées et de sentiments, des rivalités de classes, des conflits d'intérêts. Causes obscures et profondes des résolutions humaines : lorsque Philippe II et ses ministres, un Granvelle, une Marguerite de Parme, un duc d'Albe surtout, entreprirent en Comté comme aux Pays-Bas leur oeuvre double d'absolutisme et de contre-réforme, ce furent elles en dernière analyse qui, à maint combattant, indiquèrent son parti et ses raisons d'agir.

Ainsi notre tâche apparaît complexe. Ce que nous allons essayer de décrire, ce n'est pas seulement un épisode local du grand conflit qui, partout alors, mettait aux prises avec la Réforme et les libertés provinciales l'absolutisme catholique et monarchique. C'est la lutte, c'est le combat acharné de deux classes rivales - noblesse et bourgeoisie. Lutte pour le pouvoir, pour l'influence, pour la domination politique : sans doute, mais les causes profondes de l'antagonisme, ne sont-elles pas ailleurs ? C'est dans l'analyse, aussi poussée que possible, des conditions d'existence contemporaines que nous chercherons du moins à les trouver.

Les difficultés d'une telle recherche, les objections que soulève un pareil dessein, nous ne les ignorons pas. Objections d'ordre théorique : ne les trouve-t-on pas souvent formulées ? Récemment encore, analysant le livre d'Henri Pirenne sur 
les Pays-Bas au temps de Charles-Quint ${ }^{1}$ - livre vraiment beau, et qui, paru lorsque notre travail depuis longtemps déjà était achevé dans sa conception sinon dans le détail de son exécution, nous a comme soutenu après coup de son autorité - un historien, Paul Fredericq, formulait ce jugement : « Je ne sais si, quand on ferme l'ouvrage, on a la sensation qu'au XVIe siècle les querelles théologiques ont dominé toutes choses et envahi toutes les âmes. On serait plutôt tenté de croire que le développement du capital et son corollaire, le prolétariat, rendent raison de tout - même de la diffusion de la Réforme... Je crois au contraire que, s'il fut jamais un siècle où les préoccupations matérielles cédèrent le pas à celles de la conscience, ce fut le XVIe siècle. » Question préalable que l'on peut dresser devant quiconque travaille à saisir les rapports, dans un pays et dans un temps donné, des idées politiques, des sentiments religieux et des faits économiques. Mais vraiment, est-il légitime de la poser ainsi ? Et que reste-t-il en définitive de l'objection, s'il est vrai, pour reprendre l'exemple même de P. Fredericq, qu'à ses partisans la Réforme apparut, dès le début, comme la plus complète expression de toutes leurs revendications, à la fois, et comme le meilleur moyen d'en assurer le triomphe ? Ils y mirent tout ce qui était en eux, leurs besoins de foi comme leurs aspirations politiques, leurs espérances sociales comme leurs désirs de certitude morale ; ils lui confièrent toutes leurs idées comme pour les abriter derrière son nom et en assurer par elle le succès. Ainsi l'oeuvre primitive de rénovation morale que des chrétiens avaient entreprise pour fonder en eux la foi profonde, enrichie subitement et comme élargie par tant d'apports divers, se trouva embrasser le siècle dans son ensemble - en présenter comme l'image exacte et le résumé complet. Combien vains, en ce cas, les débats de préséance entre la foi et l'intérêt, entre les processus économiques et les « querelles des théologiens » ?

Restent les difficultés matérielles - avant tout, celle de reconstituer à l'aide de textes épars et fragmentaires, au hasard des trouvailles et des survivances, sans le secours possible d'aucune donnée statistique - on devrait dire d'aucun chiffre - un État social et économique très différent du nôtre et dont l'interprétation à chaque instant soulève des problèmes impossibles à résoudre. Il faut bien que la tâche soit singulièrement ardue, pour qu'à cette heure encore, aucun historien en France, à notre connaissance du moins, ne l'ait abordée et n'ait mené à bien, sinon une étude

1 Dans la Revue historique, 33e année, t. XLVII, fasc. 193, mars-avril 1908, p. 417. 
d'ensemble, du moins, plus précise, plus profitable aussi, une monographie régionale de ces questions ? Raison de plus, sans doute, pour tenter l'aventure. On peut croire cependant que nous ne l'aurions pas entreprise, si nous n'avions dès maintenant le ferme dessein de continuer nos recherches dans la même direction et, peutêtre, de pouvoir remplacer un jour les indications que nous donnerons ici par l'esquisse - sommaire aussi et provisoire - de la formation, du progrès et du développement en Comté de cette classe bourgeoise, dont on célèbre si souvent, mais dont on étudie si rarement la puissance.

Ainsi se précise peu à peu le caractère de cette étude. Étude d'histoire provinciale, nettement circonscrite dans les limites étroites d'une contrée médiocre : sans doute. Mais chapitre détaché d'une histoire provinciale : non pas. C'est une crise que nous étudions dans ses origines, ses manifestations diverses et ses conséquences ; ce n'est ni un règne ni une section de règne que nous voulons décrire. Peutêtre, tel qu'il est, ce travail apportera-t-il quelque contribution à la connaissance générale du XVIe siècle, à l'histoire des formes politiques et des institutions, des luttes religieuses et des conflits sociaux. Peut-être aussi les historiens de la Révolution des Pays-Bas y trouveront-ils quelques renseignements complémentaires sur un pays et sur des hommes qui, à bien des titres, méritent de les intéresser. Mais s'il n'avait d'autre résultat, en définitive, que d'attirer l'attention sur l'importance, sur l'intérêt d'une histoire aussi riche, aussi variée que l'histoire comtoise nous n'estimerions pas notre effort inutile.

On néglige trop en vérité, en connaît trop imparfaitement encore l'histoire intérieure de ces provinces: Dauphiné, Savoie, Bresse, Franche-Comté, de ces membres épars des vieilles dominations, des royaumes éphémères d'Arles et de Bourgogne qui, sur les frontières, furent lentes à se rallier à l'unité française. Pays rudes, dont on sait le rôle protecteur. On en signale, avec Michelet, « le vigoureux génie de résistance et d'opposition »; on leur sait gré d'avoir abrité de leurs corps, préservé des coups les plus rudes les terres «fécondes des fruits de la pensée » auxquelles leur existence souffrante et tourmentée permit de cultiver, dans une paix relative, la fleur délicate de la civilisation. Mais leur passé encore a un autre intérêt. Ces terres françaises subissent, au cours de leur histoire indépendante, des influences extérieures très diverses. Ainsi, proches à la fois et différentes des provinces plus tôt ralliées au royaume, elles peuvent fournir souvent aux historiens de la France des témoignages utiles, des rapprochements féconds. Elles sont, dans 
une certaine mesure, comme autant de champs d'expérience et de comparaison installés, maintenus aux frontières par la vie et par les siècles mêmes. Sommesnous trop présomptueux dès lors en escomptant quelque profit d'une étude attentive des destinées comtoises à cette époque intéressante et trouble de la seconde moitié du XVIe siècle où trop souvent, en France, l'activité diplomatique et militaire des guerres de religion semble avoir caché aux érudits les réalités plus humbles de l'existence provinciale, les transformations plus obscures de la vie sociale? 
PHILIPPE II ET LA FRANCHE-COMTÉ

Étude d'histoire politique, religieuse et sociale.

\section{Première partie.}

La Comté

\section{à la veille du règne \\ de Philippe II}

$\underline{\text { Retour à la table des matières }}$ 


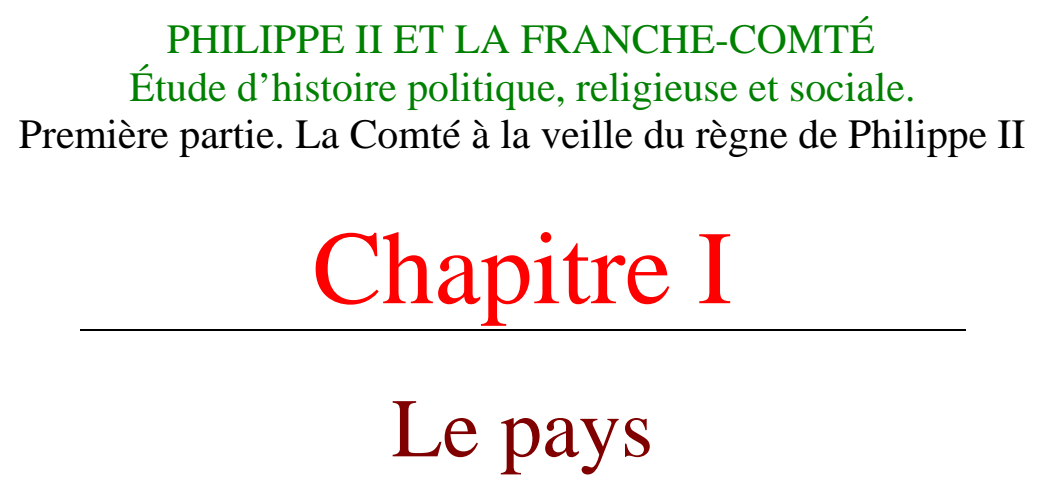

$\underline{\text { Retour à la table des matières }}$

C'est un nom d'origine historique, nullement géographique, que le nom relativement récent de Franche-Comté : il désigne un État, non un pays. Mais, tel que nous le saisissons au milieu du XVIe siècle, il résulte, comme toute formation politique, d'une collaboration étroite de forces naturelles et de forces humaines. Des conditions géographiques l'ont déterminé à chaque moment de son existence antérieure. Des conditions géographiques n'ont cessé de limiter dans une mesure variable, de diriger l'activité de ses maîtres et de ses habitants. Précisons-les d'abord. Avant d'établir sa situation vers 1556 ; avant d'isoler les éléments d'une crise décisive de son histoire, donnons à cette étude la « forte base » que réclamait Michelet ; à travers les documents d'archives, les textes fragmentaires d'une époque ignorante de toute statistique, essayons de montrer l'aspect région par région, de retracer l'image du pays comtois.

Rien d'homogène dans la Comté du nord - vaste région de plateaux et de dépressions qui, de l'Ognon aux Vosges, au seuil de Lorraine et au plateau de Langres, formait la majeure partie du bailliage d'Amont. 
Le centre même du pays était double. À l'est, entre Vesoul, Villersexel et Pesmes, s'étendaient des tables calcaires, un grand triangle de plateaux pierreux balayés des vents froids, couverts de bois maigres où se cachaient les loups. Dans les vallées, de rares villages groupaient autour de points d'eau leurs maisons en pierre grise, entourées de frênes, de charmes ou de noyers. Un sol rouge, peu profond, produisant froment et avoine ; des pâtures estimables mais peu abondantes ; pas d'industrie enfin : telle était cette contrée médiocre et peu variée.

Tout autre, à l'ouest, la région d'alluvions, de sables, de limons pliocènes que les plateaux dominent de Chariez à Pesmes. C'est le haut val de Saône - large dépression qui, par delà les limites comtoises, s'étend jusqu'au rebord du plateau de Langres. Dépression mouvementée, du reste. Partout, traversant la couche mince des remblais tertiaires et des limons, les rivières ont su mettre en relief les calcaires jurassiques. Elles modèlent, elles animent la région, et si parfois de grandes prairies mouillées « alentissent » leur cours, ce sont des travailleuses, promptes à circuler au travers des bois. Sur leurs bords, des forges, des fourneaux : il y en avait à Bougnon, près de Port, sur la Seyotte ; à Baignes, dans le verdoyant vallon de la Baignotte ; à Vy-le-Ferroux, de nom significatif ; plus loin, à Bley, à Échalonges. Tout le long de la Romaine, c'était le bruit rapide des martinets martelant la fonte à Pont-de-Planches, aux Bâties, à Estravaux, à Greucourt, tandis qu'autour des villages se heurtaient les charrettes convoyant la mine de la fouille au bocard, du bocard au fourneau, du fourneau à la forge ou menant à l'usine les bannes de charbon.

Pays double, double capitale. Au nord, assise dans une combe fertile, au bas d'une Motte escarpée dont un vieux château couronnait les cultures, Vesoul marquait la limite des plateaux et de la dépression. Ville médiocre et peu industrieuse : elle vivait surtout de son siège bailliager qui nourrissait un peuple de légistes envieux. - Gray, au sud, était de plus fort renom. Perchées d'abord sur la hauteur, ses maisons peu à peu étaient descendues par le ravin de la Grand'rue jusqu'au fleuve paisible qui coule à pleins bords vers Chalon et Lyon. Une campagne heureuse encadrait la cité ; à ses foires réputées affluaient blés du plateau, vins de Gy et de Morey, bétail des prairies, chevaux surtout : les gentilshommes comtois, lorrains et français venaient là chaque printemps acquérir les produits réputés de l'élevage comtois - de bonnes bêtes, «trottant un trot de renard qui n'ébranle l'homme », vites à la course et longues à la peine. - Ainsi Vesoul et Gray, les capi- 
tales d'Amont, reflétaient la fortune inégale des campagnes voisines. Leur horizon pourtant s'étendait au delà. Comme autant d'avenues vers l'étranger, un chapelet de pays intermédiaires entourait, précédait les plateaux, les collines et les bois du Comté : nouveau champ d'action, nouvelle zone d'influence pour les deux cités.

Au nord-est d'abord, un coin des Vosges : dur pays, de terre maigre, de climat rude. D'immenses forêts y couvraient les hauteurs, à Saint-Valbert, Saint-Bresson, Servance, Château-Lambert, Plancher-les-Mines. Dans les fourrés humides, dans les faignes tourbeuses, renards, loups, sangliers, ours même trouvaient de sûrs repaires. Des heures durant, on pouvait cheminer sous le couvert des arbres sans trouver de village. Au milieu du XVIe siècle, l'industrie n'avait pas encore pris possession de ces hautes terres boisées ; seules, avant 1560, quelques papeteries : Froideconche à l'abbaye de Luxeuil, Magny-Vernois à l'abbaye de Lure, s'étaient installées sur les rus clairs et froids ; les mines, malgré des demandes fréquentes, n'étaient pas exploitées avec méthode, et sur les croupes du ballon de Servance, les fourneaux de Miélin n'étaient pas édifiés. Par endroits cependant, la forêt défrichée laissait voir le sol maigre. Autour de Faucogney, vieille citadelle campée dès le haut Moyen Age sur le sillon du Breuchin, une contrée de plateaux assez accidentés, passablement peuplés, portait à sa surface d'innombrables étangs. Plus au sud, sur les alluvions du Breuchin et de l'Ognon, Luxeuil et Lure toutes deux serrées autour d'une abbaye, disaient les efforts des bûcherons monastiques.

À l'ouest des Vosges, la Vôge - le pays boisé du grès triasique. Nouvelle nature, nouveaux aspects - c'était un peu de Lorraine qui, par elle, se soudait aux plateaux d'Amont. Là, des bourgs indolents gardaient les abords du pays comtois : Conflans, point de passage réputé sur le Breuchin ; Faverney, groupant ses maisons trapues autour d'une abbaye ; Amance, bourg de marchands ; Jussey enfin, son cirque de près humides et ses chemins défoncés : l'enfer des rouliers et des voyageurs. Dans la Vôge même, peu d'agglomérations. Sur les cours d'eau, des scieries actives débitaient en planches les hêtres et les chênes ; centres de défrichement, ces usines rustiques faisaient reculer les bois autour d'elles - et des villages se formaient, d'aspect tout lorrain, que se disputaient les provinces limitrophes, Comté, Lorraine et Barrois. Contestée, la possession de Fougerolles, de Saint-Loup, celle de Montmotier, Magny, Tremouzey, des trois Fontenoy et de Vauvillers même ; contestés, autour de Jonvelle, Fresnes, Lironcourt, Grignoncourt, Bousseraucourt, Passavant, Vougécourt, Corre, Amenvelle ; au nord, Mon- 
thureux. Ces terres, grandes et petites, formaient ce qu'on appelait les « terres de surséance "; ne pouvant s'accorder sur leur possession, les États rivaux les avaient comme neutralisées jusqu'à règlement définitif ; du reste, travaillant également à se les annexer, ils ne tenaient pas à une solution ferme. Quant aux seigneurs, ils se trouvaient maîtres absolus des fiefs contestés ; leurs sentences judiciaires ignoraient les appels ; plusieurs s'attribuaient jusqu'au droit de monnaie. Seuls les sujets auraient pu protester : s'ils échappaient au fisc lorrain et au fisc comtois, c'était pour faire les frais des incidents de frontière sans cesse renaissants ; médiocre compensation, un renom de bons soldats trop chèrement payé.

Même situation par delà la Saône, dans la région de collines âpres et mornes qui de Gray conduisait en Champagne. Champlitte en était le centre et, barrant la route de Langres, la petite ville semblait se tourner vers la France. Des drapiers y faisaient des draps blancs ou blanchets, occasion de relations actives avec le royaume. Ils allaient à Langres, à Dijon, à Auxonne, à Sombernon surtout et dans l'Auxois se fournir de matière première ; par contre, les draps faits, les Français venaient les leur acheter pour les teindre à Dijon, Langres, Troyes ou Châtillon. D'ailleurs, c'était une famille d'origine française qui possédait la contrée presque tout entière. Vassaux à la fois du roi et du comte, mais suivant uniquement la fortune du second, les Vergy tenaient au nord-est Saint-julien et Morey, cette corniche calcaire ceinturée de vignes, au bout desquelles un village avancé semble dresser, face à la Champagne, son nom de Bourguignon. Pareillement, ils occupaient Leffond, Pierrecourt, Fouvent, les deux Champlitte, la baronnie d'Autrey. Villages disputés, contestés eux aussi entre Bourgogne, Champagne et Comté. Des terres considérables étaient en surséance : Villars-Saint-Marcellin et Raincourt ; plus bas, Charmes-Saint-Valbert, Farincourt, Suaucourt, Pisseloup, Tornay, Buxières, Fouvent-la-Ville ; Achey et Delain le long du Salon ; sur la Saône, Mantoche. En plus, quelques enclaves : Poinson, notoirement du Comté, était de toutes parts engagé en France ; Rigny, sur la Saône, Fresnes, sur la Romaine, restaient en plein Comté possession du roi de France, tandis qu'entre Duché et Comté, Chaume et Fontaine-Française étaient contestés. Là aussi, l'avantage était aux Comtois : vers 1560, au dire d'un Français, sur près de deux cents villages jadis en 
surséance, les trois quarts recouraient au Parlement de Dole. Ainsi se constituait « une nouvelle Comté par deçà la Saône 2 ».

De la proximité des pays étrangers, Gray et Vesoul profitaient toutes deux. Vers la seconde convergeaient les chemins du nord, ceux de Faucogney, de Lure, d'Épinal par Plombières et Luxeuil, de Fontenoy par Saint-Loup et Conflans ; aussi les marchands lorrains hantaient-ils ses foires ; ils y venaient rafler les bonnes monnaies locales et inonder la place d'espèces décriées. Ces opérations faites, ils pouvaient à leur gré rentrer dans leur pays, gagner par les routes du plateau la vallée du Doubs ou s'acheminer vers la Haute-Alsace par le chemin de Langres, Fayl-Billot, Port-sur-Saône, Vesoul et Villersexel où l'on passait l'Ognon.

Autour de Gray, même convergence de voies fréquentées, depuis Châtillon, Langres, Fontaine-Française. La plus importante était la Saône même. A Selles, sur le Coney, non loin des forges de Pont-du-Bois, une navigation active commençait: les habitants étaient, dès le XVe siècle, les principaux bateliers de la Saône ; c'étaient eux qui guidaient à travers les portières des moulins les lourds bateaux chargés de meules, de mortiers, de bois d'oeuvre, de fonte ou de papier. Sur les navois hasardeux, par Jonvelle ou Corre, Port-sur-Saône, Gray, Auxonne, Seurre et Chalon, les cargaisons dérivaient vers leur foyer d'appel, le marché lyonnais. Elles défilaient ainsi sur les flancs du Comté, grossies au passage de ses produits plus riches, de ses blés et de ses vins qui embarquaient à Gray. Près du pont et des grands moulins, de riches négociants surveillaient la rivière. Dans la ville haute demeuraient magistrats, officiers royaux, docteurs en droit et gens d'église ; près d'eux, les boutiquiers, les artisans que les besoins de cette clientèle faisaient vivre : bouchers, épingliers, armuriers, barbiers, couturiers. Mais dans la Vanoise, parallèle à la Saône, logeaient bonnetiers, tisserands, blanchisseurs, cordonniers, maréchaux ; dans la rue du Pont, noble Jean Hugon, le premier des marchands, possédait une maison «joignant à la porte de Saogne ». Là vivaient, à côté des meuniers, les mariniers du port ; là s'arrêtaient au passage, pour être visités et marqués, les fers de Pont-du-Bois, ceux de Fontenoy-en-Vôge, ceux de Fi-

2 B. N., Dupuy, 113, fol. $136 V^{\circ}$; l'expression est celle des commissaires français députés au partage des terres de surséance (1562). Ils s'en prennent à la pro imité du Parlement de Dole, moins éloi né que « celluy de Paris », et surtout au désir des sujets de « s'exempter des tailles, gabelles, foulles de gens de guerre, empruntz et impositions » usités dans le royaume. 
lain également, si médiocres, si rompants qu'on en autorisait sans peine l'exportation. Entre Lyonnais et Graylois, les relations d'affaires étaient actives. Narguant les édits qui défendaient l'exportation des blés, des vins, des fers, des cuirs parfois, la contrebande se faisait largement; le pavillon des seigneurs maîtres des terres de surséance couvrait commodément les denrées prohibées.

Tels étaient les pays de la Comté du nord. Dessinant une grande courbe de Lure à Pontailler, une vallée tranquille - bande verte de prairies entre des plateaux secs - les limitait au sud. Douce et lente en son cours, l'Ognon, comme la Saône, coulait «sans effort par païs gras, prairies herbues, terres fertiles et collines vineuses ${ }^{3}$ » jusqu'au profond bassin de Broie et de Saint-Pierre. Sur ses terrasses d'alluvions siliceuses, de nombreux villages se serraient, grandis aux points de passage jusqu'à former des bourgs. Tels, Villersexel, barrant le chemin de Langres àMontbéliard ; Montbozon, celui de Baume en Lorraine ; Bussières, Cussey, Chambornay, Émagny, Marnay, Pesmes, avec leurs ponts qui attiraient les routes. Ces villages de l'Ognon avaient la vie facile. Ils jouissaient à la fois des prairies de la vallée, des champs du plateau, des bois et des vignes qui bordaient les côtes. L'industrie ajoutait ses dons à ceux de la culture. Moulins, scieries, battoirs à chanvre se mouvaient sans répit ; des mines de fer proches, communiquant parfois au sol la teinte rouge du minerai, avaient fait naître des fourneaux et des forges : on en voyait sur toute la rivière, depuis Pont-sur-l'Ognon jusqu'à Balançon, en passant par Bonnal, Loulans-les-Forges, Filain sur la Linotte, Le Loignenot, Cirey. Rue industrielle ? Nullement, mais chapelet d'usines rustiques, au bord d'une eau poissonneuse, dans une campagne fertile. Ce sillon de l'Ognon, heureux et prospère, semblait résumer les aptitudes variées de la Comté du nord.

3 Gollut (L.). Les Mémoires historiques de la République séquanaise et des princes de la Franche-Comté de Bourgogne, Dôle, 1592, in-fol.

De nombreuses citations ont été extraites de cet ouvrage, par L. Febvre. (N. de l'éd.). 


\section{II}

Une longue corniche, une ligne de côtes assez semblables aux côtes lorraines et dominant de haut la vallée de l'Ognon ; puis des plateaux ondulés, pierreux, dont les eaux sont bues par de nombreuses crevasses : c'est une contrée nouvelle qui, par delà l'Ognon, s'étend jusqu'au Doubs ; contrée de passage, d'union, de jonction ; dans l'histoire du Comté, dans sa formation même, son rôle fut capital.

Le sol n'est pas fertile, mais ferme ; il forme tout entier comme une chaussée de pierre. Chaussée entre Jura et Comté du nord : lorsque, escaladant les côtes boisées de Chailley, de Vieilley, d'Amagney, on découvre à la fois les collines adoucies du bailliage d'Amont et, vers le midi, les premiers escarpements du Jura dominés par l'harmonieux Poupet - le lien qui unit deux contrées si diverses, comment ne pas le voir dans cette bande de terres dures ? Mais pareillement, entre Ajoie et Val de Saône, n'est-ce pas sur cet isthme calcaire qu'une grande voie de bonne heure s'établit : celle que pour des siècles fixa, canalisa le chemin romain de Chalon à Mandeure ?

La route ne suivait pas exactement le fleuve, le Doubs mal réglé avec ses encaissements, ses détours, ses méandres : sur les plateaux, un peu à l'écart, elle courait parallèlement à lui, le suivant, le quittant, le rejoignant ensuite. Çà et là, de gros bourgs tournant leurs façades au soleil de midi ; ainsi se succédaient, à intervalles réguliers, l'Isle-sur-le-Doubs, Clerval et Baume-les-Nonnes ; toute une population d'aubergistes, de courriers, de loueurs de chevaux y vivait de la route et de son trafic. Au long du Doubs, sur des montagnes abruptes, de vieux châteaux dressaient leurs murailles, les uns détruits depuis l'époque de Louis XI : Roulans, Vaite, Montfaucon, Montferrand ; les autres, solides encore et vigilants : telle, la redoutable forteresse d'Arguel inspectant le verger de Beure et les approches de Besançon. Surtout, la route traversait dans leur étendue les deux capitales du pays comtois : Besançon, coeur antique de la vieille Séquanie ; Dole, ville plus récente, sa rivale moderne et sa suppléante.

Englobant à la fois, dans son mur d'enceinte, le roc où se dressaient ses deux cathédrales ; la plaine où, parmi jardins et vignes, s'élevaient ses maisons bour- 
geoises ; les collines du nord enfin, conservant dans leurs noms de vieux souvenirs romains -la ville impériale tenait fortement un noeud puissant de routes. Elle était d'abord le vrai centre d'attraction de toute la région d'entre Saône et Doubs. Pour traverser le fleuve, point de pont, en effet, que le pont de Battant avec ses échoppes sur les arches antiques ; en amont, le pont de Baume restait inachevé ; en aval, ceux de Rans-Ranchot et Fraisans ouvraient, vers Salins, l'accès d'autres contrées. Mais, en même temps, Besançon tenait la voie de Bâle à Dijon. Elle maîtrisait le Doubs, recourbé en anneau le long de ses murs; elle barrait la route de terre de son enceinte neuve. Cependant, par la porte Notre-Darne et la porte Taillée, des chemins s'échappaient vers la Montagne ; l'un surtout qui, à Pugey, laissant un bras tendre vers Quingey et le Vignoble, gagnait Ornans, la Loue et Pontarlier ; Besançon était ainsi la première porte du Jura comtois.

Dole était la seconde. Assise aux bords du Doubs, sur une colline où s'étageaient en amphithéâtre ses maisons et son église neuves, la capitale du Comté n'était pas située en plein coeur du pays, mais posée sur ses bords, à deux pas des frontières. Entre elle et la France, point d'obstacle que la Saône. Du côté d'Auxonne et de Saint-Jean-de-Losne s'étendaient bien quelques bois broussailleux, repaires de brigands et de détrousseurs ; mais, plus bas, c'était une campagne plate, découverte, où, parallèles au Doubs divaguant en méandres, des chemins faciles se hâtaient vers Chalon : pays de rencontres sanglantes et de guerres; la frontière, en son milieu, était toute conventionnelle ; des enclaves subsistaient endeçà et au-delà, et des Mottes ruinées, dans ce pays sans relief, disaient toute une histoire de luttes et de coups de force.

Par contre, à l'est, du côté de la Comté, l'immense forêt de Chaux étendait ses taillis sur les galets vosgiens ; les Dolois y venaient chasser ou faire, avec leurs ânes, provision de bois. D'elle étaient nés, en face des forges d'évans, les grosses usines de Fraisans, le martinet du Rendey, la renardière de Plumont, la verrerie de Courtefontaine, la forge de La Clauge et ces nombreux ateliers de cloutiers installés dans les villages de la lisière. Tout un peuple de riverains vivait de ses taillis : paysans de Falletans, d'Éclans, d'Étrepigney, courant la forêt en charbonniers, en bûcherons, en braconniers, tandis que femmes et enfants portaient vendre à Dole des fagots de bois sec. Les arbres s'étendaient sur de larges espaces, jusqu'à une terrasse qui dominait la Loue ; ils s'arrêtaient alors, mais pour reparaître sur l'autre rive et couvrir la région fangeuse et malsaine où l'Orain et la Brenne traînaient 
lentement leurs eaux. Pour vaste qu'elle fût, cette contrée forestière n'isolait pas Dole du reste de la Comté. Aux portes de la ville commençait le val d'Amour, « campagne plate et unie » qui suivait le Doubs ; de là, par la Loye, on gagnait aisément « ce très beau val Loüe, non assés jamais loué pour sa fertilité »; entre les masses boisées du nord et du sud s'étendait ainsi une large bande de terrains féconds. La rivière, il est vrai, avec ses eaux rapides et ses crues, y causait parfois de terribles ravages ; mais, en dépit de ses fureurs de « louve ravissante », le val Louais était un passage fréquenté. Une grande route l'utilisait vers le Jura ; des ponts y franchissaient les rivières à la Loye, à Belmont, à Chamblay ; par eux se hâtaient marchands, courriers, soldats gagnant Salins et la Montagne, ou, plus au sud, Arbois et le Vignoble.

Ainsi se corrigeaient pour Dole les inconvénients d'une position excentrique ; ainsi se justifiait le propos de Gollut : «Quelque chose que l'on puisse objecter », elle était « mieux au milieu du païs qu'autre ville qui soit en la Franche-Comté ». Car, assise comme Besançon sur le Doubs ; traversée comme elle par le « chemin romain »; comme elle, point de départ d'une grande route vers la Suisse - Dole voyait en plus expirer à ses pieds cette « perpétuelle plaine, entrecoupée doucement par collines vineuses ou forêts verdoyantes » qui, entre Saône et Jura, " s'épanche », se continue « jusques à la fin du païs » - aux approches de la Bresse, de la Dombe et de Lyon.

\section{III}

Pays riche, cette « Bourgougne de campagne »; pays double lui aussi, formé de deux longues bandes parallèles au fleuve et à la montagne.

À l'ouest, la Bresse comtoise et le Finage - une contrée humide, coupée de forêts avec, çà et là, de larges éclaircies, des plaines d'alluvion couvertes de moissons. Riche aujourd'hui et bien cultivée, elle recommençait à peine, vers 1550, à être exploitée. Les guerres du XIVe et du XVe siècle avaient été dures pour ce pays frontière jadis colonisé, au XIIIe, par les hardis pionniers des « abergements » ; des hameaux, des villages entiers : la Fragneuse, près de Gatey ; le Villard, près de Gigny ; Larnaud, près de Bletterans, bien d'autres encore, avaient été 
détruits, brûlés, abandonnés, - et la broussaille presque partout avait reparu en maîtresse. Au début du XVIe siècle, on s'était remis à l'oeuvre ; des nobles, des bourgeois, habiles à profiter, avaient ouvert des chantiers de défrichement et d'exploitation. Des villages se créaient de toutes pièces ; des étangs se creusaient, se construisaient plutôt : on les laissait trois ans en eau, puis on les pêchait ; sur eux à la fois et sur l'élevage du porc se fondait l'économie d'une contrée où l'homme luttait sans répit contre les forces d'une nature inculte et redoutable. Çà et là pourtant, quelques bons terroirs annonçaient déjà un pays plus riche. Dans des vallées élargies, de petites villes s'étaient installées : Sellières, Bletterans, Arlay, Ruffey, aux environs renommés pour leur fertilité. Bourgades malsaines aux maisons basses de pisé recouvertes de chaume, aux murailles de brique dominant des mares croupissantes : grenouilles, crapauds, couleuvres, toute une vermine d'eau y pullulait. Elles n'en formaient pas moins l'avant-garde vers l'ouest des pays prospères du Vignoble comtois.

Le Vignoble : c'était le «bon pays », formant aux plateaux une ceinture dorée. À distances régulières, dans la campagne maintenant découverte, des villes s'échelonnaient: Salins d'abord, puis Arbois, «la meilleure cave de Bourgougne », la capitale des vignerons remuants et frondeurs - Arbois, enfouie dans la verdure des pampres et des vergers, et fière à la fois de son haut clocher rouge, pansu comme un flacon, et de ses fûts énormes dressés dans les celliers. Plus au sud venaient Poligny, ses murailles, ses tours, ses foires renommées ; Voiteur, au pied du promontoire de Château-Chalon ; Lons-le-Saunier, Saint-Laurent-de-laRoche, toute une ligne de marchés où s'échangeaient les produits très divers de la Bresse et de la montagne; contre le vin précieux des vignes jurassiennes, le paysan du Finage y troquait ses blés, le Granvallier ses longs fûts de sapin. A Lons, ville de plaine, héritière de deux bourgs haut perchés, Montmorot et Montaigu, des voies actives se rencontraient et se nouaient en carrefour ; les deux routes d'Orgelet et de Saint-Amour y croisaient le chemin direct de Chalon par la Bresse et celui du Grandvaux par la reculée de Conliège. Les Genevois surtout pratiquaient ce dernier ; aussi jouaient-ils aux environs de Lons le rôle des Lorrains dans la Comté du nord ; ils apportaient dans leurs bougettes de gros sacs de monnaies décriées, et les changeaient aux foires contre des écus comtois.

De toutes ces villes du Vignoble, Salins était la plus prospère. Sur la Furieuse, ruisseau rapide qui longeait ses maisons ceinturées de balcons et de galeries, mou- 
lins, scieries, battoirs, forges et tanneries se serraient à la file. De l'autre côté, sur les pentes où s'élevait la belle collégiale de Saint-Anatoile, de grosses maisons riches poussaient leurs jardins jusque dans les vignes, trouvant dans leur sol même l'eau claire de sources vives. Mais le centre, le coeur de la ville, sa grandeur et sa gloire, c'était la Saline - les deux Salines plutôt : Grande Saunerie, Puits à Muire, bonnes sources d'où, comme dit Gollut, lyrique en son gros langage, coulait continûment un Pactole de clairs écus. Dans le monde entier, les bernes salinoises étaient célèbres ; les voyageurs les plus pressés faisaient un détour pour les visiter ; un flot d'aventuriers y venait de partout : artisans subtils, inventeurs méconnus, Flamands, Italiens, Français, Allemands, proposant des recettes pour ménager le bois ou le métal des chaudières. Toute la Comté elle-même convergeait vers les sources ; vers elles chaque jour, en convois serrés, des voitures de bois se hâtaient sous les portes; vers elles, des villages les plus reculés, d'autres voitures venaient à dates fixes chercher leur chargement de sel d'ordinaire. Les longues charrettes se pressaient dans les rues étroites, traversées d'une maison à l'autre par de hardis balcons, des transports couverts surplombant la chaussée. Voituriers du Grandvaux, avec leurs chiens féroces; administrateurs, ouvriers, officiers des salines ; vignerons des côtes regagnant au soir les maisons étroites à porte cintrée ; abbés des riches monastères, nobles ou gros bourgeois réunis pour un répons du Puits-à-Muire - tout ce monde disparate se mêlait, se coudoyait en une cohue vivante.

Des routes commodes d'ailleurs, de Dole par la Loye, de Besançon par Quingey, d'Arbois par Marnoz, conduisaient à la ville ; d'autres s'en éloignaient par les plateaux, vers Nozeroy, Saint-Claude ou Pontarlier. Comme Besançon et Lons-leSaunier, Salins était une porte de la Montagne.

\section{IV}

Immense bloc de calcaires et de marnes alternant, le Jura, en effet, dominait de haut les coteaux du Vignoble.

D'abord s'étendaient au-dessus de la plaine de larges plateaux de terre rouge et légère ; un air vif circulant librement y annonçait l'approche de la Montagne et, 
sur le sol criblé de fissures, les villages ramassaient autour des puits ou des étangs leurs vastes maisons couvertes en laves grises. Çà et là, dans l'épaisseur des calcaires, des vallées s'encaissaient : entre toutes, celle de la Loue, poussant sa tête jusque vers Pontarlier. Elle animait de son activité la vaste contrée du moyen Jura ; au pied des hauts bastions rocheux, dans les replis profonds où le soleil d'été, reflété par les pierres, multiplie sa puissance fécondante, la vigne, la bonne plante, s'épanouissait à l'aise ; elle était la joie, l'espoir de la vallée. Ornans, Vuillafans, Mouthier, bourgs avenants serrés au long de l'eau, ne vivaient guère que d'elle et de la rivière, faisant dès sa source tourner roues de moulins, de scieries, de batteurs.

Mais plus haut, vers la Suisse, l'aspect changeait. Plus de tables calcaires largement déployées : des plissements en longues rangées, se serrant, se pressant, encadraient de leurs bandes boisées la dépression des vals. Sous un climat rude où s'attardent les neiges, sapins et pesses aux feuilles toujours vertes remplaçaient chênes et hêtres feuillus. A l'agriculture succédait l'élevage ; à la maison de pierre recouverte de laves, le chalet comtois, la «maison de pierre et bois » des textes, avec son soubassement de moellons, ses hauts greniers de planches, son toit d'ancelles enveloppant la demeure comme d'un vaste manteau. Énorme logis : trois ou quatre familles y vivaient, serrées pendant l'hiver sous l'immense cheminée qui montait d'un jet jusqu'au sommet du toit. Là, ce n'était plus la vie du « pays bas », vie de paysan courbé sur son sillon, mais l'existence à demi nomade du montagnon habitué aux exodes de la saison d'été, aux longs séjours dans des chalets de bois perdus en forêt sur l'herbe drue des chaux. Apre pays, au XVIe siècle encore, ce Haut Jura. La vie de l'homme n'y était qu'une lutte : lutte contre le climat, le froid, la neige ensevelissant six mois la terre sous son manteau; lutte contre les bêtes, les loups enhardis par la faim au cours des hivers, les grands ours gitant dans les fourrés ; lutte contre la forêt qu'il fallait défricher, attaquer par le fer, le feu, la hache du bûcheron, la pioche du " cerneur ${ }^{4}$ ». De ces combats variés, de cette libre existence pleine d'imprévu, le montagnon sortait plus farouche mais plus robuste aussi plus indépendant, malgré les privations, le dur régime de vie, la promiscuité du poêle mal aéré, abritant pêle-mêle les bestiaux et leurs maîtres.

4 Cerner, c'était entourer d'un fossé profond le pied des grands sapins qui mouraient ainsi rapidement ; applatir, c'était brûler le bois sur pied. 
Toute la contrée d'ailleurs n'était pas encore appropriée et colonisée. L'homme restait concentré, contracté dans un certain nombre d'espaces favorables, qu'isolaient souvent des forêts épaisses. Ce n'était pas un peuplement continu, mais un réseau à mailles un peu lâches de colonies à demi solitaires. Rien n'en donne l'impression comme un texte curieux de Gilbert Cousin. Dans sa Description sommaire de la Gaule, l'ancien secrétaire d'Érasme dresse une longue liste des «peuples » du Comté. D'abord, il cite avec les Bisontins les Cepinenses, paysans de l'Ognon, ceux du Val-Louais, de Pesmes et les Bressans : catégories singulières, et dont on saisit mal la raison d'être. Mais, dans la Montagne, voici qu'il énumère les gens du Réaumont, ceux des Vaux-de-Maillot, du val d'Ain, du val d'Angelon, du val d'Usier, du val de Mièges, de la Chaux-d'Arlier, du val de Sirod, du val de Morteau, les rudes Granvalliers, les ingénieux Fonsseniers. Cette fois, nous saisissons le sens de sa liste ; de ces noms, la plupart survivent, attestant aujourd'hui non plus la persistance entre groupes de différences originelles, mais, pour les membres de chaque groupe, l'identité des conditions de vie au sein d'un même « val ». Au temps de Cousin par contre, beaucoup, à tort ou à raison, conservaient le sentiment confus d'origines ethniques particulières. Dans ce vaste jura, colonie de peuplement ouverte aux émigrants et aux malheureux sur les confins des mondes roman et germanique, des hommes de toute provenance étaient venus en quête de terres libres: Savoyards que la misère chassait de leurs Alpes ; Allemands, terme vague qui désignait surtout des émigrants suisses, souvent des Fribourgeois ; Français aussi et Comtois : apport disparate et sans cohésion. Le peuplement s'était fait par essaims successifs ; les maîtres du pays l'avaient réglé de leur mieux. Ils avaient ouvert des chantiers, dirigé les travailleurs sur les points déserts, fixé leur statut par des chartes précises. Documents d'âge, d'esprit, d'inspiration divers ; ils ne contribuaient pas peu à donner aux divers groupements une physionomie bien particulière.

Le jeu puissant des forces naturelles et le tracé des communications déterminaient d'ailleurs quelques grandes divisions dans le domaine jurassien. Au nord, l'aspect était plus rude et les plateaux plus âpres, plus isolés aussi. Pas de grand chemin gagnant Neuchatel par le Col des Roches ; les paysans du val de Morteau, dénicheurs de faucons, charbonniers, bûcherons, récolteurs de résine et fabricants de poix, étaient seuls à connaître la Fendue du Locle ${ }^{5}$. D'autre part, point de pont

5 C'était alors le nom du Col des Roches. 
sur le Doubs que le pont de Besançon ; point de ville qui pût servir, sur l'étroit couloir du fleuve, de tête à un chemin traversant la Montagne. Aussi, tous les plateaux qui d'Ornans à Saint-Hippolyte, entre le Doubs et la plaine suisse, étendaient la monotonie de leurs champs pierreux, semblaient former à l'écart des routes comme un bloc massif ; la vie circulait autour d'eux sans les pénétrer. Seul, « le chemin Saunot », la piste des voitures conduisant aux villages le sel de Salins, rattachait aux villes comtoises les bourgs, simples marchés ruraux où le montagnon venait se procurer le grain de son hiver. Par contre, deux chemins anciens mettaient en relations villages jurassiens et villes suisses: l'un reliait SaintHippolyte à Valangin par Maîche, Charquemont, Blancheroche, MaisonMonsieur, la Chaux-de-Fonds ; l'autre unissait Morteau à Neuchatel par Montlebon, les Ponts-de-Martel et la Tourne. Assujetties à des conditions d'existence identiques, les populations, de part et d'autre de la frontière, voisinaient, commerçaient et se mariaient entre elles.

Tout un faisceau de routes délimitait au sud cette contrée mal drainée : route de Pontarlier à Besançon, survivance précaire d'une voie romaine jadis établie par Étray, Fallerans, l'Hôpital-du-Gros-Bois, détournée maintenant vers le sud et utilisant, d'Ornans à Saint-Gorgon, le couloir de la Loue ; grand chemin de Salins à Pontarlier par Dournon, Chalamont, Houtaud, piste traditionnelle des marchands lombards vers les foires de Champagne ; traverse de Pontarlier à Lons par Frasne, Champagnole, Mirebel : elle desservait les villages heureux du val de Mièges et leur capitale Nozeroy - un des gros marchés de bétail de la région, célèbre par son château où longtemps les Chalon, princes d'Orange, avaient tenu leur cour. Pontarlier, assise au bout d'une large Chaux, était la tête commune de ces routes diverses. Elle surveillait de près le défilé de la Cluse, barré en son milieu par le château de Joux ; de là, tous les chemins à nouveau divergeaient, gagnant Neuchatel par le Val-Travers, Yverdon par les Fourgs, Lausanne et Morges par les Hôpitaux.

À Saint-Cergues, une seconde porte s'ouvrait sur la Suisse : une piste récente suivait les pentes d'un col fort praticable. Pour éviter les péages échelonnés de Dole à Pontarlier, des négociants ingénieux s'étaient, en effet, avisés d'aborder la montagne par Lons et la reculée de Conliège, puis de gagner par là Orgelet, Moirans et Saint-Claude. Dès le début du XVe siècle, ce chemin neuf était en usage ; les Chalon, maîtres des péages, dénonçaient dans leurs chartes l'artifice des marchands. Au milieu du XVIe siècle, la voie continuait à être fréquentée ; la tête en 
était double, partant soit de Saint-Jean-de-Losne par Bellevesvre, soit de Tournus par Louhans. Une fois à Saint-Claude, restait à traverser la plus haute chaîne du Jura. De la vallée basse de la Bienne, on devait se hisser à dos de mulet sur la pente des monts, traverser les plateaux de Septmoncel, redescendre au fond de la Valserine, suivre la Combe et 1'Étroit de Mijoux, monter au Poyet où aboutissait également le sentier de Morbier. De là, par Saint-Cergues, on atteignait doucement la plaine vaudoise, et par Nyon le Léman.

Saint-Claude, Saint-Oyand de Joux comme on disait encore, était la capitale de tout ce haut jura. But d'un pèlerinage fréquenté, la petite ville voyait affluer les croyants de l'Europe entière, guettés sur le pas des portes par les hôteliers, les guides, les marchands de souvenirs et de ces mille objets de buis ou de bois tourné qui, déjà, faisaient son renom. Elle était, en plus, le centre du vaste domaine de l'abbaye. Domaine en pleine activité ; partout des maisons s'élevaient, des hameaux se créaient, non dans les vals seulement, mais en pleine forêt, en pleins sapins. Par montagnes entières, l'abbaye accensait ses forêts séculaires, ses joux vierges et sauvages, non plus comme jadis à des seigneurs, mais directement à des communautés - parfois, plus rarement, à ces riches bourgeois qui, là comme ailleurs, succédaient dans leur rôle aux féodaux déchus. Un jour, en 1549, c'est tout le Risoux entre la Bienne, la vallée de Joux et celle de Bellefontaine - toute une immense montagne couverte de sapins gigantesques, que trois communautés : la Mouille, Morbier, Bellefontaine, abergent des religieux. Et les colons aussitôt, hôtes farouches des bois, vêtus de peaux de bêtes, de s'enfoncer pioche en main dans les solitudes, d'y créer des clos, des «blés », des « méchonnais ». Parfois, un seul homme traite avec le monastère, et pour sa part emporte une «joux noire »confinant au Sagy. Un autre, un riche bourgeois de Saint-Claude, obtient le Sagy et le Vivier. Plus au nord, sur les terres du prieuré de Mouthe, dans la seigneurie de Châtelblanc, dans le Grandvaux, même spectacle, mêmes pratiques, même ardeur : le Noirmont, comme le Risoux, s'en va par lambeaux. Et derrière les défricheurs, les usiniers paraissent. Dans les vals, au long des cours d'eau, hauts-fourneaux, forges, martinets s'établissent. A Jougne, à Métabief, à Pontarlier ; plus au sud, à Rochejean et à Mouthe ; en arrière, sur la rivière d'Ain, ou sur la Bienne, à Morez, la métallurgie s'installe pour de longues années : rage industrielle si grande qu'on verra, à Jougne, de simples paysans, des bûcherons et des 
charbonniers, amasser diligemment du combustible « pour, avec quelque quantité de mine de fer, faire en leur chief par chacune année de sept à huit gueuses ».

Des rivaux, du reste, naissaient aux Comtois. En 1536, avec tout le pays de Vaux, les Bernois avaient occupé Saint-Cergues, jadis dépendant du Comté de Bourgogne. Par là, ils tenaient la route de Genève à Saint-Claude, route facile, sans obstacle, sans coupure, sans défense. Aussi, quelle tentation d'empiéter sur le territoire comtois ! Dans ce haut Jura, peu de seigneuries nettement délimitées : une immense forêt de sapins séculaires s'étendait de Jougne jusqu'aux Rousses, de la Cluse de Pontarlier au col de Saint-Cergues; et partout Comtois et Vaudois, partis les uns du nord, les autres du midi, taillaient champs et pâtures dans la masse sylvestre et diminuaient par un effort quotidien l'épaisseur du rideau qui les séparait. Mais les Suisses surtout s'avançaient âprement. Berne, sécularisant les grandes abbayes vaudoises, avait accensé aux villages de la plaine des Joux entières. Les communautés, chacune sur son lot, s'étaient mises à la besogne. Élargissant les clairières, installant en leur centre fermes et chalets, poussant droit devant elles en toute indépendance, elles avaient rencontré les défricheurs comtois : heurts, conflits violents et lutter ancunière. C'étaient, sur tous les points de la vaste frontière, d'incessants procès clos par des razzias : hommes et bestiaux, brutalement arrêtés, défilaient en triomphe dans les rues de Morges ou de Nyon, au bruit des tambourins, au fracas des mousquets. De temps à autre, les deux gouvernements se saisissaient des faits, décrétaient une enquête. On délimitait à nouveau la frontière. Des traités successifs, en 1524, en 1527, en 1542, en 1552, définissaient le champ d'action des rivaux. En vain : dès le lendemain, dédaigneux des textes, les Vaudois reprenaient leur marche conquérante, comme s'ils eussent voulu, clairière par clairière, occuper en détail tout le haut Jura.

Avec la terre de Saint-Oyand s'achevait, au sud, le pays comtois. Ni fleuves ni montagnes ne soulignaient d'ailleurs la frontière ; elle courait sur les plateaux au sud de Viry et des Hautes-Molunes. Vers l'ouest seulement, l'Ain séparait approximativement la vieille terre monastique du bailliage d'Aval. Une fois franchie la rivière encaissée, c'était un pays moins élevé, une nature plus riante, des coteaux ensoleillés. De petits bourgs paisibles, assis sur les routes et peuplés de marchands : Orgelet, Arinthold, Saint-julien, Montfleur, terminaient de ce côté le comté de Bourgogne. Tous ressentaient déjà l'attraction puissante du foyer lyonnais. Entre la grande cité, la Bresse comtoise et ce Jura méridional que le val 
d'Ain ouvre si largement aux influences du sud, les rapports, les échanges ne cessaient. Des marchands, courant le pays, achetaient à bas prix les filés bressans pour la fabrique lyonnaise. A côté des usines rurales (scieries ou moulins), des tissages s'étaient installés dans la région. Avec le poil des chèvres ou la laine des moutons, on fabriquait à la Tour-du-Meix, à Orgelet, Fétigny, Arinthod, des draps et des droguets, de chauds capuchons, des bonnets d'hiver pour les montagnons. Puis, c'étaient des tissages de toile, des blanchisseries, des teintureries. Dans le val de Bienne, à Vaux-lez-Saint-Claude, à Chiria, on cultivait le safran ; partout on travaillait, partout on s'ingéniait ; des inventeurs hasardeux préconisaient même des cultures de riz, des plantations de mûriers : influence du Midi, de la Provence, ou même de l'Italie. Rien de moins comtois déjà que l'activité multiple de SaintAmour, petite ville bressane aux foires fréquentées des marchands allemands, italiens ou lyonnais. Un seigneur avisé, Philibert de la Baume, en multipliait les richesses vers 1550 ; aux espèces locales il substituait des moutons d'Espagne ou d'Angleterre, plantait des châtaignes du Dauphiné, attirait sur sa terre des tisserands de Vienne, des chapeliers d'Italie, créait des foules, des usines de toiles peintes, des teintureries, des tissages. Et les savants mêmes dont il s'entourait, c'était vers le royaume, vers Lyon qu'ils s'orientaient.

\section{V}

Tel était, vers 1550, le pays franc-comtois. Ce cette description, dégageons, résumons les traits principaux.

Le premier sans doute, le plus saillant, c'est l'extrême variété du sol de la province - la diversité profonde de ses parties. Vôge, Finage, plaine de Saône, plateaux d'Ainont ou plateaux du Jura, vals et crêts de la haute montagne, qu'ontelles de commun ? Ni l'aspect physique, ni la composition des terrains, ni le climat, ni les productions - moins encore, les habitants. Sabotiers de la Vôge, au parler lorrain; laboureurs d'Amont; bûcherons et charbonniers de la forêt de Chaux ; Bressans au teint fiévreux, haut perchés sur des jambes sans mollets qui leur donnaient, de loin, un aspect étrange d'oiseaux aquatiques ; rouliers du Grandvaux, escortant par les routes leurs charrettes comblées de fromages ou de 
fusterie ; colons et défricheurs du haut Jura : par les occupations, les moeurs, le caractère, tous formaient autant de groupes distincts.

Rien de plus varié que leurs habitations, tantôt dispersées, égrenées au long des rus vosgiens ; tantôt groupées en villages compacts sur les plateaux ou dans le Vignoble ; les unes, amples et larges, abritant à la fois plusieurs familles ; les autres, petites, étroites, maisons de vignerons plus gaies sous un ciel moins rude ; celles du Val de Saône, de la Bresse, du Finage et du «bon pays », bâties de bois, couvertes de paille ; celles des plateaux aux murs de pierres sèches, aux toits d'ancelles ou de laves grises ; celles de la Montagne enfin, mi-parties de pierre et bois. - Même contraste pour l'alimentation. Tandis que, dans le plat pays, le vin était connu (trop même, s'il faut en croire Gollut) ; tandis que, dans leurs arches, les paysans y possédaient du blé, céréale de luxe, en même temps que du seigle, du millet, de l'avoine - point de vin dans la montagne; point de froment ; un pain d'orge compact préparé à l'avance et pour des semaines ; beaucoup de laitage ; du séret ; des fromages cuits dans les «fruitières »; des salaisons, quartiers de porc ou de vache ou de chèvre, « brésy » ou « côty », pendus pendant l'hiver aux grandes cheminées. Tout variait ainsi d'une région à l'autre ; ce n'étaient que contrastes et qu'oppositions. Remarque capitale, car cette variété même faisait en grande partie la force du Comté.

D'abord, si différentes, ses parties par là même étaient complémentaires. C'est un des caractères propres de la France que la juxtaposition sur un étroit espace de contrées dissemblables, unies et reliées par ces dissemblances mêmes. En Comté, le fait est frappant. Une étroite solidarité économique - raison profonde de leur accord politique - n'unit-elle pas les deux régions du jura et du plat pays ? Entre elles, les rapports sont constants parce que nécessaires; il faut à la montagne les grains de la plaine et les vins des coteaux; il faut à la plaine les bestiaux, les bois - à l'occasion même, les hommes - de la montagne : échange de denrées, contact d'habitants.

Et puis, cette extrême variété du pays comtois n'aide-t-elle pas à comprendre, n'explique-t-elle pas dans une large mesure la persistante autonomie, la vitalité durable de l'État comtois ? Point de pays, dit Gollut, qui en si peu de place trouve tant de commodités - et il le prouve. Les fruits d'une année n'y peuvent-ils « suffire à trois ou quatre » ? La Comté n'a-t-elle pas ses riches céréales, blé dans la 
plaine, seigle dans la montagne, avoine, orge, millet 6 ? Ses vins blancs et rouges, sur la table d'Érasme, ou de François Ier, ou de l'empereur Charles, ne font-ils pas sa gloire, son orgueil par le monde ? C'est en poète que Gollut, assouplissant son gros langage, célèbre les crus d'Arbois « entremeslant une miellée douceur avec une gaillarde et picquante chaleur », ou évoque « ce je ne sais quoi de souëf, qui ne peut bonnement être exprimé par la plume ». - L'élevage se pratiquait en grand, facilité par l'excellence des fourrages, l'abondance des prairies, la richesse des bois « en gland, faine, cerises », provende naturelle qui valait, à dire de paysan, « une troisième portion des graines du païs ». Les forêts, outre le bois, l'écorce, la poix de Bourgogne fabriquée aux «fourgs » de la montagne, contenaient des essaims, des bêtes à fourrure, du gibier en telle abondance qu'on en tenait boucherie ; les rivières à leur tour, prodigieux viviers, fournissaient les poissons succulents ; carpes de Saône, barbeaux de l'Ognon, brochets du Doubs, ombres de la Loue et truites de l'Ain : c'était proverbe de gourmets.

6 On peut dans une certaine mesure utiliser, pour reconstituer le tableau des cultures de la Comté, certaines données des comptes de seigneuries, et notamment, pour chacune d'elles, la liste des céréales qui faisaient l'objet de redevances en nature. Nous avons constaté ainsi que, dans toute la région sousvosgienne, les redevances exigées étaient de froment, d'avoine et de seigle (Comptes de Demangevelle, Saint-Remy, Faverney, Faucogney, etc.). - Sur les plateaux calcaires du bailliage d'Amont, il n'est plus question de seigle, mais seulement de froment et d'avoine (Comptes de Noroy l'Archevêque, Gy, Citey, etc.) ; mêmes cultures dans toute la région des moyens plateaux du jura (Comptes d'Arguel, Mandeure, Châtillon-sous-Maîche, Chalamont, Lièvremont, Vennes, Vercel, Usier, Rennes, Myon, Monnet, Montaigu, etc.). Enfin, dans le haut Jura, l'orge apparaît, et le froment disparaît généralement (Redevances de Jougne : avoine, orge - de Joux : orge, avoine, froment - de Réaumont : orge, avoine - dîmes de Bonnétage : orge, froment, avoine). Dans une requête de 1563, il est dit qu'il ne pousse aucun seigle dans le ressort de Pontarlier, « ains seulement du gros blé, moitié froment, moitié greu, pesettes et soille » (Parlem, B 166, Délib., fol. 5 et $5 \mathrm{v}^{\circ}$ ). La variété des cultures était moindre qu'aujourd'hui ; le maïs, culture caractéristique de la Bresse, manquait notamment : c'était le millet qui en tenait l'emploi ; avec ses graines pilées au mortier ou cuites dans du lait, les paysans faisaient des bouillies ou « pilés » qui leur tenaient lieu de gaudes. Textes nombreux ; cf., par ex., États, Suppl., carton 77, Don gratuit de 1574 : Demande en dégrèvement des manants de Lains près Saint-julien (Jura, arr. de Lons) : pestiférés, ils n'ont pu recueillir « leurs millots et panyts, que sont les blefs les plus suffisantz pour nourrir et alimenter les gens de labeur ». 
Et la Comté, en plus, avait le sel de Salins, doublement précieux dans ce pays d'élevage ; elle avait le fer, le plomb, l'argent l'or même, si l'on avait patience de le recueillir, et la houille, et les calcaires compacts, et ces «perrières » réputées d'où l'on tirait à Sampans le marbre rouge, à Saint-Lothain les albâtres célèbres qu'un Michel Colombe n'avait pas dédaignés ; elle avait le salpêtre pour fabriquer ses poudres et sinon l'imprimerie, du moins le papier : bref, elle réalisait pleinement l'idéal des anciennes provinces : elle était le bon pays qui se suffit en tout et se passe du voisin.

Dons précieux d'une nature libérale, sinon prodigue. La jouissance commune d'un si riche patrimoine était bien faite encore, à une époque de morcellement, de circulation pénible, de protectionnisme jaloux, pour nouer entre Comtois un lien fort et nouveau. Tout nous ramène ainsi à constater l'accord des forces naturelles et des forces humaines. Constatation qui ne doit pas, d'ailleurs, nous égarer : la part de l'homme restait prépondérante. Car c'était lui, en définitive, qui, de morceaux disparates, avait dû forger une unité politique, un État. Par quelle série d'efforts, à travers quels hasards et pour quel résultat, c'est ce qu'il nous faut étudier maintenant. 
PHILIPPE II ET LA FRANCHE-COMTÉ

Étude d’histoire politique, religieuse et sociale.

Première partie. La Comté à la veille du règne de Philippe II

\section{Chapitre II \\ L'État comtois et ses origines}

$\underline{\text { Retour à la table des matières }}$

Rien de plus complexe que la situation politique de la Comté au milieu du XVIe siècle : la définir d'un mot serait impossible.

C'était un fief d'empire. Longtemps, au moyen âge, des seigneurs d'origine germanique l'avaient possédé. Son maître, en 1550, son souverain était l'empereur, Charles-Quint. Mais à aucun degré et d'aucune façon elle n'était terre allemande. Par sa langue, par ses moeurs, par tout l'ensemble de sa civilisation morale et matérielle, par ses institutions même, elle était française et la proche parente du duché bourguignon, récemment annexé au royaume voisin. Mais, politiquement, elle échappait aux prises du roi très chrétien ; elle l'avait quitté à la paix de Senlis et, fière de son indépendance reconquise, s'enorgueillissait maintenant de rester seule fidèle aux souvenirs du particularisme bourguignon, seule digne de retenir, comme dit Gollut, « avec le nom, l'escharpe et la croix bourgougnone ».

Qu'était-elle au juste ? une province, partie d'un tout, - ou un petit État autonome ? - Province, elle l'était en un sens puisqu'elle avait pour maître un puissant souverain qui groupait sous lui des territoires allemands, espagnols, italiens et flamands : par son intermédiaire, la Comté se trouvait englobée, qu'elle le voulût ou non, dans un système politique européen. Mais c'était une province isolée, de 
toutes parts entourée de terres étrangères, une unité distincte dans la carte des États contemporains.

Petit État elle-même ? Oui, à regarder seulement la nécessaire autonomie dont elle jouissait, les libertés qu'elle retenait, les traditions qu'elle s'efforçait de maintenir. Mais cet État comtois n'était pas souverain ; aux heures décisives, il recevait les ordres d'un maître lointain qui, nécessairement, devait subordonner aux intérêts de sa politique générale les intérêts particuliers de son domaine comtois. Ainsi, de l'isolement, la Comté supportait les charges et subissait les dangers : elle ne recueillait ni l'entière liberté, ni le plein bénéfice.

Cette situation ne domine pas seulement toute la vie extérieure, la vie de relation de la province au XVIe siècle. Elle domine, elle explique sa vie et son évolution intérieure. Elle est la condition générale de l'histoire comtoise à cette époque. Essayons d'abord, pour la mieux comprendre, d'en dégager les causes et d'en retrouver les origines.

\section{I}

Origines singulièrement lointaines si, dans la Séquanie, les textes anciens nous présentent déjà comme une première esquisse de la Franche-Comté. Jura, plaine de Saône et plateaux sous-vosgiens - de cette combinaison durable d'éléments disparates, les proportions sans doute varieront avec les siècles : la formule générale est dès lors trouvée. Mais dès lors également, sur ce groupement robuste et qui vivra, des influences contradictoires s'exercent.

La terre des Séquanes, la future Comté, est une partie de la Gaule, un membre de cette personne vivante et précoce. Elle l'est par sa population, par sa langue, par toute sa civilisation matérielle. Elle l'est par sa volonté propre, par la place importante de ses chefs et de ses guerriers dans les conseils des confédérations. Elle l'est par ses voisins enfin, par tant de pepples parents qui, de tous côtés, Helvètes et Rauraques, Éduens et Lingons, l'entourant, l'encadrant, constituent autour d'elle un milieu celtique. Mais, en face d'elle, c'est la Germanie, ses moeurs et ses institutions, la masse mouvante de ses tribus instables. Et lorsque, par les Commentaires de César, les Séquanes entrent dans l'histoire, ce n'est point sous l'as- 
pect d'ennemis irréductibles des Germains : sans être leurs alliés, ils sont ceux qui traitent, qui négocient avec eux - ceux, dira plus tard Strabon, dont l'appoint promis ou refusé faisait forts ou faibles leurs voisins de l'Est.

Cette situation mixte, cette puissance transactionnelle des Séquanes entre les peuples celtiques et les bandes germaniques, leur sol même la leur conférait. Des rives du Doubs aux plaines du Sundgau, les communications sont aisées. C'est par des transitions insensibles que du Montbéliard on passe en Ferrette; c'est tout naturellement qu'à l'époque gauloise la Séquanie, absorbant l'Ajoie, s'avançait vers l'est jusqu'à l'Eckenbach. Par là, cette contrée que des Celtes peuplaient, défrichaient et gardaient, se trouvait en contact étroit avec le monde germanique. Au contraire, elle s'unissait mal, elle ne se soudait guère que par d'étroits passages aux régions de même langue et de même culture qui s'étendaient à l'ouest, en face du jura. Les immenses nappes d'alluvions siliceuses qui s'étalent en plein coeur du bassin de la Saône en font une contrée humide, malsaine, désolée, que les routes évitent et que fuit la vie. Ainsi, communications faciles, contact aisé avec les contrées étrangères du Rhin et du Danube ; relations incommodes avec les peuples parents d'outre-Saône ; possession d'une des routes les plus fréquentées d'Europe : ces conséquences de leur situation géographique déterminaient d'avance le développement des peuples assis sur le jura.

Toute leur histoire ainsi oscille entre deux pôles. Du côté de l'est, le germanisme prend pied à leurs portes, s'affermit et ne cesse de grandir. Dès le IVe siècle établi en Alsace avec les Alamans, avec les Francs, à la fin du Ve, il s'y installe à jamais. Devant lui recule progressivement l'ancien domaine séquane. De terre allodiale, le comté de Ferrette devient, au XIIIe siècle, fief de l'évêché de Bâle, s'accroît au XIVe des seigneuries montbéliardaises de Rougemont et de Belfort et rejoint peu après les domaines alsaciens de la maison d'Autriche. Dans l'ancien Ajoie, dans le Jura oriental, les évêques de Bâle, par Saint-Ursanne, s'établissent sur le Doubs, occupent les Franches-Montagnes et le val Saint-Imier. Au pied des Vosges, des relations se nouent entre la terre de Lure et l'abbaye alsacienne de Murbach, tandis que le Montbéliard, à la fin du XIVe siècle, se voit par un hasard brusquement rejeté vers le monde germanique. Bien plus, sur le Comté même s'étendent les influences de l'Est. Au commencement du XIe siècle, c'est aux empereurs que les Rodolphiens débiles ont cédé le pouvoir. Bientôt, avec Barberousse, par une alliance heureuse, le César germanique est devenu lui-même comte de 
Bourgogne : pas pour longtemps sans doute - mais ceux qui lui succèdent sont des Allemands encore, ces ducs de Méranie dont le règne dura jusqu'en plein XIIIe siècle. Ainsi, de son contact avec l'Europe centrale, la province subit les conséquences directes.

Elle s'ouvre également, elle s'ouvre en même temps aux influences de l'Ouest. Là aussi, des voisins puissants s'efforcent d'empiéter sur son territoire. Au pied des Vosges, les comtes de Champagne, gênes à l'ouest par les rois de France, convoitent Luxeuil et même Lure. Plus bas, les ducs de Bourgogne, profitant de l'éloignement des comtes germaniques, cherchent à s'installer dans les fiefs d'outre-Saône ; du reste, pour chercher à prendre la Comté en détail, ils ne désespèrent pas de la prendre d'ensemble : leurs échecs mêmes exaspèrent leur désir. Les rois de France, après eux, reprirent leurs procédés, mais avec plus de succès ; à la fin du XIIIe siècle, pour la première fois, la province, cédée à Philippe le Bel, venait prendre sa place dans l'unité française. Actions et réactions, luttes sans répit d'influences contraires : même lorsqu'en 1384, se dégageant du royaume de France, elle va, malgré les obstacles naturels, se joindre au duché sous un maître commun, la Comté ne cesse point d'en supporter le choc.

Dans cette terre où l'Empereur était devenu un étranger, on a souvent dit comment les ducs de Bourgogne, indirectement, rétablirent ou, mieux, préparèrent le rétablissement des liens avec l'Empire. Du moins ne travaillèrent-ils pas dès l'abord pour lui ; même, dans la mesure où l'Empire représentait le germanisme, ils furent ses adversaires ; leurs progrès vers l'est constituèrent nettement des progrès en Europe de l'influence française. Mais peu à peu, leurs acquisitions firent d'eux, avant tout, des princes de l'Empire. Politiquement d'ailleurs, ils luttaient contre la France, se substituaient aux Césars germaniques dans leur duel séculaire contre les rois - plus même, rêvaient de Lotharingie avec Philippe le Bon, ou réclamaient avec le Téméraire un royaume de Bourgogne. Une double évolution, les éloignant de France, les rapprochait de l'Empire - sans qu'ils se confondissent cependant avec lui.

Sous ces actions diverses, la Comté ne restait point passive ; lentement, patiemment, elle tissait d'inventions et d'emprunts la trame originale de sa vie nationale. Au roi légiste, à Philippe le Bel, elle dut ses premières, ses grandes institutions : un Parlement, une Chambre des comptes, les deux bailliages d'Amont et d'Aval. Ce fut, dans sa vie restreinte et solitaire, le brusque afflux d'un flot de vie 
nouvelle et plus générale. Par ses ducs Valois, un Philippe le Hardi, un Philippe le Bon, ces institutions furent réorganisées. Un Parlement se reconstitua. Des États, votant les dons gratuits, associèrent aux nobles et aux clercs les représentants des bonnes villes. Établie à Dole, une université y forma des légistes et accrut à la fois la puissance des ducs et celle des bourgeois. Peu à peu grandissent les libertés comtoises. Au prix d'une lutte quotidienne, les États imposent à Philippe le Bon, du moins en principe, leur contrôle financier. Plus tard, sous le Téméraire, ils dénoncent l'arbitraire des taxes dont le duc «bataillard » écrase le pays. Un esprit public se forme lentement ; un trésor de droits et de privilèges s'accroît ; une classe s'organise pour le défendre - cette classe bourgeoise dont il faisait en partie la fortune et la dignité.

Ainsi se développe l'histoire comtoise - histoire d'une individualité politique qui doit naître et grandir au milieu des conflits mais - qui, formée, trouve en elle sa force de résistance et peut vivre sa vie avec indépendance.

\section{II}

On le vit bien à la fin du XVe siècle, dans la crise qu'ouvrit, en 1477, la défaite et la mort du Téméraire. Crise décisive d'où sortit vraiment la Comté moderne : celle de Charles-Quint et de Philippe II.

Sur la province, sitôt son maître mort, ce fut une ruée confuse de prétendants : le roi et l'Empereur, l'archiduc Sigismond, l'évêque de Bâle et les Cantons suisses. Les uns voulaient le tout; les autres se contentaient d'avance d'une partie. Les comparses écartés, trois grands acteurs, seuls, restèrent en présence : Louis XI, Maximilien, les Suisses. Tenant la proie, ces derniers avaient l'avantage. Lorsque Louis XI, le 14 janvier 1477, fit avertir les Bernois qu'il allait mettre la main sur les deux Bourgognes, ils lui répondirent incontinent, le 30, qu'occupant le pays, ils entendaient le garder. Mais Maximilien s'étant mis sur les rangs, Messieurs des Ligues bientôt changèrent de sentiment ; ils se firent de compétiteurs arbitres, ou mieux courtiers : leur conquête fut promise au plus offrant - et, pendant trois ans, ce fut une lutte d'enchères passionnée. D'abord Louis XI l'emporte, enlève l'affaire pour 100000 florins. Maximilien riposte, offre 150000 : à lui la Comté. Mais il 
ne paie qu'en promesses et les Suisses sont « gens de saint Thomas, qui ne croient que s'ils ont en la main »; Louis XI revient à la charge et, lorsqu'il meurt, son successeur hérite des deux Bourgognes.

Voilà la Comté, une seconde fois, française. Dans le débat, elle avait bien failli laisser sa vie même : à plusieurs reprises, Louis XI avait proposé aux confédérés le partage de la province litigieuse : ils auraient eu Salins et ses salines. Occupée par les troupes françaises, incorporée au royaume, se résigne-t-elle du moins à être absorbée ? Nullement. C'est que, violentée, elle a dû faire dans les épreuves, elle a fait l'union de tous les siens ; c'est encore que des libertés conquises sur le souverain, le souci domine ses bourgeois : ils tremblent pour elles si leur pays se fond dans un plus grand État. Ainsi s'explique leur joie lorsqu'en 1493, échappant à la France, la Comté revient à l'héritier de son dernier duc. Faut-il dire - on l'a dit - qu'elle se rejette alors du côté de l'Empire ? Sans doute, le 19 août 1493, son père Frédéric étant mort, le roi des Romains Maximilien, devient l'Empereur. Mais croire que la Comté fuit la France par amour pour l'Empire, l'erreur serait trop forte. Au vrai, son idéal est de faire partie d'un petit groupement bourguignon-flamand qui lui assure le maintien de ses libertés et une place importante dans un État moyen. On le voit à la satisfaction qu'elle éprouve, en 1498, de l'avènement de Philippe le Beau - mieux encore, aux craintes qu'elle manifeste, en 1506, de retomber aux mains de Maximilien - aux démarches spontanées des États de Bourgogne réclamant comme souveraine Marguerite d'Autriche. Deux ans plus tard, cette princesse devenait, à leur grand enthousiasme, la maîtresse à vie du comté de Bourgogne ; jusqu'en 1530, jusqu'à sa mort, elle leur fit vivre en paix et en prospérité une vie féconde de réparation lente et d'enrichissement.

Vie inquiète pourtant. Séparée du duché, isolée entre ses deux grands ennemis, le Français et le Suisse, petite d'ailleurs et mal armée, la Comté pouvait trembler à chaque instant pour son indépendance. Une lourde tâche s'imposait à ses souverains, s'ils voulaient protéger, perpétuer cette vie délicate. D'abord, il fallait constituer une Comté homogène, rassembler la terre comtoise, trancher les litiges perpétués aux frontières, parer aux empiètements et aux démembrements. N'avait-on pas vu, en 1475, les Suisses se ruer sur la Franche-Montagne et la vendre à l'évêque de Bâle, tandis que cet évêque lui-même occupait Blamont, Clémont, Pont-de-Roide, et Sigismond, plus au nord, l'Isle, Héricourt et le Chatelot ? Prises éphémères ? Aux maîtres de la Comté, elles indiquaient du moins un péril : 
celui de voir l'étranger, réglant à son profit les vieux litiges, s'installer au coeur de la province et en préparer la conquête en détail. Et puis, plus encore, à la Comté isolée du lendemain de Senlis, il fallait un gouvernement largement autonome, formé de Comtois résidant en Comté, et capable de grouper pour le salut commun toutes les énergies. La sauvegarde d'un État si faible n'était-elle pas toute dans sa volonté de vivre ? Tâche double, mais concordante. Maximilien, Philippe le Beau, Marguerite surtout, à des degrés et pour des motifs divers, s'en firent les artisans.

À la «bonne Marguerite ", la Comté dut un sage gouvernement. Un gouverneur, homme d'épée et de noble lignage, assisté dans les cas graves par un conseil de «bons personnages »; un Parlement, orgueil et force de la bourgeoisie ; des États enfin, pour voter l'impôt : c'étaient des éléments bien choisis pour neutraliser les tendances exclusives des classes rivales et mettre en jeu les forces vives de la province. - Par contre, Maximilien s'intéressa surtout aux litiges des frontières. A travers les obscurités des rares textes publiés, on devine son rôle dans une affaire capitale : la succession, ouverte en 1504, de cette maison de Neuchatel qui tenait à la fois la Fermetey de Dambelin, l'Isle-sur-le-Doubs, la Poôté de Mathey, le val de Vit, les terres de Blamont, Clémont, le Chatelot et Bermont ; vaste domaine, convoité par une nuée de prétendants rivaux, et dont l'empereur comprit la valeur pour le comté de Bourgogne, Pareillement, c'est lui qui, en 1507, fit enlever par Louis de Vaudrey à Louis d'Orléans-Longueville, comte de Neuchatel, la forteresse de Joux, maîtresse de Pontarlier, et, dès 1513, déclara annexées les grandes terres de Vennes, Vercel et Chatelneuf-de-Vuillafans : acquisitions confirmées, en 1517, à la paix de Noyon; elles forgeaient, entre les comtés de Valangin et de Neuchatel d'une part, les plateaux jurassiens de l'autre, une chaîne de seigneuries désormais toutes comtoises. C'était le moment où les Suisses s'installaient aux frontières du Jura. Déjà, en 1476, Berne et Fribourg avaient occupé Orbe, Grandson et Échallens, terres des Montfaucon passées aux Chalon. En 1536, à son tour, le pays de Vaud tombait au pouvoir des Bernois. Voisine de ces conquérants aux dents longues, la Comté bien souvent dut se féliciter de l'heureux coup de main d'un Vaudrey et du persévérant effort qui, sur tout son front jurassien, l'avait dégagée des pays limitrophes.

Oeuvre féconde, mais insuffisante. Même groupée en un corps compact, la Comté restait faible. Il fallait, si la chose était possible, lui chercher en Europe des 
garanties et des protections ; il fallait lui assurer le bien cher entre tous : la paix. À l'aide des Suisses, ses maîtres y parvinrent.

\section{III}

Ce n'était pas sans regrets que Messieurs des Ligues, en 1477, s'étaient décidés à céder la Comté soit à Maximilien, soit à Louis XI. Elle leur était d'un voisinage utile. Ils en tiraient du blé, du vin, du fer, du sel surtout. Louis XI le savait, lorsqu'il leur soumettait ses projets de partage : n'attestent-ils pas que le roi, diplomate avisé, sentait chez eux, chez les Bernois surtout, comme un vague regret d'abandonner si riche proie ? Ils s'en dessaisirent sans doute, mais ces indécisions, ces revirements, ces continuelles oscillations entre l'empereur et le roi pouvaient justifier quelque inquiétude. Un acte précis était à désirer qui, d'une part, consacrât en termes catégoriques l'absolu renoncement des Suisses à la Comté ; de l'autre, fixât leur attitude vis-à-vis de l'Empire, et, partant, de la France. Signé, en 1511, par Maximilien et par les Cantons, cet acte fut la Ligue héréditaire.

C'était comme héritier de Sigismond d'Autriche pour les territoires qu'il tenait de lui, et, pour la Comté, comme tuteur du futur Charles-Quint, que Maximilien traitait avec les Suisses. En sa première qualité, il pouvait s'appuyer sur l'alliance héréditaire et perpétuelle de Sigismond avec les Cantons ; il n'était besoin que de renouveler l'acte et d'y faire comprendre le comté de Bourgogne. Moyennant 200 florins du Rhin par an à chaque canton, plus 100, à Saint-Gall et 100 à Appenzell, l'affaire fut conclue sans difficulté. Le nouveau traité, du reste, atteignait bien ses deux objets. D'abord, il stipulait, pour chaque partie, le respect absolu des possessions de l'autre. C'était la paix perpétuelle entre les Suisses et leurs voisins : elle dura. Surtout, il donnait aux Comtois des garanties contre toute agression étrangère ; c'était la fameuse clause du léal regard, si importante à leurs yeux, qu'au XVIe siècle, ils désignent tout l'acte par ces deux mots seuls. Si les domaines de Sigismond, ou de Charles, ou des Cantons se trouvaient menacés, les Suisses à la requête des Comtois (ou réciproquement) devaient, quel que fût l'agresseur, avoir « fidèle ou loyal regard » à ce que leurs alliés ne fussent «pressez ni molestez contre droit et raison $»$. 
Rien de moins précis, si l'on s'en tient aux mots ; rien de plus clair, si l'on s'attache aux intentions. L'acte de 1511 était incontestablement un traité d'alliance réciproque, dont la pointe se tournait contre la France. De là sa valeur aux yeux des Comtois : à tout instant, par un contre-coup des grands conflits qui se nouaient en Italie, ne pouvaient-ils être entraînés dans la querelle de leurs maîtres contre un Louis XII ou un François Ier ? Aux Suisses eux-mêmes, ce côté du traité était moins agréable. Quand ils l'avaient signé, en 1511, ils étaient en plein antagonisme avec la France. Mais, en 1516 et 1521, ils passent successivement avec François Ier une paix perpétuelle et un traité d'alliance. Si un conflit surgit entre France et Empire, liés également aux deux adversaires, voilà les Cantons bien embarrassés !

Sans doute, pour se dispenser d'agir, pouvaient-ils invoquer l'ambiguïté même des actes en présence. Le traité de 1511 notamment manquait de précision dans les termes. Le léal regard supposait, le cas échéant, une intervention militaire des Suisses ; mais rien n'en déterminait les conditions. De plus, la clause stipulant réciprocité entre les Cantons et la Franche-Comté pouvait paraître bien illusoire au regard de cette dernière ? Cependant, l'idée d'invoquer ces difficultés d'interprétation ne semble pas s'être présentée tout d'abord à l'esprit des Suisses. Leur solution fut autre : ils s'appliquèrent à prévenir les hostilités entre Comtois et Français.

Le 8 juillet 1522, à Saint-Jean-de-Losne, des représentants de François Ier rencontraient des envoyés de Marguerite et passaient avec eux, pour trois ans, une neutralité englobant, en cas de conflit entre France et Empire, d'une part la Comté ; de l'autre le Duché, le Mâconnais, l'Auxerrois, Bar-sur-Seine, la vicomté d'Auxonne, le comté de Champagne, le Bassigny, les seigneuries de Mézières et de Mouzon-sur-Meuse. Les habitants de ces pays s'interdisaient de rien machiner ni entreprendre les uns contre les autres, et les Comtois notamment prenaient l'engagement de ne fournir ni passage, ni vivres, ni troupes, ni armes à l'empereur Charles ou ses alliés, s'il voulait attaquer le Duché et les pays neutralisés. L'acte était passé « en considération de Messieurs des Ligues » : phrase essentielle ; elle donne la clef de ces négociations.

Car, l'idée d'une neutralité, ce n'était pas la première fois qu'elle se manifestait. Sans parler des tentatives obscures de 1508 - en 1512 déjà, Marguerite d'Autriche avait passé avec le roi de France une neutralité tout à fait analogue. Ce qu'il 
y avait de nouveau en 1522, ce qui explique jusqu'à un certain point que l'acte alors conclu ait souvent passé pour le premier de ce genre - c'était l'intervention des Suisses au contrat. Ils se faisaient les gardiens d'un pacte préventif, destiné à la fois à rendre inutile la clause du léal regard et à faciliter auprès des rois de France leurs intercessions éventuelles en faveur des Comtois. Ce ne serait plus seulement en vertu de l'acte de 1511 -ce serait comme médiateurs de la neutralité qu'ils réclameraient le respect d'un territoire ami. Ils s'en avisèrent dès 1523. Le connétable de Bourbon, sa trahison déclarée, s'était réfugié à Besançon. De là, levant des troupes, il les avait lancées sur la Champagne. Les Comtois, craignant des représailles françaises, eurent recours aux Suisses dans ce moment difficile. Ceux-ci répondirent sur l'heure qu'ils allaient écrire au roi de France « de ne vouloir permettre ne souffrir de envahir ne endommager, par hostilité de guerre ou autrement, les habitants dud. Comté, et ce, suivant le contenu en la neutralité ». S'il passait outre, les Suisses interviendraient pour défendre la Comté « suivant le contenu en la ligue héréditaire ». Ainsi les deux traités de 1511 et de 1522, tour à tour invoqués, apparaissaient comme complémentaires; ils se suppléaient, ils s'étayaient l'un l'autre.

De fait, la Comté leur dut une paix durable, à une époque troublée entre toutes. En lui procurant ce bienfait, ses souverains avaient bien mérité sa reconnaissance. Ils l'avaient mise à l'abri d'un coup de main, d'un rapt violent et sournois ; ils avaient tissé autour d'elle un réseau solide de fils diplomatiques. Dans leur intérêt ? Sans doute, puisqu'il était de conserver la province ; mais plus encore dans son intérêt à elle. Une convention comme celle de 1522 n'était-elle pas de nature à contrarier parfois les desseins de l'Empereur ? Ne le privait-elle pas d'une base d'opérations singulièrement commode contre la Bourgogne et la Champagne ? Maints conflits démontrent, et jusqu'à l'évidence, le désaccord de la politique «bourguignonne » d'un Philippe le Beau avec la politique impériale d'un Maximilien ; et en définitive il apparaît bien nettement que ce que cherchait avant tout, ce que désirait, ce qu'espérait se procurer la Comté en rompant avec la monarchie française, autoritaire et centralisée - c'était le maintien de son autonomie, le respect de ses privilèges, la satisfaction d'un esprit particulariste qui était l'héritage même de tout son passé. 


\section{IV}

Cet héritage, Charles-Quint ne le répudia pas lorsqu'en 1530 la mort de Marguerite lui donna la Comté. Par un codicille de cette année, en date du 28 novembre, sa tante l'avait prié, « pour non abolir le nom de la maison de Bourgogne », de « garder et retenir en ses mains led. Comté » pour le transmettre ensuite à l'héritier des Pays-Bas. Le voeu dit assez la persistance du sentiment bourguignon chez la princesse. Son neveu devait l'exaucer fidèlement.

On sait comment, dans toute la première partie de son long règne, il ne cessa de mettre la question bourguignonne au premier plan de ses préoccupations prompt à revendiquer le Duché au lendemain de Pavie ou même à proposer la reconstitution d'un État flamand-bourguignon. Qu'il fût en outre l'héritier des Habsbourg, jamais, en Comté, il ne parut s'en souvenir. Dès 1521 d'ailleurs, au partage de Worms, en cédant les domaines de la Haute-Alsace et le comté de Ferrette à son frère Ferdinand - il s'était ôté tout moyen d'unir la Bourgogne à l'Autriche antérieure, comme il semble qu'un moment la pensée en était venue à son grand-père. Le regretta-t-il plus tard comme le veut Gollut, écho d'un bruit répandu en Comté - rien à notre connaissance n'autorise à le dire ; rien ne fut tenté en fait pour revenir sur la décision prise.

Il est vrai qu'avec Charles, c'était l'Empereur lui-même qui, directement, gouvernait la Comté. Mais de cette situation nouvelle, la province tirait-elle quelque avantage ? Sans doute, en 1548, presque à la fin du règne, on vit Charles, reprenant un vieux projet de Maximilien, obtenir de la diète d'Augsbourg, par transaction en date du 26 juin, l'incorporation à l'Empire de ses provinces bourguignonnes et flamandes. Mais il ne faut pas se méprendre sur la portée réelle d'une telle union. Elle spécifiait seulement que ces provinces, groupées en une seule région, paieraient une contribution égale à celle de deux électeurs - moyennant quoi elles se verraient placées sous la tutelle et la protection du Saint-Empire. Après comme avant 1548, elles garderaient intacts lois, privilèges, immunités, droits d'appel et de juridiction. L'assistance aux diètes était facultative. Les sujets ne pourraient être cités devant le tribunal de l'Empire ou la Chambre impériale. Ils resteraient 
exempts de toutes charges financières. Bref, les clauses prohibitives étaient aussi précises que l'étaient peu les clauses positives.

En fait, par cette transaction, Charles se proposait moins de donner une garantie nouvelle aux pays d'Embas que de servir les intérêts généraux de la maison d'Autriche. À défaut d'autres preuves, l'étrange conduite qu'il tint en Comté, lorsqu'il s'agit de faire reconnaître et ratifier l'acte d'Augsbourg, l'établirait assez. Il refusa obstinément de le soumettre aux États ; l'approbation d'une assemblée spéciale lui suffit. Le Parlement de Dole, qui enregistrait les traités et les actes diplomatiques, ne fut pas plus saisi de la convention que les États. Pendant tout le cours du XVIe siècle, elle fut lettre morte pour les Comtois ; dans les documents du temps, nous n'en avons pas rencontré une seule mention. C'est que - les documents comtois confirment par leur silence les conclusions des érudits belges - elle était uniquement d'intérêt dynastique; à posséder un empereur pour comte, la Comté ne trouvait ainsi aucun avantage ; elle risquait par contre d'en souffrir.

Pour Charles-Quint, en lutte perpétuelle contre la France, la tentation devait être forte, en effet, d'utiliser l'heureuse position stratégique d'une province accrochée aux flancs du royaume. Premier péril. Mais la France, inversement, ne pouvait-elle songer à une province qu'à deux reprises déjà elle avait possédée ? La première fois qu'en 1531 les États se réunirent sous le nouveau règne, on les vit aussitôt demander à leur maître, comme si son avènement seul rendait une guerre probable, de désigner des places de refuge « en cas d'hostilité et que tout le pays de Bourgogne fût envahi ». Ils le priaient en même temps de faire fortifier quelques villes importantes - et de suite en effet, l'ordre était donné de mettre Dole en défense. Sous la direction du maréchal de Bourgogne, les travaux commencèrent. Un ingénieur réputé, un Génois, Ambroise Précipiano, donna les plans de bastions, de boulevards à la moderne. De Dole passant à Gray, il en fit une place tenable, tandis que de leur côté les Bisontins reprenaient leurs murailles. Cette activité guerrière animait la Comté - mais pour quel résultat ?

Sans doute, Gray et Dole furent rendues capables de subir un siège. C'était bien quelque chose. Occuper brusquement la province, la saisir d'un coup de main, devenait presque impossible. Pourtant, les boulevards à l'italienne de Précipiano ne donnaient toute sécurité ni aux Dolois ni aux Graylois. Il aurait fallu, pour que les places fortes donnassent leur effet, qu'elles fussent appuyées, le cas échéant, par des troupes régulières. Or, il n'y en avait pas. Lorsque les bruits de 
guerre devenaient inquiétants, on faisait vite entrer dans la ville quelques dizaines de compagnons propres à renforcer les soldats ordinaires et les milices bourgeoises. En même temps, le gouverneur faisait passer en revue les « élus » du pays ; avec les plus «duisans » on formait des compagnies. Expédient hasardeux : ces braves gens manquaient d'expérience et de goût pour les armes, sinon pour le pillage ; on avait beau leur adjoindre des étrangers « de Ferrette, Allemagne, Suisses et autres » pour les encadrer - ces amas turbulents de guerriers improvisés faisaient régulièrement plus de mal au pays qu'ils n'inspiraient de crainte aux ennemis du dehors. Quant au contingent du ban et du rièreban, rien n'était plus piteux que ses montres d'armes ; elles ne servaient, à dire de Comtois, qu'à faire connaître aux voisins du pays sa faiblesse. Dans ces conditions, le grand recours du Comté, son appui le plus sûr restait, en 1555 comme en 1530, dans les traités d'alliance et de neutralité. Or, à cet égard, ses fortifications étaient un danger : elles pouvaient lui faire illusion sur sa force. De fait, à côté de la politique traditionnelle de Marguerite, politique de neutralité avec les Français et d'accord scrupuleux avec ces Suisses dont elle disait que « le comté duquel ils seront sera toujours le plus fort » - une deuxième politique naquit, si l'on peut baptiser ainsi l'ensemble des solutions préconisées par la noblesse comtoise : levée de troupes régulières, formation de régiments - donc création par dizaines de charges militaires. De là, la boutade expressive de Granvelle, devant toutes les clameurs de ces « corneguerre » : « Plut à Dieu que n'y à Dole n'y ici, il n'y eût pierre en fortification ; le pays en serait plus à son repoz ! »

Mais Charles-Quint aussi, les murailles des villes pouvaient le rendre plus hardi, et le fait était grave. Sans doute, dès son avènement, l'Empereur avait renouvelé la ligue héréditaire. Et si, à l'expiration de la neutralité qu'en 1527, au lendemain de Madrid, la prudente Marguerite avait fait conclure pour trois années, il ne se pressa pas d'en négocier une nouvelle - du moins ne s'opposa-t-il pas à ce qu'en 1536, sous la médiation des Suisses, François Ier accordât au Comté pour un an et demi une « abstinence de guerre ». Pareillement, en 1542, il ratifia l'acte que, le 28 juillet, au lendemain de la reprise des hostilités, le Comtois Nicolas de Gilley et le Duchois Philippe Chabot avaient passé pour quatre ans - sans intervention d'ailleurs des Cantons. Mais l'Empereur, comme on voit, suivait, ne devançait pas le désir de ses sujets. Même quand il les ratifiait, il supportait impatiemment de telles conventions. Donne-t-il l'ordre de mettre les villes en défense ? 
Il ne peut s'empêcher de remarquer combien avantageuse est l'assiette du Comté pour « endommager les Français selon les occasions ». S'agit-il, en 1544, de renouveler la neutralité, et, pour la première fois sous son règne, de la renouveler conformément au précédent de 1522 ? Comme on lui demande s'il y faut comprendre le Mâconnais, la Champagne et le Bassigny, c'est d'un ton irrité qu'il répond non : la déclaration de Marguerite, reconnaissant en plus du Duché ces provinces pour neutres, « c'estoit un pact personnel, estainct par sa mort »; et voulait-on le voir immobile, les mains liées, en face du royaume ? On comprend ainsi la réflexion désabusée d'un François Bonvalot, travaillant en 1551 à un renouvellement de neutralité : «Bien entendu, écrit-il, qu'il est à croire que l'Empereur nous aymera mieux conserver par ce moyen que de nous perdre à faulte d'iceluy $» . .$.

\section{V}

Intéressant conflit, en Charles-Quint même, de l'Empereur et du comte de Bourgogne - de l'héritier de Marguerite et du successeur de Maximilien. Ainsi revivait, dans sa seule personne, le dualisme qu'on avait pu croire aboli en 1530. Ainsi, même sous un maître qui était l'Empereur et dont les soucis s'étendaient à l'Europe, la petite Comté, avant tout, songeait à son destin, à son indépendance, à son autonomie. L'Empire, elle l'ignorait. Si quelques liens, au cours d'une longue histoire, l'avaient rattachée à lui - relations pour relations, celles qu'à deux reprises elle avait nouées avec le royaume avaient été infiniment plus étroites et fécondes. Le germanisme ? Elle n'avait rien de commun avec lui. Elle pouvait haïr politiquement les Français ; elle ne s'en plaisait pas moins à manifester un curieux patriotisme linguistique " gaulois » et à revendiquer, comme un titre d'honneur, ses origines celtiques. Possédée, gouvernée par l'Empereur Charles-Quint, elle entendait rester bourguignonne sous un prince bourguignon.

Malgré tout cependant, des influences supérieures dominaient la Comté ; audessus de sa volonté, une autre s'exerçait, plus puissante et qui pouvait la plier à son service, l'asservir à ses fins. Situation anachronique : c'était au moment où, dans la France élargie, la Bourgogne à son tour venait prendre place que la Com- 
té, française par ses habitudes, avait rompu une fois encore avec le grand pays qui la guettait à l'ouest. Mais situation logique aussi. Ne résultait-elle pas d'un passé en accord avec les forces naturelles - d'un long passé de particularisme accepté, en toute lucidité, par un pays où l'action prolongée de nécessités géographiques et d'influences historiques avait créé, avait nourri un sentiment profond de nationalité ? 


\section{PHILIPPE II ET LA FRANCHE-COMTÉ \\ Étude d'histoire politique, religieuse et sociale. \\ Première partie. La Comté à la veille du règne de Philippe II \\ Chapitre III \\ Le gouvernement}

$\underline{\text { Retour à la table des matières }}$

Une petite nationalité, vigoureuse et consciente d'elle-même, mais dont les destins pour une part dépendaient d'autrui : ainsi pouvait du dehors se définir la Comté. Un petit État largement autonome, possédant ressources, traditions et institutions propres, mais soumis aux volontés d'un maître étranger et lointain : telle elle apparaissait du dedans à qui la regardait vivre de sa vie intérieure.

En d'autres termes, assurer l'existence d'une province à la fois indépendante et subordonnée, isolée mais rattachée par son souverain à un grand État : le problème était double. Nous avons vu comment Charles-Quint, acceptant l'héritage et prenant la suite de ses prédécesseurs, avait réglé les relations de la Comté avec l'Empire et les puissances voisines. Pour doter la province d'un gouvernement en accord avec ses conditions générales d'existence, ce fut pareillement la solution de Marguerite qu'il adopta.

Dès le début de 1531, les États du Comté, réunis à Dole, posaient à leur nouveau souverain une question toute pratique, mais importante : à qui recourir désormais, à l'Empereur directement ou à sa soeur, Marie de Hongrie, nouvelle ré- 
gente des Pays-Bas, pour obtenir les « dépesches » dont ils étaient « coustumiers supplier et faire requeste à leur prince et souverain seigneur » ? Charles-Quint répondit : «Il est pourvu au contenu de cet article par l'ordonnance particulière baillée à la Reyne douhairière d'Hongrie et ceux du privé conseil devers elle, touchant led. Comté et compréhension d'iceluy sous la régence de lad. dame. » Ainsi, Charles, suivant le voeu de Marguerite, ne séparait pas des États de Flandre «le plus vieux patrimoine de la maison de Bourgogne ».

C'est par lettres patentes, datées à Bruxelles le Ier octobre 1531, que l'Empereur, considérant à la fois « la situation dud. comté de Bourgogne » et la bonne affection de sa soeur Marie pour ce pays « lointain », avait décidé qu'il serait « compris soubz sa régence ». Les Comtois auraient recours à elle " pour provisions et grâces tant civiles que criminelles... par dessus le train et cours d'ordinaire justice ». Ces provisions et ces grâces seraient dépêchées au nom de Charles, « avec l'avis de ceulx du privé conseil et des finances »; mais le Parlement de Dole, les « baillifs, gruyer et autres justiciers » de la province garderaient « l'administration ordinaire de justice » sans que le privé conseil s'en dût « mesler ny empescher comme qu'il soit », si ce n'était « pour tant grande et notable occasion... que nostred. soeur, avec meurs et bon avis... cogneut estre besoing d'y pourveoir par elle-mesme ». Et non seulement, de tels cas exceptés, le conseil ne pourrait «prendre ni évoquer connaissance » d'aucune cause ou matière intéressant un ou des sujets du Comté ; mais encore, ses membres flamands n'ayant aucune expérience personnelle des hommes ou des choses du Comté, Charles-Quint ajoutait : «Voulons qu'à la dépêche de tous affaires qui se pourvoyeront devers nostred. soeur, entreviennent toujours de noz conseillers dud. Comté, habituez et expérimentez èsd. affaires, afin de les dépescher meurement. »

Tel était le lien qu'entre la Comté et les Pays-Bas nouait son nouveau maître. Lien étroit? Nullement.

Il aurait pu l'être, si l'Empereur avait étendu sur la Comté les attributions des conseils de par delà. Mais, seul, le Conseil des finances était investi d'un droit de contrôle sur la gestion du domaine en Comté : il pouvait statuer sur les demandes d'accensement ou d'amodiation - avis pris, d'ailleurs, des gens des comptes de Lille avant 1562, de Dole après cette date. Il s'occupait également des provisions de deniers, gages, pensions et mercèdes, des dépenses militaires ; bref, comme dit Gollut, de tout ce qui concernait « les biens, les trésors et le mont d'or de S.M. ». 
Pour les autres, rien de pareil. Si le Conseil privé était appelé à examiner quelque affaire comtoise, sa consultation devait lui être demandée spécialement par la gouvernante des Pays-Bas, et sans qu'il reçût par là pouvoir de rien trancher. Quant au Conseil de Malines, une délibération très intéressante que nous avons retrouvée dans les Notules inédites du Conseil d'État, à Bruxelles, nous éclaire sur le rôle que s'attribuait à lui-même, en Comté, ce corps si jaloux de ses prérogatives et si porté à les exagérer. Le duc de Wurtemberg, comte de Montbéliard, mécontent d'un arrêt du Parlement de Dole, alléguait « quelques exemples de révisions de sentences de Bourgogne faictes aud. Malines » pour solliciter pareille mesure en sa faveur. Consultés par le Conseil d'État sur la portée des précédents allégués, les conseillers de Malines répondirent n'avoir constaté sur leurs registres, « dois l'an XVII en ça, aucune sentence rendue par arrêt du Parlement à Dole... dévolue pour revision aud. grand conseil ». Si quelques causes avaient été évoqués « dud. Bourgoingne aud. grand conseil », ç'avait été « par consentement des parties ».

Du moins, à défaut d'une subordination par les institutions, aurait-on pu chercher à établir une subordination par les personnes, déléguer en Comté, dans les grandes charges, des Flamands? Mais cette rupture avec une tradition constante et chère entre toutes aux Comtois, l'Empereur n'entendait pas l'accomplir ; au contraire, c'est dans ses patentes de 1531 qu'est inscrite l'obligation de faire examiner par un ou plusieurs Bourguignons les affaires bourguignonnes venant aux Pays-Bas. Les Comtois prétendaient tirer de là qu'un de leurs compatriotes devait toujours siéger au Conseil privé, avec charge spéciale des choses de son pays. C'était forcer le sens d'une phrase mal rédigée. Mais de ce texte, même interprété de la manière la plus défavorable aux prétentions comtoises, ne résultait pas moins avec netteté la distinction d'un personnel comtois et d'un personnel flamand, cantonnés tous deux sur leur domaine respectif. De fait, s'il y eut toujours, sous Charles-Quint et sous Philippe Il, des Comtois « par deçà » dans les conseils, il n'y eut jamais alors de Flamands en Comté, ni au Parlement, ni dans les bailliages, ni dans les charges de guerre, de finance, de justice.

Ainsi, c'était un lien fort lâche qui unissait la Comté aux Pays-Bas. Ou plutôt, aucun lien n'unissait ces deux pays. L'Empereur, s'étant déchargé des affaires bourguignonnes sur sa soeur, lui avait délégué par surcroît une part de sa souveraineté : le droit de délivrer aux Comtois les « dépêches » sollicitées sur leurs re- 
quêtes. Comme Marie résidait aux Pays-Bas, comme elle y prenait l'avis du Conseil privé - c'était aux Pays-Bas et devant ce Conseil que venaient normalement les requêtes comtoises. Pour tout le reste, la Comté gardait « son ranc à part » et pouvait avec Gollut s'en enorgueillir.

D'ailleurs, toute autre organisation n'aurait-elle pas risqué d'être illusoire ? Au XVIe siècle, une grande distance séparait la Bourgogne des Pays-Bas. De Dole à Bruxelles par la voie de Lorraine et du Luxembourg, un cavalier, voyageant à bonne allure mais sans forcer les étapes, mettait en moyenne une quinzaine de jours. En 1575, le conseiller de Boisset atteint Valenciennes en onze jours : mais il est parti de Gray, à une bonne journée de Dole ; Valenciennes n'est pas Bruxelles ; enfin, il a pris par la Champagne en coupant au court. Dans un cas urgent, un messager, une estafette spécialement expédié de Comté aux Pays-Bas pour demander un avis ou des ordres, n'aurait pu être de retour, sa commission faite, qu'après un délai d'environ vingt-cinq jours. A l'ordinaire, les lettres demandaient quinze jours, plutôt plus que moins, pour arriver de Bruxelles à Dole. Par exemple, le Parlement recevait à Dole, le 4 Septembre 1566, des lettres de Marguerite de Parme en date du 17 août - donc, dix-huit jours après leur signature. En 1567, le 20 décembre, il recevait des lettres du duc d'Albe en date du 3 : délai, dix-sept jours. En 1571, le 17 juin, il en recevait d'autres datées du 31 mai : même délai. Le conseiller de Boisset, écrivant d'Anvers deux lettres à ses confrères, les 21 octobre et 2 novembre 1575, elles parvenaient à Dole, respectivement, les 10 et 17 novembre, après vingt et quinze jours de voyage. Du reste, c'est seulement en 1577 que, par ordre de don Juan, une ligne de postes fut tracée directement des Pays-Bas à Lyon par la Lorraine et la Comté. Elle se détachait à Flamisoul, dans le Luxembourg, de la grande ligne Rheinhausen-Malines tel que la décrit en 1563 l'Itinerario delle poste de Da l'Herba; quittant la Lorraine à Monthureux-surSaône, elle passait ensuite à Bougey, Fleurey-les-Lavoncourt et Dampierre-surSalon, gagnait Gray, Pesmes et Dole, puis (par Mont-sous-Vaudrey) Lons-leSaunier et, par Conliège, Arinthod sur la route de Lyon. Mais au début, cette ligne postale fonctionna très médiocrement, et d'ailleurs, les courriers mettant encore quinze jours de Lyon à Bruxelles, son établissement ne faisait guère gagner qu'un ou deux jours aux correspondances à destination de Dole.

Ainsi, tous nos textes concordent ; tous pour leur part démontrent combien une union stricte, une subordination étroite de la Comté aux Pays-Bas aurait pré- 
senté de difficultés. Au XVIe siècle, dit-on souvent, la Comté était rattachée aux Pays-Bas. Formule inexacte; il faut dire simplement qu'à cette époque, sous l'Empereur lointain et voyageur, son chef résidait à Bruxelles. Mais de ce chef, quelle était l'action sur le gouvernement local de la province ? et d'abord, quels liens, quelles relations existaient entre lui et l'homme - le gouverneur - qui en Comté représentait le prince à la tête du pays ?

\section{II}

Les hommes plutôt - car ils étaient deux, et Gollut retrace ainsi l'origine de leur double pouvoir : «Pendant que nous havons heüx noz princes résident ou visitant nostre païs... nous estions gouvernés par le prince mesme..., mais estant advenuë l'alliance de la maison impériale d'Autriche, les princes ne pouvans havoir commodité de résider auprès de nous ny de visiter souvent le païs, l'on feit institution de gouverneurs et de capitaines qui havoient leurs lieutenans ; et si en oultre l'on adjoustoit un mareschal qui, soubs ledict gouverneur, demeuroit chef des gens de guerre. »

Ces gouverneurs, ce furent d'abord des seigneurs du pays, les plus puissants de tous - les chefs de cette maison de Chalon qui possédait au milieu du Comté des domaines considérables : Jean de Chalon, par exemple, puis Philibert, son fils. Titulaires peu résidents ; du moins tenaient-ils à la province par le passé glorieux de leur lignage comme par leurs possessions territoriales. Mais, en 1530, leur race s'éteignit. Un étranger, René de Nassau, recueillit leurs domaines ; par surcroît, revêtu du gouvernement, il devint le délégué du Comte-Empereur dans une province qu'il connaissait mal et ne devait pas habiter. Si ses prédécesseurs avaient eu d'actifs suppléants - à plus forte raison en dut-il réclamer : le gouvernement fut en fait exercé, de son vivant, par quelques grands personnages comtois, un Claude de la Baume, un Claude de Vergy. Ce dernier surtout, nommé en 1537 par Charles-Quint son «lieutenant commis au gouvernement de ses pays et Comté de Bourgogne », fut, en l'absence du titulaire, le véritable gouverneur ; plus tard, en 1564, lorsque René de Chalon eut succombé sous Saint-Dizier, il assuma seul la charge de conduire la province. 
Des gouverneurs en titre, le pouvoir n'était guère qu'un nom, la charge qu'un honneur plus ou moins profitable ; ainsi le voulaient les circonstances. De leurs lieutenants par contre, il est intéressant d'examiner le rôle. Faisaient-ils figure de chefs omnipotents ? mais d'abord ils n'étaient que des suppléants. Claude de Vergy lui-même, c'était l'absence puis la disparition du titulaire qui, peu à peu, avaient fait sa grandeur. Seigneur de haute lignée, on le révérait sans doute ; mais parmi les nobles il comptait des égaux ; il n'avait pas sur tous cette supériorité de la puissance, de la fortune, du rôle historique qui avait fait des Chalon, tant qu'ils avaient vécu, les chefs incontestés des gentilshommes comtois. Trop faible pour un tel rôle, il ne l'était pas assez pour être simplement l'agent docile du maître : un instrument. Dans une province isolée, entourée de menaces, il devait conserver nécessairement, en fait sinon en droit, une large initiative. Et puis surtout, La Baume ou Vergy, le lieutenant gouverneur avait ses ancêtres, ses traditions de famille, ses alliances et ses inimitiés. Il n'était pas homme nouveau, tirant de sa seule charge toute son autorité. Ainsi, ni simple exécuteur d'ordres venus de loin, ni maître despotique d'un État provincial - qu'était-il en réalité ? L'étude des fonctions exercées, à ses côtés, par un petit conseil de gouvernement : celui des bons personnages, va nous permettre de le déterminer.

L'institution est curieuse. Sa prompte décadence explique sans doute que les érudits comtois en aient mal vu et souligné l'importance au temps de CharlesQuint. Les textes cependant ne font pas défaut ; ils présentent, il est vrai, quelques difficultés. Tantôt en effet le nom de bons personnages désigne simplement les plus notables représentants des divers ordres du pays, sans spécification particulière ; tantôt, revêtant un sens plus précis, il s'applique aux quelques Comtois de haute situation - quatre généralement - que le maître, par commission régulière, a institués « bons personnages commis aux affaires d'État ».

Or, de ces derniers, vers 1550, le rôle est considérable. Dès qu'un cas un peu grave se présente - difficulté diplomatique, danger de guerre, trouble intérieur - le gouverneur doit les convoquer et les entendre ; eux, de leur côté, doivent l'aider et non seulement de leurs conseils, mais de leur personne : obligation stricte, qu'une Marie de Hongrie ou un Charles-Quint ne cessaient de rappeler à un Claude de Vergy. À l'occasion, du reste, les bons personnages, conscients de leur responsabilité, savaient fort bien réclamer leur part de direction; n'est-ce pas l'un d'eux, François Bonvalot, beau-frère de Nicolas Perrenot, qui, priant le gouverneur en 
1551 de dénoncer à l'Empereur des menées françaises, terminait ainsi sa lettre : « Vous et nous aultres, quy avec vous sommes commis aux affaires d'Estat en ce pays, serons par ce moyen décharger de ce que méritoirement l'on nous pourrait imputer, et à vous, Monsieur, principalement, à faulte d'y donner ordre. » D'ailleurs, il suffit de lire, dans les Papiers d'État de Granvelle, les autres lettres du même Bonvalot pour sentir l'importance de sa collaboration.

Dès lors, qu'est le gouverneur ? Simplement, le premier des bons personnages, le président-né de leur assemblée à sessions intermittentes. Non seulement, il ne doit rien faire de décisif sans les consulter, mais souvent même, dans les cas difficiles, on le voit leur adjoindre un certain nombre de bourgeois ou de gentilshommes particulièrement compétents : les bons personnages au sens large du mot. Flanqué de tels conseillers, lié à leur avis - bien plus que l'homme du souverain, il est le porte-parole de l'opinion publique qu'il consulte toujours et dont il traduit les désirs à la cour des Pays-Bas et de l'Empereur. Il représente le maître en Comté, sans doute - mais, mieux encore, la Comté près du maître.

\section{III}

Ce qui est vrai du gouverneur l'est, à plus forte raison, de ce grand corps aux attributions multiples, à la compétence étendue, à l'action prépondérante dans la province qu'était le Parlement de Dole. Composé « de plusieurs personnages représentans le prince, et, en plusieurs chefs, la souveraineté d'iceluy », d'une part, il jugeait « de toutes matières par arrest, sans moyen d'appellation quelconque »; de l'autre, possédant « toutes les puissances de la souveraineté », il pouvait « adviser sur les constitutions du prince », les « émologuer, publier, surseoir à son gré », faire des édits et « dispenser contre eux »; bref, " commander ce que le prince commanderait ». Droits politiques et droits judiciaires : la définition de Gollut met bien en lumière le double caractère qu'ils conféraient à « la court de Bourgogne » : c'était un conseil de justice doublé d'un conseil d'État.

Ses origines ne remontent pas très haut. «Presque la dernière en institution entre les magistrats qui gouvernent et hont conduicts la Franche-Comté », la compagnie avait été instituée sous sa forme moderne par deux ordonnances, du 30 
septembre 1500 et du 12 février 1508-09, qui en avaient placé le siège à Dole, réglé la composition et déterminé les attributions. Charles-Quint prenant possession du Comté l'avait réinstitué par patentes du 15 février 1530-31 ; ses lettres lui attribuent un président ; deux chevaliers d'honneur ; onze conseillers dont deux ecclésiastiques ; enfin, deux fiscaux, d'abord simples avocats chargés des causes domaniales et fiscales du prince, mais plaidant à côté pour les particuliers ; puis, à partir de 1542, assimilés par le traitement aux conseillers et astreints dès lors à donner tout leur temps au service du maître. Un procureur général et son substitut formaient le parquet ; un greffier et son commis - on disait parfois, par analogie, son substitut - le greffe ; quatre huissiers ordinaires et un chapelain terminaient la liste des titulaires d'office portés sur les patentes.

Répartis depuis 1542 en deux chambres, de composition variable du reste, mais se réunissant en assemblée plénière pour les « cas d'emport » ou les affaires d'État, les parlementaires siégeaient à Dole, sauf lorsqu'une épidémie, une peste soudaine les obligeait à fuir devant le mal et à chercher ailleurs, à Salins, à Poligny, à Arbois, à Vesoul, un air moins vicié et des logis plus sains. En temps normal, chaque année, au lendemain de la Saint-Martin d'hiver (11 novembre), la grave troupe des hommes rouges, laissant là les soucis qui suivent la vendange, ralliait la petite capitale du Comté. Une séance de rentrée, où le plus souvent se trouvaient gouverneur et bons personnages ; une longue procession en robes écarlates vers la collégiale de Notre-Dame; une messe solennelle où jouaient les grandes orgues offertes par la cour - puis les travaux de l'année commençaient. Jusqu'à la veille de Saint-Thomas apôtre (21 décembre), c'était une première session terminée par les premiers arrêts ; une seconde suivait, du lendemain de l'Épiphanie (7 janvier) à la veille de Pâques fleuries ; puis deux autres encore, du lundi de Quasimodo à la veille de la Pentecôte et du lundi après l'Eucharistie à la veille de la Nativité Notre-Dame (8 septembre) : des séances d'arrêts solennels les terminaient toutes également. Chaque lundi et chaque jeudi, du 12 novembre au 15 juillet, la cour tenait deux audiences publiques de deux heures chacune ; du 15 juillet au 7 septembre, elle se consacrait exclusivement aux causes domaniales et fiscales intéressant le souverain.

Naturellement, les fonctions proprement judiciaires absorbaient la majeure partie de son temps. La cour de Dole était, dans toute la force du terme, le tribunal suprême du Comté. C'était elle qui surveillait et réglementait les justices inférieu- 
res ; relevait les appels des bailliages comtois et même du Charolais ; luttait sans trêve contre les tribunaux d'Église, les justices militaires, les franchises de l'université de Dole ; évoquait enfin les causes de ses membres, des officiers domestiques du souverain «comptez par ses escrocs », des veuves, orphelins, pupilles « et autres misérables personnes ». Il est vrai que, par contre, le prince gardait le droit d'évoquer en son consistoire toutes causes, «voire celles pendantes en la court ». Mais, comme les privilèges du Comté défendaient de tirer en cause les habitants hors des frontières, Sa Majesté n'abusait pas de son droit ; elle n'en usait que pour grandes et urgentes raisons, et laissait ordinairement intact le pouvoir judiciaire de la cour souveraine. Plus important encore, du reste, son pouvoir administratif et proprement politique.

De bonne heure en effet, dans leur propre intérêt, les souverains avaient favorisé les ambitions des conseillers. En 1510, pour ne pas remonter plus haut, Marguerite d'Autriche, les associant officiellement à la direction de la province, avait contraint le vieux maréchal Guillaume de Vergy à partager avec eux le poids des affaires. Les féodaux résistèrent ; ils organisèrent contre les légistes la plus violente campagne : en vain. Ils trouvèrent leurs maîtres dans ces bourgeois énergiques et subtils, pour lesquels d'ailleurs combattait le temps même. Il fallut se résigner, reconnaître leurs droits toujours plus étendus, subir leur autorité sans cesse agrandie.

\section{IV}

De fait, au temps de Charles-Quint, qu'était, comparée à la sienne, la part du gouverneur dans les affaires provinciales ? Sur le personnel administratif d'abord, un Claude de Vergy n'a ni prise ni autorité. Du Parlement dépendent les officiers des bailliages, de la gruerie, de la saunerie. Sans doute, bien des nominations échappent aux conseillers; le souverain en personne choisit le Pardessus de la saunerie de Salins, chef de l'importante administration des Salines ; il désigne le grand gruyer, placé à la tête du personnel forestier; il prend dans les rangs de la noblesse militaire les trois baillis d'Amont, d'Aval et de Dole. Grands seigneurs, parfois revêtus de leur charge dès l'enfance, ces derniers ne résidaient guère. Ils 
vivaient à la cour, remplissant près du maître des fonctions de domesticité, et comme l'écrit Granvelle : « Les lieutenants sont ceux qu'administrent la justice ; et n'est le bailly en chief que pour l'honneur et y bailler auctorité ». Or, ces lieutenants, les baillis les choisissaient eux-mêmes, en toute liberté : lieutenants généraux, un par bailliage, leurs véritables suppléants; lieutenants locaux, de bien moindre autorité et situation, les uns et les autres d'ailleurs faisant figure d'employés du bailli plutôt que d'officiers : employés non payés, révocables à merci au gré de qui les nommait et perdant leur place lorsqu'il disparaissait.

Dans tous ces choix, le Parlement n'intervenait donc pas. Déjà cependant, il s'assurait des droits ; il posait habilement des jalons pour l'avenir. Lorsqu'un bailli mourait, il maintenait provisoirement en charge son personnel. De même quand un lieutenant cessait ses fonctions : il pourvoyait le siège vacant d'un « commis » qui l'occupait jusqu'à installation du nouveau titulaire. Surtout - et c'était l'essentiel - une fois nommés, lieutenants généraux et locaux, avocats et procureurs fiscaux, tous les membres de l'administration bailliagère se trouvaient soumis au contrôle de la cour. Elle les surveillait, les rappelait à l'observation des ordonnances, leur distribuait des amendes, les « calangeait » même ou les déportait et les dégradait. De plus en plus s'accentuait, au temps de Charles, l'évolution qui devait aboutir à faire des lieutenants non plus les serviteurs des baillis, mais des officiers de justice indépendants de ceux-ci ; de plus en plus se resserraient les liens qui les unissaient à la cour de Dole.

Et puis, ce n'était pas seulement le personnel judiciaire et administratif, mais l'administration même du Comté que le Parlement possédait en main. Tous les ans, à la rentrée de la Saint-Martin, la cour recevait à Dole les lieutenants généraux des trois bailliages, ceux de la gruerie et de la saunerie - parfois les trésoriers. Chacun de ces personnages présentait, sous forme d'articles aussitôt enregistrés, une sorte de rapport sur sa circonscription ; il proposait les mesures de police ou de voirie urgentes; réclamait, s'il y avait lieu, l'envoi de parlementaires en mission spéciale pour suivre quelque affaire grave ; soumettait à la cour des projets d'édits, qu'elle rejetait, ajournait ou s'appropriait. Tout défilait ainsi devant les conseillers : questions de sûreté générale, de criminalité, d'hérésie ; vie rurale dans ses manifestations diverses ; réglementation des pâtures, de la chasse, de la pêche ; mise en défens des bois, des vignes, des prairies ; surveillance des métiers ; entretien des routes, des ponts et des rivières ; révision des tarifs de péage ; 
régularisation du cours des monnaies ; protection des foires et des marchés ; exportation du sel, du fer, des vins, du grain ; prix des repas dans les hôtelleries : saisi de tout, le Parlement tranchait tout, seul, souverainement.

Banni de cet immense domaine, le gouverneur du moins s'était-il réservé les questions extérieures, le soin et la conduite des négociations d'alliance et de neutralité ? Sans doute, il prenait sa bonne part des soucis causés au pays par les exigences de Messieurs des Ligues. Mais le Parlement collaborait avec lui - comme y collaboraient les bons personnages. Toute décision prise résultait d'une entente de ces pouvoirs divers et l'initiative, bien souvent, n'émanait pas du gouverneur. Mais les questions militaires ? Là, cet homme d'épée devait être le maître. N'étaitce pas lui qui, chargé par le souverain de recevoir le serment et l'hommage des féodaux à chaque mutation de fief, devait convoquer le ban et le rière-ban, le passer en revue, décréter en cas d'alarme « l'éminent péril », prendre à l'occasion le commandement des forces provinciales, surveiller enfin et diriger la fortification de Dole et de Gray ? - Sans doute ; mais là encore, se dressait devant lui le Parlement ; le Parlement, chargé, prétendait-il, de traiter avec le gouverneur et d'un commun accord tout ce qui concernait la conservation du pays, sa défense et sa sûreté ; le Parlement, toujours prêt à s'occuper des passages de troupes à travers la province et de l'administration des affaires militaires. Derrière le gouverneur qui commandait et exécutait, on trouvait souvent les conseillers qui aidaient et guidaient. Ainsi, tandis qu'à Autrey résidait un Vergy, un second gouverneur siégeait à Dole, bien plus puissant encore et bien plus compétent - un gouverneur collectif, fort de ses traditions, de la faveur du prince et de sa pérennité. Or, quels liens l'unissaient à ce prince ? dans quelle dépendance se trouvait-il de lui ?

Dépendance assez faible, si l'on regarde les faits. D'abord, le Parlement était un corps exclusivement comtois. Point d'étrangers à sa tête ni parmi ses membres - et comptaient comme étrangers, à Dole, tous les sujets de Charles-Quint hormis les Comtois. Ensuite, les conseillers se recrutaient eux-mêmes. Non qu'ils nommassent directement aux places vacantes: ils désignaient au scrutin public, en assemblée plénière, trois candidats « idoines et suffisants », remplissant les conditions requises de savoir, de pratique et de non-parenté, parmi lesquels le souverain ou son représentant aux Pays-Bas exerçait un choix définitif. Seul, le président n'était pas soumis à cette nomination ; le prince le choisissait librement, sans que rien restreignît sa liberté. D'ailleurs, le futur conseiller muni de ses lettres, tout 
n'était point fini pour lui. Il devait revenir devant la cour, présenter ses pièces au président qui, avis pris s'il le fallait des conseillers, pouvait refuser de l'admettre au serment et de l'installer. On n'avait garde d'oublier à Dole qu'en 1526, Marguerite ayant institué conseiller Humbert de Boisset « au lieu d'un sien oncle, sans nomination » - c'est-à-dire, sans qu'il eût été présenté par la cour - la compagnie l'avait tout d'une voix repoussé. Et, constatent les registres, « ceste délibération a heu tant d'effet, que jamais led. messire Humbert de Boisset n'a jouy dud. estat, encoires qu'il en eust lettres patentes ». Une fois reçu, il est vrai, c'était pour toujours ; la mort seule pouvait terminer la carrière des conseillers, même débiles et plus que fatigués - s'ils ne jugeaient pas bon de résigner leur office.

Dans de telles conditions, quelle action efficace pouvait exercer sur ce grand corps un Charles-Quint, n'ayant guère de loisirs à consacrer à la petite Comté, ignorant le détail des affaires locales et habitué précisément, pour se renseigner, à recourir au Parlement? Même remarque en ce qui concerne une Marie de Hongrie : ce ou ces conseillers bourguignons, que d'après les patentes de 1531, elle devait consulter lorsqu'une affaire comtoise venait au Conseil privé, n'étaient-ce pas presque tous d'anciens parlementaires, imbus des traditions, des partis pris, des préjugés de leur compagnie d'origine, et qui, seuls Comtois à Bruxelles, au milieu de Flamands à moitié hostiles, ne songeaient point là-bas à se séparer de leurs compatriotes ? Le gouverneur ? Mais son rôle était si restreint dans la province ! Sur tant de questions, économiques ou judiciaires, il ne devait et ne pouvait avoir d'opinion ? Et quand il en avait, ou bien elles concordaient avec celles de la cour, ou bien, si elles en différaient, le prince ou son lieutenant s'en pouvaient défier : le gouverneur, après tout, n'était-il pas un de ces féodaux contre qui les Parlements avaient été créés ?

Président du conseil des bons personnages, un Vergy représentait plutôt la noblesse près du prince que près de la Comté le prince. Mais le Parlement n'était-il pas, lui, le porte-parole de la bourgeoisie? 


\section{V}

Gouvernement particulier et Parlement de Dole : institutions permanentes, dont les représentants, désignés par le souverain, tenaient de lui leurs pouvoirs, du moins en théorie. À côté, une assemblée à sessions temporaires représentait les seuls sujets du Comté, dans la diversité de leurs intérêts sociaux.

Pleinement constitués au milieu du XVIe siècle sous leur forme moderne, les États se composaient alors de trois chambres. Celle de l'Église, ayant à sa tête, de droit, l'archevêque de Besançon ou, à son défaut, le haut doyen du chapitre métropolitain, comprenait abbés, prieurs, doyens, prévôts et délégués des chapitres, recteurs des principaux hôpitaux et quelques autres personnages. Celle des nobles, dont on élisait chaque fois le président, réunissait les gentilshommes possédant fief dans la province ; le représentant du comte de Montbéliard et celui du prince d'Orange y siégeaient en bonne place. Celle du tiers enfin, dite Chambre des villes, avait à sa tête vers 1550, de droit, le lieutenant général d'Amont ; comme membres : les deux avocats fiscaux du Parlement ; les deux lieutenants généraux d'Aval et de Dole ; les procureurs et avocats fiscaux des trois bailliages ; le lieutenant général de la gruerie ; le receveur général et les trésoriers généraux ; enfin, les mayeurs des sept villes à mairie d'alors et les échevins de quelques bourgs importants. Les trois chambres délibéraient séparément, prenaient leurs résolutions à la majorité et communiquaient entre elles par des députés. Leurs droits, d'ailleurs, étaient égaux.

Voter le don gratuit, prérogative fondamentale des États. Ils en possédaient, ils en prétendaient d'autres, sans doute : mais s'il faut distinguer celles qu'ils avaient en droit, celles qu'ils avaient en fait, celles enfin qu'ils désiraient avoir - parmi les premières, celle-là était de beaucoup la plus importante qui leur conférait dans la province presque exclusivement, le pouvoir financier.

La Comté, en effet, ignorait les impôts fixes et réguliers. C'était pour ses habitants une grande cause de fierté. Il faut voir avec quelle joie naïve Gollut ayant accumulé en une tirade rabelaisienne les noms de toutes les taxes qui foulaient lourdement ailleurs le pauvre peuple : tailles et crues, huitièmes, septièmes et qua- 
trièmes des choses vendues au détail, aides et impositions pour livres, aunes et mesures des marchandises, greniers à sel, imposition foraine, confiscations en tous cas de perte de corps, taillon pour la gendarmerie, équivalences, décimes, fiefs-francs, emprunts, s'écrie en terminant: «Dieu grâce, nous n'avons aucune nouvelle de telles charges, comme directement contraires à nos anciennes franchises. » Il fallait de l'argent pourtant ; il fallait, d'une façon ou de l'autre, trouver ces deniers qui sont (l'expression est jolie) « comme les ailes légères du corps politique ». Certes, la province offrait déjà à son maître, « comme dot de son maryage avec la république de Bourgogne », un grand et riche domaine, de revenu notable. Mais, pour subvenir aux dépenses publiques, d'autres ressources étaient nécessaires : les dons gratuits les procuraient.

Dénomination flatteuse pour l'amour-propre comtois. Il ne faut pas, sans doute, la prendre à la lettre. D'abord, les États ne se convoquant pas eux-mêmes, c'était le souverain qui, les réunissant, déterminait l'heure et la fréquence de leurs générosités. D'autre part, il ne manquait jamais de leur indiquer le chiffre de ses désirs, et si toujours les chambres en adoptaient un plus modeste, c'est que toujours aussi le prince demandait trop pour obtenir assez. Mais, ces réserves faites, les droits financiers des États restaient considérables : il les faut étudier d'un peu près, puisqu'ils étaient la source de leurs droits politiques.

D'abord, les États ne se bornaient jamais, ou presque jamais, à voter au souverain le don gratuit proprement dit. Ils décidaient en plus la levée d'un « suspect », somme moindre, mais encore assez considérable, destinée à récompenser les meilleurs serviteurs du pays : Nicolas Perrenot, le cardinal de Granvelle, le gouverneur de la province, le président de Bourgogne, les bons personnages.

Les États, en séance, taillaient, non sans controverses, leurs parts respectives, et ces privilégiés à eux seuls emportaient la bonne moitié de l'argent ; avec le reste, une commission récompensait les bonnes volontés subalternes : petits nobles, bourgeois entreprenants qui invoquaient des services militaires, des missions diplomatiques en Suisse ; enfin, le peuple infime des secrétaires, huissiers, sergents et messagers. Tout un monde de convoitises s'agitait autour du « surgect ». Pour entrer dans la commission chargée de le distribuer, de la part des plus riches et des plus grands les brigues étaient opiniâtres, et l'on vit parfois des assemblées d'États, impuissantes à satisfaire des ambitions effrénées, doubler le nombre de délégués et, au lieu de neuf, en désigner dix-huit. 
Don gratuit et sujet une fois votés, une commission de neuf membres, élue par les trois chambres, entreprenait « l'également de la contribution ». Elle dressait un état général des deniers à percevoir (don gratuit, surget, frais de perception et de répartition, sauf en ce qui concerne les commis aux récompenses, payés sur le sujet) ; puis elle divisait entre les trois bailliages la somme totale ainsi obtenue. Leurs parts contributives étaient inégales ; moins étendu, celui de Dole était aussi moins chargé ; il fournissait à peine un peu plus du cinquième de l'argent voté ; Celui d'Aval par contre était le plus lourdement imposé. L'état général dressé, la commission des neuf se scindait en trois commissions de trois membres, chacune employée à dresser l'état particulier d'un des bailliages à l'aide de l'état général, d'une part, et des prévisions de frais de perception, de l'autre. Le total obtenu, elle établissait le "rôle du gect », ou liste par prévôtés de tous les gens d'Église, bourgs et villages du ressort, avec l'indication de la taxe mise sur chacun. Des billets étaient en même temps confectionnés à l'adresse de chaque unité contributive ; ils portaient l'indication de la somme à payer et étaient signés par les trois membres de la commission. Ceux-ci, enfin, désignaient des receveurs en nombre variable, chargés de faire rentrer l'argent, et leur remettaient toutes les pièces que nous venons d'énumérer.

La répartition ainsi faite, la perception commençait. Les receveurs, leurs arrangements généraux une fois pris en commun, faisaient d'abord porter les billets aux communautés et aux gens d'Église. Des messagers spéciaux allaient les remettre à destination, en échange d'une quittance en règle. Ainsi prévenus, villageois et ecclésiastiques ou bien acceptaient sans réclamation la somme à laquelle ils étaient taxés et s'occupaient à leur tour, s'il y avait lieu, d'en faire la répartition - ou bien, la trouvant trop forte, rédigeaient à l'adresse de la commission une demande motivée en dégrèvement.

Ceci fait, quand le moment de recueillir l'argent était arrivé, receveurs et commis, assistés de sergents, se mettaient en tournée : ils allaient de cures en abbayes et de villes en villages chercher les sommes qu'ils devaient faire rentrer. Sur le total ils prélevaient d'abord le montant du don gratuit pour la circonscription et le versaient directement dans la caisse du receveur général. Avec le reste, ils réglaient les frais de perception, puis payaient eux-mêmes un certain nombre des récompenses votées par les États sur le surget. Restait un reliquat, provenant des trop perçus. Ils le remettaient à la commission d'également du bailliage en lui ren- 
dant leurs comptes sur pièces justificatives. Telle était, du moins quant à cette dernière opération, la théorie. Mais en réalité, les receveurs n'étaient jamais pressés de se dégarnir les mains, et, de leur côté, les commis à l'également, une fois en possession de l'argent, s'efforçaient de le garder le plus longtemps possible. De trois partis : mettre à rente les reliquats; les verser dans une caisse spéciale ; les laisser moyennant caution aux commis - c'était toujours le dernier, le plus profitable aux intérêts privés, que les États avaient adopté. Aussi les abus étaient innombrables. Les commis considéraient les sommes à eux confiées comme leur appartenant et il devenait presque impossible de leur faire rendre gorge, même en cas d'urgence : tant paraissait entier et sans limites le droit des députés sur les dons gratuits.

De là sortirent bientôt leurs pouvoirs politiques. Votant l'impôt, réglant son mode de perception, ils en vinrent, peu à peu et tout naturellement, à prétendre surveiller et régler son emploi. Ils insistèrent d'abord pour que les sommes qu'ils versaient fussent tout entières employées en Comté. Ils se trouvèrent ainsi amenés à examiner les conditions générales de la situation politique ; le désir leur vint de se mêler à l'action, de donner des avis sur ce qu'ils voyaient : très timidement d'abord, et en se bornant à formuler des voeux dont l'objet ne dépassait point les limites du pays. Mais peu à peu ils s'enhardirent, parlèrent plus haut ; les voeux tendirent à devenir des conseils. Le prince les ménageait ; c'était son intérêt. Il les laissa faire et l'usage s'établit à chaque session que les États dressaient une liste de revendications qu'ils faisaient transmettre au gouvernement des Pays-Bas et au souverain. D'ailleurs, les États n'étaient-ils pas la plus parfaite représentation de la province ? n'était-ce pas devant eux qu'à son avènement, tout nouveau souverain venait prêter serment de toujours respecter les libertés et les privilèges du pays ? Dès lors n'était-ce pas leur assemblée, image fidèle de la nation, qui devait avoir dans le pays la puissance souveraine ? Charles-Quint vit le danger ; il prit ses mesures en conséquence.

C'est lui qui avait rendu traditionnel et obligatoire l'usage de convoquer individuellement les députés par lettre signée de sa main. Honneur, sans doute, qu'il faisait aux États ; mais en même temps mesure de prudence : le souverain s'assurait ainsi que nul ne convoquerait l'assemblée à son insu et contre son gré ; il y fallait sa signature, donc son consentement. - Autre précaution : à chaque session, il déléguait pour le représenter plusieurs personnages d'importance. Outre le gou- 
verneur et le président du Parlement, il chargeait parfois de ce soin quelque conseiller d'État originaire de la province. De plus, les avocats fiscaux du Parlement avaient entrée en la Chambre des villes; ils pouvaient de là surveiller les débats, prévenir à l'occasion les questions indiscrètes. - Enfin, le mieux était de restreindre la durée des sessions. Jamais, tant que Charles régna, elles ne dépassèrent trois ou quatre jours. C'était juste le temps nécessaire pour entendre lecture des lettres du prince, fixer le chiffre du don, nommer les commissions, rédiger quelques voeux et se dissoudre. Toujours, d'ailleurs, la convocation des États fut pour l'Empereur mesure exceptionnelle. Il tenait beaucoup à lui conserver ce caractère, à espacer largement les sessions. Au reste, qui disait convocation d'États disait demande de subsides - et l'Empereur n'était pas maître d'en réclamer avec trop de fréquence. Surtout, il craignait qu'à se réunir trop souvent les députés ne prissent conscience de leur pouvoir et qu'une sorte de tradition et de continuité politique ne réussît à s'établir d'une session à l'autre. Ce sont ces craintes et ces hésitations sans doute qui expliquent son attitude en 1549, lorsqu'il s'agit de ratifier la convention d'Augsbourg.

Il est vrai que les États, désireux d'exercer quelque influence sur la marche des affaires politiques, trouvaient en face d'eux, dans la province, la rivalité sérieuse du Parlement. Parvenu à s'assurer des droits incontestés, celui-ci n'était pas d'humeur à les partager. Mais, en théorie, les partisans des États avaient beau jeu pour établir et prouver leur prééminence. En vain les conseillers proclamaient-ils que leur compagnie représentait « le Prince et les trois états du pays »; mieux qu'elle encore, l'assemblée des États avec ses trois Chambres y pouvait prétendre - et il ne manquait pas déjà, au milieu du XVIe siècle, de hardis Comtois pour entrevoir dans leurs espérances l'accroissement indéfini de son pouvoir politique.

\section{VI}

Telle était, vers 1550, l'organisation politique de la Comté. Organisation ingénieuse et pratique sans doute : c'est sous le règne de Charles-Quint qu'il faut chercher le point de perfection de cette vieille constitution provinciale ; c'est alors qu'il se faut placer pour bien sentir la simplicité et la solidité de ce mécanisme harmo- 
nieusement adapté aux besoins du pays. Il en assurait la protection, y établissait l'ordre et la sécurité sans étouffer cependant toute vie autonome, toute spontanéité. Le loyalisme d'ailleurs n'y perdait rien; les Comtois restaient fidèles à leurs souverains par tempérament sans doute, mais aussi par reconnaissance. Ils savaient gré à leur prince de ne jamais user, ou bien rarement, « de la puissance et du glaive que son rang lui met en la main »; ils le remerciaient de se contenter « de ce que la condition des seigneurs permet », sans les écraser de taxes ni d'impôts ; ils lui rendaient grâces enfin de ne rien faire qui pût l'opposer dans leurs coeurs à ces ducs bourguignons dont ils conservaient le souvenir si vivant.

Seulement, de l'équilibre de leurs institutions; du fonctionnement normal et régulier de leur constitution politique, ils n'avaient qu'un garant : la bonne volonté et le tact du prince. Constitution - le mot d'ailleurs est impropre. Car l'étendue, le rôle, les rapports mêmes des divers pouvoirs en présence n'étaient pas définis avec précision. Que le gouverneur, se dégageant du contrôle des bons personnages, devint plus autoritaire et plus puissant ; que le crédit du Parlement subit une atteinte; que les États enfin, cédant au courant de leur époque, s'efforçassent de jouer un vrai rôle politique : dans tous les cas, c'était le mécanisme faussé, l'équilibre rompu. Accident inévitable, puisqu'il aurait fallu pour le conjurer que la marche même du siècle s'interrompît et que le prince, restant le même, gardât le même vouloir. 


\section{PHILIPPE II ET LA FRANCHE-COMTÉ \\ Étude d'histoire politique, religieuse et sociale. \\ Première partie. La Comté à la veille du règne de Philippe II \\ Chapitre IV \\ Prospérité matérielle et nationalité}

$\underline{\text { Retour à la table des matières }}$

C'est du dehors que, jusqu'à présent, nous avons étudié et décrit la Comté. Mais sa situation, comment l'envisageait-elle personnellement; quel jugement portait-elle sur son présent, partant sur son avenir ? Question grave : les méprises des peuples sur les désirs d'autrui et sur leurs désirs propres ne sont-elles pas source de grandes vicissitudes?

Or, un fait apparaît évident. Telle qu'elle était au milieu du XVIe siècle, la Comté avait foi dans ses destinées. Elle se trouvait heureuse ; elle croyait son bonheur durable, son existence et son indépendance assurées pour longtemps. A tort ? peut-être; mais l'illusion s'expliquait. Essayons de montrer comment et pourquoi.

\section{I}

D'abord, comment la Comté aurait-elle douté de sa vitalité, puisque, loin de dépérir, elle s'agrandissait ?

Lorsque Charles-Quint avait reçu la province, vers l'est, sur les domaines des Neufchatel, l'étranger s'agitait, disputant les lambeaux de leur riche héritage. Pen- 
dant plus d'un demi-siècle, ç'avait été une histoire compliquée d'arrangements, d'échanges, de procès, d'invasions avec les épisodes les plus imprévus : occupation de Blamont, entre 1523 et 1534, par les Soleurois ; installation des Français en 1534 à Montbéliard ; vente de Clerval, Granges et Passavant à l'amiral Chabot ; efforts des Suisses dans le comté de la Roche et la Franche-Montagne, associée par son maître à la bourgeoisie de Berne. Lorsque Charles-Quint déposa le pouvoir, si le comte de Montbéliard tenait Blamont ; s'il devait un peu plus tard occuper Clémont, le Chatelot, Héricourt et conserver Granges, Clerval et Passavant - ni lui du moins, ni l'évêque de Bâle, ni les Cantons ne gardaient les autres fiefs des Neufchatel ; l'Isle, la Poôté de Mathay, la Fermeté de Dambelin, le val de Vit leur avaient échappé ; Chatillon-sous-Maîche, en face de Clémont, était incorporé au domaine comtal ; des Bourguignons enfin étaient comtes de la Roche.

Profit pareil au nord, au pied des Vosges. Là, en 1530, les vastes possessions de deux abbayes, Lure et Luxeuil, restaient indépendantes de la province voisine ; les abbés, princes d'Empire, exerçaient tous les droits de souveraineté. Longtemps, au Moyen Age, ducs de Lorraine et comtes, puis ducs de Bar, ducs de Bourgogne, comtes de Ferrette et de Montbéliard avaient convoité leur domaine temporel. En face d'eux, les Bourguignons ne lâchèrent pas pied et, à Luxeuil au moins, connurent le succès. Gardiens de l'abbaye depuis la paix d'Arras, possédant à ce titre la moitié des revenus, leurs comtes proposèrent un échange à l'abbé : contre ses droits de souveraineté, ils lui offraient leur part. En 1534, l'accord fut conclu ; la terre de Luxeuil, s'agrégeant au Comté, forma désormais un bailliage distinct.

Il est vrai qu'à Lure, Charles fut moins heureux. Sur l'abbaye, des influences s'exerçaient que sa voisine Luxeuil ne connaissait guère. Contre ses ennemis, à diverses reprises, elle avait dû recourir aux moines de Murbach. Relations qui, devenues régulières, avaient entraîné Lure loin de la Comté, dans un cercle de rapports nouveaux. Elle regardait l'Alsace plutôt que la Bourgogne; dès le XVe siècle, on y parlait l'allemand à côté du français; les abbés, communs en fait d'abord puis en droit aux deux monastères, montrèrent peu d'empressement à négocier - et la double enclave de leur territoire continua de rester étrangère au Comté. C'était un insuccès. Du moins aucun prince ne réussit-il mieux que Charles-Quint, et bien qu'indépendante, l'abbaye vécut en accord étroit avec des voisins dont elle avait besoin. Et puis, repoussé sur un point, Charles sur un autre 
prenait sa revanche. En 1537, un arrêt du Parlement de Dole, accepté en 1546 par l'abbé, proclamait la réunion du vaste domaine de l'abbaye de Saint-Claude, longtemps indépendant et fier de ses franchises. C'était tout le haut Jura, d'un coup, qui prenait sa place dans les frontières comtoises.

Ainsi se balançaient revers et succès. Balance inégale du reste : car les succès, de beaucoup, l'emportaient. La double qualité de Charles les facilitait : ne cumulait-il pas - lointain retour à une situation que la Comté n'avait plus connue depuis Barberousse -les pouvoirs du Comte et ceux de l'Empereur ? Par là s'accélérait un travail de concentration, d'unification qui, rendant la Comté plus entière, plus cohérente, accroissait sa confiance dans la destinée, son espoir de durer et de se perpétuer. Besançon en fournit une preuve nouvelle.

C'était une république urbaine distincte du Comté - une ville libre impériale. Fait étrange, au premier abord, que l'ancienne capitale de la Séquanie, séparant ses destins des destins de la province, restât en son milieu comme un corps étranger - comme « une paille en l'oeil », disaient bonnement les Comtois. L'histoire était simple pourtant. Métropole religieuse, la ville avait vu ses archevêques, accaparant la toute-puissance, forcer les Comtes leurs rivaux à leur céder la place. Contre ces prélats hautains, les bourgeois à leur tour s'étaient révoltés ; organisés en commune, négociant alternativement avec les Comtes et les Empereurs, ils avaient fini par constituer, au XIIIe siècle, un petit État maître de ses destins.

Les Comtes naturellement cherchèrent à reprendre pied dans la cité. D'abord, par un traité du 24 mai 1386, le Comte-duc Philippe le Hardi s'en fit déclarer gardien, moyennant redevance annuelle de 500 francs. En 1451, nouveau progrès : les Comtes acquirent le droit d'entretenir dans la ville un capitaine, un juge, un receveur. Le capitaine connaissait des fortifications ; le juge participait aux actes judiciaires du magistrat ; le receveur percevait pour son maître moitié des gabelles et des amendes. Ces droits, transmis de comte à comte, devaient rester jusqu'au XVIIe siècle la base des rapports de la Comté avec Besançon.

Charles-Quint n'eut garde de les négliger. Il suivit avec la vieille cité la politique prudente de Maximilien ; voyant en elle, comme son aïeul, « la retraite de tous les gens du Comté en cas d'éminant péril », il s'efforça de l'unir étroitement à la province. Empereur et comte, il avait doubles droits sur la ville impériale dont il était gardien. Il en profita. Il essaya même, en 1521, de créer un vicaire impérial 
dans la Comté avec résidence à Besançon. C'était trop s'avancer ; les Bisontins consentaient à mériter le nom de «bons subgectz » que leur donnait libéralement Maximilien ; peut-être même souhaitaient-ils «l'augmentation et accomplissement de la maison de Bourgogne, comme se originellement ilz en estoient yssez »; mais ils ne voulaient pas se livrer à Charles pieds et poings liés. Celui-ci s'appliqua du moins, par des concessions habiles, à assurer en fait l'union de la province et de la vieille capitale ; grâce à ses agents, il y réussit ; avec l'obéissance, il connut l'amour des Bisontins.

Ainsi, par ses soins et durant toute la fin de son long règne, c'était un sentiment profond de sécurité, d'orgueil et de confiance qu'à examiner la situation de leur pays, les Comtois devaient forcément éprouver. Ils achetaient la paix au prix de quelques alertes. En cas de guerre, les bastions modernes de Précipiano les tiendraient à l'abri. Ils aimaient, ils admiraient leur maître. Sa cause pour eux restait la cause « bourguignonne ». Chaque jour, par surcroît, leur petit pays consolidait ses frontières, les élargissait même. A constater ces faits, comment auraientils perdu la foi dans leur avenir ?

\section{II}

Pourquoi changer, du reste ? Dans ses étroites limites, leur pays ne possédaitil pas toutes ses nécessités ?

Des Comtois gouvernaient, administraient, jugeaient, protégeaient la Comté. Lieutenants commis au gouvernement ; bons personnages ; conseillers au Parlement ; députés des États : tels étaient les maîtres visibles du pays, les puissances efficaces ; la Comté les prenait dans son sein. Pareillement, elle formait un diocèse, dont le siège, sans doute, était à Besançon, mais dont le chef, un cadet de grande famille, possédait au Comté plusieurs seigneuries, présidait les États, siégeait au Parlement comme maître des requêtes. Enfin, dès le début du XVe siècle, Dole possédait son université. Si les facultés de médecine et de théologie ne comptaient chacune que deux chaires magistrales, occupées sans éclat par des ecclésiastiques et des praticiens locaux, dès l'origine les deux lecteurs de droit civil, les deux canonistes, l'instituaire et le docteur étranger avaient vu de toutes 
parts affluer les élèves : Allemands, Flamands, Français, Comtois surtout ; et quel avantage, pour un peuple procédurier, d'avoir, dans sa capitale, ce séminaire actif de juristes?

Pas d'imprimerie, sans doute ; les anciens ateliers de Salins, Besançon et Dole ne s'étaient pas maintenus : faible inconvénient dans un pays assez dédaigneux des travaux littéraires et de l'érudition. - Par contre, dans les bourgs importants, des « collèges de grammaire » offraient aux jeunes bourgeois l'enseignement de régents : les Bizet, les Mathieu, les Naudot, les Desprez, dont les noms vivent encore dans les vieux manuscrits. A leurs côtés, nombre d'artistes locaux : le maître maçon bisontin Richard Maire ; l' «ymageur » salinois Landry; son émule Claude Arnoux, dit Lulier; les deux frères Jean et Rémond Julyot; le dolois Bryet ; Claude le Rupt, un maître du décor polychrome ; les peintres Jacques Prévost, Bénigne Sambin, Jean Rately; les Dargent, Pierre le Jeune et Pierre le Vieux ; le menuisier Chenevière, hôte d'Hugues Sambin ; l'orfèvre Pierre de Loisy et tant d'autres. Construisant des hôtels, élevant des tombeaux, décorant des chapelles, ils suffisaient largement aux besoins d'art des Mécènes comtois : les Carondelet, les Perrenot, les Gauthiot, les Gorrevod, les Marmier. Ainsi, sur le sol même de la province, jaillissaient les sources de sa vie morale et intellectuelle.

Mais sa vie matérielle ? Bien pourvue de viandes, de grains, de vins, de sel, de minerais, que lui manquait-il pour l'assurer?

Volontiers, ses voisins la proclamaient riche ; c'était même un éloge que, sur leurs lèvres, elle n'aimait point trouver. Si hâbleur d'ordinaire, Gollut le repousse avec énergie : il faut prévenir les tentations possibles, et persuader à tous que la Comté ne « rembourserait » pas les frais d'une conquête... Du reste, le vieil historien trouve une bonne formule lorsque, signalant les défauts des voies navigables : le Doubs, impraticable ; la Saône accessible, mais sans débouchés vers le nord, il qualifie heureusement son pays : "Bourgogne en assiette de trafiques sans trafiques ». De fait, pour se suffire, la Comté ne devait point gaspiller ses ressources, et ce n'était pas entièrement sans raison que ses dirigeants, toujours, redoutaient la famine. Crainte que les blés, s'embarquant sur la Saône, ne dérivent vers Lyon ou les ports du duché ; édits draconiens prohibant leur exportation et même, en 1561, la grande année des interdictions, permettant de confisquer tous grains chargés sur la rivière « dès le port de Gray embas »; difficultés pour autoriser le ravitaillement des villages enclavés ou mis en surséance : Chaussin, Conflans, Vauvillers, 
Lure même et Fresne-Saint-Mamès ; édits encore, concernant les vins, les sapins du haut Jura, les filés bressans, les cuirs, les suifs, les fers convoités par les Suisses et par les Lyonnais : la Comté formait un vase clos dont rien ne devait s'échapper. Terreur de la disette, sentiment populaire: il anime les paysans se volant de villages à villages les bestiaux ou les grains convoyés aux foires ; sentiment étroit, mais non sans importance. A lire les requêtes des terres enclavées, implorant une place dans la communauté économique de la province - entre Comtois, entre bénéficiaires du commun patrimoine, on sent quel lien nouait le protectionnisme.

\section{III}

Et puis, au milieu du XVIe siècle, quelle vie intense, quelle activité, quelle fièvre de travail dans toute la Comté ?

Les guerres du XVe siècle l'avaient saignée à blanc. La paix faite, Marguerite à la tête du pays, les réchappés s'étaient mis en besogne. Passionnément d'abord, ils s'étaient appliqués à la terre. Relever les maisons, reconstruire les granges, remettre les champs en exploitation, reconstituer le troupeau : première tâche, la plus urgente. Mais la forêt de toute part encadrait le pays, bornait et assiégeait les terroirs découverts. Elle n'occupait plus seulement ses domaines naturels : ballons des Vosges, grèves de Saône, plateaux d'Amont et d'Aval, hautes chaînes du Jura - si vaste, que de bois en bois l'on pouvait « passer à couvert par tous les quartiers du païs » et qu'au temps de Gollut encore, les voisins du Comté se moquaient de tant d'arbres ; débordant ses limites, élargissant ses lisières, elle avait partout pris l'offensive, réoccupé les essarts, refoulé les cultures au pied des maisons. Contre elle, ce fut une ruée : travail trop vaste à la fois et trop dispersé pour qu'on en puisse rapporter des exemples : il faut se reporter aux monographies de seigneuries ou de monastères ; pour le domaine, aux registres d'accensement de la Chambre des Comptes - et nous avons vu que dans le Haut-Jura, des joux entières furent rasées, tandis que, dans le plat pays, patiemment, sournoisement, les paysans chaque jour élargissant leurs champs, poussaient avec passion leur travail destructeur. 
Tout leur était bon : bois du souverain dans les terres domaniales ; bois des seigneurs ; bois communaux surtout, " partis » entre les communiers, réduits en « héritages » avec ou sans les permissions nécessaires. Rage universelle de culture : elle gagnait les citadins eux-mêmes, accaparant les fossés aux pieds des vieilles murailles devenues trop étroites, ou dressant des treilles contre les bastions neufs. Et partout on plantait la vigne ; l'engouement était tel qu'il fallut en venir aux prohibitions et non seulement proscrire les plants trop productifs : la coutume était vieille - mais, précaution naïve, interdire de réduire en vignes les terres arables. Le plus souvent d'ailleurs, par un report naturel, on établissait « visottes » et « chapons chevelus » sur d'anciennes terres à blé, que de nouvelles suppléaient à la lisière des bois.

Pareillement, c'était une rage d'industrie. Au long des cours d'eau, les scieries, les battoirs à chanvre, les huileries montaient leurs grandes roues ; surtout, en abondance, les moulins s'édifiaient. On relevait, on réparait, on munissait de bonnes meules les vieux établissements ; avec une énergie qui, cinquante ans durant, ne se démentit pas, on en créait de nouveaux, mal placés souvent, dénués de clients, exposés au manque d'eau, aux longues mortes-saisons : n'importe; le mouvement ne s'arrêtait pas; de 1540 à 1580, un seul fonds d'archives ne nous a pas livré moins de trente permissions d'élever des moulins neufs ; de 1580 à 1595 nous en connaissons plus de quinze autres : chiffres incomplets, mais considérables. Plutôt que de besoins accrus chez les cultivateurs, ne témoignent-ils pas chez les constructeurs d'une sorte de passion fébrile?

Et voici, à côté des moulins à blé, les moulins à papier - ceux de Sirod, Balanod, Pontarlier, Dole, Arcier, Magny-Vernois, les Aynans, pour ne point parler des anciens ; voici les verreries de la forêt de Chaux ; les tuileries qui fournissent aux villes fréquemment incendiées de quoi remplacer leurs ancelles de bois ; les mines, les forges surtout et les fourneaux. En 1562, dans une enquête, les officiers de bailliage en énumèrent vingt-trois, toutes en activité ; la liste est incomplète et les années suivantes l'augmenteront amplement. Petites usines, de production faible : elles n'en nourrissaient pas moins tout un peuple d'ouvriers : fondeurs, affineurs, chargeurs, chauffeurs, tireurs et laveurs de mine, martelleurs et forgerons, maréchaux, bouviers et charretiers, garçons d'étable, charbonniers, bûcherons, charpentiers, routiers et souffletiers, sans compter les maçons, les couvreurs, le 
« médecin de cheval », les femmes mêmes, employées aux charrois et aux terrassements.

C'est que tout un peuple aussi pullulait en Comté. Des moissons d'hommes se levaient, dans le pays renaissant. Gollut, en 1592, écrit que « le peuple et le bestial » qui réside en Comté « est comme innumérable ». Avant lui, en 1574, le président Froissard dénombre avec orgueil «plus de 2000 tant villes, bourgades que villages ». Appréciations vagues et qu'on aimerait à pouvoir préciser. Malheureusement, du dénombrement qui fut fait en 1593, sur ordre du Parlement, par les officiers bailliagers, nous n'avons conservé que trois petits fragments : ils concernent la terre de Jussey et la prévôté de Montjustin dans la Comté du nord, le ressort d'Ornans sur les plateaux du Jura. Dans les trente-huit communautés de la terre de Jussey, les certificats échevinaux constatent l'existence de 2893 feux et 14700 personnes ; nous avons eu la curiosité de comparer ces chiffres avec ceux d'un recensement moderne : celui de 1896 ; les trente-huit villages en question possédaient, à cette date, 15240 habitants. Pareillement, l'état détaillé et nominatif dressé par les officiers, de tous les particuliers tenant feu et ménage dans la prévôté de Montjustin, atteste la présence en 1593, dans les vingt-trois villages de cette circonscription, de 936 ménages comprenant 4833 personnes : le total de 1896 serait de 7458 . Enfin, les 121 communautés du ressort d'Ornans comptaient 6003 feux et 32332 personnes contre 41624 en 1896.

Ces chiffres ne sont pas entièrement illusoires. Ils permettent, à tout le moins, de détruire certaines légendes, de montrer l'inanité de certains calculs ${ }^{7}$. Mais

7 D'abord nos textes précisent le sens du mot feu en Comté à cette époque. Il signifie ménage faisant feu séparé. Voici, par exemple, quelques-uns des feux de Cemboing (B 2627) : "Mongin Gilbert, son fils, sa femme et trois enfants. » - « Claude Gérard, sa femme, une servante. » - « François Vincent, sa femme et ses petits enfants. » - Mais on trouve aussi : « Nicolas la Poultre et $\mathrm{Cl}$. Valin, leur mère, leurs deux femmes, une soeur et deux enfans », soit deux familles vivant « au gros ménage » et ne constituant qu'un seul feu. De même, « Jean et Bertrand Estevenot, leurs deux femmes, deux enfants - ou Nicolas Cassin, son fils, leurs deux femmes, quatre enfants et la chambrière. - Le sens est donc très net. Sur les différentes acceptions du mot feu, cf. Sagnac, R. H. M., 15 octobre 1904, p. 51-21.

En second lieu, si on additionne ensemble tous les feux et toutes les personnes dénombrés dans les trois ressorts d'Ornans, Montjustin et Jussey, en obtient un total de 51065 personnes qui, divisé parles 9831 feux recensés, donne par feu une moyenne un peu supérieure à cinq. Résultat dont nous ne 
seraient-ils plus détaillés encore et plus abondants ; serions-nous mieux renseignés sur les corrections intéressées qu'on put leur faire subir, ils ne serviraient guère à notre dessein présent. Ce que nous voudrions saisir avec quelque précision, c'est le progrès de la population comtoise au XVIe siècle ; et pour le constater, force est bien que nous nous contentions d'appréciations générales, de chiffres non contrôlables. Du moins, tous concordent; textes législatifs, préambules d'édits attribuant la cherté à « l'accroissement du populaire »; dépositions d'échevins notant, à propos de communautés ou de régions diverses, le progrès de la population ; chiffres partiels enfin, énoncés tels quels ou extraits des textes : tous vont dans le même sens ; de tous, une même conclusion se dégage : la population comtoise est en progrès en 1550, et ce progrès dure jusqu'aux premières années du dernier quart du siècle. Progrès dû à la paix et, tout à la fois, à la multiplication sur place des Comtois et à l'émigration, difficile à mesurer, qui portait tant d'étrangers vers les terres neuves des Vosges et du Jura; progrès qui, pour la Comté, rejoignant celui des cultures et des industries, témoignait à nouveau de sa vitalité.

Partout ainsi le travail prospérait, l'homme créait la richesse. Les villages descendaient des hauteurs abruptes, des vieilles positions de défense, incommodes et

sommes pas tenté de nous exagérer la portée - d'autant que, n'ayant aucune indication digne de confiance sur le nombre des feux de la Comté au XVIe siècle, nous n'en saurions tirer parti pour une approximation d'ensemble - (le rôle des villes et villages comtois de 1600 que J. Gauthier signale, dans les archives de la Saunerie, comme dressé par feux, l'est en réalité par charges de sel : Ch. des C., B 2129 ; Invent. Gauthier, t. Ill, p. 105). Mais nous pouvons saisir quelle exagération il y a, par exemple, dans le raisonnement de dom Benoît (183, t. II, p. 478) qui, trouvant une texte de 1552 attribuant 1,800 feux à la terre de Saint-Claude, multiplie ce chiffre par 10 sous prétexte que ce pays de mainmorte devait comporter un grand nombre d'individus par feu. - Or, utilisant les demandes d'affranchissement des mainmortables de la maison de Chalon en 1583, nous nous sommes livré, pour établir l'importance numérique moyenne de la communion mainmortable, à une série de calculs qui nous ont donné des résultats infiniment plus modestes. Par ex., dans le village de Boujailles - village d'éleveurs, entouré de grandes forêts (Doubs, c. de Levier), pour lequel nous ne possédons pas moins de cinquante-huit demandes d'affranchissement, fournissant l'état dételé et nominatif des personnes formant les communions (Ch. des C., B 2037) - nous avons trouvé comme chiffre moyen général 6,022; le nombre moyen des enfants par famille est à peine supérieur à trois $(3,029)$. 
sans eau, pour s'épanouir dans les plaines passagères, aux carrefours fréquentés. Sur les routes, sur les ponts nouveaux, dans les hôtelleries, les voyageurs passaient, s'acheminant vers les frontières ou les bourgs de l'intérieur. Les vieux péages trouvaient aisément des amodiateurs. Les foires se multipliaient. Partout, communautés et seigneurs en réclamaient de nouvelles; les banquiers génois, lucquois, florentins, reprenaient le chemin d'une province où jadis tant de Lombards astucieux s'étaient enrichis ; il arrivait même que, la prospérité nuisant à la prospérité, tant de ressources concurrentes se détruisaient l'une l'autre.

Avec la forêt par exemple, cette forêt si , « nécessaire à l'entretien de la vie humaine », comme dit un texte de 1588, les paysans en usaient d'autant plus librement qu'à cette époque encore, son rôle essentiel paraissait être à tous de nourrir les troupeaux. Dans les chênaies, quand le gland donnait, on embouchait les porcs ; à la dent des chevaux, des boeufs, des chèvres même, on livrait sans scrupule les jeunes taillis ; c'étaient pratiques courantes. Plus graves, celles qui menaçaient les cultures. A peine quelques édits commençaient-ils à combattre les abus de la vive et de la vaine pâture. En 1526, Marguerite déjà avait reporté de la SaintGeorges (23 avril) à la Notre-Dame de mars la mise en ban des « prés qu'on fauchait »; mais que de licences encore. Non seulement les petits bergers laissaient leurs bêtes vaguer librement sur les « héritages » cultivés : les raisins levés, l'usage était partout de mettre les bestiaux dans les vignes; terre foulée, bourgeons coupés, plants ruinés, on devine les dégâts. Partout aussi, après la fenaison, on menait les porcs aux prairies et ces bêtes voraces, labourant le sol de leur groin, creusaient d'énormes trous, détruisaient les racines, gâtaient d'avance les récoltes futures. Que faire contre des pratiques si vieilles ? Pas de prairies artificielles, à cette époque ; faute de drainage, peu de bons prés naturels ; or, le bétail croissait : il fallait bien qu'il vive. Ainsi, dans l'éternel champ clos, se heurtaient déjà éleveurs et cultivateurs : nulle part plus qu'en Montagne, où les troupeaux étaient la grande richesse, Fréquemment, au son du tocsin, des villages s'y levaient : hommes, femmes, enfants, armés de pieux, de fourches, de faucilles emmanchées ; farouches, tous se ruaient sur la « proye » des voisins, pâturant en conscience une pâture contestée.

Mais l'industrie naissante ? La forêt, cette fois encore, lui servait de victime. Certes, on l'exploitait mal. Tantôt le bois mort pourrissait sur le sol ; tantôt les jeunes arbres tombaient sous la hache de barbares les taillant sans vergogne, les 
dépouillant de leur écorce pour fabriquer du tan, découpant en plein chêne des bancs rustiques, commettant mille scandaleux abus que les textes monotones redisent à l'envi. Qu'était-ce, au prix des coupes à ras du sol, des destructions de forêts entières pour les besoins dévorants des forges, des salines, des fours à chaux ou des fours à charbon ? L'homme ainsi se débattait au milieu des contradictions ; entre tant d'économies concurrentes, il parvenait mal à garder l'équilibre ; mais ce qui le rompait sans cesse, c'était non la misère : la prospérité.

\section{IV}

De cette activité, de cette joie de vivre et de sentir sa force, serait-ce par abus ou par illusion qu'aux hommes du XVIe siècle nous prêterions aujourd'hui conscience ? Les faits sont là, qui répondent non.

N'est-ce point alors que pour la première fois, et par les soins des Comtois eux-mêmes, des descriptions de la province s'impriment et se publient : dès 1552 celle d'un Gilbert Cousin, en attendant celle d'un Louis Gollut? N'est-ce pas alors que, par leurs soins également, se dressent les premières cartes du pays, et sinon la première, celle d'un Gilles Bouillon, du moins celles d'un Lannoy et d'un Hugues Cousin ? Les villes, à leur tour, s'occupent de leur renom, de leurs antiquités ; des plans, des vues cavalières, des notices détaillées répandent leurs aspects, leurs titres par le monde ; des guides itinéraires énumèrent les grandes routes, les hauts chemins comtois; les cosmographies reprennent et résument les notions contenues dans les descriptions ; de tous ces documents, avidement recherchés, se dégage peu à peu pour les contemporains l'image d'un pays complexe et varié.

Et ce pays, ils l'aiment, ils l'admirent : dans leur gros langage, ils le disent hautement. Il y a quelque part, dans la correspondance de Granvelle, une lettre curieuse et charmante, écrite dans l'été de 1564. Au printemps, le ministre disgracié avait quitté Bruxelles et rejoint la Comté par petites étapes ; lentement, dans sa litière, il allait de château en château, de son prieuré de Mouthier à sa terre d'Orchamps-Vennes ; c'est de là qu'en juillet, il envoyait à Seld quelques lignes apaisées - la description des lieux où se promenait sa tristesse résignée : « Suys en doulx lieux, où je vous ay souhaité mille et mille fois...., avec force belles monta- 
gnes haultes jusques au ciel, fertilles à tous coustelz, remplies de fort belles vignes et toute sorte de bons fruictz; les rivières et les vallées belles et larges, l'eau clère comme un cristal, une infinité de fontaines, truictes et ombres innumérables et les meilleures du monde ; les champs en bas fort fertilles et fort belles prayères, et, en l'ung des coustelz chaleurs grandes, et en l'aultre, quelque chaud qu'il face, ung frais délectable ; et n'y a faulte de bien bonne compagnie du pays, de parents et d'amys, avec vins les meilleurs, comme vous sçavez, du monde. » Voilà, à la louange de la nature comtoise, entre tant de dépêches et de graves avis, un couplet vraiment neuf et d'accent sincère.

Mais il n'est que d'ouvrir Gollut, de feuilleter Cousin pour en découvrir d'analogues : moins nuancés ; ces bonnes gens n'avaient point la culture d'un Granvelle ; aussi profondément sentis pourtant. Ils connaissent, ils vantent leur pays. Ils en célèbrent déjà les sources merveilleuses, l'immense cirque de rochers d'où jaillit, toute formée, la Loue rapide. Ils aiment, eux aussi, ces «belles montagnes » qu'admirait le cardinal, ces montagnes « superbes et hautaines » que décrit Gollut : hautes montagnes au sommet boisé, au pied couvert de vignes qui dominent Arbois ou Poligny ; montagnes resserrées, encadrant les villes et les villages, entourant Saint-Hippolyte d'un cercle harmonieux, ménageant à leurs pieds le beau site de Salins ; collines accueillantes qui, « doucement montant, s'arrondissant et s'appetissant en pointe », font « belle monstre de soy » et portent sur leurs flancs des bourgades heureuses : Nozeroy, sur son tertre baigné d'air pur ; Pesmes, « ville de l'un des meilleurs doux aërs et de plus belle assiste qui soit en Bourgongne »; Orgelet, dont « l'aër est tant bon » qu'il rend, nous dit Gollut, aux mangeurs rassasiés un renouveau d'appétit... Sentiments de clocher ? Sans doute, mais qui s'allient à un patriotisme de province, comme dans ce cri d'un obscur Comtois : «Vive Cromari-sus-l'Ougnon, bourg bien assis et bâti en Bourgongne, le Roy des Païs ! »

Au reste, les bourgeois du temps ne regardent pas seulement ; ils observent et déjà s'essaient à raisonner. La montagne est pour l'homme maîtresse de réflexion. Sa vie forte l'attire, pose de nombreux problèmes : dès le XVIe siècle, les Comtois en formulent les termes. Ils étudient leur Jura. Ils s'inquiètent du mécanisme de ses sources, des pertes de rivières, des gouffres, du Frais-Puits de Vesoul ou du Puits de la Brême près d'Ornans. Ils s'occupent des minéraux et des concrétions, de la formation des stalactites et des stalagmites, des grottes d'Osselle ou de la 
célèbre glacière de Chaux-lez-Passavant. Connaissance et amour de la petite patrie : éléments certains d'une nationalité ; ils vont rejoindre, renforcer les autres et notamment - pour ne point reparler de la solidarité créée, entre victimes des Suisses et de Louis XI, par un passé de misères communes - l'orgueil du nom et de la race comtoise : race saine de montagnards «allègres et dispots au possible », vieillissant sans se délabrer d'une verte vieillesse ; race glorieuse de ministres et de diplomates, fière des services rendus à de puissants souverains.

Car, ceci encore était pour la Comté source d'illusion : illusion sur la place qu'elle tenait en Europe ; illusion sur la part qu'elle gardait dans les soucis du maître. A voir Charles-Quint réserver aux Comtois dans son armée, dans ses conseils, à sa cour, tant d'honneurs et de situations enviables, la province se croyait toujours au temps de Marguerite ; il était bien passé pourtant, et sans retour.

\section{V}

Ainsi, pour résumer d'ensemble notre étude, c'était un petit groupement politique et historique assez vivant encore que la Comté au milieu du XVIe siècle. Elle n'était pas devenue simplement une province banale d'un grand État, dépouillée de toute initiative et recevant du dehors toutes ses impulsions. La spontanéité n'était pas morte en elle ; avec une assez large autonomie, elle avait su retenir quelque chose de son individualité nationale d'autrefois.

Or, c'était là l'indispensable condition de sa vie politique - cela, en raison même de sa place en Europe. Briser les ressorts de sa vie locale ; contrarier le jeu de ses institutions ; énerver les forces de résistance et d'opposition qu'elle conservait en elle, c'était risquer de la tuer, de l'anéantir toute. Car, à la place des pouvoirs locaux détruits ou mutilés, que pourraient mettre de fort, de durable, d'utile les maîtres de la Comté ? Dans un grand État, ramassé tout entier autour d'un centre, groupé activement autour d'un chef national, l'établissement d'un régime d'absolutisme centralisateur, quels qu'en soient les dangers, est du moins possible. La volonté puissante et bien servie du pouvoir central peut, dans une large mesure, suppléer à l'absence, à la pauvreté des pouvoirs locaux. Mais dans la Comté du XVIe siècle, petite, faible, isolée, de toutes parts entourée de rivaux et d'ennemis ? Ses 
maîtres étaient si soucieux, si accablés de plus grands intérêts ? Étranger et lointain, le gouvernement central ne pouvait compter là sur sa vigueur d'impulsion et son activité pour remédier au défaut d'une organisation régionale solide, saine et vigilante.

Charles-Quint l'avait-il vu nettement? En tous cas, il laissa à ses fidèles Bourguignons leurs vieilles institutions et ce gouvernement sagement équilibré qui s'était constitué au temps de Marguerite. Mais son oeuvre, sur ce point, était d'un caractère tout personnel. Il ne s'était nullement soucié de définir avec exactitude le rôle et l'action réciproque des divers pouvoirs qui se contre-balançaient en Comté. Pareillement, il s'était gardé de trop préciser la nature des rapports qui devaient unir ce pays isolé à l'Empire, aux puissances voisines, aux Pays-Bas même et au gouvernement central du souverain. C'étaient des liens très souples, un peu lâches, qu'il s'était contenté de nouer ainsi, de tisser en trame légère, en réseau à mailles espacées autour de la province ; le texte des conventions, des traités, des accords passés par ses soins laissait une part énorme à l'interprétation. Pareillement, pour accorder entre eux les pouvoirs mal définis du gouverneur, du Parlement et des États, l'intervention fréquente du souverain, son action personnelle paraissait nécessaire. Or, si la Comté, somme toute, pouvait se féliciter de l'intervention, de l'action d'un Charles-Quint - qui lui garantissait que son successeur aurait à coeur, comme lui, le maintien de son autonomie et de ses vieilles libertés provinciales ? Sa sécurité, sa destinée, son avenir étaient dans les mains du prince qui la recevrait. 
PHILIPPE II ET LA FRANCHE-COMTÉ

Étude d’histoire politique, religieuse et sociale.

\section{Deuxième partie.}

\section{Les débuts du règne \\ de Philippe II}

Noblesse et bourgeoisie 
PHILIPPE II ET LA FRANCHE-COMTÉ

Étude d'histoire politique, religieuse et sociale.

Deuxième partie. Les débuts du règne de Philippe II

Chapitre V

L'avènement de Philippe II

$\underline{\text { Retour à la table des matières }}$

Au printemps de 1556, la Comté, changeant de mains, cessa d'appartenir au vieux maître qu'elle aimait. Le 30 avril, le gouverneur Claude de Vergy recevait l'ordre d'en prendre possession au nom de Philippe II ; le 10 juin suivant, il notifiait aux États, réunis à Dole, l'abdication de l'Empereur et l'avènement de son fils. A cette date, Charles avait cédé déjà toutes ses couronnes : il ne lui restait plus que la dignité impériale. Il s'était dessaisi de Naples et de Milan le 28 octobre 1554 ; puis, le 25 octobre 1555, des Pays-Bas ; enfin, le 16 janvier 1555-56, des royaumes espagnols et de la Sicile. Pourquoi si longtemps retenait-il la Comté ? Sans nul doute, par crainte de dangers extérieurs.

La province venait de traverser une période difficile. Lorsqu'en 1552, Charles avait dû s'enfuir par le Tyrol ; surtout, lorsque les Français s'étaient jetés sur la Lorraine et les évêchés, elle avait éprouvé les plus vives alarmes. Ville impériale comme Metz, Toul et Verdun, Besançon s'était crue perdue : toute la Comté avait tremblé avec elle. Ambassade à l'Empereur pour lui demander appui ; députation aux États du Comté, " pour leur remémorer le traité de garde »; lettres à Vergy pour qu'il envoie des secours, au bailli de Ferrette pour qu'il donne des nouvelles : rien n'avait été épargné par les Bisontins. 
À Dole, l'arrivée précipitée de l'ambassadeur impérial Simon Renard, venant en hâte convoquer et présider les États, avait attesté aux yeux de tous la gravité de la situation. On avait voté un don gratuit, levé des troupes, installé des garnisons de renfort à Dole et à Gray ; surtout, on avait dépêché aux Suisses, non sans succès : les Cantons écrivirent à Henri Il et procurèrent à la Comté, le 29 juillet 1552, le bénéfice d'une neutralité valable pour trois ans. Depuis, on n'avait cessé d'être sur ses gardes. À chaque instant, des alertes appelaient des mesures de précaution, le renouvellement des édits interdisant le port d'armes ou la circulation sans lumière après le couvre-feu. En 1555 encore, un soldat de la garnison de Gray était surpris à tenter d'ouvrir, la nuit de la Pentecôte, la porte d'Apremont ; cette même année, la neutralité de 1552 étant venue à expiration, on eut quelque peine à la faire renouveler : les Français n'y consentirent que moyennant son extension au Bassigny, et, dans l'acte conclu au nom de Charles, rien ne fut stipulé quant à son héritier. Telle fut la raison pour laquelle l'Empereur retint la Comté jusqu'au jour où, la trêve de Vaucelles conclue, il put se retirer sans risques pour elle.

\section{I}

En 1556, Philippe recueillit donc la Comté. L'événement était prévu. La province suivait le sort des Pays-Bas ; or, dès 1549, le prince d'Espagne avait reçu à Bruxelles, à Bruges, à Gand, à Anvers, dans les grandes villes, le serment de fidélité de ses futurs sujets ; son père, en novembre, avait publié la Pragmatique qui réglait d'une manière uniforme la succession dans toutes les provinces de par deçà ; deux ans plus tard, à Augsbourg, il l'avait investi solennellement des provinces qu'il tenait en fief du Saint-Empire. En Comté même, en mars 1549, bons personnages et commis à l'également, réunis à Gray sur convocation du gouverneur, avaient voulu s'associer aux manifestations de commande qui marquaient le premier voyage du jeune prince ; ils lui avaient voté un don d'honneur de 25000 fr. Premier salut de la province à son futur maître ; mais salut officiel et que tous, peut-être, ne rendaient pas d'un coeur joyeux.

C'est que rarement nouveau prince eut plus mauvais renom que Philippe à ses débuts. Le raide jeune homme qui arrivait d'Espagne parut déplaisant aussi bien aux Allemands qu'au bon peuple des Flandres. Il se montrait hautain, revêche, 
malgracieux ; médiocre cavalier, plus médiocre jouteur, il était loin de briller dans les tournois ; surtout, on devinait en lui une puissance obscure de dissimulation et ses futurs sujets, d'instinct, sentaient qu'avec un pareil maître, c'en serait fini de leurs libertés, de cette autonomie qui leur était si chère. - Or, il avait un rival dans leur esprit: Maximilien, le fils de Ferdinand, le neveu de l'Empereur. On le connaissait, on l'aimait par deçà. C'était un jeune homme vif et fort indépendant vis-à-vis de son oncle : il l'avait prouvé en diverses occasions. Les Allemands le chérissaient comme "prince gentil et de grande expectation »; les Wallons et les Flamands le trouvaient « ouvert et affable »; Philippe, au contraire, était haï de tous, hormis les Espagnols. Spontanément, les voeux du peuple, aux Pays-Bas, allaient à l'archiduc. Dès septembre 1549, Marillac le constate dans une de ses dépêches : "Advenant mutation, ilz seroient pour appeler le roy de Bohesme et le faire leur seigneur ». A cette époque même, sa résistance aux prétentions de l'Empereur cherchant à faire de Philippe un roi des Romains, le rendait plus sympathique encore aux Allemands et, par correspondance, aux habitants des Pays-Bas. Eut-il dès le début des partisans en Comté ? Nous ne saurions l'affirmer, faute de textes ; mais qu'il finit par en avoir, c'est ce que démontrent certains documents saisis, en 1556, chez un secrétaire de l'ambassadeur impérial Simon Renard : le Bisontin Quiclet.

Cerveau brûlé, évidemment, cet aventurier de vaine diplomatie, mi-espion, mi-courtier. Mais deux faits sont certains : il était en relations avec le roi des Romains ; il prenait le titre de son "serviteur domestique », et dans ses papiers, entre autres lettres, on trouva un document daté de Vienne, le 28 novembre 1555, et signé de Ferdinand. C'était une réponse du prince à Quiclet, où il se défendait de songer à la Bourgogne. Après avoir remercié son correspondant d'avis, «tant de France que d'ailleurs », contenus dans une lettre écrite « doiz Besançon, du 26e du mois d'octobre dernier passé », et l'avoir prié de continuer ses bons offices «le plus souvent et distinctement » que possible, Ferdinand ajoutait : «Aussi n'avons jamais eu doubte de votre bonne dévotion et ceulx de la Conté de Bourgogne envers nous et les nôtres; et prenons le tout procédans d'ung vray, sincère et loyal coeur ; mais c'est chose à quoy ne voullons ny debvons aspirer pour être succession héréditaire, de laquelle la possession en appartient à leur vrai prince naturel et seigneur; et Dieu ne veulle que machinions chose quelconque que pourroit estre préjudiciable à l'Empereur Monseigneur et à sa postérité ». La lettre était en 
chiffre, et les conseillers chargés de l'instruction eurent beaucoup de peine à en obtenir de Quiclet le déchiffre.

Quelle importance convient-il d'attribuer à cette manifestation ? Quiclet la commenta en disant « qu'il sçavoit que ce païs-ci (la Comté) portait à S. M. et au Roy de Bohème son fils bonne dévotion; et lui sembloit que l'on l'aymeroit mieulx, luy et ses enfants, que le Sr. roy d'Angleterre (Philippe) ». Il ajoutait que «si led. Conté estoit joinct avec celluy de Ferrette, il luy sembloit que ceulx de ced. Conté en seroient plus fortz et asseurez »; aussi avait-il prié Ferdinand d'envoyer quelque bon personnage aux États du Comté «pour parler de quelque confédération avec le pays de Ferrette ». Qui l'avait chargé de ces négociations ? Personne sans doute. Mais aurait-il eu l'idée de les entreprendre s'il n'avait au moins senti chez ses compatriotes, en ces années troublées, quelques inquiétudes pour leurs destinées, quelques craintes même pour leur plus proche avenir ? Par les lettres, par les livres aussi, par les « textes anti-français en langue française » qu'importaient à Dole les libraires de Dijon ou de Lyon, la Comté suivait les événements du temps ; et après tout, y avait-il si longtemps qu'à la paix de Crépy, l'Empereur et le Roi traitaient de la reconstitution d'un État bourguignon? En 1549, le peuple, dans les Flandres, parlait couramment de l'érection en royaume des Pays-Bas ; en 1554 même, Philippe et Marie Tudor convenaient que leur premier-né recevrait Bourgogne et Pays-Bas, tandis que don Carlos aurait l'Espagne, Naples et la Sicile. - Arrangements éphémères ? Sans doute; mais de nature à entretenir, chez les Bourguignons et les Flamands, ce désir de vie propre et quasi autonome qu'un Maximilien, mieux qu'un Philippe II, paraissait d'avance pouvoir satisfaire.

\section{II}

Au début, cependant, le nouveau maître suivit les traces paternelles. A l'intérieur, il réinstitua les officiers, comme il était de règle, renomma et confirma les conseillers au Parlement, renouvela le traité de garde avec Besançon et s'engagea, aux États de novembre 1556, à employer les dons gratuits dans et pour la province même. Lorsque, sa tante s'étant retirée, il lui donna Philibert-Emmanuel comme 
successeur aux Pays-Bas, la Bourgogne et le Charolais, conformément au précédent de 1531, furent compris dans sa province ; et le secrétaire d'État chargé spécialement des affaires bourguignonnes fut le même Josse Bave qui, sous l'Empereur déjà, en avait eu la charge.

À l'extérieur, même attitude conservatrice. Depuis la crise de 1552, la Comté n'avait qu'un désir : garder le bénéfice de la Ligue héréditaire et de la neutralité. Philippe II en tint compte : la neutralité de 1555 fut transférée à son nom ; les Cantons confirmèrent l'union de 1511. Dès le 4 septembre 1556, le roi en signait à Gand la reconnaissance ; les Suisses, de leur côté, l'imitaient à la diète de Baden du 5 avril 1557, et l'on décidait, d'un commun accord, que, pour plus de solennité, quatre députés des Cantons viendraient à Dole en notifier le renouvellement. Ils furent reçus en grande cérémonie, festoyés, comblés de cadeaux : le 13 mai 1557, la Ligue héréditaire fut en leur présence proclamée au peuple.

Sans doute, toutes ces négociations n'empêchèrent pas Philippe, quelques mois après, de violer ouvertement la neutralité. La guerre ayant éclaté entre lui et le roi de France, un gentilhomme entreprenant, Nicolas de Bollwiller, réunit en Souabe I0 000 fantassins et I 000 cavaliers, pénétra en Comté, traversa la province et, franchissant la frontière française, se rua sur Lyon qu'il espérait surprendre. Mais, barrant la route, Bourg-en-Bresse résista, Une attaque de Bollwiller échoua complètement ; les reîtres, culbutés, durent précipitamment regagner la Comté. Le 26 octobre, ils étaient à Orgelet ; le 29, à Quingey ; le Ier novembre, ils gagnaient Besançon par Larnod et Beure. Deux jours durant, ils traversèrent la ville par petits paquets, de la porte Notre-Dame à la porte de Charmont : sur leur parcours, les rues transversales, les carrefours étaient barrés ; les citoyens en armes surveillaient le défilé. Bollwiller, franchissant l'Ognon à Voray, gagna Vesoul et licencia ses troupes sans les payer. Ce fut le signal d'une rébellion, et Gollut nous a conté comment un débordement propice du Frais-Puits, fontaine intermittente qui avoisine la ville, la sauva heureusement de leur brutalité. Violation flagrante de la neutralité ? Sans doute, et les Comtois ne tardèrent pas à la regretter, tremblants qu'ils furent de justes représailles. Mais là encore, Philippe II n'avait rien innové en laissant s'accomplir ce hardi coup de main : l'audace de Bollwiller avait ses précédents. 
Ainsi, dans la situation extérieure et dans le gouvernement intérieur du pays, l'avènement du jeune roi ne semblait rien modifier. Pourtant le changement de règne, à lui seul, était comme une révolution.

Les historiens comtois ne l'ont point aperçu : du père, constatent-ils, la province passe au fils : transmission normale de pouvoirs identiques. Mais le père était sympathique à ses sujets ; le fils fut un despote hypocrite et cruel. En dehors de ce contraste, rien à chercher sans doute. Or, ce contraste existe ; par leurs goûts, par leurs habitudes, par leurs personnes physiques et morales, CharlesQuint et Philippe II différaient profondément. Mais il y a autre chose, et plus grave.

Quand Charles-Quint avait pris le pouvoir, ce qu'avaient salué en lui les sujets de par-deçà, c'était le prince bourguignon. A bon droit. Car, au carrefour de l'Europe, entre la France, l'Angleterre et l'Allemagne, le fils de Philippe le Beau considérait alors les Pays-Bas comme le centre même de sa puissance ; et l'on sait l'attention qu'il portait au Comté, destiné tôt ou tard à reconstituer un tout avec le Duché. Or, les idées politiques de Charles se modifièrent, non pas brusquement : il est exagéré de prétendre - on l'a fait - que les trois premières années de son gouvernement (1515-1517) furent les trois dernières de la vieille Bourgogne. Mais, parvenu au terme d'une lente évolution, ce fut à l'Espagne et à sa grandeur que l'Empereur vieilli consacra presque exclusivement la fin de sa vie. - Pareillement, si forte au lendemain de Pavie, si marquée encore en 1522, dans ce testament où il formulait le voeu conditionnel d'être enterré aux Chartreux de Dijon, sa volonté de reconquérir le Duché dut tenir compte des faits et céder devant eux.

Malgré cette évolution, malgré le caractère de plus en plus marqué de sa politique espagnole, quelque chose du passé subsista cependant entre l'Empereur et ses compatriotes. Une illusion s'attarda chez ceux-ci - du moins chez ceux, les plus nombreux, qui ne réfléchissaient guère et ne s'informaient point. Alors qu'elle n'était plus pour Charles que «sa vache de Flandre », la Flandre, la grasse Flandre des fileuses de lin et des marchands d'Anvers, lui prêtait encore comme un reste efficace de ses vieux sentiments. Lui, de son côté, y demeurait à l'aise ; il en parlait la langue, en goûtait les moeurs, aimait à se servir de domestiques flamands : lors de l'abdication, on le vit pleurer et rejeter la faute de son attendrissement sur l'âge, mais aussi sur « l'amitié ». De même, la Comté n'était plus à ses yeux qu'un tout petit pays, difficile à garder et de mince rapport : elle s'attribuait encore un 
rôle important dans les soucis du maître. Ne la savait-il pas fidèle entre toutes ? À la cour, il s'entourait de Comtois ; dans ses ambassades, il les employait en foule ; comme premier conseiller, il en possédait un. Liens personnels, qui abusaient les peuples sur la véritable force des liens politiques. L'avènement de Philippe II les rompit brusquement.

Le père, de Flamand s'était fait Espagnol. Le fils l'était dès l'origine et comme en naissant. Élevé par des Espagnols, entouré d'Espagnols, ne parlant qu'espagnol, aux Pays-Bas il faisait réellement figure d'un étranger, d'un hôte de passage, et peu sympathique. Ne pouvait-on dès lors prévoir le retour précipité du souverain dans la péninsule, son obstination à n'en plus sortir et le caractère d'une politique qui allait faire de lui non un comte de Flandre pour les Flamands, un comte de Bourgogne pour les Comtois, un roi de Naples pour les Napolitains, mais pour tous, également et indistinctement, un roi d'Espagne?

De la mémoire du nouveau maître, tous les vieux souvenirs bourguignons étaient absents. Mais s'ils vivaient encore dans celle des sujets, quelle source de conflits et de malentendus ! Le roi d'Espagne parlera, du fond de l'Escurial. Et les Bourguignons, ne reconnaissant pas la voix de leur comte paternel, respectueux des privilèges et des traditions, resteront troublés et sans comprendre. Ainsi s'engagera, dans leur province comme aux Pays-Bas, le grand conflit aux conséquences durables de l'État espagnol et de 1'État bourguignon.

Conséquences lointaines. Il nous est relativement facile, aujourd'hui, de les démêler dès l'origine. Aux contemporains, elles furent plus lentes à se révéler. Ou plutôt, elles ne leur apparurent d'abord qu'incidemment, sous la forme spéciale d'un conflit entre deux personnels - moins, entre deux personnes.

\section{III}

Nombreuses étaient les familles comtoises qui mettaient au service de la maison d'Autriche leur connaissance du français et leur finesse diplomatique. L'une d'elles primait les autres : la famille Perrenot, d'Ornans. 
Famille de paysans, descendue des plateaux d'Ouhans dans le val de Loue. Le trisaïeul du cardinal, Antoine Perrenot, était un forgeron ; l'aïeul, Pierre, un de ces bourgeois médiocres qu'on comptait par dizaines dans les bourgs comtois. Notaire et tabellion, mari d'une anoblie, lui-même se qualifiant de noble.... avant les lettres, il vivait paisible dans sa maison d'Ornans et jamais sans doute n'aurait osé rêver la destinée future de son fils Nicolas.

Celui-ci était l'aîné de deux frères, tous deux dans les ordres. Étudiant à Dole, avocat à Ornans, marié en 1512 à une descendante de cette vieille lignée politique et marchande des Bonvalot qui, depuis des siècles, exerçait à Besançon les charges municipales, il eut les débuts des jeunes gens de sa classe qui suivaient la pratique. Mais brusquement, nommé en 1518, à trente-deux ans, conseiller au Parlement de Dole ; parvenu à ce point où s'arrêtaient communément les désirs des plus ambitieux, l'avocat d'Ornans, solide montagnon à la large carrure, partit au contraire à l'assaut du pouvoir, et, brûlant les étapes, devint en moins de dix ans une des puissances du monde. Distingué par Gattinara, mis par lui auprès de Marguerite, remarqué à son tour par Charles-Quint, toujours égal aux charges de plus en plus lourdes, aux missions de plus en plus délicates que lui confie l'Empereur il est maître des requêtes, conseiller du souverain, ambassadeur en France au lendemain de Pavie, garde des sceaux enfin à quarante-six ans - le premier personnage, à ne compter que les services, de la plus puissante monarchie de l'Europe.

Comblé d'honneurs, ce Comtois pratique dont l'appétit robuste ne se repaissait point de fumée, sut courir les profits et provoquer les dons. Dès 1527, avec quel contentement, il peut réaliser le grand rêve des bourgeois de son siècle : acheter une terre dont le nom, joint au nom patronymique, dira la réussite, l'ascension heureuse, le passage accompli de la classe moyenne dans l'aristocratie : au lendemain de Madrid, depuis Paris où il lutte et bataille, il acquiert Grandvelle pour plus de 1500 écus. En même temps, Nicolas Perrenot fonde sa dynastie. Il a quinze enfants ; il en élève onze. Six filles, par d'habiles et brillants mariages, étendront dans tous les mondes les prises de la famille; quatre garçons, dans les conseils et les ambassades, entoureront l'aîné, héritier désigné de la grandeur du nom. Celui-ci, vraiment, fut le chef-d'oeuvre de son père. Élevé à grands frais dans les meilleures universités ; engagé dans la carrière d'Église, la plus propre à un diplomate sans naissance ; façonné d'une main sûre en vue du rôle précis qui lui était réservé, à peine mis aux affaires il put d'apprenti passer maître - et, lors- 
qu'en 1550 Nicolas Perrenot eut terminé sa vaillante carrière, tout naturellement il reprit les fonctions paternelles. Cinq ans après, Charles-Quint le cédait à Philippe II. Antoine Perrenot restait, aux côtés du maître, seul conseiller « wallon » parmi les Italiens et les Espagnols.

À cette date de 1556, il n'était pas encore le Granvelle apaisé des années d'Italie, prélat magnifique et fin dont le Gaetano nous a conservé l'aspect majestueux et ce regard pénétrant, un peu mélancolique, qui prend et poursuit longuement le spectateur. Mais ce n'était plus déjà le jeune homme de trente ans qu'Antonis Moor peignit vers 1547 : ample barbe noire, cheveux souples et brillants, l'élégance discrète d'un costume de soie sombre. Dans la gravure précise, un peu froide, de Collaert il faut chercher le Granvelle d'alors, le Granvelle des années de lutte et d'énergie, l'homme de quarante ans sûr et maître de lui.

Une tête bien construite sur un corps solide ; un front haut et vaste ; une figure ouverte qu'encadrent chevelure et barbe drues, frisées court ; un grand air de prudence calculatrice ; surtout, ici encore, mais plus direct, plus soutenu, ce même regard - regard aigu qui impose et maintient son interrogation : dans cette belle effigie, à cet âge décisif de la quarantaine, le type comtois s'affirme aussi net que chez le père - moins appuyé pourtant. Qu'on regarde la toile où Titien, en 1548, a fixé les traits de Nicolas Perrenot : même tête solide, même front ample et bombé, mêmes traits accentués ; mais malgré les années et les cheveux grisonnants, il y a, dans la face colorée du grand vieillard qui porte avec l'aisance d'un Vénitien son costume somptueux de fourrure et de soie, comme un reste encore de verdeur paysanne, un certain accent d'âpreté rustique par où se marque la race proche de ses origines. Figure intéressante, où se lit tout le personnage : le Comtois d'abord et l'homme nouveau ; le parlementaire aussi et le robin. Il y a, dans ces yeux vifs, dans cette bouche aux lèvres closes, une expression de finesse rusée qui fait avec Michelet penser au procureur. Rien de tel chez le fils. Ce beau prélat de cour, souriant, d'aimable mine, joint à la santé, à la force, à l'équilibre physique, un grand air d'élégance et de distinction que le vieux chancelier n'a jamais connu.

En 1556, nulle influence plus forte que la sienne en Comté. Pendant des années, son père avait eu la haute main sur les nominations. Ancien parlementaire, Nicolas Perrenot avait peuplé de créatures la cour de Dole : on n'y comptait plus les conseillers qu'il avait « faitz et élevez de ses mains ». Par dessus des Salines, il y régnait en maître depuis 1534 ; son père, Pierre Perrenot, son gendre Guyon 
Mouchet lui servirent tour à tour de lieutenant. A la gruerie, il avait mis son gendre Claude Le Blanc. Dans l'Église, depuis 1544, son beau-frère François Bonvalot administrait le diocèse de Besançon. Antoine, après son père, prit le rôle profitable de patron des Comtois. Au pays, il gardait l'appui de ses parents. En cour, le vieil Empereur ne lui marchandait sa confiance ni son estime. Il en profita pour pousser les siens, avec ce désir passionné d'avancer sa famille qu'il avait hérité du vieux Granvelle. Son oncle par alliance, Jean de Saint-Mauris, servait maintenant au Conseil d'État, avec le titre de président ; tout dévoué au père, il le restait au fils. Surtout, l'évêque d'Arras poussait ses frères : l'un, Thomas, qu'il avait marié à Anvers, le 12 septembre 1549, avec Hélène de Brederode : mariage magnifique où « le sire des noces » avait été conduit à l'autel par le prince d'Espagne en personne, et sa fiancée par deux reines assistées de l'Empereur ; l'autre, Jérôme, qu'il s'occupait, en 1551, d'établir à son tour, dans l'intérêt souverain du crédit des Perrenot. Fort des services rendus, empressé près du maître, Antoine pouvait braver les assauts. Lorsqu'au printemps de 1554, un rude adversaire : Fernand de Gonzague, accusa publiquement le garde des sceaux défunt d'avoir un jour touché 4000 écus sonnants pour faire gagner aux Milanais un procès difficile - attaque contre un vivant à travers un mort - non seulement l'Empereur refusa d'écouter ces accusations, mais peu de temps après, le Ier mai 1555, il donnait à son ministre et à tous les Perrenot un dernier gage de son affection : il érigeait Grandvelle en baronnie au profit de Thomas, chef de la famille.

Pourtant, dès 1550 et même avant, une question se posait pour toutes les personnes un peu au courant des intrigues de cour. Lorsque le prince d'Espagne accéderait au pouvoir, l'évêque d'Arras, quelle que fût sa souplesse, garderait-il le premier rang dans les conseil ? Que Ferdinand, que Maximilien lui voulussent mal de mort, comme le prétend quelque part Marillac, peu importait : au lendemain des négociations d'Augsbourg, leur haine ne pouvait que servir $M$. d'Arras ; mais d'autres ennemis étaient plus redoutables. Les Espagnols d'abord, tous ces grands avides de pouvoir qui faisaient murmurer contre eux les Flamands : un Ruy Gomez de Silva, un comte de Feria, un don Juan Manrèze de Lara : confidents, favoris, ministres du lendemain. Des Comtois ensuite : les uns servant en cour ; les autres, plus modestes mais plus dangereux, protégés des Perrenot devenant leurs rivaux - tel, le plus redoutable - Simon Renard, de Vesoul. 


\section{IV}

Ce personnage vindicatif et passionné, dont un admirable panneau d'Antonis Moor nous a conservé les traits, était une créature de Nicolas Perrenot. Né à Vesoul vers 1513 ; étudiant à Louvain où il connut le futur évêque d'Arras ; docteur en droit, avocat à Vesoul, puis lieutenant général du bailliage d'Amont, il déploya dans ce poste assez important des qualités qui le firent remarquer par le garde des sceaux. Nommé par son crédit, en 1547, maître des requêtes ordinaires de l'hôtel pour les affaires de Bourgogne, puis, deux ans après, maître des requêtes au Conseil privé, il suivit dès lors la cour ; en janvier 1549, l'Empereur l'anoblissait et comme son ambassadeur en France, Jean de Saint-Mauris, le beau-frère de Nicolas Perrenot, demandait son rappel, il désigna Renard pour le remplacer.

Nous avons les dépêches que l'Empereur et l'évêque d'Arras lui adressaient alors régulièrement. Dépêches fort détaillées : le jeune Comtois est un débutant qu'on guide par le menu ; mais le ton en est souvent fort affectueux. Antoine, avec condescendance, encourage et conseille son compatriote; Nicolas, de temps à autre, prend lui-même la plume et stimule son zèle par quelques compliments. Pour le père comme pour le fils, Simon Renard est un familier ; l'évêque d'Arras compte sur lui comme sur ses propres frères, un Thomas, un Jérôme, qu'il aide, qu'il pousse moins pour eux que pour lui - pour assurer à jamais les bases de sa puissance.

Mais Renard n'était pas homme à se contenter d'un tel rôle. Chassé de France en septembre 1551 Par l'ouverture des hostilités ; rétabli, à dater du Ier janvier 1551-52, dans les fonctions de maître aux requêtes de l'hôtel ; chargé de diverses missions à Trente et en Comté ; témoin du siège de Metz, puis malade et convalescent aux Pays-Bas, il reçut tout à coup, dans l'été de 1553, une nomination qui devait le tirer hors de pair. Le 6 juillet, le jour même où mourait Edouard VI, trois députés de l'Empereur : Jean de Montmorency, Jacques de Marnix et Simon Renard, faisaient à Londres leur entrée. Ils avaient mission d'assurer l'accession au trône de Marie Tudor et surtout d'amener la fille de Catherine d'Aragon à conclure 
mariage avec l'infant Philippe. Négociation d'importance ; on s'explique qu'elle ait tenté le jeune diplomate.

Dès le début, en effet, il prend la direction de l'ambassade, tient le propos dans les audiences et, seul, obtient de la reine ces entrevues secrètes où l'on commence à parler mariage. Ainsi dépossédé, l'ambassadeur ordinaire, Scheyfve, proteste et récrimine. Prestement, Renard le fait rappeler, lui et les deux autres envoyés extraordinaires; il reste seul à Londres et "Monsieur le lieutenant» devient « Monsieur l'ambassadeur ». Il travaille, d'ailleurs, et réussit. Dès octobre 1553, le mariage est décidé. Les félicitations affluent vers l'heureux négociateur, et l'évêque d'Arras n'est pas le dernier à lui offrir les siennes. « Vous verrez, écrit-il le 13 novembre, par lettres que S. M. vous escript, le contentement qu'elle a de vostre négociation, et certes avec très grande raison. Et encores que $S$. M. reconnaisse voz peines, travaulx et industrie, de mon coustel y tiendray très voulentiers la main. » Renard n'avait pas besoin d'éloges pour concevoir de ses mérites une opinion plus qu'avantageuse. Il était dès lors tellement susceptible et ombrageux qu'Antoine Perrenot, lui annonçant en janvier 1554 la prochaine arrivée en Angleterre de grands seigneurs chargés de conclure définitivement le mariage, croyait devoir ajouter : "Vous ferez bien de temporiser avec ces seigneurs. Vous vous y sçaurez bien accommoder pour le peu de temps qu'ilz y seront. » Et dans cette même lettre, le félicitant à nouveau de ses succès, il tenait cependant à en revendiquer sa part : « Je rens grâces à Dieu que le travail que vous et moy et aultres qui se sont meslez de cette négociation du mariage, aye si bon succès.... »

C'est à cette époque, en effet, que l'on constate entre l'évêque d'Arras et son «bon confrère et vray amy » les premiers symptômes d'un refroidissement. Sans doute, à en croire Renard lui-même, dès 1551 Granvelle lui aurait donné des preuves non équivoques de malveillance. Mais ces allégations, rien ne les confirme. Dès la première ambassade à Paris du lieutenant débutant, que le fils de Nicolas Perrenot ait eu lieu d'en être jaloux, c'est une fable évidente. Renard par contre, ambitieux et vain, avec, peut-être, une légère tendance à se croire persécuté, à dû dès le début porter la conviction qu'un homme de sa valeur provoquait l'envie. Dans de telles dispositions, ses succès à Londres devaient à la fois le griser et l'aigrir. En fait, le 3 septembre 1554, une lettre. d'Antoine Perrenot à l'Empereur nous révèle un antagonisme entre les deux Comtois. L'évêque d'Arras, se défendant contre des calomnies lancées contre lui, prétend-il, par le secrétaire 
Érasso, relève avec vivacité ses propos « en faveur de notre ambassadeur résident en Angleterre ». Certes, il est juste "que l'on reconnaisse les services de qui ha bien servy »; mais il n'entend être sacrifié à personne. La posture est ridicule, « de qui porte le vin et boit l'eau »; et n'est-ce pas lui qui le premier, ayant l'idée du mariage, en a écrit à Renard, "lui donnant le chemin qu'il devait suivre ", et l'encourageant quand «il voulait tout laisser»? Tant de bons offices sont oubliés : qu'on lui permette, alors, de se retirer dignement en son évêché....

Ainsi, un assaut commençait contre Granvelle à l'aide de Renard. Celui-ci se rangeait-il parmi les assaillants ? En tout cas, à ce moment même, coïncidence à noter, il adresse à Philippe, maître du lendemain, des dépêches très longues et d'un ton insolite. Mémoires à vrai dire, copieux mémoires de politique étrangère : Renard, complaisamment, y développe de vastes programmes. Qu'on lise tels d'entre eux et, par exemple, la longue lettre où il préconise contre la France une politique de rupture et de guerre : avec ses critiques du passé, ne semble-t-elle pas le manifeste d'un aspirant ministre?

\section{V}

Renard n'était point seul. Dans la lettre où il défendait la mémoire de son père contre les accusations de Gonzague, Antoine Perrenot incriminait vivement " ceulx que V. M. sait assez » et qui, en haine de lui et de son oncle François Bonvalot, "se resouvenans peult-estre à ceste occasion des choses passées", cherchaient à lui faire tort jusque dans son honneur. La mention de Bonvalot éclaire ce texte obscur. Les passionnés que dénonce Granvelle, ce sont, sans nul doute, les membres, les amis, les alliés de deux puissantes familles nobles du Comté : les Rye et les La Baume.

Nous connaissons aujourd'hui tout le détail des « choses passées » auxquelles l'évêque d'Arras faisait allusion. Lorsque la Réforme eut chassé de Genève l'évêque Pierre de la Baume, ce prélat, frère du maréchal de Bourgogne Claude de la Baume, se retira auprès de lui en Comté et devint, en 1533, le coadjuteur, en 1541 le successeur de l'archevêque de Besançon. Or, sa belle-soeur, femme du maréchal, étant en 1536 «accouchée d'un beau fils », Pierre, en oncle prévoyant, se 
préoccupa d'assurer l'avenir de l'enfant. Par lettres pontificales que ratifia l'Empereur, il le fit nommer son coadjuteur ; Louis de Rye, un autre de ses neveux, administrerait le diocèse jusqu'à la majorité du jeune Claude. Le 5 mai 1544, ces dispositions prises, Pierre de la Baume s'éteignait à Arbois - et, le 16, les chanoines de Besançon, alléguant leur droit d'élection, nommaient archevêque.... François Bonvalot, le propre beau-frère du garde des sceaux Perrenot.

La partie était difficile pour l'élu du chapitre. Sans doute, Claude de La Baume avait perdu son père, haut et puissant personnage dont la vie s'était partagée entre la cour impériale et la Comté. Mais il lui restait sa mère, Guillemette d'Igny, et tous les amis, les alliés des siens. Surtout, Bonvalot allait se heurter aux fils de Simon de Rye : Joachim, l'aîné, un des plus fidèles compagnons de l'Empereur ; Gérard, le second, aussi brave que son frère et, par surcroît, excellent diplomate ; Marc, le troisième, un bouillant seigneur dont nous aurons plus loin à parler longuement. Tuteurs naturels des puînés Philibert et Louis ; tous deux dans les ordres, les trois aînés, plus unis encore par un triple mariage avec les trois soeurs, disposaient à Rome et en cour d'Empire d'une puissante influence. Sans hésiter cependant, François Bonvalot engagea la lutte. Dès le 31 mai 1544, à Spire, où Charles-Quint tenait sa cour impériale, il acceptait, entre les mains de deux délégués du chapitre, l'élection faite de sa personne. Sollicité à la fois par les deux parties, l'Empereur se tira d'affaire avec un compromis : Bonvalot laisserait l'archevêché à son jeune rival, mais en retiendrait l'administration, avec le tiers des revenus, jusqu'aux vingt-cinq ans de Claude. L'accord fut conclu le 4 janvier 1545, et Nicolas Perrenot, qui trouvait son beau-frère maladroit et un peu compromettant, put croire, comme l'Empereur, le conflit terminé.

Illusion vite évanouie. Car aussitôt les difficultés recommencèrent. La paix se faisait, somme toute, aux dépens de Louis de Rye, administrateur désigné naguère par les bulles pontificales. Aux termes d'une transaction supplémentaire, les emplois à la nomination de l'archevêque devaient être pourvus alternativement par lui et par Bonvalot ; mais, outre que la compensation était assez maigre, Bonvalot, prétextant que le Saint-Siège n'avait pas ratifié les engagements pris à ce sujet, nomma et maintint toujours ses créatures. Alors, les Rye s'agitèrent de nouveau. A Rome, ils essayèrent d'empêcher le pape de ratifier l'accord du 4 janvier ; et l'évêque d'Arras n'eut pas trop de toute son influence pour triompher de leur opposition. En Comté, on vit, à chaque vacance, des Conflits héroï-comiques. Clients et 
protégés, ceux que les Rye nommaient et que Bonvalot refusait de connaître, ceux que Bonvalot installait et que les Rye traitaient d'intrus, en venaient régulièrement aux injures, aux provocations, parfois même aux coups. Pour les « envies de Bourgogne », ce fut une belle époque.

De fait, les deux partis restèrent en guerre ouverte. Le 15 mars 1549, dans une dépêche à Montmorency, Marillac notait que le garde des sceaux, fatigué, venait d'acheter une belle maison à Bruxelles; il parlait, ajoutait-il, d'acquérir terres et seigneuries aux Pays-Bas « pour y être plus aimé qu'en Bourgogne où les grands du pays le détestent. » De même, quelques mois plus tard, relatant ses obsèques solennelles à Augsbourg, Marillac n'avait garde d'omettre un fait menu, mais significatif. Toute la maison impériale devait assister au service en grand habit de deuil. MM. de Rye et de la Chaux - Joachim de Rye, sommelier de corps de l'Empereur et Jean de Poupet, gentilhomme de la chambre - s'inclinèrent devant l'ordre du maître. Ils se rendirent aux funérailles - mais en habits de fête : en robe de soie. Petite manifestation d'une grande haine, que la mort même ne pouvait apaiser.

On devine dès lors avec quelle passion les ennemis du père, devenus ceux du fils, souhaitaient un changement de règne qui brisât net la fortune d'Antoine. Qu'ils aient songé à Renard pour servir leurs desseins, et que celui-ci, parfaitement au courant des affaires comtoises et des intrigues de cour, se soit rapproché de seigneurs pleins de crédit et fort capables de l'avancer : rien de plus naturel. Accord tacite d'abord, rapprochement de fait : les événements devaient le transformer en entente ouverte. 
PHILIPPE II ET LA FRANCHE-COMTÉ

Étude d'histoire politique, religieuse et sociale.

Deuxième partie. Les débuts du règne de Philippe II

Chapitre VI

\section{Granvelle, Simon Renard et la noblesse comtoise}

\section{$\underline{\text { Retour à la table des matières }}$}

Le 6 décembre 1555, un habitant de Rochefort, près de Dole, ramassait à terre un paquet de lettres en partie chiffrées. La trouvaille lui parut suspecte : il porta les documents à la cour. C'étaient des dépêches à l'adresse de deux Français, le capitaine d'Auxonne et le marchand drapier parisien Gilles Féret, chargés de les transmettre au secrétaire Laubespine. Elles contenaient divers renseignements confidentiels, émanant d'un agent secret qui n'en était pas à ses débuts : « J'espère, écrivait-il en effet, que le crédit que j'ay emprès mon maistre vous fera encoires de grands et notables services. » Une rapide enquête révéla le nom du traître : Étienne Quiclet, Bisontin, secrétaire et confident de Simon Renard.

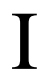

Quiclet faisait partie de ce monde d'agents subalternes, à la fois interprètes, courtiers, espions, messagers, qui s'agitaient dans l'entourage des grands et des diplomates. «Entremetteur » officiel des Bisontins en cour d'Empire, toutes les fois que ses compatriotes avaient à rédiger quelque lettre « tudesque » ou à solliciter une grâce impériale, ils faisaient appel à ses bons soins. Au cours de ses voya- 
ges, Quiclet connut les Granvelle. Alerte, intrigant, assez avantageux, il prit place parmi leurs agents, fut employé par eux et les leurs : François Bonvalot, Jean de Saint-Mauris, Bonet Jaquemet. Rien d'étonnant à ce qu'il fût entré également en rapports avec Simon Renard. Lorsque celui-ci, nommé ambassadeur en France, vint en 1549 promener en Comté son importance nouvelle, il cueillit Quiclet au passage, à Besançon, et l'emmena comme maître d'hôtel en France d'abord, puis en Angleterre. Choix malencontreux : dès 1550, l'ancien «contre-rôle » de Besançon vendait à Henri II les secrets de son maître.

Quel fut le détail de ses trahisons ? Peu importe : par ses conséquences politiques seules l'affaire Quiclet nous intéresse. Or, elles furent doubles. L'enquête révéla avec une force, une netteté singulière, la liaison des Rye, des La Baume et de leurs clients avec Renard, Quiclet et les « renardistes ». D'autre part, elle fournit à l'évêque d'Arras une arme redoutable contre son rival : cette accusation de trahison que Renard devait traîner, sans pouvoir s'en défaire, jusqu'aux derniers jours de son existence.

Sur le premier point, les textes abondent. Aussitôt amené à Dole, le 16 décembre, Quiclet déclare récuser une longue liste de parlementaires ; deux jours après, le 18, il supplie la cour de ne point communiquer ses déclarations à l'évêque d'Arras; et comme on lui demande ses raisons, il répond que, "pour estre serviteur du T.R.S. archevesque de Besançon, de la maison de la Baume et des srs de Rye, les srs d'Arras et Luxeul lui veullent mal mortellement ». Or, les récusés sont ou bien, comme M. de Thoraise, «beau-frère et neveu des srs d'Arras et Luxeul »; ou bien, comme M. de Saligney, «des favorites dud. sr de Luxeul »; ou bien encore, comme les autres : Chaillot, Saint-Mauris, Le Clerc, Sachet, Vauchard, « parens et alliez, faitz et eslevez des mains des srs d'Arras et de Luxeuil ». Était-ce pour se rendre plus intéressant que, dès la première heure, Quiclet mêlait ainsi les « partialitez » comtoises à son affaire ? Plutôt, comptait-il sur l'intervention des puissants seigneurs, un Joachim, un Marc de Rye, dont il se réclamait ouvertement ? Se voyant arrêté, il avait aussitôt prié sa femme d'avertir «MM. de Rye, de Dicey, de Besançon et autres »; plus tard, depuis sa prison, il lui écrivait que, «s'il n'estoit eslargy et lesd. srs de Rye et autres ses amis n'en faisoient: poursuites et le laissoient là, il parleroit gros ». Quels secrets prétendait-il détenir, pour se livrer à cet essai de chantage ? En tout cas, il connaissait bien les personnages dont il invoquait les bons offices. 
D'abord, il était avec eux en relations de « service ». Il raconte à plusieurs reprises, dans ses interrogatoires, comment la mauvaise grâce d'un François Bonvalot, la ladrerie maussade d'un Jean de Saint-Mauris exaspérant les espions, il les avait adressés à M. de Dicey qui, les traitant mieux, en obtenait plus. Mais si l'évêque d'Arras et Bonvalot lui voulaient «mal de mort »; si ce dernier, comme il disait de façon pittoresque, «le vouldroit avoir manger », c'était sans doute pour des raisons plus personnelles. De fait, il paraît bien que dans le conflit pour l'archevêché, Quiclet, serviteur de Claude de la Baume, s'était jeté à corps perdu dans sa querelle. Il était de ceux qui escomptaient le changement de règne ; pour trancher du personnage, il exaltait volontiers son crédit sur Renard, ou le crédit de Renard sur Philippe, et libéralement promettait sa protection à ses concitoyens pour le jour où l'ancien lieutenant d'Amont triompherait à la place des Perrenot. Renard, par ses lettres et ses propos, encourageait volontiers sa propagande.

Directement d'ailleurs, l'ambassadeur ne tarda pas à être mis en cause. Dans les perquisitions effectuées chez Quiclet, à Besançon et à Bucey-lez-Gy, des lettres de sa main avaient été saisies. Le 24 février, on en présentait plusieurs à Quiclet, en lui demandant d'expliquer certains passages. Par exemple, que signifiaient ces phrases : " Quant à la pension que l'on vous offre, acceptez-la, car je pense que l'on le fait pour mon respect. » Ou : «Quant aux cinquante écu, vous verrez ce que vous escripz et entendrez que ne puis estre payé ny en Espaigne ny en Flandres. » Quiclet répondit que, dans le dernier cas, il s'agissait d'un prêt et, dans le premier, d'une pension offerte par le comte de Montbéliard, alors en procès à Dole contre MM. de Rye et désireux d'acquérir des sympathies comtoises : explications plausibles; mais en quelle suspicion avaient-ils donc Renard, ceux qui, dès ce moment, trouvaient ou feignaient de trouver un sens suspect à ces deux passages?

Il est vrai qu'antérieurement au 24 février, l'enquête avait révélé des faits curieux. Sitôt l'arrestation connue, la femme de Quiclet, Diane de Kleberg, avait mandé en hâte "son compère », le chanoine Siméon Perrot. C'était précisément l'un des grands adversaires de Bonvalot ; frère de l'archidiacre Jacques Perrot que l'administrateur avait révoqué de ses fonctions de vicaire général et d'official, il était un des trois ou quatre chanoines qui avaient pris fait et cause pour Claude de la Baume. Diane le pria d'aller à Dole aux renseignements. Perrot accepta, mais auparavant : "Il faut donner ordre ès papiers de votre mary », dit-il, « et veulx 
avoir les lettres que mon frère lui a escript ». Précisément, Quiclet avait peu avant chargé sa femme de remettre à Perrot certains papiers. Le chanoine les prit, ainsi qu'un coffret plein de documents, puis partit aux nouvelles à Rahon, chez M. de Rye. Chemin faisant, il rencontra le vieux seigneur et en reçut conseil de se tenir tranquille. Aussi, rentré sur l'heure à Besançon et avant même de se débotter, « anrequam ocreas exuiret », renvoya-t-il à Diane les lettres et le coffret - intact, prétend-il, ouvert et crocheté au dire de Diane. Et il la pria de taire ses visites.

De son côté, au bruit de l'arrestation, le frère de l'ambassadeur, le protonotaire et chanoine Jean Renard, s'était rendu chez Quiclet. S'adressant à la femme tout émue du prisonnier, «il l'interrogea où estoient les lettres de $\mathrm{M}$. l'ambassadeur son frère, requérant que l'on les luy donnast ». - « Je y ay mis bon ordre », répliqua d'abord Diane, à qui son mari avait toujours défendu de montrer à Jean Renard ni « souffrir qu'il vit aucunes lettres estans en sa maison ». Mais le chanoine fit tant qu'elle lui montra un petit coffret rempli de papiers ; il le vida, emporta le contenu et lui aussi, se retirant, ordonna à Diane la plus grande discrétion. Quel était le sens réel de ces démarches ? Les amis d'Antoine Perrenot y virent ou feignirent d'y voir une preuve de complicité de Renard avec son « domestique »; et lorsque, au mois d'août, après quelques semaines d'interruption, l'instruction fut reprise, mais, cette fois, en présence de deux commissaires flamands, Joachim de Hontzocht et Jacques de Hessele, spécialement envoyés en Comté à ce sujet - de nouveau, on soumit à l'inculpé, pour explications, des phrases obscures de Renard ; bientôt même, à la suite de questions restées sans réponses sur des complicités possibles, on lui demanda tout net, le 25 août, "si ledit ambassadeur" n'avait pas eu « quelque intelligence avec luy » au sujet des lettres trouvées à Rochefort « ou autres, précédemment par lui envoyées aux Français ».

Les dépositions recueillies, les pièces saisies autorisaient-elles de pareils soupçons ? Il semble bien que non. Toujours Quiclet s'éleva avec force contre l'idée d'une complicité ; la torture rigoureuse qu'il subit à deux reprises ne put lui arracher d'aveu à ce sujet, et le 25 août notamment, il répondit avec force que Renard ignorait tout et que «ce qu'il craignait estoit qu'il n'en fust adverty ». Une seule accusation, d'après les documents, peut être portée contre Renard : celle de légèreté. Au dire de Quiclet, il savait - et par Quiclet lui-même - que son maître d'hôtel était l'objet de sollicitations de la part des Français. Chose plus grave, lorsqu'il était encore en Angleterre, il avait reçu de l'évêque d'Arras une lettre très 
nette, l'avertissant « qu'ung homme auprès de luy, servant de maistre d'hotel ou secrétaire », le « déchiffrait » et «donnoit advis au Connestable ». Or, loin de tenir compte de ces révélations, Renard en fit part à Quiclet ; il lui annonça « qu'il avoit répondu au sr d'Arras » et tout «à son avantage ». Si le récit est vrai, la confiance de Renard était aveugle ; mais qu'il ait fermé les yeux par complicité, rien en vérité n'autorise à le dire. Comment donc expliquer la mise en cause de l'ambassadeur? Uniquement, par les passions locales au service des Perrenot.

\section{II}

Rappelons-nous quelques dates. Au mois de mars 1555, Renard a obtenu de rentrer en Flandre. Il a quitté Londres et peu de temps après, le 17 novembre 1555, s'est vu nommer conseiller d'État extraordinaire. Puis, presque aussitôt, chargé de négocier avec les Français, il est parti en compagnie de Lalaing pour Cambrai d'abord, pour Vaucelles ensuite. La fortune lui sourit. Il est plein d'orgueil, d'espoir et d'ambition. En Comté, son frère Jean nommé, le 31 janvier 1554, chanoine de Besançon ; son frère Louis institué, le 22 octobre 1555, trésorier de Vesoul, peuvent attester à tous l'efficacité de son crédit naissant.

L'évêque d'Arras par contre est troublé. Le 4 septembre 1555, Philippe a débarqué à Calais, gagnant Bruxelles depuis Londres ; le 25 octobre, le 16 janvier suivants, il a reçu des mains paternelles les Pays-Bas, l'Espagne et la Sicile ; son règne commence, les sceaux sont renouvelés, les offices confirmés, « toutes choses changées, ne plus ne moins que si le seigneur Empereur fut décédé ». Toutes choses - mais les ministres ? Quel va être le sort d'Antoine Perrenot ? Tant d'adversaires l'entourent, le guettent, le menacent : Espagnols, animés contre lui d'une haine efficace ; Bourguignons de haut rang, ses ennemis personnels ; Flamands même, prompts à murmurer contre les Franc-Comtois, ces « demi-estrangiers ». Et le ministre s'inquiète. Il sait les bruits qui circulent à la cour et que beaucoup prédisent, sinon sa disgrâce, du moins la perte de son crédit. Auraient-ils raison ? Renard, cet intrigant, deviendrait-il vraiment un des artisans d'une telle déchéance ? Questions qu'avec l'évêque d'Arras tout son entourage se pose anxieusement. Ils sont tant de clients, de parents, d'amis, au Parlement surtout, qui ont fait fond 
sur lui, escomptent ses faveurs, tremblent quotidiennement d'en voir tarir la source... Et c'est à ce moment, c'est devant ces hommes que va venir brusquement le procès Quiclet.

Or, au XVIe siècle, les accusations de trahison étaient monnaie courante. La Comté, pour sa part, en connut maint exemple. En 1557, un an après l'affaire Quiclet, François Bonvalot ne se vit-il pas reprocher - avec quelle vraisemblance ! d'avoir voulu livrer les clefs de Besançon aux Français ? Quelque temps avant, en 1552, un certain Saint-Cry colportait contre Marc de Rye et sa femme des rumeurs calomnieuses. Et en 1555, à Bouclans, près de Besançon, vivait toujours Jean Lallemand, le négociateur du traité de Madrid, disgracié par son maître pour infidélité. Tragédie de cour, celle-là aussi ; dans la ruine de cet homme, les passions privées, l'ambition, la haine, l'intérêt, jouèrent largement leur rôle. C'était un compatriote, un subalterne désireux d'avancement, le Graylois Perrenin, qui dénonçant Lallemand y avait gagné de le remplacer. C'était un grand seigneur, Laurent de Gorrevod, compagnon tout dévoué des Rye et des La Baume, qui, poursuivant de sa haine le secrétaire d'État, avait machiné l'habile accusation qui en causa la perte... Or, coïncidence à tout le moins étrange : quelques mois à peine avant l'arrestation de Quiclet, les conseillers de Dole avaient pu se remémorer toute l'affaire Lallemand et apprendre, s'ils l'ignoraient, quelle arme redoutable entre des mains expertes pouvait devenir un soupçon de trahison. Dans un registre du Parlement, nous avons rencontré en effet, daté du 7 août 1554, un jugement rendu à requête de Lallemand contre un certain Barthoz, accusé par lui d'avoir confectionné les dépêches chiffrées qui servirent de base à ses accusateurs ? De ce rapprochement, certes, nous n'avons le droit de rien conclure. Mais ce qu'il y a de sûr, c'est que, dès février 1556, les enquêteurs mettaient Renard en cause - et que Renard lui-même, le 14 septembre 1556, dans une lettre au roi, la première à ce sujet, fait remonter nettement, sinon à Antoine Perrenot du moins à ses amis, l'origine des soupçons élevés contre lui.

À cette date du reste, le procès de Quiclet touchait à sa fin. Dans sa lettre du 14, Renard demandait à Philippe une confrontation avec son maître d'hôtel. Le roi, faisant droit à ce désir, répondit que le procès ne serait point vidé sans qu'ait eu lieu, à Dole, cette nécessaire entrevue. Néanmoins, le 23 mars 1557, la cour de Dole délibérait sur le châtiment du traître. Le rapporteur Colin proposa d'attacher le malheureux à la queue d'un cheval et de le faire traîner par les rues, à revers sur 
une claie ; on lui couperait ensuite la main droite et la tête. L'avis prévalut contre ceux des conseillers d'Achey et Courvoisier, qui le voulaient brûler ou écarteler vif. L'exécution eut lieu le 26 ; les biens du coupable furent confisqués et ses parents bannis.

Tel fut l'épilogue d'un procès qui dès la première minute avait cessé d'être criminel pour devenir politique. L'évêque d'Arras était-il intervenu pour en hâter la solution et rendre impossible toute confrontation de Quiclet avec Renard ? C'était son intérêt, sans doute, et Renard l'en accuse. Mais celui-ci était loin d'être dénué de crédit. Il rentre aux Pays-Bas à la fin de février 1557, une fois la guerre déclarée avec la France ; il y reprend sa place dans les conseils puis accompagne, en mars, Philippe en Angleterre, revient avec lui à l'armée, toujours consulté, toujours écouté avec extrême faveur. Faveur périlleuse, il est vrai : au lendemain de Saint-Quentin, Renard put en faire la dure expérience. S'étant opposé vivement à la marche sur Paris, que préconisaient Philibert-Emmanuel et ses lieutenants, il vit sa thèse triompher ; mais tous ceux qui, à tort ou à raison, considérèrent l'inaction comme une faute grave firent porter à Renard le poids de leur déception. En fait, l'année suivante, lorsque s'ouvrirent les conférences diplomatiques qui devaient aboutir au traité du Cateau-Cambrésis, Renard n'y prit point part. L'évêque d'Arras, restitué en faveur, conduisit les négociations ; à lui revint tout l'honneur du succès et, pour la première fois depuis la grande entreprise qui l'avait mis en relief, le négociateur du mariage anglais put taxer son maître d'ingratitude. Une nouvelle déception l'attendait. Lorsque Philippe, en septembre 1559, quitta les Pays-Bas, il le laissa, simple conseiller, à la cour de Marguerite de Parme. Et l'évêque d'Arras sans doute demeura lui aussi par deçà. Il ne suivit pas le maître dans ses pays d'Espagne; la haine des Espagnols le lui interdit. Mais auprès de Marguerite, à la tête de la Consulta, il devint le véritable représentant du souverain dans les Pays-Bas - et les événements devaient se charger de grandir l'importance de son rôle.

Notons-le cependant : pour les Comtois qui avaient suivi avec un intérêt passionné ce conflit, le demi-échec des deux rivaux était grave. L'évêque d'Arras pouvait bien avoir résisté aux attaques. Il n'avait plus auprès du nouveau maître cette situation unique, ce crédit sans rival dont son père avait joui sous l'Empereur. Aux Italiens, aux Espagnols surtout, les Bourguignons passaient la main. 
C'étaient les premières conséquences du nouveau règne - les premières, non les seules.

\section{III}

A la cour de l'Empereur - cour toute bourguignonne à ses débuts - les Comtois par leur bravoure, leur entrain, leur fidélité à toute épreuve, avaient su conquérir une place que ne justifiait guère l'importance matérielle de leur patrie. Qu'on parcoure les rares «états », tous publiés aujourd'hui, qui ont survécu aux ruines matérielles : dès 1517, les Bourguignons de conseil et d'épée pullulent dans l'entourage du souverain. Chambellans, panetiers, échansons, écuyers tranchants ou d'écurie, varlets servants, pages, fourriers, archers de corps - ou conseillers, ce sont les Gorrevod, les Poupet, les Vergy, les Ray, les Longvy, les Vaudrey, les Rye, les Falletans, les Grammont, les d'Achey, les d'Andelot, ceux qu'on retrouve à toutes les pages du voyage en Espagne de Laurent Vital : capitaines de navires, comme ce Mont-richard dont le chroniqueur nous décrit la fin misérable ; grands dignitaires admis sur le vaisseau royal ; figurants magnifiques des tournois d'honneur : ceux d'antique lignage, ceux de fraîche noblesse, un écuyer Grospain ou un Vaudrey-le-Fol, un Laurent de Gorrevod ou un Carondelet. D'état en état, de campagne en campagne, les mêmes noms se retrouvent, portés par les fils quand les pères ne sont plus. Ces Comtois, à Pavie, s'attaquent au roi de France, le saisissent finalement et le font prisonnier. Ils sont à Tunis en 1535, à Alger en 1541 ; ils escortent l'Empereur en 1547, à Mühlberg, lorsque solidement assis sur le «Ferry », le bon cheval de bataille de Joachim de Rye, Charles, morion en tête et javeline en main, se jette dans l'Elbe et décide du combat. Quand ils ne se battent pas, ils négocient, aussi bonnes têtes que bons bras. Faut-il trois envoyés en 1532, pour requérir les princes chrétiens contre le Turc ? Ce sont trois Comtois, d'origine ou d'adoption, que dépêche Charles : Jean d'Andelot au pape, Joachim de Rye au roi de France, Philibert de la Baume au roi d'Angleterre. Faut-il presser sur Marguerite, l'amener à se résigner au mariage Farnèse : c'est Andelot également que lui envoie l'Empereur. Exemples pris entre cent : ils attestent la confiance dont jouissaient les Bourguignons. 
Rien de plus parlant, du reste, que le mandement adressé par Charles au secrétaire Bave, le 22 octobre 1555 - presque à la veille de son départ pour Yuste. Dans ce long document - liste de récompenses pour les serviteurs que le maître allait quitter -les noms comtois fourmillent. A de modestes personnages, de modestes emplois : le garde-robe Guyon de Montrond est nommé concierge, à Lille, de l'hôtel impérial ; le sommelier Guyon de Lyon, portier de la Saunerie de Salins ; le fourrier Hugues Cousin, buissier du même établissement. À de plus relevés, des capitaineries : celle de « Ripple-monde » pour Philippe de Chassey ; la châtellenie de Bracon pour Philibert de Vautravers ; la prévôté de Gray pour Louis Taillant de Montfort ; la capitainerie de Faucogney pour Louis Nicod, gentilhomme de la maison. Puis, des pensions : 150 fr. par an au conseiller Le Clerc, longtemps maître aux requêtes de l'hôtel. Des gratifications : 350 fr. de gages par an au trésorier de Salins, Bonet Jaquemet, pour avoir effectué le « haussement » du sel ; 800 fr. pour une fois aux srs de Bitaine, Conflandey et Chatelroillaud, et 8000 , somme énorme, à Marc de Rye. Des largesses collectives : 3200 charges de sel bouchet au personnel de la Saunerie ; la remise de 300 fr. aux Bisontins sur les 500 que leur coûtait annuellement le traité de garde ; 600 fr. au Parlement de Dole pour achat de tapisseries et réfection de la salle des séances. Des dons divers enfin, trahissant la préoccupation d'assurer l'avenir d'une province isolée : 7000 écus au bailli et gouverneur de Dole, Jean d'Andelot, pour achat et transport de munitions ; la baronnie de Soye pour l'ingénieur génois Ambroise Précipiano et, afin de le fixer plus sûrement en Comté, cent écus d'or par mois et l'ordre de lui payer l'arriéré de ses gages. Libéralités extrêmes, de la part d'un souverain connu pour son avarice. Elles attestent l'affection réelle que, jusqu'aux derniers jours, il nourrissait pour son comté de Bourgogne.

Au reste, voici l'état de sa maison, en juin 1556, lorsqu'il la licencia. D'abord, cinq grands officiers ; deux sont Comtois : Joachim de Rye, sommelier de corps ; Philibert de la Baume, baron de Montfalconnet, majordome. A la tête des gentilshommes de la chambre, Jean de Poupet, seigneur de la Chaux : il devait accompagner l'Empereur, après l'abdication, jusqu'en Espagne. A la garde-robe, Guyon de Montrond ; comme aides de la chambre, Antoine de Canoz, Philibert de Vautravers, le fourrier Cousin. Parmi les pages d'honneur, Marc de Canoz; parmi les gentilshommes de la maison, Claude de Ray, Nicolas de Gilley, Claude de Plaine, Thomas de Clermont, Philippe de Chassey, Gérard de Wateville, Georges d'Ande- 
lot. Des gentilshommes de la bouche sont Fernand de Lannoy, Pierre de Vaudrey, Hugues de Villelume, Jean d'Achey, Thomas Perrenot de Chantonnay, Jean d'Andelot, le premier écuyer ; des valets servants, François de Vautravers ; des coutiliers, Guy de Montfort, François de Vergy, le comte de Pont de Vaux, J. de Montfort, J.-B. d'Andelot, Claude de Taillant, Marc de Canoz, Philibert de Montmartin... Et l'énumération est limitée ; elle ne comprend pas, notamment, les archers de corps - ces cent soldats d'élite recrutés uniquement dans les pays d'Embas. Telle quelle, ne dit-elle pas suffisamment le rôle des Comtois, leur place à la cour ?

Or, Philippe II prend le pouvoir, et tout change aussitôt. Crédit, honneurs, privilèges et pensions, tout va aux Espagnols. A l'état de la maison impériale en 1556, comparons l'état de la maison royale en 1558. Les cinq grands officiers sont tous Espagnols ; Joachim de Rye est mort le 29 septembre 1557 en Comté, à Rahon ; Philibert de la Baume, retiré sur ses terres, ne quittera plus sa seigneurie de Saint-Amour. Les huit gentilshommes de la chambre, tous Espagnols aussi ; Flamands ou Espagnols, les onze aides de la chambre, les médecins et chirurgiens, les officiers de la maison, ceux des services de bouche, les huissiers, les massiers. Sur treize personnages inscrits à la grande Fourrerie, un seul est Comtois : Hugues Cousin. Sur quatre rois d'armes et hérauts, on note deux Bourguignons ; mais cinq seulement sur quatre-vingt-trois gentilshommes de la bouche, et sur quatre-vingtdeux gentilshommes de la maison, quatre : au total, douze noms sur plus de quatre cents que contient le document - et pas un Bourguignon parmi les cinquante coutiliers, les soixante gentilshommes à la suite, les nombreux grands seigneurs énumérés longuement. En moins de deux années, quelle déchéance !

Dès cette époque, du reste, le roi est ruiné. Le célèbre Mémorial des finances qu'il dresse de sa main pour 1560 et 1561 accuse ce bilan : dépenses, dix millions trois cent trente-trois mille ducats ; recettes, un million trois cent trente-trois mille ; déficit, neuf millions, qu'il faudra "chercher en l'air» ou se procurer au moyen d'inventions usées... On s'explique que Philippe ne se montre pas «libéral de beaucoup d'argent » et que pendant des mois et des mois, les gens du roi restent sans toucher leurs gages, sauf les «plus disetteux ». Du domaine lui-même, le souverain est avare. Assez fréquemment, Charles, en Franche-Comté, avait remis à de bons serviteurs des seigneuries domaniales laissées en engagère: Apremont et Gendrey à Nicolas Perrenot, en 1538 ; Jonvelle aux d'Andelot en 1549 ; SceyenVarais, à Nicolas Perrenot, en 1550 ; Soye, en 1555, à Précipiano ; Rochefort, 
Quingey, Santans, Vercel, Saint-Aubin avaient été l'objet de concessions analogues. Or, toutes ces terres, sauf Scey et Vercel, Philippe Il va les racheter pendant son long règne, les réintégrer au domaine, et s'il concède pour sa part Vennes, en 1556 ; Usier, en 1557 ; Jussey, en 1570, ses concessions seront essentiellement temporaires ; aucune ne se perpétuera par delà sa vie.

Aussi, dès son avènement, c'est un grand exode des Comtois courtisans. Plus prononcé encore quand, quittant à jamais les Pays-Bas, le roi casse sa cour. Les petits, bien vite, reviennent au pays ; le fourrier Cousin se retire à Nozeroy, près de son frère Gilbert, l'humaniste. Le héraut d'armes Maublanc devient à Gray contrôleur des fortifications. L'écuyer Claude de Chavirey, sa lance pendue au clou, s'occupe prosaïquement de réparer ses tonneaux. Antoine de Canoz vit paisible dans ses capitaineries. Mais les grands, eux aussi, regagnent leurs domaines : Jean d'Andelot, Joachim de Rye viennent mourir en Comté ; Philibert de la Baume, Gérard et Marc de Rye, Claude de Taillant-Montfort, Claude de Ray, Jean d'Achey, tous par goût ou par nécessité se transforment en gentilshommes campagnards. Ils viennent grossir, dans la province natale, le contingent des nobles oisifs et turbulents.

Contingent redoutable déjà. Qu'on dépouille, pour les années moyennes du siècle, les registres criminels du Parlement de Dole ; ce ne sont à chaque page que brutalités, agressions, brigandages de seigneurs plus ou moins titrés. Voici des détroussements : par les soins de Christophe de Maisières et de Laurent Guilloz, sieur de Vertières, tous deux à cheval « et pourtans, avec leurs espées, hacquebuttes et pistoletz », le paysan fortuné qui se rend à la ville se voit fort proprement alléger « du petit sac de toille qu'il portait en son sein, pendu à son col, où estoient ses escuz ». Plus raffinés, Claude de Fouchier, seigneur de Savoyeux, et Humbert d'Haraucourt, seigneur de Frasnois, s'emparent dextrement, en 1549, d'un robin voyageant dans leurs parages : séquestré, menacé, violenté, le pauvre homme ne se tire de leurs griffes qu'en souscrivant une obligation. D'autres s'incrustent, sédentaires, dans quelque bonne place, et devenus intendants de seigneurs mieux titrés, se font en peu de temps une fortune respectable. Dans la terre de Ray, François et Christophe de Montfort père et fils, gentilshommes savoyards entrés sans sou ni maille au service du seigneur, usurpent terres, vignes et maisons, captent les héritages par «menasses et intimidations », et tantôt interrompant leurs audiences de justice, fondent l'épée haute sur les justiciables, tantôt raflent d'un coup 
« la virée des vaches » champoyant dans les prés, rossent les gardiens et les font composer pour délit de pâture inventé sur l'heure : dans les registres du Parlement, la liste de leurs méfaits occupe huit grandes pages.

Et puis, ce sont des duels, des rixes, des provocations où s'use la fougue des jeunes, la vigueur indomptable des vieux. En 1549, Nicolas de Gilley, Claude de la Villette, les seigneurs de Vescles, Cogna, Auxange, Boutavant « et autres leurs adhérans » s'élèvent «1'ung à l'encontre de l'aultre, usans d'invehissement, port d'armes et indehues volontez ». En 1554, pareille aventure : Claude de la Villette, récidivant, provoque Regnaud d'Asuel : il faut leur interdire "d'eulx mettre en armes, invehir et assaillir » comme au bon vieux temps des guerres privées. En 1556, une bande de gens d'épée, Claude de Voisey à sa tête, se ruent à Gy sur la maison du seigneur d'Onay, l'écuyer Begnin, un des riches du Comté, le provoquent, l'injurient, puis lui donnent l'assaut pistolets en mains. Pourquoi se gêner, du reste ? Tout le premier, le prévôt des maréchaux, Simon de Maisières, rançonne bourgeois et marchands, les arrête sans motifs afin de les relâcher contre espèces sonnantes ou de confisquer leur bourse et leurs habits : fantaisies moins innocentes encore que d'entrer à toute heure chez les villageois, d'exiger d'eux « des veaulx, des mouthons, des poules et gellynes, des eufs, des fromages et aultres choses », d'en faire sur place " chière de gourmandise ", puis de s'en aller « en emportant la reste $» . .$.

\section{IV}

Or, en avril 1559, la paix du Cateau-Cambrésis est signée. Finis, pour un long temps, les combats entre le roi Catholique et le roi Très Chrétien, les campagnes en France, sur les confins des Flandres et dans l'Artois. Mais finies pareillement, Philippe n'étant plus comme son père à la tête de l'Empire, les prises d'armes en Allemagne, les luttes contre les électeurs réformés. Jusqu'aux levées du duc d'Albe, à ses premiers combats contre les Gueux ; jusqu'à Lépante d'autre part, rien ne troublera la paix.

Vers le milieu du siècle, dans ces années de trêve qui s'écoulent entre la fin des grands conflits internationaux et le début des guerres de religion, voici les 
hommes d'épée confinés dans leur étroite province. Jeunes gens, ils sentent en eux des réserves de force, qu'ils voudraient user ailleurs qu'à la chasse. Hommes faits, ils regrettent ce qu'ils viennent de quitter : les grasses villes de Flandre ou d'Allemagne où l'on fait si bonne chère ; la cour et ses splendeurs, les fêtes et les tournois, les parades glorieuses sous le regard des dames ; les combats aussi, toute la vie d'aventures du soudard en campagne, telle que, dans ses Mémoires, nous la dit un des leurs : Ferry de Guyon. Partir à seize ans de la maison paternelle ; courir en bataillant à travers l'Italie, la Provence, la Hongrie, l'Allemagne, la Tunisie, les Pays-Bas ; connaître les bombances et les privations, les heures de liesse et les mois de souffrance ; " pasmer de soif » au soleil de Tunis ou boire à Montefiascone " d'aussi bon vin muscadel qu'il y ait en tout le monde »; dévorer ses chevaux en Barbarie, manger «dans les landes gennoises des chataignes à faute de pain » ou savourer en Flandre ces repas plantureux, cette chère si succulente que l'aigre cervoise ne la gâtait même pas : toute une existence se déroulait ainsi dans leurs souvenirs, avec ses alternatives : des hivers passés « sans croix ny pille » dans un village napolitain, à chasser lièvres et bécasses parce qu'on a perdu au jeu « tout son argent et gaignage de Thunis »; des départs misérables en campagne, « sans un denier en bourse », sans un cheval d'armes, en portant «à beaux pieds » une grosse arquebuse; des chevauchées à travers l'Espagne avec deux serviteurs fidèles, un chien et un baudet pour porter « la monnoye, les habits et le manger »; de l'argent gagné par tous les moyens, en maquignonnant des chevaux de prix, en visitant les pourpoints des morts ou des fuyards, en rachetant à bon compte de quelque reître ignare l'opulent prisonnier qui paiera grosse rançon... Ainsi venait la vieillesse, le temps du mariage, la retraite pensionnée dans quelque bourgade : fin de vie modeste, que troublaient encore une ou deux chevauchées sur le dos du Camu, « le meilleur et plus légal » des chevaux - derniers réveils avant le dernier repos.

Terminée avec le nouveau roi, interrompue tout au moins, cette libre existence. Que vont devenir en Comté les fils des fameux «chevaux bourguignons » dont Philibert de Chalon ne voulait que 4000 pour passer en vainqueur «par le milieu des roïaumes d'Orient »? - Ils serviront ? Mais, dans la Comté neutralisée, il n'y a même pas d'organisation militaire permanente. Et c'est le rêve constant de la noblesse sans doute, c'est son infatigable ambition de parvenir à mettre sur pied une milice, des régiments avec leurs colonels, leurs capitaines, leurs alphères, 
leurs enseignes, tout un état-major brillant et pensionné. Rêve qui jamais ne devient réalité : les bourgeois sont là, et les Perrenot, pour y mettre bon ordre. - Il y a des offices, des charges rémunérées ? Chimère aussi. Le gouvernement, pour longtemps, appartient aux Vergy. Les baillis ne sont que trois; ils se recrutent toujours dans les mêmes familles : la Baume, d'Achey, Bauffremont, d'Andelot, Montfort ou d'Oiselay. Le Parlement compte deux chevaliers d'honneur : mais ce sont des d'Achey aussi, des Montfort, des d'Oiselay, des Mouchet ; et déjà, à côté de ces nobles de vieille race, les anoblis figurent avec un Frédéric Perrenot. - Restent les capitaineries de Dole, de Gray, de Besançon, sources d'honneurs et d'occupations militaires. Mais ceux qui les détiennent sont déjà munis d'un bailliage, d'une chevalerie d'honneur, du gouvernement même. Au gouvernement de Dole, sous Philippe II, vont se succéder des baillis : Jean d'Andelot, François d'Achey, et des chevaliers d'honneur : Jean d'Achey, Antoine d'Oiselay ; à Gray, des baillis pareillement : Fernand de Lannoy, Jérôme d'Achey, ou le gouverneur Claude de Vergy... Par de tels cumuls se trouve réduit encore le nombre des charges laissées à la noblesse ; maigre provende, pour satisfaire les moins titrés, cette quinzaine de capitaineries secondaires - châteaux demi-ruinés, bicoques démantelées, bourgades paisibles - qui formaient leur lot : elles ne nourrissaient ni n'occupaient leur homme.

Alors, c'est le désoeuvrement et le dévergondage. Les nobles étudiants ne sont pas seuls à courir les rues de Dole après le couvre-feu, arquebuse en main et masque au visage. Par bandes également, de hardis seigneurs traînant sur leurs chausses une valetaille agressive - gros Allemands dociles, dûment « embastonnez » ou spadassins subtils d'Italie - remplissent les carrefours de leurs clameurs, enlèvent les servantes au nez des bourgeois, ferraillent pour le plaisir ou donnent l'escalade à quelque riche maison. Passe-temps éternels, sans doute ; il semble, pourtant, qu'il y ait eu alors comme une recrudescence, un surcroît de brutalités. En avril 1557-58, devant tant d'attentats « que se font journellement, de traictz d'arquebouses et pistoletz », la cour ne doit-elle pas édicter la mort pour tout usage d'armes, que le coup ait porté ou non?

À ces brutalités, les plus grands seigneurs participent largement ; entre tous, les Rye : Marc, le père, et son fils Claude-François. Père et fils de même vie et de même caractère : ce sont, disait Granvelle en 1567, « cerveaux peu reposés, et me semble le père de cerveau plus jeune encore que le fils ». Seigneur de Dicey, 
Marc, laissant ses frères Joachim et Gérard remplir à la cour des fonctions enviées, était resté dans son pays natal aux côtés de sa femme Jeanne de Longvy. Il assistait le gouverneur, lui servait de lieutenant, inspectait les fortifications ou « rabillait » l'artillerie de Dole, surveillait à Gray la fonte des coulevrines ou des canons : ces occupations lui plaisaient, l'empêchaient de songer aux misères du siècle, à l'arrogance des robins, aux fortunes scandaleuses de ces Perrenot qu'il haïssait à mort depuis l'élection de François Bonvalot.

Claude-François était son digne héritier. Chef incontesté des écuyers brutaux et violents dont on sait les exploits, il les surpassait tous par la hardiesse, l'ampleur de ses aventures. Périlleuses pour lui, mais pour son pays même : à la tête d'une petite troupe de cavaliers, n'allait-il pas se ruer, en mars 1561, sur la ville d'Héricourt, alors en possession du comte de Montbéliard, et risquer ainsi d'entraîner la Comté dans un conflit dangereux ? C'était sa façon de revendiquer des droits, d'ailleurs prescrits, et d'intervenir dans un procès pendant. - Son père le soutenait chaudement ; le magistrat de Dole l'accusa même d'avoir, abusant de ses fonctions, distrait «bonne partie des munitions » de Dole pour «accommoder » ses étranges entreprises... À l'ordinaire, secondé par son lieutenant, ce Claude de la Villette dont les registres criminels nous narrent les hauts faits, il n'était pas d'outrages ou de vexations que Marc ne fit subir aux bourgeois ou aux parlementaires qui le tiraient en cause. C'étaient entre ces puissances hostiles d'âpres conflits de juridiction. En veut-on un exemple ? En 1559, au mois de janvier, un Dolois, un clerc, Louis Theveney, est assassiné par un horloger, Jacques Benoît, aidé de plusieurs soudards de la garnison. Son coup fait, le meurtrier s'enfuit au boulevard des Bénits, où résidait le lieutenant de Marc, M. de la Villette : celui-ci le fait enfermer au château. La cour l'envoie réclamer. Démarche vaine : Benoît était le soudard du capitaine ; celui-ci le jugerait seul, et ne le rendrait pas. On insiste ; par trois fois on dépêche à Marc le procureur, le greffier, puis le substitut: il s'emporte alors, jure qu'au premier robin qui l'abordera, il fera distribuer «trois traicts de corde et d'estrappade ». Rapport à la cour, procès, citation de Marc de Rye à comparaître, défauts successifs, condamnation, plaintes au roi : ce fut pendant six mois un déluge de rapports, de doléances, de dits et contredits, de lettres et d'enquêtes que termina finalement un désaveu en règle du bouillant capitaine. Mais à peine une affaire était-elle apaisée qu'une autre surgissait, toute semblable. Après le Parlement, le magistrat de Dole : contestations par le service 
du guet, pour la garde des clefs, pour les droits du maire sur la garnison : on va de troubles en troubles, de conflits en conflits... Ainsi se manifestait l'antagonisme aigu qui, l'une contre l'autre, dressait bourgeoisie et noblesse d'épée.

\section{V}

Anecdotes banales de toute vie provinciale au XVIe siècle ? Sans doute. Mais en Comté, de par les circonstances, elles prenaient une valeur politique réelle.

D'abord, elles mettaient en cause le Parlement, gardien de l'ordre et de la paix publique. Crûment, Granvelle l'écrit : «Sans la cour, tout le pays ne serait qu'une brigandaille ». Les Montfort, les Blye, les Maisières et leurs acolytes, journellement pouvaient en faire l'expérience. Rien qui fût dur, humiliant pour leur amourpropre comme les cinglantes mercuriales nommées calanges qu'aux coupables, portes ouvertes, dans la grande salle d'audience, les magistrats avaient coutume d'infliger. Longtemps la noblesse avait combattu pour leur suppression : en 1548, aux États, elle l'avait réclamée de l'Empereur à grands cris - vainement du reste. Questions particulières, mais pleines de gravité ; c'est que le Parlement était autre chose qu'une cour de justice : un grand gouverneur collectif aux attributions multiples. Quiconque engageait la lutte contre lui travaillait, qu'il le voulût ou non, à rompre au profit de l'un d'eux l'équilibre établi dans le pays entre des pouvoirs rivaux. Surtout, en face du Parlement, les nobles tendaient d'instinct à dresser la puissance rivale des États.

Tout les y poussait, et d'abord leur intérêt matériel. Autour de chaque tenue, un monde de convoitises s'agitait : convoitises des petits, rêvant du « surget »; des moyens, escomptant leur nomination à quelque commission ; des grands enfin, nourrissant l'espoir d'une délégation en Espagne ou aux Pays-Bas. Étudions d'un peu près une liste de récompenses : à défaut de plus ancienne, celle de 1561. Sur les 30000 fr. du « surget », 6000 vont à François de Vergy, «tenant le gouvernement » ; 400 à chacun des deux chevaliers d'honneur, Antoine Mouchet de Chateauroillaud et Jean d'Achey ; puis vient une série de dons moins importants : deux de 200, douze de 100, un de $40 \mathrm{fr}$., que se partagent de simples gentilshommes : au total, 21 nobles d'ancienne noblesse emportent 17840 fr, sur les 30000. 
Même répartition en 1564, en 1569, en 1573 : mêmes convoitises aussi, plus âpres seulement à mesure que les sessions, sous Philippe II, s'espacent.

Mais s'appuyer sur les États contre le Parlement: l'attitude, politiquement, n'était pas indifférente. D'autant qu'un peu partout, autour de la Comté, les mêmes causes engendrant les mêmes effets, les assemblées d'États semblaient se réveiller, se faire plus vivantes et plus désireuses d'étendre leurs droits. Nulle part plus qu'aux Pays-Bas, dans ces provinces qu'unissait à la Comté la communauté d'une direction centrale. Là aussi s'agitaient des nobles turbulents et qu'atteignait tous la dure «faulte d'argent ». Là aussi, rongés de dettes, débordant d'énergie stérile, privés de combats, de fêtes, de tournois, les anciens soldats des guerres impériales se voyaient enfermés dans les villes, en face des bourgeois, sous la coupe des robins. Peu à peu, de même qu'en Comté les Rye et leurs amis, ils commençaient à se plaindre, alléguant que, « devant que les consaulx fussent ordonnez, le gouvernement des Estatz, finances et surintendance de la justice doivent appartenir aux seigneurs et chevaliers principaulx du pays esgallement »; revendication d'ordre politique, mais de fondement social. Et ils « se bandaient » contre « les longues robes », dénonçaient les fautes et les abus des officiers de justice, « les vilipendans et mesprisans et traictans mal », bref, témoignant contre eux les sentiments mêmes des nobles comtois contre la cour de Dole.

Coïncidence grave. Entre Bourguignons et Flamands, Guillaume de Nassau, héritier des Chalon, nouait déjà un lien personnel. Or, l'homme qu'avec toute la noblesse flamande on allait le voir combattre, c'était l'ennemi même de la noblesse comtoise : l'évêque d'Arras, bientôt cardinal archevêque de Malines. Lutte politique : mais fera-t-elle autre chose, lorsqu'elle éclatera, qu'exprimer l'antagonisme, l'opposition de deux classes rivales ? Qui veut en pénétrer les raisons profondes, c'est dans une analyse des facteurs économiques de la vie contemporaine qu'il les doit chercher. À cette analyse nous allons appliquer nos efforts. 


\section{PHILIPPE II ET LA FRANCHE-COMTÉ \\ Étude d'histoire politique, religieuse et sociale. \\ Deuxième partie. Les débuts du règne de Philippe II \\ Chapitre VII \\ La noblesse et les seigneuries}

$\underline{\text { Retour à la table des matières }}$

Lorsque, dans les textes du XVIe siècle: papiers de famille, inventaires, contrats, dénombrements, on rencontre les noms et les titres de quelques baron renommé - involontairement, à lire la liste des terres, des villages, des bourgs dont il se dit « le haut et puissant seigneur », on conçoit de sa fortune une idée favorable. Seigneur : le titre évoque un ensemble de droits presque souverains sur des hommes et des territoires ; après tant d'années, il reste prestigieux ; mais quelle réalité recouvre cette apparence ? dans quelle mesure la qualité de seigneur implique-t-elle, en plus de l'honneur, la fortune ? C'est la première question qu'on se doive poser, s'il est vrai qu'alors, posséder la terre noble était le seul droit utile dont jouissait le gentilhomme.

\section{I}

La terre noble, c'était d'abord un certain nombre d'alleux -ceux du moins qu'on tenait en justice. Ils constituaient une propriété de choix qui, n'astreignant ses détenteurs à aucun devoir envers un seigneur supérieur, ne faisait point peser sur eux les charges du fief. Malheureusement, il est à peu près impossible de déterminer l'étendue et le nombre de ces domaines. La propriété allodiale, par sa nature mê- 
me, échappe aux recensements, aux inscriptions que subit le fief ; le hasard seul nous peut mettre en présence des textes qui la concernent. Il semble bien pourtant qu'elle ait été le plus souvent de faible étendue. Pour une ou deux seigneuries Saulx, par exemple - que leurs détenteurs prétendaient franches et de franc-alleu nous trouvons plusieurs chevances allodiales. Claude de Cicon vend trois de ces pièces en 1547 : l'une, à Jussey, est du fief de Sa Majesté ; l'autre, du fief de Claude de Ray ; mais la troisième, à Combeaufontaine, est de franc-alleu; un bourgeois, Philippe Thomassin, l'achète. Chevances allodiales aussi, ces terres d'Ounans, de Chamblay, d'Escleux, de Villersfarlay qu'en 1571, dans son testament, le conseiller Nicolas Chupin affecte au soulagement des pauvres. Mais les textes sont trop rares, trop dispersés pour permettre des conclusions assurées ; ils montrent simplement que la propriété allodiale noble, quelle qu'en fût l'étendue, était loin d'être toute aux mains de la noblesse d'épée - loin aussi, infiniment loin, d'égaler en importance la propriété féodale : l'alleu était l'exception, le fief la règle.

Un réseau de seigneuries recouvrait en effet le sol de la province. Seigneuries de toute valeur, de toute qualité. Les unes, vastes, s'étendaient sur plusieurs villages, groupaient dans le Jura un val entier sous un même seigneur ou réunissaient, dans le plat pays, autour d'un vieux château, un ensemble de paroisses grandies à son ombre. Les autres, plus modestes et nombreuses, ne comptaient guère qu'un ou deux villages; d'autres enfin, véritablement infimes, ne conféraient de droits à leurs détenteurs que sur quelques maisons et quelques familles. Des neuf seigneuries que possédait en $1585 \mathrm{~J}$. de Bauffremont, l'un des plus riches seigneurs de la Comté, deux seulement: Clairvaux et Châteauvillain (partie de Bauffremont), s'étendaient sur plus de dix villages ; les autres sur quatre ou cinq, ou même un ou deux. Bien qu'elles fussent le plus souvent délimitées, et par des bornes à défaut de rivières, c'étaient des ensembles de droits, non des territoires. Seigneur de Vuillafans-le-Neuf, J. de Bauffremont ne possède pas en cette qualité un certain nombre de villages et leur territoire - mais simplement dans cinq ou six paroisses, à Vuillafans, à Montgesoye, à Echevannes, à Lavans, une série de droits particuliers, dont plusieurs indivis avec d'autres seigneurs. Le même est seigneur de Chariez et Pusey ; comme tel, il possède un mix à Montoille, quatre ou cinq ténementiers à Aroz, une cense de deux gros par an sur une pièce de terre au Vernoy, 29 gros de taille sur divers héritages à Andelarrot ; il n'a les trois justices, haute, 
moyenne et basse, qu'à Pusey seulement et à Chariez. Encore Chariez relève-t-il de Sa Majesté à cause de Vesoul, tandis que Pusey dépend de Faucogney.

Partout on constate la même variété, la même complexité. Il n'y a pas entre les seigneuries de commune mesure ; il n'y en a pas entre la grande terre de Chatelneuf-en-Vennes - tout le val du Dessoubre, avec les villages de Maisonnettes, Luisans, Bonnétage, Les Fourgs, Longeseigne, les Fontenelles, plus des droits étendus à Orchamps, Grandfontaine, Fuans, Guyans-Vennes, Bretonvillers - et la seigneurie d'Adrisans, que Marguerite de Laviron a portée en dot à son mari et qui consiste en 9 pièces de terre, 5 de pré, et deux sujets, François Rouge et Pierre Jacquot, avec leur famille, leur maison et leur meix ; il n'y en a pas entre la seigneurie de Saulx à Humbert de Haraucourt, soit 18 mainmortables en toute justice, un moulin, quelques prés, quelques champs et trois granges, le tout adjugé en 1570 pour 17100 fr. à Pierre d'Orsans - et le comté de la Roche ou la terre de Belvoir avec leur quinzaine, leur vingtaine de villages dépendants.

Comme les seigneuries, les seigneurs diffèrent. Innombrables, au regard des fiefs nobles, étaient les fiefs simples ou sans justice, et les rière-fiefs tenus par des féodaux sans prestige. Philibert de la Baume, reprenant en 1550 Chatelneuf qu'il vient d'acquérir de Jean de Damas, n'énumère pas moins de sept fiefs dépendant de sa nouvelle terre. Gaspard de Saulx, dénombrant Champdivers, en compte neuf pour sa part, outre une chevance " procédant des Carondeletz et meuvant du rièrefied dudit Champdivers, consistant en terres, prelz, censes, rentes, poules, courvées et hommes mainmortables. » A Marnay, en 1584, Laurent de Gorrevod en avoue huit. A Chatel-neuf-en-Vennes, Marc de Rye de la Palud cite : celui des écuyers de Petite-Pierre, consistant en meix, maisons, terres, héritages, censes, rentes, etc., sans aucune justice ; celui de Claude de Cusance, docteur ès droits, « consistant en deux maignies d'hommes qu'il tient en condition de mainmorte, sans aucun droit de justice »; enfin, celui des Chassagne, Henri, Hélène, et les héritiers de feu Claude. Encore, trois arrière-fiefs pour une seigneurie comme Chatelneuf, est-ce peu. À Durnes, Jean de Bauffremont, en 1585, a neuf vassaux en rière-fiefs ; à Vuillafans-le-Neuf, onze ; à Clairvaux, une trentaine au moins : quatre à Soyria, cinq à Champsignia huit à Soucia, neuf à Thoiria, etc. Poussière de terres nobles, réduites parfois à un champ, à un pré, à quelques ouvrées de vigne : aucune comparaison n'est possible entre elles : la question, simplement, est 
de savoir quels avantages et quelles jouissances pour ses possesseurs représentait chaque part de la seigneurie.

\section{II}

En Comté comme ailleurs, au cours du XVIe siècle, toute terre comprenait deux parties essentielles, d'importance, d'exploitation, de rapport différents : du domaine proche se distinguaient les mouvances.

Le domaine proche, c'était d'abord la réserve, la retenue, ce que le seigneur n'avait pas partagé entre des tenanciers : le château et ses entours, des bois, des étangs, des cours d'eau, des terres vaines, quelques champs et prés - le tout, généralement, de faible étendue : la superficie du domaine proche semble toujours plus faible que celle des mouvances. À Chatelneuf-en-Vennes, Marc de Rye, en 1592, ne possède en propre que la maison forte et ses dépendances : cours, murailles, jardin, verger, boqueteau, plus la source et le cours du Dessoubre et un clos proche les moulins ; à Luisans, quatre toitures de pré ; à Orchamps, seize ; à Fuans, cinq - et c'est tout, pour une seigneurie qui s'étend sur une dizaine de villages. À Marnay, Laurent de Gorrevod, en décembre 1584, n'a comme bien-fonds, en plus de son château, d'une maison de pierre sur le grand pont et d'une maison à double voûte avec jardin, que quelques pièces de pré, dont deux de 25 fauchées, une vigne de 300 ouvrées, et quatre corvées de 50, 45, 28 et 27 journaux ; en outre, la Vaivre de Chenevrey et deux bois. Même chose à Clairvaux : dans toute la seigneurie, qui comporte une douzaine de villages, Jean de Bauffremont, en 1585, ne garde en propre que sa maison forte, un pré de douze toitures à Soyria, un autre à Champsignia, des forêts et des bois. Il est vrai que, dans de moindres seigneuries, il est mieux partagé. Dans son fief d'Hugier, qui groupe cinq villages, il possède des bois assez nombreux : 4 sur Hugier même, 5 sur Montagney, 2 sur Sornay et 2 sur Bay ; en plus, deux vignes : l'une de 120 journaux, mais partie en désert ; l'autre de 6 o ouvrées, mais litigieuse avec M. de Gâtey ; un pré de quatre fauchées et un étang. La remarque peut être faite souvent : dans les petites seigneuries, unique ressource de la noblesse secondaire, la réserve est plus importante que dans les grands domaines; de plus, elle comprend souvent, outre quelques belles pièces, 
une multitude de menues parcelles - produits de défrichements récents, résidus d'acquisitions diverses - restées au seigneur faute de pouvoir être aisément loties ? Un verger de 10 soitures, un pré de 14, la moitié d'un de 9, deux de 8 , un de 6 et un de 5 - mais trois de 3 , cinq de 2, six de I, trois d'une demi-soiture, Soit 82 soitures divisées en 24 morceaux ; deux corvées de terre de 24 journaux chacune, une de 20 - mais une de 6 , une de 5 , deux de 4, quatre de 3, quatre de 2 et soixante-sept de I journal et demi, un journal, un tiers, un quart ou une moitié de journal ; trois vignes enfin, l'une de 18, les deux autres de 6 et de 2 ouvrées : voilà le retenue de Chatel-Rouillaud en 1578 ; impossible d'imaginer un morcellement plus grand ; les noms des parcelles, du reste, sont significatifs : beaucoup de prés, dans ce domaine riverain de la forêt de Chaux, ont nom l'Essart ; d'autres retiennent de leur forme et de leur passé le nom caractéristique de « la Corne ».

Que représentait pour le seigneur la réserve ? Sans dépenses, sans soucis, elle pouvait, semble-t-il, lui fournir le foin de ses écuries, le blé de son pain, le vin de sa table, son gibier, son bois de construction et de chauffage : il n'avait qu'à exploiter lui-même. Or, un peu partout, des corvées étaient prévues qui contraignaient les tenanciers du domaine à labourer, moissonner, faucher gratuitement, ou peu s'en faut, pour le maître. Dans les terriers, l'indication du devoir de corvée suit toujours immédiatement la mention du champ ou du pré seigneurial. Au seigneur de Chatel-Rouillaud, chaque habitant d'Arc-et-Senans doit labourer deux journaux et les ensemencer, l'un d'avoine, l'autre de froment; il doit de même deux journées de moisson; si le seigneur ne les requiert pas, pendant deux jours nul ne peut travailler qu'en lui payant un poulet. A Champdivers, les sujets n'ayant bêtes doivent faner, râteler, ramasser et charger sur le chariot les foins du seigneur, les conduire et les décharger ; ceux ayant bêtes, les charger, charroyer et décharger, le tout moyennant un liard ou " un michot». Pour dix engrognes par ouvrée, les manants de Chenevrey font les vignes du seigneur de Marnay, lui fournissent au même prix un millier de paisseaux, et, s'ils ont chars et chevaux, lui labourent trois journaux, un en carême, un en sombre, un en vahin ; enfin, ils moissonnent ses champs moyennant la dixième gerbe et charrient la récolte jusqu'à sa grange. Il n'est que d'ouvrir les terriers, de feuilleter les dénombrements pour trouver des exemples analogues.

Mais, à se tenir à de tels textes, on risquerait précisément de se méprendre sur les facilités qu'un seigneur comtois pouvait alors trouver pour exploiter lui-même 
sa retenue. C'est qu'en Comté comme ailleurs, tout l'effort de la libération paysanne avait tendu non seulement à transformer les corvées personnelles en corvées réelles - mais à muer en redevances pécuniaires les redevances en nature. $\mathrm{Si}$, dans ce pays de mainmorte solidement enracinée, le mouvement s'était propagé un peu moins vite qu'en d'autres provinces - au XVIe siècle cependant, devant la volonté manifeste des tenanciers, l'usage de plus en plus s'établissait de ne pas exiger l'accomplissement des corvées prescrites, mais d'en laisser à prix d'argent solder la valeur. D'autre part, les féodaux étaient nombreux, qui ne restaient pas rivés au sol natal. L'épée au côté, plusieurs couraient le monde ; le désir des offices et des pensions en appelait d'autres en Flandre, ou même en Espagne. Pour ces voyageurs, pour ceux aussi qui, possédant plusieurs seigneuries, n'en retenaient qu'une comme résidence, l'exploitation directe de la réserve devenait un non-sens et une impossibilité. Il ne leur fallait pas quelques sacs de blé, quelques voitures de foin mais de l'argent. De là, l'idée d'amodier les biens-fonds de la retenue : pratique fréquente dans la Comté du XVIe siècle ; les comptes nous renseignent à ce sujet.

Nous avons ceux de Citey, de la Purification Notre-Dame de 1565 à tel jour de 1568. Le seigneur, de ses champs et de ses prairies, n'a rien gardé pour lui. Amodié, le pré de Citey, grand de 7 fauchées ; il rapporte 44 fr. en 1566, 53 en 1567, 50 en 1568. Amodiés pour 19 fr. par an, les fruits de deux prairies et d'un verger attenant. Amodiées, pour 14 bichots mi-froment, mi-avoine, les terres de la réserve de Citey, celles de Mont-les-Etrelles, de Velleclaire, de Vantoux ; seules, les vignes restent exploitées par le seigneur ; il les fait « faire en chief et employer le vin en provenant en sa maison ». Chaque fois d'ailleurs, après l'amodiation des divers « héritages », le produit en argent des corvées restées sans objet est mentionné au compte : corvées de bras de Citey, rendues inutiles par la location du pré : 21 corvées à 14 gros, soit, pour les trois ans, 3 fr. $1 / 2$; corvées de bras de Longevelle, 13 corvées 1/6 par an, 3 fr. 10 gr. 4 engr. Conséquence, ou cause ? Nous avons dit déjà ce qu'était l'attitude des paysans comtois vis-à-vis des redevances en nature et des services personnels; de là ces pratiques d'amodiation de plus en plus répandues ; de là aussi la création, à l'aide de terres distraites du domaine proche, d'un certain nombre de métairies, ou, comme l'on disait en Comté, de « grangeages ». 


\section{III}

Les granges constituent en effet le deuxième élément du domaine proche. Le seigneur ne les exploite pas lui-même; il les remet aux mains d'un laboureur, fermier ou métayer, qui tantôt lui paie par année une redevance fixe, en argent, en nature ou mixte - tantôt partage avec le maître, par moitié ou par tiers, les fruits de l'exploitation. Fermiers par exemple, les grangiers de la Mare, à Anne-Nicole d'Andelot ; ils lui versaient en 1537 une redevance de 30 bichots de graine, soit 14 de froment, 10 d'avoine, 6 d'orge, plus 2 de pois. Métayers par contre, les grangiers installés par Louis de la Tour à Moncley. Les uns ne lui versent qu'un tiers de la récolte ; tel, Colin Gilet, co-amodiateur de la grange du Bas, qui livre pour sa part en 1593, 3 bichots 5 émines 1/2 de froment, 16 bichots 4 émines de seigle, 11 bichots 8 penaux et demi d'avoine, 1 bichot 5 penaux d'orge - ou Étienne Ollivier, co-grangier de Gilet, qui, sur ses 1600 gerbes de seigle, en doit 533 à son seigneur (soit, à 6 penaux les 20, 13 bichots 2 émines) et, sur ses 400 gerbes de froment, 33 (soit, à 2 émines les 20, 2 bichots 2 émines); en plus, 6 bichots 3 penaux d'avoine, 5 penaux d'orge, 8 de pois et un penal de fèves. Mais, moins heureux, le grangier Bernardet, le grangier Petit-Jean, les nouveaux et les vieux grangiers de Vurgilles paient les deux tiers de leur récolte ; de ce chef, chaque année, les receveurs devaient porter en compte une grosse quantité de grains.

Il est vrai que, dans la Comté du XVIe siècle, le grangeage n'était pas d'institution courante. Assez répandu dans certaines parties de la province et notamment dans le pays sous-vosgien, il était rare ailleurs ; toutes les seigneuries, à l'exemple de Moncley, possédée par un maître particulièrement entreprenant, ne comportaient pas des sept ou huit granges en pleine exploitation. Nombreux, les féodaux qui - tel un Jean de Bauffremont, possesseur de neuf seigneuries - ne mentionnent pas une grange dans leur dénombrement. C'était cependant, pour un seigneur, un mode avantageux de faire valoir. Déchargé de tout souci de culture, d'entretien, de gestion, il n'avait qu'à percevoir chaque année le prix du fermage convenu ou la part stipulée des produits; il assurait à ses terres des soins relativement attentifs ; surtout, si ses hommes d'affaires étaient habiles, il se procurait dans la personne du grangier un débiteur prêt à être exploité sans merci. L'usage était en effet que 
le grangier ne pût tenir d'autre bétail que de son maître ; et ce n'était pas une source de petits profits.

Seulement - nous touchons ici à l'une des grandes causes de décadence et d'infériorité économique de la noblesse - les seigneurs habiles étaient rares, comme rares ceux qui géraient eux-mêmes, utilement, leurs domaines. Ils n'en avaient, pour la plupart, ni le goût ni le loisir. Riches barons, absents du pays le plus souvent, ou simples gentilshommes, ignorants et besogneux, ils remettaient le soin d'administrer leurs biens à des receveurs, notaires ou praticiens de village, qui, se souciant peu d'innovations sans profit pour eux, se bornaient à percevoir fermages et redevances selon l'usage établi et la lettre de leurs manuels. Par là s'explique la rareté, dans les actes concernant les terres nobles, des mentions de grangeages, plus communes, nous le verrons, dans les inventaires des fortunes bourgeoises. Pour surveiller les métayers, pour les exploiter de façon rémunératrice, il fallait l'oeil du maître sans cesse vigilant, cet oeil du maître « qui engraisse le cheval », comme le prétendait un proverbe rustique. Il fallait chaque année visiter soigneusement les récoltes du grangier, en dresser l'inventaire, éventer sur l'heure ses ruses intéressées ; le surveiller de près surtout, et ne pas le laisser, comme il arrivait, partir sans dire adieu et sans payer son dû.

Pauvres hères, beaucoup de grangiers, comme ces Roussel du Val de Morteau que l'on vit un jour arriver sur les terres de Moncley, visiter la Grange du Bas et l'amodier pour six ans aux plus dures conditions. Les clauses de leur bail ne leur importaient guère. Fort empêchés de gagner leur vie, ils s'installaient dans le bâtiment ruineux qu'on leur offrait, signaient sans résistance tout ce qu'on voulait, puis au moment de payer s'en allaient nuitamment et recommençaient ailleurs la même aventure. On comprend dès lors comment des seigneurs, dégoûtés par de telles surprises, baillaient leurs fermes à perpétuité : l'exemple est précieux entre tous, de la terre de Saint-Remy au lendemain de sa confiscation par le roi en 1563. Nous saisissons là, merveilleusement, le désarroi ordinaire de l'exploitation seigneuriale. André de Ville, possesseur de la terre, y avait entretenu jusqu'à sept métairies. Mais dans quel état les trouvèrent Messieurs des Comptes, à leur entrée en possession ? Données à cense perpétuelle, la plupart d'entre elles : la grange des Dames, occupée par Laurent Vergnier, pour 3 gros de redevance, 64 quartes mi-froment, mi-avoine, 6 poules et 3 chapons par an ; la grange de la Bouloie, laissée à Jean Milet, pour 2 bichots miseigle, mi-avoine, et 18 gélines ; la vieille 
grange Saint-Bertaire cédée aux Jubelin et aux Bergerot pour 6 fr. de redevance, 6 bichots de grains (mi-froment, mi-avoine), 3 boisseaux de fèves et pois, 36 gélines, 300 de paille, 3 porcs gras, 3 milliers de paisseaux, 3 corvées de charrue évaluées 4 gros et 9 voitures de bois. Trois ou quatre autres granges restaient, il est vrai, qui s'affermaient par des baux de douze ans : la grange de Misère, aux mains de Girard Champagne, moyennant 6 quartes de froment, 18 de seigle, 24 d'avoine, 1 boisseau de pois, 1 de fèves, 1 pinte de beurre, 6 chapons, 6 poules, 3 voitures de bois, un millier de paisseaux et une corvée de charrue ; la grange Neuve, subamodiée par François Bienaimé pour neuf ans et 6 quartes de froment, 20 de seigle, 30 d'avoine, 1 boisseau de pois et 1 de fèves; la grange Bergière enfin, tenue par les Grelly pour 12 quartes de froment, 2 bichots de seigle, 2 d'avoine et 12 gélines. Mais, en 1572, c'est une fuite générale de tous les tenanciers, à commencer par les tenanciers perpétuels : à la Bouloie, Jean Millet s'est sauvé de nuit, lui et ses gens, emmenant tout «fors le seigle que se retrouva implanté ès terres », et une méchante vache qui n'avait pu suivre. Même chose à la Bergerie, où Grelly s'est sauvé ; à la grange Neuve, qui ne rapporte rien «pource que led. Bienaymé absenta lad. grange et n'y sema »; à la grange Beauregard, évacuée par Henri Hubelin. Partout les bâtiments tombaient en ruine; et les grangiers, sans doute, les auraient réparés - mais seulement si on les leur avait cédés à perpétuité. Tout le bétail enfin se trouvait dispersé, perdu, sans valeur ; de M. de Saint-Remy, Guillaume Bergerot, grangier de Saint-Bertaire, avait reçu une vache, une génisse, 2 armoillons d'un an, une truie et 3 porcs, le tout représentant un cheptel de $36 \mathrm{fr}$. Mais le loup avait mangé la vache ; le grangier s'était dessaisi des porcs et des jeunes bêtes, avait vendu la génisse et n'était plus comptable que du prix de cette vente : 14 fr. 10 gros au lieu de 36. C'était un universel désarroi - et l'on s'explique pourquoi un notaire de Voray, estimant, en 1603, la seigneurie aux nombreux grangeages de Moncley, se refusait à en évaluer le revenu annuel à plus de 2000 fr., chiffre d'apparence faible, parce que précisément, à ce qu'il déclarait, « lesd. revenuz consistoient en grangeages et ménageries, auquelx il fault de l'entretient et de l'advance, et que la chose soit tenue de près avec beaucoup de soin ». De l'entretien, des avances d'argent, du soin et de l'attention, une surveillance constante et avisée, c'était le fait d'un bourgeois, non d'un noble ; le notaire de Voray le savait du reste et, dans ses calculs, le sous-entendait. 


\section{IV}

Grangeages et réserves, c'était tout le domaine proche, la propriété véritable des possesseurs de seigneuries. Ajoutons-y encore, puisque nous nous occupons ici, non de l'origine et de la définition juridique des droits, mais, simplement, de leur nature réelle et de leur valeur pécuniaire - les " engins », comme on disait alors d'un mot commode : moulins établis au long des cours d'eau, fours, scieries, rasses ou serres de la montagne, foules à drap, battoirs à chanvre, moulins à écorce ou à huile que comportaient, en nombre variable, la plupart des seigneuries comtoises.

Toutes ces usines agricoles rudimentaires, le seigneur, s'il les possédait, ne les exploitait presque jamais directement. Moulins à écluses, établis sur les biefs jurassiens et les rivières de plaine ; moulins à bateaux assis sur le Doubs ou la Saône ; moulins à vent même, dressant au sommet de quelques crêtes, sur les plateaux sans eau, leur silhouette étrangère ; tous étaient aux mains de « mugniers » sans scrupules qui les accensaient ou les amodiaient. Ils recevaient des seigneurs leurs droits sur les moutaux, veillaient à ce qu'ils suivent le moulin et fassent en temps utile les menues réparations ; presque partout, en effet, des corvées étaient dues par les sujets des seigneuries au moulin banal dont ils devaient user : corvées pour aller chercher les meules et les charrier sur place ; pour curer les fossés, entretenir et réparer les bâtiments, etc. Amodiateur ou censitaire, le meunier bénéficiait de ces services. L'accensement perpétuel, à vrai dire, était assez rare. On le rencontrait surtout dans les seigneuries domaniales. C'est ainsi, par exemple, qu'en 1525, la comtesse Marguerite avait cédé pour 36 livres de cense annuelle et perpétuelle, à Pierre Nardin et à ses descendants, le gros moulin banal de Fraisans. C'est la tendance d'ailleurs des agents du domaine, au cours de la seconde moitié du XVIe siècle, de transformer pour les moulins, fours, battoirs, etc., les amodiations à court terme en amodiations à long terme et ces dernières en -accensements perpétuels.

Transformation motivée, le plus souvent, par le désir d'éviter de grosses réparations ou reconstructions ; nous en avons plus d'un exemple. Ainsi, les moulins 
banaux et les rebattes de Châtillon-sous-Courtine ayant été endommagés par la rivière d'Ain, rapide et incertaine, la Chambre des comptes fit décider, en 1593, la transformation en un bail de vingt-cinq ans des baux à court terme précédemment usités. De même, le petit moulin des Verrières-de-Joux se trouvait-il, « tant à cause du petit bief et peu d'eaul servant aud. moulin que pour les grandes gelées », empêché de fonctionner régulièrement, on cessait de l'amodier de trois en trois ans, pour le remettre pendant vingt-neuf ans à un tenancier disposé à l'entretenir. On n'hésitait pas, s'il le fallait, à aller plus loin, à accenser perpétuellement le moulin Burdilloz, à Mont-Justin ; celui du bief de My-lac, sur le lac Dampvauthier, ou de Dampierre, dans la seigneurie de Rougemont. Des raisons analogues, auxquelles s'ajoutait, dans certains cas, le désir de récompenser des services rendus, valent pour expliquer que les nombreux moulins créés, de 1550 à 1600, dans les seigneuries du domaine, soient le plus souvent encensés perpétuellement, ou donnés à très long bail à leurs constructeurs. Mais ce n'est pas sur le seul domaine que se rencontrent des moulins encensés à perpétuité. Bien des établissements d'importance secondaire, sur les terres des seigneurs, subissent cette condition. Dans la seigneurie de Cusance, en 1584, les moulins de Guillon sont encensés perpétuellement pour 1 bichot 18 quartes de froment blanc. Petits moulins, il est vrai : les seigneurs se sont bien gardés d'encenser pareillement ceux de Cusance, amodiés alors pour 17 bichots de froment par an, 6 charmes d'huile, 18 livres de cire, 1 livre d'épices moitié poivre, moitié gingembre, et 6 fr. d'argent. De même, en 1594, à Chatelneuf-en-Vennes, les moulins de Luisans sont dès longtemps encensés pour un bichot de froment par an ; mais ceux de Chatelneuf même, banaux pour tout le val, sont amodiés. Dans la même seigneurie, il existe trois « rasses »; toutes trois sont encensées à perpétuité pour 4 blancs de redevance annuelle : c'est le sort commun, au XVIe siècle, de ces menus établissements, coûteux de construction et d'entretien. D'autres moulins, sans être encensés à perpétuité, étaient l'objet de baux emphytéotiques ; tel, sur territoire de Cernans, le moulin de Richedor, à Anne-Nicole d'Andelot, rapportant chaque année 30 fr. « de censé enfictète », ou encore, dans le domaine cette fois, le moulin de l'étang de Quers, qui devait acquitter, une fois construit, 17 livres 2 sols est. « de cense enfiteotte».

Accensements et baux emphytéotiques étaient en réalité de véritables aliénations. Aussi la mesure paraissait-elle grave aux seigneurs, de transformer une amodiation de moulin en encensement. Ils ne s'y résolvaient que par nécessité, 
lorsque quelque accident ou simplement la vétusté ayant ruiné les engins, ils ne voulaient pas supporter eux-mêmes tout le poids d'une reconstruction ou ne pouvaient trouver d'amodiateurs. Rien de plus net à cet égard qu'un acte du 26 mars 1597 concernant les deux moulins du ruisseau de Norvaux, dans la seigneurie de Fertans. Le seigneur, Claude de Montrichard, expose longuement que ces deux bâtiments ayant été ruinés par inondation, «il ne pouvait trouver admodiateur pour tirer prouffit d'iceulx,... comm'il auroit recogneu par diverses proclamations qu'il auroit faict faire tant ès prosnes de l'église parochiale de Fertans que en aultres lieux publiques ». Il doit donc de toute nécessité les accenser perpétuellement à Aimé Bourrelier, d'Amancey, pour 16 fr. de rente foncière et 500 fr. d'entrage ; mais, mal satisfait encore par ses déclarations précédentes et soucieux de dégager entièrement sa responsabilité dans une occasion aussi grave, il fait suivre son acte d'accensement d'une sorte d'attestation signée par plusieurs notables de Fertans qui, tous, déclarent les moulins ruinés et incapables de fonctionner à moins d'une dépense de "plus de cent escuz » : l'un des déclarants va même jusqu'à témoigner « que, si led. seigneur les luy donoait pour rien à charge de les entretenir, il ne les voudroit - accordans tous ensemble que ce serait prouffit pour Sa Majesté, qui a le fied d'iceulx, qu'ils soient donnés à cense ».

De fait, bien plus fréquents étaient déjà. les baux à long terme : de cinquante ans, de vingt-cinq, dans le domaine de vingt-neuf (pour éviter la prescription trentenaire) ; plus fréquents surtout, les baux de trois, six, neuf années, laissant souvent sans doute au seigneur la charge des grosses réparations, mais lui permettant aussi de profiter à l'occasion des plus-values, des hausses possibles du prix des fermages. C'est pour six ans qu'en 1588, le prieur de Mouthe amodie à Pierre Longchamp, moyennant $500 \mathrm{fr}$. et 12 muids de grain par an, les moulins, foule et battoirs de la source du Doubs et le moulin de la Petite Chaux ; pour six ans également qu'à la même époque il amodie à Claude Lonchamp, moyennant 29 muids de graine, le moulin de Gellin. A Besançon, le chapitre amodie de trois en trois ans ses moulins de Tarragnoz, de Rivotte, de Cussey; il loue pour six ou pour trois celui de Geneuille, pour neuf ou, exceptionnellement pour seize, celui de Charcenne ; pour six ou pour neuf celui d'Étuz. De même encore dans le domaine : c'est pour trois ans que s'amodient les moulins de Quingey ; pour trois ans, les deux moulins de Pierre-Franche dans la seigneurie de Joux ; pour trois ans également celui de Chavannes, pour six celui de Rougemont. Les féodaux suivent cette 
pratique : à Marnay Laurent de Gorrevod, à Ruffey Jean de Bauffremont, amodient à court terme leurs gros moulins banaux ; quant aux fours, il en est qui, chaque année, sont remis en adjudication ; d'autres (par exemple ceux du Chapitre de Besançon) ne changent de tenanciers que tous les trois ans.

De tous ces moulins, de toutes ces usines agricoles, celles-là seules ou presque constituaient pour les seigneurs un revenu appréciable qui n'étaient ni encensées perpétuellement, ni amodiées à trop long terme. Sans doute, c'était en nature généralement que les meuniers devaient acquitter leur cens ou le prix de leur bail, et les sacs de grain qu'ils versaient entre les mains des receveurs seigneuriaux ne subissaient naturellement pas les mêmes dépréciations possibles que des redevances pécuniaires. Seuls pourtant, les établissements ruraux amodiés à court terme pouvaient procurer aux seigneurs de notables bénéfices et leur permettre de profiter aussitôt des hausses de prix éventuelles. De fait, encore que les textes que nous possédons soient bien insuffisants pour nous permettre des conclusions fermes, il semble que, de 1550 à 1580 environ, les rentes de moulins en Comté se soient généralement élevées ; qu'elles aient subi, entre 1580 et 1585, une notable hausse, suivie d'une baisse de 1585 à 1595 et, jusqu'à la fin du siècle, d'une période de stagnation.

Prenons quelques exemples. Les moulins de Bye (seigneurie de Châtillonsous-Maîche) s'amodiaient, en 1550, pour 18 bichots de froment, un porc gras et 100 livres de «chenesve » par année. En 1560, léger fléchissement : 16 bichots seulement ; en 1570, 15 ; mais la hausse est très sensible en $1580: 25$ bichots - et la baisse en 1590 et $1600: 20$ et 14 bichots. Autre exemple : le moulin vieux de Pierre-Franche, dans la seigneurie de Joux. En 1565, il rapportait 18 quartes et demie de grain, mi-orge, mi-avoine, et un porc gras d'une valeur d'un franc. En 1574, plus de porc, mais 52 quartes et demie de grain ; en 1584, 44 quartes; en 1597, 41 et demie. Le moulin neuf, lui, rapporte, en 1565, 14 quartes et un porc ; en 1570, 30 quartes, sans porc ; en 1580, 37 ; en 1590, 33 quartes. Si on néglige les variations locales, dont nous ne pouvons saisir les causes particulières, il reste que pour l'immense majorité des moulins comtois amodiés à court terme, les rentes se sont élevées fortement vers 1580-1585, pour descendre ensuite et se maintenir à un taux généralement supérieur à celui des années 1550-1580.

Ceci constaté, notons que ces variations généralement ont été faibles. Elles coïncident évidemment avec l'augmentation de la population, le défrichement des 
terres vagues, l'essartement des broussailles et des bois, la mise en culture énergique de toute la terre arable. Mais précisément, nous avons vu qu'à la même époque et pour profiter de ce même progrès, de nombreux moulins neufs s'édifiaient en Comté. Or, sur plus de quarante moulins dont nous possédons, entre 1540 et 1595, les actes de naissance authentiques, deux seulement nous apparaissent comme l'oeuvre personnelle de gentilhommes d'épée : tous les autres sont établis par des bourgeois (quelques-uns anoblis), des laboureurs aisés, ou des villes. Proportion vraiment frappante : ici encore, ce n'est pas la noblesse, c'est la bourgeoisie qui sait mettre à profit le progrès économique.

Biens-fonds de la réserve, tantôt vastes encore, tantôt réduits à rien, parfois exploités par le seigneur directement, plus souvent amodiés par lui à prix d'argent ; grangeages, mais rares et d'importance médiocre ; moulins et fours enfin, rustiques engins, les uns accensés à perpétuité ou cédés à long bail pour de maigres redevances ; les autres amodiés à court terme, aptes à bénéficier des hausses, mais trouvant alors, en face d'eux, la concurrence d'établissements nouveaux : tels étaient les éléments constitutifs du domaine proche dans les seigneuries comtoises. Éléments de valeur inégale : tous d'ailleurs ne se trouvaient pas toujours réunis dans un même domaine. Le domaine proche, ainsi défini, n'en fournissait pas moins aux seigneurs, dans la plupart des terres, souvent la moitié, toujours le tiers au moins de leurs revenus en argent. On saisira mieux les raisons d'un tel fait, lorsqu'on aura décomposé à leur tour et analysé les autres chapitres des comptes de recette seigneuriaux.

\section{V}

Qu'une seigneurie fût petite, moyenne ou grande ; qu'elle s'étendît sur les quelques maisons d'un pauvre village ou sur le territoire de paroisses entières, peu importait ; dans les deux cas, le maître ne possédait comme immeubles, comme biens-fonds, que les champs, les vignes, les prés de sa retenue, les terres de ses fermiers et de ses métayers, les fours et les moulins enfin qu'il amodiait. Le reste n'était que tenures : nobles comme les fiefs, roturières comme les censives, servi- 
les comme les mainmortes. Sur elles, le seigneur ne gardait qu'un droit éminent ; elles n'étaient plus des terres pour lui : elles représentaient des droits.

Droits d'étendue variable, et souvent bien précaires : c'était le cas surtout pour ceux qui portaient sur les tenues nobles. D'abord, comme on disait, il n'y avait en Comté que des fiefs «d'honneur ». Les fiefs « de profit», ceux dont le possesseur devait à son suzerain, en cas de mutation, quelques droits utiles comme quint, requint, lods, etc., n'existaient pas. Sur la seigneurie inféodée, le suzerain ne gardait que les droits de retenue, de mainmise et de saisie féodale dans les cas déterminés par la coutume. Encore ces droits n'étaient-ils pas aussi étendus en Comté qu'ailleurs. Par exemple, la foi et l'hommage étaient dus dans l'an et jour, à peine de saisie des fruits, mais seulement en cas de mutation du vassal et non du suzerain comme en d'autres provinces. De même, si le vassal, contestant la saisie, la prétendait nulle ou injustifiée, sa protestation était suspensive ; il jouissait de son fief jusqu'à fin du litige.

Par contre, il est vrai, les fiefs comtois étaient « de danger » - c'est-à-dire que, si le vassal aliénait son fief et que l'acquéreur en prît possession sans le consentement du suzerain, ou bien s'il tombait dans le cas de félonie, la commise était de plein droit. Mais, ici encore, des restrictions intervenaient. Ces clauses ne s'appliquaient pas aux fiefs arrivés par succession dans des mains nouvelles; le vassal pouvait disposer de son fief par testament sans requérir aucun consentement préalable, et les héritiers $a b$ intestat pareillement succédaient (s'ils étaient laïques), sans autorisation ni danger de commise. De même encore, ces dispositions ne s'appliquaient pas au vassal baillant à cense ou rente perpétuelle les biens féodaux ; lorsqu'il s'agissait de biens accensés ou arrentés déjà dans le cours des trente années précédentes - ou d'héritages en ruine, de maigre valeur, l'encenseur, l'arrenteur les pouvaient occuper sans consentement et sans danger de commise. En fait, les droits du suzerain sur les biens du vassal se réduisaient presque à rien. Il recevait la foi et l'hommage, surveillait de loin les mutations et veillait à ce qu'elles se fissent en règle : prérogatives bien minces, qui laissaient vraiment entières, ou peu s'en faut, la liberté et la propriété du possesseur de tenue noble.

Plus grande encore, plus entière s'il se peut et plus pleine, celle du possesseur de tenue roturière - du tenancier de censive. Moyennant une redevance infime, il occupe et exploite un fonds à sa guise. Le cens qui l'affecte est-il un cens simplement foncier? le plein domaine alors lui est conféré. Il ne connaît qu'une seule 
obligation : celle de payer annuellement la redevance fixée, redevance prescriptible au bout de quarante ans. Pas de lods à acquitter, en cas de vente ou d'aliénation ; pas de droit de retenue au profit du seigneur. Le cens, par contre, est-il en directe ? Le tenancier alors doit les lods et le seigneur peut, dans l'an et jour, user de retenue à toutes les mutations comportant la commise par défaut de consentement : mais à ce prix, le censitaire reste le vrai maître de sa tenure. Il l'aliène à son gré, l'échange ou la vend. Encore peut-il frauder, baptiser donation ou échange ce qui est vente : l'échange pur et simple, aux termes de la coutume, était incompatible, comme la donation, avec les droits de lods et de retenue. Sans aller si loin, il peut facilement cacher le vrai prix de vente de sa tenure, le déclarer plus faible pour réduire les lots, le prétendre plus fort pour éviter l'usage du droit de retenue. Enfin, vis-à-vis de sa censive, il garde pleine liberté : un simple déguerpissement le libère de tout, l'affranchit de redevance.

Redevance bien minime, au reste, dans tous les cas. Qu'elle fût due en argent ou en nature, c'était d'un poids singulièrement léger qu'elle pesait sur la terre ; la modicité même du cens foncier n'était-elle pas, aux yeux des juristes, l'un des éléments essentiels de sa définition ? Pour les redevances pécuniaires, le temps même les rendait chaque jour moins pesantes; la baisse de valeur continue de l'argent les réduisait à rien. Les charges en nature restaient plus lourdes; mais elles étaient plus rares aussi, et s'acquittaient souvent en produits de qualité inférieure. Il est d'ailleurs sensible qu'à la fin du siècle, notamment dans les seigneuries du domaine, un effort est tenté pour diminuer les avantages des tenanciers et augmenter les profits des bailleurs sur les censives. Ce n'est plus à perpétuité, c'est pour 80, 60 ou même 29 ans qu'à partir surtout de 1585, la Chambre des Comptes de Dole accense le plus souvent les terres, les prés, les champs que des sujets réclament à titre perpétuel. Et certains écarts entre les chiffres prétendus et les chiffres accordés sont vraiment intéressants à relever.

Au reste, rien ne serait sans doute aussi frappant que la comparaison, dans les registres de comptes seigneuriaux, du total des cens et du total des amodiations ; malheureusement, elle est rarement possible. C'est que cens, en effet, ne désigne pas seulement les redevances assises sur les tenues roturières ; il s'applique également à celles qui pesaient sur les tenues serviles, sur les terres mainmortables : et celles-ci, au total, étaient incontestablement plus étendues, plus nombreuses, plus fructueuses que celles-là. 


\section{VI}

Considérable restait en effet, au Milieu du XVIe siècle, l'extension de la mainmorte en Comté. Dans des parties entières de la province, les paysans ne connaissaient pas d'autre condition. Exception faite des villes et de quelques groupes d'habitants privilégiés, elle régnait dans le Haut-Jura, sur l'immense terre de Saint-Claude, comme, au pied des Vosges, sur celle de Luxeuil. Elle s'accroissait même en certains cantons, si elle reculait ailleurs. Les émigrants qui venaient s'installer dans la Montagne et s'attaquaient aux joux noires pour les défricher, le plus souvent devenaient mainmortables. Dans les seigneuries ecclésiastiques, les paysans l'étaient à peu près tous. Sur les domaines des Chalon, malgré les affranchissements anciens, malgré l'effort de libération des classes rurales au XIVe siècle, elle marquait encore de sa "macule » des familles entières. Mais c'était sur les terres des moyennes et petites seigneuries que se rencontraient surtout les hommes de mainmorte. Le morcellement, la dispersion des textes, l'impossibilité de dresser des listes nous interdisent toute statistique. Mais il faut se souvenir que, deux siècles encore après l'époque qui nous occupe, Perreciot évaluait à plus d'un tiers le nombre des villages comtois qu'affectait la mainmorte. Droit «exorbitant », droit « odieux », comme la qualifiait Dumoulin, était-elle en même temps un droit lucratif ? Représentait-elle autant de profits pour le seigneur que de charges pour les tenanciers ? et, puisque nous passons en revue successivement les diverses tenues, quels étaient sur les tenues serviles, sur les tenues mainmortables, les droits et les profits des seigneurs ?

À première vue, entre censives en directe et mainmortes, peu de différences. De part et d'autre, ce sont les mêmes charges. Comme les premières, les secondes doivent les lods ; comme les premières, elles doivent des redevances réelles fixes, des cens, qui ne paraissent ni plus lourds ni plus onéreux. Cens en nature, en argent ou mixtes, revenus immuables « qui ne croissent ni ne décroissent », selon la vieille expression des terriers; revenus modiques, qui représentent non le prix d'un loyer, mais la reconnaissance d'un droit éminent de propriété. Ces cens parfois se trouvent remplacés par des champarts ou terrages, un peu plus lourds, un peu moins rigides, sorte de dîmes laïques, proportionnelles à la récolte de l'année. 
Entre ces redevances et celles que fournissent les censives, pas de différence de nature à relever. Elles n'ont rien de caractéristique du servage. Elles impliquent simplement l'existence, à côté du propriétaire utile, d'un propriétaire éminent dont la propriété se révèle justement par la perception de ces redevances.

Seulement, tandis que le censitaire était libre de disposer à son gré de sa censive, le mainmortable, lui ne pouvait aliéner sa tenue ni l'hypothéquer sans le consentement préalable du seigneur. Et si, en cas d'aliénation, la possession réelle en était prise sans son autorisation, il y avait lieu à commise. De là, un premier avantage pour le seigneur. Il y en avait un second. Le mainmortable, par acte de dernière volonté, ne pouvait disposer de ses biens, même meubles et même francs, qu'au seul profit de ses parents communiers. Et s'il ne possédait pas de tels parents, tout son héritage, meubles et immeubles, biens serviles et biens francs, tombait de plein droit au pouvoir du seigneur, ou, comme l'on disait, lui faisait échute.

Commises et échutes : double espoir, double source de profit pour les possesseurs de seigneuries mainmortables. Profits d'importance sans doute : parmi les mainmortables, il en était de riches, dont le mobilier, le bétail, les créances et les obligations représentaient une petite fortune paysanne. Voici les «meubles délaissez en la succession de fut Pierre Garnier, décédé de peste à Ormoy » en 1582. Il laisse des provisions d'abord: 4 bichots de froment, 26 émines d'avoine, sans compter des gerbes non battues ; une quantité d'orge, de pois et 7 quartes de fèves. Comme bétail, il a 3 chevaux, 11 ou 12 bêtes à cornes, 6 porcs, 5 brebis, 2 agneaux. Le matériel est bon : un chariot et une charrette ferrée ; des harnais pour les chevaux ; deux charrues «bien fournies » avec soc et coultre, «l'une ayans les rouelles ferré ». Le mobilier est propre, presque confortable : trois lits «bien revestus de couverte »; « ung beau buffet »; des draps, quelques pièces de vaisselle en étain, un coffre "plein de meubles »; des provisions, bandes de lard ou jambons, des ustensiles de toute espèce. Et « l'on dit qu'il y avoit de l'argent et des obligations et lectraiges; item, environ 18 chariots de foin et plusieurs aultres pailles » sans compter des outils, des coffres, etc. : c'est l'avoir-type du cultivateur très aisé.

D'ailleurs, ce n'étaient pas seulement des terres de condition servile que tenaient les mainmortables. Souvent, leur bien franc était considérable; ils jouissaient de terres, de prés, de maisons en franchise. Veut-on quelques chiffres, du 
reste ? Généralement, les fiches individuelles fournies, en 1583, par les mainmortables de Chalon demandant leur affranchissement portent, de la main des commis aux affranchissements, deux chiffres qui les résument : l'un donne l'avoir total, l'autre les dettes du requérant. Nous avons relevé nombre de ces chiffres; ils sont assez instructifs. Voici, dans une même région (celle des plateaux situés immédiatement à l'ouest de Pontarlier), les trois villages de Bouverans, Frasne et la Rivière. Trente-sept fiches au total, comportant les indications qui nous occupent. Quatre d'entre elles concernent des familles de paysans exceptionnellement riches, et accusent un avoir de 7 050, 4 917, 3 450, 2165 fr. ; les dettes avouées sont pour les trois dernières de 1 100, 1000 et 360 fr. Puis viennent quatre fortunes évaluées 1 500, 1 400, 1 300, 1200 fr. (dettes : 600 ; 300 ; 400 ; 200 fr.). Tout le reste n'atteint pas 500 fr., une seule cote exceptée (de 522 fr.). On trouve ainsi 6 chiffres de 400 à 522 fr. ; 5 de 3 à 400 ; 5 de 2 à $300 ; 8$ de 1 à $200 ; 5$ inférieurs à 100. - A Villers-sous-Chalamont aussi, on trouve quelques grosses fortunes : une de 2658 fr., une de 1680 , une de 1465 ; ailleurs, il est vrai, elles sont beaucoup plus rares : à Amancey, la plus grosse cote ne dépasse pas 722 fr. ; à Chatillonsous-Maîche, 976 ; à Déservillers, 783 ; à Beure près de Besançon, 1112 fr. ; à Nozeroy, par contre, des Sombarde, des Poulet, gens aisés, considérés, alliés à de bonnes familles du pays, sont encore mainmortables sur le lieu et avouent des fortunes dépassant $2000 \mathrm{fr}$. A ces chiffres, naturellement, nous n'entendons pas accorder de créance certaine ; en tout temps, les fortunes ont su se maquiller, se déguiser pour échapper au fisc et nous ne savons pas dans quelle mesure les commis de 1582 ont pu rapprocher de la réalité les évaluations des tenanciers - ou s'en écarter eux-mêmes dans leurs estimations rectificatives. Il reste cependant péremptoirement prouvé qu'il y avait, en Comté, des mainmortables riches, dont l'échute avait de quoi faire envie aux seigneurs.

Pourtant, quand on examine les comptes, ce qu'au chapitre des échutes on trouve le plus souvent, c'est le mot : néant. Ou bien, lorsque, de loin en loin, quelque succession de mainmortable finit par s'ouvrir au profit du seigneur, le produit est maigre et le profit presque nul. Ingénieux et rusé pour ses intérêts, le paysan comtois savait en effet admirablement tromper le maître et le frustrer de son héritage. C'était un jeu pour lui lorsqu'il se voyait seul, sans parents dans sa communion, de vendre en secret, sous couvert d'échange, tout ce qu'il possédait. Avait-il négligé cette précaution ? Lorsque le seigneur héritier voulait vendre l'échute, les 
paysans du voisinage, ligués, s'abstenaient de surenchère. C'est à vil prix qu'il fallait finalement leur céder les dépouilles du défunt; elles leur profitaient à eux, mais non au maître. La terre mainmortable, d'ailleurs, valait moins dans les ventes que la terre franche, si elle s'amodiait au même prix. A By, en 1582, le journal de terre mainmortable se vendait $10 \mathrm{fr}$., le journal de terre franche, facilement, 15 à 16.

De plus, ici encore, une distinction s'impose entre grands et petits seigneurs. Dans un passage intéressant de l'Etat civil des personnes, Perreciot nous montre, de son temps, le petit noble, le petit gentilhomme campagnard qui vit d'un fief modeste, penché sur sa terre et sur ses tenanciers, surveillant ses mainmortables avec un soin jaloux, toujours occupé à guetter l'échute bienheureuse dont il épie la venue et finira bien par tirer profit. Le grand seigneur, au contraire, se désintéresse de telles aubaines. Aux mains de ses receveurs, de ses intendants, elles fondent vite et, mal défendues, ne lui rapportent rien. Au vrai, l'échut l'ennuie plutôt. À la place du tenancier disparu, il va falloir s'enquérir d'en installer un nouveau : interruption dans l'exploitation, tracas peut-être, profit nul en tout cas : la remarque de Perreciot ne vaut pas que pour le XVIIIe siècle. Au XVIe siècle déjà, tant vaut le seigneur comme homme d'affaires, tant rapporte la seigneurie. Et le souci des affaires, leur connaissance et leur entente, n'était pas un des privilèges de la classe nobiliaire.

Ainsi fondait peu à peu, ainsi se réduisait dans la pratique à de rares et faibles recettes, bien précaires et bien intermittentes, le droit du seigneur sur ses tenures mainmortables. Depuis l'origine, par le progrès naturel des temps, ce droit était allé en diminuant. Si, à l'extrême fin du XVIe siècle ou au début du XVIIe, les seigneurs obtiendront aisément des Parlementaires - seigneurs, eux aussi, et fort intéressés - l'interprétation favorable de plusieurs obscurités de la Coutume, ces gains compenseront mal les pertes qu'au cours des XIVe et XVe siècles, l'effort de libération des classes rurales asservies leur avait fait subir. Pour ne pas tenir compte des affranchissements purs et simples, c'est à chaque pas, lorsqu'on explore les archives du temps, qu'on rencontre, dans les reconnaissances, des paysans mainmortables, mais hors de leur seigneurie d'origine seulement : ils sont, disent les actes, " francs sur le lieu », - c'est-à-dire que, mourant sur la terre de leur maître, même s'ils ne possèdent pas de parents communiers, ils ne font pas échute. Le seigneur n'entre en possession de leurs biens qu'au seul cas où ils meurent hors de 
ses domaines. Première restriction, premier adoucissement, - première cause sensible de diminution du nombre des échutes. Il y en avait d'autres encore, et notamment l'institution du « reprêt », son interprétation très large par la jurisprudence du Parlement de Dole 8 ; la faculté pour les conjoints sans enfants de se faire des donations entre vifs au dernier survivant ; l'autorisation concédée aux bâtards mainmortables, communiers de leur mère, de recueillir son héritage, et à la mère de leur succéder à l'exclusion du seigneur - bref, toute une série de stipulations particulières, qui restreignaient d'autant les droits des seigneurs sur les tenues mainmortables. Elles leur rapportaient plus que les censives; mais, hors les cas fortuits, les années exceptionnelles de peste ou de guerre qui multipliaient les échuts, en même temps d'ailleurs que les ravages - elles ne leur rapportaient qu'un profit incertain, disputé et toujours modique.

En somme, de plus en plus, tout ce qui était tenure échappait aux prises du seigneur. Les fiefs de ses vassaux ne lui rapportaient rien. De ses terres accensées perpétuellement, les vrais maîtres étaient les tenanciers. Échutes et commises allaient se raréfiant. La tenue roturière et la tenue servile ne valaient plus, en définitive, que par les lods qu'elles devaient acquitter ou par le produit du droit de retenue.

C'étaient deux droits qui allaient ensemble et, comme l'on disait, marchaient du même pas. Leur extension, pourtant, n'était pas la même : le second s'appliquait aux tenues nobles, sous le nom de retenue féodale ; mais ces tenures échappaient aux lods. Par contre, tous deux également s'appliquaient aux tenues roturières, aux censives - non à toutes les censives, mais à celles-là seulement dans la constitution desquelles ils avaient été stipulés. Une de ces censives venait-elle à être aliénée à titre de vente, ou de contrat assimilé à vente et entraînant mutation de tenancier? Le seigneur pouvait à son gré, dans un délai de quarante jours à partir du moment où les lettres d'aliénation lui avaient été présentées, soit retenir pour lui la tenue en question en rendant le prix de l'aliénation, soit laisser s'effectuer la transaction en percevant les lots sur son montant. Lots peu élevés s'il

8 Le droit de reprêt était le droit que, d'après l'article VIII de la Coutume de Franche-Comté, la fille mariée avait de conserver ses droits à l'héritage de son père mainmortable en retournant " gésir la première nuit de ses noces » dans la maison paternelle. Disposition singulière et qui ne se retrouve pas dans les autres coutumes. 
s'agissait d'héritages francs : on ne les percevait d'ordinaire qu'au douzième. Mais sur les mainmortes, ils se levaient au tiers, au quart ou au seizième, et leur total, variable, demeurait important.

Les seigneurs s'appliquaient avec soin à conserver des droits aussi productifs. Quand il y avait eu vente d'un héritage, semblable ou autre, soumis aux lods, un délai de quarante jours, d'après la coutume, était imparti à l'acquéreur pour présenter les lettres de vente et les lods aux officiers. C'était alors un examen minutieux des contrats, une enquête serrée sur la condition des personnes et des terres pour dépister les fraudes, empêcher les tromperies, les confusions. Acheteurs et vendeurs étaient-ils bien de même condition ? Un mainmortable n'allait-il pas s'installer sur un héritage franc ou réciproquement ? Y avait-il lieu ou non d'user de la retenue ? Et encore, pour les fonds de mainmorte, si des étrangers s'en portaient acquéreurs, étaient-ils en règle avec leur seigneur originel ? Avaient-ils prêté serment à leur nouveau seigneur ? Questions importantes, souvent compliquées et difficiles à résoudre. Les hommes d'affaires s'y employaient, stimulés par leurs maîtres. Il n'y allait pas seulement pour ceux-ci de leurs profits matériels. Comme on l'a remarqué à propos d'une autre province, la Bretagne : «si les droits de mutation se maintiennent intacts jusqu'à la fin de l'Ancien Régime, c'est qu'ils témoignent de la cession primitive de la tenue, du droit de propriété supérieur du seigneur. » Dans la pratique, en effet, ce n'est plus guère que par eux, droits de retenue ou droits de lots, que s'affirme le droit du seigneur, sinon sur ses mainmortes, du moins sur ses fiefs et sur ses censives en directe. Pour lui, ils valent à la fois par ce qu'ils signifient et par ce qu'ils produisent.

\section{VII}

Tout n'est pas dit, il est vrai, quand on a énuméré les diverses catégories de tenues : nobles, roturières ou serviles, et tenté de préciser la nature et l'étendue des droits de propriété que conservait sur elles le propriétaire éminent, le seigneur. Sur la censive vit le censitaire. Sur le mixte de mainmorte peine le mainmortable. En dehors du cens assis sur leur tenue, il leur faut acquitter des charges et des droits. Ils doivent d'autres redevances, les uns et les autres, des corvées, des servi- 
ces. Mainmortables, mais censitaires aussi, il leur faut labourer, semer, faucher, moissonner pour le seigneur. Il leur faut l'aider en cas d'hostilité, satisfaire sinon à l'ost et chevauchée, du moins au guet et garde, aux menus emparements, à la retraite en cas d'éminent péril, parfois faire montre d'armes quand ils en sont requis, assister en corps aux exécutions ou à l'érection des signes patibulaires. D'origine servile, certains supportent encore le chevage ; tous acquittent la taille, même, bien souvent, lorsqu'ils se sont déjà libérés de la mainmorte. Mais francs comme mainmortables satisfont également aux droits de péage, de foires et de marchés. Le seigneur sur eux a la justice et les droits qui en découlent ; l'aide aux quatre cas, les banalités. Il perçoit donc encore, comme en plein Moyen Age, toute la masse variée des droits domaniaux.

Droits d'origine, de natures singulièrement diverses. Les uns résultent de contrats, les autres non. Certains sont réels, d'autres personnels. Tels d'entre eux (ceux qu'acquittent les censitaires) sont dus seulement à cause d'une tenue, ou de la résidence dans une seigneurie ; en déguerpissant, on peut s'y soustraire. Tels autres (ceux qui pèsent sur les non-libres) sont dus par l'homme, quoi qu'il fasse, où qu'il aille. Distinctions importantes, sans doute, au point de vue juridique ; la dernière notamment entraîne ses conséquences pratiques. D'un paysan franc, le seigneur sait d'avance ce qu'il peut attendre ; redevances, corvées, tout est réglé par les clauses précises des contrats d'accensement ou d'amodiation. Lorsque l'homme a payé, tout est fini. Au non-libre, par contre, même lorsque le temps a précisé les charges et détruit l'arbitraire des tailles, des corvées à merci - il est un bien qu'il peut toujours offrir et vendre à prix d'argent, un bien infiniment précieux : la liberté. Cette liberté dont la privation est pour le mainmortable une tare indélébile qui le suit partout, où qu'il aille, quoi qu'il fasse, lorsqu'il veut se marier, témoigner en justice, se retirer dans une ville - qu'il soit riche ou pauvre d'ailleurs, juge, prêtre, parlementaire même ou simple laboureur - cette liberté, si le seigneur ne la lui cède pas bénévolement, il n'a qu'une seule façon de l'obtenir : en l'achetant; c'est le désaveu. Mais à quel prix ? Vidant ses mains de ses biens immeubles, le tenancier qui ne recule pas devant ce sacrifice doit en plus céder les deux tiers de ses meubles. Condition singulièrement dure, devant laquelle souvent il hésite. Le seigneur le sait ; mais il sait aussi son désir ardent, son désir secret de libération et qu'il y a là pour lui un moyen sûr de faire de l'argent. 
Sans doute, affranchir des mainmortables, c'est proprement manger son blé en herbe, se priver d'échutes pour l'avenir et de désaveux. Dans la pratique cependant, et lorsqu'ils procédaient avec quelque prudence, les seigneurs réussissaient fort bien à atténuer ces conséquences dangereuses. D'abord, l'affranchissement se soldait, le plus souvent, par une aggravation des charges de l'affranchi. Et puis, à ne libérer que l'homme et non pas sa tenue, on risquait somme toute assez peu; et c'est ce qu'on faisait toutes les fois qu'il était possible - surtout lorsqu'il n'était pas question de l'affranchissement global, collectif, de toute une communauté à la fois. L'affranchi, pour ne pas retomber dans la servitude, devait laisser ses terres à de nouveaux tenanciers, mainmortables d'origine, ou qui le deviendraient dans l'an et jour du fait même de leur établissement. L'obligation était fort pénible ; un texte curieux le montre nettement; c'est un «acte judicial rendu en la justice de Nozeroy, le 19e de décembre 1592 », par lequel un nommé Aimé Girod, mainmortable affranchi de Mignovillars, seigneurie de Nozeroy, déclare renoncer à son affranchissement. Sa libération lui est, à l'épreuve, «plus préjudiciable que profitable, pour estre exclus de acquérir héritaiges censables, ce que toutefois luy estoit nécessaire ». Cas extrême ? Peut-être ; mais bien d'autres textes nous montrent le grand chagrin des candidats à l'affranchissement : celui de renoncer à ces terres mainmortables, si étendues, que leur prix plus bas rendait plus tentantes...

Du reste, pour occuper les champs qu'ils abandonnaient, les remplaçants ne manquaient pas. Il y avait en Comté tant de terres mainmortables, qu'elles devaient forcément finir par être toutes en mains : aurait-on pu les laisser stériles, inoccupées ? Ces émigrants qui venaient, poussés par la misère, chercher outreSaône une fortune meilleure ; ces colons, dont Dumoulin nous signale l'arrivée, c'est à titre de mainmortables pour la plupart qu'on les établissait sur des terres comtoises. Un édit nous apprend que, dans la grande terre de Faucogney - terre franche puisque ses habitants, «cy-devant universellement sujectz de mainmorte », avaient été affranchis en masse - plusieurs vassaux du roi, vers 1566, se mettaient à « acquérir journellement sujectz mainmortables » : il n'est pas raisonnable, constate le prince, «qu'iceulx ainsi affranchiz entrent en servitude de nosd. Vassaulx ». De plus, «ceulx estans de mainmorte acquièrent journellement meix et héritages francz d'hommes de franche condition, nonobstant que, par les coutumes et franchises dud. Faulcoigney leur soit défendu de faire telz achats, sur peine de commise des parties »; des meix, des terres ainsi conquises, ces main- 
mortables font ensuite reconnaissance à leurs seigneurs, les avouant de leur mainmorte, «nonobstant que les héritaiges ainsi acquis soient chargez, affectez et hypothéquez de cense, tailles et autres drois seigneuriaulx » envers le roi, seigneur de Faucogney. Texte remarquable, qui fait bien saisir le mécanisme de reprise de la mainmorte ; il montre en même temps combien aisément les affranchis pouvaient retomber dans la servitude. Après tout, à des miséreux que la liberté n'avait pas rendus plus riches, la rechute était-elle toujours si douloureuse ? La faim fait passer sur tant de choses : on voit fort bien une famille besogneuse de paysans francs s'installant sans scrupule sur un mieux vacant et d'un coeur léger acceptant la mainmorte. Après tout, autant devenir un mainmortable qu'un grangier, ligoté par les clauses insidieuses de contrats léonins.

Ainsi se justifient - même lorsqu'il s'agit seulement de déterminer le produit des divers droits domaniaux - les distinctions qu'entre ces droits, d'après leur origine, fondent ordinairement les juristes. Ne nous y attardons pas cependant. Sur eux tous, il est impossible que les mêmes forces, les mêmes influences de temps et de milieu ne se soient pas également exercées. D'ensemble, étudions-les ; cherchons quelle valeur pécuniaire, quelle valeur matérielle ils avaient conservée pour qui les touchait.

\section{VIII}

Conservées - le mot explique un effort de résistance. C'est que, depuis longtemps déjà, un double assaut était dirigé contre eux : par les tenanciers et par le souverain. Sous leurs coups, l'édifice cohérent, le système bien lié des droits seigneuriaux, tel qu'il existait au XIIIe siècle, lentement s'était vu ébranler, démembrer peu à peu et comme découronner. D'abord, sous la poussée d'en bas, presque partout, il avait fallu renoncer à l'arbitraire des charges et passer des contrats puis, ce premier point acquis, remplacer les charges en nature par des charges pécuniaires. C'était là, depuis le XIVe siècle, la double forme du progrès paysan.

Rien de plus frappant, à cet égard, que l'évolution des redevances personnelles corporelles : en premier lieu, des corvées. Nous l'avons dit plus haut : les corvées en nature se font de plus en plus rares, de moins en moins pesantes pour le tenan- 
cier, de moins en moins profitables pour le seigneur ; presque toutes se rachètent à des prix insignifiants et subissent dès lors les conséquences de la baisse de valeur constante de l'argent. Mais c'est même chose pour les services militaires. L'ost et la chevauchée ne se rencontrent plus guère ; les menus emparements, la retraite en cas d'éminent péril, le guet et garde, ensuite d'une délibération des États de 1585, se voient limiter et régler au profit évident des tenanciers. Et si parfois ces droits se sont transformés, eux aussi, en droits pécuniaires, les sommes qu'ils rapportent sont vite absorbées par les frais d'entretien et de garde des maisons fortes.

Corvées et charges militaires : à ces obligations, francs et mainmortables devaient satisfaire à peu près également. Mais les charges même caractéristiques de la servitude, les plus pesantes sans doute et les plus productives, elles aussi subissent l'effet du temps ; elles aussi vont diminuant, se transformant peu à peu et s'allégeant. Le chevage, presque partout, a disparu. Seule subsiste, intacte, la vieille redevance de la poule ou géline, redevance personnelle interprétée le plus souvent comme une marque de servitude ; redevance réelle parfois aussi, et payée alors, non par feu, mais par meix. La taille, de même, s'est adoucie. Lorsqu'elle reste arbitraire, elle n'est plus, du moins, exorbitante ; elle se fait raisonnable et constante ; elle ne se perçoit plus qu'à dates fixes, une fois, deux fois par an ; en quelques endroits, tous les deux ou trois ans; surtout, le plus souvent, elle s'est « abonnée ». D'arbitraire, elle est devenue fixe ; de payable en nature, exigible en argent ; c'est l'histoire, notamment, de cette taille spéciale : la jurée des bêtes, que devaient, en maintes seigneuries, les paysans du Jura. Dans cette contrée de pâturages et de forêts, le bétail, plus que la terre, était la grande richesse ; des taxes le frappaient, arbitraires d'abord : l'effort des tenanciers fut de les faire abonner ; en nature ensuite : l'effort des tenanciers fut de les rendre pécuniaires.

Surtout, au XVIe siècle, dans la Comté comme dans le Duché, la vieille servitude apparaît disloquée, morcelée, fragmentée. Il n'y a plus un système, un ensemble de droits, pesant tous ensemble sur la même catégorie de paysans - mais des droits distincts : chevage, taille arbitraire, mainmorte, qui, le plus souvent, jouent isolément. Tel mainmortable reste taillable arbitrairement; tel autre n'est plus taillable quoique mainmortable ; tel taillable, par contre, n'est plus mainmortable. Le vieux système domanial va s'effritant peu à peu. Même dans cette Comté où le régime féodal devait se perpétuer, plus fortement qu'ailleurs, jusqu'à la veille même de la Révolution, c'est une diminution progressive, un allégement continu 
des anciens droits. Histoire monotone, qu'il s'agisse de corvées, de réquisitions, de tailles, ou de ce droit d'induire aide qui se restreint d'abord aux quatre cas, puis qu'en 1585, à la demande des États, on limite plus fortement encore. Les paysans ne subissent pas, passifs, l'exploitation du maître. Beaucoup, sans doute, sont encore gens de poëte, qui ne peuvent s'assembler pour traiter de leurs intérêts communs sans l'autorisation du seigneur. Mais il y a déjà de fortes et vivantes communautés, conscientes de leurs droits et ne permettant pas qu'on les viole. Contre les seigneurs trop entreprenants, ce sont d'innombrables procès, des résistances héroïques aux commissaires à terrier, des grèves fiscales, parfois même des révoltes : telle, cette rébellion des habitants de Mont-le-Franois contre leur seigneur, un Français il est vrai, Guillaume de Mervilliers; ils rossent un sergent venu de sa part et s'écrient sans ambages : « Nous voulons nous laisser ainsi mastiner de ces chiens français ? Portons-les tous nyer en la rivière ! » François de Gorrevod, à Marnay, n'était pas plus heureux ; ses sujets l'outrageaient, lui aussi, le menaçaient de mort, s'excitaient mutuellement contre son autorité. De cet esprit de révolte et d'audace, les exemples se rencontrent, assez fréquents, dans les registres du Parlement; sachant leurs hommes « faciles à s'esmouvoir », les seigneurs devaient se montrer prudents pour « refréner une telle populasse de s'élever ». « Pays franc » par excellence, la Comté ne devait-elle pas justifier son nom ?

À l'adversaire d'en bas se joint l'ennemi d'en haut : le souverain. Lui s'attaque surtout à la justice, à ce pouvoir judiciaire des féodaux, manifestation essentielle de leur autorité seigneuriale, qui, leur permettant à la fois « d'exercer et de maintenir l'ensemble de leurs droits », était vraiment «la clé de voûte du régime ». Pendant tout le siècle, sous l'effort des baillis et des parlementaires, c'est une décadence progressive des justices féodales. Bien rares, maintenant, les seigneuries où le seigneur tire profit de ses droits de juridiction. Voici les comptes de Citey, de 1565 à 1568 : néant aux recettes pour les exploits de justice de Citey; leur produit sert à payer les gages des officiers de la seigneurie, et n'y suffit même pas. Néant également pour Longevelle, Mont-les-Étrelles Velleclaire et Mercey. À Mandeure, en 1559, l'archevêque de Besançon (qui y possède toute justice et les droits souverains les plus étendus, même celui de grâce) ne perçoit que le montant de deux amendes de 28 livres chacune. Même chose à Étalans en 1566 : la recette de la justice est de 5 fr. 4 gros (amendes et défauts). A Noroy-l'Archevêque, néant pour la justice au compte de 1548-49; il n'a pas été tenu d'assises dans l'année. 
Dans la seigneurie de Saint-Remy, les chiffres se relèvent : en 1572, exploits de justice et amendes rapportent $138 \mathrm{fr} .4$ gros ; mais la recette totale est de $1095 \mathrm{fr}$. A Gy, recette forte en 1560 : 542 livres 10 s. 4 deniers est. Mais à Arguel, en moyenne, vers 1580, la justice ne rapporte guère que $100 \mathrm{fr}$. sur un total annuel de recettes de 800 fr. En 1574, elle produit 73 fr. 2 gr. 5 engr. 1/3 ; or, la même année, les gages des officiers chargés de l'administrer s'élèvent (sans compter les denrées) à 38 fr., et les frais d'un procès criminel avec condamnation à mort, à 23 fr. 2 bl., le condamné étant insolvable. On comprend pourquoi nombre de seigneurs en venaient peu à peu à amodier d'ensemble leurs recettes de justice. Les autres, s'ils s'obstinaient à conserver intacts leurs droits de juridiction, c'était par amour-propre surtout, par orgueil ; c'était encore parce que la justice était pour eux «l'instrument indispensable de l'exploitation seigneuriale». Mais le profit restait maigre, lors même qu'il existait.

Enfin, à toutes ces causes de décadence, il convient d'ajouter pour certains droits la transformation, au cours des siècles, des conditions économiques et géographiques de l'existence. Les péages, par exemple : leur valeur forcément dépendait de la direction des courants commerciaux. Or, le temps n'était plus des foires de Champagne, attirant les marchands italiens et lombards, déterminant à travers la Comté un important transit de denrées coûteuses. Les habitants d'Augerans n'étaient pas seuls sans doute à pleurer les temps évanouis où les marchands, en longues caravanes, traversaient leur bourg et s'arrêtaient au guichet du péage ; le guichet subsistait, mais les marchands se faisaient rares. Au reste, les péages les plus importants n'appartenaient pas à de simples seigneurs ; ils étaient au souverain ou aux héritiers des Chalon : tels, sur les routes de Suisse, ceux de la Loye, Augerans, Fraisans, Salins, Chalamont, Pontarlier, le Chauffaud, Franc-Chatel et Jougne ; entre Chalon-sur-Saône et Lons, Montmorot ; sur les voies d'accès du Lyonnais, Orgelet ; au nord, enfin, au pied des Vosges, le Thillot et ChâteauLambert. De presque tous, nous avons conservé les tarifs en usage au XVIe siècle ; par les comptes et les amodiations, nous voyons qu'ils étaient encore productifs ; mais les nobles comtois devaient se contenter de moindres revenus ; quelques-uns seulement percevaient, sur des ponts à eux banaux, des droits de passage plus ou moins élevés : droits que ne compensaient sans doute pas leurs dépenses de construction et d'entretien à une époque et dans un pays où les fortes crues, les 
débâcles, l'inexpérience des constructeurs, abrégeaient singulièrement la durée de ces travaux d'art.

Moins coûteux d'établissement, des " portails », des bacs, établis çà et là sur les rivières comtoises, rapportaient des revenus d'autant plus appréciables que les frais d'entretien en étaient plus restreints ; mais dans l'ensemble, rares étaient les seigneurs qui pouvaient trouver là quelque profit notable. De même pour les marchés et les foires, bien que le nombre s'en fût multiplié dans les premières années du XVIe siècle, à la faveur du relèvement général. Dans les villes, dans les bourgades, le produit souvent en était considérable ; mais villes et bourgades, elles aussi, à de rares exceptions près, appartenaient au souverain ou aux héritiers des Chalon. Pour un grand seigneur comme Laurent de Gorrevod, possédant à Marnay quatre foires annuelles, un marché public chaque mardi et percevant, outre l'éminage, des droits étendus sur les ventes, les étalages, les bancs des halles de sa seigneurie - combien de simples nobles détenaient des villages où foires et marchés demeuraient inconnus ? Combien d'années mauvaises aussi, où les calamités humaines ou naturelles, les pestes, les grêles, les sécheresses, les brigandages, les incendies, les guerres, réduisaient à néant les transactions de toute une vaste région ? Droits de rapport singulièrement incertain, ces droits sur les échanges et les transactions, auxquels, de plus en plus, le gros commerce d'ailleurs savait échapper et se soustraire habilement. Le temps se joignait aux hommes pour ronger et détruire l'édifice ancien des droits domaniaux.

\section{IX}

Voilà passés en revue les divers chapitres d'un compte de recette. De notre analyse, deux faits semblent se dégager: l'un, que les revenus des seigneuries, loin d'augmenter, restent stationnaires quand ils ne vont pas en diminuant. L'autre, qu'à travers les mailles trop rigides et trop larges du filet féodal, les réalités de la vie économique, souple et fuyante, glissent, s'évanouissent, s'échappent à leur aise.

Au XVIe siècle déjà, la seigneurie apparaît comme un legs du passé, une institution vieillie qui ne répond plus aux besoins du moment. Elle n'est plus faite pour 
les nobles comtois du temps de Charles-Quint ou de Philippe II. Elle produit des services et des denrées, dont ils n'ont plus que faire. Elle ne produit pas ce qui leur manque et ce qu'ils veulent : l'argent. Les vieux féodaux qui l'avaient constituée n'avaient pas songé à leurs arrière-petits-fils. Ils l'avaient faite pour eux, à leur mesure et à leur convenance. Ils s'étaient ingéniés à lui faire produire ce qu'il leur fallait pour vivre largement une vie simple et, dans son fond, rustique. Ils lui demandaient tout pour la satisfaction de leurs besoins quotidiens; ils en tiraient tout : leur blé et leur seigle, l'avoine de leurs chevaux, le vin de leur table, des poules et des chapons, de l'huile et des épices, des lentilles parfois, des pois, des fèves, des noix, du chanvre brut ou même de la toile ; dans le Jura, des fromages ; sur le bord des rivières, des services de poisson. A les servir en toute occasion, ils avaient astreint, plié leurs tenanciers. Tout était prévu : réparations à leur demeure, charrois, travaux de culture, jusqu'au port des lettres que, dans maintes seigneuries, les paysans effectuaient gratuitement - jusqu'au logis confortable et gratuit qu'en cas de déplacement ils fournissaient au maître, à ses gens, à ses chevaux, à ses chiens. Commodités précieuses, pour qui ne quittait pas sa terre, demeurait sur son fief, menait une existence plantureusement rustique dans la vieille maison perchée sur le val. Mais au gentilhomme voyageur, tourmenté de besoins, de désirs nouveaux, à qui l'inaction pesait sur la terre natale ? À celui qui rêvait d'aventures, de coups de fortune soudains, de carrière brillante en quelque cour étrangère ? Il partait, et pour s'équiper, aliénait une partie des terres paternelles ; ce qu'il gardait, ordre de le louer ou d'en vendre le produit : en échange de tant de sacs de grains, péniblement convoyés du champ à son grenier par les tenanciers courbés et maugréant - c'était une bien petite, bien pauvre pile d'écus que son receveur, tous frais payés et toutes poches garnies, lui remettait finalement au règlement des comptes.

Et puis, de plus en plus, la seigneurie s'immobilise. Son revenu se fixe, devient immuable. Comme les divers droits qui le composent, elle «s'abonne », elle aussi, elle s'abonne d'ensemble ; elle ne reflète en rien le mouvement ni la vie économique du temps. Au milieu du siècle, c'est en Comté, nous l'avons vu, un effort puissant de mise en valeur. Des défrichements s'opèrent partout à la fois. Une population qui sans cesse s'accroît, entreprend la conquête des hautes joux du Jura, des broussailles du plateau, des vaivres de la plaine. De tout cet immense travail la seigneurie ne bénéficie pas ; le total des recettes ne s'en accroît nulle- 
ment. De même, le prix des fermages s'élève ; la valeur de la terre augmente. De cette hausse non plus la seigneurie ne profite pas : le domaine proche est si petit, les mouvances si vastes - et tant de redevances perpétuelles survivent, héritage d'un passé qui recule sans cesse.

On dépouille les comptes - et c'est à peine si, de loin en loin, on trouve quelque mention de «terres nouvelles » ou de « terres vaines » rapportant au seigneur un infime revenu. Telles, dans la seigneurie de Joux, ces terres « estans en la vainne Champagne » - les laboure qui veut, pour une émine d'avoine par journal ou, dans celle de Toulouse, les « terres vacquées de Darbonnay, qui se emblavent par les habitans sans admodiation, en payant par journaulx deux mesures, mesure dud. Thoulouze, de tel bled que l'on les enfruicte et sème. » On passe en revue les divers chapitres de recette - et c'est à peine si, pour un ou deux d'entre eux, on peut constater une faible augmentation, corrélative d'un accroissement de population. Quant aux essarts, aux cernois, aux défrichements, les comptes n'en renferment pas trace ; ils s'opèrent le plus souvent au détriment de bois communaux, et c'est au plus alors s'ils rapportent au seigneur quelque somme minime, quelques misérables gros de cens annuel lorsque les paysans lui ont demandé la permission d'essarter - quelques francs d'amende ou de transaction lorsque, plus souvent, ils ont agi de leur chef. De loin en loin sans doute, on découvre quelques traces d'activité réformatrice chez des représentants de la noblesse comtoise. Certains luttent, s'efforcent d'améliorer leurs terres, d'augmenter leurs revenus : infimes exceptions, à vrai dire. Par toute la Comté, le travail de défrichement s'opère sans ensemble et ne profite aux seigneurs qu'indirectement. Dans leurs livres de compte, que l'on confronte, pour la seconde moitié du XVIe siècle, les longues listes de cens portés en recette : pas de changement, d'accroissement, ni d'imprévu. C'est la rigidité qui annonce la mort.

\section{$\mathrm{X}$}

Sans doute, des deux chiffres comparés du produit total d'une seigneurie en 1550 et en 1580, le second est plus fort. Augmentation apparente plutôt que réelle : quelques exemples vont nous le faire sentir. Voici, régulièrement espacés de 
dix en dix ans, les comptes de la seigneurie domaniale de Châtillon-sous-Maiche entre I550 et 1600. Examinons le montant des recettes en argent. Elles sont :

$\begin{array}{ll}\text { En 1550, de } & 5351 . \mathrm{t} . \\ \text { En 1560, de } & 4331 . \mathrm{t} . \\ \text { En 1570, de } & 5261 . \mathrm{t} . \\ \text { En 1580, de } & 4601 . \mathrm{t} . \\ \text { En 1590, de } & 6851 . \mathrm{t} . \\ \text { En } 1600, \text { de } & 6451 . \mathrm{t} .\end{array}$

Ainsi, dans l'ensemble, il y a progression, accroissement très marqué des recettes, notamment entre 1580 et 1600 . Mais d'abord il convient de noter qu'à cette augmentation des recettes en argent correspond une diminution des recettes en nature. Voici les chiffres, en effet ${ }^{9}$ :

\begin{tabular}{llll}
\hline & \multicolumn{1}{c}{1550} & \multicolumn{1}{c}{1560} & \multicolumn{1}{c}{1570} \\
\hline Froment & 131 b. 13 q. 3c. 1/2 & 114 b. 21 q. 8 c. & 119 b. 19q. I c. \\
Avoine & 115 b. 17q. 1/27 c. & 97 b.13 q. 1/22 c. & 111 b. 18q. 2c. \\
Géline & 195 & 178 & 224 \\
Cire & 214 I. & 169 l. $1 / 2$ & $180 \mathrm{l}$. \\
$\begin{array}{l}\text { Chénevis } \\
\text { Gerbes d'estrain } \\
\text { (paille) }\end{array}$ & $120 \mathrm{l}$. & $100 \mathrm{l}$. & $100 \mathrm{l}$. \\
Épices & 800 & 800 & 800 \\
\hline
\end{tabular}

9 Dans le tableau ci-après, b. veut dire bichot, q. quarte et c. coupot. Or, le bichot, mesure de Chatillon, valait 12 penaux ou 24 quartes ; la quarte, 2 coupots ; le coupot, 12 coupes (Ch. des C., B 1399). 


\begin{tabular}{llll}
\hline \multicolumn{1}{c}{1580} & \multicolumn{1}{c}{1590} & \multicolumn{1}{c}{1600} \\
\hline Froment & 127 b. 19 q. I c. $1 / 2$ & 94 b. 19 q. 20 c. & 83 b. 6 q. \\
Avoine & 103 b. 12 q. & 77 b. 5 q. 8 c. & 73 b. 23 q. \\
Gélines & 220 & 211 & 20 \\
Cire & 178 l. $1 / 2$ & $125 \mathrm{l} .1 / 2$ & $123 \mathrm{l}$. \\
Gerbes d'estrain & $100 \mathrm{l}$. & $100 \mathrm{l}$. & $100 \mathrm{l}$. \\
(paille) & 800 & 800 & 800 \\
Épices & 11. & $1 \mathrm{l}$. & $1 \mathrm{l}$. \\
\hline
\end{tabular}

On voit, d'après ce tableau, que la diminution des recettes en grains - les principales - porte précisément sur les années (1590, 1600) où se marque l'augmentation des recettes en argent. De plus, à l'aide des prix de vente réels mentionnés dans les comptes, faisons le calcul de ce que valaient, ce qu'auraient pu rapporter en argent les denrées, si elles avaient été vendues en totalité. Ces prix sont les suivants 10 :

\begin{tabular}{|c|c|c|c|}
\hline & 1550 & 1560 & 1570 \\
\hline Froment, le penal. & 8 gros & 8 gros & 20 gros \\
\hline - le bichot. & 8 francs & 8 francs & 20 francs (?) \\
\hline Avoine, le penal & 2 gr. & 2 gr. & 10 gr. \\
\hline - le bichot & $2 \mathrm{fr}$. & 2 fr. & 10 fr. (?). \\
\hline Le part : & & & \\
\hline (1 b. from., I b. av.) & $10 \mathrm{fr}$. & $10 \mathrm{fr}$. & $30 \mathrm{fr}$. \\
\hline La géline & $1 \mathrm{~s}$. est. $=4 \mathrm{bl}$. & 1 s. est. & 1 s. est. \\
\hline La livre de cire & 5 s. est. & 5 s. est. & 7 s .est. $1 / 2$ \\
\hline $\begin{array}{l}\text { Les } 100 \text { livres de } \\
\text { chénevis? }\end{array}$ & $?$ & 34 gr. 3 engr. & 55 s. 6 d. 6 ob. t. \\
\hline $\begin{array}{l}\text { Les } 200 \text { gerbes d'es- } \\
\text { tain }\end{array}$ & 8 gr. & 8 gr. & 8 gr. \\
\hline La livre d'épices & $9 \mathrm{gr}$. & 10 gr. & $1 \mathrm{fr}$. \\
\hline
\end{tabular}

10 Nous faisons suivre d'un point d'interrogation les chiffres qui ne nous sont pas donnés textuellement par les comptes, mais que nous avons tirés des indications précises de ceux-ci. Par exemple, pour l'année 1570, nous avons dû tirer du prix du part les prix probables du bichot de froment et du bichot d'avoine. 


\begin{tabular}{|c|c|c|c|c|c|c|}
\hline & \multicolumn{2}{|c|}{1580} & \multicolumn{2}{|c|}{1590} & \multicolumn{2}{|c|}{1600} \\
\hline Froment, le penal & \multirow{2}{*}{\multicolumn{2}{|c|}{$\begin{array}{l}14 \text { gr. } 6 \text { engr. } \\
14 \text { fr. } 1 / 2\end{array}$}} & \multicolumn{2}{|c|}{20 gr. 6 bl. } & \multicolumn{2}{|l|}{16 gros } \\
\hline - le bichot & & & \multicolumn{2}{|c|}{21 francs } & \multicolumn{2}{|l|}{16 francs } \\
\hline Avoine, le penal & \multicolumn{2}{|c|}{8 gr. } & \multicolumn{2}{|c|}{9 s. 2 gr. 2 engr } & \multicolumn{2}{|l|}{8 gr. } \\
\hline $\begin{array}{l}\text { - le bichot } \\
\text { Le nart• }\end{array}$ & \multicolumn{2}{|l|}{$8 \mathrm{fr}$} & \multicolumn{2}{|c|}{5 l. 14 s 24 engr. } & \multicolumn{2}{|l|}{$8 \mathrm{fr}}$. \\
\hline $\begin{array}{l}\text { Le part : } \\
\text { (1 b. from., } 1 \text { b. av.) }\end{array}$ & \multicolumn{2}{|c|}{22 fr. $1 / 2$} & \multicolumn{2}{|l|}{ (?) } & \multicolumn{2}{|l|}{$24 \mathrm{fr}$. } \\
\hline La géline & \multicolumn{2}{|c|}{2 gr. } & \multicolumn{2}{|l|}{2 gr. } & \multicolumn{2}{|l|}{$3 \mathrm{~s}}$. \\
\hline La livre de cire & \multicolumn{2}{|c|}{7 s. est. $1 / 2$} & \multicolumn{2}{|c|}{$14 \mathrm{gr}}$. & \multicolumn{2}{|l|}{7 gr. } \\
\hline $\begin{array}{l}\text { Les } 100 \text { livres de } \\
\text { chènevis }\end{array}$ & \multicolumn{2}{|c|}{4 l. 3 s. 4 d. t. } & \multicolumn{2}{|c|}{4 l. 3 s. 3 d. t. } & \multicolumn{2}{|l|}{$5 \mathrm{fr}$} \\
\hline $\begin{array}{l}\text { Les } 200 \text { gerbes d'es- } \\
\text { train }\end{array}$ & \multicolumn{2}{|l|}{8 gr. } & \multicolumn{2}{|l|}{8 gr. } & \multicolumn{2}{|l|}{8 gr. } \\
\hline La livre d'épices & \multicolumn{2}{|l|}{$1 \mathrm{fr}}$. & \multicolumn{2}{|l|}{$1 \mathrm{fr}}$. & \multicolumn{2}{|l|}{$30 \mathrm{~s}}$. \\
\hline \multicolumn{7}{|c|}{ En les utilisant, nous obtiendrons les chiffres que voici ${ }^{11}$ : } \\
\hline \multicolumn{7}{|c|}{$\begin{array}{l}11 \text { Si nous avions additionné à la recette d'argent de la seigneurie le produit des } \\
\text { ventes qui furent réellement effectuées par les soins des receveurs pour cha- } \\
\text { cune des années considérées - nous aurions obtenu les chiffres suivants : }\end{array}$} \\
\hline & 1550 & 1560 & 1570 & 1580 & 1590 & 1600 \\
\hline Recette d'argent & $535 \mathrm{f}$ & $433 \mathrm{f}$ & $526 \mathrm{f}$ & $461 \mathrm{f}$ & $685 \mathrm{f}$ & $645 \mathrm{f}$ \\
\hline $\begin{array}{l}\text { Produit des ventes } \\
\text { réellement effec- } \\
\text { tuées }\end{array}$ & $1138 \mathrm{f}$ & $1094 \mathrm{f}$ & $3119 \mathrm{f}$ & $2277 \mathrm{f}$ & $2070 \mathrm{f}$ & $1688 \mathrm{f}$ \\
\hline Total & $1673 \mathrm{f}$ & $1527 \mathrm{f}$ & $3644 \mathrm{f}$ & $2738 \mathrm{f}$ & $2755 \mathrm{f}$ & $2333 \mathrm{f}$ \\
\hline
\end{tabular}

Les résultats, comme on voit, sont sensiblement les mêmes. 


\begin{tabular}{lrrrrrr}
\hline & 1550 & 1560 & 1570 & 1580 & 1590 & 1600 \\
\hline $\begin{array}{l}\text { Recette d'argent } \\
\begin{array}{l}\text { Valeur en argent de } \\
\text { la totalité des pro- } \\
\text { duits en nature de }\end{array}\end{array}$ & $535 \mathrm{f}$ & $433 \mathrm{f}$ & $526 \mathrm{f}$ & $461 \mathrm{f}$ & $685 \mathrm{f}$ & $645 \mathrm{f}$ \\
$\begin{array}{l}\text { la seigneurie } \\
\text { Total }\end{array}$ & $1174 \mathrm{f}$ & $3614 \mathrm{f}$ & $2800 \mathrm{f}$ & $2631 \mathrm{f}$ & $2036 \mathrm{f}$ \\
\hline
\end{tabular}

À examiner ces chiffres, un fait frappe tout d'abord : le manque de concordance entre les variations de la recette d'argent et celles du produit des denrées recueillies. Comme ce produit forme la plus grande part du revenu total, ce sont ses variations que reflète fidèlement celui-ci. Or, elles sont fonction de celles du prix de la vie à la même époque, et, dès lors, on comprend combien certaines augmentations du produit de la seigneurie sont apparentes et non réelles. N'est-il pas frappant, par exemple, que le plus gros produit constaté ait été perçu en 1570, dans une année de misère, de famine et de détresse générale ? Disette, cherté : ainsi s'explique le haut prix qu'atteignirent cette année les graines de Chatillon et, par conséquent, le chiffre très élevé de 4140 fr. que nous avons obtenu ; mais combien illusoire ce prétendu bénéfice, si le seigneur, comme consommateur, doit faire face à une hausse générale des prix égale au moins, sinon supérieure, à celle dont a joui son blé et son avoine ? De la somme qu'il perçoit, quel est le pouvoir d'achat ? Voilà la vraie question, et la seule qui importe. 
Même résultat, si nous résumons les comptes de Joux :

\begin{tabular}{|c|c|c|c|}
\hline Recette d'argent & 1566 & 1575 & \\
\hline & $986 \mathrm{f}$ & $930 \mathrm{f}$ & \\
\hline Recette d'orge & 28 q. 3 é. à 8 le q. & 45 q. 7 é. à $6 f$ 1/2 & \\
\hline Recette d'avoine & $\begin{aligned} 110 \text { q. } 3 \text { é. à } 5 \mathrm{f} \text { le q. } & \\
& =551\end{aligned}$ & 101q. à $4 \mathrm{f} 4$ bl. & $\begin{array}{l}=296 \mathrm{I} \\
=412 \mathrm{f}\end{array}$ \\
\hline & 777 & & $708 \mathrm{f}$ \\
\hline Produit total & $1,763 \mathrm{f}$ & & $1,638 \mathrm{f}$ \\
\hline
\end{tabular}

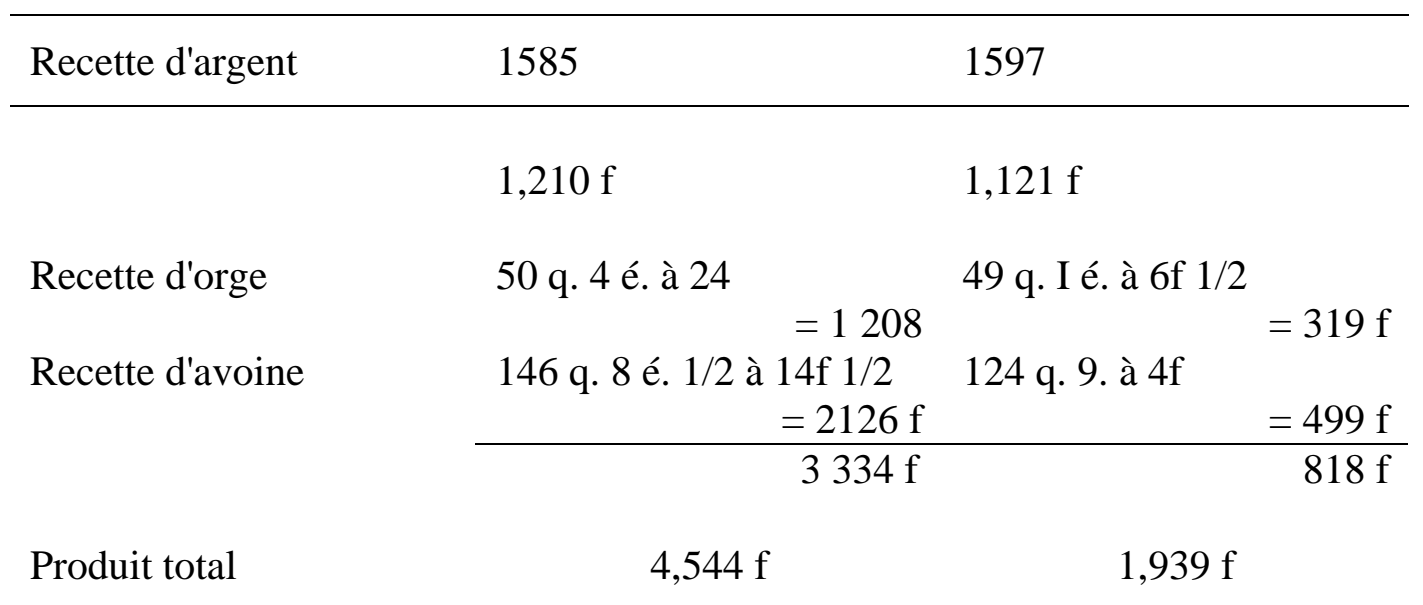


Même résultat encore, avec ceux de Vuillafans-le-Neuf :

\begin{tabular}{|c|c|c|c|c|c|}
\hline & & \multicolumn{2}{|c|}{1566} & \multicolumn{2}{|c|}{1576} \\
\hline \multicolumn{2}{|c|}{ Recette d'argent } & \multicolumn{2}{|c|}{$213 \mathrm{f}$} & \multicolumn{2}{|c|}{$196 \mathrm{f}$} \\
\hline \multirow{6}{*}{$\begin{array}{l}\text { Recette } \\
\text { de }\end{array}$} & Froment & \multicolumn{2}{|c|}{$\begin{array}{l}77 \text { b. I p. I c., à } 15 \text { gr. } \\
\text { l'ém. = } 577 \text { f }\end{array}$} & \multicolumn{2}{|c|}{$\begin{array}{l}79 \text { b., à } 9 \text { gr. l'é. } \\
\text { I0 gr. = } 355 f \text { f } 6 \text { gr. }\end{array}$} \\
\hline & Avoine & \multicolumn{2}{|c|}{$\begin{array}{l}28 \text { b. } 5 \text { é. } 3 \text { c., } \\
\text { à } 6 \text { gr. } 1 / 2=94 \mathrm{f}\end{array}$} & \multicolumn{2}{|c|}{$\begin{array}{l}25 \text { b. } 3 \text { c., } \\
\text { à } 4 \text { gr. } 1 / 2 \quad=56 f \text { gr. }\end{array}$} \\
\hline & Vin & \multicolumn{2}{|c|}{$\begin{array}{l}2 \text { m. } 3 \text { c. } 3 \text { ch., } \\
\text { à } 13 \text { f le m. = } 28 f 6 \text { gr. }\end{array}$} & \multicolumn{2}{|c|}{$\begin{array}{l}5 \text { q. I s. } 3 \text { ch., } \\
\text { à } 15 \text { f le m. }=20 f\end{array}$} \\
\hline & Pois & 3 é., à 3 gr. & $=9$ gr. & 3 é., à 3 gr. & $=9$ gr. \\
\hline & Cire & $\begin{array}{l}21 \text { b. } 1 / 2, \text { à } \\
4 \text { gr. } 1 / 2 \text { la } 1\end{array}$ & $=7 f 10$ gr. & $\begin{array}{l}31 \text { l. } 1 / 2, \\
\text { à } 4 \text { gr. } 1 / 2\end{array}$ & $=11 \mathrm{f} 9 \mathrm{gr}$. \\
\hline & Gélines & 25 à 4 bl. = & 2f $4 \mathrm{bl}$ & 25 à 4 bl. & $=2 \mathrm{f} 4 \mathrm{bl}$ \\
\hline \multirow{2}{*}{\multicolumn{2}{|c|}{$\begin{array}{l}\text { Valeur totale en ar- } \\
\text { gent des produits en } \\
\text { nature } \\
\text { Produit total de la } \\
\text { seigneurie }\end{array}$}} & \multicolumn{2}{|c|}{$711 \mathrm{f}$} & \multicolumn{2}{|c|}{$447 \mathrm{f}$} \\
\hline & & \multicolumn{2}{|c|}{$924 \mathrm{f}$} & \multicolumn{2}{|c|}{$643 \mathrm{f}$} \\
\hline
\end{tabular}




\begin{tabular}{|c|c|c|c|}
\hline & & 1586 & 1596 \\
\hline \multicolumn{2}{|c|}{ Recette d'argent } & $563 \mathrm{f}$ & $272 \mathrm{f}$ \\
\hline \multirow{6}{*}{$\begin{array}{l}\text { Recette } \\
\text { de }\end{array}$} & Froment & $\begin{array}{l}118 \text { b. I é. 1/2, à 4f l'é } \\
=2838 \text { f }\end{array}$ & $\begin{array}{l}69 \text { b. } 4 \text { é., à 3f I bl. l'é. } \\
=1,260\end{array}$ \\
\hline & Avoine & 31 b. I c., à 2f 2 bl. $=378 \mathrm{f}$. & $\begin{aligned} 27 \text { b. } 4 \text { é. } 3 \text { c., à } 30 \text { gr } \\
=416 \text { f } 8 \text { gr. }\end{aligned}$ \\
\hline & Vin & $\begin{array}{l}\begin{array}{l}1 \mathrm{~m} .1 / 2 \text { et } 6 \text { ch., à } 20 \mathrm{f} \text { le } \\
\text { m. } \\
=31 \mathrm{f}\end{array}\end{array}$ & $\begin{array}{l}\text { I m. I q. } 2 \text { s. } 4 \text { ch. } 2 / 3 \text {, à } \\
22 \mathrm{f}(?) \\
=40 \mathrm{f}\end{array}$ \\
\hline & Pois & 3 é., à 3 gr. $\quad=9$ gr. & 3 é., à 3 gr. $\quad=9$ gr. \\
\hline & Cire & $\begin{array}{r}20 \begin{aligned} 1.1 / 2 \text {, à } 7 \text { gr. } 1 / 2 \\
=12 f\end{aligned} 9 \text { gr. }\end{array}$ & $\begin{aligned} & 21 \text { 1., à } 7 \text { gr. } 1 / 2 \\
& =13 f \text { I gr. } 1 / 2\end{aligned}$ \\
\hline & Gélines & $=8 f \quad 4$ gr. & 34 à 2 gr. \\
\hline \multirow{2}{*}{\multicolumn{2}{|c|}{$\begin{array}{l}\text { Valeur totale en ar- } \\
\text { gent des produits en } \\
\text { nature } \\
\text { Produit total de la } \\
\text { seigneurie }\end{array}$}} & $3268 \mathrm{f}$ & $1737 \mathrm{f}$ \\
\hline & & $3831 \mathrm{f}$ & $2009 \mathrm{f}$ \\
\hline
\end{tabular}

Enfin, voici, résumées dans les tableaux ci-contre, les variations de revenu d'Arguel pendant la période 1574-1584, si intéressante en Comté pour l'histoire des prix. 
TABLEAU 1. - Recettes brutes de la seigneurie

Abréviations : b. = bichot ; é. émine ; p. = penal (I b. = 6 é. = 12 p.).- Fr. = francs ; gr. = gros; bl. blanc ; engr. = engrognes $(\mathrm{I} \mathrm{fr.}=12$ gr. $=48 \mathrm{bl} .=144$ engr.). - M. = muids; $\mathrm{s} .=$ setiers ( $\mathrm{Im} .=16 \mathrm{~s}$.).

\begin{tabular}{|c|c|c|c|}
\hline & 1574 & 1575 & 1576 \\
\hline Argent & 824 fr. 9 gr. & 651 fr. 2 gr. & 558 fr. 9 gr. \\
\hline Froment de cense & 2 b. $1 / 2$ p. & 2 b. I p. & 2 b. I p. \\
\hline de terrage & 35 b. 4 é. & 33 b.2 é. I p. $1 / 4$ & 27 b. I p. $1 / 4$ \\
\hline Avoine de cense & I p. $1 / 2$ & " & " \\
\hline de terrage & 67 b. 3 é.1/2 I/4 p. & 67 b. 4 é & 68 b. 5 é. \\
\hline Vin & $16 \mathrm{~m} .9 \mathrm{~s}$. & $15 \mathrm{~m} .3 \mathrm{~s}$. & $8 \mathrm{~m} .6 \mathrm{~s}$. \\
\hline $\begin{array}{l}\text { Divers (cire, géli- } \\
\text { nes) }\end{array}$ & 25 fr. Io gr. $1 / 2$ & 25 fr. I0 gr. $1 / 2$ & 25 fr. 10 gr. $1 / 2$ \\
\hline $\begin{array}{l}\text { Évaluation en } \\
\text { argent de la valeur } \\
\text { totale des produits } \\
\text { en nature } 12\end{array}$ & $1345 \mathrm{fr}$. & $510 \mathrm{fr}$. & $575 \mathrm{fr}$. \\
\hline $\begin{array}{l}\text { Évaluation en } \\
\text { argent de la recet- } \\
\text { te brute totale } 13\end{array}$ & 2169 fr. 9 gr. & 1161fr. 2 gr. & 1133 fr. 9 gr. \\
\hline
\end{tabular}

12 Chiffre fictif, calculé d'après les prix de vente de l'année.

13 Chiffre fictif, obtenu en additionnant les recettes en argent à l'évaluation en argent de la valeur totale des produits en nature. 


\begin{tabular}{|c|c|c|c|}
\hline & 1577 & 1578 & 1579 \\
\hline Argent & 613 fr. 9 gr. & $540 \mathrm{fr}$. & 570 fr. I gr. \\
\hline Froment de cense & 2 b. I p. & 2 b. I p. & 2 b. I p. \\
\hline $\begin{array}{l}\text { de terrage } \\
\text { Avoine de cense }\end{array}$ & 35 b. I p. & 35 b. 4 é. & 29 b. $1 / 2$ p. \\
\hline de terrage & 64 b. I p. & 76 b. I é. I p & 69 b. 5 é. \\
\hline Vin & $\mathrm{I} 0 \mathrm{~m}$ & $13 \mathrm{~m} .3 \mathrm{~s}$. & $7 \mathrm{~m} .4 \mathrm{~s}$ \\
\hline $\begin{array}{l}\text { Divers (cire, gélines) } \\
\text { Évaluation en argent de }\end{array}$ & 29 fr. 10 gr.1/ & 247 fr. 2 gr. $1 / 2$ & 47 fr. 2 gr. $1 / 2$ \\
\hline $\begin{array}{l}\text { la valeur totale des pro- } \\
\text { duits en nature } 14\end{array}$ & ? 15 & 475 fr. 16 & $542 \mathrm{fr}$. \\
\hline $\begin{array}{l}\text { Évaluation en argent de } \\
\text { la recette brute totale } 17\end{array}$ & ? 18 & 1015 fr. 19 & $1112 \mathrm{fr}$. \\
\hline
\end{tabular}

14 Chiffre fictif, calculé d'après les prix de vente de l'année.

15 Ces deux chiffres sont en partie fictifs. Le compte de l'année n'indique pas les prix de vente des denrées; il donne seulement le chiffre global de vente des denrées portées au compte de la recette nette, soit 413 fr. ; le chiffre de 475 fr. que nous avons porté sur le tableau n'a donc qu'une valeur approximative ; de même, par conséquent, celui de 1015.

16 Les comptes de 1583 et de 1584 ne mentionnent aucune recette de vin en nature ; il résulte des indications qu'ils contiennent que les vignes du roi furent affermées ces deux années-là et rapportèrent, en 583,212 fr. et en 1584, 163 fr. Ces deux sommes sont à défalquer de la recette en argent, avec laquelle les comptes les confondent ; cette recette est dès lors de 526 fr. en 1583 et de 604 en 1584.

17 Chiffre fictif, obtenu en additionnant les recettes en argent à l'évaluation en argent de la valeur totale des produits en nature.

18 Ces deux chiffres sont en partie fictifs. Le compte de l'année n'indique pas les prix de vente des denrées ; il donne seulement le chiffre global de vente des denrées portées au compte de la recette nette, soit 413 fr. ; le chiffre de 475 fr. que nous avons porté sur le tableau n'a donc qu'une valeur approximative ; de même, par conséquent, celui de 1015.

19 Les comptes de 1583 et de 1584 ne mentionnent aucune recette de vin en nature ; il résulte des indications qu'ils contiennent que les vignes du roi furent affermées ces deux années-là et rapportèrent, en 583,212 fr. et en 1584, 163 fr. Ces deux sommes sont à défalquer de la recette en argent, avec laquelle les comptes les confondent ; cette recette est dès lors de 526 fr. en 1583 et de 604 en 1584 . 


\begin{tabular}{|c|c|c|c|}
\hline & 1580 & 1581 & 1582 \\
\hline Argent & 726 fr. 5 gr. & 840 fr. I gr. & 762 fr. 2 gr. \\
\hline Froment de cense & 2 b. I p. & 2 b. I p. & 2 b.. I p. \\
\hline de terrage & 34 b. 4 é. & 37 b. 2 é. & 33 b. 2 é. \\
\hline Avoine de cense & " & " & " \\
\hline de terrage & 71 b. 3é. I p. & 70 b. I é. I p.1/4 & 74 b. I p. \\
\hline Vin & $16 \mathrm{~m} .10 \mathrm{~s}$. & $20 \mathrm{~m} .6 \mathrm{~s}$. & $10 \mathrm{~m} .9 \mathrm{~s}$ \\
\hline $\begin{array}{l}\text { Divers (cire, géli- } \\
\text { nes) }\end{array}$ & 47 fr. 2 gr. $1 / 2$ & 47 fr. 2 gr. $1 / 2$ & 47 fr. 22 gr. $1 / 2$ \\
\hline $\begin{array}{l}\text { Évaluation en } \\
\text { argent de la valeur } \\
\text { totale des produits } \\
\text { en nature } 20\end{array}$ & $750 \mathrm{fr}$. & $1125 \mathrm{fr}$. & $523 \mathrm{fr}$. \\
\hline $\begin{array}{l}\text { Évaluation en } \\
\text { argent de la recet- } \\
\text { te brute totale } 21\end{array}$ & $1476 \mathrm{fr}$. & $1695 \mathrm{fr}$. & $1285 \mathrm{fr}$. \\
\hline
\end{tabular}

20 Chiffre fictif, calculé d'après les prix de vente de l'année.

21 Chiffre fictif, obtenu en additionnant les recettes en argent à l'évaluation en argent de la valeur totale des produits en nature. 


\begin{tabular}{|c|c|c|}
\hline & 1583 & 1584 \\
\hline Argent & 738 fr. 10 gr. & $767 \mathrm{fr}$. \\
\hline Froment de cense & 2 b. I p. & 2 b. I p. \\
\hline de terrage & 35 b. I p. & 38 b. 3 é. \\
\hline Avoine de cense & " & " \\
\hline de terrage & 68 b. 4 é. & 67 b.3 p.1/2 \\
\hline Vin & ? 22 & ? 23 \\
\hline Divers (cire, gélines) & 47 fr. 2 gr. $1 / 2$ & 47 fr. 2 gr. $1 / 2$ \\
\hline $\begin{array}{l}\text { Évaluation en argent de } \\
\text { la valeur totale des pro- } \\
\text { duits en nature } 24\end{array}$ & 638 fr. 4 gr. $1 / 2$ & $627 \mathrm{fr}$. \\
\hline $\begin{array}{l}\text { Évaluation en argent de } \\
\text { la recette brute totale } 25\end{array}$ & 1165 fr. 2 gr. $1 / 2$ & $1231 \mathrm{fr}$. \\
\hline
\end{tabular}

22 Les comptes de 1583 et de 1584 ne mentionnent aucune recette de vin en nature ; il résulte des indications qu'ils contiennent que les vignes du roi furent affermées ces deux années-là et rapportèrent, en 583,212 fr. et en 1584, 163 fr. Ces deux sommes sont à défalquer de la recette en argent, avec laquelle les comptes les confondent ; cette recette est dès lors de 526 fr. en 1583 et de 604 en 1584 .

23 Les comptes de 1583 et de 1584 ne mentionnent aucune recette de vin en nature ; il résulte des indications qu'ils contiennent que les vignes du roi furent affermées ces deux années-là et rapportèrent, en 583,212 fr. et en 1584, 163 fr. Ces deux sommes sont à défalquer de la recette en argent, avec laquelle les comptes les confondent ; cette recette est dès lors de 526 fr. en 1583 et de 604 en 1584.

24 Chiffre fictif, calculé d'après les prix de vente de l'année.

25 Chiffre fictif, obtenu en additionnant les recettes en argent à l'évaluation en argent de la valeur totale des produits en nature. 
TABLEAU II - Recettes nettes, les dépenses défalquées

\begin{tabular}{|c|c|c|c|}
\hline & 1574 & 1575 & 1576 \\
\hline Argent & $700 \mathrm{fr}$. & $417 \mathrm{fr}$. & $133 \mathrm{fr}$. \\
\hline Froment de cense & 2 b. $1 / 2 \mathrm{p}$ & 2 b. I p. & 2 b. I p. \\
\hline de terrage & 29 b. 4 é. I p. $1 / 2$ & 27 b. 2 é. $1 / 2$ & 22 b. I p. $1 / 2$ \\
\hline Avoine & 63 b. 2 é. 1/2 I/4 p. & 63 b. 4 é. & 64b. 5 é. \\
\hline Vin & $16 \mathrm{~m}$ & 15 m. $12 \mathrm{~s}$. & $8 \mathrm{~m}$. \\
\hline Divers & 25 fr. 6 gr. & 25 fr. 6 gr. & 25 fr. 6 gr. \\
\hline $\begin{array}{l}\text { Produit des ventes } \\
\text { réelles } 26\end{array}$ & $1270 \mathrm{fr}$. & $464 \mathrm{fr}$. & $385 \mathrm{fr}$. \\
\hline Revenu net total & $1970 \mathrm{fr}$. & $881 \mathrm{fr}$. & $518 \mathrm{fr}$. \\
\hline
\end{tabular}

\begin{tabular}{|c|c|c|c|}
\hline & 1577 & 1578 & 1579 \\
\hline Argent & 389 fr. & $414 \mathrm{fr}$ & $195 \mathrm{fr}$. \\
\hline Froment de cense & 2 b. I p. & 2 b. I p. & 2 b. I p. \\
\hline de terrage & 2 b. 3 é. I p. & 28 b. 4 é. & 23 b. $1 / 2$ p. \\
\hline Avoine & 34 b. I p. & 72 b. I é. I p. & 65 b.1/2 p. \\
\hline Vin & $9 \mathrm{~s}$. & 12 m. 12 s. & $7 \mathrm{m.l} \mathrm{s.}$ \\
\hline Divers & 29 fr. 3 gr. & 46 fr. 7 gr. & 46 fr. 7 gr. \\
\hline $\begin{array}{l}\text { Produit des ventes } \\
\text { réelles } 27\end{array}$ & $97 \mathrm{fr}$. & $459 \mathrm{fr}$. & $513 \mathrm{fr}$. \\
\hline Revenu net total & $486 \mathrm{fr}$. & $873 \mathrm{fr}$. & $708 \mathrm{fr}$. \\
\hline
\end{tabular}

26 Chiffre réel, dont les éléments se trouvent dans les comptes.

27 Chiffre réel, dont les éléments se trouvent dans les comptes. 


\begin{tabular}{|c|c|c|c|}
\hline & 1580 & 1581 & 1582 \\
\hline Argent & $534 \mathrm{fr}$. & $651 \mathrm{fr}$. & $518 \mathrm{fr}$. \\
\hline Froment de cense & 2 b. I p. & 2 b. I p. & 2 b. I p. \\
\hline de terrage & 28 b. 3 é. $1 / 2$ & 31 b. 2 é. $1 / 2$ & 30 b. 2 é. \\
\hline Avoine & 67 b. 4 é. & 66 b. 2 é. $1 / 2$ & 70 b. I p. \\
\hline Vin & $16 \mathrm{~m} .2 \mathrm{~s}$. & 19 m. $10 \mathrm{~s}$. & $10 \mathrm{~m}$. \\
\hline Divers & 46 fr. 7 gr. & 46 fr. 7 gr. & 46 fr. 7 gr. \\
\hline $\begin{array}{l}\text { Produit des ventes } \\
\text { réelles } 28\end{array}$ & $690 \mathrm{fr}$. & 1077 fr. & $535 \mathrm{fr}$. \\
\hline \multirow[t]{2}{*}{ Revenu net total } & $1224 \mathrm{fr}$. & $1728 \mathrm{fr}$. & $1053 \mathrm{fr}$. \\
\hline & & 1583 & 1584 \\
\hline \multicolumn{2}{|l|}{ Argent } & $498 \mathrm{fr}$. & $568 \mathrm{fr}$. \\
\hline \multirow{2}{*}{\multicolumn{2}{|c|}{$\begin{array}{r}\text { Froment de cense } \\
\text { de terrage }\end{array}$}} & 2 b. I p. & 2 b. I p. \\
\hline & & 28 b. I p. & 32 b. 4 é. \\
\hline \multicolumn{2}{|l|}{ Avoine } & 64 b. 4 é. & 63 b. 3 p. $1 / 2$ \\
\hline \multicolumn{2}{|l|}{ Vin } & & \\
\hline \multicolumn{2}{|c|}{ Divers } & 46 fr. 7 gr. & 46 fr. 7 gr. \\
\hline \multicolumn{2}{|c|}{ Produit des ventes réelles 29} & 327 fr. 6 gr. 30 & 415 fr. 31 \\
\hline \multicolumn{2}{|l|}{ Revenu net total } & $825 \mathrm{fr}$. & $983 \mathrm{fr}$. \\
\hline
\end{tabular}

28 Chiffre réel, dont les éléments se trouvent dans les comptes.

29 Chiffre réel, dont les éléments se trouvent dans les comptes.

30 Pour comparer utilement ces chiffres à ceux des années précédentes, il faudrait y ajouter les 212 fr. et les 163 fr. qui proviennent de l'amodiation des vignes - ou du moins leur reliquat, défalcation faite des dépenses. Ces sommes, par contre, seraient à déduire de la recette nette d'argent pour ces deux années.

31 Pour comparer utilement ces chiffres à ceux des années précédentes, il faudrait y ajouter les 212 fr. et les 163 fr. qui proviennent de l'amodiation des vignes - ou du moins leur reliquat, défalcation faite des dépenses. Ces sommes, par contre, seraient à déduire de la recette nette d'argent pour ces deux années. 
TABLEAU III. - Prix de vente réels des produits en nature

\begin{tabular}{|c|c|c|c|}
\hline & 1574 & 1575 & 1576 \\
\hline $\begin{array}{l}\text { Froment de cense } \\
\text { de terrage } \\
\text { Avoine } \\
\text { Vin }\end{array}$ & $\begin{array}{l}\text { " } \\
16 \text { gr. 1/2 l'é. } \\
17 \text { bl. I engr. l'é. } \\
23 \text { fr. I gr. le m. }\end{array}$ & $\begin{array}{l}\quad \text { " } \\
9 \text { gr. } 3 \text { bl. } \\
18 \text { bl. I gr. } \\
10 \text { fr. I gr. }\end{array}$ & $\begin{array}{l}\text { 9gr. } \\
3 \text { gr. I bl. } \\
16 \text { fr. } 1 / 2\end{array}$ \\
\hline & 1577 & 1578 & 1579 \\
\hline $\begin{array}{l}\text { Froment de cense } \\
\text { de terrage } \\
\text { Avoine } \\
\text { Vin }\end{array}$ & $\begin{array}{l}\text { " } \\
? \\
? \\
?\end{array}$ & $\begin{array}{l}" \\
? \\
? \\
?\end{array}$ & $\begin{array}{l}44 \text { gr. l'é. } \\
4 \text { gr. l'é. } \\
5 \text { gr.I bl. } \\
15 \text { fr. } 1 / 2\end{array}$ \\
\hline & 1580 & 1581 & 1582 \\
\hline $\begin{array}{l}\text { Froment de cense } \\
\text { de terrage } \\
\text { Avoine } \\
\text { Vin }\end{array}$ & $\begin{array}{l}15 \text { gr. I bl. } \\
14 \text { gr. } 1 / 2 \\
5 \text { gr. } \\
15 \text { fr. }\end{array}$ & $\begin{array}{l}22 \text { gr. } \\
9 \text { gr. } \\
10 \text { gr. } \\
16 \text { fr. }\end{array}$ & $\begin{array}{l}15 \text { gr. } \\
10 \text { gr. } \\
4 \text { gr. I bl. } \\
11 \text { fr. I gr. }\end{array}$ \\
\hline & & 1583 & 1584 \\
\hline $\begin{array}{l}\text { Froment de cense } \\
\text { de terrage } \\
\text { Avoine } \\
\text { Vin }\end{array}$ & & $\begin{array}{l}15 \text { gr. } \\
12 \text { gr. 1/2 } \\
4 \text { gr. }\end{array}$ & $\begin{array}{l}15 \text { gr. } \\
13 \text { gr. } 3 \text { bl. } \\
15 \text { bl. I engr. } \\
\text { ? }\end{array}$ \\
\hline
\end{tabular}


Le premier tableau indique les recettes brutes. Nous avons calculé, pour mieux fixer les idées, ce que pouvaient valoir en argent, aux cours de l'année, les denrées perçues; le chiffre obtenu ainsi est un chiffre fictif, puisque toutes les denrées n'étaient pas vendues chaque année ; tel quel, il permet d'utiles constatations. Les variations du revenu annuel ne sont pas, pour ainsi dire, quantitatives. A très peu près, en 1574, le receveur d'Arguel emmagasine autant d'avoine, de froment, de vin, de cire, de gélines qu'en 1575 ; mais ce qui vaut 1345 fr. en 1574 n'en vaut que 510 en 1575 ; rien d'étonnant dès lors à ce que la recette brute puisse être évaluée 2169 fr. dans le premier cas et 1161 dans le second. C'est le milieu économique, non la seigneurie, qui se transforme.

Tous ces chiffres ainsi - auxquels, nous le répétons, nous n'attribuons pas de valeur absolue, mais que nous citons seulement à titre d'exemples et d'illustrations - ramènent à l'envi les mêmes conclusions. Pour personne, au XVIe siècle, mais pour le noble moins que pour tout autre, la seigneurie n'est, ne saurait être un instrument de fortune, un moyen d'enrichissement. Par l'industrie au contraire, par le commerce et la finance, des fortunes se créent, des richesses s'accumulent. Le prix de la vie, cependant, s'élève de plus en plus. Réduit au revenu de ses terres, le noble, dans ce mouvement général, dans cette universelle ascension vers la fortune, reste immobile, stationnaire - donc déchoit. Il assiste, impuissant, à la dislocation, à la destruction lente du vieux système d'exploitation domanial qui fit jadis la grandeur et la fortune de ses ancêtres - qui pèse sur lui maintenant et l'écrase, de tout le poids d'une chose morte, d'un mécanisme usé. 
PHILIPPE II ET LA FRANCHE-COMTÉ

Étude d'histoire politique, religieuse et sociale.

Deuxième partie. Les débuts du règne de Philippe II

\section{Chapitre VIII}

\section{Les sources de la fortune bourgeoise : le commerce, l'usure, la conquête de la terre paysanne}

$\underline{\text { Retour à la table des matières }}$

Ainsi, la noblesse féodale déclinait. Tandis que, sans vouloir toujours se l'avouer, elle sentait lui échapper charges, faveurs et richesses, un peuple d'hommes nouveaux, acharnés au labeur, âpres et subtils au gain, s'élevait peu à peu et, par l'argent, se hissait au pouvoir. De cette ascension, suivons les étapes.

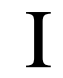

À l'homme qui n'avait rien, que la convoitise ardente de la richesse, deux moyens de fortune s'offraient, les plus rapides : le commerce et l'usure. À eux recourait la masse des gagne-petit en marche vers les sommets.

Au commerce d'abord, et non pas au commerce sédentaire, réglé, spécialisé déjà et contrôlé, qu'en leurs boutiques des villes et des villages pratiquaient merciers, drapiers ou bouchers. Commerce rémunérateur sans doute, à une époque de paix et de renaissance économique : mais d'abord, son exercice supposait une aisance préalable que tout le monde n'avait pas. Bouchers, merciers, drapiers étaient 
des maîtres, non de simples ouvriers. Il leur fallait de l'argent pour monter boutique, acquitter les droits, entrer dans la confrérie de leur métier, se faire agréer par les maîtres établis. Ceux-ci tendaient, en effet, soit à s'organiser en métier juré, soit du moins à surajouter leur autorité à celle des officiers locaux chargés des règlements. Tels, par exemple, les bouchers. Leur métier était libre, presque partout, mais s'exerçait sous le contrôle des seigneurs ou des municipalités. Or, les textes nous les montrent, groupés et coalisés, s'efforçant d'en interdire la pratique à tous les nouveaux venus. Voici ceux de Jussey en 1537 : « Enrichis grandement par le moyen de leur boucherie », ils prétendent, dit une requête, empêcher tous autres de s'établir, « si premièrement ilz ne sont à par eulx receuz avec serrement, à grosses sommes, comme de 50 ou 60 fr. »; c'est-à-dire qu'en cherchant à se constituer en métier juré de type classique, ils s'efforcent d'établir le monopole de la vente à leur profit. Voici ceux de Lons, en 1573 : des nouveaux concurrents admis par le châtelain, ils exigent un banquet si somptueux que le récipiendaire ne s'en tire à moins de 25 fr. : "Chose très exhorbitante », dit le procureur Tubet, « et à raison de laquelle plusieurs n'osaient avancer d'être de leur métier ». Mêmes faits à Gray, où un règlement devient nécessaire en 1563 ; à Dole, où il faut, en 1562, interdire aux maîtres de rien percevoir « pour nouvelle création »; à Salins, dont les détaillants demandent au souverain, en 1589, " d'anéantir » une des trois boucheries de la cité et de leur donner « en arrentement ou assencement perpétuel, pour eux, leurs hoirs et ayans causes, les bancs, taules et places » des deux établissements conservés ; à Port-sur-Saône enfin, dont il faut poursuivre, en 1553, les bouchers coalisés pour « indeues conventions, monopoles, entreprises contre les auteurs de S. M. », ou, de nouveau, à Jussey, dont les bouchers réclament, en 1589, l'interdiction pour les paysans de mettre chair en vente, à peine de 50 livres. En vain, contre ces prétentions, le Parlement s'insurge et prétend sauvegarder la liberté commerciale : moeurs, usages, exemptions de droits aux fils, aux veuves des maîtres, tout pousse, tout tend au monopole ; la vie est la plus forte et les métiers se ferment.

Pour le plus grand profit des maîtres eux-mêmes ? C'est une question. Ne devaient-ils pas s'endormir, s'engourdir dans la certitude de leur gain assuré, consolidé par le monopole ? A Lons, d'après nos textes, les bouchers - ils étaient sept ou huit - s'entendaient par serment, « suyvantz certains statuz qu'ils disoient avoir en leurd. confrérie, pour faire prix et taux de leur chair entre eulx, laquelle ilz ache- 
toient le plus souvent par ensemble - de manière qu'il convenoit passer par leurs mains ». A Jussey de même, aux jours de marché, les bouchers ne tuaient «que quelque meschant vaiche, veaul maigre ou vielles brebis », et par commune entente, tant qu'il restait de la viande à l'un d'eux, « les aultres n'en osaient tuer ni vendre ». Procédés ingénus et mesquins, peu faits pour amener un accroissement des ventes, un essor puissant des entreprises individuelles : par la «marchandise », non par eux, se créaient alors, de rien, les fortunes.

Le marchand : c'était l'intermédiaire actif qui ne se contentait pas de débiter sur place une catégorie de produits particuliers. Libre de son temps et de son initiative, insoucieux des règles et des prohibitions, il vendait de tout, successivement ou simultanément, au hasard des rencontres et des occasions. Marchand de bois aujourd'hui, demain courtier en fer, acheteur de filés dans le pays bressan ou vendeur de farine dans la haute montagne, toujours en route et en éveil, courant sur son bidet les foires et les marchés, il n'attendait pas la fortune en dormant. Entrer en relation avec les campagnards frustes et pressés d'argent, leur enlever à bas prix ce qu'ils possédaient et le revendre ensuite, soit aux consommateurs, soit aux metteurs en oeuvre : fourreurs, tisserands, tanneurs - soit, mieux encore, à des intermédiaires plus riches, concentrant entre leurs mains avides de grands monopoleurs la récolte patiente des menus «d'ordinaires », - tel était le secret de ses opérations. Tout lui était bon : grains, vins, viandes, beurres et fromages, fourrures et peaux, le suif des chandelles ou la cire des cierges. Contre ses agissements, sans se lasser, le Parlement publie des édits et provoque des enquêtes - vaines, mais instructives. Voici, de 1576, une série de dépositions sur la vente des cuirs et des souliers. La cause des hauts prix ? l'accaparement. Accapareurs, les charretiers qui courent la campagne, menant par les grandes routes leurs convois de blé ou de sel de Salins ; aux paysans, ils achètent les peaux brutes, puis les revendent à plus gros qu'eux. Accapareurs, les bouchers qui conservent dans le sel leurs cuirs crus, pour les passer à des intermédiaires qui, à leur tour, spéculeront dessus. Accapareurs enfin, les tanneurs, ou du moins les plus riches : ils font pacte d'avance avec les bouchers et leur achètent en bloc toutes les peaux d'une année.

Ce qui est vrai des cuirs l'est des filés. Une foule de personnages actifs, industrieux, parcourent, aux époques convenables, les villages de la Comté du Sud, aux quartiers d'Arinthod et de Fétigny, achètent fils et toiles en grande quantité et les exportent vers la Bresse ou Lyon. Même chose pour l'huile, le salpêtre, le bois, le 
suif, le grain ; dans toutes les villes, dans toutes les classes, c'est une rage véritable de spéculation ; il n'est ruse ni fraude dont les comtois ne s'avisent pour tourner les édits et « prouffiter » quand même. Lorsque, par leurs soins, tout est épuisé ; lorsque dans les campagnes, aux mains des paysans, il ne reste rien dont on puisse trafiquer - alors, suprême ressource, ils accaparent l'argent; à la fin des foires, contre le méchant billon des pays étrangers, ils échangent sans vergogne la bonne monnaie comtoise.

Arrivaient-ils ainsi à de très grosses fortunes ? Certes, les avantages ne leur manquaient pas. La Comté, nous l'avons vu, n'était pas mal située. A ses portes, trois grosses villes, trois places commerciales : Bâle, Lyon, Genève. Aux frontières, des pays aux besoins variés : France, Lorraine, Savoie, plaine du Rhin et de Suisse. Sur son territoire même, des routes fréquentées vers l'Italie lointaine, la plaine du Rhône ou la haute Allemagne ; à Besançon, à Poligny parfois, à Dole même, des banquiers italiens ou allemands facilitant les transactions lointaines. Mais peu d'importations et peu d'exportations - rien ne prévalait là contre. À Besançon, sans doute, à Salins, à Dole, à Gray, des marchands prospéraient - les uns plus sédentaires, les autres plus mobiles : nul qui réalisât dans sa petite province une de ces fortunes colossales, triomphantes, qui mettaient hors de pair les rois de la finance à Augsbourg, à Gênes, à Lyon, à Anvers. Qu'importe ? Dans la médiocre et moyenne Comté, les fortunes des nobles aussi étaient modestes. Et ce qu'il faut noter, ce qui nous intéresse - ce qui inquiétait les seigneurs du temps -, ce n'était pas la réussite exceptionnelle de quelques-uns, mais l'effort collectif, l'effort puissant et multiple de toute une classe, amassant sou à sou des richesses patientes - et par le trafic, mais par l'usure aussi, se taillant peu à peu sa place au soleil.

\section{II}

D'un tel effort, la victime était le paysan. Lui qui, déjà, faisait vivre le noble, il créait encore la richesse du bourgeois ; deux classes superposées profitaient de son labeur - et la plus proche l'accablait le plus. 
C'est que, dans une société où sans cesse croissait le rôle et le pouvoir de l'argent, le paysan restait démuni de numéraire ${ }^{32}$. Petit cultivateur, il lui fallait sur sa récolte annuelle, une fois prélevé le blé du pain et des semailles, payer les redevances au seigneur, au curé. Les rendements restant faibles, l'année, par surcroît, n'était-elle que médiocre ? A acquitter la dîme, les droits domaniaux, le don gratuit et les dépenses de la communauté, toute sa récolte échappait au laboureur ; parfois, même, il se trouvait manquer de grain pour son hiver. Or, ses ressources n'étaient pas variées. Riverain de la Loue, sa fortune reposait sur la vigne. Bressan, son existence dépendait du gland. La grêle frappait-elle le vignoble ? La glandée manquait-elle ? Point de compensation possible ; c'était la misère totale, immédiate. Pour y parer, deux moyens - deux seulement : une vente, un emprunt. Le paysan emprunte ; c'est la première étape

Parfois, c'est au village qu'il trouve son préteur. Tous les cultivateurs ne sont pas misérables. Quelques-uns possèdent de vastes exploitations, des troupeaux à eux - parfois, au lendemain des foires, un petit sac d'écus. Contre bonnes garanties, ils le prêtent et le mettent en travail. Dans leurs demandes d'affranchissement, en 1582, les mainmortables de Chalon indiquent souvent leurs dettes ; les motifs en sont simples et toujours les mêmes : achat de grain, de bétail ou d'herbe. Or, pour les petites sommes, beaucoup de créanciers sont des paysans du village ou des pays voisins. Mais, quand le chiffre s'élève, c'est à la ville, au marché le plus proche que le cultivateur s'adresse pour emprunter. Il y connaît du monde : des notaires, des gens de loi, d'usage fréquent à une époque et dans un pays de chicane; des bourgeois aussi, possesseurs au village de quelque domaine; des marchands enfin. Il s'adresse à eux - et ils l'accueillent bien : c'est un profit certain qui vient les trouver. Que demande l'emprunteur ? Deux choses : un peu de grain pour finir son hiver ou commencer les semailles ; un peu d'argent pour faire face à ses charges, à ses paiements urgents. Dans la maison où il frappe, le paysan trouve l'un et l'autre - parce que le bourgeois se procure l'un par l'autre.

Le prêt à intérêt demeure en effet prohibé. C'est par simple prêt sur obligation ou, le plus souvent, par constitution de rente que l'argent se cède et se met en travail. Or, du paysan, le citadin aisé ne peut guère exiger une rente à prix d'argent -

32 La transformation même des redevances en nature en redevances pécuniaires ce progrès - augmentait les besoins d'argent du laboureur. 
puisque, précisément, l'argent lui manque. Plus ordinairement, on constitue la rente en nature : le paysan se fait avancer une somme contre versement annuel d'une quantité de blé, d'avoine, de seigle, de vin parfois ou de fromage. Le tout vient s'entasser dans les greniers des villes, y former ces « amas » que dénoncent si souvent les ordonnances du temps: gardées soigneusement en prévision des mauvaises années, les denrées trouveront alors des débouchés rémunérateurs ; d'ailleurs, contre bons écus sonnants ou nouvel engagement, le paysan pourra toujours en obtenir quand la misère, derechef, viendra peser sur lui. - Voilà la théorie : il faut voir la pratique. Il faut saisir sur le vif, à l'aide de faits concrets et d'exemples réels, les agissements coutumiers des prêteurs en quête de profits, en mal de fortune.

Loyalement, honnêtement pratiqués, les achats de rentes constituées à prix d'argent pouvaient procurer d'appréciables bénéfices. Le taux normal pour de tels placements variait, en effet, de 12 1/2 à 16,66\%. Peu de risques : contre son débiteur rustique, le créancier n'était pas dénué de garanties. Connaissant le droit et la procédure, il avait à son service, outre les gens de loi, la loi elle-même, civile et ecclésiastique - puisque l'Église mettait l'excommunication au service des préteurs. D'autre part, un édit d'avril 1530, pour parer aux abus des rentes en nature, avait établi un prix légal pour la mesure de froment, de seigle, d'orge, d'avoine et de vin, fixé à 10 \% le taux des intérêts exigibles dans l'avenir, et permis la réduction sur ces bases des rentes constituées à un taux supérieur. La législation laissait, comme on voit, aux prêteurs la possibilité d'assez beaux bénéfices ; leurs abus leur en assuraient d'autres, et de plus enviables.

Remettre 100 fr. à un cultivateur, mais le faire s'obliger pour 120 ; le contraindre en même temps, comme condition du prêt, à acheter des denrées à un prix majoré ; vendre au taux le plus exorbitant des prolongations de terme chichement mesurées : ces pratiques étaient courantes, d'innombrables dossiers judiciaires l'attestent. Veut-on quelques exemples ? Voici, en 1532, cité devant la cour, Claude Pelissonnier d'Arlay : il est allé jusqu'à séquestrer un débiteur : dix livres d'amende seulement, vu son ignorance. Jean Vuillet, boucher de Pontarlier, pour des prêts de six mois, n'exige pas moins de 2 gros par franc - soit 20 \% d'intérêt ; en plus, il vend à ses débiteurs du bétail à double prix : amende de 3 000 livres et restitutions. François Monnier, du Russey, prête 11 fr. à Antoine Poillevay, qui ne le rembourse pas au jour dit : Monnier lui prend 3 fr. et quatre 
peaux en valeur de 6 fr., tout en portant son compte de 11 à $14 \mathrm{fr}$. Au nouveau terme, Poillevay ne peut payer ses 14 francs: deuxième prolongation, mais, «pour l'attente », Monnier s'empare de 18 gros et d'un chapeau : la dette sans doute aurait continué de s'accroître si 20 livres d'amende n'étaient venues rappeler à l'ordre le créancier. Toujours et partout les mêmes faits, réédités à d'innombrables exemplaires. Jacques Disse de Saint-Oyan, quand il prête 100 fr. à un paysan, le fait s'obliger à en rendre 120 dans le délai d'un an : à défaut, 20 fr. par année de retard. Un homme de Septmoncel tenait de lui 30 fr. : deux années durant, il en exigea 12 fr. d'intérêt. S'il prêtait 130 fr., l'emprunteur devait en reconnaître 165, et chaque année en payer 24 pour l'intérêt. Plus subtil encore, François Malarmey dit Mercerot. D'abord, il n'était pas si sot que de rendre aux débiteurs leurs obligations, encore qu'acquittées : il courait chance ainsi de se faire payer deux fois, si décret se faisait sur eux. Donnait-il 100 fr. à rente ? il retenait 2 écus sur la somme : c'était, expliquait-il, « par coustume à lui particulière... et pour espingles ou chapperon pour sa femme ». Et c'était encore pour les « espinglés de sa femme », qu'ayant donné à rente à un homme du Bizot $100 \mathrm{fr}$. à $8 \%$, ce mari galant le contraignait d'abord à payer 2 écus ; mais il n'oubliait pas sa propre garde-robe : sur 100 fr. laissés à $8 \%$ à un homme de Vercel, il en retenait 4, alléguant sans vergogne «que c'estoit pour avoir une paire de chaulces, et qu'il failloit que son argent luy proffitast de quelque chose ».

Ainsi se constituaient les rentes en argent. Mais les rentes en nature ? L'édit d'avril I530 avait stipulé que, dorénavant, les arrérages des rentes constituées en froment et en blé seraient payables en argent au taux de $10 \%$, et peu après, en 1553, sur requête du procureur fiscal d'Aval, Hugues Colin, il avait été décidé par la cour que dans le bailliage d'Aval, au ressort de Pontarlier, « consistant en pays froit et stérile, auquel à difficulté l'on peut semer et recueillir froment » et où par conséquent « les orges et avenne se vendoient à hault pris », le taux serait abaissé à $8 \%$. C'est-à-dire - on ne saurait être trop clair en pareille question - qu'un prêteur ayant avancé, par exemple, une somme de $100 \mathrm{fr}$, à deux paysans, l'un du bailliage d'Amont, l'autre de la Montagne, moyennant le paiement chaque année, sous forme de rente, d'une même quantité de froment - ses deux débiteurs étaient autorisés à cesser de lui livrer ce froment et à lui payer en échange tous les ans, l'un, l'homme de la plaine, $10 \mathrm{fr}$; l l'autre, le montagnon $8 \mathrm{fr}$. S'ils préféraient d'ailleurs s'acquitter en nature, libre à eux ; mais leurs redevances devraient être 
calculées, dans ce cas, en se basant sur les prix officiels, aux mêmes taux de 10 et $8 \%$.

Seulement, comme il convient, les prêteurs s'ingénièrent à tourner la loi. Il était défendu au bailliage de Pontarlier de constituer des rentes d'orge et d'avoine à haut taux que de $8 \%$. Mais l'édit ne parlait pas de rentes de seigle - et pour cause : dans la montagne, le seigle était inconnu ; il n'y croissait que « du gros bled, mi-froment, mi-greu, pesettes et soille ». On baptisait seigle le mélange en question et tout était dit : on pouvait constituer, devant le silence des textes, des rentes en seigle. En novembre 1563, la cour les interdit. Nouveau subterfuge des prêteurs : on se mit à constituer des rentes « pour pris d'argent en huile, vin, fromages, beurre, marron à paisseler vignes, charrées de bois à brûler et aultres semblables choses et danrées » en quoi s'exerçait, au dire des officiers d'Aval, "plus grande usure et interestz ausd. subjectz que ne faisaient esd. rentes de bled ». Il fallut procéder à leur égard comme pour les rentes de grains et les rendre perpétuellement rachetables « en rendant pour les débiteurs aux créanciers les sortz principaulx, arreraiges et fraiz raisonnables ».

En vain ! La fraude toujours reparaissait et trouvait moyen de s'exercer. Pour une poursuite engagée, pour un usurier condamné, que d'autres continuaient, des années durant, leur trafic criminel ! C'étaient des spéculations sur les récoltes en pied, « les blés en herbe » achetés à vil prix aux malheureux paysans à court d'argent et revendus cinq ou six fois de suite par des intermédiaires de plus en plus rapaces ; c'étaient, malgré les édits, des arrérages énormes en nature exigés pour des prêts minimes; ou, dans la Montagne, de curieux trafics sur les fromages. Voici par exemple un ingénieux habitant de Saint-Claude, Regnaud Michault. Un habitant de Montépile lui doit 30 fr. ; qu'il lui livre, à la Saint-Denis prochaine, huit quintaux de froment et il sera quitte : les huit quintaux valaient dans les $40 \mathrm{fr}$. La Saint-Denis arrivée, l'homme ne s'acquitte pas. Michault prolonge son terme, le reporte à la Nativité Notre-Dame, mais en réclamant pour sa peine trois nouveaux quintaux. Vient la Nativité ; toujours pas de paiement : Michault alors « fait brisée » des trois derniers quintaux à la somme de 24 fr., contraint son débiteur de la lui payer comptant, et moyennant ce léger acompte, prolonge l'échéance des huit quintaux restants jusqu'à l'autre Saint-Denis. Toujours pas de paiement : il « brise » derechef le fromage à 74 fr., en reçoit 24 comptant et pour les 50 autres 
fait s'obliger l'homme de Montépile à terme d'un an : l'exploitation recommence et se perpétue sans trêve...

Exemple typique : nous ne l'avons pas choisi parce que rare et singulier, mais pris au hasard parmi cent analogues. Toute dette s'éternisait et vraiment malchanceux ceux qui, dans de telles conditions, ayant fait un prêt n'en retiraient pas deux ou trois fois le montant. Qu'on ne pense pas, surtout, qu'il s'agit d'exceptions d'usures extraordinaires provoquant des poursuites par leur énormité. Outre que, en se tenant dans les limites légales, on pouvait réaliser d'assez jolis bénéfices - le nombre même des poursuites nous est une preuve de la fréquence, de la généralité de telles pratiques. Il fallut, en 1584, publier contre les usuriers un édit général, « rafraîchissant » toutes les mesures antérieures et dont copies furent adressées à tous les curés pour publication au prône ; il fallut à diverses reprises et notamment en 1596, au lendemain des ravages de Henri IV, protéger les pauvres gens contre la férocité de leurs créanciers acharnés à saisir leurs grains et leurs bestiaux ; et rien de plus parlant, de plus significatif que le ton de certaines suppliques et requêtes adressées au roi, ensuite de poursuites, par des usuriers notoires - condamnés, alors que cependant, comme ils le constatent avec quelque étonnement, « doiz leurs jeunes eaiges, et que raison leur a commandé, ilz se sont esvertuez vivre en gens de bien sans avoir donné occasion à personne se plaindre d'eulx ». Il est vrai que « leur à la fortune esté si prospère qu'ilz ont par travail et administration de leurs biens anciens augmenté icelluy, de quoy sont esté envieulx aucuns » : et voilà la raison de leurs mésaventures...

De telles pratiques, du reste, ne sont pas le monopole d'une classe particulière de prêteurs ou de spéculateurs. Le numéraire est rare encore, relativement - plus rare dans une petite Comté que dans une vaste France. La demande est forte d'autre part: aussi, tout l'argent disponible travaille-t-il, au plus haut prix possible. C'est une souffrance pour qui possède quelques écus d'or, quelques thalers ou quelques ducats de les sentir oisifs, infructueux au fond d'un coffre cadenassé ; c'est une obligation, presque un devoir de conscience de les mettre à louage, de leur faire produire d'autre or et d'autre argent ; grosses ou petites, infimes ou colossales, toutes les fortunes se mobilisent - et l'on voit des filles de chambre, des domestiques dont les économies ne montent pas à cent francs, n'en point garder un sol vaillant par-devers elles : tout est placé, tout travaille, tout court le monde et porte intérêt. 
Ce n'étaient pas quelques spécialistes avisés et retors - mais toute une classe, toute la bourgeoisie urbaine et campagnarde, des petits patrons artisans aux gros marchands accapareurs, des simples sergents et des humbles huissiers aux notaires, aux procureurs et aux gens du roi, qui fondait sur la misère paysanne l'édifice laborieux et patient de sa fortune.

\section{III}

Tout s'enchaîne d'ailleurs. On commence timidement par des prêts, par des achats de rente en argent, en nature : et l'on se trouve un jour, presque sans effort, avoir à sa merci la propriété paysanne elle-même.

Pour le cultivateur vivant au jour le jour, sans avances, sans réserves, sans numéraire ni moyen de s'en procurer - qui sait ce qu'était le prêt devine aisément ce que devait être l'emprunt. Même s'il avait eu le bonheur d'échapper aux hommes de proie qui le guettaient ; même s'il était adressé à des gens soucieux des édits, la situation du débiteur était singulièrement dangereuse, pour peu que le prêt fût de quelque importance. Ou bien, peu à peu, le fardeau des rentes qu'il devait constituer pour faire face à ses besoins l'écrasait et paralysait son action ; ou bien, s'il avait emprunté avec clause de restitution à court terme, quelque accident fâcheux, quelque « orvale » imprévue venait brutalement détruire ses calculs et ses espérances : c'était la remise rendue nécessaire, et jamais accordée sans accroissement de charge. Lentement ainsi, progressivement, la propriété paysanne se couvrait de dettes ; chargée d'hypothèques, accablée de rentes, à la moindre secousse, au premier heurt, elle se détachait, tombait comme un fruit mûr.

Secousses fréquentes d'ailleurs, heurts rudes et répétés. Pour transférer des mains du cultivateur à celles du bourgeois le domaine rural où peinait le censitaire, il n'était même pas toujours besoin de la longue et savante préparation des prêts à gros intérêts, des échéances renouvelées, des rentes constituées à un taux abusif. A lui seul, le jeu des forces naturelles, des éléments déchaînés, des épidémies meurtrières du temps suffisait à la tâche.

Que de calamités alors, guettant le paysan désarmé et le laissant ruiné, incapable de se relever, de reconstituer l'édifice incertain de son existence! Tantôt les 
grandes eaux ravagent les champs, mangent les rives, dévastent et saccagent tout. Les années de fortes crues, c'étaient, sur les rives des fleuves déchaînés, d'épouvantables dégâts : les digues crevaient, les rivières s'épandaient en lacs agités sur les terres ensemencées et emblavées, bloquaient les paysans apeurés dans leurs demeures, puis souvent, prenant un nouveau cours, remaniaient entièrement la topographie des propriétés riveraines. Et combien de dégâts ? A ces poussées subites, les ponts ne résistaient pas ; ponts de bois ou de pierre, passerelles à piétons ou "grands ponts » de hauts chemins, tous s'effondraient, se disloquaient, s'en allaient au fil de l'eau rapide. Les grandes eaux de 1565 rompent les ponts de Mouthier, de Montgesoye, d'Ounans, de Belmont sur la Loue; ceux de Rans et d'Orchamps sur le Doubs, sans compter toutes les digues à Peseux, à Parrecey, à Jousserot, à Longwy. Plus fortes, celles de 1571: elles ruinent les deux ponts d'Ornans, celui de Cléron, et, sur le Doubs, ceux de Fraisans, Rans, Orchamps, Rochefort et Dole : pauvres ponts que les communautés s'épuisaient à refaire : à la première crue, ils repartaient à nouveau avec les eaux boueuses... C'étaient des frais énormes, des corvées continuelles, les communautés s'endettant pour pouvoir satisfaire aux ordres du Parlement et des officiers bailliagers, impitoyables : ne fallait-il pas des ponts en bon état, pour donner passage aux armées qui incessamment, à travers la Comté, se dirigeaient vers les Flandres ou le Milanais ?

Et l'argent, les corvées n'étaient pas tout. Le Doubs emporte-t-il, en 1565, la nef du Temple à Dole ? Voilà les habitants de Falletans mi-ruinés : impossibles maintenant, leur trafic coutumier, leurs voyages à Dole où ils allaient porter des fardeaux de bois et des fagots. Le pont de Cléron s'en va au fil de la Loue : les paysans, gênés dans leurs travaux, ne savent plus comment accéder à leurs prés, à leurs champs situés au-delà de la rivière : ils doivent passer au pont de Maizières, à deux heures de chez eux... Sur les villages ainsi durement frappés, si quelque orvale nouvelle vient tomber par surcroît, c'est la misère et la ruine immédiate ; comme à Ounans, en 1565, on ne voit plus un seul feu « où on face pain que d'avance et encroires, à moityé de leur mange ».

Or, ces orvales se multipliaient. Après l'eau, le feu: des incendies terribles qu'on ne savait arrêter, et qui en quelques heures détruisaient entièrement, par les temps de sécheresse ou de grand vent, toutes les maisons d'un village ou d'une ville à vastes toits communs, parfois en tuile mais, plus souvent, en chaume ou en bois. Les textes sont innombrables, qui nous gardent le souvenir de telles calami- 
tés : c'est Gevrey près de Dole, où le feu prit à la Saint-Marie-Madeleine de 1565 : il commença « à l'ung des bout du village » et «brusla trente-six maisons par telle impétuosité que, tout ce que led. feug rencontra, il brusla, jusques à ce qu'il ne trouva plus aulcune chose, voire tous les arbres et fumiers estans devant led. maisons, saulfz voz révérences ». C'est Rans et Ranchot qui, pareillement, ont subi « l'orvale de feu »; c'est Cicon, détruit complètement par un sinistre, qui restait ruiné encore plus de douze ans après. Péniblement, il fallait aux laboureurs se construire de pauvres cabanes de bois, se reconstituer un outillage, un rudimentaire matériel d'exploitation, et les dettes nouvelles, s'ajoutant aux anciennes, des années durant les écrasaient - jusqu'à ce que, vaincus, ils cédassent la partie et s'en allassent mendier par les chemins ou aux portes des villes...

Et puis venaient encore les calamités naturelles : les gelées tardives, les orages, les grêles rendant intenables les champs de certains villages plus exposés que d'autres - les pestes surtout, terribles non pour ceux-là seulement que le mal atteignait et qui, «barrés » dans leurs maisons ou, le plus souvent, dans une loge de bois, attendaient une mort inévitable - mais pour tous leurs compatriotes du village, tous proscrits, tous repoussés par les paysans des alentours, dans leur crainte justifiée de la contagion. Plus de relations pour eux avec les vivants; plus de sel ni pour le pot, ni pour les bêtes, personne ne consentant à leur en apporter; les denrées les plus nécessaires manquant à leur vie; les ouvriers agricoles ne consentant à se louer qu'au prix de salaires exorbitants ; les bestiaux lâchés sans gardiens à travers les champs, pâturant à leur gré les blés et les avoines, et les maigres récoltes des champs désertés pourrissant sur place.

Quand cinq ou six années mauvaises se succédaient - ce fut le cas en FrancheComté, de 1565 à 1575 - quand aux maux naturels s'ajoutaient encore les maux humains, les charges de guerre, les pillages des gendarmes et les passages des troupes, le tableau des misères paysannes était complet, achevé. Nous avons peine à nous figurer combien dures étaient, pour le paysan d'alors, telles obligations disparues - celle du guet et garde par exemple. Dès que la Comté craignait pour la sûreté de ses frontières, on décrétait l'éminent péril, et l'on conviait les paysans des villages voisins à venir dans les villes fortes, à Gray, à Dole surtout, monter la garde. Lourde charge : à Belmont, en 1565, il faut chaque jour que trois ou quatre des habitants, parfois six, quittent leurs travaux et s'en aillent à Dole, à deux bonnes heures de chemin, prendre la faction : «Vous délaisse penser quelle foule et 
servitude », comme disent les bonnes gens dans leurs doléances. En 1567, la charge est pire encore : il faut quatorze hommes, pour Dole quotidiennement ; en 1570, il n'en faut plus que six, mais ils doivent, en revanche, reconstruire leur pont, quatre fois rompu au cours de l'année...

Partout ainsi les mêmes plaintes, plus aiguës quand s'ajoutent, à ces obligations normales et traditionnelles, la charge exceptionnelle d'un de ces passages de troupes que nous décrirons plus loin, et qui valait un orage de grêle pour les pauvres paysans pillés et foulés. Ne prenons qu'un exemple, celui des gens de la Loye se déclarant ruinés, en 1569, par tous les maux qu'ils ont dû supporter : montres d'armes générales, faites par le gouverneur et $M$. de Ray ; fournitures de denrées : 12 bichots de blé, 6 boeufs, 24 moutons à l'armée du duc d'Albe ; nouvelles montres d'armes, de cavaliers et de gens de pied, faites par MM. d'Achey et d'Esternod, où ils durent envoyer cinquante des leurs, trente-deux à pied et dix-huit à cheval, " auxquelx il convint acheter lesd. chevaulx pour ce que aud. lieu de la Loye ne se y tient et nourrit que jumens » - sans compter les armes : " cinquante acquebutes et autant de morrions, que leur revint le tout à plus de $2000 \mathrm{fr}$. »; séjour au village de la compagnie de M. de Clairvaux et des gens « du duc de Naiguera »; imposition de 100 fr. pour les murailles de Dole; charge biquotidienne de six hommes de guet à fournir à Dole chaque matin et chaque soir... La conclusion, c'est que leurs biens vendus par décret ont été rachetés " par plusieurs seigneurs, tant des lieux de Dole, Salins que autres, de sorte que la quarte partie des héritages du finage et territoire de lad. Loi ne leur compétent et appartiennent... »

Doléances générales, maux universels : jusqu'aux prêtres qui, partout, crient famine devant la misère de leurs paroissiens ; jusqu'aux pèlerinages qui doivent chômer. Plus de pèlerins, plus d'aumônes au prieuré de Monsieur Saint-Renobertles-Quingey; plus de pèlerins, plus d'aumônes au glorieux Saint-Antoine de Choisey.

La conséquence est nette. À de telles crises répétées, successives, la petite propriété paysanne ne résiste pas, ne peut pas résister. Déjà grevée le plus souvent de charges usuraires, de rentes ou d'hypothèques - sans compter les redevances seigneuriales ni les dîmes - sous ces coups nouveaux, elle succombe finalement : une dernière secousse, et, s'abandonnant, elle tombe aux mains du bourgeois qui la guette. Au milieu du siècle, en Comté, à la faveur des années mauvaises, des 
guerres, des passages incessants de troupes, c'est une immense opération de déssaisissement, d'expropriation des petits propriétaires paysans par les bourgeois des villes qui s'accomplit - tout un transport en bloc, préparé de longue date, soudain réalisé, des champs, des vignes, des prés aux mains des gens de loi, des gens d'affaires et des marchands.

\section{IV}

Vers le milieu du siècle, l'opération se prépare, mais commence à peine. Déjà cependant quelques plaintes s'élèvent - isolées encore et timides. Par exemple, en 1567, les manants d'Hotelans se plaignent assez vivement de n'avoir pour la plupart «beufz, chevaulx ny charrue » et « sont ainsi que grangiers »; ceux de la Borde Dame Nicole tiennent « à haut pris » les deux granges du feu sr Thomassin et du « feu sr du Deschaulx ». Avec le temps, les plaintes deviennent plus vives : en 1569, les gens de Champrougier près Poligny disent avoir dû vendre leurs héritages « tellement qu'ilz sont tous grangiers »; ceux d'Arguel, près Besançon, n'ont plus de terre à eux, « ains seullement nourrissent leurs pauvres femmes et familles à labourer journellement pour aultruy, mesme pour ceulx de Besançon et aultres... qui tiennent et possèdent les terres et héritages " ; ceux de la Loye enfin, près de la forêt de Chaux, ont vu leurs biens, vendus par décret, rachetés par plusieurs seigneurs « tant des lieux de Dole, Salins que autres ». Et le curé de Miéry, auprès de Poligny, la même année, montre ses paroissiens « devenus grangiers, au lieu qu'ilz estoient riches et propriétaires » tandis que l'abbesse de Château-Chalon signale « qu'environ cinquante mesnagiers dud. lieu sont aller habiter ailleurs, ou morts, et les biens vendus par décret à vil prix ».

Mais, en 1575 surtout, les textes se multiplient et de façon saisissante. Les années précédentes, depuis 1570, avaient été cruelles ; au froid, à la peste, aux sécheresses, aux inondations s'étaient ajoutés encore les maux de la guerre ; quand, un nouveau don gratuit ayant été voté aux États de 1574, les collecteurs se mirent en mouvement - de tous les villages comtois, mais de ceux-là surtout qui avoisinaient les villes, une même plainte s'éleva, contre l'accaparement des propriétés paysannes par les bourgeois, profitant de la détresse, s'enrichissant de la misère 
rurale. Nulle part, peut-être, les doléances ne sont plus concordantes, plus unanimes qu'aux environs de Salins, la plus grande, la plus riche des cités comtoises. Salinois, les Trousset, les Alepy, les Belin, qui tiennent les héritages de Chauxsur-Champagny ; ils en ont « la meilleur et plus grand part » et cultivent « en leurs chiefz », de manière que les pauvres manants «leurs sont seulement serviteurs et mercenaires ». Salinois également, les Moreau, les Marchand, les Belin, qui possèdent les terres de Champagny même: les habitants ne sont plus que «locateurs ». Dans le val d'Héry, à Fonteny, à Pont-d'Héry, les gens vont mendiant, ayant pour la plupart dû céder leurs biens à « plusieurs particuliers habitants dud. Salins »; même spectacle à Cercenne, sous le mont d'Aresches, ou, sur le plateau, à Montmarlon : les paysans mendient «sauf ung seul »; ils ont dû tout vendre, « tant à plusieurs de Salins, Lemuys que aultres, tenans la plus grande partie des biens, terres et héritages dud. Montmarlon ». Les biens qu'ils gardent encore ne valent pas cinquante francs "saulf d'ung seul » - et cela, la requête y insiste (comme celle de Cercenne d'ailleurs et bien d'autres), "dois les derniers impostz » - c'est-à-dire depuis 1569. Mêmes plaintes à Saizenay, à Clucy, au hameau du Tilleret, où il n'y a que deux maisons, l'une à des bourgeois de Salins, « héritiers de fut Estienne Grand », l'autre « au sieur Boisset, de Pesmes ». A Moutaine, les manants demeurent « en petites maisons appartenans à aucuns habitants de Salins »; aux Arloz, en dessous d'Ivory, ou ne vivent que deux familles, « depuis la derrière imposition, tous et ung chacun les meix, maison, terres et héritages dud. Arlost sont estez réduictz et acquis tant par les furent Jacques et Symon Marchant et leurs successeurs que aultres habitants dud. Salins et faubourgs d'illec, les tenans et possédans entièrement, ormys ung petit meix et maison, ensemble quelque peu de jardin estant alentour »; c'est le grangier des Marchant qui signe la requête. A Dournon enfin, sur le plateau, il n'y a que 12 ou 13 feux dont 3 de pauvres gens «ne vivans que au labeur de jour à aultre » et 3 de grangiers ; « le surplus a bien peu de moyen ».

Plaintes monotones : elles s'élèvent de partout, et il faut les transcrire, les résumer du moins pour avoir l'impression de ce que fut réellement cette vaste opération de conquête et de prise. Par Vers, dont ils possèdent déjà les trois quarts, les bourgeois de Salins s'avancent sur le plateau ; mais comme eux, ceux de Poligny, de Lons s'emparent de la terre dans les villages voisins. Ils travaillent la Bresse, s'y glissent, s'y infiltrent dans les communautés. A Maufflans près Mantry, les 
étrangers tiennent six fois plus que les natifs, et voici des noms avec des chiffres : Pierre, fils de feu Pierre Pelissonnier d'Arlay, possède 102 journaux de vigne, 12 journaux de terre, 29 voitures de pré, 2 maisons et le four «qu'iceulx habitants furent contrainctz luy vendre pour survenir aux debtes dud. villaige». - « Les heritiers feu mre Jehan Corvoisier, d'en médicine, demeurant à Lons-le-Saunier », ont une bonne grosse maison de pierre couverte de tuile, 20 journaux de vigne, 12 de terre, quelques prés. Pareillement sont cités Claude Midoz de Sellières, les héritiers feu Claude Pelissonnier, les Maigret, les Boisson de Saint-Germain, Mlle de l'Espinette, d'autres encore « tant d'Arlay, Sellières que Toulouse » : ce qui leur échappe n'est suffisant " pour nourrir trois bons mesnaiges "; d'où la nécessité de réadmodier desd. estrangers les vignes, terres et prelz pour vivre comme povres grangiers ». - Même chose à Passenans, un village voisin : il n'y a plus que cinq propriétaires au village ; le reste est grangier ou locataire. A la Chapelle-Voland, en pleine Bresse marécageuse, les habitants ont dû vendre « depuis quarante ans en ça » plus de vingt étangs dont ils tiraient profit, sans compter des meix «esquelx sont esté construictz cinq grangeages et plusieurs aultres héritages tant à ceux d'Arlay, Blecterans que aultres ». A part une douzaine de ménages, tous les autres tiennent leur bétail de commande «et les terres qu'ilz labourent, pour la plus part, à louhage et terrage. ».

Même chose dans le Vignoble. A Ménétru, près Voiteur, la plupart des terres sont tenues par des Dolois ou des Salinois, comme à Conliège, à Vevy, Publy, Blye et Chatillon - ou sur le plateau, à Mirebel, à La Mare. Aux environs de Clairvaux, à Barésia, quatre grangeages occupent « le quarte et quarte partie des heritaiges..., gens estrangiers ». A Soucia, sauf une douzaine de familles «aians petit moien de vivre et mettant chacun deux bestes à charrue », le surplus (soit 24 ou 25 feux) a dû vendre son bien pour continuer à vivre. A Marigny de même, depuis trois ans, le nombre des feux s'est réduit de 70 à 48 ; les biens des absents ont été vendus et acquis «par plusieurs gens non résidans aud. lieu, comme est Mgr du Parret, Jacques et Humbert Parchet de Chastillon, messire Pre Bonnier, le sieur curé dud. lieu ». Enfin, dans la Montagne, aux environs de Pontarlier notamment, mêmes constatations, même spectacle encore à Frasne, à la Rivière, dans les villages qui bordent le lac Dampvauthier: à Saint-Point, Malbuisson, Vaux et Chantegrue, Chaudron, etc. Au grand et petit Malpas, « ung nommé Guillaume Franchet de Pontarlier, escuier, tient en nosd. villaiges la quantité de 50 
journaulx de terre arribles et vingt soipture de prelz; it. les héritiers de feu Jacques Vuillaume de Ponterlier (20 journaux) ; it., ungne nommée damoiselle Anne Glaine (14 j.) ; it., ung nommé Pierre Vannod et Jehan Perrenet d'Oye (20 j.) ; Guillaume Louvrier et Anathoile Gyrard de la Plainée (30 j.) » D'autres encore sont là : bref, la moitié du village est à des étrangers. - Toujours les mêmes faits, toujours les mêmes doléances : innombrables en Comté sont les paysans qui, jadis « seigneurs propriétaires des meix, maisons et heritages », comme disent naïvement ceux de Touillon et Loutelet, ne sont plus que tenanciers, locataires ou grangiers.

Textes tendancieux, dira-t-on, ceux de pareilles requêtes, destinées à attendrir les commis aux dégrèvements ? Sans doute, et il ne faut point prendre trop à la lettre leurs affirmations, surtout, peut-être, quant à l'exacte proportion des héritages passés en possession de bourgeois ou d'étrangers riches. La concordance des plaintes, leur presque universalité, la précision des exemples allégués ne laissent pas moins à ces documents une valeur réelle. D'ailleurs, d'autres textes, et de plus objectifs, nous restent ; par exemple, pour une région de la Comté toute différente, une curieuse enquête entreprise en 1574, dans la terre de Faucogney, sur la répartition des biens-fonds entre résidants et non-résidants. A chaque page, ce sont des exemples frappants de bourgeois luxoviens, notaires ou marchands, possédant terres, prés, vignes, meix, maisons, étangs remplis de carpes - le tout dispersé, émietté, fragmenté, visiblement conquis au jour le jour par de multiples opérations d'achat ou de saisie. A côté, des livres terriers, des rentiers de seigneuries où le départ est fait entre habitants et forains ; encore, des documents administratifs : rapports d'officiers bailliagers, signalant avec force les effrayants abus commis dans la Montagne par les acheteurs de terres, spéculant sur la misère paysanne et enlevant, par des artifices de procédure, aux proches parents des dépouillés la faculté d'user du retrait lignagier. Tous ces textes concordent, se confirment, s'éclairent les uns les autres ; tous attestent la généralité des pratiques décrites, l'ampleur d'opérations aussi faciles à mener que vraiment efficaces. 


\section{V}

Du sol conquis, qu'allaient faire les nouveaux acquéreurs ? Le garder, l'exploiter directement ? Chose possible, sans doute, pour les cultivateurs aisés, arrondissant leur domaine grâce à la détresse du voisin. Il y en avait de tels, et même assez nombreux. Mais les autres, ceux des villes?

Pour eux, deux partis, avantageux tous deux. L'un, propre à ceux qui ne voulaient surveiller, guider, exploiter en détail un grangier : c'était de spéculer sur les biens-fonds en les revendant avec bénéfice. Que l'opération se pratiquât souvent, nous avons un moyen commode de le constater. Sur ces achats, l'administration seigneuriale veillait : nous l'avons dit plus haut, les transactions foncières étaient étroitement contrôlées, et dans toutes les terres, celles du souverain comme des vassaux, on était d'ordinaire attentif à ce que des champs, des prés, des vignes mainmortables ne fussent pas occupés par des tenanciers francs ou réciproquement. S'agissait-il cependant d'un riche bourgeois qui, par décret ou autrement, s'était rendu acquéreur de quelques fonds de mainmorte ? Par tempérament, les lettres d'achat étaient scellées, moyennant engagement par l'acheteur de vider ses mains dans un délai donné - deux ou trois ans généralement, parfois six - et de remettre à un mainmortable capable de tenir. La revente était, en ce cas, pour l'acquéreur franc, une obligation légale.

Ils sont intéressants, ces petits cahiers de «lettres scellées » ou refusées au scellé que les archives renferment en assez grand nombre ; presque à chaque page, on y peut rencontrer de curieux exemples d'opérations bourgeoises. En veut-on un ? Au Latet, seigneurie de Vers, deux paysans de Labergement-Sainte-Marie achètent, en juillet 1574, un domaine pour 515 fr.. Le vendeur est un riche notaire de Salins, honorable Louis Coquelin ; les biens sont de mainmorte et l'acte n'est scellé qu'à charge pour les acheteurs de s'avouer mainmortables envers S. M. D'où provenaient ces terres à Coquelin ? Évidemment d'un achat antérieur, ensuite de vente judiciaire. Conjecture que confirme par hasard cette petite trouvaille : dans un autre registre, deux ans auparavant, on voit le même Coquelin acheter précisément par décret au Latet, pour 210 fr., les biens de feu Vuillemin Noiroz, à 
charge de les revendre sous les trois ans à mainmortable. Voilà, sans nul doute, l'opération complète.

Par dizaines, dans les registres de lots, si on prend la peine de les dépouiller minutieusement, se retrouvent les traces de pareilles transactions. Nombreux d'ailleurs et divers, leurs auteurs. Voici, aux environs de Besançon, des marchands : à Abbans, un certain Jean Danon, à plusieurs reprises, achète et revend des terres, des prés enlevés à bas prix sous condition de les céder à mainmortables dans les trois ans. Personnage aventureux qui, entre-temps, ne dédaignait pas les longues expéditions, les courses difficiles jusque dans le Milanais, où il achetait des armes. A Arguel, agissent les Chevannay, Daniel et Michel, surtout certain Catherin Lebry, marchand de Besançon, dont les achats, en 1574, 75, 80, 81, se multiplient, s'étendent inlassablement; à côté, le maître charpentier Philippe Bressand; la femme du marchand Thiébaud Mussot; Jean Bretin, le potier d'étain ; les de Mesmay, Michel, Antoine et Jean, bourgeois d'Arguel ; le marchand Le Maire ; le tanneur Thiébaud Arbilleur ; noble Jean Brocard ; noble Jean de la Borde ; le maître pelissonnier Antoine Guignoire ; bien d'autres encore, plus ou moins connus, plus ou moins riches, mais tous adonnés à l'art de marchandise et de leurs capitaux, consacrant une partie à ces spéculations sur les biens fonciers...

Ces spéculations étaient faciles, exigeant peu d'activité. On le devine aux fréquentes mentions de femmes veuves. A Arguel toujours, en 1574, en 1575, achète et revend demoiselle Perrot, veuve de noble homme Jean Sauget ; en 1582, demoiselle de Mesmay, veuve de Claude Loys, docteur en droit. A Sainte-Anne, en 1579, opère une Salinoise, demoiselle Belin, veuve de Jean Guillon de Salins. A Vers, c'est demoiselle Marguerite de Vers, veuve de l'écuyer Louis Marchant de Salins, ou Louise Cussemenet, veuve de Pierre Marchant ; toutes de familles notables, toutes mentionnées non une fois par hasard, mais à plusieurs reprises, des années durant, pour des opérations relativement importantes. Et puis, ce sont d'autres bourgeois, des officiers de justice, des receveurs de seigneuries, des notaires surtout, à l'affût des décrets : tel ce Thomas Charpentier, citoyen de Besançon, qui figure si régulièrement dans les registres d'Arguel, entre 1574 et 1582 - pour ne point parler de ses collègues, les Jean Guyot, les Blaise Landry, les Laurent Dayne, moins fréquents ; tel encore, ce Charles Golu de Salins, receveur de la seigneurie de Sainte-Anne, acheteur infatigable qui opère partout, à Vers, à Dournon, à Sainte-Anne, tantôt seul, tantôt de compte à demi avec des « amys esleuz 
ou à eslire », tantôt pour lui enfin, tantôt pour des clients. Anoblis, enrichis, posés, les bourgeois comtois n'en continuaient pas moins avec passion leurs achats, leurs ventes, leurs échanges - plus ou moins licites parfois : de l'écuyer Pierre Amyot, de Salins, la Chambre des Comptes, en 1583, refusait d'approuver et de sceller plusieurs transactions, jugées préjudiciables au roi et au domaine, et qu'il avait conclues dans la seigneurie de Vers. Exemples pris entre cent ; de tels documents encore confirment, avec éclat, la véracité des doléances rurales que nous avons transcrites quelques pages plus haut.

Mais acheter pour revendre n'était pas le fait de tous. Pour beaucoup, pour la plupart même des acquéreurs de biens-fonds, le but était autre. En suivant de près les ventes judiciaires, ou en acculant les paysans à la ruine par des opérations usuraires, ils entendaient bien se créer à peu de frais des domaines ruraux, fermes ou métairies, où le cultivateur exproprié par eux reprendrait - mais à leur compte cette fois et non au sien - son labeur obstiné. Voici, exemple frappant, la liste des biens-fonds amassés par un conseiller au Parlement de Dole, Pierre Cécile, telle que nous la donne un inventaire après décès. C'est une véritable accumulation de prés, de vignes, de champs isolés, morcelés, séparés les uns des autres, achetés visiblement au hasard de ventes, de décret, d'occasions successives - au hasard, mais avec un plan suivi : dès que, dans une contrée, sur un territoire donné, assez de " corvées », de « semées », de « fauchées », d'ouvrées », auront été acquises, le riche bourgeois de ces terres éparses fera une grange ; dans une maison de ferme, il mettra, pour les faire valoir, une famille paysanne. À Orchamps, l'opération était faite ; Pierre Cécile possédait un grangier ; à Damparis, Belvoye et la Borde, « le conseiller Cécile, dit l'inventaire, estoit en délibération de y mectre un grangier pour ensemencer les terres », quand la mort était venue briser ses projets. Transcrivons quelques chiffres : ils sont saisissants. A Dole ( $\left.f^{\circ} 16\right)$, le conseiller possède quinze parcelles de terre différentes : une de 5 journaux, trois de 4 , une de 3 , quatre de 2 , cinq d'un journal et demi, une d'un journal ; en plus trois prés, trois vignes ( $\mathrm{f}^{\circ} 28$ ), une maison dans la grande rue, une dans la rue de Fripapa, une avec jardin et grange où il réside, et une grande qu'il loue ( $\left.f^{\circ} 23 \mathrm{~V}^{\circ}\right)$. À Parcey ( $f^{\circ} 17$ ), il a 27 pièces de terre et 5 pièces de pré ( $\left.f^{\circ} 24\right)$; à Crissey ( $\left.f^{\circ} I 8\right), 4$ pièces de terre ; à Gevry, 2 ; à Taveau, 5, plus un meix acquis par décret et amodié 22 fr. par an ; à Damparis, Belvoye et la Borde ( $\left.f^{\circ} 19\right)$, 18, plus les moulins et batteurs de Beauregard amodiés pour huit bichots et demi, et 10 prés d'une à six 
voitures d'étendue : tous les éléments d'une grange profitable. À Sampans, trois quarts de journal - une amorce pour l'avenir ; à Bermont, plusieurs pièces déjà, rapportant 9 quartaux 1/2 de graine par année, et 3 prés; à Orchamps ( $f^{\circ} 20$ ), de très vastes possessions : 38 champs, 20 prés, deux meix avec maison et verger ( $f^{\circ}$ 26) ; à Gendrey ( $\left.f^{\circ} 21 \mathrm{~V}^{\circ}\right), 15$ pièces tant terres que prés ; à Our, 20 ; à Etrepigney (f॰ $\left.22 \mathrm{~V}^{\circ}\right), 19$; à Rans, 4 ; à Ranchot, 3 ; à Fraisans, plusieurs champs; à Goux et la Villette, deux prés ; à Molay, 3 ; à Foucherans, I ; une vigne à Monnières, 3 à Thervay, 4 à Liesle, 3 à Arbois, ainsi qu'un meix et maison ( $\left.f^{\circ} 27 \mathrm{~V}^{\circ}\right)$... Au total, près de 250 pièces de terre et de pré, 3 maisons de ville, 3 maisons de village, et 14 vignes disséminées sur le territoire de plus de 25 villes ou villages différents le tout, sans compter les terres et les prés de Pontarlier et lieux circonvoisins, biens patrimoniaux du conseiller et qui, « selon le partage fait avec MM. les Cécile », étaient amodiés pour neuf ans et 91 quartes de grain par an ( $f^{\circ} 28$ ).

Voici un conseiller encore, un collègue de Cécile, Fernand Seguin. Il laisse, quand il meurt, en 1569, une grange à Saint-Aubin, la grange Guyod-Bernard, qu'il amodie tous les six ans ( $f^{\circ} 46$ ). C'est lui qui l'a faite, morceau par morceau : achat d'une corvée de 36 journaux en 1546 ( $f^{\circ} 22$ ) ; d'un pré de trois soitures en 1553 ; d'un champ en 1559, etc. A Orchamps, même effort ; dans la seule année 1564, il y acquiert successivement, le 5 mai, des terres et des prés ( $\left.f^{\circ} 29\right)$; le 12 , à deux reprises, de nouvelles terres et de nouveaux prés ; d'autres le 5 juin, le II, le 29 ( $f^{\circ} 28$ et $28 \mathrm{~V}^{\circ}$ ); un champ le 9 juillet, un pré le Ier octobre ( $\left.f^{\circ} 30\right)$ : soit une dizaine d'opérations en trois mois. A la même époque, il travaille pareillement à Étrepigney, à Cinq-Cens, à Goux, etc. ; il faudrait en détail transcrire tous ces textes, constituer les monographies qui font défaut pour donner au lecteur cette impression de vie, d'activité intense qui de cent textes pareils émane nécessairement.

Pourquoi une telle passion pour la terre paysanne ? Rien de plus explicable. D'abord, entre villes et campagnes, le divorce était loin d'être absolu. Les bourgeois citadins aimaient peu acheter les denrées nécessaires à leur subsistance. Le rêve des plus petites gens, réalisé souvent - leurs testaments, leurs inventaires le prouvent - était de posséder trois ou quatre journaux de terre pour produire leur blé, leur vin, une chènevière si possible à cause du linge. Plutôt qu'au boulanger, on aimait recourir au fournier - et les familles bourgeoises trouvaient leur avantage à des relations d'échange avec une famille de cultivateurs, dont elles tiraient, à 
l'occasion, outre les provisions courantes : lard, beurre, volailles, fromage même des corvées encore, des charrois et de multiples services domestiques. De là, une première cause de ces achats de terre, de ces constitutions de granges qui nous apparaissent si nombreuses dans les textes.

Il y en avait d'autres, et celle-ci, notamment, que l'argent consacré à de telles acquisitions pouvait, aux plus exigeants, paraître bien placé. Cela, non seulement parce que, le plus souvent, les clauses des baux de grangeage étaient sévères, exigeant du cultivateur, en outre des charges principales, une foule de menus services et de redevances - mais encore parce que le maître, toujours, se réservait le monopole de toutes les transactions, de tous les emprunts, de toutes les opérations financières ou économiques du fermier. C'était lui et lui seul qui, en cas de besoin, lui avançait l'argent ; lui et lui seul qui lui vendait des graines pour les semailles, du fourrage dans les années mauvaises, parfois même du bois ; lui surtout qui lui fournissait son bétail par des baux à cheptel rémunérateurs.

\section{VI}

La pratique était universelle, ou presque : son extension même atteste combien elle devrait ordinairement procurer de bénéfices. Ce n'étaient pas seulement les plus riches familles de cultivateurs qui, dans les campagnes, s'y livraient avec passion, mais, dans les villes, nombre de bourgeois, naturellement conduits à de telles opérations par les conditions de vie mi-rurales, mi-urbaines, que nous notions plus haut : dans les cités les plus populeuses d'alors, on pouvait voir chaque jour encore, comme à Besançon, les bergers de quartier rassembler au matin la " proie » communale et la ramener le soir des pâtures voisines dans les étables privées. Mais notaires et bourgeois ne gardaient guère ainsi que les quelques bêtes nécessaires à la vie plus facile de leur ménage ; les autres, ils les plaçaient à la campagne chez des cultivateurs empressés à les tenir. À quelles conditions ? Nos textes malheureusement sont assez rares. Dans tous, cependant, il s'agit de baux à mi-croît et décroît : le bailleur seul fournit tous les chefs ; le preneur s'oblige de les nourrir pendant quelques années, au bout desquelles se partage entre eux tant le croît - les profits de l'exploitation par croissance et multiplication des bêtes - 
que le décroît, ou leur diminution en nombre et en qualité ; le capital, estimé au préalable, était toujours réservé au bailleur. Ces baux appelaient des réserves de la part des casuistes : prenant texte d'une bulle de Sixte-Quint, en date du 28 octobre 1585, ils condamnaient les cheptels où le preneur supportait la moitié du décroît ou mépert. De fait, en Comté, les conditions de tels contrats étaient rudes, et, par exemple, le Parlement, assimilant à une vente l'estimation préalable du bétail, en tirait cette conséquence que le cheptélier, en cas de perte du capital advenue par cas fortuit, guerre ou pestilence, devait supporter la moitié de la perte du capital décision abusive au gré de nombreux juristes.

Pourtant, si les baux à cheptel pouvaient passer pour redoutables aux preneurs, c'était moins sans doute par leurs clauses mêmes que par les innombrables abus auxquels, trop souvent, ils pouvaient donner lieu ${ }^{33}$. C'étaient, tantôt, de fausses estimations ; tantôt d'intempestives ruptures de contrat, le maître profitant de la clause relative à l'exigue ${ }^{34}$ pour la réclamer au lendemain d'un rude hiver ou d'une épidémie et rejeter ainsi sur le cheptelier la moitié du mépert ; tantôt, enfin, des prêts, des avances d'argent, de grain, de fourrage, consenties au preneur par le

33 Le Traité des Chetels décrit bien (I. I, ch. v, \& VI) ces fraudes, et permet de comprendre certains textes obscurs, Par ex., en trouve dans un arrêt du Parlement de Dole contre un usurier (B 1084, Arrêts, fol. 307 vº, 7 septembre 1585), ce grief que l'inculpé avait donné à un paysan « la somme de 100 fr. sur son bestial, qu'estoit bien de plus grande valeur, qu'il confesse pour ce tenir à titre de commende au défendeur ». Le Traité rend compte de cette opération dans le passage suivant (p. 71) : " Ils [les usuriers] prêtent une somme de deniers pour sureté de laquelle ils se font engager du bétail pour, sur les fruits et croît qui en proviendront, être payés annuellement des arrérages de la somme prêtée ».

34 « Exiguer, dit le Traité des Chetels (I. II, Ch. XXIII, p. 363), c'est estimer le bétail donné à cheptel à l'effet de connaître si la société a été profitable et de régler, après le capital prélevé par le bailleur, le partage du croît et en cas de mépert, déterminer ce qui en doit être supporté par le preneur. » La plupart des baux à cheptel contenaient la clause « qu'il sera permis au bailleur de demander l'exigue toutes et quantes fois il lui plaira » (ibid., p. 369) ; cf., par ex., ceux des Moutet, cités plus haut : «led. retenant sera tenu de nourrir... lesd. vaiches... et du tout faire exigue quant l'une des parties en requerra l'autre ». Il est vrai qu'ici la réciprocité est stipulée; elle n'empêche pas la clause d'être abusive ; elle donne simplement au preneur le moyen de molester à son tour le bailleur en requérant l'exigue «dans des circonstances auxquelles le maître auroit peine à placer son bétail » (ibid., p. 369) 
bailleur. Les avances faites, comment les recouvrer ? Sur la portion du croît réservée au cheptelier ? Oui ; mais s'il n'y avait pas de croît suffisant, ou pas de croît du tout ? Le recouvrement se faisait alors sur les autres biens du cheptélier : première porte ouverte à une dépossession, à une expropriation profitable et sans risque. Et puis encore, c'étaient toutes les usures traditionnelles, les forts intérêts réclamés pour l'argent ou les fournitures avancées, les ventes au-dessus des cours, l'achat de leur troupeau aux paysans ruinés, puis ce troupeau remis à eux, sur l'heure, à titre de cheptel, - fraudes ingénieuses, où excellait un peuple d'usuriers. Voilà ce qui explique la fréquence de tels placements, la faveur manifeste dont ils jouissaient auprès de la bourgeoisie des villes. Ils n'étaient pas seulement fructueux en eux-mêmes, le plus souvent - en dépit des quelques risques à courir ; ils étaient encore, ils étaient avant tout un nouveau moyen pour le citadin d'amener entre ses mains l'objet de sa convoitise : la petite propriété paysanne.

Quelle est d'ailleurs la part exacte à faire à la commende dans le troupeau comtois de cette époque ? Il est bien difficile de le déterminer. Le XVIe siècle n'est guère un siècle statisticien, et de tous les documents qui nous renseignent sur la composition, l'étendue et la répartition de la population animale du temps, singulièrement rares sont ceux qui contiennent des données utilisables sur la propriété des bêtes. En voici un pourtant, assez instructif : le recensement, à trois dates différentes, en 1557, 1558 et 1563, du troupeau de Valempoulières, assujetti à payer au seigneur la « jurée des bêtes ». Valempoulières est un village assis sur le plateau qui domine Poligny, mais au delà de la grande ride de l'Euthe, assez loin de toute ville, par 650 mètres d'altitude. Or, en septembre 1557, trente-deux paysans figurent sur le rôle. Trois d'entre eux seulement possèdent en propre tout leur bétail, trois paysans aisés ou même riches : l'un d'entre eux avoue 6 boeufs, 3 juments, 5 vaches et 6 brebis. Neuf paysans, par contre, n'ont de bétail que du bétail loué : pauvres gens et pauvre bétail : une chèvre, une vache, une ou deux brebis, quelquefois deux vaches... Restent vingt tenanciers qui, tout à la fois, ont des bêtes à eux et des bêtes louées : le gros du village et du troupeau. Négligeons les chiffres de 1558, à peu près identiques aux précédents : en 1563, c'est sensiblement la même répartition. Sur trente-neuf déclarants, six, dont quatre très pauvres, sont propriétaires de toutes leurs bêtes ; treize les tiennent exclusivement d'autrui ; vingt sont de condition mixte. Ces chiffres disent assez l'importance et le nombre des baux de commendise. 
Serrons encore d'un peu plus près les textes. Dans les trois années, la proportion des bêtes louées aux bêtes possédées reste, au total, à peu près la même : 232 bêtes déclarées en 1557, 125 provenant de commende ; 220 en 1558 et 116 ; 253 en 1563 et 148. Mais voyons le détail. En 1557, celles qui se louent le moins sont les bêtes chevalines ; sur trente-deux déclarants, vingt-deux ont des juments (38 juments en tout) ; tous, sauf quatre, les possèdent en propre. Même chose en 1563 : trente-neuf déclarants, vingt-cinq possesseurs de juments (41 juments), quinze possédant en propre toutes les leurs, six les tenant toutes en commende, quatre de condition mixte. Par contre, les boeufs presque tous sont des boeufs loués : vingt en possèdent en 1557, dix-sept en 1558 ; or, dans les deux années, deux seulement de ces dix-sept et de ces vingt déclarants possèdent leurs boeufs en propre ; en 1563, sur vingt-trois déclarants, tous, sauf un, les tiennent en commende. Enfin, les vaches : trente en ont, en 1557 (56 vaches en tout) ; sept seulement possèdent toutes les leurs en propre ; ils en ont 19, presque trois par tête en moyenne ; vingt-trois les ont en commende et la moyenne pour eux s'abaisse à I,56 par tête. En 1563, le même fait se répète : trente-deux paysans possèdent 58 vaches ; sept n'en ont qu'à eux, tous les autres (sauf deux, mixtes) tiennent les leurs en commende.

Chiffres bien arides, semble-t-il ? Du moins, à notre sens, ont-ils cet avantage de nous aider à préciser le double caractère que revêtait la commende - à la fois opération d'industrie rurale et spéculation financière. Par le louage du boeuf, animal de travail et d'engrais, le bourgeois exerce, de compte à demi avec le cultivateur, l'industrie rurale et pastorale ; par le louage de la vache ou de la chèvre, les deux bêtes du pauvre, les soutiens indispensables de leur vie - il prend barre sur le paysan besogneux et se ménage déjà comme un moyen d'accès vers sa petite propriété, réservée peut-être à une vente prochaine ?

$$
\text { *** } * \text { * }
$$

Ainsi s'édifie, ainsi grandit patiemment la fortune bourgeoise aux dépens de la fortune paysanne. Ainsi, partis de rien, de petites gens s'élèvent ; par le prêt, par l'usure s'accroît leur richesse mobilière ; par l'achat, par l'expropriation se crée, aux moindres frais, leur richesse foncière. Accapareurs, monopoleurs, acheteurs de blé en herbe, vendeurs de blé en grain, placeurs de bétail, changeurs, contrebandiers, ils font tous les métiers, trouvent à gagner partout, ne laissent jamais 
passer sans la saisir une occasion de profit. Infatigables d'ailleurs, acharnés à la peine, durs pour eux comme pour les autres, ils sont vraiment les maîtres du temps. Par leurs mains avides et subtiles passe tout ce qui se vend et tout ce qui s'achète ; rien qui ne les serve et ne les enrichisse : la prospérité comme le malheur, l'abondance des années de liesse, remplissant les grands muids dans les celliers, accablant les greniers sous le poids des récoltes, comme l'indigence des saisons de sécheresse et de ruine, contraignant le producteur à l'achat onéreux, à l'emprunt usuraire précurseur de la vente. Du paysan aisé, du paysan ruiné, ils tirent à la fois une égale substance ; ils dévorent le premier, ils asservissent le second. Et la guerre elle-même, suprême calamité qui achève et consomme la détresse paysanne, profite à leur fortune, à leur audace tranquille : dans l'entreprise des charrois, des fournitures et des vins, il y avait, nous le verrons, des fortunes pour qui savait ou osait les tirer. 
PHILIPPE II ET LA FRANCHE-COMTÉ

Étude d'histoire politique, religieuse et sociale.

Deuxième partie. Les débuts du règne de Philippe II

\section{Chapitre IX}

\section{Les sources de la fortune bourgeoise: Les offices, la robe, la conquête de la terre noble}

$\underline{\text { Retour à la table des matières }}$

Marchandise et prêt ; achat et vente de biens ; création de granges ; exploitation des paysans : première série de moyens sûrs pour parvenir à la fortune. Il y en avait d'autres. A côté de la bourgeoisie trafiquante se développait, parallèlement, la bourgeoisie de robe et d'offices.

Juge, receveur, procureur, le bourgeois, au XVIe siècle, sert les seigneurs sur leurs domaines. Notaire, avocat, praticien, il sert les parties dans leurs procès. Conseiller au Parlement, maître des comptes, officier de bailliage, il sert le prince enfin. Dans les offices variés, les fonctions multiples qu'il remplit, il trouve à la fois un moyen d'accéder à la fortune et de la décupler.

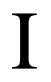

Du pauvre au riche, du modeste au puissant, c'est toute une hiérarchie de la robe : en bas, les petites gens, à peine dégagés de la rusticité, qui vivent sur les terres du dernier rang et y trouvent quelque emploi. 
Pour être là le receveur, l'homme d'affaires et de confiance du maître, celui qu'on voit toujours courir par les terres, surveiller jalousement les tenanciers, leur faire en temps prescrit exécuter les corvées et payer les redevances, point besoin de mérites rares, de long apprentissage ; le tenancier qui, sachant lire un peu, écrire et compter, parvenait par surcroît à la faveur du maître, obtenait aisément ces humbles fonctions. De même encore, dans les seigneuries de basse justice, c'était un emploi presque accessible à tous que celui de juge, de maire ou de prévôt, comme on disait. Pas besoin, pour « congnoistre des causes civiles, tant personnelles jusques à cent solz, que réelles jusques à litiscontestation exclusivement » pas besoin, pour trancher les menues contestations, de connaissances juridiques même rudimentaires. Cette justice était le plus souvent cédée comme une ferme, au plus offrant; elle représentait simplement, pour quelques paysans aisés, un petit supplément de revenus ; mais, cumulée, comme il arrivait, avec les fonctions de receveur, elle donnait à qui l'exerçait un peu d'autorité sur les sujets, et sinon du prestige, du moins du profit : il faut suivre, dans les textes, la série des plaintes portées pendant tout le siècle contre les abus des praticiens de village composant avec les coupables, percevant des frais exorbitants et abusifs : on se rend compte ainsi qu'amodiée à bas prix, la justice devait permettre au juge fermier de rentrer dans ses fonds sans la moindre peine.

Et sans doute, c'étaient de très petites gens, ces receveurs, ces juges des petites seigneuries. Mais déjà, au-dessus de la foule des manants, ils s'élevaient d'un degré. Et puis, souvent, par surcroît, ils s'intitulaient notaires. Le notariat formait, au XVIe siècle, comme le premier échelon du cursus honorum bourgeois. Échelon facile à saisir, du reste. Muni d'un bon formulaire, qu'il sût dresser un acte ou plutôt le transcrire correctement : le premier venu pouvait passer tabellion, rédiger baux et contrats. Et le souverain n'était pas seul à pouvoir créer des notaires en Comté : quelques seigneurs, quelques abbés jouissaient de ce privilège ; Besançon, pour sa part, fabriquait chaque année quatre ou cinq nouveaux notaires impériaux ; l'officialité, pour des fins mercantiles, prodiguait le titre non à des praticiens mais à des marchands, à des cabaretiers, à tout un peuple rapace de " proufiteurs ». Notaire et receveur : c'étaient des titres déjà, honorables à porter. L'argent que se faisaient, par leurs doubles fonctions, de tels personnages ne restait pas inactif entre leurs mains. Ils savaient habilement mettre leurs deniers en travail et c'est d'eux bien souvent que sortaient, gradués en droit cette fois, licenciés ou 
même docteurs, tous ces praticiens, ces légistes, ces officiers de justice et de finance qui se multipliaient, s'élevaient en tel nombre.

Les légistes, eux aussi, comptaient leur menu peuple : humbles gens, mais munis déjà de nominations, investis de fonctions publiques que tout leur effort allait à régulariser. Tels, les sergents de bailliage, les huissiers ordinaires et extraordinaires du Parlement, les concierges de prison, les scribes, les commis, les jurés au greffe. Vers ces menus offices, c'était une vraie ruée, un incessant afflux de candidats. Dès 1533, le Parlement signalait le nombre croissant des sergents et la nécessité d'en « reséquer » le nombre selon les termes des vieilles ordonnances : elles autorisaient pour Amont 66 sergents ; zour Aval, 90 ; pour Dole, 56. De telles places, cependant, n'étaient pas des sinécures. Le métier avait ses risques; mais il faisait vivre son homme ; les déplacements étaient payés à un taux suffisant ; surtout, forts de leur prestige, les sergents ne se gênaient guère pour terroriser les pauvres paysans, et leurs pilleries ne se comptaient pas. Plus relevés déjà, les huissiers, nommés par le président du Parlement - les quatre huissiers ordinaires surtout, jaloux de leurs prérogatives et de leurs préséances, et tirant de leurs charges d'assez beaux bénéfices; comme les concierges des prisons, ils logeaient chez eux les accusés de marque. Petites gens, petits métiers ; mais productifs déjà et considérés. Ils n'exigeaient pas de long apprentissage, ni d'études difficiles. Voici, dans une requête, le curriculum d'un huissier du Parlement, Guillaume Grabusset : dès sa jeunesse, suivant «le train et pratique judiciaire », il est entré commis aux écritures, au greffe du bailliage de Dole ; après cinq ou six ans, il a été reçu «notaire du tabellioné dud. Dole, par fut messire Jehan de Marenches, lieutenant général »; puis, tout en gardant son office notarial, il s'est fait instituer huissier ordinaire par le président Froissard ; l'état d'huissier du parquet étant vacant par décès, il le réclame et, vu ses services, l'obtient. Le voilà classé, personnage officiel, occupant un emploi porté sur les lettres d'institution du Parlement : avec un peu de chance, il conquerra l'aisance et se retirera heureux. De fait, leurs testaments, leurs contrats nous montrent assez à l'aise ces auxiliaires subalternes de la justice. Avant son mariage, l'un d'entre eux, Joseph Perrin, mort commis au greffe du Parlement en 1571. possédait seulement par indivision avec son frère, outre la moitié d'une maison de la rue d'Arans, amodiée 36 fr. par an à l'orfèvre François de Bruxelles, une dizaine de journaux à Gevry, et trois ou quatre ouvrées de vigne à Rochefort et Champvans. Pendant son mariage, il put doubler ce petit 
avoir, acheter par décret, à Dole, rue du Vieux-Marché, une maison tout entière à lui, un jardin de ville, quatre journaux pour son blé et quatre ouvrées et demie de vigne pour son vin. Tous frais, toutes dettes payés, il resta à sa veuve 175 fr. d'argent liquide; dans les caves de son beau-père, elle trouva des tonneaux, 9 queues de vin vieux, 4 queues 1/2 de vin nouveau; dans ses greniers, 2 bichots de froment; dans ses coffres, des constitutions de rentes et des obligations; dans sa maison enfin, tout un mobilier qui dit l'aisance et presque le confort. Meubles solides, sérieux : dans la chambre basse, une table double de noyer, des chaises à dossier ou revêtues de tapisserie, deux lits de noyer avec, sous l'un d'eux, « ung chariot de bois de chasne "; le grand lit, avec, sous le chariot, son "petit lit de plume garni de cussin » pour l'enfant ; " deux ciez de toille de lin garnis de franches custodes et rideaulx de mesme »; des mantes, des couvertes en tapisserie à feuillage ; des tentures ; dans la cheminée, « une apotance et barre de fer servant de commande » ou de crémaillère ; en belle place d'honneur, « une petite effigie de Dieu, revêtu de petite robe de dammas blanc » et des cadres au long des murs : « trois ymages enchassées de bois, dont la première est une Jude et la seconde est la Samaritaine, et l'aultre est une figure du Vieux Testament », sans compter « unze aultres petites images enchassées, tant en toille que papier». Ajoutez-y des coffres de cuir bouilli, quelque vaisselle d'étain : lave-mains, aiguières, vinaigrettes, et un «buffet de chasne ferré »; dans la chambre haute, des garde-robes et des armoires, des coffres de bois et de cuir bouilli abritant vêtements et linge ; pendues au mur, les armes, la selle du cheval, le harnais ; serrées et pliées soigneusement, deux capes de drap noir bandées de velours ; un manteau de drap, des robes d'hiver « en serge d'ascot fourré », en camelot tourné ou fourré d'agneau noir ; des habits plus courts : « ung robon de toille fourrée ; deux say de camelot, l'ung tanné, l'autre noir ; ung quasaquin de caffath bandée de velours »; des pourpoints en satin blanc piqué, en bombasine, avec manches de satin ; des chausses enfin, austères, en drap noir à bandes de velours, ou plus élégantes, tailladées, "descoppées », avec du "velours vyolet». Tout dit l'aisance ainsi : le coffre au linge et ses six douzaines de serviettes en chanvre gros et fin, ses neuf serviettes de lin, ses trois "serviettes de banquet», et des nappes encore : 19 nappes de chanvre, deux grandes nappes de lin, 46 linceux, des custodes, des ciels ; en réserve, 24 aunes de toile de lin, 30 de toile de chanvre, sans compter les filés. A la cuisine, batterie reluisante de pots, plats, chaudières, bassins, chandeliers, chauffe-lits en étain, en cuivre, en «matière blanche », en laiton ; l'argenterie même et 
les bijoux ne sont pas à dédaigner : sept cuillers d'argent, «six desquelles sont marquées de la marque du deffunct »; un grelot d'argent «à us d'enfant »; deux bracelets d'or ; cinq boutons d'or " propres à mettre ès patenostres »; une petite croix d'or ; trois boutons « à gourgias »; deux bagues d'or, « en l'une desquelles est atachée une turquoise et en l'autre ung ruby »; une autre bague d'or « en laquelle est enchâssé une pierre blanche taillée en forme de diamant »; deux souvenances d'or « chacune de deux boucles et deux boutons aussi d'or » ; un demiceint d'argent. Ce n'était pas un pauvre, ce commis au greffe ${ }^{35}$.

Or, de condition à peu près pareille, de fonctions et d'emplois équivalents, ils étaient une année déjà, ces subalternes de la justice et de l'administration - une armée qui ne cesse de s'accroître, de s'étendre, de se régulariser au cours du siècle. On en trouve à Dole autour du Parlement, au greffe (on compte déjà en 1545, greffier non compris, dix commis et clercs assermentés); au parquet; à la conciergerie ; on en trouve également, depuis 1562, autour de la Chambre des comptes ; à Salins, à la Grande Saunerie ; dans les sièges de bailliage, de gruerie, les seigneuries de haute justice : commis de trésorerie, scribes et « libellances », clercs de la Saunerie, greffiers et commis greffiers des bailliages, secrétaires et comptables : tous d'ailleurs, dans la mesure de leurs moyens, faisant travailler leur argent, le plaçant, le prêtant contre obligation, achetant des rentes, des terres, es maisons parfois. Ainsi s'amassent les pécules, pour pousser les enfants plus avant dans le monde.

35 Sa fortune apparaît équivalente à celle d'un marchand aisé. On peut la comparer à celle du parcheminier Vernier, de Besançon, dont nous possédons l'inventaire, du 7 novembre 1586 (Officialité, G 708). Mêmes quantités de linge ou à peu près ; même mobilier ; les habits diffèrent parce que les robes manquent chez ce marchand vêtu de court ; mais les bijoux sont équivalents : Vernier possède, lui aussi, six grandes cuillers d'argent et une petite ; une bague d'or avec émeraude ; une avec turquoise ; deux bagues dorées ou demi-dorées, avec un grenat ; une souvenance et douze « seignes » d'or ; enfin, un Agnus Dei d'argent doré, le tout taxé par l'orfèvre Chassignet à 51 fr. 9 gr. Pareillement, ses étains sont taxés 40 fr. ; son linge, 85 ; les couchages et les lits, 78 ; les meubles de bois, 80 ; les armes et ustensiles en métal, 30 ; les habite, 40. Répartition à peu près analogue, comme on voit. 


\section{II}

C'était chose chère alors que l'instruction. Pour prendre ses grades aux universités, il fallait plus que l'aisance : la fortune. Plusieurs, dépourvus d'argent, réussissaient pourtant à goûter la science. Ils se faisaient précepteurs d'enfants nobles, de petits bourgeois riches, les accompagnaient aux « études », s'instruisaient avec eux et par eux. Mais c'était forcément la minorité ; devant les autres, heureusement, l'immense domaine de la pratique s'ouvrait. A qui désirait être procureur, occuper en justice, postuler aux bailliages ou au Parlement, quelques années d'apprentissage à l'officialité de Besançon suffisaient : tous les actes s'y dressaient en latin ; avec, en plus, le sens et le goût des affaires et de la procédure, on pouvait faire figure et gagner sa vie largement. L'idéal cependant restait le doctorat: c'était la grande porte, l'entrée large et commode dans la voie des honneurs et de la fortune.

Au jeune docteur, tout sourit dans la vie. Disert, érudit, il se fait avocat, devient l'un des fameux « patrocinans » de la Comté ; ennemi de la pratique «comme de chose mercenaire et contencieuse », il consulte simplement et visite les procès ; moins indépendant, il s'enquiert d'un office. Veut-il être avocat fiscal, procureur fiscal, lieutenant de bailliage, local ou général : il a le choix entre une cinquantaine de postes. Dans la gruerie, il peut être lieutenant général, lieutenant local ou procureur ; dans la Saunerie, lieutenant ; dans les finances, receveur général, trésorier, auditeur ou maître des comptes ; sur les terres de Chalon : bailli, lieutenant, président d'Orange, procureur de Chalon, auditeur des comptes de Chatel-Guyon ; à Dole, enfin, à l'université, lecteur en droit ou en belles-lettres : un peuple de légistes trouve à s'employer.

Et ce peuple gagne. Combien? Les gages de tous ces officiers étaient faibles ; ils ne représentaient qu'une partie de leurs gains réels ; mais les textes manquent pour évaluer ceux-ci. Que valait par an une lieutenance bailliagère ? Nous l'ignorons. Avant 1586, lieutenants généraux et locaux n'étaient gagés ni par le souverain ni par les baillis leurs maîtres ; aussi passaient-ils leur temps en commissions, d'où ils tiraient grands profits. Les États de 1569 s'émurent de cette si- 
tuation ; ils réclamèrent qu'on donnât aux lieutenants des gages « annuaux et honorables », prélevés sur les exploits de justice, ou qu'on leur concédât le droit « de prendre sportule pour les vidanges des procès ». Cette dernière idée fut retenue ; les ordonnances de 1586 leur accordèrent le droit réclamé par les États ; mais nous n'avons pas eu la chance de rencontrer un texte capable de préciser les profits des lieutenant ; même indécision, quant aux procureurs et aux avocats fiscaux des bailliages : nous savons simplement qu'après la réforme de 1586, ceux de Vesoul, Montmorot et Dole eurent 200 fr. de gages fixes, les autres, 160. Les maîtres des Comptes, à Dole, touchaient 400 fr.; les auditeurs, 300 ; 300 également le receveur général du Comté, 200 le receveur de Chatelbelin, qui était en même temps trésorier d'Aval et Dole : en cette qualité, il percevait le vingtième de sa recette annuelle et, par exemple, en 1589, n'encaissait pas moins de 19671.7 s. 5 d. Pour tous ainsi, à côté des émoluments réguliers, il y avait le casuel. Si le Pardessus de Salins n'émargeait que pour 300 livres aux comptes de la Saunerie, que représentaient pour lui les gratifications, les avantages en nature: logement, chauffage, sel, mobilier même, dont il bénéficiait largement ?

Et puis, les cumuls n'étaient pas interdits. Lieutenants généraux ou locaux, procureurs et avocats fiscaux des bailliages, substituts même trouvaient, dans les seigneuries à justice du Comté, des emplois rémunérateurs, qu'on ne jugeait pas toujours incompatibles avec leurs fonctions. Lieutenant général d'Amont, Simon Renard, en 1547-48, était en même temps châtelain de Noroy-l'Archevêque pour l'archevêque de Besançon. Avocat fiscal d'Amont, Claude Belin était également, dès 1553, « conseiller et lieutenant » des seigneuries du duc de Montbéliard : en 1565, il touchait de ce chef $100 \mathrm{fr}$. de gages fixes, deux bichots de graines et une gratification de 100 fr. pour entretenir aux études son fils aîné. Or, à la même époque, il servait de bailli à la dame de Chantonnay, Nicole Bonvalot, et nous le voyons peu après, en 1556, rendre des arrêts comme bailli de Beaujeu. Pareillement, Philippe Florimond, lieutenant général du bailliage de Dole, est bailli d'Abbans en 1572 ; Guillaume Demongenet, lieutenant local de Vesoul, bailli de Rougemont en 1583 ; le lieutenant de Marenches, en 1565, lit en même temps à l'Université. Ces multiples cumuls n'allaient pas toujours sans inconvénients : on en interdisait parfois de trop compromettants, et les officiers d'Amont signalent, en 1568, les agissements suspects de certains substituts de procureurs fiscaux qui, châtelains de seigneuries diverses, s'efforçaient d'empêcher qu'on appelât de leur 
justice à celle de la cour. Il en était de plus graves encore : ceux qui, périodiquement, conduisaient devant le Parlement des officiers de la Saunerie ou de la gruerie, coupables de malversations, de faux, de dols, et renvoyés d'ailleurs sans trop de sévérité : les dossiers de toutes ces affaires scandaleuses démontrent nettement qu'à édifier leur fortune, les légistes apportaient la même avidité, le même manque de scrupules que les « monopoleurs », leurs contemporains.

Pour ceux que n'arrêtaient point de telles mésaventures, de brillantes espérances restaient permises. N'avait-on pas vu un Simon Renard, petit lieutenant d'Amont, devenir ambassadeur et membre du Conseil privé ? Ne devait-on pas voir Philippe Il nommer au Conseil des troubles un Claude Belin, simple avocat d'Amont, et, en 1582, un lieutenant de gruerie, Jean Froissard, au Conseil privé, puis à la présidence de Bourgogne - ou faire d'un Benoît Charreton, Premier des Comptes à Dole, un conseiller et commis des finances aux Pays-Bas, puis un trésorier de l'Épargne, administrateur des confiscations, chevalier, baron de Pimorin, seigneur de cinq ou six notables seigneurs ? Fortunes exceptionnelles, sans doute, mais à tout lieutenant, à tout avocat un peu actif et bien apparenté, l'ambition était légitime de pouvoir un jour, revêtu d'écarlate, siéger dans la grande salle du Parlement où le plus haut seigneur, et le plus orgueilleux, ne pouvait pénétrer que nutête et sans armes.

D'une pareille situation, les profits ne laissaient pas d'être enviables. Tels que les avait fixés l'ordonnance de 1509, les gages du président de Bourgogne s'élevaient à 500 fr. par an; ceux des chevaliers, conseillers et procureur général à 20 S. par jour, soit $365 \mathrm{fr}$. par an. Ces chiffres étaient modestes : quand, au milieu du siècle, la hausse des prix commença, les parlementaires réclamèrent une augmentation. Philippe II, lors de son avènement, l'accorda ; il porta, par patentes du 18 février 1556-57, les gages des conseillers de 20 à24 S. par jour, ce qui fit 438 fr. ou 140 écus par an ; le président toucha 1241 1. t. Dès 1575, du reste, les parlementaires envoyaient un des leurs "par deça », démontrer que leurs 140 écus ne répondaient ni à leurs besoins ni à leur dignité : le prix des denrées avait, déclaraient-ils, triplé en quelques années. Le gouvernement des Pays-Bas refusa, cette fois, d'écouter leurs plaintes : à la fin du siècle, en 1600, le président touchait toujours ses 1241 1., les conseillers leurs 438 fr. Mais combien leur valaient, à tous, les commissions, les délégations, les enquêtes qu'on leur payait à part, les consultations sur procès qu'ils donnaient volontiers, les frais de voyage qu'ils se faisaient 
allouer ? Nous ne savons ; mais il suffit de parcourir les testaments, les inventaires, les contrats qui évoquent la splendeur des fortunes parlementaires, pour comprendre le propos des plaideurs comtois : «que les conseillers du Parlement n'avaient été trois ans en l'estat, qu'ilz estoient riches de haute richesse. »

Aux gages de ces légistes, comparons ceux des gentilshommes pourvus d'offices. Le gouverneur a 1200 livres, comme le président. Il est vrai que ses pensions sont plus fortes: François de Vergy, en 1589, touche 3400 1. de ce chef ; mais c'est un vieux serviteur, au bout d'une longue carrière. Les trois baillis, de gages réguliers, touchent : celui d'Amont, 160 fr. par an ; celui d'Aval, 140 1. est. ; celui de Dole, 120 ; c'était moins qu'après 1586, un procureur fiscal de Vesoul ou de Dole. Il est vrai qu'ici encore intervenaient les pensions ; mais elles n'étaient pas de droit - et montaient-elles toujours aussi haut que les profits « casuels » des officiers royaux ? Quant aux deux chevaliers d'honneur du Parlement, ils étaient traités sur le pied des conseillers. Restaient les capitaineries; mais celles qui n'étaient pas aux mains des gouverneurs, des baillis ou des chevaliers d'honneur, ne rapportaient rien : une dizaine de francs pour les châteaux intenables ; pour les autres, de 30 à 60 1. par an, 100 au plus, avec souvent la résidence obligatoire. Minces ressources au total et rares privilégiés. Nous aurions aimé en dresser la liste complète à différentes dates. L'entreprise, malheureusement, est impossible. Les pensions et les gages se trouvaient alors assignés sur les caisses des deux trésoriers de Vesoul et d'Aval et Dole, recevant les «clairs deniers » des recettes domaniales des trois bailliages, et sur celle du receveur général, alimentée à la fois par les clairs deniers de ces deux trésoriers, ceux du trésorier de la Saunerie, de divers administrateurs locaux, du receveur de Chatelbelin et même, pendant un temps, du receveur des confiscations. Or, la plupart de ces comptes ont disparu, et lorsque l'un survit, les deux autres sont perdus. Une seule année fait exception : nous avons, pour l'exercice 1589-90, les comptes des deux trésoriers et, pour l'exercice précédent (1588-89), ceux du receveur général. Utilisons ces documents : malgré la différence de date, ils peuvent permettre une étude d'ensemble.

Nous y trouvons cités les officiers suivants : I gouverneur, touchant 12001. t. ; 3 baillis à 160 fr., 140 et 120 l. ; 2 prévôts des maréchaux, l'un à 300, l'autre à 150 fr. ; 11 capitaines de châteaux domaniaux et 6 de châteaux de Chalon, soit 17 au total, deux capitaineries domaniales étant dépourvues de titulaires. De ces 17 officiers, aux gages variant de 6 l. est. à 30 fr. pour les châteaux domaniaux, et de 
10 à 100 fr. pour les châteaux de Chalon 8 seulement appartiennent à d'anciennes familles nobles. En tenant compte des cumuls, on constate, d'une part, que 23 emplois propres à la noblesse sont énumérés dans les trois comptes ; de l'autre, que 13 noms de nobles d'épée s'y rencontrent. Les capitaineries qui, pour des raisons diverses, ne sont pas portées sur ces trois documents, sont au plus une vingtaine ; la moitié d'entre elles pouvaient être confiées à des représentants d'anciennes familles ; en évaluant très largement les probabilités, on aboutit, les cumuls défalqués, au chiffre de 25 à 30 nobles trouvant, en temps normal, dans les offices et les charges militaires de leur pays un emploi plus ou moins faiblement rémunéré de leur activité.

Il faut y joindre les pensions. Sur la recette de Vesoul, en I589-90, en sont assignées deux, l'une de 200, l'autre de 40 l. Celle de Dole, la même année, en supporte quatre, deux de 600, une de 700, une de 800 . La recette générale, en 158889, en fournit vingt-neuf, variant de 81 l. 2 s. 2 d. t. à 2000 l. t. Au total, 35 pensions, réparties (car, là encore, il y a des cumuls) entre 29 titulaires, dont 17 seulement appartiennent à la noblesse d'épée, les autres étant des anoblis de plus ou moins vieille date. Beaucoup de ces personnes sont d'ailleurs, en même temps, des titulaires d'office : le gouverneur, par exemple, ou les baillis. En récapitulant, en ajoutant aux titulaires de pensions les titulaires d'offices mentionnés dans nos comptes, en ajoutant à ceux-ci l'un des chevaliers d'honneur, Antoine d'Oiselay (l'autre était Frédéric Perrenot), en y adjoignant encore le gruyer, - un Antoine de la Baume, un Philibert de Montmartin - on arrive au total d'une cinquantaine de nobles pourvus, en Comté même, d'offices et de pensions, moitié d'entre eux à peine touchant, de ce chef, des sommes importantes. Qu'était ce chiffre, comparé au chiffre total des nobles comtois - surtout, à celui des officiers, des gagés, des pensionnés bourgeois?

\section{III}

Depuis le début du siècle, qu'on suive attentivement l'histoire de ces derniers : c'est un progrès, une multiplication continue des offices. 
En 1531, outre le président, les deux chevaliers et les deux fiscaux, il n'y a que onze parlementaires. Trente ans après, il y en a quatorze ; et les jeunes ne cessent d'en réclamer l'augmentation. En 1562, une Chambre des Comptes s'installe à Dole : voilà cinq ou six offices importants à pourvoir, sans compter les subalternes. En 1569, à la suite des troubles, toute une administration des domaines confisqués, avec receveurs et trésoriers, s'organise. En 1586, régularisation de l'institution bailliagère : les lieutenants locaux se muent en généraux, des fiscaux s'installent dans chaque siège secondaire, des greffiers à vie dans les bailliages, une cinquantaine d'offices se consolident. Et de partout, vers ces postes fructueux, c'est une ruée d'appétits et d'ambitions neuves : ambitions de robins, mais de marchands aussi.

Le juriste ne se fait pas négociant. Le négociant, par contre, fait volontiers de son fils un juriste : c'est qu'au riche la robe confère, en plus, le prestige. Voilà pourquoi Claude Darc, d'Amance, un marchand fortuné, marie trois de ses cinq filles à des docteurs - et, s'il garde pour l'aider « son bien aimé Guillaume », il fait docteur lui-même son cadet Simon. Rien de curieux comme les passages, d'un accent personnel rare en de telles pièces, que, dans son testament, il consacre successivement à ses deux héritiers. Simon, le docteur, n'est pas le préféré : il n'aura que $6000 \mathrm{fr}$. en constitutions de rente - $6000 \mathrm{fr}$., ce qu'ont reçu de dot chacune de ses soeurs. Mais, ajoute le père, je le tiens quitte en plus « de toute la dépence qu'il m'a fait, tant à la poursuite de ses estudes que de son entretien, dez vingtquatre à vingt-cinq ans passez, et tant à Paris, Fribourg-en-Bisco, Cologne, Rome, Naples, Dole que aillieurs, en quoy il a continué et continue jusques à oires, encoires qu'ilz sont passez huict ans qu'il est docteur ; que se monte et revient (ainsi Dieu m'aide !) à plus de douze mil francs. » - Quel contraste avec l'autre, le marchand, qui, depuis vingt ans, manie et négocie les affaires de la maison, « ayant exposé les meilleurs ans de sa jeunesse et mis sa personne maintes fois en grand péril et danger, pour les longs voyages » qu'il a dû faire « en pays estranges et loingtains, ayant, pendant les vingt ans, par ses labeurs et travaulx, accreu et augmenté le bien paternel beaucoup plus que led. docteur n'a dépencé... » Oui, mais le docteur n'en a pas moins son utilité. Il est messire ; il vit à Dole d'une vie facile ; il atteint à une dignité supérieure, et sa famille en bénéficie.

Une vraie caste de robins s'organise strictement. Si les gros marchands unissent volontiers leurs enfants et nouent entre eux, de Gray à Besançon, de Dole à 
Salins, des liens étroits d'affection et d'intérêt, bien plus encore les parlementaires s'affermissent, s'enracinent dans leurs offices par des mariages choisis. Ici encore, citons des faits précis. Voici la liste des conseillers inscrits sur les lettres de réinstitution du Parlement par Philippe II, le 23 juillet 1556 : ils sont neuf, sans compter les deux conseillers clercs, un avocat fiscal, le greffier et le procureur général. Or, des deux conseillers clercs, l'un, Jean de la Tour, est de la même famille qu'Humbert de la Tour, qui siégera comme conseiller clerc également, de 1575 à 1591 ; l'autre, Guy de Poligny, est, par sa soeur Anne, le beau-frère de l'ancien président Marmier. Passons aux laïques. Le premier, Henri Colin, est le frère d'Hugues, procureur fiscal d'Aval depuis 1548 au moins jusqu'à 1577; il est le père de Jérôme, qui, lieutenant à Pontarlier de 1565 à 1568, épousera, en octobre 1574, une fille du trésorier de Salins, Bonet Jaquemet, et deviendra ainsi le beaufrère de François Grandjean, à qui il succédera au Parlement en 1586. - Etienne le Clerc, fils d'un procureur postulant à l'officialité de Besançon, est, par sa deuxième femme, Guillemette Thomassin, gendre du feu conseiller Thomassin ; par sa fille Léonore, beau-père du Premier des Comptes Renobert de Mesmay. - Sur le troisième, Jean Courvoisier, nous n'avons pu recouvrer d'indications généalogiques précises ; mais le quatrième, Etienne Fauche, a pour frères le professeur de droit civil Nicolas et l'avocat Jean ; il est probablement le père de l'avocat fiscal Nicolas, gendre de la femme du conseiller Chuppin, et certainement le beau-père du conseiller Simon Bourrelier, de Malpas. - Le cinquième, Luc Chaillot, est fils du conseiller Christophe; sa première femme, Louise de Saint-Mauris, est la soeur du fiscal Guillaume ; son frère Jean, le gendre du conseiller Robert de Bergières; ses soeurs Barbe, Guillemette et Jeanne, les femmes de l'avocat fiscal de Dole, Humbert de Boisset, du conseiller Musy et du greffier Barnard. - Le sixième, Nicolas Chuppin, mari de Louise de Battefort, veuve en premières noces du receveur général Jean Mouchet, est l'oncle du futur conseiller Mairot. - Le septième, Pierre Sachet, par sa femme Jeanne Boudier, est le beau-frère du trésorier Bonet Jaquemet et, par sa fille Claudine, le beau-père du futur président Pierre Froissard de Broissia. - Sur le huitième, Pierre Vauchard, les renseignements nous manquent ; mais le neuvième, Charles Grandjean, est le père du futur conseiller François et, par sa femme Claudine Mairot, l'allié de ces Mairot de Pesmes qui devaient fournir en Guyon un conseiller. 
Un seul fiscal figure sur la liste : Guillaume de Saint-Mauris, gendre du professeur dolois Étienne Nicod, frère du célèbre avocat Prudent, beau-frère du conseiller Chaillot, cousin germain du conseiller clerc Jacques et du futur procureur général Luc de Saint-Mauris. Quant au procureur général Marin Benoît, il épousera en secondes noces Françoise Nicod, veuve du fiscal Saint-Mauris et par sa première femme Marguerite Clereval, dont la soeur Claudine avait épousé le greffier Vaulchier, il sera le beau-Père de son successeur, Henri Camu. Enfin, le greffier Étienne Barnard est le neveu par sa mère, Pierrette de Boisset, du conseiller clerc Mercurin de Boisset, de l'avocat fiscal Humbert de Boisset, du trésorier de Vesoul Jean de Boisset ; un premier mariage, avec Françoise Delivran, le fait beau-frère du conseiller Seguin; un second, avec Jeanne Chaillot, gendre du conseiller Christophe et beau-frère du conseiller Luc, de son oncle Humbert de Boisset et du conseiller Claude Musy.

Écheveau singulièrement emmêlé, comme on voit. Du reste, un tel tableau, dressé au hasard de patientes recherches et de menues découvertes, ne saurait prétendre à être complet, et dans la réalité, les liens de famille de ces parlementaires étaient sans doute plus compliqués encore! Tels quels, ces exemples montrent comment s'unissaient, se recrutaient, se soutenaient entre elles les races orgueilleuses des robins dolois. Et qu'il serait aisé de les multiplier ! Voici la dynastie des Boisset - les descendants du conseiller Mongeot : ses fils, le conseiller Louis et le professeur Mongeot, son petit-fils le grand-juge de Saint-Oyan, Guillaume ; les descendants du procureur général Guillaume : ses deux fils, l'avocat fiscal de Dole Humbert et le conseiller clerc Mercurin. - Voici les Boutechoux, Jacques, avocat fiscal au Parlement sous Charles-Quint ; Claude, le gendre de Vandenesse avocat fiscal lui aussi, puis conseiller au Parlement, puis président ; Hugues son frère, maître des requêtes au Conseil privé. - Voici les Chaillot, les Grandjean, les Saint-Mauris, les Colin déjà signalés; les Froissard de Broissia, descendants d'Anatoile, président d'Orange : Pierre, le président, gendre du conseiller Sachet ; Jean, son puîné, lieutenant de la gruerie, puis conseiller au Conseil privé, puis président à son tour et beau-père du procureur général Luc de Saint-Mauris... Ceux-là mêmes dont la race ne s'épanouit pas en aussi riche, aussi magnifique floraison, tiennent par des liens multiples à leurs confrères : tel, un Simon Bourrelier de Malpas, petit-fils du procureur général Guillaume de Boisset, gendre du conseiller Étienne Fauche ; un Jean Colard, fils d'un conseiller au Parlement du 
duché, neveu d'un procureur dijonnais, allié aux Camus et aux de Marenches, beau-frère par sa femme du fiscal d'Amondans ; un président Jaquinot, allié par sa première femme à la famille bailliagère des Demongenet, par la seconde à la famille parlementaire des Chaillot ; un Jean le Moine, neveu par alliance du président Marmier, apparenté aux Barnard, aux Mairot, aux Boutechoux - et tant d'autres. Entre tous, les femmes, les veuves créent des liens compliqués. Comme on se marie très tôt, on se remarie souvent; des familles s'accolent, s'entremêlent, se poussent aux honneurs d'un même effort, d'un pas semblable : telles, celle des Renard et celle des Lulier, ou, familles bailliagères, celles des Poinsot et des Demongenet.

Car eux aussi, lieutenants, procureurs ou avocats de bailliage, ils forment des dynasties, une vraie caste, fermée. Dans le court espace d'un demi-siècle, entre 1550 et 1600, quelle longue liste déjà : ce sont les Demongenet, lieutenants locaux de Vesoul avec Louis (1547-1552); Pierre (I554-I562); Jean Guillaume (1583-1599) ou, avec François, procureurs fiscaux d'Amont à Vesoul. Or, François épouse Bonne Belot, d'une honorable famille du Comté, fille de Jeanne Droz, nièce de l'ancien procureur d'Amont Jean Poinsot ; celui-ci avait succédé dans son état à son père Thiébaut Poinsot, qui lui-même avait remplacé son père Jean : François Demongenet, tout jeune, put dans les papiers des Poinsot « comprendre et congnoistre les charges, devoirs et choses requises à l'administration et exercice de tel état de procureur » et souder l'une à l'autre deux dynasties bourgeoises. A côté, voici les Thomassin, lieutenants généraux d'Amont, avec le futur conseiller Adrien (1581-1593), ou lieutenants locaux de Vesoul, puis lieutenants de Gray avec Nicolas (1565-1580) ; dans le bailliage d'Aval, les du Tartre père et fils, Pierre (1548-1556) et François (1566-1571), tous deux généraux, tous deux bien mariés ; à Poligny, les Le Jeune, Mathieu et Gilbert, ce dernier conseiller de 1586 à 1590 ; à Pontarlier, les Colin : Henri, sr d'Arçon, et Jérôme, lieutenants ; Hugues et Charles, procureurs fiscaux à Montmorot - et tant d'autres : les Vigoureux, Thiébaud le père et Quentin le fils, tous deux avocats fiscaux d'Aval ; les Belin, Claude, le père, fiscal d'Amont avant d'être conseiller, et ses deux fils : Charles, fiscal d'Amont, et Claude, bailli de Luxeuil ; les Thiébault, Renobert et Pierre, procureurs fiscaux de Dole ; les Heberling père et fils, lieutenants locaux à Dole : Horibald, beau-frère du conseiller Phénix, et Quentin, gendre du conseiller Poly. Et ce sont pareillement les Poly de la gruerie, les Delesmes du greffe, les Denys et 
les Thiébault du greffe et du parquet, une centaine de familles tout au plus accaparant les emplois, les honneurs, monopolisant à leur seul profit le service du prince et le prestige de la robe. Quelque création nouvelle s'opère-t-elle en Comté ? Une Chambre des Comptes par exemple est-elle rétablie à Dole ? il faut voir comment conseillers et fiscaux travaillent à s'annexer maîtres et auditeurs. Le Premier, Constance de Marenches, frère du fiscal Louis, est gendre du conseiller Pierre Febvre ; Renobert de Mesmay, son successeur, épouse successivement Philippa de Boisset, soeur et fille des conseillers Louis et Mougeot, et Léonore le Clerc, fille du conseiller Étienne; Nicolas Racle, qui vient ensuite, est, par sa femme Jeanne Froissard, le beau-frère des deux présidents de Broissia, Pierre et Jean ; et ce sont mêmes alliances pour un Jean Camu, frère du procureur général Henri ; un auditeur Viron, mari d'une Lulier ; sans compter les receveurs ou les trésoriers.

Importants personnages, et qui, forts de leurs fonctions, de leurs alliances et de leurs richesses, avaient de quoi inquiéter la noblesse secondaire. Entre un pauvre homme d'écuyer, noble mais gueux, et un conseiller au Parlement, quelle mesure possible ? Et quel avantage restait-il au noble, si le robin, puissant déjà, s'anoblissait, prenait un nom de terre, se titrait de Montcourt s'il se nommait Chaillot, de Crillat s'il s'appelait Gaillard, ou de Landon au lieu de Quentin le Veau?

La noblesse, en effet, n'apparaissait plus au grand bourgeois comme un idéal inaccessible. Elle était proche de lui, et presque à sa portée. Riche par le commerce, l'usure, l'exploitation du peuple des campagnes, il se retournait contre le noble appauvri et, tentant contre lui une action décisive, entamait la conquête de la seigneurie.

\section{IV}

Pour vivre de la terre noble, le bourgeois, sans doute, n'attendait point d'en avoir la pleine propriété. Il s'y installait, il en bénéficiait déjà quand le noble la tenait encore. C'était un personnage que « le superintendant : aux affaires et négoces » de tel grand seigneur : un Rye, un La Palud, un Montmartin. Gradué en droit, licencié pour le moins, le plus souvent docteur, homme de bon conseil et 
d'activité sans défaillance, toujours prêt à courir les champs sur son bidet, il savait faire fortune par des moyens licites. Tel, l'intendant favori de Nicole Bonvalot, « le bon secrétaire Amyot », qu'elle couche avec éloges sur son testament et dont Jaquemet disait, avec une sorte d'admiration : "Il s'est si sainement conduit que, sans avoir faict tort à sa bonne maîtresse, l'on l'estime riche de plus de trente mil frans, que n'est peu; et en trouvera l'on peu de telle faculté que soit propre pour mectre en cette charge. » D'autres comme lui, acquérant richesse et considération à manier les affaires d'autrui, devenaient la souche de familles prospères ; mais, contre la seigneurie, les bourgeois tentaient des entreprises plus directes - et, pour commencer, l'amodiaient.

Le noble était mal préparé à gérer ses domaines. Il n'avait ni toujours l'instruction, ni surtout l'ensemble de qualités et de défauts requis pour exploiter utilement terres et tenanciers. Et puis, il était absent, fréquemment ; au pays même, ses terres étaient dispersées, éloignées l'une de l'autre, difficiles dès lors à surveiller de près. Bienvenu, le bourgeois, homme d'affaires et calculateur émérite, qui offrait au seigneur de le décharger de tout soin moyennant un bon bail. Le noble réfléchissait, consultait ses registres. La somme offerte, sans doute, ne montait pas au chiffre qu'atteignaient, les bonnes années, les recettes totales de la seigneurie. Mais, de ce chiffre, ne fallait-il pas déduire les frais d'exploitation, les gages d'officiers, les mille dépenses inévitables d'entretien ? Et les mauvaises récoltes ? Et le fastidieux souci des procès, les difficultés de tout ordre avec les tenanciers, les décisions à prendre, les rapports à ouïr ? N'était-il pas tentant de pouvoir, d'avance, asseoir son budget, tabler fermement sur une somme connue, payable à jour fixe ? S'il y avait au marché quelques écus à perdre, ne seraient-ils pas regagnés en tranquillité, en sécurité morale et matérielle ?

Le bourgeois, de son côté, a son compte fait d'avance. Il sait que le prix du bail qu'il propose ne représente pas le produit réel de la seigneurie directement et durement gérée par lui, sans intermédiaire, sans receveur interposé. Il sait que les tenanciers, sous lui, rendront davantage, qu'il pourra en tirer ce que le noble, malhabile ou ménager de ses hommes, n'en saurait obtenir. Toutes les chances sont pour lui et, sauf le cas fortuit d'une série de mauvaises années, son marché lui laissera aux mains de clairs écus... Tous les deux ainsi, l'amodiateur et l'amodiataire, trouvent leur avantage au marché - mais l'avantage de l'un est positif, si négatif celui de l'autre. 
Voilà le secret de tant d'amodiations, faites par des marchands ou des bourgeois des villes. Locataires tantôt isolés, tantôt groupés en société, réunis à plusieurs pour une même entreprise. Dans ces associations se rencontrent parfois, à côté d'un spéculateur citadin, un ou deux gros cultivateurs, aptes à conduire euxmêmes l'exploitation du domaine amodié, à lui faire produire son plus fort rendement. Lorsqu'en 1594, Oudot Agnus, gros marchand de Gray, de la famille de ces Agnus qui, entre autres "marchandises », faisaient le trafic du fer sur la Saône, s'associe avec Thevenin et Sébastien Caignoz de Noiron pour amodier de Fernand Gauthiot d'Ancier les «seignories, prouffits et revenus de Noiron et Nanthouard ; » lorsqu'il s'engage à en cultiver les terres pendant neuf ans, bien et dûment, à « en faire marner jusques à 34 journaulx, en mettant à chascung journaulx 400 tomberés de marne bonne et suffisante », il est évident que ce marchand avisé escompte les bénéfices que ses deux associés, hommes du pays et cultivateurs, ne manqueront pas de réaliser en exploitant directement les terres louées ? Calcul juste, à compter le nombre d'actes analogues qui nous sont parvenus.

Actes de toutes formes et de toutes conditions, conclus pour trois, six ou neuf années, tantôt laissant au locataire, avec toutes les charges, toutes les sources de revenus, tantôt spécifiant un partage, tantôt exceptant du contrat la jouissance de certains immeubles ou de certains droits : tels qu'ils sont, ils attestent quels besoins fréquents avait du bourgeois le noble d'épée, et de quelle hypothèque l'activité bourgeoise frappait déjà la seigneurie. Mais d'autres, mieux encore, nous éclairent sur ce point.

Le 18 décembre 1586, « en la chambre devant de noble Gaspard Monyet », citoyen de Besançon, comparaissent un prêtre, messire Fr. Regnaud ; un receveur de seigneurie, Mathieu Vermot, de Métabief, et un marchand, Jean Vuillard, tous trois venant au nom de l'abbé commendataire de Saint-Paul à Besançon, l'évêque de Lausanne Ant. de Gorrevod. A Monyet, ils remettent, en pièces de deux gros, la somme de 864 fr., pour satisfaire, disent-ils, le Monyet « de semblable somme de 864 fr., pourtée pour l'admodiation faite par mon Rme Seigneur au Monyet des mayries et seigneuries de Naysel et Merey ». L'acte stipulait, en effet, que moyennant restitution de pareille somme, l'amodiataire serait tenu de quitter l'amodiation. D'une telle convention, la portée est nette : elle équivaut, pour le bailleur, à un emprunt sur gages. Et voilà que nous entrevoyons, pour la bourgeoisie marchande en possession du numéraire, une source nouvelle de profits et d'en- 
richissement. Comme elle vit du paysan, comme elle l'exploite en lui prêtant de l'argent, vivrait-elle donc du noble, pour les mêmes raisons et par les mêmes moyens ?

\section{V}

C'est le troisième acte, en effet, du drame économique que nous décrivons à grands traits. Le bourgeois vit de la seigneurie comme receveur, homme d'affaires et de confiance du seigneur. Il en vit comme locataire. Il en vit enfin comme prêteur : c'est son gage.

Pas plus que ses tenanciers, toutes proportions gardées, le noble de moyenne ou de petite condition n'apparaît, en effet, riche de numéraire. Le moindre paiement le laisse préoccupé. On le voit bien, dans les testaments ou les contrats, à tant de précautions prises pour échelonner les échéances, éviter de trop soudains débours. Lorsque damoiselle Marguerite de la Thouvière, veuve de l'écuyer Marc de Reculot, lègue à sa fille Jeanne, en plus de sa dot, une somme de $500 \mathrm{fr}$., elle la stipule payable trois ans seulement après son obit. Délai notable, qui permettra aux fils héritiers de prendre à loisir leurs dispositions. Les trois ans écoulés, s'ils n'ont pas la somme, ils devront servir à leur soeur les intérêts, mais au taux très réduit de 5 \%. Mêmes mesures en ce qui concerne la dot des trois filles non mariées: Louise, Isabelle, Dorothée; chacune aura 1000 fr., payables deux ans après son mariage, ou sinon, la rente à $5 \%$. - D'une prudence analogue, nombre de testaments nobles.

Or, le noble a-t-il quelque besoin d'argent ? Pour lui comme pour le vilain, il n'est que deux solutions : la vente ou l'emprunt. Bien souvent du reste, les deux n'en font qu'une. Un seigneur, par exemple, dans un moment de gêne passagère, constitue une ou plusieurs rentes. Mais d'abord il lui faut donner un ami comme caution, ou laisser prendre hypothèque sur ses biens. Ensuite, les taux sont élevés, donc lourds les arrérages ; fréquemment, en signant le contrat, le noble emprunteur a trop présumé de ses capacités. Dans son embarras, il emprunte à nouveau, ajoute de lourdes charges aux anciennes, embrouille si bien ses comptes qu'au bout de quelque temps, la vente s'impose à lui. Claude de Cicon seigneur de Ri- 
checourt, sa mère Huguette de Baissey et son frère Guillaume ont, le 13 novembre 1544, à Vesoul, constitué à Philippe Thomassin, docteur en droit, une rente annuelle de 180 fr., en échange d'une somme de 1000 écus d'or soleil ; ils ont dû, pour ce, faire hypothéquer leurs biens. Or, ils se sont bientôt trouvés en retard pour leurs paiements. En 1547, ils devaient déjà 60 fr. sur le terme de 1545, plus les $180 \mathrm{fr}$. de 1546 : au total, $240 \mathrm{fr}$. Quel remède ? Ils savent bien - ils l'écrivent que 180 fr. se trouvent malaisément, qu'il leur est difficile, "sans grandz interestz », de débourser pareille somme chaque année ; «à raison de quoy, pour plus facilement et à moindre fraiz et interestz estre payer et satisfaict led. messire Philippe », ils lui cèdent trois chevances sises à Jussey, à Combeaufontaine et à Ternuay. Les voilà délivrés de leur dette et de leur rente, ils respirent sans contrainte mais pour un temps seulement.

Car les dettes recommencent. Après Thomassin, les Thierry: damoiselle Françoise Garnier, veuve de noble Pierre Thierry ; François Thierry ; Alonze sa soeur, veuve de noble Chaillot, conseiller au Parlement de Dole. A eux aussi, Claude de Cicon emprunte. À eux aussi, il doit vendre des terres pour les désintéresser. En 1561, ils ont de lui entre leurs mains : une constitution de rente de $32 \mathrm{l}$. 10 s., assise jadis, le 25 mai 1541, sur les tailles et fours de Richecourt et d'Aisey, en échange d'une somme de 460 l. t. ; une obligation de 300 fr., datée du 15 février 1546 ; une cédule de 249 fr. 14 s. t., datée du 2 mai 1556 ; enfin, une créance de 45 fr. 13 s., arriéré de paiement de la rente de 32 l. ; au total, 1100 fr. Comment les payer, sinon en biens-fonds ? Et voilà cédés aux prêteurs tous les droits de Claude de Cicon à Jussey, ses censes et ses terres, six pièces, vingt journaux en tout et la semée de dix quartes, sans compter quatre prés, dont l'un de trente fauchées.

Tout le monde fait de même. Au moindre imprévu, l'emprunt ; comme gage, la seigneurie. Claude de Mugnans et son frère François perdent un procès; il leur faut payer 743 fr. 8 gros. Vite, ils vendent deux rentes, l'une de 8 écus d'or sol. à Antoine Mareschal, docteur ès droits, cogouverneur de Besançon, moyennant 100, écus ; l'autre de 16 écus à Jeanne Belot, veuve de Léonard Jacquot, citoyen de Besançon, moyennant 200 écus. Restent à solder les frais du procès - environ 1500 fr. Nouvel achat de rente au chanoine Boitouset, official de Besançon, et à sa soeur Jeanne Ragu ; Jeanne de Corbessain, femme de Claude, sert de caution ; 
de là, nouvel acte de son beau-frère François, s'obligeant envers elle lui et ses biens, pour la couvrir de tous risques éventuels...,

Et presque toujours, le dénouement se ressemble : c'est la vente. Guy de Montureux, sr de Melisey, s'est obligé envers la veuve de Georges Mercier, de Melisey, à la somme de 3000 fr. ; elle le poursuit en justice pour paiement. Le bon seigneur, dans une pièce notariée, nous fait part de ses réflexions : "Considérant, écrit-il piteusement, qu'il n'a moyen pour satisfaire à lad. somme sans vandre et alliéner le bien et chevance qu'il a aux lieu, finaige et territoire de Montjustin, comme pièce à luy moings dommageable ", il vend à noble Adrien de Salives, conseiller au Parlement de Dole, tout ce qu'il possède à cet endroit : une maison ancienne et sa tour ; 14 main-mortables de dure condition, des prés, des vignes, des terres, des bois, des droits de justice, ses tailles et droits de prise, le tout pour 2700 fr. Encore Adrien de Salives ne paie-t-il comptant que 2 200, et s'engage-til pour les 500 autres envers la veuve Mercier. Quant aux $300 \mathrm{fr}$. restants, Guy de Montureux les assigne sur un sien moulin de Melisey ; il le cède à ses créanciers jusqu'à leur complet désintéressement.

Beaucoup, plutôt que d'emprunter, vendaient immédiatement. En mai 1553, le seigneur de la Chaux, Jean de Poupet, un des familiers de Charles-Quint, se trouve à court d'argent : vite il passe procuration à son maître d'hôtel, Christophe de Villey, pour qu'il vende de ses biens à réachat, ou qu'il les grève d'hypothèques et de rentes jusqu'à concurrence de 6000 écus d'or. Rentes rachetables, ventes à réachat : la stipulation est des plus importantes. C'est que, lorsqu'il se résout à une aliénation, le noble, pour rendre plus facile son sacrifice, peut se dire d'abord qu'il cède un bien peu productif : les droits seigneuriaux étaient si minimes et si peu susceptibles de s'accroître. Surtout, ne vendant qu'à réachat, il peut nourrir un espoir, trop souvent chimérique : celui de rentrer un jour en possession du domaine aliéné.

Il le fait parfois, du reste. La seigneurie, avons-nous dit, n'est pas un territoire, mais un ensemble de droits. A y regarder de plus près, c'est une valeur - et une valeur que, précisément, la faculté de rachat rend bien plus mobile qu'on ne pourrait croire. C'est une valeur qui se négocie, se transmet, se prête à de multiples opérations - quelques-unes, audacieuses. Voici la terre de Dramelay, dont Rousset nous dit les aventures successives. Ph.-Fr. de Luyrieux, seigneur de Meximieux, l'achète en 1512 à Philiberte de Luxembourg. Il la vend peu après, à rachat, à 
Louis du Saix. En 1531, il la reprend aux héritiers de ce seigneur. Mais, en 1543, son héritière à lui, Isabelle de Luyrieux, la vend à rachat à J. de Meyria et à J. Mouchet. Le fils d'Isabelle, Philibert de la Chambre, la rachète ; mais ses héritiers, le 29 octobre 1561, la vendent au conseiller Nicolas Chupin. - Autre exemple : l'amiral Chabot épouse Françoise de Longwy qui lui apporte les terres de Gevry et Neublans. Il les reprend de fief en 1532. Mais en 1541, il les vend à rachat pour 38720 l. t. à Ruy Fernandez d'Almeida, ambassadeur de Portugal. Pas pour longtemps d'ailleurs, puisqu'en février 1543, nous le voyons reprendre de fief ces deux seigneuries, et qu'à son tour, en 1547, sa femme, devenue veuve, les reprend. De tels exemples pourraient se multiplier : ils montrent clairement la vraie portée de beaucoup de ces ventes à rachat. Ventes avantageuses parfois, qui pouvaient faire bénéficier le vendeur des fluctuations du cours de la monnaie : Grivel, dans ses Décisions, en rapporte un exemple classique. Il s'agit des seigneuries domaniales d'Apremont et Gendrey. En 1435, le duc Philippe de Bourgogne les avait cédées à Philippe de Ternans, jusqu'à concurrence de 500 l. t. par an. Si le revenu dépassait ces 500 l., le surplus reviendrait au duc qui se réservait en outre, pour lui et ses hoirs, le rachat moyennant 5000 saluts d'or de 70 au marc. En 1538, les héritiers de Philippe de Ternans présentent requête à Charles-Quint pour céder Apremont et Gendrey à Nicolas Perrenot de Granvelle. Accordé ; mais la clause de rachat sera réinsérée, textuellement. La vente fut faite pour 5000 saluts d'or, payés en 5333 écus d'or soleil, l'écu sol pris ainsi pour 45 s. 9 gr. : au total, c'était 12000 fr. monnaie, ce qui mettait le salut à 48 s. t. - Or, en 1599, l'archiduc Albert prétend racheter Apremont et Gendrey. Il offre 12000 fr. à Frédéric Perrenot. Celuici refuse, proteste : En 1435, prétend-il, le salut d'or valait 35 sols; en 1538, 48 ; en 1599, il en vaut 66 et 8 deniers : c'est 20 000, non 12000 fr., qui sont dus. À cette époque du reste, il n'existait plus de saluts d'or ; mais l'écu soleil était passé de 27 gros en 1538 à 40 en 1599.

Champagney eut beau argumenter, citer Bodin : le Parlement jugea valable l'offre des 12000 fr. Cas extrême sans doute. Mais il attire notre attention sur certaines conséquences possibles des ventes à rachat - si fréquentes, que souvent les seigneurs engagistes du domaine, plus avisés que Frédéric Perrenot, faisaient par le souverain augmenter le « rachat ». 


\section{VI}

Au reste, toutes les ventes à rachat ne se terminaient pas par une reprise, et toutes les ventes n'étaient pas à rachat. Chaque jour se multipliaient les prises des enrichis d'origine bourgeoise sur la terre noble ; chaque jour, de " nouveaux riches » devenant « nouveaux nobles » prenaient possession d'une de ces demeures au grand toit d'ancelles couronné de girouettes, dont leurs pères jadis ne franchissaient le seuil qu'en receveurs ou en amodiataires.

Sans doute, il fallait être noble pour acquérir un fief ou le tenir. Mais d'abord, fréquentes étaient les usurpations de noblesse que les édits s'avouaient impuissants à réprimer. Nul n'aurait dû se dire noble ni être tenu pour tel, qui ne descendît de famille ancienne ou n'eût titres ou lettres authentiques du souverain. Mais comme la lettre d'anoblissement ne créait pas à vrai dire la noblesse ; comme elle était plutôt, dans nombre de cas, " une sorte de reconnaissance d'une possession déjà ancienne » et que son octroi devait être précédé d'une assez longue période de " vie noble » - il arrivait souvent que tel bourgeois notable, dans ces petites villes comtoises où les officiers, chargés d'appliquer les édits, se trouvaient les parents ou les alliés des contrevenants, franchissait sans droits ni lettres la distance qui séparait un « honorable » d'un «noble homme », et acquérait un fief sans trop de difficultés.

Rares étaient les fâcheux qui s'en indignaient. Le noble authentique, le descendant d'ancienne famille se trouvait, à l'égard de telles usurpations, partagé entre deux sentiments contradictoires : son orgueil de race, mais son intérêt aussi. La vente de ses terres n'était-elle pas une des nécessités si fortes, si reconnues de sa situation qu'en 1607, dans leur mandement restrictif, les archiducs ne craignent pas de dire que l'occupation des terres nobles par les roturiers, loin de préjudicier à la vieille noblesse, la favorise : elle lui donne moyen « de tant plus facilement trouver acheteurs et en avoir le plus haut prix. » Quelle lumière projetée par cette phrase officielle sur la situation économique de toute une classe sociale !

Du reste, les «permis de tenir fief » aux roturiers étaient d'usage fréquent en Comté. Ils s'accordaient aux Pays-Bas, sur requête des intéressés, après une in- 
formation prise par les fiscaux bailliagers du ressort : ceux-ci s'enquéraient de l'honorabilité, du genre de vie et des moyens financiers du requérant ; les renseignements par eux recueillis devaient fournir les éléments nécessaires pour taxer la concession sollicitée et fixer la quantité de terres nobles que le solliciteur aurait droit d'acquérir. Premier pas vers la noblesse ; il suffisait souvent : le détenteur roturier d'un domaine féodal ne manquait guère avec le temps de "prétendre les titres, rangs et exemptions des nobles ». Parfois cependant, il se mettait en mesure d'obtenir une lettre authentique de noblesse : c'était la seconde étape.

Nul pays où l'on fût, plus qu'en Comté, prodigue de ces faveurs. Le souverain direct du pays, le comte, n'était pas seul à les distribuer. A côté de Charles-Quint et de Philippe II, Ferdinand Ier, Maximilien II, Rodolphe II créent à Lure et surtout à Besançon de nombreux anoblis, ou distribuent des titres enviés de comte palatin ; aussi, pour amples qu'elles soient, les listes déjà dressées sont bien incomplètes ; il les faut grossir à l'aide des documents que renferment, en abondance, les dépôts de Lille et de Bruxelles. Surtout, il faut porter dans cette tâche d'autres soucis que les généalogistes. Les concessions, tantôt, étaient onéreuses : c'était le cas pour celles qu'à prix d'écus obtenaient les bourgeois dont la richesse constituait le seul titre ; tantôt gratuites, pour les autres : soldats de fortune suivant les armées ; serviteurs domestiques du souverain ou secrétaires de hauts personnages ; robins surtout : lieutenants de bailliage, de gruerie, officiers de la saunerie, fiscaux, avocats, gens des Comptes, professeurs à l'Université, tous arguant de leurs services, de leurs alliances, de leurs dignités municipales ou de leur parenté. C'était chaque année un lot nouveau d'anoblis se jetant à la curée des domaines féodaux.

À ces affamés d'honneurs et de profits, ce n'étaient pas ses terres seulement que devait céder l'ancienne noblesse, mais tout le fonds solide de son patrimoine ces rentes sur la saunerie, entre toutes, qui constituaient au XVIe siècle une des valeurs les plus sûres, les plus estimées du portefeuille commis. Il faut entendre Gollut, avec son gros esprit et dans son gros langage, célébrer le bonheur sans pareil des seigneurs rentiers, pour qui les eaux salées valaient bons vins d'Arbois eaux merveilleuses et « qui hont, écrit-il avec une convoitise naïve, ceste secrette propriété de se faire de plus en plus désyrer, d'autant que l'on en boirat d'avantage ; et c'est pourquoy ceux qui y trempent le doigt, et le sucent, puis après entrent en un appétit très grand d'en boire à pleine gorge ;... mais le mal est que ceux qui 
sont arrivés à la fontaine ne permettent pas facilement que l'on s'en approche. » Ils n'en gardaient cependant pas si bien les abords que de nombreux bourgeois n'y pussent accéder.

De 1553 à 1573, sur dix-sept ventes de rentes sur la saunerie, ou reprises de fief consécutives à vente, cinq seulement sont faites par des nobles anciens à des nobles anciens. Toutes les autres sont au profit de bourgeois enrichis, anoblis : Nicolas Cussemenet de Salins, celui-là même que nous avons vu, plus haut, acheter des terres aux environs de sa ville ; Claude Alix ; le procureur général Marin Benoît ; Claudine Croichet, Philibert et Marc Marchant, Claude Belin, Guyenet et Étienne Girardot. Pareillement, de 1575 à 1584, les acheteurs sont des maîtres des Comptes, comme Jean Camu ; des parlementaires, comme le président Froissard ; des docteurs en droit et des marchands : Ph. Merceret, Cl. Belin, H. Lulier, Melchior Guierche, Claudine Boudier, Fr. Merceret, Jean Moisson, Constance Colin, Pihilippe Alix, Guillaume et Jean Dagay, Marc Gay de Poligny. C'est ainsi jusqu'à la fin du siècle, avec Aimé et Claudine Sachet, le maître des Comptes Nicolas Barrillet, l'anobli Luc de Cointet - tout un peuple. L'énumération serait trop longue, trop monotone, de toutes ces ventes et de tous ces achats. Mais peu de textes donnent, comme ceux-là, l'impression d'un assaut général contre les vieilles familles, d'une fatalité sans merci pesant sur elles.

Fatalité si forte, tenant tellement à leur mode même d'existence, à leurs conditions de vie, que parmi les vendeurs, on relève déjà les noms de bourgeois anoblis : ceux qui, ayant renoncé aux offices ou au négoce pour suivre les armes ou la cour, participent bientôt aux causes normales de ruine et de décadence des seigneurs qu'ils imitent. Destin significatif, par exemple, celui d'un Nicolas de Gilley, descendant d'une famille bourgeoise de Salins, anoblie le 2 janvier 1494 en la personne de Jean : actif, entreprenant, courageux, Nicolas est échanson de Marguerite d'Autriche, gentilhomme de la maison de Charles-Quint, ambassadeur en Suisse et en Savoie, négociateur en 1542 du traité de neutralité des DeuxBourgognes, baron de Franquemont par la grâce de l'Empereur, puissant, riche, battant monnaie à son nom, achetant des terres : Crilla en 1527 ; l'Aigle en 1529 ; Marnoz et Aiglepierre en 1533 ; Mouchard en 1541 - puis peu à peu se ruinant, atteint lui aussi par les dures conditions de l'existence noble, forcé de céder ses rentes, ses terres, à sa mort adjugées par décret... 
Ce ne sont dans les textes, quand d'heureuses trouvailles permettent de les reconstituer en séries, qu'exemples de féodaux, héritiers de vieilles souches, contraints d'abandonner pièce par pièce leur patrimoine. Voici un écuyer, François de Gevigney. En 1541, il vend à Jean Laviron, sr d'Adrisans, ses biens et chevances de Cuse, Nans et Adrisans. En 1545, il vend à Jean de Civria, Sr de Borcia, ses possessions de Rougemont et ses droits sur les moulins et forges de Bonnal. En 1546, il vend à Pierre de Rougemont le Vieux et Guiette Galandot, sa femme, une rente perpétuelle de froment et d'avoine. En 1547 enfin, la ruine, la vente par décret. En regard, que l'on mette tant d'exemples typiques de couples bourgeois, officiers ou marchands, gagnant, prospérant, acquérant sans répit droits et rentes féodales, chevances allodiales et seigneuries - et, pour n'en prendre qu'un, mais le plus significatif, le plus frappant, on pourrait dire vraiment le plus grandiose : que l'on suive dans les textes les progrès continus, les achats successifs d'un Nicolas Perrenot, incarnation typique du bourgeois d'office.

En 1527, c'est le premier achat, l'acquisition pour 3000 fr. de cette terre de Grandvelle, dont la famille dès lors devait porter le nom. En 1533, nouvelle opération : le chancelier achète à Jean d'Achey les seigneuries de Maisières, Recologne, Boult et Bussières. Puis viennent, en 1535, le 4 septembre, Cromary; en 1536, le 15 juin, Morey et la Rochelle ; en 1537, le 17 octobre, Champagney. Le 30 septembre 1538, reprise pour 1200 fr. d'Apremont et Gendrey, terres domaniales, sur Blaise de Pontailler et sa soeur Philiberte. En 1540, nouveaux achats : Vaux, le 23 janvier ; Beaujeu et une petite seigneurie à Essertennes le 24 juillet ; en 1541, le 18 février, Saint-Julien-en-Montagne ; en 1543, le 14 février, Pierrecourt ; en 1545, le 16 janvier, Saint-Loup-lez-Gray et ses dépendances ; en 1547, le 3 janvier, une chevance à Arbois, et le 15 juin, un sixième de la seigneurie de Lods ; en 1548, le 30 avril, Avanne, payé 7000 fr à Pierre d'Aumont, et le 25 mai, la moitié de Rochefort contre 222 écus d'or comptés à Claude et à Antoine de Laubespin. En 1548 encore, le 30 juin, c'est la ratification par l'Empereur de l'achat du maréchalat héréditaire de l'archevêché de Besançon ; c'est, le 20 août, la vente, par Claude de Fauquier et ses enfants, d'un tiers de Lods, pour 3555 écus d'or ; l'achat, le 27 novembre, de ce que tenait à Apremont Claude Boutechoux, de Gray ; en 1549, le 10 avril, l'acquisition à Champagney de la seigneurie dite de Chalegray, et, en Flandre, du domaine de Cantecroix, près d'Anvers. En 1550 enfin, achat pour 8350 fr., au décret de Claude de Vienne, de la terre domaniale de 
Scey-en-Varais : c'est ainsi, jusqu'à la mort du vieux chancelier, une progression continuelle, une accumulation sans défaillances. Et nous n'avons pas tout dit. Nous ignorons les dates d'acquisition de Rosey, de Maîche, de Dannemarie, de Chantonnay, d'Avadans, de Venères, de la chevance d'Avrigney, de Montureuxen-Ferrette ; nous n'avons point parlé des achats de rente à la Saunerie : 200 fr. sur le partage de Chalon, acquis pour 4000 fr. sur Guy de Cléron, le 3 mai 1541 ; 262 fr. et demi sur le partage de Vignory, acquis du même la même année ; les revenus de Cl. de Binans sur la Chauderette de Salins, achetés pour 800 fr. le 9 décembre 1543 ; un quartier de muire au Puits acquis, pour 800 fr., d'Anatoile de Falerans le même jour, à la même date ; d'autres rentes encore, en 1546, en 1547... - À côté, les immeubles : le palais Granvelle, à Besançon ; l'hôtel de Champagney, à Battant ; la maison Vauthier, à Ornans, etc. Accumulation sans répit, méthodique du reste : terres domaniales tenues en engagère; terres privées acquises à rachat ou définitivement, en totalité ou par partie ; meix, maisons, vignes, prés, rentes, droits féodaux : chaque nouvelle conquête de Nicolas Perrenot marque un recul de la vieille noblesse.

Et sans doute l'exemple est singulier. Mais s'il n'y a pas en Comté deux chanceliers Granvelle, il y a des Lallemand, des Marmier, des Gauthiot, tout un peuple de parlementaires ou de marchands couronnant leur fortune par l'achat de terres nobles - et travaillant d'une ardeur égale à la diminution de ces anciennes familles féodales, dont chaque jour restreignait la part de propriété. Voici, au hasard, quelques conseillers : Nicolas Chupin se titre seigneur d'Arinthod ? C'est qu'il a acheté cette terre et celle de Dramelay à Claude et à Jean de la Chambre. Claude Jaquinot se dit seigneur de Goux : il a acquis la seigneurie de Thomas de Clermont. Louis de Boisset s'intitule seigneur d'Épercy, parce que les frères de Chatillon lui ont vendu leur part de ce domaine. C'est à Roberte de Vienne, en 1573, à Nicolas de Watteville, en 1576, que Luc Chaillot enlève Annoires puis Brevans ; à Philippe de Saubief, en 1564, que Jean Chappuis retire le château et la chevance de Grozon. Ces exemples pourraient aisément être multipliés, car le nombre des seigneuries restant le même, toute acquisition bourgeoise était généralement la contrepartie d'une vente nobiliaire ; ces acquisitions d'autre part ne cessaient pas, parce que la possession d'une seigneurie était le couronnement glorieux, le couronnement longtemps rêvé d'une fortune - la consécration d'une existence de labeur heureux et satisfait. 


\section{VII}

Du reste, peu de dangers pour les anoblis dans l'achat de ces terres nobles qui valaient si peu de profits aux vieilles familles. D'abord, entre leurs mains expertes, la seigneurie rendait davantage. Surtout, ils ne cessaient pas, possesseurs de fiefs, de travailler encore, toujours, à l'édifice de leur fortune. Titulaires d'offices productifs, hauts officiers de justice ou de finance, monopoleurs ou prêteurs enrichis, mais jamais satisfaits, ils ne s'arrêtaient pas de faire fructifier leur argent, d'acheter rentes, terres, maisons, de suivre les « décrets », de créer des granges et des domaines ruraux. Au lendemain comme à la veille de leur anoblissement, toute la vie économique du pays continuait de leur passer par les mains.

À cette résurrection, que nous avons décrite, des campagnes comtoises appauvries par les guerres, ce sont eux qui travaillent - et qui gagnent largement. Dans les dossiers de la Chambre des Comptes, les requêtes abondent, de marchands ou d'officiers royaux qui demandent la permission de pratiquer des essarts. Et ils ne se contentent point de quelques arpents. Jean de Saint-Mauris, en 1537, se fait accenser tout le bois de Valory, territoire de Malange ; Claude Grenier, en 1540, toute la Corne de Chaux, soit 357 journaux de forêt ; Nicolas Lulier, en 1543, le bois de Plumont, entre Rans et Etrepigney : 400 journaux de buissons et d'épines à " réduire à plain » pour que le bétail puisse, dit la requête, y « paître commodément ». Et le mouvement continue : en 1547, cent journaux à nouveau pour Jean de Saint-Mauris; en 1550, 120 pour le receveur Constance de Marenches; en 1560, 130 à Philippe Guierche, puis 200 au même, en 1565 ; toute une côte boisée à Philippe Marchant et, près de Gray, au lieu dit Bougeailles, 160 arpents à François Orillard. Sur le sol reconquis, les bourgeois établissent de toutes pièces des villages. Fondation typique, celle du vieux Granvelle. Sur sa terre de ce nom, en 1549, il crée entièrement le hameau du Perrenot. Dans un bois de mille arpents, trente-deux familles sont cantonnées par ses soins ; chacune reçoit un lot de trente-deux arpents ; trente-et-un devront être défrichés et réduits en culture ; le dernier contiendra la maison, le verger et le curtil. Chaque famille sera franche, mais paiera au seigneur, outre une somme de 31 écus, représentant la valeur du lot, une 
taille annuelle de 4 blancs, une géline de carêmentrant, la dîme d'un vingtième sur toutes les moissons et une rente annuelle de 30 gros.

Cela, dans le plat pays. En montagne, dans le Jura, où, nous l'avons vu, le mouvement redouble d'intensité, ce sont les bourgeois encore qui le mènent. De curieuses figures de riches défricheurs apparaissent dans les textes : un Louis de Boisset, conseiller au Parlement, seigneur d'Épercy, qui ne dédaigne pas, en 1563, d'accenser de l'abbé de Saint-Oyand une forêt, le bois de Ban, sise entre Désertin et les Bouchoux, et d'y établir des familles de colons ; un Claude Varondel, notaire et greffier de la grande judicature, qui relève le domaine ruiné de Chevry, $\mathrm{y}$ ramène des paysans, le remet en culture, édifie à son usage un château à grand toit selon le goût du temps ; un Charles Girod, notaire et échevin de Saint-Claude, qui, en 1541, accense une place dite au Vivier, près du lac des Rousses, et, en 1542, tout le canton du Sagy ; un Jean Blanchod encore, bourgeois de Saint-Oyand, qui, pour sa part, emporte la Teppe-Paget, le Cernois Moureau et le Cernois Manon, entre l'Étroit de Joux, le bief de la Chaille et le haut du pré de la montagne de Monfied. Varondel meurt riche, anobli, prospère. Blanchod marie sa fille au futur président Jean Froissard de Broissia. Son fils, noble Claude, en 1565, achète une seigneurie pour 1300 écus d'or. Pareillement, Girod meurt anobli, honoré, puissant, châtelain d'Épercy, et quant à Louis de Boisset, lorsque, après une vie exceptionnellement longue, il disparaît en 1596, c'est une multitude de biens-fonds, de droits, d'usines, de cernois, de granges dispersés à travers tout le Jura, qu'il lègue à ses fils. Guillaume, l'aîné, a la plus grosse part : la terre d'Épercy en toute justice ; la prévôté héréditaire des Montagnes ; celle de Martigna ; les maisons, granges, colombiers, mainmortes, terres, pêches, bateau, dîmes de Martigna ; la moitié du moulin de Menouille, sous Vouglans ; un étang, des prés, des terres à Moirans ; la prévôté héréditaire de Viry ; les meix, maisons, scieries, colombier, bois, granges, vivier, terres, prés, censes, mainmortes de Viry ; six ou sept granges en mainmorte, « avec les lods du tier denier de la chose vendue », disséminées dans la montagne, à Désertin ; une autre grange à Désertin, avec des prés et un bois banal d'une lieue de circuit ; une grande maison à Saint-Claude, avec curtils et vergers; enfin, une maison, une vigne, une chevance à Perrigny, près de Lons-le-Saunier. Quant au second fils, Humbert, il se voit attribuer le reste des biens de Saint-Claude, non spécifiés; les biens et chevances de Moiron, près de Lons-le-Saunier; quatre granges en divers lieux ; une maison à Dole, les chevances de Sampans et de Jou- 
he, et les cens et rentes sises au territoire de Dole. Rien qui dise mieux l'acharnement patient des robins à grossir leur fortune par des achats répétés - à suivre, en trois ou quatre endroits différents, une politique prudente et méthodique d'acquisitions.

Et c'est le même spectacle, la même activité dans le vaste domaine des entreprises industrielles. Les Nardin de Besançon exploitent les usines à fer de Fraisans ; les d'Anvers, de Besançon aussi, possèdent celles de Scey-en-Varais ; les Grégoire dirigent celles de Vy-le-Ferroux, s'y enrichissent, achètent des seigneuries, occupent des offices ; les Jaquinot, par Jacques, frère du conseiller puis président Claude, tiennent les forges de Greucourt. Sans doute, ils ne sont pas absolument les seuls à fournir toute la besogne. Plusieurs, parmi les nobles, essaient de lutter pour la fortune. Rares exemples: le genre de vie des gentilshommes les éloignait trop de soins si patients et si intéressés. Ils n'y savaient porter cette ardeur minutieuse que les plus grands bourgeois ne cessaient de déployer.

Rien de curieux à cet égard, comme la lecture des longues lettres d'affaires qu'échangent un Granvelle et ses agents : Viron, Bonet Jaquemet, Chavirey surtout, et même Morillon. On reste stupéfait du détail extrême qu'exige le cardinal de l'ampleur et du nombre de ces missives, lues, dépouillées, annotées par lui de la première à la dernière ligne, cela au moment où les plus graves affaires politiques réclament son attention, où, dans sa vie même, les événements les plus importants s'accomplissent. Lettres de quatre pages sur les précautions prises pour ne rien laisser échapper, à Montbenoît, d'une échute mainmortable et réaliser un gain de quelques francs ; compte-rendu détaillé, tous les ans, de la visite des fourrures du cardinal, tenues une à une et battues par le pelissonnier ; cris d'allégresse et louanges au Seigneur lorsqu'on n'y a point trouvé d' "artisans »; surtout, énormes rapports sur la situation de ses greniers. Bénéficiaire de nombreuses abbayes, il recueillait, chaque année, des quantités considérables de blé, d'orge, de seigle, d'avoine, dont la vente formait l'un de ses revenus les plus assurés. Mais à une époque où les prix, sur les marchés locaux, encore presque complètement indépendants les uns des autres, variaient avec l'intensité que nous avons notée ; où, d'une année à l'autre et d'un village à l'autre, l'importance des récoltes différait si profondément, c'était un art singulièrement difficile, une opération pleine de risques et d'aléas que de déterminer l'heure opportune pour vendre, pour bénéficier des cours les plus élevés. Chaque année, dès lors, ce sont d'interminables let- 
tres de Chavirey au cardinal, notant pour lui les cours, faisant les prévisions, réclamant des ordres. Le problème est si complexe ? D'abord, il ne se pose pas partout dans les mêmes termes : "Il convient vendre précisément l'avenne au commencement de febvrier, à Besançon, Damparis et Villepater, pour être les lieux fertiles et hâtifs de semer, et à Moustier en my-febvrier, avant que ceulx que veullent semer se pourvoient ailleurs. » L'avoine - mais le froment n'obéit pas aux mêmes lois, ni l'orge, ni le seigle... Et puis, la spéculation n'a pas toute liberté. Elle n'a pas pleinement le choix du marché. Vendre tous les grains d'une terre sur un marché assez éloigné, mauvais calcul, même si les prix obtenus sont meilleurs ; car on risque d'affamer les sujets, de leur faire réduire leurs semailles, de diminuer ainsi la récolte future. Accaparer les blés pendant les bonnes années, faire d'importantes réserves, opération simple en théorie pour qui n'a pas un besoin immédiat d'argent. Mais, si plusieurs années fécondes se succèdent ? On ne sait pas, on ne peut pas conserver les grains indéfiniment. Au bout de trois ans, le blé perd, se dessèche, tend à se gâter. Heureux celui qui trouverait un moyen de garder le froment en grenier pendant cinq ou six ans, «austant beaul et frais comme quant l'on l'y met. » C'est la grosse question, la pierre philosophale des propriétaires : Granvelle n'a cure d'en négliger la solution. De Naples, il expédie un secret à Chavirey. " Dieu doit qu'il puisse proffiter, s'écrie l'intendant tout ravi ; que pourra estre pour les riches et non pour les pauvres, pour ce que, si la recepte a lieu, chacun gardera son bled et ne vendront que les nécessiteux. » Heureux qui pourrait réduire les pauvres à « acheter pour vivre la graine à la voulonté des riches!»

Le cardinal ainsi prend note de tout, compare les cours, donne son avis : il a de l'expérience, du coup d'oeil, de la décision. «Il faut vendre », lui écrit Bonet Jaquemet ; attendez, répond-il : les cours monteront encore ; et les cours montent, en effet. C'est qu'il est le maître et n'entend laisser à personne le soin de disposer à sa place. Il y a dans sa correspondance, à cet égard, des petitesses étonnantes, et qui nous surprendraient si, précisément, nous n'avions toujours présente à l'esprit l'origine du cardinal, si nous ne le replacions pas dans son milieu, si nous ne songions qu'une longue hérédité l'avait façonné aux mesquineries de gagne-petit qui continuaient à faire, autour de lui, la prospérité de toute une classe. Telle histoire de pains de beurre est purement stupéfiante. Abbé de Montbenoît, et faisant gérer en recette son abbaye, le cardinal disposait de beurre, de bon beurre de montagne 
perçu en redevance. Il avait donné ordre qu'on en offre quelques pains, chaque année, à sa mère et à ses soeurs. Mais, vers 1566, il amodie Montbenoît ; plus de recette de beurre, partant plus de distributions. Les soeurs du cardinal réclament à Chavirey le cadeau traditionnel. Mais le cardinal n'a pas donné d'ordres ; et comment passer une pareille dépense ? Voilà Chavirey tout ému et qui conte au maître ses perplexités : "Madame», la redoutable Madame, la veuve du garde des sceaux, l'accuse d'être trop chiche ; elle lui a dit, à Besançon, « que l'on ne debvoit délaisser telles gratieusetez, combien que l'abaye fut admodiée ». Peut-être, mais Chavirey n'entend pas « faire le libéral du bien d'aultruy »; et le cardinal peut être tranquille : «Ne passera l'on la volonté de V. I. S., bien saichant que, à la saison en laquelle nous susmes, il est requis regarder les choses de près. » Paroles selon le coeur du maître. Ne s'indigne-t-il pas un jour, dans une lettre à Morillon, des prétentions outrecuidantes d'une nièce «qui demandoit toilles et robbes » sur la recette d'un de ses domaines. « Elle est jeune, forte et coquarde par trop, écrit l'oncle courroucé, de présumer commander ny là ny ailleurs! » Et il ajoute : « La recepte dudit Hacquenie est bien aux mains de Goville ; mais qu'il entende bien que c'est à moy à qui il en a à donner compte, non à elle; et qu'il ne se joue de disposer d'un denier sans expresse charge mienne ! » Ainsi se font, ainsi se maintiennent les bonnes maisons...

Mais ces remarques mêmes entraînent une conclusion. Ce qui sépare, ce qui oppose nobles et bourgeois, ce n'est pas un conflit économique seulement ; c'est un conflit d'idées encore, et de sentiments. Par leur genre de vie, par leur éducation, par leur conception générale du monde et de l'action, deux classes s'affrontent durement ; il nous faut décrire ce genre de vie, analyser ces conceptions rivales, si nous en voulons sentir le conflit dans toute son acuité. 
PHILIPPE II ET LA FRANCHE-COMTÉ

Étude d’histoire politique, religieuse et sociale.

Deuxième partie. Les débuts du règne de Philippe II

Chapitre X

\section{La vie bourgeoise}

$\underline{\text { Retour à la table des matières }}$

Qu'il y eût antagonisme, opposition d'idées et de sentiments entre les simples bourgeois des villes et les grands seigneurs de cour, on l'admet aisément. Mais qu'il y eût plus d'écart, moins de ressemblance dans les goûts, les tendances et les désirs entre un de ces grands seigneurs et un riche anobli qu'entre cet anobli et un simple bourgeois, on est moins porté à le croire tout d'abord. On déchiffre les actes de famille, les testaments, les inventaires qui font revivre pour nous les fortunes d'autrefois ; et quelle distance, entre la situation d'un modeste citoyen de Dole ou de Gray, et celle d'un Marmier ou d'un Gauthiot d'Ancier?

Voici la fille d'honorable Richard Maire, maçon, citoyen de Besançon. Maire est un homme connu, un architecte renommé en son temps, le propre constructeur de la maison de ville de Besançon et de nombreux hôtels particuliers, dont l'hôtel de Champagney dans la rue Battant. Il travaillait pour les Bonvalot, les Granvelle, bien d'autres encore : « estant architecte et d'esprit, écrit de lui au cardinal son homme d'affaires Chavirey, l'on le paye selon le prouffit qu'il fait au maître et seigneur pour lequel il va, étant souvent fois mandé des plus grands de Bourgogne pour pourjecter bastimens. » Or, sa fille Anne, lorsqu'elle épouse honnête Claude Nicolin de Besançon, ne reçoit que 120 fr. de dot en argent. Le reste de son apport 
est tout en nature. Ce sont des habits, des meubles, un trousseau; la robe et la cotte nuptiale, « doublez et fourrez comme il convient »; un bon lit de plume garni « de cussin, ciel, dossiel, couverte et custodes »; une douzaine de " linceulx », douze aunes de nappes, douze serviettes, douze chemises, douze devantiers, douze "gourgières ", le tout "bon et suffisant»; quelques vieux habits, de "menues bagues ", des " crochetz à chainette d'argent et un demi-cein à charnières d'argent »; deux coffres enfin, deux solides coffres en bois ferrés et fermant à clef : voilà « trousselée » et prête à entrer en ménage la fille d'un gros maître de métier bisontin.

Ce contrat est typique. Toute une classe de marchands, de maîtres artisans, de menus robins n'offre pas à ses filles d'autres avantages. Qu'il s'agisse de Michel Maignin, vigneron, et de Jeanne Varey (elle aura $300 \mathrm{fr}$. de dot, une robe et une cotte de drap, son lit de plume, ses deux coffres, 18 linceux, 18 aunes de nappes, 18 serviettes et une douzaine de "chemises, gourgières et devantiers ») ou de Jacques Thiébaud, vigneron, et de Jeanne Celezot ; d'honorable Gérard Dorney, chapelier, et d'honnête Perrenette Garnier, fille d'un recteur des écoles du Chapitre ; de Pierre Fourcault, vigneron, et de Claudine Giponnet, fille d'un chirurgien : mêmes clauses et mêmes promesses, même pénurie de numéraire, même modestie rustique des trousseaux. On est loin, semble-t-il, de ces bourgeois, " hommes de bons moyens » qui se savaient riches de 60000 à 80000 fr., possédaient « des oncles de 15000 livres », et dénombraient avec orgueil leurs chaînes d'or et leurs diamants.

Mais d'abord, il faut se défendre d'une illusion commune. L'énumération détaillée de pièces de vêtement ou de lingerie, de chemises ou de nappes, n'a rien de spécialement modeste ou rustique ; rien qui permette, en tout cas, d'opposer aux plus opulents les bourgeois moins huppés. Lorsque le vieux marchand Claude Darc d'Amance - un homme puissamment riche, dont les dons testamentaires en argent s'élèvent seuls à 36000 fr. - partage entre ses deux fils le gros de sa fortune, il entre dans des détails d'une minutie qui ne saurait s'expliquer par le manque d'abondance. A son fils le docteur, il donne un lit garni, une couchette, une table de noyer, des coffres et des coffrets, « 6 chaises appellées quaquetoires, qui viennent de Besançon, et 6 scabelles pour servir à table »; il lui lègue du linge : 12 linceux, 12 serviettes, 6 grandes nappes et 2 serviettes de banquet, sans compter « 100 livres d'estaing, comme plat, escuelles, salières, assiettes, saulcières, pintes 
et aultres ouvraiges servans à l'assortiment d'ung mesnaige » - le tout, à faire venir de Flandre ou à prendre à Besançon, «selon qu'il vouldra ». De même, le gros marchand bisontin Jean Mareschal le Vieux, assurant par codicille l'existence de sa seconde femme, Jeanne Nobis, lui lègue explicitement, outre « le lict de plume où elle et moy couchons ensemble », 6 linceux, 6 nappes, 6 serviettes, 6 petits plats, 6 assiettes, 6 saucières, « un pot de pinte, ung pot d'un chaveaul, une ayguière, le tout d'estain et marquez à sa marque ». Riches comme pauvres descendent aux mêmes détails ; gardons-nous de fonder sur eux d'apparentes distinctions.

Et puis, dans la noblesse également, de singuliers écarts s'observent entre les fortunes. Que de pauvres écuyers, réduits à végéter dans quelque bourg rural quand ils ne devaient pas solliciter sur leurs vieux jours la triste aumône d'un pain d'abbaye. Ci-devant garde-robe de Charles-Quint, Guyon de Montrond, retiré en Comté lors de l'abdication, lègue 10 écus d'or à sa soeur Jeanne et à ses deux neveux : voilà la part de la famille dans l'hoirie. Au serviteur, Claude Clerc de Melincourt - pour gueux qu'il fût, tout noble avait servant et servante - le manteau de drap noir bandé de velours des jours de fête, et le manteau, « aussi de drap noir », des jours ordinaires. La servante a 30 fr. Le reste va à une servante maîtresse, Clauda Jeannin, dont le vieux gentilhomme a eu une fille, Barbe, naguère légitimée. Elle aura l'usufruit de diverses petites pièces de vigne, de terre, de pré ; elle jouira, «sa vie naturelle durant », d'une rente annuelle de 12 fr., d'un bichot de froment, d'une « chambre à feug » dans la maison du maître, ainsi que « d'ung lict de plume garni d'ung cusin de plume, d'une couverte de mante, d'ung ciel de toille à franges garni de custodes aussi de toille ; 12 aulnes de nappes, 2 douzaines de serviettes, 2 pots de cuuvre, une pelle de cuivre et ung chaudron d'airain ». Mobilier aussi reluisant, ou presque, que le trousseau de damoiselle Marguerite de Laval, fille de noble Estienne, seigneur de Calmoutier, qui, se mariant à Nicolas Bernard de Colombier, reçoit de ses parents un lit garni, 12 draps, 12 nappes, 12 serviettes, 2 coffres ferrés, une robe, un cotillon de drap, une vache et son veau, et $100 \mathrm{fr}$. de dot un an après le mariage : à peine ce que donnaient à leurs filles ces bourgeois modestes dont nous inventorions plus haut les revenus. Toute une classe de nobles vit ainsi dans la gêne - et tel, plus relevé, un Précipiano, par exemple, capitaine général des fortifications du Comté, laisse derrière lui, entre autres 
sommes à acquitter dans le prudent délai de quatre ans, une dette de 30 fr. à son boulanger.

Or, de l'inégalité constatée des fortunes nobiliaires, on est peu tenté de conclure à la non-existence d'un esprit commun, d'une solidarité effective d'actes et de croyances entre les nobles d'épée. Puissants barons et gentilshommes gueux, on sait qu'ils ont mêmes préjugés, mêmes croyances, même idéal ; mais combien plus encore tient au bourgeois modeste le bourgeois opulent ? Tandis que le gentilhomme descend d'un gentilhomme comme lui, et de situation généralement équivalente à la sienne propre, le parlementaire, l'anobli puissamment riche ne sort-il pas souvent d'un petit marchand ou d'un maigre robin ? Le mouvement d'ascension qui porte sans trêve de la médiocrité aux sommets les mieux doués, les plus entreprenants ou les plus heureux des bourgeois, n'a-t-il pas ce résultat forcé de maintenir, entre les aspirants et les nantis, une communication constante, une communauté sensible de pensées et d'actions ?

En fait, par delà les antagonismes d'ordre économique ; par delà le conflit des intérêts matériels, ce qui aggrave encore, ce qui rend plus durable et plus vive l'opposition de la noblesse d'épée et de la bourgeoisie accédant aux honneurs et à la richesse, c'est bien une dissemblance, un contraste profond d'idées, de sentiments et d'occupations. Par l'effet de conditions économiques nouvelles, tandis que la société du Moyen Age se transforme peu à peu et s'effrite, une autre société grandit, où l'âpre concurrence développe ses effets ; où la respectabilité personnelle cessant de s'attacher au loisir aristocratique et au jeu de la force, va de plus en plus à l'activité laborieuse d'hommes nouveaux, pour qui la pauvreté est le plus grand vice. Ces hommes nouveaux, du petit au grand, ce sont tous les bourgeois, menaçant de leur effort les vieilles classes dominantes.

\section{I}

Comment, par quels traits se distinguent donc nobles et bourgeois ? en quoi diffèrent leurs vies respectives ? et, pour commencer par eux, à quels signes persistants reconnaître la communauté d'origine, la parenté réelle des parvenus et des 
candidats au pouvoir ? Il ne s'agit pas ici, naturellement, d'une analyse psychologique plus ou moins arbitraire, mais d'une étude fondée sur des faits et des textes.

D'abord, dissipons une illusion possible. De la base au sommet, c'étaient hommes d'action et d'initiative que les bourgeois des cités franc-comtoises. Il ne convient pas de se les représenter comme des sédentaires, gens d'horizon borné, de vie paisible et molle. Sans doute, ils aiment la bonne chère, les longs banquets prolongés toute une journée à la mode paysanne, coupés en leur milieu par une courte promenade et repris ensuite jusqu'à la satiété. Sans doute, ils se plaisent à la paix confortable de leur intérieur, à la douceur tiède de leurs lits de plume ; ils n'ignorent pas les haines, les rivalités de clocher, la tyrannie de l'opinion dans les petites villes, les mille intrigues secrètes et patientes de la vie provinciale. Mais d'abord, ils ont tous voyagé, ou presque. Beaucoup, aux années de jeunesse et de force, ont couru le monde, étudié à leur aise les nations diverses. Que les marchands voient du pays, on s'y attend assez. Le métier le veut. Il faut hanter les foires, aller soi-même acheter la marchandise, soi-même aller l'offrir, traverser monts et vaux à cheval, en armes, parfois seul, parfois accompagné d'un serviteur fidèle, parfois à la tête d'un lourd convoi, sans crainte des soudards, des brigands, des aubergistes suspects... Mais les autres ? Gens de métier, avant de s'établir maîtres, ils ont fait souvent leur tour de France, parcouru la Bourgogne et les villes du Rhône, Bâle parfois et l'Alsace. Gens de loi, ils ont fréquenté les universités lointaines, séjourné en France, en Allemagne, en Italie, aux Pays-Bas. Les matricules des universités étrangères sont là, qui nous disent en détail l'expansion comtoise, les séjours en Allemagne pour apprendre la langue, les voyages dans cette Italie que, pendant le Moyen Age, tant de liens économiques avaient unie à la Comté. Matricules d'Heidelberg, avec leurs mentions fréquentes de Bisontins et de Montbéliardais ; matricules de Paris, avec leurs listes abondantes de futurs ecclésiastiques d'origine comtoise ; matricules de Ferrare où les noms de Franc-Comtois abondent. Sur dix-neuf étudiants comtois dont les registres de cette dernière université nous ont transmis le curriculum, treize sont anciens élèves de Dole ; douze de Cologne ; onze de Pavie ; cinq de Louvain ; cinq de Padoue ; trois de Poitiers ; deux de Toulouse ; deux de Paris, et un de chacune des universités d'Orléans, Bourges, Avignon, Fribourg-en-Brisgau, Pise, Sienne, Naples et Rome.

De ces pérégrinations, nous conservons d'ailleurs d'autres témoignages - et notamment quelques-uns de ces curieux albums, décorés de blasons et de miniatu- 
res, où, sous forme d'amicales dédicaces, la jeunesse du temps conservait le souvenir de ses premiers voyages : tel, l'Album Amicorum d'Antoine Mouchet, neveu du cardinal de Granvelle, durant ses séjours à Louvain, Paris et Padoue, ou encore, le petit cahier de papiers rares, couvert de signatures et d'épigraphes, du jeune Simon Sauget, voyageur en Orient et à Constantinople - émule et prédécesseur de ce Valimbert, Besançonnois, chevalier de Jérusalem, que chantera peu après le poète Chassignet :

Chevalier que le ciel en Bourgogne a fait naître Comme un autre Postelle, afin de reconnoistre Les païs plus lointains...

C'étaient là les aventuriers - les émules de ceux qu'emmenait sur ses galères un don Juan d'Autriche voguant vers Lépante. Mais combien qui, plus modestes, se bornaient à courir par toute l'Italie :

O qu'il fait beau marcher à la fraîche Diane.

Sus, Froissard, il ne faut perdre ce beau matin ;

Allons au Capitole, allons au Palatin...,

Admirons les grands faicts de ce peuple latin...

Ainsi des amis conservaient pour eux le souvenir de ces heures légères - tandis qu'au fond de leurs coffres précieux, ils serraient les diplômes rapportés de si loin.

Or, tous ces déplacements, tous ces voyages supposaient de l'énergie. Énergie physique et morale, esprit d'initiative et d'entreprise. Les voyages étaient si longs encore, si périlleux - et dès qu'on était chargé, quel surcroît d'ennuis et de difficultés. Le marchand, le banquier qui devait transporter quelque grosse somme un millier de francs, par exemple - immédiatement devait prendre un cheval de renfort, marcher à petites étapes et veiller aux brigands. Le plus souvent, en cas pareil, on dissimulait et, comme les pauvres gens dans leurs doublures ou même leurs souliers, les riches cachaient au fond de tonneaux pleins leurs écus-soleil ou leurs philippethalers ; précautions que rendait souvent inutiles la rapacité d'auber- 
gistes criminels ou de guides douteux. Mais, pour de simples étudiants, les périls n'étaient pas moindres. En Comté même, les routes les plus fréquentées n'offraient pas toujours une pleine sécurité : Geizkofler, dans ses Mémoires, nous en sert de témoin ; et les frontières franchies, c'étaient d'autres dangers : les passagers d'Espagne ou d'Italie ne "s'engoulfaient» pas toujours d'un coeur léger : maintes tempêtes, maints pirates les pouvaient assaillir ; nombre d'étudiants, à la veille de gagner «les escoles d'Ytalie », passaient leur testament, «doubtant le péril et danger de la mort ».

Et puis, au XVIe siècle, tout bourgeois est soldat, sait manier son épée, armer son arquebuse. Lorsqu'on parcourt les requêtes en anoblissement des registres de Bruxelles ou de Besançon, on est très frappé du nombre de légistes, fils de marchands ou d'officiers royaux, qui ont servi d'abord le prince aux armées. Grave conseiller maître à la Chambre des Comptes, Nicolas Barillet a, dans sa jeunesse, suivi aux Pays-Bas, sous le duc d'Albe, la cornette de M. de Clairvaux. Procureur fiscal d'Aval au siège de Salins, François Cécile a pareillement guerroyé dans le Levant, en 1572 et 1573, sous le baron de Chevreaux, "chief des aventuriers bourguignons ». Son frère Guyon, moûtier de la Saunerie, a pris part au siège d'Harlem, "par delà ». Guillaume Coquelin, riche bourgeois de Salins, avant d'épouser la fille du conseiller Jaquinot et de venir paisiblement gérer l'héritage paternel, a été chevau-léger sous le marquis de Treffort, au service du duc de Savoie. De semblables exemples abondent - et nous ne parlons pas, naturellement, des jeunes bourgeois qui se vouent tout entiers à la carrière des armes, poursuivent des grades modestes et revivent, pour leur part, la carrière mouvementée d'un Ferry Guyon.

Et puis, ceux-là mêmes, officiers, magistrats, docteurs en droit, qui n'ont pas eu de si belliqueux débuts, ils ont tous, pendus dans quelque coin, morion, pertuisane, arquebuse, selle et harnais. Nombreux, les robins qui possèdent leur monture ; les autres trouvent, en cas de besoin, une cavalerie de louage; pour tous, l'équitation est un art professionnel. Le vieillard seul chemine en litière; les hommes, sur leur bidet. Receveurs de seigneuries en tournée d'inspection, officiers de bailliage allant tenir assises ou venant à Dole pour la Saint-Martin ; percepteurs du don gratuit apportant aux receveurs l'argent des prévôts ; parlementaires eux-mêmes, chargés d'enquête ou de mission : c'était, sur les routes du Comté, un perpétuel défilé de cavalerie bourgeoise. Souvent d'ailleurs, officiers, docteurs 
et financiers, comme au temps de leur jeunesse, devaient monter en selle pour de plus longs voyages : la Comté, politiquement, ne se suffisant pas à elle-même, les chevauchées étaient fréquentes d'ecclésiastiques vers Rome, de laïques vers la Flandre, l'Espagne ou l'Allemagne ; dans tous ces pays vivaient des colonies comtoises, avec notaires et tabellions, membres sédentaires et membres errants ; les nécessités de ces négociations en pays lointain ne furent pas étrangères, peut-être, à la formation, en Comté, de tant de diplomates.

\section{II}

Ainsi, celui-là se tromperait lourdement qui prétendrait trouver dans l'ardeur belliqueuse des uns, dans la résignation pacifique des autres, la grande différence entre nobles et robins. Pourtant, leur énergie est-elle bien du même ordre ?

Le noble fait la guerre pour la guerre. Il la fait tout naturellement, pour ainsi dire : c'est sa fonction de porter les armes; plus, c'est son unique fonction. Il se bat sans grand souci des raisons qui meuvent les adversaires ; il se bat le plus souvent sur un sol étranger, avec. pour ou contre des étrangers ; il se bat pour se battre, parce qu'il est homme d'épée. Mais le bourgeois des villes, le robin, le marchand qui, en cas de danger, met morion en tête et décroche sa hallebarde ? Portet-il les armes vraiment comme le noble ? Le gouverneur de Gray, le vieux Jérôme d'Achey, sentait bien que non, et traduisait vivement son sentiment lorsque, dans les rues de la petite cité, dès qu'il les voyait, il chargeait canne haute les miliciens bourgeois... Braves gens cependant, très capables de défense et d'action ; mais leur activité guerrière était intéressée et momentanée. C'est là le grand point. L'activité du bourgeois, toute son activité a un but et qu'il avoue : le profit. Les épisodes aventureux peuvent être relativement fréquents dans son existence ; jamais ils n'excluent cet esprit d'ordre, de régularité, d'exactitude financière et de lucre, qui est le fond même de l'esprit bourgeois. Cet ensemble de qualités et de défauts qu'engendre la pratique de menues affaires : de la patience, une attention continue aux détails, l'habitude de dépenser moins qu'on ne gagne et la crainte de tout ce qui est extraordinaire - il se retrouve pleinement dans l'esprit des Graylois, des Dolois, des Salinois du temps; il se manifeste avec netteté, sinon dans leurs 
écrits, trop souvent impersonnels et fâcheusement rhétoriqueurs, du moins dans leurs actes privés : testaments, inventaires ou contrats de mariage.

Dans les petites villes comtoises, mi-rurales, mi-urbaines, on était encore près des moeurs paysannes. L'intérêt menant le monde, on lui faisait sa part, nettement ouvertement. Les moralistes, dans les lieux communs, s'en scandalisent :

... Auctus

Cuncta premit nummus...

déplore en latin le poète Bercin ; rhétorique empruntée : de savoir compter et gagner, nul ne rougit et, plus réaliste, le conseiller Courvoisier constate brutalement :

Qui n'a secourt que de son gendre, Et n'a beste que chièvre à vendre, Voisin rivière et advocatz, Il n'en a pas fort grand soulas...

Ce n'est pas à dire que le désir de lucre tue tout sentiment désintéressé. Ceuxlà mêmes qui comptaient le mieux étaient souvent aussi les plus préoccupés d'alléger les maux qu'ils sentaient autour d'eux ; on ne serait guère embarrassé de recueillir, au travers des testaments, les preuves répétées, non pas d'une certaine charité ostentatoire, satisfaite de vêtir quelques pauvres pour accroître la pompe de funérailles coûteuses, - mais d'une ingénieuse, touchante et discrète sympathie pour ces foules paysannes, arrachées de leur champ par l'évolution sociale et le triomphe même de la bourgeoisie - prolétariat de mendiants faméliques, continuellement accru au cours des années. Un conseiller, Nicolas Chupin, non seulement lègue aux pauvres, avec son or et son argent, le prix de sa vaisselle et de ses livres, mais ordonne des distributions répétées aux nécessiteux et aux prisonniers et consacre aux malades de l'hôpital tout le revenu annuel de ses chevances d'Ounans, Chamblay, Escleux, Villers-Farlay et Chissey. Un autre, Guyon Mairot, demande qu'incontinent après son décès, sa femme fasse moudre un bichot de blé, et que « d'icelluy soit fait du pain qui soit, le plus discrètement que faire se pour- 
ra, distribué aux pauvres de ce lieu jusqu'aux moissons prochaines ». Souci de discrétion ; souci d'ordre aussi ; ils se montrent curieusement chez le président Jaquinot qui, ayant « tousjours désiré de veoir quelque bon ordre pour contenir les pauvres, sans estre veuz discourans de porte en porte ", lègue $40 \mathrm{fr}$. de rente au magistrat de Vesoul pour, "en prévenant toutes aultres villes de ce comté de Bourgogne et en leur servans d'exemple, donner tel ordre en la ville que lesdits pauvres ne soient mandians, ains leur soit distribuer leur nourriture en leurs maisons ».

On trouve pareillement, et en abondance, des dotations de jeunes filles, des secours aux veuves, des legs à de jeunes enfants abandonnés, des fondations ou des subventions d'hôpitaux : toutes générosités dont l'efficacité sans doute, et les conséquences, étaient très discutables, non les causes ni l'inspiration. Mais parfois aussi, les testaments renferment des prières, des exhortations plus personnelles encore et plus intéressantes pour nous. Jean Brenot d'Orchamps-Vennes, riche en maisons, en terres, en rentes et en dîmes, déclare donner « réachat et pouvoir à tous ceulx et celles qui lui ont constitué censes, tant d'argent, froment que vin, de rambre et racheter lesd. censes... deans dix ans prochains après son trespas, en payant et ramboursant les sors principaux, arréraiges escheuz et frais raisonnables. » Girard Francolin, de Besançon, notaire de la cour d'officialité, non seulement quitte et remet à ses parents et lignagers tout ce qu'ils pouvaient lui devoir pour conduite de procès - mais ordonne « que tous aultres qui luy debvront argent, qu'ilz diront l'en avoir payé ou donné quelque somme, ilz soient creux par leurs seremens jusques à la somme de 20 sols tournois et au dessoubz » - pourvu encore «qu'ilz soient gens d'apparence ». Quel jour projettent sur l'état d'esprit de leurs auteurs de telles «largesses », inscrites solennellement dans des actes privés et entourées de pareilles restrictions? Plus largement humain, certes, le licencié Guillaume de Ferrières : il prie ses fils « de humainement et bénignement régir et gouverner, et par traicté, leurs hommes et subjectz qu'il leur délaisse ; car, ainsi fesant, Dieu leur dona grâce de, apparpétuité, bien garder et entretenir leurs biens et chevances, voires de l'augmenté et accroistre ? » Encore, de ses bons sentiments escompte-t-il, comme on voit, la récompense future.

Point d'embarras, point de gêne à mélanger ainsi conseils généreux et espoirs de profit. Viglius apprend la mort, à Dole, de son neveu Théodore. Il accueille la nouvelle, écrit-il aussitôt au fidèle Hopperus, « non sine magno dolore, post mul- 
tos in eo enutriendo sumptus a me factos ». Et Bonet Jaquemet conte ainsi à Granvelle une visite au célèbre Prudent de Saint-Mauris : « Je trouva l'avocat de Saint-Mauris si perplex et empesché après ung sien filz qui estoit mallade et qui labbouroit à la mort - le trespas duquel, s'il advenoit, porteroit dommaige aud. de Saint-Mauris de plus de dix mil frans - que je n'eus le moyen négocier avec lui. » Et sans doute, ce n'était pas seulement pour les 10000 fr. que l'avocat était «si perplex » - mais n'est-il pas vrai qu'à travers ces textes, la famille bourgeoise apparaît avant tout comme une association d'intérêts - on pourrait presque dire un groupe économique?

\section{III}

Le mari et la femme sont deux bons associés, travaillant d'un même coeur à « amasser du bien » - formule consacrée, et qui revient dans les actes comme un vrai refrain. De leurs gains en commun, les conjoints parlent d'une manière attendrie. Un mari reconnaissant, un tisserand bisontin, Mathieu Bonnier, lègue à sa femme tous ses biens, « considérant qu'elle a heu peine et travaulx avec luy et qu'elle l'a aydé à amasser le bien que, par la grâce de Dieu, s'ils possèdent présentement ». Une femme, Françoise Delivran, lègue à son mari, le greffier Barnard, sa part des acquêts, « bien saichant, déclare-t-elle, les acquisitions avoir esté faictes par son industrie, dilligence et grant travail et labeur ». Deux conjoints, deux usuriers d'ailleurs, de Grandfontaine-lez-Domprel, se complaisent à écrire comment, « doiz leurs jeunes âges et que raison leur a commandé », s'étant « esvertuez vivre en gens de bien », ils ont été si heureux «et leur a la fortune esté si prospère, qu'ils ont par travail et administration de leurs biens anciens augmenté icelluy » et suscité l'envie. Gagner, accroître, c'est le but avoué.

Juridiquement, d'ailleurs, le mari et la femme forment une société indivise dont l'homme est le chef et que caractérise une large communauté. Aux termes de la coutume, et sauf convention particulière, les acquêts ne s'étendaient que pour les nobles seuls aux meubles à la fois et aux immeubles; pour les roturiers, ils se limitaient aux immeubles seuls. Mais nombreux étaient les contrats bourgeois où les règles de droit valables entre nobles se trouvaient réclamées et spécifiées. Tel 
quel, le ménage bourgeois constituait une société assez étroite et égalitaire - impliquant moins, sans doute, comme on l'a prétendu, une haute conception de la femme et de son rôle dans la famille et la société (conception qui serait d'origine, de nature chrétienne), qu'une large pratique de ce communisme familial dont tant de traces subsistaient dans les moeurs. Le groupe familial restait puissamment organisé. En Comté, le mariage n'émancipait que les filles mariées ; à Besançon, il n'émancipait ni filles ni garçons. Le fils établi, tenant ménage séparé, ne pouvait, sans l'autorisation paternelle, «ni acheter biens à son seul profit et iceulx revendre », ni s'obliger, traiter, passer testament ou donation, constituer procureur et se défendre en jugement. Il fallait, pour qu'il jouisse de toutes ces facultés, que le père consentit à les lui octroyer - qu'assis au côté du juge compétent, « ouvrant et élargissant » les mains de son fils agenouillé, il lui donnât ainsi les droits sollicités.

Souvent, par contre, à la mort du père, ses descendants demeuraient ensemble, sans division ni partage des biens. La mère survivante restait avec eux, gouvernait le ménage comme au temps de son mari et laissait confondus dans les biens des enfants ses droits matrimoniaux, sa dot et sa part d'acquêts. Solution qu'imposaient, dans leurs testaments, beaucoup de pères de famille - au moins pour leurs enfants jeunes, car ils connaissaient les difficultés qu'en cas de désaccord, la communion de biens amenait entre frères. Si le vieux Granvelle, Nicolas Perrenot, désire que ses enfants « demeurent en bonne union et communion de biens le plus longtemps que faire se pourra convenablement pour leurs propres biens et conservation de sa maison ", néanmoins, "considérant que souvent fois, à l'occasion d'icelle communion s'engendrent grandes inimitiés, différentz, procès et inconvéniens ", il procède à partage par un acte distinct. De même, le conseiller Louis de Boisset, soucieux d'éviter « les difficultés, discordes et dissentions que la communion des biens et hoiries ont de coustume engendrer et appourter », partage entre ses deux fils sa riche succession. Mais beaucoup adoptent un moyen terme : l'indivision jusqu'à vingt-cinq ans, le partage ensuite ; c'est la solution du conseiller Chaillot, du président Jaquinot surtout, qui déclare entendre que ses trois fils : Nicolas, du premier lit ; Vincent et Louis, du second, « demeurent en communion jusques à ce que led. Nicolas soit eagé de 25 ans » et qu'ils soient «nourriz et entretenuz avec ses aultres enffans » par sa seconde femme, Jeanne-Baptiste Chaillot, usufruitière de tous les biens maritaux, y compris la part de son beau-fils. 
Communions profitables souvent, quand bien dirigées et que les bénéficiaires vivent en bon accord. Dans un intéressant passage de son testament, Françoise Nycol, la seconde femme du procureur général Marin Benoît, déclare avantager une de ses filles, Marguerite, à l'exclusion de l'autre, Jeannette, « faisant, dit-elle, égard aux grands proffictz faictz » par cette fille et son mari « pendant la communion que a esté entre nous ». Communion qui pouvait avoir été heureuse ; les liens ne manquaient pas, du moins, pour en tenir réunis les membres : la fille en question, née d'un premier lit, était mariée au fils du second mari de sa mère, et Françoise Nycol et Marin Benoît avaient uni non seulement leur double viduité, mais leur progéniture...

C'est que, dans la société d'alors, les remariages étaient extrêmement fréquents. Aux termes des statuts synodaux, l'âge de nubilité était à quatorze ans pour les garçons, à douze pour les filles ; dans le cours d'une longue existence, il y avait place souvent pour deux ou trois unions. Événement si normal, si prévu, que certains maris s'en accommodaient d'avance : l'un d'eux, le Dolois Jean Chaillot, ne va-t-il pas, "pour mieux contenter sa femme », Jeannette Bergières, jusqu'à lui donner la somme de 100 fr., « que luy seront payez par ses héritiers trois ans après qu'elle sera remariée en secondes noces » ? De fait, dans de nombreuses familles, les enfants de lits différents vivaient côte à côte fraternellement et gardaient un accord qu'attestent: les textes. C'est ainsi, par exemple, que le conseiller Duchamp, non content de léguer 200 écus d'or à sa mère remariée, donne 500 fr. à ses frères et soeurs utérins. Le procureur général Henri Camu confie à sa seconde femme, à charge de les élever " comme une bonne mère doit », ses enfants Pierre et Jean, fils d'un premier lit. De tout leur soin, du reste, les parents s'efforçaient de tenir balance égale entre enfants du même lit, comme entre demi-frères et demisoeurs ; comme le déclare Anne de Poligny, la femme du président Marmier, "après l'honneur et le service de Dieu » leur plus cher désir étant d'assurer " l'amitié et union réciproque de leurs enffans », ils s'ingéniaient de leur mieux à «retrancher toutes occasions de division ». Il faut voir avec quel soin Françoise Nycol cherche à équilibrer ses legs entre ses filles : Désirée Benoît, d'une part ; Jeannette et Marguerite de Saint-Mauris, de l'autre. Il faut voir, dans son testament, les efforts de Claudine Mairot, la femme du conseiller au Parlement Grandjean, pour « pourveoir à ses enffans de deux lictz et faire tellement qu'entre eulx ne s'en retrouve difficulté » - ou ceux du président Jaquinot pour satisfaire égale- 
ment les enfants que lui donnèrent Marguerite Demongenet et Jeanne-Baptiste Chaillot. Très rares, les parents qui avantageaient notablement l'aîné ; pour les filles, en tout cas, les dots se distribuaient toujours en toute égalité - et dans la rigueur de cette justice distributive se marquait un des traits du caractère bourgeois.

Fait curieux, et qui de prime abord semble en opposition avec un tel respect des droits acquis : ce sont plusieurs exemples que nous avons trouvés non d'une sollicitude des pères pour leurs fils naturels - rien d'extraordinaire dans le souci d'en assurer l'existence ou de légitimer ces irréguliers - mais d'une telle sollicitude comprise et partagée par leurs femmes et leurs enfants légitimes. En 1546, un lieutenant de bailliage, Louis de Cise d'Arbois, après avoir doté les « données » de ses deux frères : Jean, chanoine d'Arbois, et Thiébaud, passe aux siennes propres, et stipule dans son testament que Claude et Claudine, qu'il a eus d'une servante, devront être élevés, nourris et mariés par sa fille légitime Charlotte, femme d'un riche bourgeois de Poligny et sa principale héritière. - Influence des moeurs de la noblesse ? Sans doute. Nous verrons tout à l'heure avec quelle indulgence les femmes des grands seigneurs accueillaient la descendance illégitime de leurs maris. Sentiment d'intérêt bien entendu ? Peut-être. Dans de curieuses lettres à Granvelle, Claude de Chavirey, son homme de confiance, et Antoinette Grenier, femme de Claude, le prient tous deux et très instamment de s'intéresser aux deux « donnés » du vieil écuyer Grenier de Besançon - le père d'Antoinette. Ils en donnent le motif, candidement : si le cardinal pourvoit les deux bâtards, le vieil homme sans doute, tranquille de ce côté, « aura plus de voulenté de respecter la femme et les quatre filz » de Chavirey, «dont le plus vieulx n'a que quatre ans cinq moys ». Respecter, ici, veut dire coucher sur testament... - mais il y a autre chose encore, sans nul doute. Ces "donnés ", après tout, sont des forces. Pourquoi les laisser perdre pour la famille ? Ne vaut-il pas mieux qu'elle les englobe, et qu'ils viennent se fondre dans la communauté ? Ainsi s'enrichissent, ainsi s'étendent et prospèrent les dynasties bourgeoises. 


\section{IV}

Dynasties respectées, parce qu'elles étaient fortes et portaient l'avenir. Dans les petites villes, les droits de bourgeoisie - source d'honneurs à la fois et de profits 36 - contribuaient puissamment à leur éclat. Surtout, à qui la portait, la robe conférait une dignité, un prestige, une autorité réelle ; elle créait peu à peu une véritable caste. Le doctorat n'était point sans doute un titre de noblesse ; mais un «messire » valait presque un «noble homme ». - Et nous touchons ici à un second trait, à un second caractère de la société bourgeoise : société instruite et dont le savoir faisait la force.

Savoir peu désintéressé : la littérature tentait médiocrement les robins. Certes, au degré le plus haut, quelque chose les touchait de ce désir de gloire qu'apporte la Renaissance. Des amis qui écrivaient, des pédagogues et des magisters, dont ils étaient les Mécènes utilitaires et parcimonieux les imprimaient tout vifs, célébraient leurs louanges, d'un médiocre avocat de Baume ou d'Arbois faisaient - tel un Gilbert Cousin dans sa Description - un homme de haute science et de coeur magnanime, dignement célébré en phrases cicéroniennes. Eux-mêmes composaient des dédicaces, des épigrammes, des allégories en latin ou en grec : point de grammaire, de manuel juridique, de recueil obscur de versification qui ne porte en tête ses douze ou quinze pièces dédicatoires : ce qu'on y lit de plus clair, c'est généralement le nom et les titres de leurs auteurs. Mais pendant tout le siècle ou presque, la Comté, dotée pourtant de presses au XVe siècle, ignore l'imprimerie. C'est seulement en 1589 que le juge bisontin Morelot, saluant dans sa ville natale le retour d'une presse : celle de Jacques Foillet, pourra adjurer les cogouverneurs « d'entretenir les arts et les bons artisans », et de favoriser « ces gentils esprits ».

$36 \mathrm{Si}$, dans l'usage courant, bourgeois désignait les roturiers non mainmortables, au sens strict, il désignait « les habitants des villes ou des bourgs associés par la commune à la bourgeoisie du lieu ou en possession de l'état de bourgeois » (Dunod, Histoire des Séquanois et de la province séquanoise... p. 377), cela, par opposition aux « habitants » ou aux « manants ». Les bourgeois (à Besançon, on disait les citoyens) constituaient une petite aristocratie ; ils possédaient des droits politiques ou du moins électoraux, des droits de chasse, de pêche, de port d'armes, etc. 
Qui commencent ici de dresser une presse.

Aucuns s'élèveront parmi vostre jeunesse

Et me seront témoins qu'en l'air de Bezanson

S'eslevent des esprits gaillards et à foison...

En fait, Bisontins et Comtois gardaient presque tous leur « gaillardise » secrète. On a tôt fait d'énumérer les quelques poètes, latins ou français, du terroir : un Julyot, un Flory, un Morisot, un Vuillemin, une Pautrard ; déracinés, un Boissard ou un George Guiot; plus connu, un Mathieu, auteur de tragédies bibliques ou le contemporain, l'émule provincial de Malherbe : Chassignet. Cette pénurie relative tient sans doute à des causes multiples. Français de langue, ces Bourguignons ne l'étaient pas pleinement de culture ni de relations. Si quelques-uns, pendant leur jeunesse, fréquentaient à Paris, à Toulouse, à Poitiers, c'était vers l'Italie plutôt, vers les Pays-Bas, vers Bâle encore et vers l'Allemagne que regardait la masse. Plus que Ronsard, ils lisaient l'Arioste, et tous n'auraient-ils pu dire «à leurs livretz allant soubs la presse en France » :

Petit livret qu'en azard te veulx mettre, En France aller, fontaine d'éloquence, Doubte-tu point rencontrer quelque maistre Qui mocquera ta rustique loquence ?...

Il y a, dans leurs imitations des poètes français de la Pléiade, quelque chose d'un peu gros, une redondance maladroite de termes épais qui peut-être, commune à la plupart d'entre eux, trahit un défaut de l'esprit local - peut-être aussi s'explique par leur isolement, leur éloignement de Paris et de cette cour des Valois où s'affinait peu à peu et se purifiait la langue.

Par là, dans la littérature d'imitation antique, ils devaient, semble-t-il, se sentir plus à l'aise ? Mais, pas plus que le poète français, il ne faut, en Comté, chercher l'humaniste, l'habile imitateur de Virgile et d'Ovide ou l'orateur brillant, aux périodes cadencées. C'est vers les pays du nord : Allemagne, Suisse, Flandre, qu'en pareille matière s'oriente la Comté. Comme eux, elle goûte dans la science moins la science même que les avantages, les satisfactions d'ordre matériel qu'elle peut 
procurer. Elle aura des écoles de médecins, parce que la médecine est utile ; des écoles de droit, parce que les juristes enseignent les moyens du pouvoir et la science du gouvernement. Mais les travailleurs désintéressés : philologues, philosophes, littérateurs, en seront bannis par l'indifférence de tous. A une seule condition, ils recevront asile : s'ils enseignent. Pédagogues et théologiens seront les bienvenus pour former aux belles-lettres, d'utilité première, les esprits solides des futurs procureurs. Et pareillement dans leurs bibliothèques, point de sourire. Les poètes, les conteurs français sont absents : les livres latins dominent.

Voici, daté de 1574, le catalogue d'une bibliothèque de notaire bisontin. Longue est la liste de ses ouvrages anciens. Des historiens : Suétone, Salluste, Valère Maxime ; quelques poètes : Juvénal, Virgile, les Fastes et les Métamorphoses d'Ovide, les Épigrammes de Martial, les Fables d'Ésope, les Comédies de Térence ; de Cicéron, l'oeuvre presque entière : les Discours, les Épîtres familières, les lettres à Atticus, à Brutus, à Quintus, les traités moraux, le de Officiis, le de Amicitia, le de Senectute, le Songe de Scipion, la Rhétorique à Herennius et le de Inventione. Enfin, des grammaires, des dictionnaires, des morceaux choisis, le de Corrupti Sermonis Emendatione de Mathurin Cordier; les Institutiones in grœcam linguam de Nicolas Clenard ; la Dialectique de Jean Kayser (Cœsarius) ; le Lexicon de Calepinus et diverses rhétoriques de Rivius, d'Omer Talon - sans compter plusieurs éditions des Institutes et des Adages d'Erasme. En regard, combien courte la liste des livres français : deux recueils d'ordonnances du Comté ; un livre de piété : le Pain Dominical des Paroisses ; quelques vieux romans de chevalerie : Gérard de Roussillon, la tierce partie de Lancelot du Lac, Miles et Amys ; avec une traduction française des Épîtres d'Ovide, « ung dialogue intitulé le Peregrin », la «Déclaration des abutz des médecins » et le recueil de Ferry Julyot telle est, complète, la table « des livres en françois dud. Pierre Fleuriot». Un seul livre, « en italiain, intitulé : Ultimi Canti d'Orlando Furioso » - voilà tout ce qui représente la littérature moderne et la poésie de la Renaissance.

Bibliothèque sérieuse, on le voit, et lectures austères. Moins que d'autres encore ! Nous avons l'inventaire dressé après décès, en 1569, des livres du conseiller Seguin. Soixante-dix-neuf ouvrages sont dénombrés ; tous, absolument tous, sont des livres de droit : droit civil, droit canon, répertoires, commentaires, consultations, etc. ; ce sont les oeuvres de Bartole, en 6 volumes ; un Corpus Juris, en 5 ; 7 volumes des oeuvres de Jason, 9 de Balde, 8 d'Alexander, 5 de Paul de Castro, 
etc. Et pas un poète ni latin, ni français : les Épîtres de Phalaris, les oeuvres de Panormita, un Pline en français, la Belli Sacri Historia de Guillaume de Tyr, un Justin, un Aulu-Gelle, la Maison Rustique de Charles Estienne et la Vénerie de Jacques du Foillon - voilà les plus frivoles ouvrages du conseiller Seguin. - Mais son confrère Cécile ? En 1587, Jean Tarlot, libraire dolois, prise sa bibliothèque ; il dénombre 133 ouvrages, la plupart en plusieurs tomes : cours de droit canon ou de droit civil, de l'impression lyonnaise des de la Porta ; Marciani et Bartholomei consilia ; Decisiones Fr. Marci ; Decisiones Rotae ; Arrêts de Papon, Baldi lecturae in jus civile ; Consilia Chassanei, Alexandri, Jasonis, Paulis, Castrensis, Decii, Socini... Qu'on excepte les Catilinaires, les Histoires de Paul Jove, une Bible, le De officiis, un Dictionnaire latin-français, un Lexicon graco-latinum, les Épîtres de Phalaris et les lettres de Bembo, plus « un livre en papier escript de la propre main du feu sr conseiller Cecile, et luy servant de lieux commungs » - tout est livre de droit dans cette bibliothèque.

C'est que leurs livres, pour ces durs juristes, sont moins des amis et des confidents que les instruments indispensables de leur fortune et de leur élévation. La science est leur gagne-pain : plus encore et mieux, la source de leur pouvoir, de leur dignité, du triomphe collectif de leur classe sociale. La puissance nobiliaire se fonde sur l'épée; le gentilhomme s'enorgueillit, à la fois, d'une longue lignée d'ancêtres batailleurs et de son oisiveté de grand seigneur. Le bourgeois, lui, est le fils du livre.

\section{V}

Aussi quel soin d'assurer à tous ceux qui le touchent les avantages d'une instruction créatrice de richesses et de dignités ? Les testaments, sur ce point, parlent haut : bien rares ceux qui ne comportent pas quelque clause relative à l'instruction des fils, des neveux, d'un jeune frère ou d'un orphelin. Le conseiller Phénix, après avoir légué aux Mineurs de Dole ses livres de piété, assure à son petit-neveu Servois Boillot ses « alymens et entre-tenemens » en sa maison, tant qu'il aura « vouloir d'étudier ». Un notaire de Quingey, Jean Garçon, laisse 20 fr. à chacun de ses petits-enfants pour que leur père « ayt meilleur moyen » de les entretenir aux éco- 
les. Si Françoise Delivran cède à son mari, le greffier Barnard, sa part d'acquêts, c'est à condition qu'il entretienne trois ans à l'école, à raison de 20 fr. par tête et par an, ses deux neveux Guillaume et Laurent; et c'est à charge de les bien « eslever aux escolles, comme une bonne mère doit faire », que le procureur Camu confie ses deux enfants à sa seconde femme. Le docteur Desbarres, à Étienne Lardon, son filleul, donne, outre divers habits de deuil, $50 \mathrm{fr}$. et des livres, pour l'aider à poursuivre ses études. Pareillement, le conseiller Mairot lègue ses livres à son neveu François ; le conseiller Saint-Mauris, les siens à son frère Prudent ; le président Jaquinot, les siens encore à son fils Nicolas « en cas il suyve sa profession »; sinon, aux cadets ; par dizaines, semblables textes pourraient être allégués. C'est que, nombre de robins l'ont transcrit sous la férule du maître, le vieux quatrain que nous avons trouvé dans un cahier de modèles d'écriture du temps :

Vive la plume magnifique,

Le papier et le parchemin !

Qui d'escripre sçait la pratique

Il peut bien aller par chemin !

ou celui-ci encore, tout aussi expressif :

C'est grand honneur de bien sçavoir escrire

Lettre commune, et autre bravement.

Cela pourra à un jeune homme suffire

Pour quelque jour parvenir grandement...

Quoi d'étonnant, dès lors, dans cette floraison de collèges secondaires qui s'établissent et prospèrent vers le milieu du siècle dans presque toutes les petites villes comtoises ? Pour les loger convenablement, les entretenir de régents «capables et suffisants », les magistrats s'épuisent, dépensent sans compter leur temps et leur argent. Dole, en 1546, achète pour 1600 fr. à Henri Colin la maison de Citeaux et y installe le collège de grammaire que fera seul disparaître, en 1590, le collège des jésuites. Salins dépense 1500 l., en 1565, à acquérir la maison Trousset, où le recteur et ses régents dresseront pendant tout le siècle une jeunesse turbulente dont ils se plaignent « de ne pouvoir jouyr ». Gy, en 1572, une toute petite bourgade, obtient de Philippe II une maison confisquée pour y tenir école, à charge d'y faire chanter, à titre de redevance, un Salve regina quotidien. Baume-les- 
Dames, en juin 1583, consacre elle aussi 2800 fr. à loger ses régents, et Pontarlier, en 1588, aménage ses classes dans le vieux château.

Les particuliers à leur tour s'émeuvent. Ce sont des dons, des fondations généreuses. A Besançon, les Granvelle donnent l'exemple. Nicolas Perrenot et Nicole Bonvalot instituent, en 1545, un collège de grammaire et de théologie. François Bonvalot, en 1557, fonde sept bourses annuelles, de 25 fr. l'une et d'une durée de cinq ans, pour donner l'instruction à des jeunes gens pauvres. A Salins, en 1568, l'avocat Marceret lègue 100 livres aux écoles, pour nourrir, coucher et enseigner deux enfants orphelins. A Dole, en 1575, Pierre Froissard crée cinq bourses pour des enfants pauvres. Toute une classe sent ainsi et marque chaque jour de quel prix pour elle est l'instruction et l'éducation. Éducation sévère, du reste : si le règlement du collège de Gray prescrit, en 1583, de réserver « le chastoy de verges » aux seuls « manants et trop négligens », vu que, « par honte, remontrances, admonitions et libéralités, la jeunesse est plutôt retenue en devoir et office » - par contre, le vieux recueil de modèles que nous citions plus haut déclare tout net aux Arboisiens :

Père qui l'enfant flatte, Nourriture trop délicate, Liberté et sotte doctrine Sont cause que l'enfant mal fine...

Le bon maître est celui qui punit fort ; et un honnête garçon de dix-sept ans, Sébastien Ganne, un fils de boucher, traduit parfaitement le sentiment commun des parents et des enfants d'alors, en incriminant le régent Pautrard «parce que, au lieu de donner craincte à ses disciples et leur enseigner choses utiles et profitables, il leur faisoit d'ordinaire des comptes ». Le bon jeune homme se rencontrait ainsi avec Ferry Julyot : c'est la morale même de ses « Lamentations » :

Estudier doyvent pères et mères Bien chastier leurs enfants en jeunesse. Laisser ne faut l'enfant né en souplesse Tailler les saulx agiles qu'il peut faire, Car, s'il cognoit liberté volontaire Il se pourra en sautant outrager... 
Rudement ainsi, dans les collèges et les écoles secondaires se forment les futurs officiers de bailliage, les avocats ou les gens des Comptes. Humbles officines où, sous l'oeil du recteur, trois ou quatre régents leur inculquent le latin et parfois un peu de grec : de là sortent, armées pour la vie, les troupes sans cesse accrues des médecins, des juristes, des professeurs de lettres et de droit. À tous, dès leur jeunesse, l'école confère les qualités maîtresses du bourgeois : la netteté, le sens des réalités pratiques, l'amour de la régularité, de l'ordre extérieur, et cette sorte d'horreur pour les agitations de la rue et du peuple que tant de textes anciens pouvaient renforcer. Dans leur vie, plus tard, ce seront les mêmes idées chez les uns et les autres, les mêmes besoins et les mêmes désirs. Épris de satisfactions profitables, ils connaîtront le luxe sans doute - mais un luxe sérieux, confortable, fait pour eux plus que pour les autres. Tous, ils auront l'amour du cossu, le même goût pour les beaux meubles bourguignons et les maisons solides, soigneusement bâties de matériaux de choix ; la même prédilection pour les jardins bourgeois, bien propres, bien tenus, avec leurs plates-bandes encadrées de buis taillés ; le même sens héréditaire du « loyal travail ». Ils dépenseront beaucoup en vêtements somptueux - les femmes surtout, «mesprisant l'estat de bourgeoisie » et dont le bon Julyot flétrit sans ménagement les artifices coûteux, les épaisses lingeries, utiles

Pour offusquer la peau ridée de gresse

ou les durs « cartons busquez »

Que bien souvent l'estomach tant oppresse

Qu'en coeur failly, la dame tombe en presse.

Écarts individuels que le ridicule punit :

Contrefaisant thoretz de damoiselles, Ne vela pas des gentilles donselles?

Mais après tout, ce faste sert encore : il est l'enseigne voyante des fortunes faites. Plus solide, le luxe des bijoux, cette passion pour la joaillerie et l'orfèvrerie qu'attestent - en Comté comme ailleurs - les inventaires et les testaments. Chaînes d'or, aiguières d'argent, pate-nôtres de corail, salières artistement travaillées, médailles précieuses rapportées d'Espagne ou vases sacrés, souvent légués à des égli- 
ses : c'est tout un faste magnifique, mais un placement aussi, une façon commode d'employer le surcroît de numéraire dont ne savaient toujours que faire les très riches bourgeois.

Ainsi, sûrs d'eux-mêmes et de leur avenir, fiers de leur situation et de leur prestige, robins et marchands étalent au grand jour l'orgueil de leur succès. Tout comme les nobles déjà, ils parlent de leurs "maisons », de "la conservation, augmentation et soubstènement d'icelles ». Ils ont le souci de leur nom, de leurs ancêtres dont ils gardent soigneusement les portraits, du tombeau de famille qu'ils désirent aussi beau, aussi somptueux que possible. Et déjà quelques-uns d'entre eux semblent s'évader de leur classe, devenus vraiment des nobles et pareils aux plus grands. Illusion : par quelque trait, toujours, leur origine encore proche se trahit. Leur luxe même, leur faste n'est pas celui des hauts barons. Luxe neuf d'abord, et qui n'est point hérité. Luxe confortable, et tout adapté aux besoins quotidiens de son possesseur. Luxe éclectique aussi, luxe cosmopolite de voyageurs à l'esprit ouvert.

\section{VI}

Voici l'inventaire mobilier de l'un d'entre eux - un des plus prospères, Fernand Gauthiot d'Ancier, fils de ce Simon dont Castan jadis a retracé l'histoire. C'est d'abord une profusion de bijoux, un ruissellement d'or et d'argent mis en oeuvre : Bassins dorés aux armes du défunt ; vases sacrés, calices, patènes, paix émaillées ; salières à coquilles, toutes sculptées et fouillées, portées par des enfants ou par des satyres ; statuettes d'animaux : cerfs, pies, chouettes, chevaux en argent doré ou en vermeil ; muscades garnies d'argent, avec couvercle et pied sculpté ; carcans de diamant, colliers d'or, pendants, enseignes de chapeaux garnies d'émeraudes, de perles, de rubis ; médailles à l'effigie de Philippe II ; bagues, coeurs de diamant, chapelets de corail, sceaux et cachets, médailles antiques : c'est un vrai ruissellement de pierreries et de métaux précieux. Et pareillement, les meubles sont magnifiques : buffets, tables, cabinets sculptés de l'école bourguignonne ; quelques-uns d'entre eux, débris des somptueux mobiliers d'autrefois, font encore l'orgueil de nos musées locaux. Les étoffes, les vêtements sont de prix : soies brillan- 
tes, lourds brocarts, velours aux couleurs vives. Mais les oeuvres d'art surtout, par leur choix, sont intéressantes.

Tableaux italiens ou de goût italien. d'abord. Voici « dix-sept peintures faictes à plaisir, où sont peinctz des visages de courtisanes »; deux « portraictz de courtisanes peinctes jusques aux genoux, que sont les peintures de la signora Francisque et signora Geneva ». Souvenirs des années de jeunesse, des séjours heureux à Rome ou à Venise - ceux qu'évoquait le bon Claude de Pontoux :

Selincourt, allons voir la gaye Luciane, L'Esmeralde aux yeux verds, la belle Véronique A qui tu es amy (mais tu n'es pas l'unique) ; Nous la ferons baller à la Venitiane...

Pareillement, voici une peinture « d'une femme qui tient une escrevisse de laquelle elle faict mordre un enfant »; une autre, «d'ung bain d'hommes et de femmes »; une « histoire de Zani, ledit Zani tenant à sa main une chandelle »; et des Suzanne, des Cléopâtre, des Sodome et Gomorrhe, prétextes à nudités gaillardes et faciles qui portent leur date et disent bien leur époque.

Mais la Flandre, au XVIe siècle, est l'autre pôle de la culture comtoise. Et voici des tableaux flamands ou de goût flamand : "Cinq peintures à destrange, fasson de Flandres, où sont peintz divers personnaiges - le tout à plesir et pour drôlerie »; une peinture faite au naturel, « estant une histoire de fêtes de villaiges, façon de Flandres » - ou encore, " une peincture où est représentée une cuysine, fasson de Flandres, où il y a une femme qui fait des gaufres ». Puis viennent les portraits : portraits historiques, « deux peinctures faictes à huille, où sont peinct à l'une le roy Philippe, et l'aultre la royenne Marie »; " la personne du prince d'Orange »; François Ier et Bourbon, Charles-Quint et Madame Marie, Philippe II, don Juan, Élisabeth de France, Claude de Lorraine, sans compter - vieux souvenir bourguignon - les « quattre ducs de Bourgoigne avec leurs femmes ». Portraits de famille aussi : un de " fut Symon Gaulthiot; deux de Jean Gaulthiot et l'aultre de damoiselle Anne de Chassault, femme dud. Jean Gaulthiot» - sans compter « trois tableaux faict à huille où sont représentés au naturel Symon, Jehan et Fernande Gaulthiot, ayeul, père, filz ». Et encore des estampes de de Lau- 
ne, d'Aldegrever ; des livres de «Termes »; des recueils de dessins, des cartes géographiques, de riches manuscrits ornés de miniatures, des ouvrages en albâtre de Saint-Claude, des statues de pierre de Dole ou de Sampans, des horloges d'Allemagne, des coffres de Hollande, tous les produits variés - somptueux ou délicats - des civilisations les plus diverses de l'Europe...

Même éclectisme au reste dans les curiosités et les goûts littéraires des Gauthiot : même largeur, même ouverture d'esprit. De la très riche bibliothèque de Fernand - héritée en partie sans doute de son père - nous possédons également l'inventaire. Ici, nulle grammaire, nul dictionnaire. Rien qui sente l'école ou le pédant. Comme auteurs anciens, rien que des historiens : Polybe, Quinte-Curce, Hérodote, Josèphe, Salluste, Diodore. En plus seulement, la République de Platon voisinant avec celle de Bodin, les Épîtres de Sénèque avec l'Institution du Prince et, naturellement, les Vies et les Moraux de Plutarque. De Cicéron, rien : lacune significative. Par contre, toute l'ardente curiosité de la Renaissance pour l'homme, la nature et le monde habité. Voici les cosmographies : la belle cosmographie de Munster, in-folio (taxée 6 fr.) ; le Theatrum Orbis d'Ortelius (12fr.); la cosmographie de Thevet; les Planzs de du Pinet. Voici les vieilles chroniques : la Nef des histoires ; les Chroniques de France d'Olivier de la Marche, la Mer des Chroniques, "quatre volumes de l'histoire de Froissard», le Loyal Serviteur, les «Cronicques de Saint Loys ». À côté, les histoires provinciales, les Mémoires ou les grosses compilations du temps : l'histoire de Bretagne d'Argenteau, les Annales d'Anjou, «l'Histoire des neuf rois Charles » de Belleforest, les Mémoires de du Bellay et les discours politiques de La Noue ; l'histoire du Berry ; le « Cathalogue des conestables de France » et les Annales de Bourgogne de Paradin ainsi que les « Origines » de Saint-julien de Balleure; surtout, des histoires de peuples étrangers ou lointains : Guichardin ; l'Histoire d'Espagne de Louis Turquet ; celle du Portugal d'Osorio ; Olaüs Magnus, de Gentibus Septentrionalibus ; Martinus Cromerus, de Gestis Polonorum ; l'Histoire des Medicis, la République des Suisses et celle des Turcs; des récits de voyage en très grande abondance : les « Navigations de Christophe Coulon et aultres »; le Libvre des navigations et voyages de l'Affrique » voisinant avec «l'Art de naviger »; la France Antarctique de Thévet et l'Histoire de Georges Castriot; les «Cronicques du Perul », l'Histoire de Mexico et celle des Indes, les Navigations orientales et la « Description de l'île de Cipre ». Puis, cet autre monde qui est l'homme : l' « Anathomie de Andrey Vesal 
avec 1es pourtraicts de Graham » et celle d'Ambroise Paré ; des recueils de médecine, Paracelse, Galien, trois ou quatre « remèdes de la peste », des recettes pour les hommes et pour les chevaux, le «Guydon des Apoticaires» et les «Propos populaires de la médecine »; des naturalistes enfin : Belon, des Oiseaux ; Rondelet, des Poissons ; l'Histoire des Plantes de Léonard Florisque ; plus pratiques, le de Re Metallica d'Agricola, le Jardinage d'Antoine Museau, la Maison Rustique, le Bon Ménager, la « Practicque pour distiller confiture », un traité « des profits champestres et ruraux » et un « Dialogue Metyorologique ». Qu'on y joigne quelques ouvrages de piété : la Légende dorée, les Sermons de Peronet, un traité « de l'Estat de l'ame après le trespas », l'Hermès Trismégiste et deux paires d'heures à l'usage de Besançon ; les ouvrages de droit nécessaires à un Comtois possesseur de terres: Ordonnances du Comté, Pratique de Saint-Mauris, Arrêts de Papon, «Enchyridion des causes criminelles » et Pratique des notaires ; diverses plaquettes, « tant pour instruyre les héraulx d'armes que des fortifications, du roty et de la salade, de la chasse aux loups et des échecs »; deux cents livres de musique, recueils de motets et de chansons, messes et Magnificat, tablatures : on aura le tableau très complet et très varié des curiosités intellectuelles d'un puissant anobli.

Pas de littérature, comme on voit, ou très peu ; surtout, pas de littérature française : toute la Pléiade reste ignorée. Par contre, poètes et conteurs italiens sont là, et à plusieurs exemplaires : l'Orlando Furioso, «Bocquase, des Nobles malheureux », le Courtisan de Balthazar Castiglione, les Facéties du Pogge, les nouvelles de Sansovino et celles «du Bande »; Guichardin et les Discours de Machiavel : voilà, avec quelques vieux romans de chevalerie, Perceforest, Lancelot du Lac, Amadis de Gaule et les «Quattre fils Emond », ce que lit le riche Fernand Gauthiot d'Ancier lorsqu'il veut se délasser l'esprit dans ses belles demeures de Gray ou de Besançon.

Ce luxe intellectuel des beaux livres bien choisis, bien reliés, des somptueux manuscrits couverts de veau rouge et enrichis de dorures, complète, couronne, achève le luxe matériel de ces opulents et fastueux parvenus. Au-dessus de la bourgeoisie dont ils ne se détachent encore qu'à demi, ils excitent l'envie et l'émulation de tous les robins patients, de tous les marchands acharnés au trafic ; à côté de la noblesse de nom et d'armes qui peut bien parfois s'unir à eux mais sans les adopter pleinement cependant, sans oublier jamais une différence d'origine qu'atteste encore la différence des préoccupations, des attitudes et de la culture, ils 
marquent l'achèvement de tout un lent mouvement social - la dernière étape du bourgeois en marche vers le succès. 
PHILIPPE II ET LA FRANCHE-COMTÉ

Étude d’histoire politique, religieuse et sociale.

Deuxième partie. Les débuts du règne de Philippe II

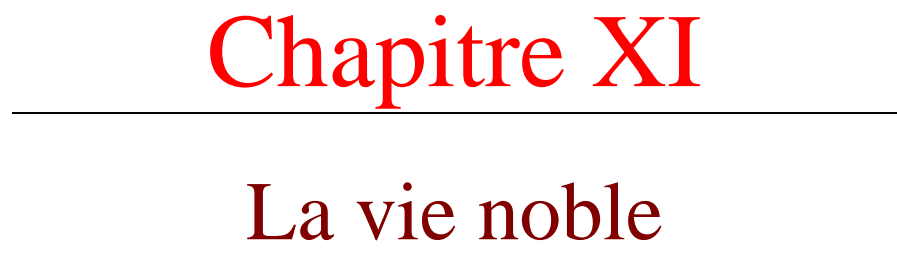

$\underline{\text { Retour à la table des matières }}$

Lorsque, détournant ses yeux de la prospérité rivale du haut bourgeois, le noble fait un retour sur sa situation propre, comment ne verrait-il pas que l'heure est décisive, comment ne tenterait-il pas, dans le duel qu'il sait engagé, une offensive hardie, conforme à ses goûts et à ses traditions ?

Sans doute, s'il vivait économe et paisible sur ses domaines, il pourrait connaître l'aisance. Il trouverait là, sans peine, tous les éléments d'une existence enviable. Des chevaux dans ses écuries - ces bons chevaux comtois courageux et vites que célèbre Gollut; des meutes nombreuses dans ses chenils, de grands parcs remplis d'animaux divers ; pour les services domestiques, l'armée des tenanciers ; une table plantureuse, fournie à volonté de vins, de volailles, de poissons, de gibier : c'était de quoi provoquer la jalousie de maint seigneur lorrain ou champenois. Or, de ces ressources, la noblesse usait largement ; mais, ni les plaisirs variés de la chasse, en plaine ou en forêt, à la bête rousse ou à la bête noire ; ni la vie de loisir dans les vieux châteaux : ceux du plat pays, avec leur ceinture de murailles et de tours, ou ceux de la Montagne, d'allure rustique, avec leurs enceintes successives, leurs galeries et leurs balcons de sapin ; ni les mille commodités qu'à son 
possesseur offrait la seigneurie, n'apaisaient leurs désirs d'une existence plus large et plus variée.

À gérer leurs domaines, quelques-uns s'essayaient. Ils tentaient de ressaisir leurs droits menacés de plus en plus par les tenanciers, fondaient des villages, à l'imitation des anoblis, cherchaient enfin dans les « engins » quelques ressources accessoires. Antoinette de Montmartin, en 1575 ; à la même époque, Philibert de la Baume, créent les papeteries de Sirod et de Balanod. Des gentils-hommes, suivant l'exemple des abbayes, bâtissent et entretiennent quelques usines à fer. Antoine de Grammont fonde, en 1563, les fourneaux de Miélin; Ch.-Ph. de Croï, aux confins du Comté, élève les forges de Fontenoy; Philibert de Coligny, en 1589, dresse celles de Ceffia. Encore, sont-ce seigneurs étrangers et terres limitrophes. Quelques Comtois, cependant, suivent l'exploitation des petites usines qu'ils se trouvent posséder : Philibert de Montmartin, par exemple, et Louis de la Tour exploitent directement les forges de Loulans et de Moncley. D'autres s'intéressent aux «minières ». Pierre de Canoz, en 1568, demande à tirer de la houille en Comté ; Louis de la Tour, en 1581, préoccupé de fournir à ses forges du combustible, sollicite à son tour le droit d'exploiter, dans les terres d'Arguel et de Montfaucon, «pierre de oille et ardoise ». En 1565, c'est Jean de Vaudrey, seigneur de Beveuge, qui réclame la concession des mines d'argent de ChâteauLambert et du val de Servance ; dans la première compagnie qui les travailla réellement, de 1574 à 1582, on trouve, parmi des noms de bourgeois ou d'anoblis récents, celui d'un grand seigneur, le bailli de Dole Jean-Baptiste d'Andelot. C'était là pour lui, comme pour ses "coparsonniers », une sorte de spéculation assez intéressante, plutôt qu'une exploitation méthodique et régulière; l'argent qu'à grand'peine et grands frais rendait la mine ne l'enrichissait pas ; il lui permettait seulement de se faire fabriquer, pour la curiosité, quelques belles pièces de vaisselle de table. Mais, qu'on compte les nobles qui prenaient goût à de telles « entremises ». A peine, pendant tout un demi-siècle, en rencontrera-t-on une douzaine. Les autres maintenaient fermement leur réputation de «mauvais ménagers ». Ils dépensaient, ils ne gagnaient pas. Plus que personne, pourtant, n'auraient-ils pas eu besoin de ressources accrues? Tant de dépenses lourdes grevaient leur budget, que ne connaissaient ni robins ni marchands. 


\section{I}

D'abord, tout gentilhomme avait son rang à soutenir. Il avait au coeur la fierté de son nom, le culte de sa race, l'orgueil du passé et des ancêtres dont le souvenir lui avait été légué par ses parents. A Granvelle qui, l'ayant fait nommer bailli de Dole en 1564, lui demandait de " faire mettre un titre de signourie au mandement », Jean-Baptiste d'Andelot répondait fièrement : « Monsieur, je n'estime rien plus honorable pour moy que mon nom, car cela ne me peult l'on jamais ôter ny vandre ». Une des grandes craintes du noble de vieille noblesse, c'est de voir sa race disparaître ; un de ses grands soucis, d'assurer, s'il y a lieu, un relèvement de nom et d'armes par où se satisfasse sa piété familiale. Or, du fait de ce passé dont il est respectueux, une multitude de charges traditionnelles pèsent sur le noble et viennent obligatoirement grever son budget. Ces charges, les textes les énumèrent : rentes perpétuelles, héritées des ancêtres, fondations pieuses, versements aux églises, aux monastères, aux hôpitaux du voisinage ; funérailles surtout, coûteuses, solennelles, interminables.

Bien rares étaient ceux qui, comme Pierre de Vaudrey, baron de Courlaoux, demandaient d'humbles obsèques faites « à la moindre pompe que l'on pourra »; encore prévoyait-il, le bon seigneur, que, pour subvenir aux siennes, il faudrait vendre ses chevaux, ses habits et ses meubles. Mais les autres ! C'étaient des messes par centaines; 800 pour Gérard de Rye, seigneur de Balançon ; 300 pour Marguerite de la Thouvière, veuve de l'écuyer Marc de Reculot : 100 le jour de son enterrement, dont 3 grandes en haut, à diacre et sous-diacre ; 100, quarante jours après les obsèques ; 100, enfin, au bout de l'an. Et Marguerite de la Thouvière n'était pas de très puissante ni très riche famille. Et puis, quel décor à la cérémonie : chapelles ardentes, défilés de pauvres vêtus de deuil, de veuves ou d'orphelins portant es torches ou des cierges, sonneries de cloches, distributions de vivres, sans compter les monuments à ériger, les charniers spéciaux à faire aménager dans les chapelles, les épitaphes à dresser, les statues tombales souvent multipliées en diverses églises - si le défunt, par exemple, donnait à l'une son coeur, à l'autre sa dépouille. De tels soins faisaient partie de ce qu'un noble devait à sa 
race ; les omettre était cause de remords, et nombreux étaient ceux qui, pour mieux s'assurer une sépulture décente, la préparaient eux-mêmes de leur vivant.

Autres charges encore : les anniversaires, les fondations perpétuelles, toutes dépenses obligatoires pour qui voulait mourir selon son rang ; les aumônes aux prêtres et aux moines, sans nombre. Louise de Longwy, veuve de Gérard de Rye, lègue 30 fr. au curé de Thervay, 30 au curé de Montgesoye, 30 à celui de Vuillafans, 500 aux chapelains de sa chapelle funéraire, 20 aux Clarisses et 20 aux Dominicains de Besançon, 20 aux Cordeliers de Dole, 20 au couvent Saint-Éloi de Pontarlier... Le tout sans préjudice des donations pieuses qui trouvent leurs analogues dans les actes bourgeois : largesses aux « châsses principales ayant cours en Comté » pour que le défunt soit participant aux prières des hôpitaux ; dons d'habits ou d'étoffes pour le service du culte : une robe de velours à l'église d'Orchamps, une de damas blanc à celle de Flangebouche, pour en faire des tuniques ; un legs de 100 fr. à l'église de Vitrey pour achat de vêtements sacrés et façon d'une horloge ; 120 fr. laissés à Notre-Dame de Montroland pour prix d'une chasuble aux armes du donateur. Et les causes charitables ne manquent point non plus : en faveur des pauvres, des hôpitaux, des assistants aux obsèques ; dots de pauvres filles «de bonne fame et renommée »; de pauvres orphelins anonymes ou spécifiés, comme ces trois petits enfants, « sçavoir : le petit Nicolas, Cathelin et Laurence » que Girard de Fauquier entend voir instruire « en quelque artz et mestier » par les soins de ses héritiers. Ainsi s'en va le noble, entouré d'un cortège de libéralités.

Dépenses de mourants : celles des vivants pour le moins les égalent. Les noces, par exemple, étaient aussi coûteuses, aussi solennelles que les funérailles ; et ce n'était pas le produit de l'aide perçue sur les tenanciers qui couvrait les frais de la cérémonie, des bals, des tournois, des ballets, des spectacles. Mais les seules dépenses de la vie courante suffisaient déjà à absorber partie des revenus du seigneur.

Tout noble, en effet, possédait sa maison - une armée de serviteurs, de servantes, de valets qu'il traînait avec lui au moindre déplacement. Rarement, les testaments permettent d'en faire l'exact dénombrement: ils ne mentionnent que les favoris, les privilégiés, les plus fidèles ou les plus anciens des domestiques ; mais quelle liste déjà ! Marguerite de la Thouvière a trois « serviteurs », un " charreton », un valet, cinq servantes - sans compter deux receveurs et les officiers de ses 
seigneuries. Au testament de la belle et célèbre Antoinette de Montmartin, femme de ce Jean de Poupet, seigneur de la Chaux, qui était un des favoris de CharlesQuint, figurent un maître et une maîtresse d'hôtel, Jean de Boigne et sa femme Antoinette de Chemilly, tous deux de noble naissance; trois demoiselles de chambre, Jeanne du Tartre, Catherine Masson et Jeanne de Montoiche ; deux pages, un chapelain, un tailleur, un petit laquais et un valet - le tout, sans compter les serviteurs particuliers de son mari ni les officiers de ses seigneuries. Veut-on la maison d'un gentilhomme suivant les armes ? Le 27 août 1558, à Louvain, « au logis où pend pour enseigne le Sauvaige », Pierre de Vaudrey rédige son testament. Voici les valets d'armes: Francisque Encalada qui sert le maître depuis vingt ans ; il aura 300 fr. de rente annuelle, rachetable à 8\%, une maison à Courlaoux et le «cortault gris » de son seigneur. Pierre Trippon sert depuis quatorze ans : il aura $100 \mathrm{fr}$. de rente, également rachetables ; Huguet et Jaquet, moins anciens, se contenteront à moins. Puis vient le cuisinier Philibert; deux valets, le palefrenier, le page, le sommelier ; Joseph, garçon d'étable, et le bossu, portier de Courlaoux, sans compter l'écuyer Desle de Montjustin. En tout douze personnes, récompensées pour leurs services. Chiffre modeste, du reste, si on le compare à celui qu'accuse le testament de Jeanne, propre soeur de Pierre et veuve du puissant seigneur Claude de Ray.

Le Ier janvier 1581, sentant venir la mort et ne voulant laisser à personne le soin de gratifier ses domestiques, elle dressa la liste complète de ses gens de service. En tête, le précepteur du fils, Étienne Regnauld, un prêtre, docteur en droit et curé de Bucey, dont les gages annuels étaient de 200 fr. : il aura 100 écus d'or en reconnaissance « du bon devoir et office » qu'il prit à instruire J.-B. de Ray. Puis le secrétaire et le sous-secrétaire, le receveur domestique de Vaudrey et le valet de chambre de la testatrice. Ensuite, un tailleur à 60 fr. par an ; son aide ; un sommelier de cave à $3 \mathrm{fr}$. par mois ; un cuisinier à $40 \mathrm{fr}$. par an ; un muletier et un palefrenier à 3 fr. par mois ; un charretier à 20 fr. par an ; un valet d'étable à 14 fr. ; un portier ; quatre petits laquais, dont deux reçoivent quelque argent : 40 et $30 \mathrm{fr}$., « que seront convertis et emploiez pour leur faire apprendre ung mestier ». Encore, des domestiques de ferme : le «moutonnier » et sa femme, à 15 fr. par an; le bouvier ; un ex-palefrenier et un ex-valet. Les femmes maintenant : des suivantes et des femmes de chambre, quatre en tout, emportant des legs assez notables (400, 300 et, pour deux, 100 fr.). La boulangère, Claude Garnier, reçoit 40 fr. et une 
vache de 10 fr. ; trois servantes, dont l'une a des filles, complètent la liste avec « le petit Jehan, povre, résidant à l'hôpital à Dole », qui sera «mis à ung maistre pour apprendre métier » et le " petit Andrey, autrement dit le petit Dauphin », qui reçoit le produit « de l'eschutte mainmortable de son feu père ». En dernier lieu, damoiselle Anne de Vaudrey, sa soeur Claudine et Barbe de Laubespin, nièces de la testatrice et ses «demoiselles domestiques », récompensées chacune d'une paire de bracelets d'or à 20 écus la paire ; puis les officiers de la seigneurie de Ray : Jean du Pin, le capitaine ; Pierre Mathieu, le bailli ; Nicolas Vaselaire, le procureur ; Vuillemin Coullon, le châtelain ; tous seront continués dans leurs offices « leurs vies naturelles durant, avec les mêmes gages et traictemens qu'ils ont heu par cy-devant ». Ainsi s'achève ce tableau, où ne figurent pas moins de 28 hommes et de 12 femmes emportant au total - leurs gages non comptés - plus de 1700 fr. de récompense : le revenu annuel d'une bonne fortune bourgeoise.

\section{II}

Encore toutes ces dépenses comptent-elles peu, relativement à celles que la guerre entraîne. Grande occupation, gros souci du noble. Combattre reste à ses yeux, comme par le passé, sa vraie, son unique fonction. Au jeune homme, fils ou neveu. qui lui est cher et qu'il désire aider dans la vie, le gentilhomme ne lègue pas de livres comme le bourgeois - mais une bonne épée ou un cheval de bataille : tel, François de Gorrevod, attribuant à son neveu Charles-Emmanuel «ses armes et grands chevaux ", ou Claude de Bernaud léguant à son chef des montures de campagne. Pareillement, lorsqu'il rédige ses dernières volontés, ce n'est pas à la veille de gagner «les escolles d'Ytalie », mais de fuir par le Tyrol avec CharlesQuint comme Jean d'Andelot en 1552 ; de s'encheminer, pour le service de Dieu et de Mgr de Savoie, au siège de Genève comme François de Gorrevod en 1586, ou de prendre sa part d'un combat décisif comme ce Jean de Chassagne, mort plus tard sous Harlem d'un coup de mousquet, mais qu'un texte curieux nous montre, en septembre 1572, monté sur une galère "appellée la Grue de Sicile, voguant contre le Turc «soubz la charge et conduicte du sr baron de Chevreaux, esleu pour chef des gentilshommes bourguignons par l'altèze de don Jouan d'Autriche » et passant à l'heure du combat ce qu'on nommait un testament militaire : «Estant 
les armées prêtes à combattre en la Morée près Navarrin, et à veue l'une de l'aultre, le canon tirant, ayant les soldatz chrestiens morrion en teste, l'arquebuse et meiche allumée au poing et jà la confession générale accoutumée à faire en tel cas faicte, led. Jehan de Chassaigne interpella et requist nobles seigneurs Claude de Rye, sgr de Vuillafans; Bonaventure de Jaquelin, sr à Joue ; Claude de Butte, sr de Malan ; Thiébaud de Ton, sr de Ougers ; Anthoine de Laval, sr de Prantigney, et Jacques Michel, tous ils présentz, de luy estre tesmoings et se resouvenir qu'il faisoit, nommoit et instituoit son vray héritier Jehan de Chassaigne son cousin, pour les amytiés et cordialitez qu'il avait receu de luy »...

Or, rien de plus coûteux que de telles expéditions. Frais d'équipement et de remonte personnelle, lourde charge déjà pour un gentilhomme modeste qui se contente de servir sous les ordres d'autrui. On ne part pas seul ; il faut des serviteurs, des palefreniers, des laquais. Claude de Bernaud, gagnant les Pays-Bas en 1578 pour y servir avec les compagnies bourguignonnes, emmène trois serviteurs, un laquais, quatre chevaux : c'était le train ordinaire. De même, les « aventuriers bourguignons » qui faisaient si martiale figure en 1572, dans le Levant, à bord de la Grue de Sicile ou des autres galères de don Juan, savaient ce que leur coûtait l'expédition. Ou plutôt, leurs créanciers le savaient mieux qu'eux-mêmes. Les manuscrits Granvelle renferment à cet égard de piquantes révélations. Une nuée de Comtois s'était abattue sur le royaume de Naples, qu'administrait alors comme vice-roi le cardinal ; et ce dernier, par politique sans doute, leur avait ouvert sa bourse généreusement. Il aimait s'entourer d'une clientèle de nobles qu'il obligeait, aidait, poussait aux honneurs : son beau-frère Ferdinand de Lannoy en savait quelque chose. Henri de Vienne, baron de Chevreaux, lui avait emprunté cent écus : c'est qu'avant de partir " pour l'emprise du Levant », il avait été en Flandre déjà, avec le duc d'Albe ; et il avait eu beau vendre des terres et des droits, ses dépenses sans doute avaient été trop fortes. - Granvelle avait prêté ; mais quand il fallut rendre ! Pendant des mois, en 1572, en 1573, en 1574, Chavirey et Bonet Jaquemet, les hommes de confiance du cardinal, se désolent, se désespèrent des faux-fuyants, des retards, des fugues continuelles du baron : la dette court toujours, le débiteur aussi ; avec lui, une bonne dizaine de moindres gentilshommes, ceux-là précisément qu' « interpellait » Jean de Chassagne aux rives de Navarin et Jean de Chassagne lui-même. En 1575 encore, ni eux ni M. de Chevreaux n'avaient remboursé leur créancier; partis aux Pays-Bas pour la plupart, ils y 
consumaient leur peu de revenus; et le bon Chavirey concluait tristement : « S'est discoutoisie, d'emprunter ce qu'ilz sçaivent ilz n'ont moyen de rendre »...

Encore, presque tous allaient-ils en guerre isolément. Que dire des plus riches, des plus haut titrés, de tous ceux dont le rang n'était pas de rester en sous-ordre ? A équiper, colonels ou capitaines, des régiments ou des compagnies, en dépit de la solde et des sommes remboursées par le Trésor - avec combien de retards, du reste, et de difficultés - les bourses les mieux garnies s'épuisaient d'un seul coup. L'espoir de se distinguer, d'attirer sur soi l'attention du souverain ou de son lieutenant - un duc d'Albe, un don Juan - soutenait les jeunes nobles, les excitait, dédaignant les conseils de prudence, à faire de folles dépenses qui les ruinaient souvent. Espoir trompeur, du reste. Pour un noble qui, sur la fin de sa vie, arrivait à toucher - ou, plus exactement, à se voir assigner - un traitement notable, combien d'autres qui ne trouvaient pas l'occasion rêvée de frapper un coup, de rendre un grand service, de « faire faction sur quoi fonder récompense »... Et ceux-là mêmes qui y parvenaient, c'était par toute une vie d'expédients, d'embarras, de dettes, d'aliénations, qu'ils devaient acheter leur douteux succès.

\section{III}

Mais quoi ? toute son hérédité faisait du noble un soldat. A la guerre seulement, en campagne et en armes, il se sentait à l'aise, en partie délivré des contraintes journalières qui pesaient sur lui. Plus de robins, plus de juges ni de parlements. L'épée, comme jadis, sanctionnait le droit, et le noble, qui jamais ne s'était plié sans révolte aux usages de la justice moderne ; le noble qui, obscurément, dans le fond de sa conscience héritée d'une longue lignée de féodaux, regrettait toujours la procédure d'antan où, sans accusateur, pas de procès possible ; où le duel judiciaire était de règle ; où les témoins pouvant être «faussés » par l'accusé et provoqués par lui, la force, l'audace physique jouait son rôle; le noble enfin qui, s'inscrivant en faux contre le progrès des moeurs, revenait invinciblement aux guerres privées, aux défis d'homme à homme et aux duels meurtriers - se trouvait alors, dans la liberté des étapes militaires, dans la licence des picorées matinales, comme rendu à lui-même, débarrassé des mille contraintes qui l'oppressaient, 
autorisé pour un temps trop court à vivre, conformément à son idéal, une vie toute dominée non par l'idée du droit, mais par le sentiment de l'honneur.

Qu'aurait-il fait, du reste, s'il n'avait point servi ? Qu'était-il capable de faire ? Non qu'il faille exagérer la rudesse, la brutalité, l'ignorance de tous les nobles. Quelques-uns, destinés plus tard à fréquenter la cour, recevaient, semble-t-il, une éducation assez soignée. Du moins, les confiait-on de bonne heure aux soins d'un précepteur, prêtre du voisinage, humaniste même, spécialement engagé et grassement rétribué. Dans son école de Nozeroy, Gilbert Cousin, l'ancien secrétaire d'Érasme, ne nourrissait pas de lettres antiques que les seuls rejetons de la bourgeoisie, les enfants du conseiller Colin ou du marchand Hugon. La liste de ses disciples comporte des noms plus sonores, et par exemple ceux des frères Guillaume et Jean de la Baume, neveux et protégés du puissant abbé de Baume Guillaume de Poupet. jeunes gens destinés à l'Église, il est vrai. Mais d'autres recevaient la même éducation, qui entendaient bien demeurer dans le siècle : tel, ce jeune homme qui, de Nozeroy, écrit au célèbre Curione pour lui exposer ses hésitations entre la carrière des lettres et celle des armes.

Et puis, de ces jeunes nobles, certains voyageaient. Leurs gouverneurs les conduisaient en Allemagne : n'avaient-ils pas besoin d'en connaître la langue ? Ils s'en serviraient plus tard dans les armées, encombrées de reîtres et de lansquenets, ou dans les ambassades, chez les Suisses, gardiens de la neutralité, ou chez l'Empereur, maître de Besançon et suzerain du Comté. Voilà pourquoi, le 19 novembre 1551, le docteur Jacobus Curionus Hofemianus, recteur de l'Université, inscrit sur les matricules d'Heidelberg les noms comtois de François d'Achey de Georges et Marc de Grandmont, avec « Joannes Boissardus, horum minister », et « Hugo Babetus, horum paedagogus »; Guillaume et Jean de Montfort les suivront peu après, si jeunes qu'on ne peut les admettre au serment. - D'autres vont à Louvain, y apprennent le «thiois », puis passent en Italie ; mais presque tous, c'est à Dole qu'ils ont commencé leurs études. Sur les registres des recteurs, quelques grands noms figurent : en 1542-43, François de Vergy, Cleriadus de Ray, Claude de Gorrevod ; en 1543-44, Georges d'Andelot et Claude de Cicon ; en 1545-46, Antoine de Gorrevod ; en 1546-47, Pierre d'Andelot ; en 1554, Claude de Cusance et Hugues de Grandmont ; en 1557, Antoine de Gorrevod à nouveau, en même temps que les deux Marnix, Jean et Philippe. Et ces matricules, qui toujours distinguent 
soigneusement les nobiles des ingenui, parfois comportent une classe spéciale d'illustres.

Seulement, jusqu'à quel point ces jeunes seigneurs profitaient-ils de leur passage « aux escolles » ? Ils n'y prenaient point de grades - sauf, bien entendu, ceux se destinaient ou que l'on destinait à la carrière d'Église. Poussaient-ils très loin leurs études ? Pour l'affirmer, il faudrait d'autres textes, et plus désintéressés, que les témoignages emphatiques de leurs anciens maîtres ; or, nous n'en avons point, que quelques lettres adressées à Granvelle, leur protecteur, par un ou deux jeunes nobles, ses parents par alliance : manifestations un peu spéciales, du reste. Et que cinq ou six Comtois de haute lignée soient qualifiés, pendant le siècle, de Mécènes, par des humanistes ou des écrivains de leur pays, le fait n'autorise pas des conclusions sur le goût de la noblesse pour la littérature. Un seigneur, il est vrai, le baron de Marnoz, et qui tenait son rang à la cour d'Espagne, nous a laissé plusieurs ouvrages en latin ; il était, au dire de Gollut, « chevalier non seulement très valeureux et vaillant, mais encore très docte et bien versé en toutes disciplines libérales et en la congnoissance de plusieurs langues »; éloges que, dans son Passe-temps, Jean Lhermite souventes fois reproduit et confirme. Mais ce "gentil esprit » était précisément de noblesse récente et de souche roturière ; son grandpère, au temps du Téméraire, avait reçu la qualité de noble. L'exception, dès lors, ne prend-elle pas un sens tout particulier?

C'est qu'au fond, quelque culture qu'aient : pu recevoir certains nobles, quelque distinction d'esprit et quelque connaissance qu'ils aient pu posséder, il n'en reste pas moins que la science, le savoir était fait de roturier et non de gentilhomme. Les bourgeois - un Gollut par exemple, dans ses Paroles Mémorables - ne s'y trompaient pas. Anecdotes significatives, et qu'il redit avec une complaisance visible, celle de Charles-Quint avec le Titien, ou, mieux encore, du grand Empereur et de ses courtisans : Ils se plaignaient, explique le chroniqueur, de ce que Granvelle était employé aux affaires principales, tandis que le maître semblait les dédaigner : «L'Empereur respondit : Que voulez-vous que je vous communique, estans ignorants, sans sçavoir et cognoissance? Faites que voz enfants soyent sçavans et je m'en serviray ; aultrement, n'attendés pas que j'en face autre compte que de soldatz ou escuyers ou serviteurs domestiques de ma maison et non du publique. » Tout l'orgueil spécial du bourgeois est dans cette histoire, renouvelée de Charlemagne. Et vingt réflexions, vingt mots de Granvelle dans sa correspon- 
dance témoignent du même état d'esprit : ses remarques méprisantes sur M. de Rye " qui n'a pas assez étudié » pour juger sa devise : Durate, ou sa condescendance pour les Vergy - de bons seigneurs, mais qui avaient plutôt besoin qu'on les conseille... Son oncle, Jean de Saint-Mauris, avait trouvé un jour, pour qualifier Nicolas Perrenot, une formule en apparence banale, fort expressive en réalité. Dans la dédicace qu'il lui fait d'un ouvrage juridique, il le nomme : «Inter doctos nobilissimus, inter nobiles doctissimus ». Superlatif à part, la définition s'applique fort bien à toute une classe : celle des Perrenot, des Bonvalot, des Lallemand, de Saint-Mauris lui-même.

Le noble, du reste, savait fort bien ce que la science pouvait représenter pour lui. Lorsque, dans son testament, il s'occupe d'instruction - le cas est assez fréquent - ce n'est jamais pour ses héritiers directs, pour ses propres enfants. Être élevé, être mis aux écoles : il réserve le traitement aux fils de ses officiers ou de ses hommes de loi, à ses bâtards aussi, toutes gens qui ont besoin de lutter pour conquérir un rang. Les féodaux - nombre d'entre eux du moins - n'ont pas le mépris de l'instruction. Mais ils se rendent un compte exact de son utilité sociale : et cette utilité n'est pas pour eux.

Quelque chose sans doute illustrerait ces remarques avec plus d'éclat : la liste de leurs livres. Mais nos recherches sur ce point n'ont pas été fructueuses. Un seul catalogue nous est parvenu : celui des quelques ouvrages que possédait un modeste écuyer, Henry de Vy, seigneur de Marcey, décédé en 1581. Pièce intéressante, du reste. Un livre de droit : les Arrêts de Papon, et « ung petit formulaire de lectres », voilà la part - restreinte - de l'utilité. Des Heures à l'usage de Besançon ; une vie du Christ et « ung livre de l'imposture des dyables » constituent celle de la piété. La morale maintenant et l'histoire: les fables d'Ésope en français; les "Sept sages de Romme », livre mis de côté pour les filles du défunt, ainsi que trois ouvrages; " l'ung des merveilles du monde; l'aultre de l'amy flateur; et l'aultre des sept sages de Romme en ung volume »; la «Fontaine de toute science »; un Sommaire des cronicques des faictz des Empereurs depuis Jule César » ; une «Vie des Empereurs »; comme auteurs latins, un Lucain ; comme histoires récentes, un "Commentaire des dernières guerres de la Gaule Belgique » et un «Commentaire premier du sr Alfon du Lohe, des troubles de Flandres». Enfin, lectures d'agrément : «trois livres des oeuvres de Ronsard reliez en cuir rouge »; les Histoires Tragiques ; les Cent six nouvelles et plusieurs romans de chevalerie : 
Huon de Bordeaux, l'Histoire de Malram, roy de Jhérusalem ; la Belle de Vienne ; Mélusine, sans compter « six volumes d'Amadis » : tout un fragment de la bibliothèque de Don Quichotte. Point de livres italiens, qu'une traduction dépareillé de Paul Jove. Liste bien décousue, comme on voit. Rien qui ressemble là aux bibliothèques pesantes, méthodiques, utiles des notaires ou des robins. Pour le possesseur de ces livres, acquis ou hérités un peu au hasard, n'est-il pas évident que l'étude n'est pas un moyen de fortune?

\section{IV}

Au vrai, s'il veut améliorer sa situation, une seule ressource lui reste - bien hasardeuse d'ailleurs. Lorsque, las de courir après $M$. de Chevreaux qui l'évite, las de lui réclamer les cent écus que le cardinal lui avait prêtés, Claude de Chavirey avoue son impuissance, il se nourrit pourtant d'une dernière espérance : « L'on dit, écrit-il à son « patron », l'on dit qu'il se doibt marier en France richement : il en fauldra tirer ce que l'on pourra »...

Il était de belles dots, en effet, et d'enviables. Dans son testament, Jeanne de Vaudrey déclare que sa fille, Renée de Ray, femme du gouverneur François de Vergy, avait eu pour ses biens et droits paternels et maternels 60000 fr. « en dot et mariage ». Les quatre filles de Jean d'Achey avaient chacune de leur père 10000 fr. de dot, plus 1000 fr. d'habits : c'est ce que donne également Hélène de Brederode à sa fille Péronne. Filles uniques, Guillemette de Montmorot et Dorothée de Poitiers en avaient 8000 ; 6 000, les deux aînées de Claude de Montfort ; 5 000, Jeanne-Baptiste de Cicon, sans compter 6000 fr. qui lui revenaient d'une tante ; 5 000, Jeanne et Claudine de Pontailler, ou Péronne de la Baume, et 4 000, Antoinette de Rye. Encore convient-il de remarquer que les testaments n'indiquent bien souvent que la dot attribuée, soit par le père seul, soit par la mère seule à leur fille. - D'autres dots, sans doute, étaient plus modestes. A ses quatre filles par exemple, Marguerite de la Thouvière ne pouvait attribuer que 1000 fr., plus 100 fr. pour leurs robes. Somme encore appréciable pour un écuyer de faibles ressources. 
Seulement, ces dots n'étaient pas très nombreuses. Dans la famille noble, l'égalité de partage n'est plus la règle. L'orgueil du nom, le souci du rang à maintenir, ces sentiments de fierté héréditaire que nous avons notés plus haut, ici encore interviennent et jouent un rôle actif. Quand il y a plusieurs fils, des mesures énergiques s'imposent au père ; de même, quand il y a trop de filles. Claude de Montfort, chevalier d'honneur au Parlement, a de sa femme Anne de Coue quatre fils et cinq filles. Comment partager ses biens entre tant d'héritiers ? Il n'hésite pas : des cinq filles, il en écarte trois ; deux déjà sont « en la religion de Remiremont » ; la troisième devra y entrer à son tour et se contenter, elle aussi, de 500 fr. Des quatre garçons, l'un est chevalier de Malte : on l'entretiendra jusqu'à ce qu'il obtienne une bonne commanderie, mais il ne sera pas partie prenante aux biens paternels. Ceux-ci consistent en diverses seigneuries : Montfort d'abord, une grosse terre avec neuf villages et des droits sur trois autres ; le fief de la tour de Lizine ; la seigneurie d'Alaise, mouvante de Montmahoux : c'est la part de l'aîné. Le second se contentera d'Aresches et de divers biens à Salins, Parrecey, Annoires, etc. Le troisième, enfin, n'aura qu'Aiglepierre. Exemple typique : il est inutile d'en rapporter d'autres; toute fille noble n'était donc pas une « noble héritière »; toute fille n'avait pas sa dot assurée.

La conséquence, c'était que la conquête d'une riche « damoiselle » n'était pas fort aisée pour le gentilhomme besogneux. Car les parents veillaient soigneusement à ce que les futurs conjoints fussent de situation matérielle au moins équivalente. Dans beaucoup de testaments, c'est une condition imposée à la fille, si elle veut toucher l'intégralité de sa dot, que de se marier par avis de son père, ou de sa mère, ou d'un frère aîné, laissés juges des avantages et des inconvénients de l'union projetée. Ainsi, pour les nobles plus encore peut-être que pour les bourgeois, le mariage prenait avant tout figure d'une affaire, d'une négociation diplomatique et financière entre puissances. Non que les sentiments d'affection fussent absents. C'est, dans les testaments nobles, la même reconnaissance très souvent exprimée des maris pour leurs femmes - ou réciproquement ; le même souci d'assurer la vie, la sécurité matérielle des veuves ; les mêmes legs, les mêmes dons, les mêmes institutions d'usufruit que dans les testaments bourgeois. Il semble bien que la plupart des familles aient été fort unies, que nombre de frères aient se rendre le même témoignage que les d'Andelot de Pesmes, Pierre et Jean : 
En bonne paix et union, Fraternité et dilection, Ces deux frères en grand accord Ils ont vécu jusqu'à la mort..

La communauté, l'indivision de biens souvent maintenue pendant de longues années n'entraînait pas toujours des discordes à sa suite ; et de même, beaux-frères et belles-soeurs, enfants de lits différents, gendres et beaux-parents témoignent bien souvent par des dons, par des legs, de la bonne entente qui régnait entre eux. D'ailleurs, les secondes et même les troisièmes noces étaient fréquentes. Voici les Vergy : marié deux fois, Claude, le vieux maréchal, le contemporain de Marguerite. Mariée deux fois, sa fille Antoinette. Marié deux fois, son neveu François qui lui succédera au gouvernement ; et sa nièce Chrétienne, soeur de François ; et Claude Il, fils aîné de François ; et Anne, soeur de Claude II ; et Cleriadus, demifrère du même... Le double mariage est de règle dans la famille. Et que d'exemples pareils, si l'on passe en revue les personnages marquants de cette époque : Marc de Rye, Jean d'Andelot, Claude de la Baume, Jean de Bauffremont, etc. ; tous, sur ce point, imitent les Vergy. On s'unissait si jeune ! En 1574, à Perronne Perrenot alors âgée de neuf ans, on propose déjà d'épouser M. de Vuillafans. Antoinette de Chassault avait une quinzaine d'années lorsque mourut son père Philibert. Or, depuis longtemps elle était mariée à Jean Gauthiot d'Ancier qui la brutalisait. Cet exemple d'union malheureuse n'est pas unique. Les jeunes nobles turbulents et sans cervelle qui semaient la terreur sur les « hauts chemins » n'étaient certes pas des maris exemplaires. Non seulement ils engendraient, au hasard de leurs caprices, toute une progéniture d'enfants illégitimes - c'était péché véniel et leur entourage semblait accepter avec philosophie ces accidents - mais parfois, c'était la fortune, la santé même, tout l'avenir de leur femme qu'ils perdaient sans remède : tel ce neveu de Granvelle, Antoine de Laubespin, dont la femme, Marie de Noyelle, adresse à Bonet Jaquemet, en 1573, un si poignant appel... Erreur des parents, constate Chavirey ; le mari est trop jeune, trop gâté, trop accoutumé à se voir passer tout. En fait, la plupart des pères se montraient plus prudents et les soins mêmes, les garanties dont s'entouraient les unions, les longues tractations qui les précédaient, s'ils évitaient aux filles des surprises douloureuses, devaient ôter aussi aux jeunes gens l'espoir de fortunes subites, d'unions inespérées et providentielles. 


\section{V}

Réalité maussade. D'autant que, devant le gentilhomme comtois, un rival encore se dressait : l'étranger, le Lorrain, le Savoyard, le Français surtout qui, s'introduisant dans les vieilles familles, épousait les héritières et occupait les héritages.

Nous ne parlons pas des quelques gentilshommes - savoyards ou bressans pour la plupart - qu'en récompense de leurs services les souverains, à diverses reprises, installèrent dans des terres domaniales. Tels, à Vercel, les Peloux ; à Santans, Étrepigney, Cinqcens, les Salenove ; à Soye, les Précipiano ; à Usier, les Wateville ; à Quingey, une Claudine de Semur ; à Vennes, un Ferdinand de Lannoy ; quelques autres encore. Transplantés dans la province à cause de leur attachement pour ses souverains, presque tous y prennent femme, s'y établissent à demeure, s'assimilent sans difficulté les idées et les moeurs de leur nouveau pays bref, deviennent rapidement de vrais nobles comtois.

D'autres, qui d'eux-mêmes s'installent en Comté, subissent vite la même transformation. Un Philibert de la Baume, seigneur de Montfalconnet et de Sandres, comte de Coligny-le-Neuf, qui achète en 1548 à Jean de Damas la baronnie commise de Saint-Amour, ne saurait être un étranger pour ses voisins du bailliage d'Aval ; car, si François Ier en 1539 l'a fait son bailli de Bresse ; s'il reste un des conseillers écoutés d'Emmanuel-Philibert, il a pris part aussi aux expéditions de Tunis et d'Alger et vaillamment servi l'Empereur dans la guerre à la fois et dans les ambassades. Pareillement un Laurent de Gorrevod, seigneur de Marnay, bien qu'il n'abandonne pas la cour de Savoie, mérite des Bisontins le titre de «bon et grand amy » : les Comtois à leur tour pouvaient l'appeler ainsi. Sur les confins de l'évêché de Bâle, les La Palud-Varambon de Bressans se transforment en Comtois ; ils s'éteignent d'ailleurs dans la maison de Rye. Les la Baume-Montrevel eux-mêmes, dont le rôle est si grand dans la Comté du XVIe siècle, sont partis de la Bresse et restent longtemps fidèles à leurs origines : fils d'un maréchal de Bourgogne et frère d'un archevêque de Besançon, François de la Baume, par exemple, cumule charges comtoises et charges savoyardes ; bailli d'Amont et ca- 
pitaine de Besançon, il est en même temps chambellan du duc et gouverneur de Savoie, Bresse, Bugey et Valromey. Point de péril dans une telle situation : ni péril économique ni péril militaire, encore qu'au XVIe siècle les rois de France aient pendant un temps occupé la Bresse ; péril par contre dans les mariages qui ne cessaient d'unir à des Bourguignons, à des Lorrains, à des Champenois les filles trop nombreuses des féodaux comtois.

Dès 1534, à la suite d'un voyage dans la province, Henri de Nassau signalait à l'Empereur le danger de ces alliances et que, « par faulte de bonne garde et provision des maisons et places d'aucuns seigneurs étrangers pourrait advenir et succéder inconvéniens ». Il énumérait « la maison de Gevrey, appartenant à l'admiral de France ; celle de Villerssecel au comte de Varax ; Pesmes au comte de Montrevel ; Savigney-en-Revertmont au sr de Sermoyac, et Ruffey près Blecterans au sr de Ruffey, et aultres ». L'amiral, c'était Philippe Chabot, mari d'une Comtoise, Françoise de Longwy, une des belles par le monde au dire de Brantôme ; seigneur de Gevry, il occupait le château de Neublans sur les frontières. Son fils Léonor, comte de Charny et de Buzançois, épousera lui aussi une Comtoise de même nom : Françoise de Longwy, fille de Joachim de Rye et d'Antoinette de Longwy ; il est vrai que, par contre, une Chabot, Catherine, avait épousé un Vergy, Claude. - Le comte de Varax est un la Palud; le comte de Montrevel, un la Baume : Jean, fils de Marc, chevalier de l'ordre du roi de France, son panetier ordinaire, capitaine d'une compagnie de ses ordonnances, gouverneur de Bresse, Bugey, Valromey et Savoie. - Ruffey était à la maison de Vienne, maison à branches multiples et vassale à la fois du roi et de l'Empereur. Situation fort commune à cette époque : elle se représente pour toutes les grandes familles féodales du Comté. Ç'avait été le cas des Chalon ; c'était celui des Bauffremont, des Cusance, des Longvy, des Vergy même : ces derniers prenaient le plus souvent alliance en dehors du Comté ; toutes les soeurs du vieux maréchal Claude épousent des étrangers : Marguerite, un Jean de Gruères ; Pauline, un Michel de Viry ; Rose, un Guillaume de Mervilliers ; Hélène, un Pierre de Barbançon. Sa fille Antoinette épouse pareillement un Choiseul, Jean, baron de la Ferté-sous-Amance, lui-même fils d'un Choiseul et d'une dame de Ray. Pendant ce temps, d'autres étrangers se poussaient en Comté, y prenaient pied. Dans les reprises de fief, voici des noms français : Pierre d'Aumont, baron de Châteauroux, est seigneur d'Etrabonne et cède à Granvelle, en 1548, la terre d'Avanne. Jean d'Aumont, maréchal de France, son fils, reprend de 
fief en 1568 ces deux seigneuries. Gaspard de Saulx-Tavannes, nommé en 1561 lieutenant général du duché, épouse Françoise de la Baume-Montrevel, dame de Pesmes - celle-là même qui plus tard, par un second mariage, deviendra Mme de Carnavalet. Au nord, sur la frontière lorraine, le fils d'André de Ville, Jean, d'une famille lorraine transplantée en Bourgogne, épouse la fameuse Nicole de Savigny, fille de Georges II et de Nicole de Haussonville dont nous verrons le rôle et les attaches françaises; et les de Ville éteints, leur terre de Saint-Remy passera aux de Luz. Invasion pacifique, mais pourtant redoutable : à la moindre alerte, la Comté en prenait cruellement conscience - et nous aurons à noter plus loin le passage à la Réforme ou l'appui donné à l'envahisseur par maints de ces gentilshommes trop fraîchement bourguignons.

Et sans doute, les Comtois pouvaient prendre leur revanche. Il en était qui épousaient des étrangères : tel, le vieux maréchal de Vergy à qui un premier mariage, avec Hélène de Gruères, transmet le comté de ce nom ; un second, avec Philiberte de Vienne, des fiefs et tènements nobles en France. Pareillement, Aimé de Balay épouse Anne de Saulx ; Claude de Montfort, Élisabeth d'Haraucourt ; François de Vergy, Catherine Chabot, fille de Léonor. Mais ces exemples sont rares ; la revanche était partielle et du reste médiocre. Car la neutralité de 1522, par son article VI, avait beau assurer aux nobles comtois qui serviraient dans les armées impériales la libre jouissance, en cas de guerre, des fiefs et des biens qu'ils pouvaient posséder au Duché : outre qu'il n'était question que de ces biens-là, les menues violations de la neutralité, si fréquentes, pouvaient trop aisément justifier des représailles ; et en cas de violence, la réciprocité aurait été difficile aux Comtois : la force militaire était non à eux, mais à leurs voisins.

Ainsi tout semblait se tourner contre la vieille noblesse comtoise. Les conditions d'existence politique de son pays se révélaient aussi désavantageuses pour elle que les conditions d'existence économique d'un siècle presque uniquement favorable aux progrès de la robe et de la marchandise. 


\section{VI}

A défaut de filles nobles, il y avait, il est vrai, les filles d'anoblis. Richement dotées parfois : le président Jean Froissard de Broissia et sa femme Claudine Blanchod en ont trois : ils leur donnent 15000 fr. ; le conseiller Chaillot et Alonze Thierry, deux : à chacune ils attribuent, le mari 3000 fr. et la femme 4 000. Le président Jaquinot va jusqu'à 6000 pour celles du premier lit : elles sont quatre. Sa seconde femme, Jeanne-Baptiste Chaillot, lui avait apporté 20000 fr., dont 9000 en dot, 3000 de sa tante Jeanne, 3000 de sa tante Claude, 5000 enfin de sa tante Renée Jacob. Un peu moins riches, l'ambassadeur Renard, le rival de Granvelle, et sa femme Jeanne Lulier, ne donnent à leurs quatre filles que $4000 \mathrm{fr}$. Mais il n'y a pas que la dot. Il y a les legs des parents, des oncles, des tantes; il y a, si le mari survit, ce que sa femme lui laisse, ou même, si elle n'a pas eu le temps de passer testament, ce qu'un beau-père généreux lui concède, « ayant égard aux grandes et perfaictes amytié » dont il comblait sa fille... Or, des mariages mixtes noblesse d'épée et noblesse de robe - on en rencontre sans doute des exemples en Comté. A tous les degrés de la fortune et de la grandeur, la fusion s'opère, là comme ailleurs, des vieilles familles avec les familles parvenues : la liste entre toutes est parlante, des gendres et des brus du vieux Perrenot : Léonard de Grammont, Jean d'Achey, Guyon Mouchet de Chastel-roillaud, Claude le Blanc, Hélène de Brederode, Antoine de Laubespin, Ferdinand de Lannoy, Marc de Beaujeu, Claude de Chaluns, Pierre de Montluel, Constance de Berckheim... Mais reprenons les noms des riches héritières que nous citions plus haut : des filles de Jean Froissard, mariées à des de Mesmay, à des Saint-Mauris, à des Masson, aucune n'est pour un représentant de la noblesse militaire. Nous ignorons les alliances de Victoria et de Claude-Françoise Chaillot; pareillement celles de Jeannette, Thiennette et Claudine Jaquinot: mais les filles que le président Jaquinot avait eues de sa première femme, Marguerite Demongenet, et qu'il dotait de $6000 \mathrm{fr}$. chacune, s'unissent toutes à des anoblis de souche marchande ou à des officiers : un Pelissonnier, un Racle, un Malessue, un Jean de Santans. C'est que, pour rechercher, pour épouser ces beaux partis, les jeunes gens de même classe ne faisaient point défaut - et le mot de classe, ici, s'impose d'autant plus que tout l'effort 
de la noblesse d'épée allait précisément, et contre ses intérêts, à accroître, à renforcer les barrières, les limites, les distinctions puériles entre les hommes - cela, dans le temps même où, sous la poussée bourgeoise, craquaient de toutes parts les vieux cadres sociaux.

Une étiquette rigide s'établit partout. Aigri, mécontent, trop souvent humilié, le noble avec passion recherche les satisfactions de l'amour-propre et de la vanité. Rigoureuse, la distinction s'opère entre "noble homme un tel » et «noble seigneur un tel ». Mais elle ne suffit pas; il faut plus de précision toujours, plus de distance aussi entre les groupes et les individus. Les titres apparaissent. Longtemps, dans la province, il n'y avait eu de comtes que le souverain. On en crée d'autres. En 1574, après de longues instances, les Vergy obtiennent, pour la première fois, l'érection en comté de leur terre de Champlitte. Elle prend le pas maintenant sur les baronnies, qui dominent elles-mêmes les simples châtellenies. C'est un appétit furieux de distinctions, d'honneurs, de privilèges. Tout noble qui a servi réclame une chevalerie. Tout noble veille, avec une inquiétude jalouse, sur les usurpations possibles de ses voisins. En 1595, à la fin du siècle et du règne de Philippe II, des édits paraîtront qui résumeront, qui codifieront tout ce lent travail. Édit sur les titres : nul, s'il n'est de noble race ou muni de lettres, ne pourra se dire écuyer ni porter armoiries. Nul, s'il n'en a titres ou patentes royales, ne pourra se qualifier de baron. Nul ne s'appellera chevalier, ni sa femme « Madame », s'il n'a été armé par ses souverains ou s'il n'a reçu d'eux lettres authentiques. Et ce sont encore d'autres prescriptions, sur la barre de bâtardise, sur les anoblissements par les princes étrangers, toute une minutie de réglementation sur des vétilles protocolaires. Mêmes mesures pour régler l'emploi des qualificatifs : Excellence, Altesse, Illustre ou Illustrissime Seigneurie. Ne sera Monseigneur que le seul lieutenant général des pays d'Embas ; les autres, unanimement, seront « Monsieur » - Messire, s'il s'agit de chevaliers ou d'ecclésiastiques. Et ce sera lourde faute de donner à quelqu'un plus haut titre qu'il ne vaut...

Puérilités émanant directement d'Espagne et datées de Saint-Laurent-le-Royal. La noblesse s'en repaît. Sans doute, les privilèges qu'elle réclame, elle se trouve impuissante à en garder le monopole. Elle doit les partager avec les plus riches, les plus puissants, les mieux arrivés de ces bourgeois qu'elle exècre - et ceux-ci ne perdent pas une occasion de rappeler qu'eux aussi, ils sont nobles. Lorsque les gouverneurs de Besançon, en 1592, déclarent par écrit au Parlement de Dole 
«qu'ils ne peuvent exempter les nobles et gentilshommes dud. Besançon de la garde et subsides, non plus que les autres citoyens », c'est parmi les conseillers une belle clameur. Tous s'indignent et vocifèrent. L'un parle de recourir à l'Empereur ; l'autre de provoquer " une bonne lettre » du gouverneur des Pays-Bas ; un troisième, d'en saisir Philippe Il et son représentant «qui ont bien moyen de fâcher » les Bisontins. Beau zèle d'anoblis. Mais les nobles de vieille noblesse s'emploient toujours à maintenir les distinctions salutaires. Plus les parvenus les serrent de près, plus ils se fortifient, se retranchent pour ainsi dire dans l'orgueil de leur naissance, plus ils nourrissent en eux le sentiment d'une supériorité d'origine : cela du moins, comme le disait de son nom Jean d'Achey, «ne leur peut-on vendre ni ôter ».

Il est vrai que de leur côté, leurs rivaux, dès qu'ils le pouvaient, usaient de leurs privilèges jusqu'au bout... Mais ils le pouvaient bien rarement, et, en cas de conflit, n'avaient jamais le beau rôle. Ces gentilshommes d'épée étaient de moeurs si hautaines ! Il faut lire, dans les papiers Granvelle, les lamentations de ce pauvre Chavirey - un anobli à la troisième génération - lorsque le cardinal l'expédie d'aventure au château de Joux, avec un train de meubles à mettre en lieu sûr. « N'y retourneray de bon cueur la seconde fois, écrit-il piteusement, et me feit l'on demeurer à l'entrée plus d'une heure pour observer cérémonie de maison-forte, et demye-heure pour partir... » S'il se rebiffait, que d'avanies pour le nouveau noble. Le « petit Bouclans », qui n'était pas, certes, le premier venu - son père était Jean Lallemand, le secrétaire d'État de Charles-Quint - sut ce qu'il en coûtait d'être trop familier avec les grands seigneurs. Un jour, chez Egmont, à Bruxelles, dans une de ces beuveries si chères aux " grands maîtres ", il se permit d'interpeller Claude-François de Rye. Fâcheuse inspiration !. Le pauvre anobli se vit en un clin d'oeil rappeler ses origines, injurier, gratifier d'assiettes à travers la figure et chasser de table « avec hurlerie ». Et un parent des Perrenot, l'écuyer Bordey, connut lui aussi pareille mésaventure. Rabroué vertement par un Wateville, il dut suivre le conseil du cardinal, «se retirer doucement » et renoncer à toute satisfaction : « Je suis certain, écrit le cardinal, que la partie lui refuseroit le combat avec honte, et plus l'on remue l'ordure et plus elle put. - Le mal est, ajoutait-il avec sagesse, que l'on veult voler plus hault que les plumes ne peuvent porter. » Et ailleurs : « Nostre cousin, le sr de Saulcy, feroit mieulx d'estre plus retenu et moings hanter telles gens ; mais pour faire de l'homme de court, il veut mectre le nay partout... » 
Travers dans lequel Granvelle lui-même, tout prince de l'Église, tout ministre qu'il fût, n'avait garde de tomber. « Ne dira personne avec vérité, écrivait-il en 1577, à son cousin Bellefontaine, que je présume d'avoir crédit en court. » C'est qu'il avait appris par de rudes épreuves la nécessité de compter avec l'envie. De bonne heure, du reste, il en avait eu le sentiment pour tout ce qui touchait à sa famille. Si grand, si puissant, si en faveur qu'il fût, lorsqu'il était question, en 1551. d'un mariage pour son frère Jérôme : « Ce que j'estime plus en ce party, lui écrivait-il, est que la mère fut simple gentil-femme, et les soeurs mariez avec contes, et qu'elles sont nourries ainsi bas et avec toute humilité, congoisçant le marquis [c'était le père] qu'il ne les pourroit marier avec princes de sa qualité. » Souci bien significatif chez cet homme dont le père, encore en vie, jouissait alors du crédit que l'on sait auprès du maître - chez cet homme qui, élevé à la cour, comblé de tous honneurs, admis dans la familiarité confiante des plus grands princes, se rappelait cependant - lui qu'on accusait tant de hauteur et d'orgueil - la modestie toute proche de ses origines. De telles préoccupations ne l'abandonnèrent jamais. Il les manifeste à nouveau par exemple, en 1574, lorsqu'on parle vaguement de marier une de ses nièces à un jeune homme de la famille de Rye. Union qui ne sourit pas au cardinal : trop de hauteur chez ce prétendant éventuel. Mieux vaut un mari plus modeste, plus empressé, meilleur «ménager » aussi - le point est important - mais surtout moins entiché de grandeur.

Moderata durant. « J'écrits souvent ce mot », répète le ministre. En tout cas, l'idée d'une opposition nécessaire, fatale, longuement irréductible des deux noblesses : la jeune et l'ancienne, ne l'abandonne jamais. Aux précautions qu'il se croit tenu de prendre, lui, le plus vraiment noble, le plus grand, le plus puissant des anoblis comtois, ne peut-on mesurer la distance qui, réellement, (séparait encore les deux classes ? Son exemple ne témoigne-t-il pas jusqu'à quel point le conflit de sentiments doublait renforçait, aggravait encore le conflit d'intérêts ? 
PHILIPPE II ET LA FRANCHE-COMTÉ

Étude d'histoire politique, religieuse et sociale.

\title{
Troisième partie.
}

\author{
La Comté \\ et la révolution \\ des Pays-Bas
}

$\underline{\text { Retour à la table des matières }}$ 
PHILIPPE II ET LA FRANCHE-COMTÉ

Étude d’histoire politique, religieuse et sociale.

Troisième partie. La Comté et la révolution des Pays-Bas

Chapitre XII

\section{Guillaume d'Orange en Franche-Comté}

$\underline{\text { Retour à la table des matières }}$

Reprendre, récapituler d'ensemble les résultats de notre longue enquête sur la situation respective des classes possédantes et dominantes en Comté, pendant la seconde moitié du XVIe siècle - tâche superflue sans doute, et redite vaine. Analysant les facteurs de la vie politique comtoise de 1550 environ à 1560, nous avons rencontré, au premier plan, l'antagonisme très net de quelques grandes familles : les unes, nobles d'antique et de haute noblesse ; les autres, bourgeoises d'origine, récentes d'illustration. Rivalité des Rye, des La Baume, des Bonvalot et des Perrenot pour la possession de l'archevêché ; affaire Quiclet ; duel sans merci d'un Simon Renard et d'un Antoine Perrenot ; turbulence d'une noblesse inquiète et agitée, accrue encore, au milieu, au tournant du siècle, par les conséquences d'une abdication, d'un avènement et d'un traité de paix qui introduisent dans ses conditions d'existence un trouble, une gêne nouvelle - il ne nous a point semblé que ces événements pussent s'expliquer seulement par des circonstances de fait, des incompatibilités d'humeurs individuelles, des considérations morales ou psychologiques. Nous avons cru au contraire - et toute l'histoire intérieure du Comté 
depuis un siècle en ça semblait nous amener à une telle conclusion - que ces faits politiques, ces rivalités de personnes trouvaient dans un malaise social, dans un conflit économique de profondes raisons d'être. Les chapitres qui précèdent ont démontré, à tout le moins, que ce conflit était réel. Dans quel milieu, sous l'empire de quelles préoccupations, avec le souci de quels intérêts matériels évoluaient les protagonistes de l'histoire comtoise: nous le savons maintenant. Nous devrons nous le rappeler, pour comprendre leur action en les regardant agir.

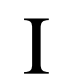

C'est vers 1560 que nous avons interrompu plus haut le récit des débuts de Philippe II en Comté. Sitôt la paix signée au Cateau-Cambrésis, nous avons vu comment le fils de Charles-Quint, mal à l'aise dans ses Pays-Bas, avait songé à regagner l'Espagne. Le duc de Savoie, Philibert-Emmanuel, remis en possession de ses États, se préparait lui aussi à quitter les Flandres. Il fallait le remplacer. Ce fut à Marguerite de Parme, sa soeur naturelle, Flamande de naissance mais Italienne de goûts, que Philippe remit la lourde tâche d'administrer les pays d'Embas : les dix-sept provinces et la Comté.

Le 8 août 1559, des instructions royales conféraient à la nouvelle régente "pleine, libre et absolute puissance » dans son gouvernement. Mais, le même jour, des instructions secrètes restreignaient notablement ses droits. Elle ne devrait jamais prendre résolution que par «bon avis et mûre délibération des consaulx d'Estat et privé »; le roi se réservait nombre de prérogatives : disposition des principaux bénéfices et des abbayes comtoises « excédents deux mil frans de revenu par an »; nomination des gouverneurs de province, des capitaines de Dole et de Gray, des « chiefz de tous collèges de justice », des baillis d'Amont, d'Aval et de Dole, du Pardessus de la Saunerie de Salins; octroi des grâces pour lèsemajesté et des privilèges perpétuels aux villes, communautés et particuliers. - Surtout (et ceci ne figurait pas sur les instructions) un véritable gouvernement occulte, la Consulta, était établi auprès de Marguerite, moins pour l'aider encore que pour la contrôler. 
Trois membres le composaient. Un fonctionnaire docile et timoré, - Viglius, président du Conseil privé et du Conseil d'État. C'était un Frison, grand admirateur d'Érasme dans sa jeunesse - un juriste plutôt qu'un politique : il était faible, sans caractère, prompt à se résigner, le sachant d'ailleurs ; fidelis servus, perpetuus asinus : il s'applique le proverbe, un jour, dans une lettre familière à son compatriote Hopperus. Du reste, en ce qui concernait les Comtois, assez bien disposé pour eux : il avait étudié à Dole, trois années durant, et se rappelait volontiers ses souvenirs de jeunesse, le gai séjour dans la petite ville, l'hospitalité accueillante de ses habitants. - A côté de Viglius, Berlaymont, un financier, un grand seigneur de médiocre talent et dont l'habileté s'employait tout entière à ménager les partis opposés. - Enfin et surtout, l'évêque d'Arras.

Aux côtés de Marguerite, c'était lui, à vrai dire, le représentant qualifié du roi. Souple, habile, ne s'embarrassant point de principes gênants : «Je me contente, écrira-t-il un jour, de m'entendre bien avec mon maître.... et ma foi est de procurer de faire mes affaires et de m'employer, en ceux du maître et du public, en ce que l'on voudra et non plus ». - Il avait regagné assez vite la pleine faveur de Philippe. Ses avis prévalaient en cour ; son influence s'exerçait, souveraine, clans les affaires d'État; en Bourgogne, dans son propre pays, où tant d'ennemis jadis avaient escompté sa disgrâce, c'était lui qui dispensait les places et les faveurs.

Gouvernement nouveau, ce gouvernement à plusieurs têtes : par son esprit, par ses tendances, par ses pratiques. Sans doute, Philippe en l'établissant n'avait rien innové ; les mêmes rouages, les mêmes procédures, les mêmes institutions subsistaient qu'au temps de Marguerite ou de Marie de Hongrie. Mais la substitution au Conseil d'État, pour toutes les affaires graves, de la Consulte ; la prééminence accordée à ce petit comité sans statut officiel, sans responsabilité publique ; le caractère même de Marguerite, sa dissimulation, ses ruses, ses habiletés de demi-Italienne ; enfin, le rôle de l'évêque d'Arras, représentant spécial de l'absolutisme, comme délégué du maître auprès des conseils et de la gouvernante - tout contribuait à dénaturer, à fausser le fonctionnement et l'esprit des vieilles institutions.

Or, une transformation analogue allait se produire dans le gouvernement local, en Comté. Le vieux maréchal Claude de Vergy le détenait et s'était occupé d'en assurer aux siens la survivance. A défaut de fils, il avait un neveu : François (M. d'Autrey) ; dès 1557, sur les prières de l'oncle, Philippe nommait le jeune homme 
lieutenant : on le vit siéger comme tel, à Dole, au Parlement, à l'audience solennelle de la Saint-Martin. Rassuré sur l'avenir, Claude s'éteignait peu après : le 9 janvier 1560, sa succession s'ouvrait. Deux candidats surgirent : François, naturellement - mais surtout, concurrent redoutable, l'héritier des Chalon, Guillaume de Nassau.

La mort de son cousin René au siège de Saint-Dizier, en 1544, avait fait de ce jeune étranger le plus riche seigneur de toute la Comté. Il y possédait plus de trente seigneuries, toutes admirablement groupées. Au nord, près de l'Ognon, Rougemont se trouvait isolée. Mais le long du Doubs, les châteaux se serraient : Vaire, sur sa terrasse ; Montfaucon, démantelé sous Louis XI ; Arguel, solide encore et menaçant ; plus au sud, Abbans : ainsi les Chalon surveillaient les accès, les abords de Besançon. - Autre groupe sur la Loue et le Lison, aux avenues de Salins : dans la ville même, Chatelguyon ; aux portes, Château-Belin ; sur la route de Quingey, Rennes ; sur celle d'Ornans, Montmahoux et l'imprenable SainteAnne ; Vers et Chalamont sur celles de Champagnole et de Pontarlier. Toutes les routes transversales entre plat-pays et Haut-Jura passaient en partie sur les terres des Chalon. Par Arbois, Sellières, Bletterans, Arlay, Lons-le-Saunier, Montaigu, Saint-Laurent-de-la-Roche, les ancêtres avisés de Philibert s'en étaient assuré tous les points de départ. Avec Valempoulières, Montrond, Mirebel, Châtillon-sousCurtine, ils avaient occupé les cols de la ride montagneuse qui marque la limite des premiers plateaux. La Rivière, Dammartin, Houtaud, Lièvremont leur livraient les abords de Pontarlier dont ils tenaient, à Jougne, la clef principale. Montrevel, Monnet, Nozeroy, Chatelneuf, les faisaient maîtres des routes de l'Ain ; Rochejean et Chatelblanc, du haut Doubs ; Réaumont les campait près du Val de Morteau ; Orgelet, Montfleur, Chavannes sur les routes de Lyon. Ainsi s'étendait ce vaste domaine, admirablement composé jadis, avec un sens stratégique et topographique indéniable.

Sans doute, pour Guillaume, l'avantage d'une distribution si ingénieuse des terres était moindre que pour ses prédécesseurs. Le temps n'était plus, des barons indépendants derrière les murs de leurs châteaux. Mais la valeur économique du domaine subsistait, considérable : dans les greniers des châteaux s'entassaient les grains de la Bresse et des premiers plateaux ; dans les caves, les vins de Rougemont, d'Arguel, de Salins, d'Arbois et de Lons. Les forêts du Jura - les énormes joux qu'aux Chalon les moines avaient inféodées - donnaient les bois de charpente 
et de construction. Des péages subsistaient à Chalamont, à Jougne ; surtout, à Salins, à la grande Saunerie, les héritiers de Jean de Chalon continuaient de détenir, vers 1545, un tiers et un sixième des parts contre un tiers seulement qu'y possédait le Comte : chaque année, en moyenne, la recette s'en montait à 10000 livres. En 1567, lorsque Philippe II confisque les seigneuries comtoises du Taciturne, la recette totale s'élève à près de 50000 livres.

Sans doute encore, Guillaume ne jouissait pas de toutes les possessions de ses devanciers. Lorsqu'il avait demandé au Parlement de Dole mainlevée de son héritage, un arrêt du 17 avril 1545 lui avait relâché la totalité de la succession, moins le partage d'Auxerre en la Saunerie, et les sept seigneuries du partage de Châteaubelin. Le procureur argua que la restitution de ces terres et de ces revenus, jadis, n'avait été que provisionnelle, et faite en faveur de ces seuls Chalon authentiques dont le sang ne coulait plus aux veines du requérant : d'où procès naturellement, et qui s'instruisait à Malines devant le grand conseil. Mais même réduit ainsi, le domaine de Chalon assurait à son possesseur une influence énorme en Comté. Sur ce petit État, tout un peuple vivait : receveurs, juges, baillis, greffiers, procureurs, sergents, forestiers - tous à la nomination du prince d'Orange. Au-dessus des officiers locaux, les généraux : un receveur, centralisant tous les revenus ; des auditeurs des Comptes, siégeant régulièrement à Chatelguyon; un superintendant remplaçant le maître absent et chargé du contrôle ; pour la justice, en plus d'un président d'Orange, un grand bailli avec un lieutenant et un procureur général tenant les assises dans les seigneuries ; à Dole, un procureur pour suivre les procès ; dans les châteaux, enfin, des capitaines, commandant soudards et morte-paies : car les murs, les tours, les donjons d'Arguel, de Sainte-Anne, de Saint-Laurent, de Jougne restaient debout et garnis d'hommes, de vivres et d'artillerie. Au dispensateur de tant d'offices, au maître de si grands biens, quelle influence dès lors était réservée - on le devine. 


\section{II}

Cette influence, Guillaume enfant, longtemps, n'avait pu songer à l'exercer. C'est en 1553 seulement qu'il avait atteint ses vingt ans - et, sans compter, on l'avait vu d'abord dépenser en fêtes sa fougue et son argent. Puissamment riche l'ensemble de ses revenus pouvait se monter à 200000 florins - il avait cependant fait des dettes formidables ; du reste, il semblait en prendre son parti avec philosophie : Affaire de race, écrivait-il gaiement à son frère Louis ; en bons Nassaux, nous sommes « un peu movès ménaigiers en nostre jeun temps ; mais quand nous serons vieux, serommes mellieur, comme feu M. nostre père. » En réalité, sa situation n'était pas sans difficultés ; le départ de Philippe pour la péninsule, l'exclusive faveur témoignée par le roi aux Espagnols, la paix qui se prolongeait et le laissait inactif - tout ce concours de circonstances fâcheuses le rendait mécontent de lui et des autres. A ses côtés, un peuple de nobles turbulents et déçus s'agitait : Guillaume devenait un personnage qu'il fallait se garder de mécontenter. Aussi l'embarras de Marguerite fut-il grand lorsque, sitôt connue la maladie du vieux maréchal Claude de Vergy, il se mit sur les rangs et revendiqua hautement sa succession.

Comment le satisfaire sans sacrifier en François de Vergy toute la noblesse locale ? Marguerite, habile, suggéra un compromis. Guillaume aurait le gouvernement, mais « aux mesmes termes précisément qu'avoit son feu prédécesseur immédiat », René de Nassau : c'est-à-dire que, pour exercer réellement le gouvernement, le roi commettrait « pour lieutenant dud. sr prince d'Orenge et en l'absence d’icelluy, le sr de Vergy moderne, nepveur, beau-filz et héritier du dernier décédé, agréable au pays et de la plus noble maison d'icelluy. » La combinaison fut admise et le 12 avril, tout était réglé ; Guillaume prêtait serment aux mains de Marguerite et François recevait sa commission royale. En même temps, le conseil des bons personnages se trouvait renouvelé. Pour remplacer François Bonvalot et le président Marmier, décédés, le roi nommait Ferdinand de Lannoy, comte de la Roche, qui allait, en 1560, entrer par alliance dans la famille Perrenot - et Jean d'Achey, seigneur de Thoraise, qui, ayant épousé Marguerite Perrenot, se trouvait 
le beau-frère de l'évêque d'Arras. Ainsi s'affirmait avec éclat le crédit restauré du prélat.

Événements d'importance, ces nominations : essayons d'en noter le caractère. Tel que Philippe venait de le créer, le gouverneur en titre, Guillaume, n'était qu'un gouverneur honorifique. C'était une dignité, non une charge qu'on lui avait donnée ; le gouverneur réel était François de Vergy. Or, on avait déjà connu, en Comté, un partage analogue. Sous René de Nassau, Claude de Vergy, lui aussi, avait exercé le pouvoir dans sa réalité sans en connaître d'abord tous les honneurs. Analogie, non similitude. Lorsqu'au gouverneur absent un suppléant avait alors été donné, nul n'avait songé qu'à régler pour le mieux une situation de fait. En 1561, par contre, c'était le même jour qu'on créait, à la fois, titulaire et suppléant ; c'était la volonté prévoyante du roi et de la régente qui, d'avance, délimitait les champs d'action respectifs de Fr. de Vergy et de G. de Nassau. Le prince, quand il sera en Comté - mais on espère bien qu'il n'y paraîtra pas - aura « la maniance entière des affaires »; mais le reste du temps, Marguerite entend que Vergy soit «immédiatement soubs elle »; elle n'est pas femme, elle l'écrit, à laisser diminuer son autorité - l'autorité du roi - sur la Franche-Comté. Et comme le jeune homme est mal rompu aux affaires ; comme il est nécessaire de contrôler, de guider, d'éclairer ses débuts ; comme la prudence incite naturellement à ne point le gratifier d'honneurs trop rapides, de tout ce concours de circonstances, les unes préméditées, les autres fortuites, il résultera que François de Vergy, suppléant d'un titulaire dont on craint l'influence, se trouvera plutôt représenter le roi auprès de la province que la province auprès du roi. Nuance sans doute ; mais qu'il faut indiquer dès qu'on la perçoit.

Autre point. François de Vergy voit auprès de lui, au moment même de sa nomination, la régente et le roi maintenir et compléter le conseil des bons personnages - ce Conseil d'État de la Franche-Comté. Précaution nécessaire, qu'impose son inexpérience. Mais à mesure que l'autorité du nouveau « commis » s'affirmera ; à mesure qu'il donnera de son loyalisme et de ses bonnes intentions des gages non équivoques, la place du Conseil se fera plus restreinte. De loin en loin, Vergy le convoquera à Gray ; mais la gouvernante n'y tiendra pas la main, ni le nouveau roi. Finies, les recommandations incessantes d'un Charles-Quint, d'une Marie de Hongrie à un Claude de Vergy ; finies, les insistances pour que le gouverneur collabore étroitement avec ses conseillers. Devant ce silence, cette sorte d'aban- 
don tacite d'une vieille institution qui jouait en Comté le rôle important que nous avons noté, François, peu soucieux de partager avec d'autres les prérogatives sinon les responsabilités - de son pouvoir, espacera de plus en plus les assemblées. Les bons personnages de leur côté, se désintéressant de fonctions aussi intermittentes, ne tenteront rien pour remonter le courant - et le jour viendra où les États, s'émouvant, mais trop tard, de cette disparition, devront réclamer le rétablissement des « super-intendants » abolis en fait. Anticipation sur l'avenir : mais il convient de noter, à ces débuts du nouveau règne, les mêmes manifestations en Comté qu'aux Pays-Bas d'un esprit d'absolutisme et de centralisation.

Enfin, quelle que fût l'habileté du compromis imaginé par Marguerite, n'étaitce point chose grave, l'introduction de Guillaume en Comté avec le titre de gouverneur, - cela, au moment précis où les populations de "par deçà » commençaient à manifester contre le successeur de Charles-Quint, ou plus exactement contre un nouveau régime de gouvernement, des sentiments non équivoques de colère ? Déjà, dans les villes, bourgeois et marchands murmuraient à l'envi contre l'arrogance des soldats espagnols, le mépris affiché des États généraux et le projet d'envoyer au secours des catholiques français 2000 hommes d'armes des bandes d'ordonnances. Or, voici qu'à leur tour les nobles d'épée, les guerres étant finies et la cour disparue, élevaient leurs doléances à côté des bourgeois. Plus d'emplois pour eux, plus d'occasions de servir, d'acquérir gloire, honneurs, profits. Le roi n'est plus là, et d'ailleurs ne goûte que les seuls Espagnols. La gouvernante est venue, trainant derrière elle un peuple d'Italiens et d'Espagnols, décriés, arrogants, odieux aux Flamands. Un Armenteros tranche du gouverneur et, surnommé par tous Argenteros, vend les offices au plus offrant. Enfin, la Consulte annihile presque le Conseil d'État - et c'est un Comtois, Granvelle, qui a la haute main sur les affaires d'État.

Doléances anciennes déjà ; l'évêque d'Arras les connaissait bien. Dès 1553, au temps même du vieil Empereur, il écrivait à Emmanuel-Philibert, capitaine général des Impériaux, pour lui signaler « le sentiment que les seigneurs de par deçà ont, pour leur sembler que l'on ne tienne au camp le compte d'eulx que convient ». Ils prétendent, continuait-il, qu' « aux affaires qui se sont adonnez, vous avez toujours employé Espagnols et Italiens... sans autre de par deçà que le seigneur de Rye, qu'ilz tiennent encoires pour demy-estrangier. Et toutes fois, en démonstrent plus de satisfaction que des Espagnols ou Italiens ». En 1559, il aurait pu envoyer 
cette lettre à Marguerite sans y rien changer. Tout au plus n'aurait-il pas été tenté d'écrire que, de sa présence à lui, « demy-estrangier », aux Pays-Bas, les seigneurs montraient "plus de satisfaction que des Espagnols ou des Italiens »; il savait le contraire, à n'en pas douter.

Très vite, il avait attiré sur sa tête toute l'impopularité du nouveau régime. Il était l'étranger venu pour vexer les Flamands, pour attaquer de front, saper leurs privilèges. On le disait promoteur de cette création des nouveaux évêchés qui lui valut, en 1560, le trône archiépiscopal de Malines. Il passait déjà pour l'âme damnée de ces "pourceaux d'Espagne », que les pasquilles allaient dénoncer brutalement. Surtout, ce parvenu avait la haine des "grands maîtres », des seigneurs admis au Conseil d'État et que la Consulte rejetait dans l'ombre : haine qui se fit plus vive, plus générale encore, à partir de 1561.

\section{III}

C'est à cette date que le prince d'Orange prend place ouvertement parmi ses adversaires. Sous quelle influence ? Gachard incline à croire que Granvelle, élevé en février au cardinalat, créé prince de l'Église en un temps et dans un milieu où ce titre conférait les prérogatives les plus étendues, dut, par sa morgue, piquer son ancien ami ? La supposition est plausible. Mais comment ne pas noter également que Claude de Vergy meurt en janvier 1561, et que la rupture de Guillaume avec le nouveau cardinal coïncide avec sa nomination au gouvernement de FrancheComté ?

Une des premières lettres de félicitation qu'avait reçues l'héritier des Chalon avait pour signataire M. de Dicey, Marc de Rye, l'adversaire résolu de Granvelle. Une des premières lettres qu'il dut écrire, en sa qualité de gouverneur, était adressée au même personnage, à l'occasion de cette folle tentative, de ce coup de main hasardeux sur Héricourt que venait d'essayer Claude-François, son fils. Lettre grave, un peu sévère même, de quelqu'un qui blâme les imprudences, songe à l'intérêt supérieur du Comté - au total, semble s'intéresser à sa nouvelle charge et sollicite des renseignements pour pouvoir en faire état au Conseil. Tendances gênantes et pour la gouvernante et pour Granvelle. Dans le Comté, paisible en appa- 
rence et prolongeant, sous le nouveau règne, son existence ancienne, des symptômes de troubles apparaissaient déjà. Lorsqu'en juillet 1561, Ch. Grandjean, conseiller au Parlement de Dole devenu membre du Conseil privé, avait été chargé, par les commissaires royaux, de «porter le propos » à l'ouverture des États, n'avait-il pas exprimé le désir «que les Estats se tinssent amyablement et sans bruit, comme de toute ancienneté a esté fait et observé, sans que personne y dut prendre plus d'autorité qu'il appartiendroit, ains qu'en l'assemblée, au lieu accoutumé, chacun mis à son ordre, les opinions se rendissent librement et franchement sans être attirées violemment ou aultrement » ? Recommandations inusitées. Elles témoignaient, à tout le moins, de quelques préoccupations sur les tendances de certains Comtois. Mais, d'autre part, y avait-il place, dans la province, pour l'influence d'un Guillaume de Nassau ? Et celui-ci, s'il entendait réellement intervenir dans les affaires comtoises, n'allait-il pas en Bourgogne, comme déjà en Flandre, rencontrer Granvelle et se heurter à lui ?

Car, le protecteur de la bourgeoisie, c'était plus que jamais l'ancien évêque d'Arras, devenu cardinal archevêque de Malines, et muni depuis peu - héritage de son oncle François Bonvalot, mort le 14 décembre 1560 - de plusieurs abbayes de première importance : Luxeuil, notamment, et Saint-Vincent de Besançon, qui augmentaient encore son influence. «Écrire à M. d'Arras »ou, bientôt, à « M. le cardinal », c'était le grand recours, le premier remède aux difficultés. Un plaideur mécontent, Prudent de Rubilly, inonde le Comté et les Pays-Bas de requêtes injurieuses contre des parlementaires (le président Desbarres, notamment, et le conseiller Colin), les accusant «de tenir, au lieu d'une équité de justice la vraie face et figure de brigandage » et, dans une affaire de succession, d'avoir usé « des mêmes actes que les Juifs firent, quand ils répartirent les vêtements de N.S. JhésuChrist »; le premier avis qu'ouvre le premier opinant à la première délibération, M. de Montfort, c'est que «l'on doit envoyer à M. d'Arras copie dud. libelle et d'autres précédents, injurieux ». A Dole, entre les bourgeois, le capitaine Marc de Rye et son second la Villette, la situation s'aggrave-t-elle ? Par lettres du magistrat, presque au jour le jour, Granvelle est averti des phases du conflit. C'est auprès de lui que se disculpent les conseillers en butte à des attaques, à lui que s'adresse la troupe des candidats. - Il est le grand patron, l'universel chargé d'affaires, celui dont on attend tout, à qui l'on demande tout. Rôle flatteur, peut-être, 
périlleux à coup sûr : il exposait le cardinal aux rancunes des évincés, aux colères des déçus, aux maladresses, surtout, des clients subalternes.

Or, sans tarder, en 1561 déjà, en 1562, ses éternels ennemis, sentant le parti qu'ils pourraient tirer de la situation, entreprirent de dresser Guillaume contre lui. En février 1561, le magistrat de Dole, se plaignant de la Villette, annonce à son protecteur que le lieutenant de $\mathrm{M}$. de Rye, "pour faire sa cause meilleure » et « tirer en hayne » les Dolois envers le prince d'Orange, lui avait fait entendre «que le tout de cette négociation ne luy estoit communicquée, encoires il soit gouverneur de Bourgogne ». Granvelle, d'autre part, était tenu au courant des propos et des gestes de Marc de Rye. Entre autres, dans les premiers jours de juin 1562, le docteur Jacques Morel lui rapportait une conversation curieuse qu'il avait tenue, à Dole, avec le vieux seigneur. Celui-ci, «mectant en avant plusieurs et divers propoz en suyte de divises ", s'était mis à parler "sur le succès, heurt et fortune des hommes, qui sont transitoires et aultres durables; et parlant de votre divise : Durate, dict que vostre Durate pourroit bien changer ». Le cardinal, à ce coup, se sentit piqué. Il répondit vivement, après avoir rappelé tout ce que M. de Rye et ceux de sa maison lui devaient, à lui et à Nicolas Perrenot : "Quant à ma divise de Durate..., dites luy de ma part qu'il n'a pas assez étudié pour sçavoir entendre et beaucoup moings pour controller ma divise » ; mais il ajoutait aussitôt : « Du moings ne luy donneray-je occasion de luy estre aultre que amy s'il ne m'en baille cause... » Et de même, comme la Villette, au retour d'un voyage en Flandre - il était allé se défendre en incriminant violemment les Dolois - lui avait écrit : « Estant de retour à Dole, plusieurs furent esbéis que je fusse revenu lieutenant de Mgr de Dicey; et aucuns se sont tant avancé de parler que de dire que V. S. ne leur avoit tenu ce que leur aviez promis, qu'estoit de me faire déporter dud. estat de lieutenant». - Granvelle lui répondit avec vivacité : "Si vous me connaissiez bien, vous sçauriés que j'use partout ung mesme langaige, et seroit mon désir qu'il y eust bonne intelligence entre M. de Dissey, vous et lesd. de la ville de Dole ». Mais à tous ces indices se révélait clairement la campagne entreprise.

Un nouvel incident, bientôt, acheva d'en déterminer le sens. En dépit de sa richesse, Guillaume n'avait pas des finances prospères. La tentation était forte pour lui d'exploiter la province qu'on lui avait donnée et, s'il ne pouvait personnellement y résider, d'y déléguer du moins un des siens, son frère, par exemple, ce be- 
sogneux Louis qui lui écrivait mélancoliquement de Dillenburg, le 10 mars 1562 : « Nous trouvons monter nous debtes jusques à 300000 florins de Francfort, lesquels nous font 14000 florins de pension annuelle ». A cette époque déjà, le parti était pris : le 12, en effet, Granvelle, tout ému, annonçait au roi que Guillaume avait dessein « d'envoyer son frère, le comte Louis, en Bourgogne, afin de tâcher qu'il ait la charge du gouvernement pour lui dans cet État, excluant M. de Vergy ».

Le roi comprit le danger. Non seulement, si un parent du prince, si son frère s'installait en Comté, il y pourrait prendre, appuyé sur l'immense domaine des Chalon, un ascendant considérable - mais encore il grouperait sans doute tous les mécontents, susciterait des querelles et des divisions, ferait de la Comté un deuxième foyer de turbulence et d'opposition. D'ailleurs, Granvelle en avertissait le souverain : les conseillers ne manquaient pas au prince pour l'engager dans cette voie dangereuse, s'il était vrai, comme il le croyait, que tout se machinât « avec intelligence et pratique de M. de Dissey ».

\section{IV}

Le projet de Guillaume ne devait pas aboutir. Mais au moment même où Granvelle, dans ses lettres à des compatriotes, affectait l'optimisme le plus assuré, une campagne violente, comme jadis à la suite de l'affaire Bonvalot, allait recommencer contre lui en Comté. Mêmes raisons profondes et mêmes protagonistes : au premier plan, de grands seigneurs, avec leur clientèle de nobles secondaires ; par derrière, Renard.

A l'automne de 1559, Granvelle avertissait Gonzalo Perès que son ancien protégé était devenu le conseiller ordinaire des mécontents, et de tous parlait le plus librement. Bien vite en effet, Renard, esprit net, causeur très séduisant, prit sur Egmont et sur le prince d'Orange un ascendant marqué. Et comme d'assez bonne heure l'effort des opposants se porta contre Granvelle - à cette orientation son rival fut-il complètement étranger ? - on devine si le mortel ennemi du cardinal dut se trouver à l'aise dans les rangs des seigneurs. C'est à lui que, dès le début, Granvelle attribue quelques-uns des pamphlets les plus violents, des libelles les plus 
venimeux qui se répandent aux Pays-Bas contre « l'archivilain », le « rouge dragon » d'Espagne. C'est lui qu'il accuse de semer de faux bruits, de persuader à Egmont et au prince que le prélat voudrait les voir mettre à mort. Lorsque la Villette lui rapporte les propos « d'aucune Dolois » à son égard : « je soubsonneroye, répond le cardinal, ne sçay si je me forcompte, que ce pourroit estre quelque invention des ordinaires de ce vénérable Renard ». A la guerre ouverte des deux hommes, les moins familiers du cardinal maintenant font allusion publique. Et c'est Renard, en effet, qui concerne l'action maintient les relations entre les divers ennemis du cardinal : ceux des Pays-Bas, ceux d'Espagne et ceux de FrancheComté.

Un autre Comtois le secondait dans sa tâche : Jean de Poupet, seigneur de la Chaux, bailli d'Aval, ancien sommelier de corps de l'Empereur. Ce puissant personnage avait fait à la cour une brillante fortune. Aux côtés d'un Joachim de Rye, d'un Jean d'Andelot, il s'était élevé aux premières charges de la maison impériale, et lorsque Charles-Quint, ses abdications faites, était parti à Yuste, c'était Jean de Poupet qu'il avait choisi pour l'accompagner. Le maître mort, son vieux serviteur avait repris auprès de Philippe II un service de cour, et plein d'antipathie pour la race des Perrenot, dont la fortune était fâcheuse à sa noblesse hautaine, il s'était vite rangé parmi les adversaires du cardinal et les partisans de son ennemi Ruy Gomez. Renard, aisément, s'était insinué dans ses bonnes grâces, et le vieux seigneur était devenu bientôt un des intermédiaires actifs des «renardistes». En Comté, Jean de Poupet avait un collaborateur naturel et plein d'ardeur : son frère cadet Guillaume, abbé commendataire de Baume-les-Moines, de Goailles et de Balerne - un homme âgé déjà, membre du conseil des bons personnages, loué comme un Mécène par maint artiste et maint humaniste comtois : il ne ménageait pas ses peines, aux côtés de MM. de Rye, pour recruter des ennemis au cardinal et des amis au prince.

Renard animait tous ces hommes de sa haine. Par eux, il faisait passer en Comté les pamphlets composés contre le cardinal ; par eux, il répandait dans les rangs de la noblesse caricatures, pasquilles, estampes satiriques. Il faisait circuler de prétendues lettres du cardinal au roi contenant, entre autres conseils supposés, celui de couper la tête à Egmont, à Hornes et à demi-douzaine de leurs partisans ou encore, d'établir dans les pays de par deçà l'inquisition d'Espagne avec toutes ses pratiques. Ainsi peu à peu les passions s'émouvaient. La noblesse turbulente, 
qui saluait les Rye comme ses chefs ; les écuyers hardis, les hobereaux endettés qui, satisfaisant sur les grand'routes leurs instincts de brutalité et de rapine, trouvaient chaque jour en face d'eux la justice haïe des robins dolois - tous suivaient de près les événements des Pays-Bas. Aux revendications des seigneurs flamands ne pouvaient-ils pas s'associer?

Pour le conseil d'État, où ils siégeaient en nombre, les « grands maîtres » de par deçà réclamaient la suprématie sur les autres conseils ; ils rappelaient avec complaisance le temps où, disaient-ils, tout le gouvernement, la gestion des finances, le contrôle de la justice appartenaient «aux seigneurs et chevaliers principaulx du pays esgalement »; mais les nobles comtois n'avaient-ils pas aussi tout un passé brillant à revendiquer, tout un présent d'humiliations à modifier ? Les Flamands, couverts de dettes, brutaux et violents contre leurs créanciers, s'insurgeaient violemment contre les juges bourgeois et, couvrant leurs rancunes d'un prétexte honorable, dénonçaient, " pour le bien du pays », les pratiques d'une justice corrompue et tarée. Les Bourguignons, ruinés comme eux et comme eux brutaux, ne se livraient-ils pas aux mêmes pratiques ? Dès juillet 1561, les féodaux, pris d'un zèle subit pour l'intérêt public, avaient sommé le Parlement de commencer par lui-même la réforme profonde des abus judiciaires ? Et quel effet devait produire sur un la Villette, un Blye, un Citey, le récit de telle scène violente aux Pays-Bas - par exemple, de la rencontre si caractéristique du comte d'Hochstraate et du robin Longin, président de la Chambre des Comptes du Brabant ? - « Tous vous aultres de longues robes estes villains, et vous estes un villain, et tous villains font villainies, ... et vous assheure que bientost l'on vous retranchera si courtes ces longues robes que vous n'aurez de quoy vous couvrir! »Combien, avec bonheur, l'auraient dite à Dole à quelque conseiller, la phrase du noble comte que, plus réfléchi et plus politique, le prince d'Orange vainement s'efforçait de calmer. - Enfin, aux Pays-Bas, la noblesse tenait pour les États. Mais en Comté même, les seigneurs ne tiraient-ils pas de leur convocation maint avantage ? L'assemblée des trois ordres leur donnait le seul moyen qu'ils eussent de faire entendre leur voix officiellement, de s'associer collectivement à la marche des affaires provinciales, et même de manier un peu ces deniers dont la gestion, par ailleurs, et le profit leur échappaient chaque jour. Ainsi, ce n'étaient pas des individus seuls qui nouaient un lien entre les Pays-Bas et la Bourgogne ; ici et là, des conditions politiques et sociales analogues déterminaient la naissance d'idées et de sentiments pareils. 


\section{V}

Peu à peu cependant, et sentant le danger, le cardinal, au milieu de 1562, reprit l'offensive avec énergie. On l'attaquait : ramassant ses forces pour une lutte sans merci, avec une fureur qu'il ne montra jamais qu'en cette seule occasion et contre ce seul ennemi, il fonça sur Renard et remit en avant la trahison de Quiclet. Le duel à mort s'engageait - et le cardinal d'abord put se croire vainqueur. A l'ancien ambassadeur qui réclamait des juges, le roi, en effet, répliqua soudain, le 22 décembre 1562, par un ordre formel de quitter les Flandres et d'aller résider et servir en Comté.

Le coup était rude ; surtout, il était imprévu. On le voit à l'émotion qu'il provoqua, tant en Espagne qu'aux Pays-Bas : les archives de l'Audience, à Bruxelles, nous ont conservé deux lettres intéressantes à cet égard. L'une de Tisnacq à Philippe II ; elle est du 21 décembre 1562. Alors à Madrid et secrétaire d'État pour les pays de par deçà, Tisnacq accuse réception au roi de l'ordre donné la veille : il a écrit la lettre au conseiller Renard ; mais il a des scrupules, et l'affaire lui semble de si haute importance qu'il se permet de les soumettre au roi avant d'expédier le paquet à Bruxelles. « J'ay opinion, Sire, écrit le secrétaire, qu'il [Renard] vouldra prétendre et supplier d'estre ouy et se purger par justice sur ce dont l'on le vouldroit charger, et que les seigneurs de par delà diront que cecy aura esté pratiqué soubz main par Monsieur le Cardinal. » La seconde lettre, qui est de Courteville à Viglius, nous renseigne à la fois sur les motifs de cette intervention et sur son succès : C'est parce que l'ordre d'écrire à Renard n'était venu «de bouche, mais par écrit, ce pendant que S. M. a été dehors » que, « en envoyant les lettres à signer », Tisnacq avait fait quelques réserves : « Mais nonobstant ce, lesd. lettres ont été renvoyées signées, et a escript S. M. de sa main que le personnage [le Cardinal] ne l'avoit sollicité, et mesmes tenoit qu'icelle n'en savait à parler, et qu'elle escripreroit sur ce point à Madame, aussi de sa main. Et ainsi, les lettres se sont envoyées à S. A. ; ne sais ce que S. M. lui en escript particulièrement; cecy est seulement ung mot en confidence. » Plus heureux que Courteville, nous connaissons sinon le texte de la lettre royale à Marguerite, du moins la minute que prépara Tisnacq. Il y est démontré longuement que l'ordre du roi à Renard ne comporte 
pas de déshonneur pour lui ; que la prétention de Renard d'attaquer Granvelle n'a pas de fondement ; enfin, que la lettre de rappel n'a pas été provoquée par le cardinal. Déjà en effet, apostillant la lettre de Tisnacq, du 21, le roi avait protesté vivement contre la supposition de son garde des sceaux; mais dans son projet de minute, Tisnacq, toujours prudent, n'écrit pas moins en marge, vis-à-vis du dernier paragraphe : «Cecy se polroit omettre s'il sembloit meilleur ». La réflexion trahit, chez le garde des sceaux, la crainte d'une fausse manoeuvre. La lettre royale, en fait, ne fut pas autre chose.

Renard, hardiment, refusa de partir. Dans une longue lettre au roi, il se déclara la victime innocente des menées cardinalices ; il protesta que jamais il ne s'était mêlé des « difficultez et resentemens » que plusieurs seigneurs avaient eus contre Granvelle ; il ajouta enfin qu'il ne saurait servir le roi en Comté puisqu'il n'avait plus là-bas «ny office, ny service »; qu'au reste, le voulût-il, il ne pourrait partir " pour ne pouvoir aller à chariot ny à chevalz » à cause de sa santé et pour être retenu par ses créanciers. Cette réponse faite, avec plus d'ardeur que jamais, il reprit sa campagne, incitant entre tous les conseillers du Conseil privé à se solidariser avec lui.

Avait-il raison lorsqu'il faisait remonter à Granvelle la responsabilité de sa disgrâce ? Certes, le cardinal avait entrepris contre lui une campagne sans merci, nous l'avons vu. Mais avait-il conseillé à Philippe cette mesure précise : le rappel en Comté ? Aucun compte n'est à tenir des démentis de Philippe, dont on sait la puissance et le besoin de dissimulation. Tout au plus peut-on penser que Granvelle n'a pas conseillé directement au roi l'usage de la formule : «Aller résider et servir en Comté ». Servir ? Granvelle savait bien que Renard n'en avait pas le moyen ; il devait prévoir, semble-t-il, les objections que son ennemi ne manquerait pas de faire à un ordre conçu en de pareils termes.

Toujours est-il que, l'ancien ambassadeur ayant passé, et largement, le délai prescrit par son maître - celui-ci, le 25 février 1563, lui enjoignit pour la seconde fois de regagner la Comté. Pour la seconde fois aussi, Renard refusa et réédita ses arguments. Il était malade. Il avait en mars 1561 remis tous ses offices entre les mains de Marguerite de Parme. Il ne pouvait donc pas servir en Comté. Il n'avait d'argent ni pour désintéresser ses créanciers qui lui réclamaient sur l'heure 12000 florins, ni même pour payer son déménagement qu'il estimait, au moins, à un millier d'écus. Surtout, et c'était là son argument capital : comment pourrait-il subsis- 
ter en Comté ? Il n'y vivrait pas trois jours seulement « sans oultraige ou sans partialité ouverte ». Tout le monde n'y était-il pas parent, ami ou créature du cardinal ? « Ceux qui sont entremis aux affaires d'estat du pays sont parents et beauxfrères du cardinal ; en la cour du Parlement de Dole, les président, chevalliers et six ou sept conseillers de la court sont aussi ses parens ou alliez, et les aultres tous promehuz de sa main. Tous les fiscaulx des bailliages d'Amont, d'Aval et de Dole dépendent de lui ; tous les officiers de la saulnerie sont ses frères, beaulx-frères, parens, alliez et serviteurs; l'état de gruyer est ès mains de son beaul-frère; le gouvernement du Charollois ès mains d'ung aultre sien beau-frère ; les principales capitainneries du pays sont ès mains de ses beaulx-frères et nepveurs; l'estat de bailly de Dole ès mains de son nepveur ; les trésoreries générales du pays, celle de la saulnerie, celle de Dole ès mains de ses parents, serviteurs et alliez. Enfin, tous offices et bénéfices, grâces, placets de bénéfice passent pour la plupart par ses mains ; ... dix ou douze abbayes dud. pays sont tenues tant par luy que par les siens et plusieurs priorité et aultres bénéfices »; bref, toute la Comté n'était qu'un fief des Perrenot, et - concluait Renard - V. M. peut penser comme le suppliant, s'il y mettait les pieds, serait bien venu de leur clientèle...

Avec un prince comme Philippe II, méfiant, jaloux de son autorité et toujours prêt à prendre ombrage de ses ministres, la lettre de Renard était d'une suprême habileté. Au moment d'ailleurs où il la rédigeait, ses amis : Orange, Egmont, Hornes, adressaient de leur côté une requête au roi (11 mars 1562-63) ; ils lui demandaient le rappel de Granvelle. C'était contre le cardinal un assaut terrible. Tandis que Guillaume, aux Pays-Bas, semblait mettre un soin particulier à se concilier les faveurs des Comtois, en Comté même, MM. de Rye faisaient rage. Des serviteurs de Marc couraient le pays au nom de leur maître, allaient de châteaux en châteaux, colportant pamphlets et calomnies contre le cardinal, sollicitant des adhésions à la campagne entreprise contre lui. Il n'était pas jusqu'à la décision prise, le 15 mai, par Philippe II de donner à Renard les juges qu'il demandait et de le recevoir à purge quant au procès Quiclet, qui n'animât et ne soutint le zèle des ennemis de Granvelle. En vain le cardinal montrait-il partout des lettres de Philippe II, l'assurant de sa confiance; en vain s'employ-ait-il à ce que le procès de purge de Renard fût instruit, devant le Parlement de Dole, par des juges à sa discrétion ; en vain annonçait-il contre son ennemi des révélations décisives - dans le temps même qu'il quêtait contre lui, en Comté, des dénonciations et des récits propres à lui 
nuire : l'insolence de ses adversaires croissait de jour en jour ; Renard, ironique et impudent, se promenait, visitait ses amis, faisait des parties de chasse en dépit de ses maladies diplomatiques ; Egmont refusait de partir en Espagne comme Philippe II l'en avait prié, du moins pour s'entrete-nir de la situation présente et, comme il disait, de "l'affaire du cardinal »; les seigneurs déclinaient à nouveau toute participation au Conseil d'État, tant qu'y siégerait le représentant du gouvernement absolutiste ; finalement, au mois d'août 1563, Marguerite de Parme, cédant à son tour, envoyait en Espagne son fidèle Armenteros, et demandait elle aussi le départ du cardinal.

On sait le dénouement : le 22 janvier 1564, une lettre autographe de Philippe Il apportait à Granvelle l'autorisation de prendre un congé et d'aller en Comté visiter sa vieille mère. Le 13 mars, le cardinal quitte Bruxelles; il est à Besançon le 29. Pour les seigneurs, pour Renard, pour Marc de Rye, Guillaume de Poupet et leurs clients comtois, c'est le triomphe. De la lettre de Philippe, du prétexte imposé par le roi et invoqué par le ministre, de l'attitude et des déclarations du cardinal, personne n'est dupe - et contre celui que la disgrâce vient d'atteindre, c'est une ruée nouvelle et plus sauvage. Des agents de Renard, établis à Dole, cherchent à intercepter ses lettres. On ne rencontre partout en Comté que domestiques et secrétaires des seigneurs flamands, chargés de missions auprès de MM. de Rye. Marc s'oublie jusqu'à déclarer en public que, si par malheur il perdait quelqu'un de ses procès devant le Parlement, il tuerait de sa main le cardinal ou le ferait dépêcher par quelques bravi. On tente habilement de brouiller Granvelle avec M. de Vergy, et comme on n'y réussit pas, on sème des bruits habiles : tantôt, on le redit, le prince d'Orange doit envoyer son frère prendre à sa place le gouvernement ; tantôt son fils, M. de Buren, doit venir le suppléer, en s'aidant des conseils de M. de Rye. Celui-ci d'ailleurs, dès le printemps de 1564, a fait prendre à ses serviteurs la «livrée » des ligueurs flamands. Son fils Marc-Claude et tous ses partisans portent eux aussi les flèches emblématiques des réaux de Castille, « lesquelles, réunies en faisceaux, ne peuvent se rompre, mais que l'on brise en les prenant une à une ». Ainsi, de plus en plus, les affaires de Flandre trouvaient en Comté leur répercussion ; de plus en plus, sous l'effort de Renard et de MM. de Rye, une solidarité politique s'établissait entre les deux pays ; pour l'un comme pour l'autre, le mot de Viglius se justifiait : c'étaient les beaux temps «de la rose rouge et blanche » qui tendaient à renaître dans les États de Philippe. 


\section{VI}

Une telle situation n'était pas sans émouvoir fortement Granvelle. Certes, il avait reçu en Comté un excellent accueil, et sa visite au pays natal était loin d'être à son désavantage. Autour de lui, ses partisans se groupaient, raffermis, rassurés, enhardis par sa présence même. Sa conduite, d'ailleurs, était d'une habileté consommée. Il partait peu, observait sur les affaires de Flandre la réserve la plus absolue, affectait une tranquillité d'esprit parfaite, semblait goûter pleinement le repos de son congé. Congé temporaire, congé sollicité par lui : il le disait, l'écrivait, le répétait sans cesse aux personnes de son entourage et même, plus loin, à un Armenteros ou à un Viglius. Lentement, doucement, dans sa confortable litière, il allait de ville en ville, de château en château, visitait à Gy le jeune archevêque Claude de la Baume, rencontrait à Gray M. de Vergy et le bailli d'Amont, son beau-frère Ferdinand de Lannoy; par Beaujeu, il s'acheminait vers Vesoul, puis vers Baudoncourt et les terres de l'abbaye de Luxeuil ; et c'étaient ensuite de belles et calmes journées passées dans le Jura, à Mouthier-Hautepierre, à Ornans, berceau de sa famille, au château d'Orchamps-Vennes, au bourg de Nozeroy, dans la ville de Salins : voyages triomphaux, avec des réceptions solennelles aux portes des cités, des cadeaux somptueux offerts respectueusement par les magistrats, des cortèges empressés de parents et d'amis.

Imperturbable, le cardinal soutenait son rôle. C'étaient des vacances seulement qu'il prenait là : la Flandre bientôt le reverrait, plus puissant, mieux « autorisé » que jamais. Son grand souci n'était-il pas, d'ailleurs, de recevoir des nouvelles de ses beaux jardins, de cette merveilleuse villa de la Fontaine qu'il avait fait élever aux portes de Bruxelles, et qu'il lui tardait tant de retrouver ? Chaque semaine presque, de longues lettres de l'écuyer Bordey ou du maître des Comptes Viron lui décrivaient les progrès de ses plantes rares, la belle venue « de l'herbe Nicotia des Indes », celle qui a poussé « joingnant l'angelica » et qui ne saurait vraiment être plus belle avec ses larges fleurs « de couleur incarnate pâle ». Au long des pages s'alignent les menus détails, sur les truites des viviers, les tortues et les écrevisses des bassins, sur « le grand abricot » au coin du vivier, « qui se trouve malheureusement en danger de mort, avec trois pommiers et quatre cerisiers ", sur les oran- 
gers précieux du cardinal ou sa collection d'instruments de musique : douces choses familières, abandonnées la veille, qu'on retrouvera le lendemain... Mais du rôle qu'il soutenait, tout au fond de lui-même, Granvelle n'était pas dupe.

Non que pussent l'émouvoir les menaces ou les violences - cette mascarade grossière par exemple qui, le 19 juin 1564, au baptême du fils du comte de Mansfeld était représentée devant le prince d'Orange, le duc de Deux-Ponts, le comte de Hornes, et tout un parterre de hauts seigneurs : un cardinal, pourchassé par des diables couverts de queues de renard symboliques, était roué de coups sur la scène par le fils de Mansfeld, au grand plaisir de tous les assistants. Mais Granvelle souffrait dans son amour-propre et dans sa clairvoyance. Il savait que les seigneurs ses adversaires avaient pris sur Marguerite une influence sérieuse ; que la gouvernante, circonvenue par eux, lui devenait hostile et ne s'enquérait jamais de ce qu'il devenait. Viglius était privé de tout crédit, tandis que Renard, insolent et fat, se faisait délivrer des certificats de grand ministre par des Espagnols, courtisait Egmont et le prince d'Orange, posait sa candidature au Conseil d'État. Et la haine montait contre lui ; de jour en jour, des nouvelles lui venaient qui lui ôtaient davantage l'espoir de reparaître en vainqueur dans les provinces; Morillon luimême, en juillet 1564, dans un billet confidentiel qu'il le suppliait de détruire, l'écrivait au cardinal : lorsqu'il serait pour revenir aux Pays-Bas, il devrait se munir de lettres expresses du roi le réaccréditant auprès de Marguerite : autrement, « il serait à craindre que l'on vous refuserait l'entrée »...

Une satisfaction cependant allait être donnée au ministre déchu. A la fin d'août 1564, au moment même où Renard enhardi réclamait de Marguerite sa réintégration au Conseil privé ; au moment où, renversant les rôles, il menaçait Granvelle de révélations formidables - pour la troisième fois l'ordre lui vint de venir en Espagne s'expliquer devant le roi sur certaines affaires concernant son service. Cette fois, Renard n'osa pas désobéir. Il partit. Disciple jusqu'au bout de son ancien protecteur, il fit d'ailleurs un beau départ. Il déclara à qui voulait l'entendre que Philippe le mandait pour le mettre à la place du garde des sceaux Tisnacq ; puis, faisant sonner bien haut les paroles d'adieu que ses amis les seigneurs et notamment Egmont lui avaient adressées ; bien lesté d'argent, gratifié par Marguerite d'un viatique de 2000 florins, au mois de septembre 1564, à la tête de son «train de chariozs et chevaulx qu'il at jusques à XII », il prit chemin par la France et, le 22 novembre, arriva à Madrid. 
Succès pour Granvelle, ce départ du rival écarté à son tour des Pays-Bas ? Le cardinal, s'il l'espérait bien, n'osait le dire trop haut. Il connaissait l'humeur changeante du maître et les vicissitudes de la fortune. Des événements graves, en Comté même, attiraient d'ailleurs son attention et l'obligeaient à se tenir toujours sur ses gardes. Pour importants qu'ils fussent, les conflits de personne n'absorbaient pas en eux toute l'histoire compliquée de cette époque de troubles. Sous le nom d'un Granvelle, d'un Renard, d'une Marguerite de Parme ou d'un Guillaume d'Orange, c'était l'irréductible opposition d'intérêts sociaux et de systèmes politiques inconciliables qui se manifestait durement. 
PHILIPPE II ET LA FRANCHE-COMTÉ

Étude d'histoire politique, religieuse et sociale.

Troisième partie. La Comté et la révolution des Pays-Bas

Chapitre XIII

La mission de Moron

$\underline{\text { Retour à la table des matières }}$

Dans leurs mémoires sur la révolution des Pays-Bas, Viglius et Hopperus notent tous deux comment les seigneurs, vers 1564, se prirent d'une belle passion pour le bien public. Vaillamment, on les entendait dénoncer les abus de la justice, le gaspillage des finances, le désarroi de toute l'administration ; et, les critiques faites, ils proposaient le remède : augmenter le nombre des conseillers d'État, mettre « en iceluy autres dix ou douze chevaliers et seigneurs principaux, révérez et respectez par le peuple, en leur donnant semblablement autorité sur tous les consaulx, tant de justice, des finances que d'autres. » En d'autres termes, les nobles d'épée réclamaient pour eux tout le gouvernement et qu'on leur subordonne la bourgeoisie de robe. - Mais en même temps, Viglius et Hopperus notent que le zèle réformateur des grands maîtres se faisait plus vif en matière de finances et qu'à ce moment précis, on vit ressusciter et se réengager « divers procès et négoces », tant anciens que nouveaux, tous « au préjudice de S.M., comme du ChastelBelin et encore de la saunerie en Bourgoigne ; item, du terroir de Malines en Brabant ». Ces textes vont nous expliquer, en partie du moins, l'origine de la vaste enquête administrative et financière qui, en 1564 et 1565, émut si fortement les esprits en Comté. 


\section{I}

Le 20 avril 1564, Viglius avertissait Granvelle qu'un individu du nom de Moron venait de revenir d'Espagne aux Pays-Bas porteur de lettres du roi pour Marguerite, Orange, Egmont et Hornes, priant ces personnages de « le favoriser en ce qu'il donnera à entendre pour le prouffit de S. M. ».

Ce Moron était un intrigant - un de ces agents secondaires sur qui déjà Quiclet nous a renseignés. D'origine savoyarde - son nom l'indique - il figure comme garde-robe sur l'état de la maison de Charles-Quint au moment de la retraite à Yuste. Mi-diplomate, mi-espion, il s'était employé au service du duc de Savoie Emmanuel-Philibert, du roi d'Espagne Philippe II, peut-être même, avec une éclectisme non désintéressé, du roi de France Henri Il. Or, soudain, on le vit en Espagne et en Flandre se faire le promoteur de réformes administratives, judiciaires et surtout financières dont il promettait au souverain les plus louables effets.

De ses projets, les uns s'appliquaient aux affaires flamandes. Moron remontrait, au dire de Viglius, que « jusques icy l'on a mal entendu les affaires d'Estat et mesmes en ce du vin et aultres choses; mettant en avant plusieurs moyens de nouvelles impositions lesquelles, si fussent si practicables comme il luy semble, nous n'aurions guère à faire de l'accord des aydes des estatz... Ung aultre moyen mect-il en avant, de se servir des biens des gens d'église; et Dieu sait avec quel zèle cela vat ». Mais c'était surtout aux affaires comtoises que le Savoyard appliquait sa critique. Il faisait, ajoutait le bon Viglius, « une grande exclamation de la mauvaise conduicte de la saulnerie de Bourgogne, et que, audit pays, se trouvent aultres saulneries qu'on debvroit rnectre en pratique et dont S.M. prouffiteroit merveilleusement. Après, il parle aussi du rachapt des terres engaigées en Bourgongne et à vil pris, et vouldroit que Monsieur le Prince [Guillaume d'Orange] allast par delà pour, ès choses susdites, mectre l'ordre requis. »

Qui avait inspiré à Moron un tel zèle ? Qui l'avait documenté - si le mot n'est pas trop ambitieux - sur les affaires comtoises, suffisamment du moins pour qu'il en pût parler et étourdir de sa faconde les mal renseignés ? Il faudrait pour en juger connaître le détail de la vie et des relations du personnage. Mais notons 
d'abord que le moment choisi était opportun. En 1562, le 26 août, Philippe avait signé des lettres d'institution à Dole d'une Chambre des comptes provinciale. De réinstitution plutôt ; à la fin du XVe siècle déjà, pareille compagnie avait fonctionné dans la capitale du Comté ; mais en 1500 on l'avait supprimée ; la Chambre des Comptes de Lille avait été chargée, à ses lieu et place, de l'examen des comptes et de la gestion du domaine dans les trois bailliages. Seulement, Lille était loin. La distance imposait annuellement aux officiers de finance comtois de longs, périlleux et coûteux voyages. Les Lillois d'autre part connaissaient mal la situation du Comté et le domaine en souffrait. Pour toutes ces raisons, Philippe, en 1562, institua donc deux maîtres, deux auditeurs, un clerc non signant et un huissier-concierge que deux Lillois, le conseiller maître Clément et le greffier Vincart, vinrent installer à Dole.

Ces deux officiers se livrèrent sur place à diverses enquêtes. Ils remarquèrent et notèrent divers abus, rapportèrent aux Pays-Bas tout un dossier sur les finances et le domaine du Comté. Il y avait là de quoi étayer les assertions sans doute vagues de Moron ; aux observations des deux délégués de 1562 les arguments du Savoyard vinrent s'ajouter - et l'envoi d'une mission d'enquête en Comté fut décidé bientôt par Marguerite de Parme. Saisi de l'affaire, le Conseil des finances appela auprès de lui le conseiller au conseil de Flandre Jacques Hessele ; celui-ci avait déjà été délégué à Dole lors de l'affaire Quiclet et c'était à lui qu'on pensait confier la nouvelle mission décidée au milieu de mai 1564. Mais les délibérations, les préparatifs se prolongèrent. Finalement, Hessele resta aux Pays-Bas et, à la fin d'août, ce furent, sous la conduite du procureur Jean de Brune, les deux Lillois Clément et Vincart qui partirent : on leur avait adjoint, « pour mener le chariot », messire Guillaume de Moron, chevalier.

Or, à tous ces préliminaires, Guillaume d'Orange avait pris un intérêt très vif. Lorsqu'il avait recueilli l'héritage de son cousin René, si le Parlement de Dole, par arrêt du 17 avril 1545-46 lui avait bien relâché toutes les terres et seigneuries comtoises du défunt, il avait retenu cependant, pour l'Empereur et en son nom, les seigneuries dites du partage du Château-Belin et, à la Saunerie de Salins, ce que l'on nommait le "partage d'Auxerre ». A cette retenue, Guillaume ne s'était pas résigné. Il avait protesté, et un procès s'était engagé devant le grand Conseil de Malines. Le prince ne s'en désintéressait pas ; il suivait l'affaire de près et la faisait suivre. Granvelle accuse quelque part Renard d'avoir, lorsque le procès était 
en discussion devant le Conseil privé, trahi au profit du prince le secret professionnel et pris des notes pour lui au cours des débats, afin de lui signaler les points faibles de ses mémoires. Dans ces conditions, une mission envoyée en Comté avec pouvoir de se faire ouvrir les archives, d'étudier les documents et en particulier ceux de la Saunerie, était une bonne aubaine pour le prince s'il y faisait adjoindre un agent tout dévoué. Or, cet agent, il l'avait sans peine rencontré en Moron.

D'autre part, la mission n'était pas dénuée d'importance politique. Si toute l'administration de la Comté était, comme l'avait écrit Renard à Philippe, aux mains de Granvelle et de ses créatures ; si receveurs, trésoriers, gruyer et pardessus se trouvaient parents, amis ou clients des Perrenot; si des abus pouvaient être dénoncés dans leur gestion, des malversations révélées, des scandales découverts - quel coup droit au prestige, à l'autorité du cardinal ; quel succès pour ses ennemis, pour MM. de Rye et leur clientèle, pour tous ceux qui de leurs voeux appelaient une prise effective du gouvernement par Guillaume de Nassau ?

\section{II}

A la fin d'août, au début de septembre 1564, la mission partit donc et gagna la Bourgogne. Tout de suite, Moron marqua nettement ses intentions; il alla droit chez M. de Dicey et passa plusieurs jours dans son château d'Amance. Pour MM. de Rye et leurs partisans, ce fut une grande joie : partout, ils répandirent le bruit que la mission avait pleins pouvoirs de tout vérifier et de tout contrôler ; qu'entre autres questions, elle trancherait souverainement les débats toujours pendants entre le magistrat de Dole et le lieutenant de Marc de Rye, la Villette; que d'énormes scandales allaient être découverts, les principaux officiers de la Saunerie suspendus, de telles économies réalisées qu'il ne serait plus besoin de voter dorénavant des dons gratuits ; surtout, que la plus-value du domaine serait consacrée à réaliser le voeu de toute la noblesse pauvre, à entretenir une force permanente d'hommes d'armes et de chevau-légers qui procurerait des commandements, des soldes, des pensions aux gentilshommes oisifs et peu fortunés. 
C'étaient des vantardises, inutiles et maladroites. La bourgeoisie comtoise, d'abord émue, se rassura bien vite lorsqu'elle connut la véritable teneur de la commission départie à Moron et à ses collègues. Elle devait consister, plus modestement, à examiner de près l'état du domaine, celui de la grande Saunerie, de la gruerie et de la monnaie de Dole, avec pleins pouvoirs pour se faire renseigner soit par les officiers compétents, soit par les fiscaux, soit par le Parlement. Des débuts de Moron, il ne resta qu'un mauvais souvenir. Son origine savoyarde et la nationalité flamande des enquêteurs qui l'accompagnaient n'étaient pas déjà pour plaire à des Comtois. Le bruit qu'il visiterait, lui étranger, les fortifications de Dole et qu'il trancherait, lui Savoyard et client de Marc de Rye, les différends des Dolois et de la Villette, Savoyard également et lieutenant du même Marc de Rye s'il se trouva faux en définitive, n'en irrita pas moins le sentiment national des bourgeois de la province. Enfin, maladroitement, Moron s'aliéna M. de Vergy. Au lieu de l'aller voir, de l'entreprendre, de le gagner s'il pouvait à sa cause, il ne se dérangea même pas pour lui remettre en mains propres les lettres de crédit qu'on lui avait données. Le plan qu'il avait imaginé n'était sans doute pas mauvais : ruiner dans la bourgeoisie même le crédit de Granvelle en frappant, en persécutant les fonctionnaires qui se rattachaient à lui ; exciter d'autre part et rallier plus encore autour de MM. de Rye et du prince d'Orange la noblesse pauvre, jalousant la bourgeoisie : avec de l'habileté, de la souplesse, on aurait pu sans doute y parvenir. L'humeur brouillonne, la fatuité bavarde des « meneurs du chariot » ne devait aboutir qu'à lasser tout le monde.

\section{III}

Les enquêteurs s'étaient mis à la tâche. A Dole, au début d'octobre, ils avaient longuement interrogé les fiscaux. Puis ils s'étaient enquis des divers officiers de la monnaie de Dole. On se plaignait de longue date, en Comté, de l'insuffisance des frappes, du peu de diligence d'un personnel non spécialisé et même, à l'occasion, de ses malversations. Néanmoins, au dire de Granvelle, les enquêteurs ne trouvèrent rien à reprendre de ce côté. Ils passèrent alors à l'examen des comptes de la grande Saunerie. Le 27 octobre ils étaient à Salins : Granvelle à cette date y signalait leur présence à Viglius et notait soigneusement qu'ils continuaient de prendre 
leurs instructions chez M. de Dicey : le bon seigneur, à cette occasion, était luimême allé « tenir ménage à une sienne nouvelle acquisition, à deux petites lieues de Salins », et les commis y avaient séjourné quatre jours à ses côtés.

C'était une administration compliquée que celle de la Saunerie. Dès le XIVe siècle, la politique des comtes de Bourgogne avait été de concentrer le plus possible entre leurs mains les salines éparses en Comté - de s'assurer le monopole du sel. Les sources les plus riches et les plus abondantes se trouvant à Salins, leur effort avait tendu progressivement à ne laisser subsister qu'elles et, réserve faite des petites salines de Saulnot et de Soulce, deux usines seules, au temps de Philippe Il, subsistaient en Comté, à Salins : le Puits à Muire du Bourg-Dessous et la grande Saunerie.

Possédé par des rentiers - ecclésiastiques ou laïques - le Puits était un établissement privé ; le souverain avait seulement sur lui les droits que lui conférait la possession d'un certain nombre des 419 quartiers 26 celles 3/4 que se partageaient les actionnaires - les "parsonniers ». Certes, sans se lasser, les comtes avaient tenté de mettre la main sur cette active Saunerie. Mais leurs entreprises avaient toutes échoué. Les rentiers seuls avaient la haute main sur l'administration et la gestion du Puits, et lorsque chaque année, au mois de janvier, ils se réunissaient en séance générale ou « répons », le prince, représenté par le trésorier de la grande Saunerie, n'avait droit qu'à une voix, tout comme le plus petit de ses coparsonniers. Il n'en allait pas de même à la grande Saunerie, sans doute, le souverain ne possédait pas tous les quartiers : il en détenait les trois sixièmes, contre un sixième à divers seigneurs et deux au prince d'Orange. Mais il avait la haute main sur l'administration et la gestion de l'établissement. C'était lui qui nommait non seulement le pardessus, à la fois chef du personnel et de l'exploitation, juge d'un tribunal spécial pour les affaires de sel, président enfin du conseil de Saunerie - mais encore les principaux officiers que le pardessus surveillait de haut.

La tâche de tous ces officiers était complexe. Cela, non seulement parce que la fabrication même du sel était difficile et compliquée : les opérations étaient nombreuses, sur lesquelles veillait un personnel très spécialisé, préposé à l'entretien des puits, au fonctionnement des machines élévatoires et de leurs moteurs à chevaux, à la cuisson des muires dans les différentes bernes, à la réception, au paiement et à la comptabilité des énormes quantités de bois que dévorait l'usine ; mais encore parce que, le sel une fois produit, retiré des chaudières et aggloméré en 
pains ou salignons de différentes marques, sa répartition et sa vente entraînaient toute une série nouvelle d'opérations minutieuses, définies soigneusement par de longs règlements. Une trentaine d'officiers, personnages d'importance, tous qualifiés de nobles hommes ou d'écuyers, gravitaient autour du pardessus, à la Saunerie, et régnaient sur un peuple de menues gens, ouvriers, hommes de peine, commis qui souvent les suppléaient et desservaient leurs emplois.

Ce personnel touchait des gages dérisoires. Le taux en avait été fixé par Jean sans Peur et n'avait pas varié depuis. Le Portier, le mieux payé de tous les officiers, ne touchait que 601 . est. par an, et le Clerc Vendeur de la Porte Oudin, le moins favorisé, devait se contenter de 171.18 s. 4 d. est. De là, beaucoup d'abus nécessaires, inévitables. Non seulement les officiers jouissaient largement de toutes les prérogatives attachées à leur charge ; non seulement ceux qui étaient logés à la Saunerie se faisaient délivrer, gratuitement ou presque, leur bois de chauffage, leur lumière souvent, en plus des meubles et ustensiles de bois fabriqués pour eux à la Saunerie même ; mais inévitablement, ils cherchaient dans des pratiques plus ou moins régulières des accroissements de gain que les envieux volontiers dénonçaient. Dans la vente des vieux fers, des menus charbons, du sel d'extraordinaire surtout, ils trouvaient aisément prétexte à des accords, à des marchés avantageux pour eux sinon pour le souverain. Du haut en bas de l'administration des Salines, depuis le pardessus qu'on accusait souvent de faire vendre à son profit des charges de sel qui ne provenaient pas toutes de libéralités officielles, jusqu'aux charretiers et distributeurs du sel d'ordinaire, qui Couramment revendaient avec bénéfice les salignons achetés par eux à Salins, ou encore en cédaient illicitement des quantités notables à des contrebandiers comtois ou étrangers, c'était ainsi toute une série de menues pratiques frauduleuses, que la complication même d'une comptabilité en plusieurs parties rendait assez difficiles à constater.

Or, la grande Saunerie de Salins était, au milieu du XVIe siècle, un véritable fief de la famille Perrenot. Le 27 septembre 1534, Nicolas Perrenot avait été nommé pardessus par Charles-Quint. Au mois de septembre 1550, son fils Thomas - M. de Chantonnay - lui avait succédé dans cet office. Comme lieutenant, Nicolas avait choisi son propre père, Pierre, le châtelain d'Ornans ; puis, en mars 1537-38, à la mort de Pierre, Guyon Mouchet, seigneur de Château-Rouillaud, qui précisément venait de devenir son gendre. Guyon Mouchet à son tour avait pris un lieutenant : Guillaume Amyot, écuyer salinois, d'une famille toute dévouée aux 
Granvelle ; enfin, depuis le 10 décembre 1546, le Trésorier de la Saunerie était Bonet Jaquemet, l'un des hommes de confiance de Nicolas et d'Antoine Perrenot. On comprend dès lors pourquoi, aux Pays-Bas, Moron faisait une si grande « exclamation » de la Saunerie - pourquoi, dès avant son départ, il proposait tout net de déporter pour un an les trois principaux officiers de la Saunerie «afin de mieulx cognoistre la vérité ». De fait, à Salins même, une fois surmonté l'embarras des premiers jours devant la complication de la comptabilité et de l'administration, l'attitude des commis fut nette. A en croire Jaquemet, ils n'entendirent que des témoins à charge et provoquèrent les délations en faisant luire aux yeux de qui les aiderait le transfert des offices détenus en si grand nombre par les Perrenot.

\section{IV}

En même temps, sur un autre terrain, les commis poursuivaient une campagne analogue. Aux termes de leur charge, ils devaient examiner l'état du domaine, rechercher les entreprises faites à son détriment, noter les poursuites que depuis trente ans les fiscaux auraient dû intenter de ce chef. Le programme était minutieux ; mais Moron, volontiers, l'aurait résumé d'un mot : inquiéter le cardinal et ses frères au sujet de leurs "gagières ». Nous avons vu comment au début du règne de Philippe II, Apremont, Gendrey, Jonvelle, Scey-enVarais, Soye, Rochefort, Quingey, Santans, Vercel, Saint-Aubin, puis Vennes et Usier, toutes terres domaniales, se trouvaient aux mains de seigneurs, comtois ou étrangers, qui en percevaient les revenus, les uns à titre de récompense, les autres en garantie de quelque prêt, certains enfin en solde d'opérations financières avec le Trésor. Or, dès le début, Moron s'était élevé contre ces engagères ; il proclamait bien haut la nécessité de racheter les domaines ainsi concédés, et se faisait fort, grâce à ces rachats et à une gestion sévère, de faire rapporter annuellement au domaine cent mille florins de plus-value ; on sait à quel usage il vouait d'avance ces fonds.

Aussi, dès leur arrivée en Comté, les commis y firent-ils lancer un mandement ordonnant production de tous les titres d'aliénation et d'accensement des biens domaniaux. Et ils se mirent à compulser de près les dossiers de la Chambre des Comptes. Seulement, de même qu'au sujet de la Saunerie, Moron s'était vanté 
d'écraser les Perrenot, de même, à propos des « gagières », il laissa entendre que le rachat serait, pour eux, un coup terrible. C'était une erreur. Certes, Granvelle exagérait lorsqu'il déclarait à Marguerite, en décembre 1564, que lui et ses frères ne tenaient que deux gagières : Scey-en-Varais et Apremont. Le cardinal n'aurait dû oublier ni Gendrey, qui avait suivi le sort d'Apremont ; ni la moitié de Rochefort achetée, en 1548, par Nicolas Perrenot aux Laubespin et passée à Laurence Perrenot sa fille, ni même Vennes, accordé en viager par Philippe Il a Ferdinand de Lannoy. Mais il restait vrai qu'aucune de ces seigneuries n'avait été donnée directement par le souverain à Nicolas Perrenot ; elles avaient été achetées par lui à de précédents engagistes ; surtout, si l'on rachetait les gagières, la mesure atteindrait, plus que les Perrenot, d'autres détenteurs de biens domaniaux : le cardinal citait, non sans malice, le prince d'Orange et le comte de Pont-de-Vaux. A ce dernier, dont la veuve possédait Quingey, il aurait pu ajouter les d'Andelot, qui jouissaient de Jonvelle; Ant. de Canoz, qui tenait Santans ; Précipiano, Gérard de Watteville, François de Peloux, qui respectivement exploitaient Soye, Usier et Vercel. Qu'il s'agit du domaine ou de la Saunerie, la mauvaise foi de Moron était évidente - quels que fussent d'ailleurs les abus commis.

\section{V}

Cependant, la besogne des enquêteurs n'avançait guère. Moron, avec ses vantardises dénuées d'effet, commençait à lasser les moins difficiles. Il s'était définitivement mis à dos M. de Vergy; le 15 novembre 1564, Bave n'avisait-il pas Granvelle que les enquêteurs, depuis plus de six semaines en Comté, ne s'étaient pas encore présentés au lieutenant-gouverneur? Le cardinal, de son côté, manoeuvrait habilement. Trop fin pour laisser voir qu'il se sentait visé, il faisait de celui qui, supérieur aux petites tracasseries, s'employait généreusement à faciliter la tâche des commis dans l'intérêt supérieur du service. En dessous, il ne perdait pas une occasion de rallier ses partisans et de ramener à lui l'opinion publique ; on le vit de reste aux États de décembre 1564.

Lorsque, le 4, le conseiller au Parlement Grandjean, devenu conseiller au Conseil privé, ouvrit la session au nom du souverain et exprima le désir d'obtenir 
le vote « d'une bonne somme, comme de six-vingt mille francs, payables à bref terme », le cardinal n'eut garde d'aller à l'assemblée. Il s'y jugea suffisamment représenté par ses beaux-frères Lannoy et d'Achey, par les deux Mouchet, et une foule d'amis et de créatures. Marc de Rye, d'ailleurs, n'y alla pas non plus : il était malade, et c'était en vain qu'il avait réclamé la remise de la session. Mais ses partisans y furent en bon nombre, avec, pour guide et guide malencontreux, le frère du défunt seigneur de la Chaux: Guillaume de Poupet, l'abbé de Baume-lesMoines.

On entendit d'abord des lettres courtoises de Guillaume d'Orange. Le gouverneur du Comté y protestait de son dévouement aux habitants et aux intérêts du pays. Lettres que d'aucuns, écrit Granvelle, «baptisarent pleines de gluz »; présentées par le juriste flamand Stratius devenu, de professeur à Dole, bailli général des seigneuries de Chalon, elles ne firent pas grand effet sur l'assemblée, et ce fut seulement lorsqu'on aborda le chapitre des récompenses que les passions contenues s'émurent soudain.

Une somme de 20000 fr. avait été votée pour être distribuée aux meilleurs serviteurs de la Comté. Une liste provisoire comprenait, dans l'ordre, le prince d'Orange ; son lieutenant, M. de Vergy ; Granvelle ; son frère Chantonnay, pardessus de la Saunerie; Guillaume de Poupet; Ferdinand de Lannoy et Jean d'Achey, seigneur de Thoraise, chevalier d'honneur au Parlement, les deux beauxfrères du cardinal ; le premier président Pierre Desbarres - ces quatre derniers en leur qualité de bons personnages ; enfin le conseiller Grandjean, délégué du roi aux États ; le président Viglius et le secrétaire d'État Bave. Aussitôt, l'irascible abbé de Baume-les-Moines protesta. Dans la Chambre du clergé, il s'éleva violemment contre la longueur d'une liste qui ne contenait tant de noms, disait-il, que pour restreindre la part du prince d'Orange ; il fit une violente sortie contre M. de Chantonnay, «son plus cruel ennemi » et qui n'avait que faire d'être récompensé par les États de Bourgogne pour des services rendus au roi en ambassades ; il déclara nettement que M. de Vergy n'avait aucun droit de figurer sur la liste, puisqu' « il n'estoit gouverneur, mais M. d'Orange »; enfin, il récrimina contre le mauvais rang où on l'avait placé, sans tenir mieux compte de ses trente années d'excellents services.

Attaques maladroites : elles permirent aux granvellistes de reconquérir d'un coup tout leur prestige et de se donner aisément le beau rôle. Ferdinand de Lan- 
noy, averti des attaques de Guillaume de Poupet, se rendit aussitôt en Chambre du clergé et y prit la parole. Il fit, devant l'abbé, muet et tête baissée, un éloge bien senti du cardinal et de son frère Thomas, qui n'en étaient pas à compter leurs services ni à les rendre en vue de récompenses ; il s'éleva vivement contre « aulcuns petitz galandz » qui tâchaient d'exciter le prince d'Orange contre lui-même et ses amis ; enfin, d'un grand air de générosité, il requit ses auditeurs de bien vouloir exclure de la liste le cardinal, M. de Chantonnay, Jean d'Achey et lui-même, afin d'une part d'augmenter la récompense du prince d'Orange, de l'autre de distribuer de menues sommes aux gentilshommes les plus nécessiteux. Ainsi, Ferdinand de Lannoy se révélait diplomate supérieur et digne de son beau-frère.

Ce fut un triomphe. On vota aussitôt $8000 \mathrm{fr}$. au prince d'Orange et 6000 à François de Vergy. Neuf commis, payés 50 fr. chacun, furent nommés pour répartir les 6000 fr. restants; et le frère de Marc de Rye, M. de Balançon, eut beau se lever devant le jour et s'en aller de maison en maison « avec la lanternette » pour "gaigner voix pour ses amys »: on donna $800 \mathrm{fr}$. à Viglius, 800 au président Desbarres, 800 à Grandjean, rien du tout au pauvre Guillaume de Poupet qui s'en alla furieux et tomba malade de déconvenue ; le reste, distribué entre une multitude de gentilshommes besogneux, servit à les rallier à la cause de Granvelle et de ses parents : n'était-ce pas à leur désistement qu'ils devaient cette précieuse aubaine?

"D'hommes d'armes, de chevaux légers ni d'aultres choses », de tous les beaux projets qu'exposait Moron et que Marc de Rye devait développer aux États, il ne fut fait mention. Par contre, on se plaignit fort, non seulement en Chambre des villes, mais en celle des nobles, de l'ingérence de Moron - un sujet du duc de Savoie qui avait porté les armes contre son maître au service du roi de France, puis à nouveau retourné sa casaque - dans les affaires militaires du Comté, et Ferdinand de Lannoy déclara tout net que s'il venait jamais dans sa place de Gray, il saurait le recevoir comme il convenait. Enfin, les États n'ayant voté que 50000 fr. au lieu de 120000 que demandait le roi, Granvelle ne manqua pas, dans ses lettres, d'insinuer que la faute en était sans doute aux bavardages du Savoyard : il avait tant prédit une plus-value énorme du domaine grâce à ses réformes, que les députés confiants avaient jugé inutile de saigner davantage un pays épuisé. 


\section{VI}

A cette date cependant, Moron n'était plus en Comté. Il était reparti aux PaysBas dans les derniers jours de novembre, afin d'obtenir de plus amples pouvoirs et notamment le droit d'ordonner des arrestations sans recourir au Parlement de Dole. Il devait en même temps proposer la substitution, pour les Salines, de l'amodiation à la régie directe, la vente ou mise en ferme des offices qui n'étaient pas vénaux jusqu'alors; le retrait des terres domaniales engagées ; enfin, l'obligation pour tous les sujets, nobles ou non, de produire les titres et d'établir l'origine de leurs biens-fonds. D'ailleurs, à peine arrivé aux Pays-Bas, il y reprit son ancienne attitude, se remit à visiter le prince d'Orange, Egmont et les seigneurs, attaquant le cardinal avec plus de violence que jamais.

Mais là-bas aussi, les temps étaient changés. Tandis que les commis, en Comté, se heurtaient à des résistances croissantes, Moron rencontrait de vives oppositions. Lorsqu'il vint demander le droit de suspendre le pardessus et les principaux officiers de la Saunerie pour trois ans ; de se saisir de tous leurs comptes et papiers ; de traduire leurs personnes, le cas échéant, non devant le Parlement, mais « par deçà » ; lorsqu'à propos du domaine il sollicita le pouvoir exorbitant de saisir sans débats les biens domaniaux qui seraient détenus sans titres : si le Conseil des finances, docile à ses suggestions, approuva, paraît-il, ces étranges demandes, Viglius et Hopperus en signalèrent l'énormité et s'enquirent au Conseil qui était ce Moron et d'où provenait son zèle ?

Granvelle, mis au courant, ne chômait pas non plus. Il écrivait billets sur billets au roi, excitant sa méfiance en lui déclarant que les commissaires avaient travaillé pour le seul prince d'Orange ; que leurs enquêtes avaient le seul but de renforcer à Salins la position du prince ; que ce dernier parlait même de s'y rendre à son tour, et de revendiquer l'entière propriété de la grande Saunerie. De même, lorsque Moron, las de ne rien obtenir aux Pays-Bas, s'embarqua au début de 1565 pour l'Espagne, le cardinal fit tenir à Gonzalo Perez une lettre de PhilibertEmmanuel «monstrant peu de contentement de ceux de Rye » et qualifiant Moron « du plus grand huguenot qui soit en France ». Fit-il mieux encore ? Toujours 
est-il que, peu après son arrivée, Moron, en septembre 1565, fut pris par l'Inquisition, et, son procès dûment instruit, brûlé vif comme hérétique. Dans une lettre du 28 septembre à Chantonnay, Granvelle conte l'aventure. Il ajoute que les «renardistes » comtois, ceux de Vesoul où résidait le trésorier Renard, frère de Simon, et ceux d'Amance, c'est-à-dire MM. de Rye, prétendaient que le cardinal avait tout mené : quelques granvellistes d'Espagne auraient, d'après eux, convié Moron à un banquet, puis, l'ayant «mis en propos » sur les affaires de foi, l'auraient subtilement amené à en parler « un petit plus avant » qu'il ne convenait. «Et sur ce, fut troussé », ajoute le narrateur, sans juger à propos de confirmer ou de démentir la version « renardiste ». Qu'il y eût eu part ou non, il jugeait évidemment le tour de bonne guerre.

Peu à peu, du reste, des nouvelles favorables lui venaient d'Espagne. A la fin de novembre 1564, Renard était arrivé àMadrid. Assez froidement accueilli par Philippe, il avait espéré un moment reprendre son crédit en s'appuyant sur Egmont, venu de son côté en mission près du roi. Tant que le comte séjourna à Madrid, Renard fut sans cesse «à ses oreilles » - et lorsqu'il repartit, le pria de demander pour lui l'autorisation de rentrer aux Pays-Bas. Le roi refusa tout net et, en mai 1565, décidant la reprise de l'affaire Quiclet, lui donna trois juges, tous trois Espagnols. Le cardinal, prévenu, se recueillit pour un dernier effort, ramassa toutes les charges qu'il prétendait connaître contre son adversaire, et les envoya à Gonzalo Perez. L'espoir lui revenait : il sentait, il savait que le désir du roi était de retenir près de lui Simon Renard, de faire traîner son procès en longueur et d'éviter ainsi qu'il ne retournât mettre au service d'Egmont et des seigneurs flamands ses talents de diplomate et, comme on disait alors, d' « homme de lettres ».

Peu lui importaient, dès lors, les bruits que, sans se lasser, les renardistes comtois, crédules les uns, habiles les autres, ne se lassaient pas de faire courir. Le président du Parlement de Dole, Pierre Desbarres, entrait-il en agonie, le 7 juin 1565 : aussitôt, ils faisaient « bruire » à Dole « que le Renard est jà président ». Quelques mois plus tard, alors que l'ancien ambassadeur était toujours retenu par son procès, et au lendemain même des lettres adressées du bois de Ségovie, le 20 octobre 1565, à Marguerite, il était des naïfs pour déclarer encore « que le Roy avait fait présenté à Renard pour être chancelier en Espaigne, président de Flandres ou de Bourgoigne à son choix ». A côté, La Villette, le lieutenant de Marc de Rye à Dole, se portait candidat à l'office de gruyer, vacant par la mort d'un beau- 
frère de Granvelle, Claude le Blanc. Et Claude-François de Rye s'en allait en Flandre, au dire de Morillon, "pour penser être mareschal de Bourgogne ». Le cardinal laissait dire et laissait faire le temps : il savait bien qu'il travaillait pour lui.

De même, en l'absence de Moron, la commission d'enquête avait continué son oeuvre - avec moins de fracas, il est vrai. De Salins, elle était revenue à Dole. Elle s'était informée longuement du personnel des bailliages, des avocats et procureurs fiscaux, s'ils recevaient argent ou présents des plaideurs. Le 25 avril 1565, l'avocat d'Amont, Claude Belin, signalait à Granvelle son passage à Vesoul, « où ils n'ont trouvé ce que aucungs désiroyent ». Il se moquait, en passant, de la lourdeur flamande: "Quelques esprits bourguignons eussent autant promptement pour le moins négocié que lesd. Srs », et il avertissait le cardinal que les enquêteurs avaient pris comme " ministre », pour faire " amas de tesmoings », le jeune Renard, - c'est-à-dire Louis Renard, le frère de Simon, trésorier de Vesoul. Mais leur besogne touchait à sa fin et perdait d'ailleurs, peu à peu, de son caractère agressif et politique du début. Sans doute, il y eut à la mission un épilogue judiciaire. Au mois d'octobre 1565, sur le vu des papiers rapportés par elle, le lieutenant des Salines, Guyon Mouchet, beau-frère de Granvelle, fut mandé en Flandre par Marguerite pour répondre aux accusations dirigées contre sa gestion. Avec lui durent partir les trois clercs des rôles que l'enquête avait surtout chargés. Les commis furent mandés, confrontés avec les officiers de Salins : Guyon Mouchet sut très rapidement se faire mettre hors de cause ; mais il n'en fut pas de même des trois clercs : le 26 janvier 1565-66, Marguerite de Parme avertit le Parlement de Dole qu'elle les renvoyait devant lui ; elle lui transmettait toutes les pièces et informations des commissaires à leur endroit et désignait trois personnages pour les suppléer à leurs frais durant les poursuites. Comme l'écrivait Morillon, si l'on cherchait à leur «jeter le chat aux jambes », c'était en désespoir de cause et parce qu'on « ne pouvait mordre sur le pardessus et son lieutenant ». Le prince d'Orange avait suivi l'affaire avec un intérêt passionné ; mais, malgré ses efforts pour faire suspendre ou même destituer les inculpés, il n'avait pu forcer la main à Marguerite. Le procès, d'ailleurs, traîna en longueur : deux ans plus tard, dans une lettre du 29 janvier 1567-8, le duc d'Albe sera obligé de le rappeler au souvenir du Parlement. 


\section{VII}

Ainsi se terminait sans éclat l'enquête si bruyamment entreprise par Moron. On aurait tort, pourtant, d'en nier l'importance. S'il n'en résulta point le discrédit, la ruine, le déshonneur des Perrenot, elle n'eut pas moins une double série de conséquences positives.

D'abord, pour l'administration, l'enquête fut le point de départ d'importantes réformes. Moron avait bien pu être partial, et les commis, en leur qualité de Flamands, lents et méticuleux ; outre qu'ils connaissaient déjà le Comté, ils purent, au cours de leur mission, s'initier à nombre de questions délicates. Peut-être ne fut-il pas mauvais qu'ils eussent pris, dès le début, une attitude de méfiance et de dénigrement systématique. Leur seule présence contraignit la bourgeoisie d'office à une observation plus stricte des règlements. Pour ne donner qu'un exemple, estce pur hasard si, au début de 1565, les uns après les autres, trésoriers et receveur général du Comté se voient convoqués à Dole par la Chambre des Comptes et si cette compagnie, instituée depuis trois ans, se rappelle qu'aux termes de ses lettres elle en doit exiger caution, comme de tous les comptables de parties du domaine ?

Menues conséquences : il y en eut de plus graves. Le 26 janvier 1565-66, Marguerite signait une ordonnance réformatrice de la Saunerie qui se référait nettement, dans son préambule, aux travaux de Brune, de Clément et de Vincart. En même temps, frappée des arguments de ces commissaires, la gouvernante mettait à l'étude l'amodiation de la grande Saunerie ; elle soumettait au Parlement deux mémoires rédigés l'un pour, l'autre contre la régie directe. Et sans doute, cette initiative n'aboutit pas tout de suite : les réformes ne se réalisaient pas si vite en Comté sous le régime espagnol ; il n'en est pas moins vrai que les arguments de Moron et de ses adjoints ne furent pas omis lorsque, en 1601, les archiducs décidèrent d'affermer la Saunerie.

Même chose pour le domaine. Non seulement la présence des commissaires stimula le zèle des maîtres des Comptes ; non seulement leurs avis provoquèrent l'ouverture d'une vaste enquête sur les aliénations de parties du domaine ; mais encore, l'idée fondamentale de Moron : le rachat des "gagières », fut, avec des 
tempéraments, mise à exécution par l'ordre du souverain. De 1564 à 1598, une seule seigneurie de l'ancien domaine, Jussey, fut donnée en engagère ; par contre, six des terres engagées soit par Charles-Quint, soit par Philippe lui-même, à ses débuts, furent rachetées tour à tour et réintégrées ; la mort de Philippe Il n'arrêta pas le mouvement ; il devait se continuer sous les archiducs.

Constatations que l'on pourrait multiplier. Ce ne sont pas seulement les terres, les seigneuries, que les agents du domaine, pendant tout le dernier tiers du XVIe siècle, s'efforceront patiemment de reconquérir. Vis-à-vis des rentiers de la grande Saunerie, des parsonniers du Puits à Muire, copropriétaires du souverain dans ces deux établissements, ils s'inspireront de principes analogues, tendront au monopole avec persévérance. Les grandes enquêtes de 1564 et 1565 semblent amorcer toute une série de mesures qui aboutiront, en 1570, à la réunion dans les mains du roi, des trois partages de la grande Saunerie - plus tard à la concentration, dans les mêmes mains, des quartiers disputés du Puits à Muire.

Enfin, ce n'est pas sans doute par une coïncidence purement fortuite qu'une importante réforme de l'institution bailliagère s'accomplit en Comté en 1565 et 1566 - au lendemain même de la mission flamande. Non, sans doute, que cette réforme n'eût d'autres antécédents que les remarques et les conclusions des enquêteurs flamands sur les officiers des trois bailliages. Entre autres, les États de Bourgogne, à la session de juillet 1561, avaient porté plainte de la mauvaise administration des bailliages, et le Parlement, à la session de 1564, semble avoir fourni sur la question une sorte de rapport. Mais à l'accomplissement de la réforme dès longtemps désirée, les commissaires flamands ne purent évidemment qu'aider. Elle consista dans la création, en chaque siège de bailliage, d'un lieutenant général, alors qu'auparavant on ne comptait qu'un lieutenant général par bailliage, assisté, dans les divers sièges, de lieutenants particuliers ou locaux ; c'est-àdire que la compétence des lieutenants particuliers fut accrue et qu'ils reçurent, en matière judiciaire, même pouvoir que les anciens lieutenants-généraux dont ils prirent le titre. Du reste un seul lieutenant conserva, après comme avant la réforme, le droit de se présenter devant la Cour, à la rentrée de la Saint-Martin, et de lui présenter les doléances du bailliage : ce fut, pour Amont, le lieutenant de Vesoul ; pour Aval, celui de Montmorot; pour Dole, celui de Dole. Chacun d'eux, d'ailleurs, fut assisté dans son siège (à Vesoul, à Montmorot, à Dole) par un lieutenant local. 
Ainsi, qu'il s'agît de la gestion du domaine ou de l'administration des bailliages, les mêmes idées de régularisation, de concentration, de centralisation, se manifestaient en Comté et se traduisaient dans les faits au cours de ces années troublées, mais fécondes. Sans doute, la transformation qui, lentement, s'opérait ainsi, n'avait rien d'anormal, rien d'imprévu. A quelques années de distance, l'évolution des institutions comtoises répétait celle des institutions françaises, et il serait puéril de la rapporter à l'initiative, au labeur d'une commission d'enquête. Mais ce qui reste vrai, c'est que de telles modifications furent hâtées peut-être et facilitées par l'effort des conseillers flamands, dont il ne faut pas juger l'oeuvre du seul point de vue d'un Renard ou d'un Granvelle. Et déjà, il convient de noter que le gouvernement de Philippe II avait réussi à tourner au profit de ses vues propres des querelles particulières et des rivalités de personnes ; ne se trouvaient-elles pas collaborer finalement à l'oeuvre de centralisation absolutiste que le fils de Charles-Quint entendait poursuivre aussi bien en Comté que dans les Pays-Bas?

Mais en même temps, la mission de Moron avait accru les haines et, comme disait Granvelle, les «partialités ». Elle avait souligné, par le parti pris même de Moron, l'antagonisme qui opposait la pauvre noblesse d'épée à la riche bourgeoisie d'office. La noblesse même, elle l'avait divisée en deux camps : d'une part, les Rye et leurs clients, quelques écuyers d'aventure, besogneux, violents et prêts à tout ; de l'autre, François de Vergy, irrité du manque d'égard des commissaires, gêné de la situation mal définie qu'il occupait vis-à-vis du prince d'Orange, maintenu en relations cordiales avec Granvelle par les soins et les attentions d'un Ferdinand de Lannoy ou d'un Jean d'Achey. Entre les deux partis, la grosse masse des nobles comtois, hésitants, troublés, sentant sous sa forme actuelle le conflit mal engagé et se réservant pour l'avenir. Situation d'autant plus grave qu'aux querelles de personnes, d'autres sources de conflit s'ajoutaient chaque jour : c'étaient au Comté, c'étaient à Besançon, les progrès rapides et inquiétants de la Réforme. 
PHILIPPE II ET LA FRANCHE-COMTÉ

Étude d’histoire politique, religieuse et sociale.

Troisième partie. La Comté et la révolution des Pays-Bas

\section{Chapitre XIV}

\section{Besançon et la réforme de Franche-Comté}

$\underline{\text { Retour à la table des matières }}$

Comment Charles-Quint avait su s'attacher fortement la petite république bisontine ; comment, grâce à la souplesse et à la vigilance de ses agents, il s'était attiré l'affection de ces Bisontins qui, en 1536, ordonnaient des prières pour lui chaque jour à midi, et, en 1566, dressaient contre leur maison de ville l'effigie du souverain regretté - nous l'avons vu plus haut. Ces résultats étaient d'autant plus remarquables que la politique impériale avait rencontré des adversaires nouveaux : les partisans bisontins des idées de Réforme.

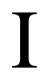

Que ces idées de bonne heure se soient implantées dans la cité, rien d'étonnant sans doute. Besançon n'était point alors une ville morte. Non seulement elle avait participé au mouvement de renaissance économique qui marque en Comté les premières années du XVIe siècle ; mais, grâce en partie aux concessions de Char- 
les, elle était devenue une place commerciale assez active. Dotée du droit de monnaie ; embellie de constructions nouvelles ; munie de routes d'accès meilleures, elle avait vu les étrangers prendre de plus en plus le chemin de ses foires. En 1534, son magistrat, non sans habileté, avait su attirer les Génois « qui avoient délaissé faire leur résidence ès lieux de Lyon et Moulinest et se tenaient en la ville de Lons-le-Saulnier »; depuis cette époque, une colonie de Génois, de Lucquois, de Milanais et de Florentins n'avait cessé de demeurer en la ville et d'y exercer, outre le négoce et la banque, diverses professions manuelles ou libérales. Hôtes remuants, turbulents, prompts à la main : on avait dû leur interdire, le 5 mai 1560, de porter l'épée dans les rues ; ils n'en avaient pas moins adopté la cité ; quelquesuns à la longue en devinrent citoyens et, les foires ayant un instant été délaissées par eux vers 1560, ils réclamèrent à nouveau, en 1565, l'autorisation de tenir banque en ville sous l'autorité de leur consul.

Ces Italiens n'usaient pas seuls de l'hospitalité bisontine. De nombreux Allemands, des Strasbourgeois, des Bâlois, des Wurtembergeois, la traversaient aussi pour se rendre à Lyon, ou y séjournaient au temps des foires. Des Genevois encore, des Vaudois, des Neuchatelois s'y rencontraient avec des Flamands ou des Bourguignons du Duché. Les auberges étaient nombreuses qui hébergeaient ce monde disparate, et, par moments, une foule cosmopolite se pressait dans les rues étroites de la cité, au long des boutiques d'armuriers et d'orfèvres du pont de Battant, ou sur la petite place de l'église Saint-Pierre.

Les Bisontins, de leur côté, ne restaient pas tous sédentaires. Sans doute, une partie de la population était, par tempérament et par métier, obstinément fixée au sol natal et ne le quittait jamais. Comme la plupart des cités du temps, Besançon était encore une ville à moitié agricole. Non seulement, dans son enceinte même, entre le Doubs et la rue des Granges d'une part, la rue Saint-Vincent et la rivière de l'autre, derrière les maisons alignées en étroite bordure, s'étendaient de vastes clos plantés de vigne, d'immenses jardins potagers et fruitiers; non seulement maint bourgeois y possédait étables et tect à porcs, et le berger communal rassemblait chaque matin pour la mener paître la « proye » du quartier - mais, sur la rive droite, à Arènes, à Charmont, à Battant surtout, six mille vignerons menaient dans de petites maisons à caves profondes leur vie casanière et laborieuse.

Race énergique, vivante, originale. Ces durs ouvriers, d'humeur indépendante et frondeuse, qui, chaque matin, dès le petit jour, se pressaient aux portes, la hotte 
sur le dos, attendant le moment de gravir les pentes raides de Bregille ou de Trochâtey, pouvaient bien par leur turbulence, leurs démonstrations collectives et violentes, les manifestations redoutées de leur confrérie de Saint-Vernier, exciter la méfiance du magistrat : de même que la vigne était « la vraie subsistance de la cité », ces vignerons, petits propriétaires ou métayers, fournissaient les authentiques représentants du vieil esprit local, méfiant et hostile à tous les étrangers, passionnément attaché aux anciennes traditions. Sur leur masse, les idées de Réforme n'eurent point de prise ; ils formaient dans la ville un noyau solide qu'elles n'atteignirent, qu'elles n'entamèrent jamais.

Mais, réserve faite de ce groupe bien défini de sédentaires, la population bisontine - habitants et citoyens - était, dans ses diverses classes, d'humeur plus voyageuse. D'abord, elle comprenait un prolétariat mouvant de mendiants, de vagabonds, d'oisifs : ouvriers sans ouvrage, paysans déracinés surtout, expropriés de leurs domaines ruraux et venus à la ville chercher un refuge. Dans une lettre au magistrat de la cité, en date du 7 décembre 1555, les chanoines signalent la présence en ville de «beaucoup de pauvres gens, dont les aulcuns sont chargez de femmes et d'enfants et néanmoins ne labourent ou travaillent, ainsi au contraire sont continuellement réduictz en lieux publics comme ès portes de ceste cité et ailleurs, où ils jouhent tout ce qu'ils peuvent avoir et quelquesfois sommes d'argent beaulcoup plus grandes que leurs biens ny leur labeur ne les leur peuvent fournir ». Pratiques à réprimer, population à surveiller de près, car - la phrase est bien curieuse et bien expressive - de cette vie oisive, de ces habitudes de fainéantise, de jeu et de mendicité «provient, avec le temps, le désir d'entrer en pensementz de choses nouvelles ».

Pareillement, les gens de métier inquiétaient les chanoines, et non sans raison. Tous n'étaient pas citoyens, ni Bisontins de naissance ou de long établissement. Beaucoup étaient étrangers. A chaque page presque on rencontre, dans les registres de délibération ou de comptes, au XVIe siècle, mention de couturiers ou de chaussetiers génois, de tanneurs savoyards, de Français ou Flamands de conditions diverses. Contingent flottant, celui-là également, et qu'au dire du Chapitre, il fallait tenir à l'oeil : beaucoup de ces ouvriers ne provenaient-ils pas de villes suspectes ? Moins inquiétants, sans doute, les autres : les Bisontins d'abord, citoyens ou habitants, connus souvent de père en fils dans leur quartier, et même cette multitude de compagnons qui, dans les campagnes comtoises, ne cessent d'affluer 
vers Besançon au milieu du siècle, y louent boutiques, s'y font passer maîtres et souvent sollicitent leur admission à la cité. Mais ceux-là encore avaient voyagé, fait leur tour de France aux années de jeunesse, couru de ville en ville élargi leurs idées et hanté des suspects.

Et c'étaient encore les marchands, les petits, en relations d'affaires fréquentes avec Genève, Lausanne, Neuchatel d'une part, Bâle et Lyon de l'autre ; les gros, ces « nouveaux riches », qui, à l'exemple de leurs collègues des Pays-Bas et en leur qualité de parvenus, se trouvent disposés à faire bon marché de la tradition tous ceux qui « en prospérité de leurs gaing et marchandise luxurient en curiositez nouvelles ». Grands voyageurs, ces brasseurs d'affaires. Cosmopolites par nécessité, sans cesse à courir les pays étrangers ; dès leur jeunesse, aux universités d'Italie ou d'Allemagne, ils envoyaient leurs fils apprendre les langues et se préparer à leurs courses futures.

Enfin, au sommet, les rejetons des grandes familles bourgeoises qui constituaient la vraie noblesse de la cité. Dirigés par leurs pères vers les carrières de robe - tous, aux années de jeunesse, connaissaient la vie errante de l'étudiant, faisaient leur tour de France, d'Allemagne et d'Italie ; puis, plus tard, devenus cogouverneurs, dans des voyages d'affaires, des missions politiques et diplomatiques en Allemagne, en Flandre, en Espagne, à Rome même, reprenaient contact avec les étrangers. Ainsi, dans la population variée de la petite république, les moyens d'accès ne manquaient pas aux idées nouvelles.

\section{II}

Aussi favorables à la Réforme, les conditions politiques et municipales.

D'abord, depuis que les Bisontins avaient arraché à leur archevêque les franchises et les libertés qu'ils gardaient jalousement, la lutte n'avait pour ainsi dire pas cessé entre le prélat et ses anciens sujets - non plus qu'entre ceux-ci et les ecclésiastiques de la cité. A chaque instant, des conflits de juridiction surgissaient. Besançon était le siège d'un tribunal à compétence étendue : l'officialité diocésaine. Procès intéressant la conscience, exécution des promesses faites sous serment ; matières spirituelles ou réputées telles (mariages, dîmes, bénéfices) ; pour- 
suites pour dettes; actes de dernières volontés surtout : l'official connaissait de toutes ces questions et sa juridiction était naturellement une source de difficultés perpétuelles avec le magistrat. De plus, des trois tribunaux concurrents qui fonctionnaient à Besançon, le plus éminent, la Régalie, était à l'archevêque : il en constituait le juge et les officiers. Deuxième source de conflits, les cogouverneurs jalousant le prélat et cherchant à lui enlever ses droits. Enfin, les immunités ecclésiastiques, notamment celles du chapitre, solidement établi sur la pente de SaintJean, derrière la Porte-Noire, autour des deux cathédrales - troisième cause de querelles, de procédures tragico-comiques entre les bourgeois et les ecclésiastiques.

Que ces querelles se soient faites plus âpres au moment même où les idées de Réforme commençaient à se répandre en Allemagne, en Suisse, en Alsace ; qu'attirant l'attention sur les moeurs plus ou moins fâcheuses du clergé local, elles aient fourni d'arguments les partisans des doctrines nouvelles, nous le savons depuis longtemps. Une sorte de rapport, destiné à l'Empereur et rédigé en 1534 par le secrétaire de la commune, Lambelin, dénonçait violemment la mauvaise conduite des ecclésiastiques vivant à Besançon « en nombre d'environ quatre cens, qu'est à peu près la quarte partie d'icelle ». Ils sont, déclarait le rapporteur, " gens dissoluz, vivants en toute lubricité » et de si petite littérature ou érudition en la Sainte Écripture « que l'on n'en treuvera aulcung, ou bien peu d'eulx, souffisant à prescher la parole d'icelluy »; ils font « négociations, marchandises, vendaiges et transactions » des sacrements pour pouvoir entretenir leurs chevaux, leurs meutes, leur "friande cuisine", sans compter «habondance de jeunes commères ». Bref, c'étaient, énumérés par Lambelin au nom du corps de ville, les griefs ordinaires des réformateurs contre le clergé catholique. Griefs justifiés : aux preuves fournies, d'autres aisément pourraient être ajoutées ; quant au parti que purent tirer les réformés et du manque d'autorité des ecclésiastiques ainsi discrédités, et des luttes passionnées de la municipalité contre l'archevêque et le chapitre on le devine, à lire une lettre de Calvin à Viret datée de Genève, le 23 avril 1537. A ce moment même, l'archevêque, le fougueux Antoine de Vergy, venait de quitter Besançon à grand fracas, de transférer à Gy sa cour d'officialité et d'excommunier en partant tous les citoyens. Calvin, aussitôt averti des événements, avait songé à en profiter ; et il annonçait à Viret l'envoi sur les lieux d'un de ses disciples, Jean de Tournay, pasteur d'Aigle, chargé de voir de ses yeux si « la moisson 
n'était pas mûre » et si quelque fissure ne permettrait pas à la Réforme de faire irruption.

Non moins que ces événements, la constitution même de la cité pouvait encourager de pareilles espérances. "La forme », comme dit Gollut, en était « populaire ». Chaque année, le 24 juin, au jour de la Saint-Jean-Baptiste, tous les citoyens, « de quelque qualité qu'ils fussent », se rassemblaient, se groupaient respectivement sous les sept bannières des sept quartiers, et réunis à l' " Hôtel Consistorial », élisaient de leur nombre vingt-huit notables, quatre par quartier. Les notables à leur tour, tiraient de leur sein quatorze gouverneurs : ceux qui, toute l'année, allaient administrer la petite république. L'État bisontin avait donc deux Conseils : l'un, élu au suffrage universel des citoyens ; l'autre au suffrage restreint. Elle connaissait à la fois les congrès et les referendums : les congrès, car dans toutes les occasions difficiles les gouverneurs «s'agrégeoient» les Vingt-Huit ; les référendums, car, «si le faict méritait une approbation générale », tout le peuple devait être assemblé à peine de 60 sols contre les défaillants. Mais à l'ordinaire, les Quatorze exerçaient seuls le pouvoir. Point de président nommé ; chaque semaine, à tour de rôle, un nouveau membre occupait le fauteuil ; siégeant les lundi, mercredi et vendredi, les élus tranchaient les questions d'administration et de police, instruisaient et jugeaient les procès civils et criminels avec le concours du «personnage d'autorité », de «l'homme de lettres » que le Comté entretenait auprès d'eux ; seul, dans certains cas, en matière civile, le Conseil aulique pouvait réformer les décisions de leur tribunal souverain.

On comprend combien cette organisation, qui, répartissant le pouvoir entre plusieurs, le rendait moins redoutable et d'autre part laissait à tous l'espoir d'arriver sinon au Conseil des Quatorze, du moins à celui des Vingt-Huit, devait favoriser les progrès de la Réforme. Cela, d'autant que, presque dès le début, en vertu même de la situation géographique et des relations économiques et politiques de Besançon, c'est le calvinisme qui menace la ville. Si jusqu'en 1560, et même plus tard, dans les édits du magistrat de Besançon comme dans les ordonnances du Parlement de Dole, le seul nom de Luther et de luthériens désigne encore les Réformés, l'expression depuis longtemps avait perdu son sens originel. En 1523, ce sont évidemment les erreurs propres de Martin Luther que le chapitre métropolitain de Besançon condamne. En avril 1524, ce sont bien des luthériens, de langue allemande par surcroît, "Germani », dont Érasme, dans une correspondance 
curieuse, signale la présence dans la ville libre ; mais dès 1524, c'est Farel, réfugié de Meaux à Bâle puis à Montbéliard, qui inquiète la ville et le magistrat par ses prédications ardentes aux frontières du Comté ; et si Farel procède de Luther, c'est par l'intermédiaire de Briçonnet et de Lefèvre d'Étaples. Sans doute, en février 1529, les chanoines s'émeuvent grandement, lorsqu'ils apprennent "1'inconvénient survenu à Basle, ayant totalement délaissé notre Sainte Foy, ... avec menasses de vouloir pouser oultre et venir jusques à Besançon »; mais bien plus s'émeuvent les gouverneurs l'année suivante, lorsqu'à la suite des violentes prédications de Farel, les Neuchatelois, saisis d'une plainte des chanoines de leur collégiale, envoient, selon une vieille coutume, trois de leurs bourgeois prendre les « entrevues » à Besançon et solliciter du magistrat son avis sur l'émeute du 15 octobre 1530. C'est un moine de France, ce curieux François Lambert, né à Avignon d'une famille d'Orgelet et devenu prédicateur général des Observantins, qui, en 1525, adresse aux Bisontins le premier appel en faveur des idées nouvelles ; c'est un Français, un moine également, le religieux Minime Coquillard, de Reims, qui, dégradé et exécuté en février 1528, est à Besançon le premier martyr de la religion nouvelle. Aussi, dès son premier séjour à Genève, dès avril 1537, Calvin déjà s'inquiète de Besançon ; à partir de cette date, sous le nom de luthéranisme et de secte luthérane, c'est lui, sa doctrine et ses émissaires que les gouverneurs, pendant un quart de siècle, trouveront en face d'eux et devront combattre.

Or, on l'a noté souvent : propagandes luthérienne et calviniste diffèrent profondément, non par les procédés seuls, par la rigueur d'une doctrine définie dans ces «formulaires communs d'instruction pour les petits enfants et les rudes du peuple », qu'excella à répandre et à rédiger l'Église de Genève - mais encore, et surtout, par l'attitude des deux réformateurs vis-à-vis de l'État et du pouvoir civil : l'un se contentant, avant tout, de prêcher ; l'autre, avec son énergie et sa logique coutumières, inspirant à ses disciples le souci de fonder un nouveau type d'Êtat de subordonner, comme dans la république théocratique de Genève, à l'autorité religieuse l'autorité civile et laïque.

De là, dès le début, le caractère politique que tendent à revêtir à Besançon les manifestations de l'esprit réformé. D'abord avec Lambelin et ce curieux intrigant, Simon Gauthiot d'Ancier, dont Nicolas Perrenot, vigilant, fit échouer toutes les tentatives ; ensuite, à diverses reprises, lors des élections annuelles du magistrat et notamment en 1540 : le menu peuple, excité par quelques gros patriciens ga- 
gnés aux idées nouvelles, montra par une rébellion qu'il était prêt, lui aussi, à exploiter à son profit personnel et au profit de ses idées le naturel antagonisme des citoyens pauvres contre le patriciat urbain - du «popolo minuto » contre le «popolo grasso ».

\section{III}

De tels incidents trouvaient en Comté un retentissement immédiat : c'est que, Besançon protestant, la situation aurait été singulièrement grave pour la province entière.

D'abord, ç'aurait été la rupture brusque de l'unité morale d'un pays dont, malgré tout, la cité impériale ne se distinguait pas radicalement. Surtout, ç'aurait pu être la fin de sa demi-indépendance - la confiscation de sa nationalité. Si Besançon, en effet, allait à la Réforme, elle se heurterait à l'opposition violente du Comté. Celui-ci, l'entourant de toutes parts et pouvant la bloquer, était l'arbitre de ses destinées, et, seule, tout le pays environnant refusant de la suivre, la cité ne pouvait changer de religion. Mais appuyée sur une puissance capable de tenir tête aux forces comtoises, elle deviendrait libre de ses croyances ? Voilà pourquoi un parti s'y était formé, qui tournait les regards vers la Suisse et reprenait à son compte les vieux projets de partage de Louis XI, terreur de Charles-Quint, de Granvelle et de tous les Comtois.

Dans une lettre curieuse adressée à Calvin, Farel, en 1537, dénonçait la tactique des moines catholiques vis-à-vis des réformés bisontins : se trouvaient-ils devant un suspect et ne pouvaient-ils le poursuivre pour ses opinions ? vite, ils l'accusaient de trahir sa patrie et de livrer Besançon aux Suisses. La remarque est juste - mais les griefs des moines étaient, sans doute, moins imaginaires que ne voulait bien le dire le réformateur. Il n'y avait pas longtemps alors qu'un messager de Gauthiot d'Ancier, au moment où cet ambitieux se remuait le plus, avait porté un billet non équivoque aux ministraux de Neuchâtel : "Les Leuther sont là à Neuchâtel, et s'ils peuvent venir jusques à Vercel, nous sumes tous riches; car il ne fauldroit que pour ung soir de nuyt seulement prendre tous les navois qui sont chez Baulme à Besançon... pour passer grand nombre de gens et arriver au port 
dessoubz le Sainct-Esperit. » Paroles prophétiques : elles s'expliquaient d'ailleurs aisément. La Réforme venait de permettre aux Bernois des agrandissements territoriaux inespérés. En guerre avec le duc de Savoie, ils s'étaient rués brusquement sur le pays de Vaud, s'étaient rendus les voisins immédiats de la Comté. Cette proximité, ces succès militaires avaient ranimé leurs vieilles ambitions et justifiaient, avec les craintes des uns, les espérances des autres.

D'autre part, depuis très longtemps, Besançon entretenait avec ses voisins d'outre-Joux des relations étroites. Non seulement elle était comprise dans la ligue héréditaire; mais, à diverses reprises, elle avait passé avec les Cantons des conventions spéciales. En 1518, par exemple, elle avait conclu avec eux un traité de combourgeoisie valable pendant quinze ans, que Charles-Quint - alors Charles d'Autriche - avait vainement tenté de faire rompre. Il fut plus heureux, il est vrai, lorsque la question de son renouvellement se posa, en 1533 ; sur ses instances, deux gouverneurs furent dépêchés auprès de Messieurs de Berne, de Fribourg et Soleure, pour dénoncer le pacte. Mais Besançon restait en relations étroites avec les villes vaudoises, avec Nyon, Morges, Lausanne, Genève et, surtout, Neuchâtel. La constitution municipale de cette cité était calquée sur la sienne ; lorsqu'une difficulté d'interprétation se produisait, les ministraux recouraient aux bons avis des gouverneurs : c'était ce qu'on nommait « prendre les entrèves ».

Or, la Réforme avait fourni aux Suisses, surtout aux Bernois, une série de prétextes pour surveiller de près les affaires comtoises et bisontines. Ils s'étaient constitués patrons et protecteurs de tous les adhérents aux doctrines nouvelles. Pas de mois presque, aux époques troublées, où quelque lettre affectueuse ou menaçante de Messieurs de Neuchâtel ou de l'Avoyer et Conseil de Berne ne vînt rappeler aux Bisontins la vigilance de leurs bons amis et voisins. On comprend combien de telles interventions pouvaient, en encourageant ces "politiques » que Granvelle opposait aux simples « sectaires », légitimer les suspicions de ceux qui travaillaient à maintenir la Comté dans son intégrité.

Tant que Charles avait vécu, le péril avait pu être conjuré. Non sans difficulté parfois : en 1537, lorsque Gauthiot d'Ancier, aidé de Lambelin et de quelques Bisontins influents, travaillait de tout son pouvoir à de graves changements, il avait fallu l'habileté de Nicolas Perrenot pour en venir à bout. Mais, grâce à ses concessions de privilèges, à sa politique générale de bonne entente avec la ville, Charles avait pu à diverses reprises faire intervenir son Parlement dans les affaires 
de l'ombrageuse petite république. Il avait pu de même, lors d'élections décisives, envoyer dans la ville des commissaires impériaux, chargés de surveiller les opérations et de faire pression sur les citoyens. De pareils expédients soulevaient naturellement des protestations, et les interprètes les plus hardis, les traducteurs les plus énergiques du sentiment municipal humilié, c'étaient les réformés. Il est curieux de trouver, sous la plume de Farel écrivant à Calvin, une plainte véhémente contre la lâcheté des Bisontins qui permettaient au Parlement d'intervenir dans leur ville en 1540. Il les accuse de trahison comme s'il était lui-même Bisontin et se sentait atteint dans sa fierté civique. Évidemment, il n'est qu'un écho : celui de coreligionnaires dont les correspondances le mettaient au courant. Mais c'est déjà, sous sa plume, quelque chose des exhortations républicaines qu'une quinzaine d'années plus tard, un autre réformé, Antoine du Pinet, prodiguera aux Bisontins et qui de ses ouvrages passeront dans ceux de Belleforest.

Mais déjà, vers la fin du règne de Charles-Quint, la surveillance impériale s'étant ralentie, la Réforme avait repris ses progrès dans la cité libre. L'avènement de Philippe II vint les précipiter.

\section{IV}

Ici encore, le changement de souverain n'était pas seulement un changement de personnes. Si Charles-Quint, somme toute, avait réussi, c'était grâce sans doute à la souplesse de ses diplomates, mais aussi - personne n'a pris la peine de le remarquer - aux pouvoirs qu'il détenait. Empereur et comte, suzerain de la ville libre et gardien de l'ancienne capitale comtoise, il avait à Besançon doubles droits, partant doubles moyens d'action. Mais Philippe ? Au lendemain de son avènement, Besançon trouve en face d'elle, d'une part, un roi d'Espagne comte de Bourgogne, conservant dans ses murs un juge, un capitaine, un receveur ; de l'autre, un Empereur, suzerain de la cité, mais suzerain lointain, s'entendant assez mal avec le roi d'Espagne et peu porté à s'occuper d'une petite ville libre, de langue française, comme égarée dans les domaines espagnols. Le magistrat bisontin fut donc, sans grand contrôle, livré à lui-même ; le résultat ne se fit pas attendre ; en peu de temps Besançon se posa, hostile, en face du Comté. 
D'ailleurs, le Parlement de Dole ne fit rien pour conjurer cette hostilité : au contraire. Dans les dernières années du règne de Charles-Quint, entre magistrat et conseillers, les conflits s'étaient multipliés. Conflits sans motifs - ou du moins, sans motifs sérieux. En 1553, c'était de la part du Parlement une citation à comparaître personnellement, à peine de 500 livres, adressée au procureur-syndic de Besançon, à deux sergents et à deux gouverneurs de la cité, pour «indehues entreprises aux auteurs, domaines et droits de S.M. ès bois de Chailluz » - une simple question de limite, qui soulevait aussitôt un grand conflit de juridiction : ambassades au Parlement, discours orgueilleux des Bisontins, éloge de leur cité « magnifique et illustre, ayant été en grandeur et estimation passez estoient deux mil ans », d'autant plus chaleureux qu'il s'adressait à des Dolois, citoyens d'une ville sans titres d'antiquité ; répliques du substitut, déclarant ironiquement «que l'on sçavoit assez l'ancienneté... de la cité de Besançon », mais que la question n'était pas là ; procédures et citations nouvelles ; deuxième affaire greffée sur la première par les Bisontins, à propos d'un prisonnier à eux réclamé par le Parlement ; finalement, surséance, sur lettres formelles de Charles-Quint... A peine terminée cette tragi-comédie, une seconde renaissait. Le 4 juin 1554, un des huissiers du Parlement, chargé d'aller notifier aux chanoines de Besançon quelque acte de procédure, ne s'avise-t-il pas de demander aux gouverneurs la permission de s'acquitter de sa tâche ? La cour, évidemment, ne pouvait tolérer pareille démarche. Et voilà le malheureux suspendu pour trois ans, la procédure annulée, un second huissier expédié sur l'heure pour notifier à Besançon ces mesures réparatrices. Colère des gouverneurs qui, à leur tour, citent par-devant eux ce second huissier : après bien des démarches et des ambassades, un accord intervient - mais si bref ! L'année suivante, en 1555, les habitants de Tallenay, village du Comté, envoient leurs porcs au bois de Chailluz, sous la conduite de trois jeunes enfants. Aussitôt, 60 à 80 Bisontins, dûment « embastonnez d'espées, paulx et aultres bastons », se ruent sur les porcs, et les ramènent héroïquement prisonniers à Besançon. Les manants protestent : on leur rend des injures, non leurs bêtes. Et voilà de nouveau le Parlement saisi, un arrêt rendu, les Bisontins à leur ordinaire envoyant à Dole une ambassade ; les envoyés arrêtés et mis en prison - un déluge d'écritures, de rapports, de lettres au souverain et d'actes procéduriers. Événements ridicules, sans doute, mais tant de querelles et de rancunes amassées, quels qu'en fussent les motifs, créaient entre Comtois et Bisontins une atmosphère épaisse de malentendus. 
A cette époque, le magistrat n'avait guère donné lieu encore de douter de son zèle contre-réformateur. S'il avait reçu en grâce, sur présentation de lettres impériales, un des partisans de Lambellin, le libraire Richard Boissoneaul, il avait par contre, en 1553, renoncé à prendre comme recteur des écoles le célèbre Guillaume Postel, jugé peu orthodoxe ; il avait, en 1554, poursuivi plusieurs suspects : un recteur d'école, un teinturier, un tanneur, un peintre, un serrurier, un marchand, un brodeur, un vigneron, d'autres encore, qui avaient été s'établir en pays hérétique. Surtout, en 1555, avertis qu' « à la dernière diette tenue à Auspourg, a esté résolu qu'en toute la Germanie et ès villes de l'Empire sera loisible à ung chacun tenir telle loy que bon luy semblera », les gouverneurs s'étaient empressés d'aller au chapitre déclarer qu'ils s'opposeraient de toutes leurs forces - « usque ad ultimam guttam sanguinis » - à ce que, sous ce prétexte, bannis et fugitifs rentrent sans condition. Beau zèle, un peu de parade, peut-être : il pouvait en tous cas faire illusion. Or, brusquement, en 1560, une série d'événements importants vint révéler aux Comtois les progrès de l'hérésie dans la vieille cité. On sait le rôle considérable que jouèrent, au début de la Réforme, les moines prédicateurs. Le François Lambert, dont nous citions plus haut l'appel aux Bisontins, est un type excellent de ces religieux ardents qui, à force de dénoncer les abus, finissaient par se ranger au sentiment des réformés. Déjà, le premier martyr de la Réforme à Besançon avait été, en 1528, un Minime, un Rémois. D'autres moines, entre 1560 et 1562, allaient provoquer dans la ville impériale une véritable mobilisation des forces de Réforme.

Le 14 février 1559-60, l'administrateur du diocèse, le beau-frère de Nicolas Perrenot, François Bonvalot, venait à la tête d'une délégation du chapitre faire au corps de ville une requête. Deux beaux Pères prêchaient le Carême dans la cité : l'un dans la vaste et belle église des Cordeliers, l'autre chez les Jacobins, dans ce couvent de Rivotte où résidait l'inquisiteur diocésain. Or, si le Jacobin, Fr. Nicolas Garapy, était de doctrine et de parole irréprochables, le Cordelier, Fr. René Peschart, gardien de Bourg-en-Bresse, usait de si fâcheux paradoxes qu'ils se pouvaient interpréter « en deux façons contraires l'une à l'aultre ». Ne l'avait-on pas vu, le dimanche de la Septuagésime, reprendre, (à son sermon d'après-disné », 1'Évangile du jour que le matin même le Jacobin avait expliqué, « et en plusieurs passages, dire le contraire de ce que l'autre avait presché, combien il n'eust aulcunement failly ? » Par prudence, et pour ne point alimenter de controverses, on 
donna congé aux deux prédicateurs. Mais si Fr. Garapy obtint du chapitre attestation «de suis bonis fama, honore et fructuosis predicationibus » (tel était le latin dont on usait alors), Fr. René Peschart reçut du corps de ville pareil certificat « de science, dévotion et catholicité ». Après quoi il sortit de la ville, et reprit sa vie errante.

L'affaire n'était point passée inaperçue. Elle avait eu des suites à Besançon même : le 11 mars 1560, les chanoines à nouveau signalaient au magistrat la distribution de billets diffamatoires «tendans à ung scisme », la diffusion, chez plusieurs, tant citoyens qu'habitants, de bibles en français et livres prohibés, enfin le chant dans les rues, « dois l'issue du beau-père cordelier », des psaumes de David en français. Et Marguerite de Parme, avertie par la cour de Dole, écrivait aussitôt au conseil de ville une lettre pour le remercier d'avoir expulsé le Fr. René Peschart. Mais ce n'était qu'un début. Trois mois plus tard, en juillet I560, de nouvelles affaires éclataient en effet. D'abord, un Cordelier venait, le 18, raconter aux gouverneurs que « le jour de la montre du Saint-Suaire dernier », alors qu'il passait devant une maison à lui inconnue, une femme l'avait fait entrer pour boire un verre de vin. Le Cordelier but « pour l'honneur de Dieu », et d'après son dire, une conversation s'étant engagée entre lui et l'hôtesse, à un certain moment la fille de celle-ci suggéra : "Ma mère, respondez-luy ce que dit Mathieu en un tel chapitre ». Science suspecte : on emprisonna la femme et la fille. - Le 29, nouvel incident. Le conseiller François Seguin se présente au conseil avec lettres de la cour de Dole. Il expose qu'on vient d'arrêter à Salins un Français, un bonnetier, Oudot Constantin de Gentilly, près Paris, saisi « de plusieurs livres apocrifes, meschans et malheureux, composez aud. Genesve contre nostre Saincte-Foy ». Il les portait de la part de son maître, Pasquier Massier, de Genève, à un nommé Blaise Jouffroy, «faiseur de toille royée » qui habitait à Besançon «au bout du pont »; il apportait en outre des lettres commerciales à divers citoyens. On perquisitionna chez Jouffroy, mais on n'y trouva rien, « fors une payre d'heure de l'impression Jehan le Coq » qui n'était pas suspecte ; Blaise était bon chrétien et ne savait pas lire. Telles furent du moins les conclusions des gouverneurs. Elles n'empêchèrent pas la cour de Dole de faire brûler les livres d'Oudot Constantin par la main du bourreau, de le faire lui-même battre de verges depuis les halles jusqu'à la porte de Besançon et d'adjuger au plus offrant sa marchandise. Les gouverneurs décidèrent, le 17 octobre 1560, de renouveler l'édit contre les Luthériens et de passer 
revue de tous les habitants mâles de la cité, excédant quatorze ans : ils devraient jurer fidélité à l'Empereur, à la cité et à la religion catholique. La revue fut faite, du 21 octobre au 8 novembre. Et l'on remarqua qu'elle servit de signal à plusieurs départs subits d'étrangers.

Enfin, au printemps de 1561, nouveaux procès criminels. Un Cordelier, Jacques Messor, avait prêché brillamment l'Avent de 1560. Le vicaire général Lulle le retint pour le Carême suivant ; mais, le 9 avril 1561, il venait avec des chanoines trouver les gouverneurs et leur dénonçait le Cordelier comme ne cessant de vomir des injures contre le chapitre, ses traditions et ses offices : « et tellement a colloré ses propoz que plusieurs jeunes gens se sont eslevez contre lesd. de l'église comme ung tas de meschantz..., chantans les psalmes de David en François, gettans pierres contre les maisons desd. ecclésiastiques, et leur impropérans plusieurs convices et injures ». Le lendemain 10, nouvelle émeute, nouvelle démarche du clergé, nouvelles dénonciations : on renvoie, le Carême étant fini, les trois prédicateurs qui en avaient eu charge, le Jacobin, le Carme et le Cordelier, en leur remettant trois écus à chacun. Et quelques jours après, on reçoit la nouvelle que le Fr. Messor venait d'être arrêté au Comté de Bourgogne. Au départ de Besançon, il avait gagné Genève, s'y était muni de livres et de brochures, puis, déguisé en laïque, avait imprudemment repassé la frontière dans le dessein de rentrer à Besançon. Arrêté à Quingey et conduit à Dole, la cour aussitôt instruisait son affaire.

Ce fut par la ville une grosse émotion ; plus encore, en Comté. Dès avril, les chanoines avaient eu des pourparlers, par l'intermédiaire de leur trésorier, avec le président et quelques conseillers du Parlement au sujet des progrès redoutables de l'hérésie. Des lettres avaient été écrites par le chapitre à l'archevêque, au Parlement, au général des Cordeliers. D'autre part, les gouvernements d'Espagne et des Pays-Bas s'inquiétaient. Granvelle écrivait à Seld, le vice-chancelier de l'Empire, tandis que Marguerite de Parme s'adressait directement à l'Empereur, puis au Parlement, au magistrat de Besançon et à Philippe II. Le cardinal, de son côté, envoyait lettres sur lettres dans son pays natal : aux chanoines de Besançon qu'il exhortait à bien vivre « et circonspectement », à Philippe II, au chanoine Jean de la Tour. Toutes traduisaient de vives appréhensions : à Seld, Granvelle montrait ses concitoyens prêts peut-être à «se rendre Suysses », à s'aider du recès de la diète d'Augsbourg et à réclamer la liberté de conscience ; Marguerite, de son côté, enjoignait au Parlement de ne pas se laisser désarmer « par l'intercession qu'ordi- 
nairement ont accoustumez faire les voysins en cas semblable ». Il sévit en effet : le 27 août, Fr. Messor était condamné à être dégradé, puis décapité et son corps partagé en quatre quartiers qui seraient exposés aux issues de la ville.

En attendant, les troubles continuaient à Besançon. En vain l'Empereur, sur la demande de Marguerite, s'était hâté de dépêcher à Besançon un commissaire impérial, le baron de Bollwiller, qui, assisté du président du Parlement et du conseiller Fauche, était venu haranguer le magistrat à la veille des élections, en juin 1561, et exhorter les citoyens à ne choisir que de bons catholiques. Le conseil avait décidé une procession générale à Saint-Ferjeux, mais ses réponses à l'Empereur et surtout à Marguerite laissaient percer quelque impatience d'une surveillance si exacte. De même, le Parlement ayant envoyé aux gouverneurs les noms de citoyens qu'il prétendait hérétiques, il lui fut répondu que ces citoyens avaient toujours vécu en bons catholiques. Le conseil de ville n'était pas seul à manifester sa nervosité : l'un des trois prédicateurs du carême, le Carme, Fr. Nicolas Harnays, ayant déclaré dans un sermon la cité « corrompue d'hérésies », son auditoire entra en fureur ; on dut expulser le prédicateur, non sans lui demander attestation écrite que, dans ses dix mois de séjour à Besançon, il n'y avait trouvé que gens « vertueux et catholiques ».

\section{V}

Histoire monotone, dès lors. Le groupe des réformés continue ses manifestations : un jour, c'est une verrière de l'église Saint-Jean-Baptiste qu'on trouve cassée, et dans l'église même, une image de Notre-Dame de Pitié renversée ; c'est, dans la rue Saint-Vincent, une statue de Saint-Jean-Baptiste qui est abattue la nuit et jetée dans la fontaine de Battant. Les réunions se multiplient ; réunions nocturnes, contre lesquelles les gouverneurs ordonnent un «surguet » à minuit ; réunions privées, chez des artisans, chez un menuisier, François le Bourguignon, qui quitte la ville et part pour Balançon, sur les terres de Gérard de Rye. Des libelles, enfin, se colportent dans les rues, s'affichent sur les portes, - et dans le silence de la nuit, des groupes nombreux chantent à pleine voix les psaumes en français. 
En face des réformés bisontins, les contre-réformateurs comtois. Le clergé diocésain d'abord, chapitre métropolitain en tête - ce dernier mettant à dénoncer l'hérésie un acharnement où il entrait peut-être un peu de rancune. Diplomate consommé, Granvelle le redoute du moins ; à diverses reprises, il gourmande un zèle assez maladroit. Le Parlement ensuite, mettant, lui aussi, dans ses démonstrations, quelque excès, quelque ressouvenir des anciennes querelles. A l'arrièreplan, les puissances : le roi d'Espagne, Marguerite, l'Empereur, le pape même. Plusieurs fois, des commissaires impériaux ou comtois viennent à Besançon surveiller les élections, exhorter les citoyens à garder la foi. Le 29 juin 1563, un Bollwiller - le baron Jean - fait grandes doléances d'assemblées à Chamars, où l'on chantait les psaumes. Le 20 juin 1565, Antoine d'Oiselay et le conseiller Chappuis, délégués l'un par Vergy, l'autre par sa compagnie, viennent se plaindre que les psaumes se chantent partout, que le Benedicite se dit en plusieurs familles selon la forme de «ceulx de Genève », que le carême s'observe mal et que «les gens d'estouffe » de la cité n'assistent plus qu'à peine aux services divins.... Doléances monotones, elles aussi, et qui attestent seulement la marche régulière, les progrès tranquilles des nouvelles idées dans la ville impériale.

Entre les réformés et les contre-réformateurs, le conseil de ville enfin - les gouverneurs. Leur indécision, leur hésitation est visible. Sans doute, de temps en temps, ils ordonnent des poursuites. Jette-t-on à bas quelque image de piété ? Ils promettent dix écus à qui trouvera le coupable. Accuse-t-on le cordonnier Nicole " d'aucuns faits touchant le sainct Sacrement de l'aultey », ils l'enferment aux prisons de la régalie, où on le torture. Parle-t-on d'une surprise de la ville par certains étrangers, aperçus rôdant vers le bois de Chailluz : ils ouvrent une enquête, interrogent un vigneron. Mais ces mesures sont timides, effacées, modestes; point d'initiative: ils n'en trouvent que pour incriminer les moeurs du clergé local. Alors, l'énergie leur revient et la verve. Ils dénoncent sévèrement les violences du chanoine Bordet, «la vie scandaleuse de Me Guillaume Portessain et d'aultres gens d'église de ceste cité, aussy de leurs chamberières et servantes »; ils envoient au chapitre une députation demander l'expulsion des femmes suspectes du quartier capitulaire. Et s'ils repoussent énergiquement la dédicace à eux faite par Antoine du Pinet, le 18 avril 1564-65, de son traité de la Conformité des Églises réformées et de l'Église primitive, oeuvre évidente, disent-ils, « d'aulcuns malvuillans de la cité pour la tirer en hainne envers les princes » - ils répondent avec ai- 
greur aux questions indiscrètes des Comtois : «le temps, père de vérité », fera bien connaître leur zèle et leur affection au bien public....

Attitude qui irritait violemment les Comtois, on le conçoit sans peine. Connivence voulue ? indécision sincère ? tolérance ? Un peu tout cela, sans doute ; mais le fait était là : lentement, parmi les petites gens d'abord, parmi quelques riches et influents marchands ensuite, la Réforme calviniste se glissait et faisait des progrès. Besançon, ainsi, était loin d'être, dans la région, un élément de calme et de paix. La formation dans ses murs d'une petite communauté protestante active et entreprenante, l'indécision du magistrat, tiraillé entre son catholicisme traditionnel, son individualisme municipal et sa sympathie pour les Suisses, tout contribuait à troubler le pays, à aggraver les divisions. L'unité morale du Comté, et son unité nationale en souffraient. 
PHILIPPE II ET LA FRANCHE-COMTÉ

Étude d’histoire politique, religieuse et sociale.

Troisième partie. La Comté et la révolution des Pays-Bas

Chapitre XV

\section{La réforme en Comté}

$\underline{\text { Retour à la table des matières }}$

Besançon n'était pas seule à connaître l'existence et la propagande d'un petit groupe ardent de réformés : la province qui l'entourait avait vu, elle aussi, et de très bonne heure, se développer quelques groupements d'adeptes des idées nouvelles 37 .

Sans doute, leur tâche était assez malaisée. La Comté était un pays de campagne ; et l'on sait, d'une manière générale, que les milieux ruraux se montrèrent plus rebelles que les milieux urbains à l'action du protestantisme. Le paysan était très attaché à ses anciennes croyances, dont les siècles n'avaient pu transformer les manifestations extérieures, et la vieille conception d'une religion-contrat, unissant l'homme à la divinité par une sorte de pacte aux conditions précises, n'avait

37 Pour tout ce chapitre, et une fois pour toutes, nous renvoyons à l'étude spéciale et détaillée que nous avons consacrée à la Réforme en Comté, d'après les documents du fonds du Parlement, de 1523 à 1575 Febvre (L.), Notes et documents sur la Réforme et l'Imposition en Franche-Comté, Paris, 1911. On y trouvera, aux Pièces, les textes que nous alléguons - et dans l'Introduction et les Appendices, nombre d'indications précises que nous nous sommes borné à résumer ici d'un point de vue spécial. 
pas cessé de vivre en son âme. Le Comtois, d'ailleurs, est défiant, à la fois, et fidèle : défiant des « nouvelletez », fidèle aux traditions. Dans le portrait qu'il aime à tracer de lui-même, dans ses contes, ses légendes, ses devises, c'est le grand trait qu'il a visiblement à coeur de bien mettre en lumière : Deo et Caesari fidelis in perpetuo, inscrivaient sur leur maison de ville les Bisontins. Ils étaient, ce faisant, des Comtois authentiques. Il y a dans de telles devises, dans de telles conceptions collectives, une force morale.

Et puis, le pays se prêtait mal à une oeuvre méthodique de prédication et de propagande. La montagne, pendant six mois inaccessible, avec ses villages rares, ses habitations dispersées, ses populations disséminées l'été par les forêts et les pâtures, séquestrées l'hiver sous d'épaisses couches de neige, n'était point, sans doute, d'un abord facile. Dans le plat pays, comment animer, éveiller à de nouvelles conceptions la masse amorphe des paysans ? Il aurait fallu, dans des villes converties et gagnées, installer des foyers de propagande d'où auraient rayonné les idées de Réforme : mais les villes étaient médiocres, peu ou pas industrielles; l'étranger y était vite remarqué, noté, surveillé ; toutes les familles se connaissaient entre elles et s'épiaient jalousement; et qu'en masse, elles vinssent aux idées nouvelles, il n'y fallait compter : à défaut d'autres liens, l'intérêt suffisait à tenir la bourgeoisie attachée à l'Église.

Sans doute, une grande force venait à la Réforme, en Comté, de l'adhésion des pays limitrophes - de la conversion aux idées nouvelles de Bâle, de Montbéliard, de Neuchatel, Lausanne et Genève. Sur les frontières - wurtembergeoise, bâloise, neuchateloise, vaudoise - à la faveur des échanges incessants, des relations d'affaires ou même de famille, le protestantisme pouvait espérer se glisser en Comté, séduire et gagner les villages riverains : et l'événement d'ailleurs, jusqu'à un certain point, devait justifier ses espérances. Mais ce qui faisait là sa force causait en même temps sa faiblesse - puisque, pour le Comtois de Gray, de Dole, de Salins, le protestant ainsi se confondait avec l'ennemi. Français du Lyonnais, de la Bresse, du Duché, il était le descendant des soldats de Louis XI ; Suisse, l'adversaire toujours inquiétant, le voisin peu aimé et sans cesse redouté que soutenait par derrière l'ambitieux Bernois; Montbéliardais enfin, le ravisseur d'Héricourt, de Clémont, du Chatelot. Ainsi, dans l'adversaire de sa foi, le Comtois pouvait craindre l'ennemi de son pays. 


\section{I}

De bonne heure, cependant, la province connut les tentatives de la Réforme. Dès 1524, l'agitation, à Bâle, d'Oecolampade, la venue de Farel d'abord à Bâle puis à Montbéliard, ses prêches à Saint-Maimbœuf, toute cette première et vive effervescence avait ému les Comtois. Des réunions s'étaient tenues, où assistaient les principaux personnages de la province ; des députés avaient été dépêchés à Berne et à Fribourg pour les prier d'intervenir ; et la guerre des Paysans, l'irruption en Comté, par la porte de Bourgogne, de bandes armées et fanatisées que la noblesse avait dû écraser à Villersexel, en juillet 1525, avait marqué la fin de cette première période.

Quelques années plus tard, au printemps de 1528, l'exécution à Besançon d'un religieux minime, le Fr. Coquillard, rappelait le péril aux maîtres du Comté. C'est alors qu'apparaissent les premiers édits du Parlement contre l'hérésie : le «mandement défensif » du 3 mars 1528, interdisant de parler de Luther, de sa secte, de ses adhérents « et actes en dépendants »; puis, en 1532, le 15 juillet, le mandement sur les blasphémateurs établissant toute une échelle de peines, les blasphèmes étant cause de la colère céleste.... Mais ces armes, pour l'instant, restaient inemployées, et les Comtois se bornaient à surveiller jalousement leurs frontières, du côté de Montbéliard ou de Neuchatel.

Ce fut seulement en 1535 qu'éclata vraiment la première crise de répressions et de poursuites en Comté. Ce qu'elle fut, nous l'avons dit ailleurs : la persécution, provoquée par les moines, opérée par la cour de Dole, fut tournée à la fois contre la Renaissance et contre la Réforme. C'était le moment où Pierre Toussaint, s'installant à Montbéliard, y reprenait avec passion l'œuvre interrompue de Farel, le moment aussi où les Bernois, en guerre contre le duc de Savoie, se ruaient brusquement sur le pays de Vaud et y introduisaient la religion nouvelle. Dès le 7 septembre 1535, un édit du Parlement interdisait de se servir dans les écoles de livres hérétiques comme ceux de Mélanchthon, d'Ulrich de Hütten. D'autres édits suivaient, énuméraient les prohibitions, déterminaient les pénalités. La distinction en même temps se précisait entre le rôle, les moyens d'action, la compétence de l'In- 
quisition diocésaine d'une part, du Parlement de Dole et de ses «placards » de l'autre. Et pendant qu'à Besançon le secrétaire d'État Lambelin se voyait juger et exécuter, maîtres d'école, humanistes, médecins, humbles ouvriers des lettres salutaires, obscurs partisans de la Renaissance classique et de la Renaissance chrétienne étaient dénoncés, inquiétés, traqués sans relâche par des moines fanatiques; à Dole, des habitants suspects devaient s'enfuir en Suisse et s'expatrier. C'était pendant trois ans sur la province un lourd et dur régime de compression intellectuelle.

Nouvelle tourmente, sanglante celle-là, en 1549 et 1550 . Cette fois, des têtes tombent. Il ne s'agit plus, comme en 1535, d'inquiéter de doux et inoffensifs Érasmiens, des lettrés épris de la clarté des lettres antiques, de la douceur d'un christianisme humanisé - mais de frapper, d'intimider des partisans résolus des idées de Réforme. Aussi des victimes expient leurs convictions : à Gray, en mai 1549, un Français, Quentin Bussi, coupable d'avoir porté à diverses fois des propos scandaleux « contre Dieu, notre mère Sainte Église, la Saincte Foy Chrétienne et Catholicque, le Sainct Sacrement de l'aultel et la Saincte Croix »; à Dole, le 21 novembre 1549, Pierre de Pradines ; à Saint-Amour, le 8 février 1550, deux prêtres, Jean Bodet de Vosbles et Étienne Cervat dit Barbier, de Saint-Martin-duMont en Bresse : on les dégrade avant de les décapiter ; à Lons-le-Saunier, en mai 1550, un domestique, Louis Conod, de Morges en Savoie ; à Dole encore, le 21 juillet 1550, le libraire et mercier d'étain Jean le Mid. Les édits se multiplient, plus minutieux, plus menaçants : le 29 mars 1550, contre les mauvais livres ; le 4 mai, contre les traductions des livres saints en français. Des missions d'enquête sont organisées par les soins du Parlement de Dole. En février 1550, deux conseillers, un fiscal et un juré au greffe enquêtent à Saint-Amour. Pendant l'été, à deux reprises, un substitut d'abord, le procureur général ensuite, avec un conseiller et un fiscal, visitent les villes du bailliage d'Aval et procèdent à des inculpations. D'innombrables poursuites sont entreprises, à Saint-Amour, à Moirans, à Orgelet, à Lons-le-Saunier, à Saint-Julien, villes et bourgades situées à la fois dans le rayon d'action de Genève et de Lyon. Jusqu'en 1553, avec l'exécution à Dole d'un avocat, Paris Panier ; jusqu'en 1554, avec celle, à Gray, d'un réfugié français, Nicolas du Chesne, les persécutions sanglantes se prolongent.

Crise terrible qui épouvantait les suspects, repliés sur eux-mêmes, cachant livres et papiers, vivant, comme dit Cousin, d'une pauvre vie chétive d'escargots 
apeurés. Alors, il fallait soigneusement renoncer à toute étude, à tout travail intellectuel, à tout enseignement libre ; alors, il fallait se cacher pour écrire une lettre en Suisse ou en Allemagne ; il fallait en retrancher toute allusion aux événements contemporains, vivre dans l'ombre, dans le silence, dans la crainte, s'interdire toute parole un peu haute, tout geste un peu large, toute pensée un peu indépendante. Les plus catholiques des écrivains, un Morisot par exemple, détracteur acharné des Colloques d'Érasme, parsemant ses Dialogues de prières au Christ, invoquant le nom de Jésus presque à chaque ligne, étaient obligés, comme un Gilbert Cousin, plus hardi et plus suspect, de chercher des protecteurs pour leurs écrits, pour leur pensée, et notamment de recourir à la bienveillance du vicaire général de l'archevêque, l'Espagnol Antoine Lulle, un homme intelligent semble-t-il, mais qui parfois devait lui-même céder au courant, et suivre ces moines violents et fanatiques dont il ne pouvait s'empêcher de flétrir les excès. On comprend que, pour vivre d'une telle vie, accepter de telles épreuves et les subir sans défaillances, il ait fallu des âmes d'une trempe particulière, des coeurs fermes et de grands caractères : leur rareté relative dès lors s'explique et se justifie.

\section{II}

Philippe II devenu comte, la surveillance ne se relâcha point - tout au contraire. Un des premiers actes du nouveau souverain fut, le 7 août 1556, de mettre sous sa protection particulière ces Cordeliers qui menaient si vivement la lutte contre l'hérésie. Par patentes enregistrées au Parlement, il fit du président de Bourgogne leur gardien. En même temps, il prenait contre un des plus grands esprits du siècle, le jurisconsulte Dumoulin, une mesure de rigueur dont l'annonce produisit une vive émotion.

Dumoulin, dans l'hiver de 1555, rentrait d'Allemagne en France. Georges de Wurtemberg-Montbéliard, l'arrêtant au passage, le pria de bien vouloir examiner à Dole quelques procès qu'il avait pendants devant le Parlement. Le grand juriste, dans cette ville de juristes, trouva l'accueil le plus magnifique ; une première fois, cédant au voeu unanime des conseillers, des bourgeois et du magistrat, il consentit à professer à l'université trois leçons solennelles. Une seconde fois, après quel- 
ques jours de captivité que la brutalité maladroite du comte Georges lui fit subit à Blamont, il fut reçu en triomphe dans la vieille cité comtoise et dut, sur la prière des États alors réunis à Dole, commencer un cours suivi sur le titre de verborum obligationibus. Une foule recueillie se pressait au pied de sa chaire ; la ville, pour le retenir, s'imposait les plus lourds sacrifices ; les disciples enthousiastes, comblant le maître de cadeaux et de prévenances, organisaient en son honneur une visite des Salines ; déjà, tous rêvaient pour Dole la gloire d'enchaîner quelques mois un tel hôte, lorsque brutalement une lettre de Philippe II vint couper court à leurs espérances et les mettre en demeure d'expulser « incontinent et sans délay » Dumoulin, " pour estre ses oeuvres assez suspectz et sa doctrine non trop convenable à l'institution de jeunes gens ». La lettre, datée du 12 octobre, fut ouverte le 12 novembre; le soir même, le major Seguin et le lieutenant de la Villeneuve étaient chargés de voir Dumoulin et «par bons moiens, honnestes et gratieux, le faire retirer et aussi tous artisans étrangers, faisant observer l'ordonnance faite aux hostes de révéler ceulx qui arrivent loger en leurs maisons ». Ainsi le Parlement, en la généralisant, cherchait à atténuer l'odieux de la mesure. Mais lorsque, le 13 décembre 1556, un capitaine vint, cerner le logis de Dumoulin et lui intimer l'ordre de partir dans les trois jours, il y eut à l'université et dans la ville une véritable émeute. Le jurisconsulte dut faire une dernière leçon devant un auditoire tout frémissant et d'autant plus indigné que la mesure royale aboutissait à servir contre Dole les intérêts rivaux de Besançon : Dumoulin, en effet, acceptait de s'y rendre.

Les conseillers, dès lors, n'eurent garde de négliger les affaires religieuses. Le 7 septembre 1556, c'est un déséquilibré, Claude Marchant, de Saint-Vit, qu'ils poursuivent et condamnent à cinq ans de bannissement, 300 livres d'amende et l'amende honorable en chemise, cierge aux mains, pour un coup d'arquebuse lâché avec blasphèmes sur un crucifix. Le 10 mai suivant, c'est un libraire de Lyon, demeurant à Chalon, Simon Mugnier, qu'on trouve saisi aux halles de plusieurs livres « plains de blasphemes, hérésies et erreurs luthériennes, composés par Calvin et aultres »; les livres sont brûlés, le libraire condamné à crier merci sur un échafaud, battu de verges par l'exécuteur et banni à perpétuité. C'est ainsi toute une série d'affaires plus ou moins importantes, de poursuites pour blasphèmes et mauvais propos, pour détention de livres prohibés, pour représentation d'une farce pleine de reparties suspectes et scandaleuses, pour prêches douteux d'un ecclésiastique. L'amende honorable, le bannissement perpétuel, terminent ordinairement 
ces procédures ; il s'y ajoute rarement une peine plus rigoureuse, et, par exemple, pour les blasphémateurs, l'ablation partielle de la langue. Malgré ces poursuites cependant, il apparaît nettement qu'en Comté comme à Besançon, de 1555 à 1560, il se produit dans la répression de l'hérésie - et peut-être dans sa manifestation une accalmie, un répit. Lassitude des magistrats ? défaillance des propagandistes ? préparation lente, obscure, d'un effort décisif ? On se rallierait volontiers à cette dernière hypothèse, lorsqu'on voit avec quelle ardeur, avec quel ensemble, de 1560 à 1564, les militants de la Réforme reprennent leurs tentatives.

Ce sont d'abord trois étrangers, porteurs de mauvais livres et de mauvais propos. L'un, François Poisier, d'Orléans, venant de Genève, est trouvé saisi, entre autres livres « en français » prohibés, du "catéchisme dud. Genève, des pseaulmes en ryme, d'ung Nouveau Testament aussi en françois et de certaine ymage et effigie faite par dérision de notre Saint-Père le Pape » ; décapité à Dole le 4 juillet 1560, après destruction de ses livres et mutilation de sa personne, - on lui coupe la langue. Le second, Antoine Vyal, un Savoyard des environs de Chambéry, muni d'un Nouveau Testament couvert de « damnables apostilles » et convaincu d'avoir dogmatisé, est exécuté sept jours après, le 11, au gibet de Dole. Le troisième, enfin, est ce bonnetier ambulant, Oudot Constantin, qui se dirigeait vers Besançon, portant dans sa balle des livres hérétiques ; il put s'estimer heureux d'être simplement condamné à la fustigation et au ban perpétuel. La série continue, du reste. En août 1561 succombe le cordelier Fr. Messor, puis, six mois plus tard, le colporteur breton Olivier Amont. C'est une surveillance rigoureuse, continue, des étrangers : soudards allemands ou messins surpris en train de manger chair un vendredi ; voyageurs barrisiens ou lorrains trouvés porteurs de livres prohibés ; prêtres d'orthodoxie douteuse, l'un renvoyé à son juge ordinaire, l'archevêque de Lyon ; l'autre condamné par défaut au bannissement et à la confiscation ; colporteurs encore, allant de Genève en Lorraine ou en France, et fanatiques iconoclastes, tous connaissaient le poids de la justice comtoise, et le Parlement, s'il méritait les remerciements d'un Philippe II, répondait également aux désirs de rigueur d'une Marguerite de Parme. 


\section{III}

Un fait frappe cependant. Tous ces accusés, toutes ces victimes, sont des étrangers et, généralement, des gens de peu. Sur quinze condamnés à mort dont nous possédons les dossiers, de 1537 à 1564, nous comptons trois prêtres, un cordelier, un libraire, un avocat, un domestique, deux colporteurs. Sauf l'avocat, Paris Panier, ce sont tous gens sans attaches profondes en Comté, sans relations bourgeoises; et sur les quinze, sept sont incontestablement des étrangers. Or, n'y avait-il pas dans les villes de Comtois suspects ? N'y avait-il pas, en Comté même, diverses catégories de partisans des idées nouvelles ?

Sans doute, contre les réformés de Moirans, d'Orgelet, de Saint-Amour, de Saint-Julien, de toutes les petites bourgades du bailliage d'Aval limitrophes de la Suisse, le Parlement en 1549, en 1550, prend des mesures d'apparence énergique. Mais en réalité, ce sont les accusés eux-mêmes qui, dans presque tous les cas, s'infligent leur peine ; la cour de Dole, en les bannissant perpétuellement par défaut, ne fait qu'enregistrer la décision des inculpés, renonçant à leur pays pour ne pas renoncer à leur foi. Mais les condamnations effectives sont très rares. Exception faite des deux prêtres décapités en 1550 à Saint-Amour, on ne trouve que deux ou trois condamnations à l'amende, pour mauvais propos ; par contre, on note des acquittements. Souvent d'ailleurs, les affaires traînent interminablement. Des jeunes gens de Pesmes, inculpés d'avoir joué une farce hérétique en 1558, ne sont jugés qu'en 1574 - soit seize ans après leur inculpation. Le cas n'est pas exceptionnel. Un notaire, Catherin Baratte, est accusé, au début de 1552, de transgression des édits sur la foi. C'est seulement en 1557 que l'instruction de son affaire est terminée. Son fils, Adrien Baratte, mis en cause une première fois en juin 1559, n'est condamné (par défaut) au ban perpétuel que deux ans après, en 1569. Pendant ces longs délais, l'inculpé, relâché sous caution, vivait à sa guise et attendait tranquillement le rappel de sa cause - qui parfois ne revenait jamais.

Et puis, en dehors de ces hommes du bailliage d'Aval, d'Orgelet, de Moirans, de Saint-Amour, pays frontières, perdus aux confins méridionaux de la Comté, il est frappant de voir qu'à cette époque, on ne trouve pas d'autres Comtois inculpés. 
Point de poursuites à Dole, à Salins, à Gray, à Baume, à Vesoul ; du moins, point de traces de poursuites dans les registres du Parlement. A Lons-le-Saunier, une très grave affaire éclate en 1550 ; mais l'étude, précisément, en est curieuse. Le Louis Conod de Morges qui avait payé de sa tête, le 6 septembre, ses propos hérétiques, avait été, à Lons, le serviteur d'un apothicaire, Ph. Robinet. Or, en même temps que lui, le procureur général avait inculpé ses maîtres - l'apothicaire et sa femme, Simonne Pelissonnier, ainsi qu'un nommé Guillaume Millier dit Rodet et un prêtre, messire Odot Gauldot. Puis, le procès continuant et de nouvelles informations ayant été prises, le beau-frère de Robinet, Pierre Pelissonnier le jeune, d'Arlay, avait été trouvé suspect d'hérésie et mis en cause également : prudemment d'ailleurs, tous les accusés s'étaient enfuis, et la cour, « considéré l'énormité des cas dont ils sont chargez », les avait condamnés au ban par défaut, en mettant leurs biens sous la main du roi. Mesure grave : les Pelissonnier d'Arlay étaient de très riches gens ; ils se qualifiaient de nobles et d'écuyers, tenaient fiefs et rièrefiefs et menaient large vie. C'étaient de ces parvenus, de ces « nouveaux riches », dont la fortune se fondait à la fois sur la richesse foncière, le commerce et l'usure, et qui très souvent inclinèrent volontiers, hommes nouveaux, vers les idées nouvelles. Mais leur richesse même rendait bien difficile leur expatriation en pays réformé ; d'autant que leur avoir aurait dans ce cas été confisqué. Un an après leur fuite, ils revenaient donc, munis de lettres de rémission. Et l'instruction de leur affaire reprit, mais avec une lenteur prudente. Ce fut d'abord la série habituelle des remises, des renvois ; puis leur nom disparut des registres - et des années passèrent. Alors, le 23 février 1559-60, un écuyer, un noble de nom et d'armes, Josse d'Asuel, s'indigna, et dans une curieuse requête à la cour, incrimina véhémentement la négligence du procureur général à poursuivre les inculpés. Il signalait d'abord que Pierre Pelissonnier et Antoinette Matal, sa mère, "non nobles n'ayantz tache de noblesse », tenaient au Comté « plusieurs chevances et héritages en biens féodaulx, tant en fief et arrière-fief de Sad. Majesté ou de ses vassaulx ", cela «sans de ce avoir pouvoir, consentement ni permission de prince »; et il réclamait la commise contre eux. Ensuite, quant aux poursuites criminelles, il notait que, par la faute et négligence du procureur, un «des quartiers des témoings » au moins étaient morts, dont on se fût bien aidé pour connaître la vérité. Le procureur répondit, montra ses informations et ses pièces, déclara que l'affaire suivait son cours normal - et d'ailleurs, le train de justice n'en alla pas plus vite : 
c'est seulement en 1567, soit dix-sept ans après la première inculpation faite, que l'affaire fut jugée - et que les accusés se virent tous acquittés.

Cette affaire est typique, et la protestation de Josse d'Asuel en souligne bien le sens et la portée. Si prompt à juger quand il s'agit d'un étranger, de quelque colporteur ou de quelque fugitif arrêté en Comté - d'un simple licencié en droit même, qui par son labeur s'est fait une situation, mais que sa famille abandonne et trahit comme Paris Panier - le Parlement, devant ces bourgeois puissamment riches, hésite, temporise, laisse traîner les choses et finalement, au bout de dix-sept années pendant lesquelles les inculpés ont pu continuer à trafiquer en paix, rend un arrêt d'indulgence manifeste : les opinions émises au cours de la délibération en font foi. Et sans doute, nous avons déjà relevé d'aussi longs délais pour de moindres personnes. Il faut bien cependant que l'attitude du Parlement ait eu quelque chose d'étrange pour qu'un Josse d'Asuel s'en soit ému.

Autre point, d'ailleurs. Que Josse ait eu des motifs particuliers d'intervenir dans l'affaire, on peut le soupçonner aisément. Il était noble, noble d'épée, noble pauvre. Les Pelissonnier, par contre, ces bourgeois parvenus, employaient, comme tous leurs pareils, une partie de leur fortune à l'achat de terres nobles. L'Histoire d'Arlay nous renseigne sur ce point. Successivement on voit Pierre Pelissonnier acheter, en 1566, à Antoine de Maigret, la vigne de la Maigrette, à Montmorin ; en 1568, le tiers de la chevance que Claude de Bernaud, fils d'Étienne, possédait à Arlay et Saint-Germain; en 1569, à Gérard de Bernaud, les deux tiers de la même chevance ; - bien plus, en 1571, à Claude d'Asuel, propre fils de Josse, plusieurs censes, rentes et redevances faisant partie de la chevance de Vuillafans, Quel jour jeté par ces opérations sur la conduite de Josse d'Asuel en 1560 ? N'expliquentelles pas l'animosité, la rancune de ce hobereau endetté contre les gros bourgeois qui, une à une, retiraient aux nobles de leur entourage les antiques chevances léguées par les ancêtres ? Et n'était-ce pas chose grave, dès lors, que le vieil antagonisme politique et judiciaire de l'épée et de la robe pût revêtir encore un aspect religieux - qu'aux doléances des justiciables contre la lenteur des juges, des soupçons pussent se joindre contre leur orthodoxie? 


\section{IV}

Soupçons faciles à exploiter. Les souverains, un Philippe II, une Marguerite de Parme, ne se méfiaient-ils pas des gens de justice ? Gens de justice, gens de lettres ; ces hommes qui avaient travaillé, fréquenté les universités étrangères et peut-être recueilli à Orléans la parole d'Anne du Bourg ou étudié à Bourges aux côtés de Calvin, - ces juristes qui voyaient leurs maîtres préférés incliner presque tous vers les idées nouvelles, ne devaient-ils pas, comme Pontus Payen, trouver chose dure de rechercher la conscience de tant de gens paisibles qui ne demandaient autre chose que de vivre tranquillement en leurs maisons - encore plus grande cruauté de les faire mourir, puisqu'ils ne donnaient aucun scandale ? Euxmêmes, n'étaient-ils pas suspects de Renaissance et d'humanisme ? Qu'on parcoure les ouvrages de Gilbert Cousin : dès le début, dès 1536, au moment où les moines partent en croisade contre la Renaissance, ce sont des constatations comme celle-ci : "Dolani senatores fere omnes dici non protest quanto animo bonarum literarum patrocinium susceperint. » C'est à Erasme lui-même qu'écrit ainsi Cousin ; et ces «Dolani senatores », il en donne les noms : ce sont les frères Fauche, Jean et Nicolas, les conseillers Vauchard et Chuppin, le greffier Delesmes, le procureur général Marin Benoît, Henri Colin surtout, son oncle à la mode de Bourgogne : "Colinaeum, quem ob res ab eo magnifice gestas Callineum semper nomino. » Parle-t-on de poursuites contre l'ancien secrétaire d'Erasme ? des chanoines vindicatifs le dénoncent-ils ? Colin intervient, écarte les poursuites. N'avait-il pas confié à l'humaniste ses deux fils ? - Et le Parlement, sans doute, se renouvelle ; de jeunes conseillers remplacent les anciens ; mais à toutes les époques, Cousin trouve en lui des protecteurs : il est difficile de supposer qu'ils ignoraient les attaches bâloises de leur protégé ou ses déclarations exemptes d'équivoques dans plusieurs ouvrages que guettait l'Index ? En 1554, comme en 1536, dans la crise violente que nous avons décrite, alors qu'au lendemain de la mort de Panier, tous les amis de Cousin et même ses parents l'évitent, le fuient, le dénoncent presque l'humaniste sait et dit qu'il a au Parlement des défenseurs certains. Huit ans plus tard, quand, en 1562, Cousin signale à Amerbach les manoeuvres inquiétantes de ces « Sarabaytes » qui se dressent contre lui et parlent de le faire poursuivre par la 
Cour de Dole, ce sont encore des conseillers qui interviennent, refusent d'accepter les dénonciations, suggèrent à l'humaniste le compromis habile qui retardera encore une fois sa perte. Quels étaient ces conseillers ? Ceux, peut-être, que trois ans plus tard Granvelle signalait comme suspects àPhilippe II - en même temps qu'il lui dénonçait les tendances à l'indulgence du Parlement tout entier dans les affaires de foi ? Josse d'Asuel, en tout cas, n'avait pas attendu l'avis du cardinal pour intervenir, déclarer douteux le zèle orthodoxe du Parlement et laisser entendre que, par esprit de caste, par sentiment de solidarité bourgeoise, il était bien capable de négliger ses devoirs les plus impérieux.

Rajeunissement du vieux thème connu, des doléances traditionnelles contre les partialités de la Cour souveraine, mais rajeunissement singulièrement habile et dangereux. La connivence avec les réformés, la « dissimulation » dans les poursuites, l'indulgence relative dans la répression : fautes impardonnables, véritables crimes pour les officiers d'un Philippe Il d'Espagne, d'une Marguerite de Parme. Et qu'en telle matière le soupçon était aisé à répandre ! Qu'il était aisé, par exemple, de signaler l'indulgence (qu'elle fût ou non justifiée) du Parlement pour tous les lettrés ou les gens de robe - son indulgence pour me Philibert Very, recteur des écoles de Lons-le-Saunier, deux fois cité devant la Cour, deux fois absous par elle, alors qu'il avait fait jouer par ses disciples « un dialogue désordonné »; son indulgence pour messire Philibert de Branges, docteur ès droits, inculpé d'avoir, six semaines durant, logé « ung escripvain de la ville de Thoulouze » grandement suspect, qui chantait les psaumes en français, appelait les prêtres « paillardz, meschants gens » et récitait le Benedicite à la mode de Genève... Dans tant de procès pour hérésie, dans tant d'affaires religieuses, dans la marche même et le développement des idées réformées en Comté et à Besançon, que de griefs à exploiter contre le Parlement, que d'armes à ramasser pour des coups décisifs ? N'était-il pas en effet, aux yeux de Philippe II et de Marguerite, n'était-il pas en réalité le seul gardien du catholicisme en Comté, le seul adversaire sérieux des réformés ? 


\section{V}

Pour lutter contre l'hérésie grandissante, impossible, en effet, de compter sur l'Église. En Comté comme ailleurs, du sommet à la base de la hiérarchie ecclésiastique, tout n'était qu'abus, désordre, excès et licence. Chefs et soldats, tous sentaient la réforme nécessaire ; aucun n'osait ou ne voulait la faire. Et c'était du dehors qu'elle devait leur venir.

Nous n'avons pas ici à rechercher en détail les causes d'une semblable impuissance - à étudier en elle-même et pour elle-même l'Église comtoise. Mais, dans la mesure où, comme celle de la Réforme, son histoire intéresse l'histoire générale, il nous faut indiquer les traits principaux d'une situation fertile en conséquences.

A la tête du diocèse, point de chef véritable. Nous avons dit plus haut comment, en 1544, le cardinal Pierre de la Baume étant mort, deux compétiteurs s'étaient disputé son trône archiépiscopal : un homme âgé et de souche bourgeoise, François Bonvalot, allié des Granvelle ; un enfant et de noble naissance, Claude de la Baume, parent des Rye. En dépit du compromis de 1545, les deux partis en présence n'avaient pas désarmé. «Une église ne peult avoir deux espoux, comme une femme deux maris ", écrivait, dès le début de la querelle, le doyen du chapitre bisontin, réclamant contre le Lillois du Rez l'administration provisoire du diocèse : en fait, pendant plus de dix ans, l'Église de Besançon allait démentir cette vérité usuelle : temps béni pour les envies de Bourgogne et toutes les rancunes, toutes les prétentions rivales des diffërents corps ecclésiastiques.

François Bonvalot est administrateur du diocèse ; il touche le tiers des revenus. C'est un homme de talent. Issu d'une des plus vieilles familles de la bourgeoisie bisontine ; beau-frère du garde des sceaux Nicolas Perrenot et de l'ambassadeur Jean de Saint-Mauris ; chargé lui-même, à diverses reprises, de missions délicates à Rome, à Genève, en France surtout où il passa deux ans ; instruit d'ailleurs et lettré, correspondant affectueusement avec Érasme, le festoyant de son mieux, s'intéressant aux débuts d'un Richardot - c'était un homme fort au-dessus de la moyenne et capable de bien diriger un grand diocèse. Mais d'abord, il n'en avait pas la pleine licence. Il n'était qu'administrateur, et non archevêque. De ses 
auxiliaires nécessaires, de ses officiers, aux termes mêmes du compromis de 1545 il n'avait pas seul le choix ; et, sans doute, il ne respecta point le compromis mais sa conduite sur ce point fut cause, précisément, de difficultés sans nombre. Nul emploi qui ne fût âprement revendiqué par un candidat des Rye et un candidat des Bonvalot: débat pour la régalie entre Gérard de Rye et Pancras Bonvalot, entre Humbert Jeantet choisi comme lieutenant par Gérard, et le docteur Lambert, désigné par Pancras ; débat pour le vicariat général et l'officialat, dont Bonvalot chasse le chanoine archidiacre Perrot pour investir le chanoine Renard; débat pour la suffragance, à la mort de l'évêque suffragant Simard, entre Guillaume de Fourbi et François Richardot. Et quels débats ! Ce sont des accusations passionnées, des dénonciations sans merci, la vie privée des uns et des autres scrutée dans ses détails, âprement, étalée au grand jour pour la joie et le profit de tous les réformés. Fils de faux monnayeur, capteur d'héritages, parvenu sans scrupules : tel est Humbert Jeantet au dire de Bonvalot. Homme sans moeurs et qui, « chief de justice craint et redoubté aud. Besançon », a profité de sa situation pour entretenir, douze années durant, au vu et au su de tous, une femme mariée ravie à un mari qui la réclame vainement sans pouvoir la « ravoir » - tel est le chanoine Perrot au dire de Jean Renard. Mais à Bonvalot lui-même, ses ennemis s'en prennent directement. Dans le somptueux hôtel qu'il s'est fait constuire sur la pente de SaintJean ; dans l'aimable cabinet qu'il s'est ménagé au fond de ses jardins, ne sait-on pas quelle galante compagnie reçoit cet administrateur par trop épicurien ? Ses deux fils naturels, Thomas et Charles Bonvalot, ne sont-ils pas les preuves vivantes de sa liberté d'allures et d'existence ? Ainsi clament ses ennemis, un Perrot, un Guyot, un Claude Boni surtout. Peu recommandable personnage, ce dernier, chanoine de Poligny et neveu d'un confesseur de Madame Marguerite. Entré au service de François Bonvalot, puis disgracié par lui, il racontait partout comment, étant tombé amoureux « de la plus favorite des garces » du prélat, celui-ci l'avait forcé à résigner, au profit de son bâtard Charles, la cure jurassienne dont il l'avait pourvu - puis dans une scène violente, l'ayant fait dépouiller tout nu par ses gens, l'avait jeté à terre, battu à coups de poings et de pied - le tout, avec force détails scabreux... Vilaines gens, au total, et vilaines affaires. On devine si les esprits éveillés par les critiques calvinistes et luthériennes les accueillaient avec empressement, et plus ou moins fondées, les colportaient partout... 
Or, lorsqu'en 1557, Claude de la Baume, devenu majeur, se fut installé au palais de Porte-Noire, rien ne fut gagné cependant pour l'Église. Car le nouveau prélat était le type parfait de ces cadets de grande famille que des convenances privées faisaient dès leur naissance vouer à une carrière qu'ils n'avaient point choisie. Assez peu doué pour l'étude, en dépit des protestations intéressées de son précepteur et futur vicaire général Ant. Lulle ; sans goût pour les lettres ni pour les lettrés; grand chasseur par contre et grand amateur des exercices violents où se complaisaient les futurs chevaliers, il se montra bientôt désireux de connaître les joies de la vie profane - impatient des lisières qui pouvaient le contraindre. Toucher et dépenser ses revenus d'archevêque, il y consentait aisément ; approfondir la théologie, recevoir les ordres, surveiller son diocèse : occupations de manants et qui de moins en moins lui agréaient. En 1564, marchant vers la trentaine, cet archevêque qui n'était même pas sous-diacre fit la rencontre d'une aventurière subtile : Nicole de Savigny. C'était la veuve d'un gentilhomme comtois, Jean de Ville, qui, passée maîtresse de Henri Il : le roi lui avait même laissé un à la cour de France, y était devenue un instant la bâtard, son « petit Saint-Henri », comme elle l'appelait. Cette femme artificieuse n'eut pas de peine à séduire le prélat bisontin. Elle prit sur lui un tel ascendant qu'au dire de Granvelle elle l'amena au mariage ; et l'on eut ainsi quelque temps en Comté le spectacle rare d'un archevêque laïque et prétendu marié...

\section{VI}

On devine les conséquences d'un semblable état de choses. Sous un tel chef, qui donc aurait songé dans le clergé à prendre l'initiative des réformes nécessaires ? Le chapitre cathédral ? Mais, comme tous les corps privilégiés, il songeait surtout à profiter des circonstances pour renforcer encore ses privilèges. Dès l'avènement de Claude, les chanoines avaient réussi à obtenir de lui, le 19 février 1557-58, d'importantes concessions - dans le temps même que le Parlement de Dole négociait avec le prélat un concordat avantageux pour la justice laïque. Du reste, composé de personnages aux moeurs généralement dépourvues d'austérité, le chapitre se mettait peu en peine d'héroïsme. Ce qu'en 1567 le prieur de Bellefontaine écrivait à Granvelle de ses hauts dignitaires - qu'ils excellaient à nager 
entre deux eaux - se justifiait depuis longtemps déjà. En vain, le suffragant Simard, le futur évêque d'Arras Richardot, le vicaire Lulle, avaient, chacun

pour leur part, cherché à l'entraîner dans des voies meilleures : ils étaient trop petits personnages pour y réussir. Aucune année, presque, ne s'écoulait sans que des incidents publics ne fissent à nouveau soulever par le magistrat la question scandaleuse des chambrières, et c'était en vain qu'un Granvelle, un Jacques de Saint-Mauris, un Hugues de Grammont - peu suspects cependant d'excessive austérité - prêchaient la réserve, la retenue, la décence extérieure aux plus compromettants de ces ecclésiastiques dont les excès défrayaient la chronique maligne.

Même spectacle dans les couvents et les abbayes. Les moines, les religieux apparaissent dans les textes comme d'assez pauvres gens, mal instruits, peu heureux, surtout préoccupés de défendre leurs droits matériels contre les abbés et les amodiateurs d'abbaye. Victimes assez souvent d'une exploitation sans vergogne, ils se montraient violents à l'occasion et dévergondés. Il faut lire ce qu'écrit Granvelle, par exemple, des moines de Montbenoît dont il a entrepris malgré eux la réforme - de leurs révoltes, de leurs menaces, de leurs crimes mêmes. Quand l'abbaye brûle, ne soupçonne-t-il pas les religieux de n'être pas restés étrangers au sinistre ? Plus de vie commune, du reste. Partout, le régime des prébendes, la séparation et la liberté d'existences toutes profanes, le goût passionné de la chasse surtout, des moeurs privées dont témoignent fâcheusement d'abondantes demandes en légitimation. Quant aux abbés eux-mêmes, riches toujours et souvent nés ; tenant pour la plupart leurs bénéfices en commende, bien rares étaient ceux qui ne se faisaient pas prier pour entretenir en bon état les bâtiments de leur abbaye, procéder à temps aux réparations les plus urgentes, entretenir le nombre de moines requis, former des novices et les mettre aux écoles, distribuer enfin les aumônes coutumières. Ce ne fut point pour eux, mais contre eux le plus souvent, qu'il fallut procurer de nécessaires réformes.

Enfin, le clergé séculier, les simples prêtres. Ce que Fray Lorenço écrivait à Philippe II des curés de par deçà, «mercenaires ignorants au point de ne savoir quelle doctrine est catholique et quelle hérétique ", s'appliquait parfaitement à leurs collègues des villes et des villages comtois - réserve faite des exceptions qui, à toute époque, viennent confirmer la règle. Les curés en titre ne résidaient pas toujours. Beaucoup, du reste, jouissaient de plusieurs cures à la fois. Souvent aussi, les cures appartenaient à quelque chanoine de Besançon ou d'ailleurs, qui natu- 
rellement se souciait surtout des revenus. Les desservants dès lors, réduits à la portion congrue, se voyaient contraints de lutter pour vivre. Ce n'est pas sans doute par hasard et sans raisons positives que les Statuts synodaux leur font défense d'exercer nombre de métiers singuliers. D'autre part, ils n'avaient guère les moyens de se désintéresser de leur casuel ; or, les paroissiens n'étaient pas riches et bien que les communautés pleines de bon vouloir consacrassent la majeure partie de leurs ressources à l'entretien du culte, c'était à chaque instant d'âpres luttes entre prêtres et fidèles pour le paiement des droits curiaux. Dès que l'année était mauvaise, le clergé rural souffrait. Il faut lire les demandes en dégrèvement que chaque nouveau «don gratuit » provoquait de la part des ecclésiastiques : tout n'était pas mauvais vouloir, ou rébellion de privilégiés soucieux de leurs privilèges, dans les doléances des simples prêtres que la misère de leurs paroissiens faisait eux-mêmes misérables. Prêtres peu instruits du reste : nul séminaire encore, nulle école spéciale pour les former ; et quant à leur vie, trop souvent on rencontre sur les registres criminels du Parlement des noms d'ecclésiastiques inculpés de violence, d'indélicatesse, de faux monnayage, de brigandage même ; très souvent aussi, dans les dossiers de légitimation ou de confiscation on saisit la trace d'enfants naturels, de fils de prêtres formant parfois de nombreuses et véritables familles.

Mais, à tous les degrés de la hiérarchie ecclésiastique, ce qui frappe d'abord, ce qui visiblement prime tout - c'est le souci du temporel. Rien en témoigne-t-il davantage que la persistance dans le diocèse de ces curieuses, de ces scandaleuses pratiques d'excommunications pour dettes dont nous avons ailleurs décrit le mécanisme ? On sait comment pour maintenir l'achalandage d'une cour de justice siégeant, hors du Comté, à Besançon, l'official, qui ne disposait point des moyens matériels, des agents d'exécution nécessaires pour contraindre les parties au respect de ses sentences, procurait ce respect à l'aide de moyens spirituels - en lançant contre ceux qu'il avait jugés et qui refusaient de se plier à son jugement la peine, terrible entre toutes, de l'anathème. Pratique étrange et qui, bien souvent, aboutissant à mettre au service des pires usuriers, des plus cyniques exploiteurs la plus redoutable des armes ecclésiastiques, tuait chez les malheureuses victimes de tels abus leur confiance et leur foi dans l'Église même.

Or, depuis des années, les souverains du Comté poursuivaient contre ces errements une campagne vigoureuse : peu désintéressée, certes; elle n'en mettait 
pas moins de leur côté la justice et le bon sens. Campagne sans effets. En vain Marguerite, en vain Charles-Quint, le Parlement de Dole et les États, traduisant le sentiment populaire, s'élevaient contre l'emploi « indiscret» de l'excommunication par des créanciers contre leurs débiteurs ; trop de particuliers, trop de riches, trop d'hommes d'affaires et de loi étaient intéressés au maintien d'abus, si criants cependant que Granvelle - peu suspect de parti pris contre la justice d'Église écrivait le 22 décembre 1572 à Bellefontaine, un ecclésiastique lui aussi et soucieux des droits ecclésiastiques : " J'ai souvent dit que, pour m'avoir semblé le revenu procédant des excommunications contre conscience, je ne voulu accepter l'archevesché lorsque feu $\mathrm{M}$. le cardinal de la Baume en voulait disposer en ma faveur. "

Ainsi, l'Église ne pouvait guère songer à mener contre l'hérésie une lutte efficace. Avant de réformer autrui, elle devait se réformer elle-même - être réformée plutôt, puisque les abus se trouvaient si profondément enracinés en elle. D'où, pour le Parlement, l'obligation d'agir sur le terrain religieux - et, puisqu'il était seul à pouvoir et devoir agir, un redoutable surcroît de responsabilité.

\section{VII}

Au reste, d'autre façon encore une pareille situation avait sa gravité. Qu'un Claude de la Baume fût à sa tête, c'était un danger pour l'Église comtoise, car un tel homme, tout laïque de tempérament et de désirs, tout plein du regret d'une vie profane - de la vie, telle que la menaient ses frères, ses oncles, tous les siens : vie militaire, vie de cour, vie d'intrigues - pouvait être entraîné à prendre de cette vie sa part, à épouser les idées, les sentiments de ses proches, à devenir ainsi dans son diocèse même une cause nouvelle de trouble et d'indécision.

Or, Claude de la Baume était le parent, l'ami, l'allié de tous les gentilshommes qui suivaient avec sympathie, en Comté, les événements des Pays-Bas - de tous ceux qui, dans le grand conflit commençant, prenaient rang contre Granvelle aux côtés d'un Egmont et d'un Guillaume d'Orange. Conflit politique et social, nous l'avons vu ; conflit religieux aussi. S'il n'y avait chez la plupart des seigneurs aucune sympathie pour la Réforme ; s'ils restaient presque tous attachés de coeur au 
catholicisme, du moins inclinaient-ils peu à peu vers des idées de douceur et de tolérance relative que développaient en eux, à la fois l'amour de leurs privilèges provinciaux menacés par l'absolutisme royal et la haine d'une inquisition, de jour en jour plus odieuse au pays. Or, ces idées, Réforme, absolutisme et ContreRéforme, faisaient juste assez sentir leurs effets en Comté pour que certains pussent les comprendre et les partager : ceux-là mêmes que le plus familièrement hantait l'archevêque. D'autre part, bien qu'elles émanent d'adversaires, peut-on complètement négliger certaines indications que renferment diverses lettres contemporaines ? Aveuglé par son amour pour Nicole de Savigny - dont le fils, André de Ville, devait entrer plus tard en rébellion ouverte contre Philippe II Claude de la Baume chercha un instant à vendre son diocèse, sans scrupule de simonie. Alla-t-il plus loin ? envisagea-t-il véritablement, comme semble l'indiquer Jean de Saint-Mauris dans une phrase d'ailleurs obscure, la possibilité de rester archevêque tout en épousant Nicole de Savigny - c'est-à-dire de pratiquer à la faveur d'événements politiques une sécularisation profitable? Accusation en l'air ? Peut-être : on ne saurait en tout cas la porter sur la foi d'un témoignage unique, d'ailleurs obscur et hostile. Mais n'était-ce pas grave, déjà, que de semblables bruits pussent courir sur les dispositions religieuses du prélat, sur l'emploi de ses voyages et, par exemple, sur son assistance à des prêches huguenots ? Vérités, mensonges ou exagérations : le résultat restait le même, si les récits qui couraient la province achevaient de mettre en désarroi des fidèles et un clergé privés de direction - déconcertés par ceux-là mêmes qui auraient dû, avec sûreté, leur indiquer la voie et la suivre en personne.

Par là encore, la Réforme, indirectement, n'était pas un facteur négligeable de l'histoire comtoise. Développant ses effets dans un milieu déjà troublé, elle contribuait à le désagréger au reste. Au Parlement, elle divisait les conseillers. D'un côté, les quelques hommes qui, par tempérament ou par doctrine inclinant davantage vers la répression, se montraient disposés à servir, sans trop de résistance, l'absolutisme et la Contre-Réforme : pour la plupart, des amis de Granvelle, des clients, restés fidèles au ministre déchu. De l'autre, les modérés, les tolérants, ceux qui, portés vers l'indulgence, partageaient les sentiments et les idées des seigneurs flamands et, dans leur pays même, désertant le parti du cardinal, se rangeaient plus ou moins ouvertement parmi ses adversaires. Entre ces deux groupes, réservant leur décision, les timides, les prudents, soucieux d'éviter tout excès de 
zèle, toute démonstration compromettante : ainsi se classaient les hommes en face des idées. - Mais, surtout, la Réforme divisait la noblesse. Non qu'elle recrutât dans ses rangs des partisans nombreux et zélés ; mais, d'abord, la grande majorité des gentilshommes d'épée, très loyalistes et très catholiques, s'émouvait profondément de ses progrès. Insoucieux des nuances qui séparent un homme d'étude aux curiosités suspectes d'un hérétique déclaré - beaucoup d'entre eux s'indignaient volontiers contre les longueurs, les hésitations, les scrupules de la cour. Avec cette naïveté des hommes qui possèdent la force pour seul moyen d'action, ils se persuadaient que la question était très simple - de celles qu'on résout par des exécutions ; et les lenteurs juridiques, les distinctions de droit, l'intérêt même que plusieurs parlementaires manifestaient pour les idées qu'ils devaient étouffer, toute cette conduite prudente, indécise, ambiguë, leur paraissait une trahison, une sorte de forfaiture. - Ennemis du Parlement eux aussi, les autres gentilshommes, ceux qui, par relations ou par affinité, inclinaient à suivre, à propager dans leur pays le mouvement commencé par « delà ». Mais si leur hostilité avait de pareils motifs les manifestations s'en montraient différentes ; et leur liberté plus grande vis-à-vis du souverain ou, du moins, du système politique qu'il appliquait ; la moindre vigueur de leur parti pris catholique ; leur tendance progressive à la tolérance, bien des traits ainsi pouvaient et, de plus en plus, devaient les séparer de la masse même des gentilshommes comtois - en faire un petit groupe actif, mais isolé. - Ainsi se formaient peu à peu, se dégageaient et s'organisaient, les forces qu'une crise violente devait mettre aux prises. 
PHILIPPE II ET LA FRANCHE-COMTÉ

Étude d’histoire politique, religieuse et sociale.

Troisième partie. La Comté et la révolution des Pays-Bas

Chapitre XVI

\section{Les gueux et la Comté la confrérie de Sainte-Barbe}

$\underline{\text { Retour à la table des matières }}$

Dans l'Église, dans l'État, dans la société comtoise vers 1565, ce n'étaient donc que conflits, abus et rivalités, - mais conflits masqués; rivalités sourdes, abus qu'on dénonçait et qu'on ne poursuivait pas. Sur le pays, un malaise pesait, dont tout le monde ressentait la gêne ; promenant de villes en bourgs, de prieurés en abbayes, son oisiveté forcée, Granvelle, mieux que nul autre, pouvait s'en rendre compte.

Sans doute, Renard restait toujours en Espagne, mais rien de décisif n'intervenait à son égard. Était-il bien en cour ? Il le disait. Il vantait l'accueil cordial du roi. Il parlait avec assurance de ses promotions futures, et ses partisans répétaient ses propos. - Mensonges, répliquaient les cardinalistes. Lentement, mais sûrement, s'instruit le procès du maître de Quiclet; et c'est en vain qu'Egmont s'est intéressé à sa cause. - Malgré tout, dans les esprits mal habitués encore aux lenteurs, aux hésitations, aux brusques revirements du fils de Charles-Quint, un doute subsistait. 
Même chose, quant aux dispositions du gouvernement de «par deça ». Sans doute, en 1565, Moron avait été brûlé vif en Espagne. Sans doute, les commissaires flamands avaient été rappelés par Marguerite. Mais, en octobre 1565, ne faisaient-ils pas mander encore aux Pays-Bas le lieutenant de la Saunerie et les clercs des rôles ? Le premier se tirait d'affaire sans trop de peine; mais le « chat qu'on leur avait jeté aux jambes » embarrassait cruellement les autres. Indécision, là encore, et alternatives.

Granvelle lui-même, quelle était sa position ? Il demeurait en congé, disait-il. Il visitait ses terres et ses parents. Il attendait l'heure de retourner aux Pays-Bas. Mais cette heure ne venait pas vite. Ce congé se prolongeait singulièrement et finissait par ressembler à un exil. Et puis, qui croire ? Ses partisans, qui prétendaient toujours son départ de Bruxelles volontaire ? Ses adversaires qui, aux PaysBas, parlaient d'un rappel direct par le roi ? Le cardinal ne s'abandonnait point ; lorsqu'un coup imprévu menaçait, il savait déclarer que le roi n'était aux Indes », qu'on savait où le trouver et l'entretenir. Ne gardait-il pas sa confiance ? Ne lui adressait-il pas, comme par le passé, de longues dépêches ? - Mais Marc de Rye, cruellement, répondait que le cardinal « recopiait ses vieilles lettres »; que le roi ne lui écrivait plus que très rarement ; surtout, qu'il le laissait toujours inactif en Comté. Et les parlementaires, prudents, louvoyaient, ne sachant de quel crédit pouvait jouir encore leur ancien protecteur...

Son départ, il est vrai, aurait pu les fixer, s'ils avaient su avec certitude que, par une lettre du 22 octobre 1565, c'était le roi qui lui avait enjoint de gagner Rome ; de s'y rendre sans mission, sans mandat, sans utilité ; d'y aller comme on fuit, par une seconde disgrâce aussi cruelle que la première. Mais les circonstances favorisèrent Granvelle. Durant qu'il protestait auprès du roi, le pape Pie IV mourut. Il pouvait partir, dès lors, sans étonner personne, en prétextant le Conclave. Et il quitta la Comté pour n'y plus revenir. Le hasard lui sauvait la face ; son départ n'en était pas moins grave ; il allait précipiter, au sein du Parlement, une évolution déjà commencée, mais dont sa présence en Comté avait gêné jusque-là et retardé le cours. 


\section{I}

Au début de juin 1565, le président Desbarres était mort. Son agonie commençait à peine que déjà des candidats se portaient à sa succession ; et nous avons vu que Prudent de Saint-Mauris annonçait à Granvelle aussitôt : « Les renardistes font bruyre que le Renard est jà président..., jaçoit que d'aultres dient qu'il est arresté en Espagne, » - phrase qui peint admirablement l'incertitude des mieux renseignés.

Granvelle, naturellement, mit en avant des candidats à lui. Pierre Sachet d'abord, beau-frère de Bonet Jaquemet et frère de Jean Sachet, chanoine de Salins, à qui le vieux Perrenot, jadis, avait confié ses fils. Ce conseiller qui, pendant quelque temps, avait servi en Flandre, puis en France, était un des clients dévoués du cardinal. Mais il mourut en octobre 1565. Granvelle, alors, proposa d'autres candidats : le conseiller Vauchard, un valétudinaire ; Jean Chappuis, le successeur de Pierre Sachet au Parlement ; Claude Belin surtout, l'avocat fiscal du bailliage d'Amont - une curieuse figure de Comtois passionné et plein de « partialitez ».

C'était, à cette époque, un homme déjà âgé, frisant la soixantaine, très vert d'ailleurs, l'oeil vif, le teint coloré, le poil brun, une face ouverte et franche : la face d'un homme de bien, écrivait Morillon. De fait, il était ce qu'il paraissait : brave homme, excellent mari, excellent père, adorant ses enfants : il en avait neuf, « tous fort obéissants », et qu'il prenait à tâche de bien élever, - plus soucieux, au demeurant, de leur laisser bonnes instructions et vertuz que grandz biens ». Il avait obtenu en 1541, après des études dont ses condisciples gardaient le souvenir, la charge d'avocat fiscal d'Amont. Il l'exerçait àVesoul depuis ce temps, ne sortant de la ville que pour les devoirs de sa charge ou pour aller à Gy faire ses vendanges. Officier modèle, très scrupuleux dans l'exercice de ses fonctions, il savait ses mérites et aimait à leur rendre justice lui-même. De fait, par sa science juridique non moins que par son «beau-dire », il s'était acquis un renom professionnel que le comte de Montbéliard avait consacré en chargeant Belin du soin de procès épineux entre tous. Comment ce personnage avait-il connu les Granvelle ? Weiss dit quelque part que des difficultés avec Simon Renard, lieutenant du bailliage dont il 
était l'avocat, avaient attiré sur lui l'attention de Granvelle. Le renseignement, que rien ne confirme est peut-être suspect ? Toujours est-il qu'en 1564, il s'avouait serviteur de la maison des Granvelle depuis vingt-cinq ans ; il est certain, d'autre part, que Nicole Bonvalot l'avait en particulière estime ; lui aurait-elle, sans cela, en 1568, lorsque Belin prit séance au Parlement, envoyé, par une attention délicate, « la robe d'escarlatte de fut Mgr de Grandvelle » ?

Tel était l'homme sur qui le cardinal avait jeté les yeux et qu'il présentait à Philippe II comme le meilleur, le plus docte, le plus catholique des candidats. Or, le plus docte, il l'était sans doute ; le plus catholique, il pouvait l'être encore ; mais le meilleur, au total ? Tout d'une pièce, raide, cassant, peu civil, incapable de plier lorsqu'il croyait avoir raison, très fier de son savoir d'ailleurs et ne dissimulant pas un mépris vigoureux des ignorants - Belin était un naïf, fort droit en son privé, mais ne soupçonnant rien des habiletés de cour. Morillon, qui possédait au plus haut degré les qualités que Belin n'avait pas, disait de lui finement : «Belin est sage et bonne personne, mais s'étonne de peu ». Et encore - éloge certain, qui enveloppait un blâme discret : «L'on ne peult tout avoir, et la vertu et érudition doivent estre surtout respecteez et plus que la civilité... combien que icelle soit bien séante ? » - Surtout, Belin avait un défaut, un gros défaut, particulièrement au regard du cardinal : il était partial, d'une de ces terribles partialités de Bourguignon qui faisaient le désespoir de son protecteur. Ce Comtois de Gy et de Vesoul était trop de son pays et ne s'en pouvait dédire.

Si Granvelle avait ses candidats, Renard, ou plutôt ses partisans comtois, ne manquaient pas d'avoir le leur : non Renard en personne, mais son beau-frère, le docteur Terrier, une créature des Rye, d'ailleurs homme de loi assez réputé. Guillaume d'Orange, lui, patronnait plutôt un Flamand. C'était un juriste renommé, Stratius, le professeur le plus en vue de l'université de Dole au temps où Dumoulin y avait séjourné. Installé en 1551 par l'entremise de Granvelle dans la chaire extraordinaire qu'occupait toujours un maître étranger, puis, après quelques années d'un enseignement brillant mais trop intermittent au gré des Dolois, nommé conseiller au conseil de Brabant ; rappelé à Dole enfin et réinstallé dans ses fonctions anciennes en 1562 par la grâce du cardinal - il n'avait pas tardé à les négliger de nouveau pour entrer au service du prince d'Orange. Ami de M. de Dicey et de son lieutenant La Villette, il avait pris parti pour eux contre les Dolois, puis s'était posé auprès de Guillaume en victime de sa fidélité orangiste. Le prince alors 
l'avait engagé àson service ; grand bailli de Chalon, Stratius avait quitté Dole, vendu ses livres, fixé sa résidence à Salins : c'était là, dans la seigneurie de Chatelguyon, que siégeait la Chambre des Comptes particulière des Chalon.

Ainsi, à la première présidence, les candidats ne manquaient pas. Était-ce leur nombre même ? le sentiment accru de sa responsabilité à une époque particulièrement troublée ? En face de tous ceux qu'on lui recommandait, Philippe demeurait indécis et irrésolu. En vain le Parlement, en vain le plus ancien conseiller, Henri Colin, exerçant une vice-présidence qui lui pesait, en vain Granvelle et M. de Vergy suppliaient le roi de pourvoir à la vacance, de donner une tête au grand corps judiciaire : la réponse invariable, quand il en venait une, était : « J'y songerai ». Et tout demeurait en suspens. Rien de plus urgent pourtant qu'une décision. Car en 1565, en 1566, l'audace de toute une partie de la noblesse comtoise croissait de jour en jour - et l'esprit de révolte faisait d'étranges progrès.

\section{II}

Au mois de janvier 1564, Granvelle avait signalé nettement le but de MM. de Rye et de leurs partisans en Comté : "Ourdir une ligue semblable à celle des Flandres. » De fait, ces seigneurs s'étaient empressés d'adopter les «flèches » emblématiques, de faire porter à leurs gens « la livrée » flamande, et de suivre fidèlement les directions de par delà. Avaient-ils fait plus - souscrit à des déclarations précises, rédigé un acte d'association explicite ? Point de doute à ce sujet.

Au mois de mai 1565, la cour était avertie que « le sr de Moureaul d'Andelot » - c'est-à-dire Pierre d'Andelot, fils de Jean, bailli de Dole et premier maître d'écurie de Charles-Quint, un des héros de Pavie - était venu en Comté et y «pratiquoit quelque chose de nouveau ». Il distribuait à des gentilshommes "certaines médailles qu'il avait apporté de par delà » - médailles des Gueux, évidemment, avec leurs besaces gravées. Le Parlement, qui savait l'état des Flandres, ayant « desja quelque sentiment des troubles et séditions que s'y mouvoient » et craignant que Pierre ne « fut venu en ced. pais pour y faire le semblable », l'invita à comparaître devant lui pour affaires concernant le service de S. M., « espérant de l'interroger et le faire répondre de telles menées ». Mais Pierre « s'absenta incontinent » et les 
conseillers - qui sans doute n'en furent point fâchés - se contentèrent de faire connaître ces faits à Bruxelles par l'intermédiaire du fiscal Boutechoux.

Quelle était cette «négociation » de Pierre d'Andelot ? On sait que le jeune homme, pris plus tard et supplicié aux Pays-Bas, prit une part très active au soulèvement des Gueux. Mais que fit-il en Comté, au mois de mai 1565 ? D'après le président Clerc, il y aurait apporté « un pacte formidable » dont les manuscrits Granvelle nous conserveraient le texte. On y trouve en effet une «Déclaration d'association » du prince d'Orange, de ses frères, des comtes d'Egmont et de Hornes avec «aultres soussignés et qui seront par cy-après reçus en nostre présente association, tant du pays d'Embas que du conté de Bourgogne ». Par cet acte, les confédérés s'engageaient « à maintenir l'Église, non composée de bâtiments et de la main des homes, mains de la primitive église et selon la tradition récente et cateschisme de M. Calvin, et selon celle-ci vivre et mourir ». Ils acceptaient la suprématie « des synodes et assemblées... pour les affaires secrètes, et conduire à chief le tout ou nom du Seigneur ». Enfin, ils s'engageaient, pour ce qui est de la Comté, à y reconnaître « la seule domination du prince d'Orange et des seigneurs ses frères, ayant en singulière recommendation les seigneurs de Rye, de Moureaux dit d'Andelot et aultres noz associés ».

Quelles sont exactement la valeur, la provenance, la date même de cette pièce ? Est-ce bien elle qu'apporta en Comté Pierre d'Andelot ? Surtout, y servit-elle réellement de base, avec ses affirmations calvinistes si nettes, à la « confrérie » que dressèrent MM. de Rye et leurs amis - et qui prit le titre, peu calviniste de confrérie de Sainte-Barbe ? Les faits vont répondre d'eux-mêmes et les dates.

Dans leur rapport au duc d'Albe, les conseillers poursuivent en effet : A peu près à cette époque, « nous estans réassemblez au lieu de Salins...., sur aultre avertissement lors à nous faict par M. de Vergy, nous disputâmes deux d'entre nous pour se transporter en divers lieux et s'informer discrètement de quelque confrairie que l'on disoit avoir esté dressée en ced. pais par aucuns gentilshommes. » A la Saint-Martin suivante, ces « députés, » par-devant la Cour et M. de Vergy, firent leur rapport, « et comme il n'apparissoit qu'il y eust quelque sinistre ny maulvaise intention en l'exécution d'icelle confrairie, de laquelle ilz n'avoient encoires esté que sept ou huit gentilshommes, dont les quatre étaient décédez - il fut advisé que le sr de Vergy parleroit aux survivants et leur deffendroit l'usaige et entretaine- 
ment : de lad. Confrérie ». Depuis, ajoutent les conseillers, «n'en a esté ouy parlé ».

Récit officiel, comme on voit, plein de réticences et d'obscurités. Il est, d'ailleurs, arrangé en forme de plaidoyer. Mais, plus objectif, le procès-verbal des délibérations de la Saint-Martin 1566 nous est parvenu. Et il confirme ces indications. Ce fut au conseil « d'après-disné » du 12 novembre, à Salins, que, en présence de M. de Vergy, les enquêteurs Chaillot et Chiflet firent rapport « de leur besogné et information par eulx faicte sur la nouvelle confrérie de Sainte-Barbe, érigée entre aucuns gentilshommes de ce pais ». Tous deux, opinant en premier, proposèrent de, "par avis de mon sr de Vergy, commis au gouvernement, faire publier un édict prohibitif de faire lighes, confédérations ni nouvelles confrairies semblables à celle cy dessus mentionnée, sans le sçeu et permission du Roy, mettant à néant icelle confrérie et prohibant d'en user ». Mais le conseiller Colard émit aussitôt cet avis contraire : "Que l'on ne doit faire aucun édict sur ce, pour non irriter la noblesse, attendu la déclaration de l'intention de ceulx aians érigez lad. confrairie, estans sept seulement en nombre, aucuns desquelz et des principaulx sont déjà décédez ». Les deux thèses s'opposaient nettement ; les conseillers se partagèrent entre elles. Vauchard, un granvelliste convaincu, opina comme Chaillot et Chiflet, demandant au surplus qu'on mît « leur besogné ès mains des fiscaulx pour faire leur devoir »; Chuppin, Boutechoux, Chappuis, le conseiller clerc Fr. de Poitiers, les deux chevaliers d'honneur, M. de Chateauroillaud et M. de Thoraise, le procureur général, enfin, demandèrent tous qu'on fît l'édit en question ; Sonnet lui-même émit l'avis que l'on fît « led. édict pour l'advenir », en annulant pour le présent la confrérie de Sainte-Barbe ; mais Fauche se rangea à l'avis de Colard, et surtout M. de Vergy déclara pour sa part - il parlait presque en dernier, après les conseillers et les chevaliers d'honneur - " qu'il suffiroit pour le présent qu'il fist venir devers luy ceulx qui sont de la confrairie pour leur remontrer leur faulte et leur défendre en user, ains l'abolir et mettre à néant ». Le viceprésident, Henri Colin, appuya aussitôt cet avis. Mais la grande majorité s'étant prononcée pour un édit, il fut " advisé et resolu que l'on verroit les pièces au bureaul pour plus meurement peser et concevoir la forme dud. édict. » Que se passat-il alors? Nous l'ignorons. La lettre du Parlement au duc d'Albe nous indique simplement que l'avis de Vergy prévalut, en fin de compte - et qu'il n'y eut pas d'édit. 
Il est fâcheux que le «besogné » de Chaillot et Chiflet ne nous soit pas parvenu. Mais dans l'ensemble, les faits apparaissent assez clairs. La démarche de Pierre d'Andelot, en mai 1565, était liée évidemment à la signature, aux Pays-Bas, du compromis, et à la formation dans les provinces de la confédération des nobles ; il s'agissait, sans aucun doute, de nouer un lien serré entre les mécontents de par deçà et ceux de par delà. Mais Pierre apportait-il en Comté l'acte même dont les papiers de Granvelle nous ont conservé le texte ? En tout cas, cet acte ne saurait avoir été la base même de la confrérie de Sainte-Barbe. Les origines de ce groupement remontent bien plus haut. Ici, un texte est formel : la lettre du Parlement à Marguerite, du 25 novembre 1566. D'après elle, le 12 novembre, Chaillot et Chiflet, les deux enquêteurs, firent rapport «de ce qu'ilz avoient trouvé et qu'ilz avoient recouvrez les articles » qu'ils recherchaient, c'est-à-dire « quelques articles en forme de confrairie » qu'avaient « soubsignez » plusieurs gentilshommes comtois. Or, ils déclarèrent que, " par iceulx articles, apparessoit qu'il y avoit cinq ou six ans passez qu'ilz avoient esté concluz » et que, d'ailleurs, la plupart de leurs signataires étaient « jà décédez ». Cinq ou six ans passés ? On serait conduit ainsi aux environs de 1560, tout à fait aux débuts de l'agitation entreprise contre Granvelle. Reste à savoir, il est vrai, en quoi consistaient ces « articles » et qui en avait conçu l'idée première, et s'il n'y avait pas eu évolution d'un groupement fraternel en groupement politique ? Notons que, depuis longtemps, il existait en Comté, ouverte à la vieille noblesse de nom et d'arme, une confrérie de Saint-Georges, d'esprit mi-catholique, mi-chevaleresque ; d'où, sans doute, l'idée d'une création analogue ? Lorsqu'on l'interrogea sur le port de la livrée et des flèches emblématiques, Egmont répondit qu'il s'agissait d'abord, dans sa pensée et dans celle des seigneurs, de couper court aux dépenses extravagantes que les jeunes gentilshommes faisaient pour vêtir leurs domestiques. Quelque pensée analogue de solidarité entre gens de même classe inspira-t-elle d'abord les promoteurs de la confrérie de Sainte-Barbe? Nous l'ignorons; mais toutes réserves faites sur ce point, sur la date ou ce groupement prit réellement corps et sur la portée primitive des statuts, il apparaît bien qu'il n'attendit pas pour naître la venue d'un Pierre d'Andelot. Quant au compromis, c'est en décembre 1565 qu'il fut «ordonné » et approuvé aux Pays-Bas, - s'il faut en croire, du moins, Cock de Neeringen. Et c'est en mai que doit se placer le voyage d'Andelot. 
Il n'en est pas moins vrai que les événements des Pays-Bas, seuls, pouvaient donner tout leur sens aux manifestations des mécontents comtois - et que, par les Rye, par Pierre d'Andelot et les deux Marnix, par Nicolas de Citey aussi, gentilhomme d'Egmont passé au service de Claude-François de Rye, ils trouvaient « par deçà » une répercussion directe et presque immédiate.

\section{III}

Au reste, l'agitation ne se limitait pas à quelques gentilshommes. Dans ces années troublées, tout s'émeut en Comté et tout se dérange. Pendant que ClaudeFrançois de Rye, courant les grands chemins d'Europe, s'en va au printemps à Vienne représenter le duc de Savoie aux obsèques de l'empereur Ferdinand et mener dans la ville la vie crapuleuse - beuveries formidables, rixes d'ivrognes, coups d'épée - que menaient habituellement les jeunes «maîtres » de son temps, des émeutes, des voies de fait, des manifestations publiques se produisent en Comté, à Salins notamment, pour la plus grande peur des amis de Granvelle.

C'est qu'aux moins pessimistes l'heure pouvait sembler grave. Qu'on imagine un pays dévasté, ravagé par une terrible épidémie de peste, gagnant l'une après l'autre toutes les villes du Vignoble ; les bourgeois aisés, les magistrats, les étudiants fuyant le fléau de cité en cité ; le Parlement et la Chambre des Comptes errant de Dole à Gray, puis de Dole à Poligny et de Poligny à Salins ; des déplacements soudains, des appréhensions continuelles, le désarroi d'installations provisoires ; par là-dessus, l'émotion soulevée par les nouvelles de Flandre, la démarche des nobles auprès de Marguerite, la multiplication des prêches calvinistes, en attendant, en août 1566, la ruée des Gueux sur les églises... Et voilà qu'en Comté, toutes proportions gardées, le peuple par endroits s'agitait aussi.

Nulle part plus qu'à Salins. C'était la ville industrielle, la ville ouvrière, active et remuante du Comté. Or, une question municipale s'y trouvait posée, de longue date. En 1561, partie des habitants - les petites gens - s'étaient concertés pour éliminer du magistrat les gros bourgeois et, aux élections, avaient réussi à élire comme notables des personnages tirés « de la lye du peuple ». Scandale, protestations : le Parlement, peu favorable aux tendances démocratiques, cassa les élec- 
tions ; les meneurs furent même jetés en prison. Peine perdue. Une seconde fois les Salinois renommèrent les mêmes notables; et il fallut bien accepter leur vote. Nous sommes très mal renseignés sur ce mouvement. Qu'étaient au juste, que voulaient ses meneurs ? Nous l'ignorons ; mais une indication nous paraît à retenir. Marguerite signale dans une de ses lettres qu'au moment même de l'élection, des billets avaient été affichés à la porte du couvent des cordeliers, « scandaleux à l'encontre de l'état ecclésiastique et même des gens de religion ». Alliance à noter, de préoccupations politiques, de revendications sociales et de protestations religieuses.

Or, en 1565, en 1566, Salins à nouveau est en effervescence. D'abord, la question municipale reste posée. Ce qui avait permis au menu peuple de triompher dans les élections de 1561, c'était le règlement de l'archiduc Philippe, en date de 1497, qui donnait aux habitants le droit d'élire directement leur maire et les huit échevins. Mais, de même qu'en 1526 à Dole, Marguerite d'Autriche avait fait supprimer le système trop démocratique de l'élection directe, de même le Parlement, mécontent de son échec de 1561, finit par rendre, le 8 janvier 1566, un arrêt d'après lequel majeur et échevins seraient dorénavant choisis à Salins non par les habitants, mais par le magistrat sortant, le conseil et six notables de chaque paroisse. Épisode d'une histoire très générale. Après Dole, Salins ; après Salins, Arbois, en 1575 : successivement, dans toutes les villes à mairie, les droits des habitants se voyaient restreints ; le suffrage de plus en plus était remis aux riches.

Et puis, à Salins, les orangistes s'étaient beaucoup remués, au temps de Moron et des commissaires. Les riches granvellistes, les officiers importants qu'enquêtaient les Flamands, c'étaient les membres ordinaires du magistrat local - ceux que le populaire turbulent aurait voulu remplacer par des hommes à lui. La ville, d'ailleurs, était le siège de la Chambre des Comptes du prince d'Orange. Stratius y avait fixé sa résidence. Le conflit entre le cardinal et ses ennemis y intéressait directement tout le monde. De là sans doute les troubles qu'en 1565, en 1566, on signale dans la ville. Un nommé Jean Guillon, officier de la Saunerie, orangiste convaincu, mène le train. Il portait au cou la médaille des Gueux - et ce n'étaient, le soir, qu'assemblées populaires, tumultes, insolences qui terrifiaient les gens paisibles. Il faut lire dans les lettres de Bonet Jaquemet le long récit de ces menus événements, des tentatives faites pour " voler et brûler sa maison » à lui, partisan avéré du cardinal - tandis que presque chaque jour, des hommes armés se prome- 
naient, chantant «à gorge desployée les pseaulmes de David en François » ou allant «faire efforts » ès maisons des chanoines de Saint-Anatoile. Petites manifestations, mais significatives, d'un mouvement de Réforme à tendances politiques et sociales.

\section{IV}

Or, ce qui émouvait le plus Bonet Jaquemet, c'était l'inaction du Parlement en présence de tels faits. Sans doute, les conseillers continuaient d'instruire quelques affaires de foi. En 1565, ils bannissaient pour cinq ans et faisaient battre de verges un paysan de Charbonnières près d'Ornans, coupable d'avoir chanté des chansons « mal sentans de nostre saincte foy et religion catholicque »; ils bannissaient perpétuellement un artisan du Valdahon pour mauvais propos et détention de livre prohibé ; perpétuellement aussi, pour « huguenotterie », un homme de Romainmôtier et sa femme ; un prêtre, le curé de Malans ; un Français de la Brie ; un libraire établi à Poligny. Mais n'est-il pas frappant que contre ces suspects - ils n'étaient pas tous étrangers ni en fuite - le Parlement ne prononce que le bannissement ? L'étude des délibérations à ce propos est assez curieuse. Deux partis, très nettement, se trouvaient en présence à la cour : celui des indulgents et celui des violents. S'agit-il, par exemple, d'Étienne Denvis, de Romaimnôtier ? Vauchard et Chappuis, les deux candidats de Granvelle à la présidence, réclament la mort ; Seguin et Chuppin, le bannissement avec fustigation ; mais Sonnet, Chiflet, Chaillot, Le Clerc, Colin, le simple bannissement. Indulgence naturelle ? Lassitude de poursuivre, de condamner toujours ? Il y avait autre chose : la peur de se compromettre en une saison troublée. Qui serait maître le lendemain ? qui aurait l'influence ? le prince d'Orange gagnerait-il la partie qu'il semblait de plus en plus vouloir engager ? Granvelle n'était plus là pour en imposer aux hésitants, aux timides. On le savait à Rome, et disgracié. Au moment même où il était parti, Claude-François de Rye n'avait-il pas gagné Bruxelles, en annonçant partout qu'il en reviendrait maréchal de Bourgogne?

Et puis, la présidence restait vacante : tout conseiller ne se croyait-il pas l'étoffe nécessaire pour remplacer Desbarres à la tête de la compagnie ? Sans doute, la 
nomination dépendait du roi, régulièrement. Mais renardistes et orangistes déclaraient à tout venant qu'ils feraient désigner le président par Marguerite, nonobstant les termes de sa commission. Et des conciliabules se tenaient partout, les ambitions s'enfiévraient. Belin, aux aguets, épiait tout le manège, le dénonçait point par point au cardinal. Litanie de menus faits, qui emplissent ses lettres et celles de Jaquemet ou de Chavirey : à Poligny, M. de Rye a logé chez le conseiller Chuppin. A Rahon, un vendredi, MM. Sonnet et Terrier sont allés au chateau. Et quel coup de théâtre, quel triomphe pour les orangistes quand, en octobre 1566, une lettre de Marguerite arrive au Parlement, lui ordonnant de se réunir, de désigner sur l'heure le plus suffisant des conseillers pour la présidence... Le dépit donne presque de l'esprit à cet aigre Belin. Il dépeint les renardistes « riant à gorge déployée de ces nouvelletez et disant qu'ilz ont bien trouvé le moyen de traverser les desseins de leurs ennemis »; il montre l'émotion des parlementaires, chacun songeant à soi, dépêchant aux nouvelles, épiant ses voisins : "de tous costelz, les messagiers courent en Flandre »; et quand, incapables de céder les uns aux autres, comptant tous sur les intrigues de cour, les conseillers décident de répondre à Marguerite «que tous estoyent suffisants » - quelles railleries. Peste ! tous suffisants! Les conseillers de Dole se prisaient à leur prix...

Passions égoïstes, mesquines intrigues. Tout en Comté alors en était obscurci ; tous s'enlisaient dans une inaction calculée. Il fallait attendre, ne pas se prononcer. Du côté des Rye et du prince d'Orange, il y avait pour les parlementaires bien des causes d'appréhension et de mécontentement. Les turbulents seigneurs qui entouraient un Claude-François et que les conseillers bien souvent avaient vu devant eux, frémissants et haineux sous la calange du procureur général, ne pouvaient passer en vérité pour les amis des robins, les protecteurs des conseils de justice. D'ailleurs, ni le candidat de Renard, Terrier, ni celui du prince, Stratius, n'appartenaient à la compagnie ; c'était là une atteinte à l'esprit de corps des conseillers. Surtout, pour créer à Stratius des partisans, pour profiter de l'influence qu'ils avaient sur Marguerite, le prince d'Orange et ses partisans n'avaient-ils pas mis en avant la nécessité d'accroître numériquement la cour ? Vieux projet. Déjà, au mois d'avril 1562, un des clients de Granvelle, le docteur Jacques Morel, « ayant entendu les choses estre en termes d'accroistre ceste court de parlement de quelques conseillers supernuméraites, pour fournir et faire deux chambres entières », suppliait son protecteur de l'y faire nommer directement par Marguerite, sans présen- 
tation de ses futurs confrères. Granvelle avait répondu tout net à l'importun qu'il trouvait les surnuméraires inutiles ; qu'il doutait qu'on en créât ; qu'au demeurant, si en en faisait, Morel n'aurait qu'à se faire connaître des conseillers en exercice et désirer, puis présenter par eux : «Fault en ces choses entrer par la porte » : ainsi terminait-il sa leçon de morale.

Mais la mission de Moron avait fait renaître l'idée. Les enquêteurs flamands, saisis de plaintes sur la lenteur du Parlement, sur la multitude des procès «qui pendaient au clou », avaient proposé de faire quatre surnuméraires ; pour commencer, le 7 février 1566, un juriste assez renommé, le professeur de l'Université, Louis de Boisset, recevait patentes de « conseiller supernuméraire et commissaire » au Parlement, avec " entrée, voix et opinion comme l'ung de noz aultres conseillers ». La cour se fâcha. On ne l'avait pas consultée. On violait ainsi ce droit de présentation auquel elle tenait tant. Et puis, multiplier les conseillers, n'était-ce pas diminuer les profits de chacun d'eux ? Bref, Louis de Boisset fut fort mal reçu - ou plus exactement ne fut pas reçu du tout. On refusa de l'installer, et il dut s'en retourner à Bruxelles « vers ceux qui l'avaient mis » pour quérir des lettres d'introduction péremptoires - et aussi de nouvelles patentes. Car il semble bien que d'abord, Marguerite l'ait nommé « commis aux enquêtes » - c'est le sens probable du terme de " commissaire » qui suit celui de supernuméraire - et que cette désignation anormale ait particulièrement ému les conseillers. Petits froissements sans doute : Boisset s'appuyait sur le prince d'Orange. Mais Granvelle ne pouvait plus rien. Il n'avait plus, on le savait, les bras assez longs pour atteindre Madrid depuis Rome. Et d'ailleurs, ce n'était pas Madrid, mais Bruxelles, qui importait.

Ainsi les conseillers laissaient faire, laissaient aller. Sans doute, à Salins, après des mois d'inaction, ils consentaient à écouter les plaintes de Bonet Jaquemet. En février 1566, ils bannissaient un peintre, Girard Paget, accusé d'avoir "painct escussons tendast à diffamation d'aultruy ». En juillet, ils inculpaient trois Salinois pour chants scandaleux, un autre pour blasphèmes, injures et "trait de pistole » contre personne ecclésiastique; cinq autres enfin, dont Jean Guillon lui-même, pour « homicide, port d'armes, blasphèmes, outrages et paroles irrévérentes ». Actes d'énergie tardive ; mais rien ne les suivit; les uns après les autres, les inculpés furent relâchés sur simple serment «de ne porter épées ny aultres bastons invasifz » et de ne plus s'assembler pour chanter par les rues. Le silence se fit. Et 
M. de Châteauroillaud d'écrire au cardinal : « M. de Thoraize mon cousin, et M. le trésorier Bonet communicquons ensemble souvent de tout ce qui se passe, et des menées et faveurs qui vous ont estées faictes et faict l'on journellement à la court. Vous avez bien emploier le bien et les honneurs que leur avez faictz, car ilz le recongnoissent comme les aultres du passé ». L'heure, évidemment, n'était pas à la fidélité.

\section{V}

Un seul espoir restait aux granvellistes : voir le roi quitter la péninsule et venir aux Pays-Bas remettre tout en ordre. Qui sait ? le cardinal peut-être reviendrait avec lui et reprendrait faveur? Chaque jour du reste, n'apprenait-on pas que le projet de voyage se précisait et que les préparatifs commençaient ? A M. de Vergy, le roi lui-même, au début d'octobre 1566, écrivait qu'il regagnait Madrid " pour y donner ordre à son département ». On équipait huit navires en Flandre pour aller au-devant de lui. Surtout, des lettres menaçantes venaient, en septembre, du bois de Ségovie ; le 2, la cour, réunie à Poligny, les recevait par les soins de Madame. Certes, le roi y déclarait qu'il n'était pas besoin de rappeler leurs devoirs à ses conseillers ; mais c'était avec une force une insistance singulière qu'il leur recommandait de surveiller un pays " avironné de voisinaige si dangereulx », de se tenir en garde sans défaillances, de rester l'oeil ouvert et la main sur le glaive. Le Parlement, cette fois, dut s'émouvoir, écrire aux officiers bailliagers des lettres particulières pour animer leur zèle, renforcer et renouveler les édits, mesures que justifiait la situation. Au Comté même et autour du Comté, partout, la Réforme gagnait. A l'est, vers le Montbéliard, dans les derniers mois de 1565, les ministres avaient remplacé les curés dans tous les villages des trois grandes seigneuries d'Héricourt, de Clémont et du Chatelot. Sur la frontière lorraine, des prêches se tenaient ouvertement à la côte de Fontenoy. Les paysans comtois, passant la frontière, $y$ allaient en curieux ou même en adeptes. Les officiers d'Amont signalaient des maisons où l'on faisait déjà « conventicules et prières à la mode des huguenotz »et les réformés cherchaient à établir à Deuilly un ministre et un centre religieux. Aux frontières du Duché, à Malange, ressort de Gendrey - tout près de Dole - un étranger, un Français «ayant pour femme une que, l'on dist, vouloir 
estre nonnain ». chantait les psaumes en français, déclarait que «l'on ne debvoit pas croire aux prebstres ", et à Archange, plus près encore de Dole, un nommé Jean Laignel soutenait « le faict des huguenotz » et disait entre autres que, « s'ilz venoient en ce pays, il leur yroit au devant». Enfin, au sud, sur la frontière lyonnaise, " près des lisières tant de Genève que de Bresse ", du côté de Saint-Amour, d'Orgelet, de Moirans, les suspects abondaient ; le Parlement, en septembre 1566, décidait de faire la rentrée en novembre, à Poligny, « pour les tenir de près et descouvrir s'il est possible ce qu'il en peult estre ».

A l'intérieur, même péril. A Amance, fief des Rye, les nouvelles doctrines s'infiltraient au désespoir à la fois et à la joie mauvaise de Belin, toujours empressé à charger Marc de Rye et son fils. A Usier, M. de Wateville scandalisait ses sujets en mangeant chair en carême et en vivant autrement que ne le portent « les statuz et ordonnances de nostre mère Saincte Église ». Une foule d'émissaires, de messagers, de prêtres même s'agitaient, qu'on inquiéta plus tard, au temps du duc d'Albe : le prêtre Claude Payen de Jussey, son frère Didier, tous deux amis de Pierre d'Andelot ; Jean Pescheur, de Jussey également, qui fit plusieurs voyages aux Pays-Bas pour y chercher des lettres ; le chanoine Mathieu Maire de Jallerange, qu'on interrogea, en 1570, sur ses relations suspectes avec un rebelle ; le docteur Bouquet, ami de Stratius ; bien d'autres encore, sans compter les protagonistes. Le relâchement était partout. Et dans le désordre croissant, les bons catholiques, tournant leurs regards vers l'Espagne, ne pouvaient que répéter avec Belin : « Dieu veuille donner la main-forte à Sa Majesté ! ». 
PHILIPPE II ET LA FRANCHE-COMTÉ

Étude d’histoire politique, religieuse et sociale.

Troisième partie. La Comté et la révolution des Pays-Bas

Chapitre XVII

\section{Le passage du Duc d'Albe}

\section{$\underline{\text { Retour à la table des matières }}$}

En dépit de ses promesses, Philippe II ne vint pas ; mais le duc d'Albe partit, le fanatique résolu à faire aux rebelles tout le mal possible, à utiliser, pour une impitoyable répression, l'armée redoutable qu'il traînait à sa suite. Cavaliers aux chevaux de sang, aux armures de prix ; fantassins des régiments de Lombardie, de Naples, de Cerdagne, de Sicile ; piquiers alertes, puissants hallebardiers, mousquetaires portant sur l'épaule leur arme nouvelle et jeunes soldats escortant les bagages - c'était une masse de plusieurs milliers d'hommes qui, lentement, allait traverser l'Europe et se ruer sur les pays de par deçà. Terrible machine de destruction et de meurtre, admirée des soldats, crainte des hérétiques, maudite des paysans et du menu peuple.

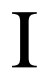

Le 4 juillet 1567, tout ce monde était à Chavannes et, par Montfleur, remontait le Suran, gagnait Gigny, la seigneurie de Montaigu et Lons-le-Saunier. A leur tour, les Comtois pouvaient applaudir la prestance des gens d'armes, le bel ordre des piétons, la richesse des accoutrements qui, d'un simple soldat, faisait l'égal 
d'un capitaine français ou allemand. Mais ils n'y pensaient guère. Ils songeaient bien plutôt à tout ce que « cette horrible Babel de bouchers espagnols et de sodomites italiens ", comme dit Michelet, allait causer de privations, amener de souffrances dans leur pauvre pays, si fort éprouvé par la peste, les orages et les inondations. Depuis trois mois déjà, on s'occupait, en Comté, à réunir des vivres, à préparer les étapes, à rassembler bestiaux, fourrages et provisions. Depuis trois mois, des ouvriers récoltaient du salpêtre, fabriquaient de la poudre et des mèches, forgeaient des piques, tandis que les officiers du gouverneur ou les commis du duc réparaient les chemins, dressaient des ponts, levaient quatre compagnies de cavaliers bourguignons, achetaient les chevaux, équipaient les hommes, faisaient venir d'Allemagne épées, morions et cuirasses. Ferdinand de Lannoy, bailli d'Amont et beau-frère de Granvelle, présidait à tous ces travaux avec M. de Vergy - et partout on s'empressait, on prenait ses dispositions avec une activité que le retard du duc rendait plus fébrile. Dans un village comtois, petit et misérable, c'était une terrible chose que l'invasion brutale des soudards réclamant le gîte et les vivres, consommant en une journée les provisions d'une année entière, quand ils ne mettaient pas le feu aux toits de chaume et aux granges de bois sec. Eux passés, cétait la famine et pour longtemps les greniers vidés, les granges dépouillées, les caves à sec : une véritable ruine pour le malheureux paysan.

Le duc d'Albe semblait peu pressé de délivrer la Comté de ce fléau. Lentement, il avait traversé la Bresse savoyarde. Terrifiés, les Genevois, derrière leurs murailles, tremblaient et tous les jours se demandaient si ce flot humain n'allait pas brusquement se précipiter sur la Rome protestante, en battre les remparts et l'engloutir. Lentement aussi, le duc traversa la Comté. Le 11 juillet, il n'était encore qu'à Lons-le-Saunier ; de là, il pouvait à son gré se diriger sur Dole ou sur Besançon ; il passa entre les deux, gagna la forêt de Chaux par Domblans, Brainans, Aumont, Saint-Cyr, Ounans, la contourna par Germigney, Chissey, Rans, Ranchot, Orchamps. Le 15, à Santans, il écrivait une lettre de courtoisie à Mme de Granvelle, la mère du cardinal ; le 17, le magistrat de Dole lui portait à Ranchot pour quarante écus de confitures sèches et de dragées. Après les Genevois les Bisontins s'émouvaient. D'un instant à l'autre, les plus timorés, les plus compromis dans le mouvement réformé s'attendaient à voir le reclus de la citadelle signaler au loin, sur la route de Dole ou de Quingey, le duc d'Albe et ses cavaliers. Marc de Rye était dans la ville à ce moment, tandis que toute la noblesse comtoise 
s'empressait autour du maître de demain. Un petit-fils lui était né au commencement de juillet. Le vieux gentilhomme l'avait porté dans la ville impériale, où il songeait, paraît-il, à prendre sa résidence ; c'est là qu'eut lieu le baptême, le 10 ; la duchesse de Parme avait accepté d'être marraine ; M. de Bassompierre vint lever l'enfant en son nom. Tranquillement, sous les yeux de l'adversaire pour ainsi dire, la cérémonie s'accomplit avec force bruit, canonnades et larges volées de cloches ; les gouverneurs furent priés au banquet et au souper ; ce fut le dernier beau jour de M. de Dicey.

Cependant, le duc d'Albe avait visité Dole et Gray, tandis que son armée, passant en rase campagne, évitait ces places fortes. Plus vite maintenant, par Marnay, Gy, Port-sur-Saône, ses troupes se dirigeaient sur la Lorraine, sur Fontenoy, qu'elles atteignaient au commencement d'août. Le 8, le duc était à Luxembourg. Partout, «la même terreur silencieuse " avait accompagné ses pas ; derrière lui, il laissait des ruines et des souffrances. Aux dépenses très fortes qu'avait occasionnées son passage, aux habituelles exigences de ses gendarmes, les malversations des entrepreneurs s'étaient jointes. On accusait communément les commis aux vivres d'avoir volé plus de 100000 écus. C'étaient presque tous des bourgeois de Gray, la ville de commerce de la région, peuplée de trafiquants avides et sans grands scrupules. Le scandale était si criant que les officiers d'Amont durent commencer une information et renvoyer plusieurs inculpés devant le Parlement.

Misères matérielles. Mais qu'étaient-elles, au prix des avantages politiques et moraux du passage ? Certes, le roi, s'il s'était décidé à partir, aurait soulevé plus d'enthousiasme, suscité plus d'énergies encore que l'Espagnol bilieux dont Antonis Moor sut rendre, de façon si frappante, l'aspect sec et glacial. Quels résultats, pourtant ? En Suisse, en Lorraine, en France, partout les réformés, huguenots et gueux, avaient senti l'instant solennel, l'heure décisive ; ainsi, la lutte allait commencer, impitoyable, aux Pays-Bas, gagner de là les contrées voisines, s'allumer partout à la fois et devenir vraiment européenne. Les catholiques, d'autre part, à voir défiler lentement cavaliers et fantassins, tout ce puissant appareil de combat, eux aussi s'étaient émus et dressés en armes. Derrière les terzos espagnols, les hommes se levèrent. On renonçait à combattre la Réforme par le glaive de la loi, les arrêts de justice et les prêches des moines ; l'épée allait trancher le débat ; tous ceux qui en avaient une la tirèrent du fourreau. 


\section{II}

Ces effets, en Comté, se firent vite sentir. D'abord, les nobles d'épée, ceux du moins qui n'étaient pas en relation avec les gueux, se réjouirent. Guerre civile ou guerre étrangère, peu importait pourvu qu'on pût se battre, se distinguer, conquérir des grades et des pensions. La cour de Philippe II offrait si peu de ressources ! D'une liste « des gentilshommes de la bouche, de la maison et autres serviteurs du roi » en date du 28 juin 1567, Gachard a extrait les noms qui intéressent les pays d'Embas. Or, sur 110 gentilshommes de la bouche, seuls Jean de Bauffremont, seigneur de Sombernon ; Frédéric Perrenot, seigneur de Champagney ; Philibert de Montmartin et Gérard de Wateville peuvent être réclamés par la Comté. Et sur 116 gentilshommes de la maison, trois seuls sont Comtois : Jean de Gilley, J.-B. d'Andelot, Philippe de Chassey : au total, sept Bourguignons sur 226...

La guerre, les levées venaient donc à point. Déjà, dans les quatre compagnies de cavalerie levées par les soins de Vergy, plusieurs gentilshommes trouvaient des commandements : son fils Claude ; Jean de Bauffremont (M. de Clairvaux) ; M. de Ray ; Henri de Vienne, baron de Chevreaux, sans compter les sous-ordres. Et puis, la terreur semée par l'armée n'était-elle pas, déjà, une revanche de la force et des militaires ? Il est vrai que les bourgeois, les clients de Granvelle, eux aussi, reprenaient confiance à l'annonce du passage. Albe aux Pays-Bas, n'allait-ce pas être la ruine des «adversaires », la disgrâce en Comté de M. de Rye, la fin du crédit dont se targuaient les seigneurs auprès de la régente - par contre-coup la revanche, au moins locale, de Granvelle ? Depuis quelque temps du reste, la fortune devenait hostile aux ennemis du cardinal. Claude-François de Rye, alors à Bruxelles, s'était blessé à mort en voulant, d'un geste brusque, ramasser sa dague tombée sur le sol : transporté dans l'hôtel du comte d'Egmont, il y était mort quelques jours après, laissant sa jeune femme enceinte d'un fils posthume. Terrible coup pour les siens - pour son père, le vieux Marc, à qui l'on n'avait d'abord osé faire part d'un tel malheur ; mais pour tous ceux « de sa dévotion » aussi, comme dit Belin, pour les conseillers empressés autour de sa veuve, pour les renardistes d'Amance, de Salins, de Besançon : il y avait là de quoi leur faire «baisser les cornes ». Or, au printemps de 1567, ils pouvaient apprendre, successivement, la 
remise en vigueur par Marguerite des placards sur les assemblées illicites ; la déroute, entre Valenciennes et Tournai, des bandes révoltées de la West-Flandre ; la capture, le 5 mai 1567, de 120 défenseurs de Viane, parmi lesquels Pierre d'Andelot ; la défaite le 13, à Austruwel, d'une troupe de gueux enrôlés à Anvers et commandés par Jean de Marnix ; enfin, après la prise de Valenciennes, la soumission d'Anvers et la reddition d'Amsterdam, le départ d'Orange, le 22 avril, pour l'Allemagne. Événements décisifs qui faisaient écrire à Belin, notant la consternation des renardistes : «La plupart de la compagnie que sçavés [le Parlement] ont tant mangé de pommes d'orange que maintenant l'odeur leur en faict avoir mal de teste ».

Les conseillers faisaient néanmoins à leur mauvaise fortune beau visage. L'état de Président restait toujours vacant, et Belin, candidat de Granvelle, se plaisait à noter leurs déconvenues ; mais ils ne manifestaient ni plus d'ardeur à réprimer les troubles de Salins, ni plus de complaisance pour le cardinal, dont ils faisaient traîner interminablement les procès ; ni plus de zèle enfin à châtier l'hérésie. Le seul Belin paraissait s'en soucier ; sans cesse à courir par monts et par vaux, tantôt il allait instrumenter à Autoreille, seigneurie de Gy, contre un huguenot coupable de dogmatiser ; tantôt il procédait - avec quelle satisfaction, on le devine - contre un marchand d'Amance, sujet et créature de M. de Rye ; tantôt il interrogeait à Vesoul « un rustique de Mailley » trouvé possesseur d'un livre hérétique, ou « un de Mostereul-sur-Saône » qui avait à Jonvelle parlé contre la foi. Mais personne en Comté ne marchait sur ses traces; et à Vesoul même, à ses côtés, Belin pouvait voir son propre collègue, le procureur fiscal François Demongenet, laisser s'échapper non sans soupçon de complaisance un prêtre, le vicaire d'Oiselay, beau-frère et peut-être complice du « rustique » de Mailley.

\section{III}

Pourtant, lorsque le passage du duc d'Albe fut annoncé, lorsque son armée approcha du Comté puis bientôt le traversa, la cour de Dole sembla se réveiller un peu. C'est en juillet que se fait le passage; et c'est le 5 août qu'elle confirme en l'aggravant la sentence du lieutenant de Gray, prononçant la mort contre le dog- 
matiseur d'Autoreille, le marchand Lopin. Pareillement, c'est le 12 août, que le lieutenant de Vesoul condamne le huguenot d'Amance, Jean Darc, un marchand également, à avoir la langue tranchée, la tête coupée et le corps pendu au gibet de Vesoul. A ce moment, le vieux Marc de Rye se mourait à Bouclans d'un catarrhe ; cependant, conduit en appel devant la cour, son protégé put garder la vie sauve ; on le condamna seulement, le 6 septembre, au ban perpétuel après fustigation et section de la langue; le même jour, six hérétiques de Saint-Amour, dûment contumaces, étaient, eux aussi, déclarés bannis et leurs biens confisqués.

Au reste, ce n'était pas seulement le zèle d'un officier bailliager comme Belin, ou le passage du duc, qui contraignait le Parlement à se mettre en mouvement : la cour de Rome, elle aussi, intervenait dans les affaires comtoises et prouvait à tous qu'il ne s'agissait plus de « dissimuler ». Le 14 août 1567, deux brefs du pape arrivaient à Besançon. L'un était destiné, conjointement, au haut doyen du chapitre métropolitain et à l'Inquisiteur de la Foi ; l'autre, par l'intermédiaire de ces personnages, au Parlement. Ils dénonçaient à la cour comme hérétique, et la priaient de poursuivre en vertu des placards, l'ancien secrétaire d'Érasme, ce doux et paisible Gilbert Cousin qui continuait à étudier, à enseigner et à prier dans sa petite patrie, Nozeroy. Fort ébahis, au dire de Bellefontaine, que l'on eût « telles gens à l'oeil de si loing », les parlementaires firent diligence. Cousin s'était enfui ; deux conseillers purent le saisir à temps, l'arrêter à Jougne et le ramener à Dole. La cour faisait, cette fois, preuve de zèle ; mais elle ne pouvait s'y tromper : au pape, au roi, elle était suspecte de tiédeur et tout en cette affaire le montrait clairement. Qu'il fallût, de Rome, lui rappeler son devoir contre un «suppôt de Satan », n'était-ce pas la preuve d'une mollesse coupable - peut-être même d'une complaisance criminelle? « Je loue Dieu, écrit Jean de Saint-Mauris à ce propos, que le Roy sçait tout et qu'il y veut mettre ordre ; ce ne serat jamais trop tost, car il y ha jà trop longtemps que beaucoup d'ordures y règnent ». Et les chevaliers d'honneur, eux aussi, manifestaient des sentiments pareils. Comme le vice-président Henri Colin, le grand protecteur de Cousin, fort ennuyé sans doute de sa mésaventure, demandait à être excusé en l'affaire, ils déclarèrent tout haut «que si c'estoit contre leurs enfants, qu'ilz en congnoistroient, attendu le faict en soy ». Protestation significative contre les tiédeurs de la bourgeoisie parlementaire. Après le roi, après le pape, les catholiques ardents du Comté reprochaient aux conseillers leurs temporisations - les sommaient d'agir vite et sans complaisances. 
Fait intéressant, cette prise à partie des robins par des clercs et des nobles d'épée. Elle pouvait faire prévoir de nouveaux événements.

\section{IV}

Belin, nous l'avons vu, était candidat à la présidence. Candidat de Granvelle qui le patronnait chaudement. Lui-même, il se croyait des chances. Le 29 décembre 1566, en envoyant au cardinal copie de ses lettres d'institution comme avocat d'Amont, il lui annonçait que Renard avait écrit d'Espagne à son frère l'officier « que le Roy tenait fort sur l'advocat d'Amont »; dans toutes ses lettres, du reste, à mots couverts - car il était prudent - il remerciait chaudement son protecteur de ses entremises.

Belin, cependant, ne fut pas président. Le 15 septembre 1567, il reçut simplement de Marguerite l'ordre de venir par delà pour le service du roi. Ordre qui s'explique, d'une part, par la constitution du Conseil des Troubles : la nomination des juges, fiscaux et secrétaires de ce conseil, par le duc d'Albe, est du 5 septembre 1567 ; de l'autre, par la vacance, au Conseil Privé, du siège de conseiller réservé ordinairement à un Bourguignon depuis le décès récent du conseiller Grandjean. Comme l'écrivait Morillon à Granvelle, c'était à la fois « pour estre du nouveau Conseil et aussi au lieu de feu M. Grandjean » que l'on attendait à Bruxelles, l'avocat d'Amont ; il n'apprenait d'ailleurs rien à son correspondant, puisque c'était Granvelle lui-même qui s'était employé activement à faire appeler Belin aux PaysBas.

Belin partit donc. Il partit, non sans difficultés. Si Mme de Granvelle, la mère du cardinal, eut l'attention de lui faire tenir, à Jussey, « une belle robe de satin et une chamarre de damas », les « adversaires » pensèrent lui faire une dure conduite. Son zèle, sa vigilance, son éclatante partialité, ce qu'il mettait d'agressif dans sa fidélité au cardinal, tout contribuait à attirer sur lui la haine des renardistes et des orangistes. Plusieurs fois déjà, on l'avait averti de se tenir prudent, de ne pas voyager seul en territoire ennemi, à Gy par exemple, son pays natal, où l'archevêque Claude de la Baume était seigneur. Celui-ci l'accusait d'avoir dressé avec son beau-fils les requêtes présentées contre lui au pape et au chapitre de la part de 
Mme de Saint-Remy. D'autre part, les clients de MM. de Rye détestaient cordialement le promoteur du procès de Jean Darc, et lorsqu'il quitta la Comté pour la Flandre, un d'entre eux, Nicolas de Citey, partit à ses trousses pour lui faire en chemin un mauvais parti. Belin le crut du moins et le dit; naturellement, il en conçut pour les « adversaires » un renouveau de haine et, sitôt arrivé en Flandre, installé au Conseil des Troubles en qualité de fiscal, s'inquiéta de MM. de Dicey et de Rye : tous deux étaient morts ; leur disparition laissait le champ pleinement libre aux investigations.

Seulement, dans le milieu tragique des Flandres, à cette heure de crise et de répression sanglante, le nouveau fiscal bientôt s'affola. On l'avait mis au procès d'Egmont, et les haines autour de lui grondaient. Maladroit du reste, dépourvu de tact, il mêlait ouvertement le cardinal à ses passions, en se prétendant l'instrument de ses vengeances. Rien qui pût davantage déplaire au souple ministre, qui, de Rome, commençait à juger trop brutale la politique d'Albe. Il faut lire la curieuse, la vivante lettre que, le 23 décembre 1567, il écrivit à sa créature pour la morigéner à la fois et la remonter ; c'est un incomparable document pour la psychologie du cardinal. D'être haï, entouré de menaces et d'embûches, Belin s'émeut. Quelle pusillanimité ? « Les injures et les pilules, on doit les avaler sans macher, pour non sentir l'amer ». On l'emploie à des besognes trop compromettantes à la fois et trop modestes? « Pour Dieu, employez-vous en ce qu'ilz voudront et comme ils voudront. Ils ne vous donneront si bas lieu qui ne soit melieur que celui que vous teniez en Bourgogne ; s'ilz vous veulent entre les fiscaux, servez au goût du duc ». Et, faisant un retour sur lui-même : «Qui veut parvenir, il faut qu'il souffre ; ... qui veut s'avancer ne doit tant craindre sa peau... Si vous fussié été en ma place et en mon lieu quant, deux ans durant, l'on me disoit tous les jours que l'on me donneroit des coups de poignard, vous fussiés mort de peine... ; j'ai avalé cela doux comme lait. » Quant au reste : « Vous dites que l'ami ne doit être fiscal parce qu'il m'était ennemi mortel. Vous m'avés en cela fait un merveilleusement grand déplaisir, et de m'entremesler en cette sorte dans vos affaires... J'ai toujours fait et fais profession de non vouloir tenir personne pour ennemi, quelque mal qu'ilz m'aient voulu ; ... vous me ferez trop plus grand plaisir de non faire jamais mention à moi, ni en mal ni en bien, comme si vous ne m'eussiés jamais vu. »

Dure leçon. Belin en fut tout « esploré »; Morillon, peu sensible de son naturel, en a pitié. Ce Belin, « c'est très bonne personne et de grand zèle, sed non se- 
cundum artem »... - Et puis, la leçon était trop belle, trop forte pour lui. Il n'était point capable d'en profiter. Avec un peu plus de réserve, il continua ses investigations passionnées ; Granvelle, au reste, n'entendait pas l'en empêcher : « Il est bon, lui écrivait-il, que l'on veuille voir les signatures de la confrérie, et je crois bien que Citet et celui qu'est icy [Claude de la Baume] en sçauraient à parler, et Renard et Sonnet, et quelques aultres de la compagnie. Vous pouvez discrètement découvrir, en la charge que vous avez, beaucoup de choses »... De fait, Belin «n'en dormait » au dire de Morillon ; mais toujours excessif et dépourvu de sang-froid, au moindre accident, se forgeait des romans. Il faut voir ses inquiétudes et ses suppositions, ses craintes d'assassinat et ses transes mortelles lorsqu'il sait en route le messager chargé d'apporter depuis Dole les documents relatifs à la Confrérie de Sainte-Barbe. Et quelle joie délirante, lorsque les papiers, enfin, sont en lieu sûr - avec la preuve tangible que M. de Rye avait été vraiment l'âme du complot...

Or, l'action d'un Belin avait son importance pour la Comté. Seul Bourguignon, parmi tant d'Espagnols et de Flamands, ses avis, ses opinions tiraient de son origine même une valeur particulière ; ses affirmations sans cesse renouvelées, qu'il s'était trouvé en Comté de grands coupables ; que la justice n'avait pas contre eux fait tout son devoir ; qu'il y avait eu des fautes et des complaisances - toutes ces récriminations étaient mal faites pour rétablir, dans l'entourage du duc d'Albe, le crédit ébranlé du Parlement de Dole. Chose grave, alors que tant d'événements s'accomplissaient ailleurs, qui trouvaient en Comté leur répercussion.

\section{V}

C'était d'abord la ruine définitive de Renard, au lendemain de la capture d'Egmont et de Hornes - cependant que Montigny, « son prototype », était enfermé à Simancas. Renard, lui, restait libre. Mais on le surveillait de près. On lui faisait tenir un questionnaire sur sa conduite. Tandis qu'il se débattait, le duc d'Albe, sans succès d'ailleurs, faisait rechercher par Belin les charges anciennes et des preuves nouvelles. C'en était bien fini du rival de Granvelle. Presque en même temps, le prince d'Orange était frappé. Plus méfiant qu'Egmont et Hornes, il ne s'était point laissé prendre par le duc d'Albe. Du moins celui-ci fit-il instruire son 
procès et saisir ses biens. Dès le 19 décembre 1567, un conseiller du Parlement de Dole était expédié en hâte à Sainte-Anne et à Chatelguyon pour saisir l'artillerie, les meubles et les titres qu'il trouverait dans ces deux seigneuries. C'est que partout, sur les frontières, des troupes cheminaient, des armées s'organisaient pour le compte des huguenots ou des gueux. Le fils de l'Électeur Palatin s'occupait activement à réunir les 9000 reîtres qu'il allait amener, après la bataille de SaintDenis, à Condé et à Coligny. A Lausanne, $\mathrm{M}$. de Citey et un secrétaire du prince d'Orange, travaillant pour leur maître, racolaient force gens de pied. En France, les huguenots s'armaient, coupaient les communications, isolaient la Comté en empêchant les transactions. Par surcroît, l'hiver s'annonçait mal ; des pluies terribles détrempaient les routes, grossissaient les fleuves, préparant, comme l'écrivait Ferdinand de Lannoy, « bon chemin pour les reystres passer rivières et ruisseaux et fanges et petitz jours et longues nuitz pour estre mal logez ». Les temps n'étaient pas sûrs, la vie difficile.

Sainte-Anne occupé, la saisie d'ailleurs se poursuivit méthodiquement. Après échange de vues entre Parlement et Chambre des Comptes sur le mode de gestion des seigneuries confisquées, une ordonnance de M. de Vergy mit sous la main du roi, le 4 février 1567-68, toutes les terres et seigneuries appartenant à Guillaume d'Orange. La prise de possession fut faite, à la fin de juillet, sur arrêt du Parlement, par Vergy lui-même assisté de deux conseillers. Les biens de Jean de Marnix et de son frère Philippe en Comté s'y ajoutaient : leur seigneurie de Toulouse avait été saisie également. D'ailleurs, tout resta en l'état. Le receveur des seigneuries de Chalon, Jean de Mesmay, fut chargé d'achever l'année en cours, puis à nouveau, au début de 1569, continué provisoirement dans ses fonctions. Pareillement, toutes les amodiations conclues au nom du prince furent maintenues, mais refaites au nom du roi ; dans les seigneuries non amodiées, des receveurs furent institués par la Chambre des Comptes, à charge d'appliquer les principes de gestion en usage dans le domaine. Au reste, nulle distinction dans le mode d'administration ne subsista bientôt plus entre l'ancien domaine et le domaine confisqué ; lorsqu'en 1569 un receveur général des confiscations fut institué, le propre receveur général du Comté, Philippe Marchant, fut choisi et remplit ces fonctions jusqu'en 1579.

Entre temps, les comptes et pièces d'archives saisis à Chatelguyon avaient été examinés par la Chambre des Comptes. Le receveur général, Jean de Mesmay, et 
l'auditeur et greffier des comptes de Chalon, Jean Picquenet, ayant signalé beaucoup de documents comme restés aux mains d'Étienne Stratius, grand bailli de Chalon, la Chambre les fit saisir et inventorier par un auditeur et un conseiller au Parlement conjointement. On trouva là des pièces intéressantes ; surtout, au dire de Ferdinand de Lannoy, des « écritures » de Stratius, ce " gentil Stratius » à la déconfiture duquel Morillon pensait lorsqu'il annonçait au cardinal la confiscation des domaines de Chalon. Le grand bailli avait, paraît-il, écrit sur Granvelle « cosas diabolicas ». On découvrit aussi, parmi différentes lettres «toysant à aucuns de la court », des missives autographes du prince de Condé à certains conseillers et au premier de la Chambre des Comptes, les « advertissant de la confiance que avoit en eux en tous ses affaires et aussi que ils le avyseroient de ce que passoit par deçà ». Les accusations étaient graves ; mais leur imprécision donne fort à penser qu'elles n'avaient pas grand fondement : Lannoy, sans doute, est un simple écho de bruits calomnieux pour le Parlement.

La situation n'en devenait pas moins fort critique pour la cour de Dole. Belin avec toutes ses ardeurs, ses récriminations et ses campagnes rétrospectives, avait enfoncé dans l'esprit du duc d'Albe, fort prêt à l'accueillir, l'idée que les conseillers étaient « à demi-gâtés » et que, par eux, on ne pourrait rien savoir. Vergy, de son côté, pensait, disait, écrivait la même chose. Une conspiration se formait contre le Parlement, d'éléments dissemblables, de bourgeois et de nobles qu'on n'avait point coutume de trouver réunis. La situation avait bien changé depuis les débuts du règne de Philippe Il. Alors, c'était Granvelle, qui couvrait une assemblée peuplée de ses créatures, représentant sa classe et ses intérêts ; pareillement, c'était lui que prétendait atteindre, en attaquant le Parlement, une troupe fougueuse de gentilshommes d'épée, haïssant le chef incontesté, l'incarnation la plus haute de la bourgeoisie. A l'écart, le gros de la noblesse avec $M$. de Vergy se réservait, observait, attendait son heure. Et voilà que cette heure était venue ; voilà que la disparition, la disgrâce ou la ruine de ces passionnés qui attaquaient, dans le Parlement et dans la famille Perrenot, toute une classe conquérante et victorieuse avait marqué non pas le triomphe de ce Parlement, mais le début d'un nouvel assaut. La masse de la noblesse, Vergy en tête, sortait de sa réserve, et pour son compte recommençait l'attaque - tandis que Granvelle, dans son Italie lointaine, s'il ne se désintéressait pas du conflit, semblait penser du moins que les fautes du Parlement méritaient une leçon - et qu'en Flandre ou en Comté même, beaucoup 
de ses partisans, parmi eux des bourgeois, des légistes, des hommes de robe comme Belin joignaient leur propre effort à l'effort des nobles. De ce renversement des attitudes et des situations, la Réforme surtout était responsable, et l'on pouvait mesurer maintenant l'importance de ses manifestations. Ne fournissaientelles pas, à ce moment décisif, aux uns les raisons, aux autres les prétextes de leur attitude et de leur action?

\section{VI}

Dès février 1568, le duc d'Albe avait expédié, au dire de Lannoy, des commissaires à Dole, chargés de se rendre compte de tout, et surtout de la manière dont étaient observées les ordonnances. Les conseillers, déconcertés par les événements, se sentaient épiés, surveillés, jalousés. Pendant ce temps, l'autorité qui leur échappait passait aux gens de guerre. Sous la menace des invasions, devant les allées et venues des huguenots et des reîtres, les villes principales de la province avaient renforcé leurs garnisons. Le gouverneur avait fait passer en revue, dans les trois bailliages, le ban et l'arrière-ban ; et si beaucoup de féodaux avaient fait défaut, si quelques-uns des plus guerriers et des mieux entraînés s'étaient trouvés absents, servant le roi aux Pays-Bas ou hors du Comté, de nombreux gentilshommes étaient accourus cependant, dans l'équipement requis, et s'étaient mis à suivre soit le rière-ban, soit le gouverneur. Sous les ordres de MM. de Lannoy et de Vergy, ils faisaient bonne garde aux frontières, bien décidés à « faire donner au diable » la Comté par les ennemis, s'ils tentaient jamais d'y pénétrer.

Fréquentes étaient les alertes. C'était le moment où Jean-Casimir venait une première fois au secours des huguenots français par la Lorraine ; où Condé et Coligny rejoignaient ces alliés précieux et s'avançaient avec eux sur la Loire, tandis que le prince d'Orange faisait des levées en Allemagne. Il n'était bruit que de guerres, de marches et d'entreprises. Besançon s'armait en décembre 1567, recevait de Lannoy l'offre d'une garnison espagnole, réparait ses murailles, murait, sur le Doubs, les portes et les fenêtres des cordeliers. Tant que les reîtres et Condé furent proches des frontières, on demeura sur le qui-vive. Eux partis, nouvelles appréhensions : 12000 Suisses n'allaient-ils pas les rejoindre à travers le Comté ? 
Puis, les craintes évanouies, on annonça en septembre que, Guillaume ayant vendu ses biens au duc de Wurtemberg, celui-ci allait venir en prendre possession. Les cavaliers comtois veillaient attentivement et faisaient bonne figure ; mais ils coûtaient cher à entretenir. Les finances étaient au plus bas, et la bourgeoisie murmurait contre les dépenses militaires. La noblesse, indignée, en prenait texte pour crier à la trahison. Lannoy écrivait à Granvelle, le 24 février 1568, que si les huguenots approchaient jamais de Besançon, «sur l'ombre de leurs forces, quelques malereux pourroient trayr la ville ». Et $M$. de Vergy chargeait, en mars, Gaspard de Saulx-Tavannes d'interroger un aubergiste du duché ; il avait dit à un marchand de Pesmes « qu'il y avait dans Dolle plus de trois ou quatre cens huguenautz qui avoient délibéré surprendre la ville ». Quatre cents huguenots dans Dole ! L'assertion valait d'être vérifiée....

Telle était, en Comté, la tension des esprits, tel l'antagonisme des intérêts. On comprend, dès lors, quelle émotion dut provoquer, quelle explosion de joie chez les nobles, quelle tristesse et quel accablement chez les parlementaires, la lettre que, dans les derniers jours de mars 1568, le duc d'Albe adressa à M. de Lannoy. Elle donnait au bailli d'Amont l'ordre de procéder immédiatement dans les trois bailliages, par lui-même ou par des lieutenants, toutes formalités et juridictions ordinaires mises de côté, à une enquête générale sur les agissements aussi bien de la confrérie de Sainte-Barbe que des suspects de «luthéranisme » répandus un peu partout en Comté. Lettre extraordinaire qui, au mépris de toute hiérarchie et de tout droit, annulait l'autorité du Parlement et revêtait des pouvoirs les plus étendus non pas même le gouverneur de la province, mais un simple bailli l'homme qui, depuis plusieurs mois, s'était montré le chef le plus actif de la noblesse comtoise, le plus zélé des gentilshommes armés pour la défense du pays.

Lannoy, tout de suite, songea à Salins, la grande ville turbulente où le Parlement avait si peu sévi. La peste du reste, en 1567, y avait été terrible et avait arrêté les investigations. Aussi, le bailli d'Amont y lança son lieutenant, et celui-ci fit vite une copieuse récolte de « huguenotz »; le 31 mars, Lannoy en avertissait le duc d'Albe ; il lui envoyait triomphalement la liste des arrestations, avec leurs motifs. «Les uns, écrivait-il à Granvelle, ont fait actes de lutériens ; les autres ont esté consentans d'un meurtre ; aultres sont de nuit marché avec enseygne déplyé pour joindre les conjurés ; autres se sont vanté publiquement entre eus que, dedens peu de temps, et il seroyent maître des byens de l'église à Salins et que cela 
estoit pour eus et chasseryent tous les prestres et gens d'église ». Toute sa lettre est d'un même ton, joyeux et satisfait ; par trois fois il revient sur cette idée « qu'il en i arat des honteux en ce pays, voiant le peu de devoir que la court fyt sur ces affaires de sy grande importence ». Les conseillers, naturellement, se montraient fort émus de cette procédure. Jamais on ne leur avait signifié pareillement en quelle méfiance on commençait à les tenir. Sans doute, ils protestaient, marris de l'aventure, déclarant « que cela n'apartenoyt à nulluy que à eus de fère ces informations » - puis, ironiques, demandaient au lieutenant de M. de Lannoy : «Que porrés-vous feyre ? pensés-vous fère rnélieure informacion que la court a feit ? » Le bailli laissait dire et continuait son œuvre. Il s'enquérait d'un prêtre « qui avait presché en Amance choses contre nostre Sainte Foy ». Il s'occupait de la confrérie de Sainte-Barbe, dont « le commencement » venait de feu M. de Rye. «Si vyvoit, écrivait-il, je pense qu'il serroit en cage, et je ne sçay si ses biens en porroient encore répondre. » On emprisonnait un orfèvre de Gray « pour avoir faict certaines médailles de gerbes de flesches ». Les prisons se remplissaient à Dole, à Gray, au château d'Autrey, résidence favorite de $\mathrm{M}$. de Vergy. Le mariage de la veuve de Claude-François de Rye avec un Français, Léonor de Chabot-Charny, achevait d'indisposer la noblesse comtoise contre la famille de Rye. Belin suivait attentivement à Bruxelles toutes les informations. C'était le moment le plus terrible de la réaction; le 4 juin 1568, Egmont et Hornes montaient sur l'échafaud où Pierre d'Andelot les avait précédés ; la terreur régnait partout ; jamais les pays de pardeçà n'avaient connu de pires jours.

Cependant, l'ardeur de la noblesse comtoise, la passion de Ferdinand de Lannoy s'apaisaient peu à peu. Maintenant que l'on avait sévi, que les inculpés de Salins tenaient sévère arrêt ou prison fermée, il fallait raisonner. Peut-être s'étaiton laissé entraîner un peu loin ? Toujours est-il que les arrestations avaient été faites à la fin de mars 1568 ; que, le 27 juin, Morillon avertissait Granvelle que l'instruction n'avançait guère, et qu'on ne trouvait « fondement de procéder contre la mémoire de $\mathrm{M}$. de Rye ni du borgne Guillon »; enfin, que le 12 novembre 1568, à la rentrée de vacances du Parlement, celui-ci était saisi de l'affaire et délibérait sur «ce qu'estoit à faire à l'encontre des prisonniers de Salins.... accusez d'avoir commis crime de lèse-majesté ».

Après discussion, on en fit deux groupes. Les uns furent relâchés à caution ; les autres, plus compromis, gardés en prison close. On les veillait de près : le 
concierge de la prison les ayant laissés communiquer ensemble fut révoqué sans pitié. Cependant les interrogatoires révélaient peu de nouveau. Les inculpés avaient pris part à des manifestations séditieuses. L'un d'eux notamment, Jean Trouhet, avait écrit « une chanson et libelle diffamatoire » contre plusieurs tant de Salins que du Comté ; il avait de plus déclaré que le prince d'Orange « rentrerait en ses terres et services, qu'il serait maître ». Le 29 mars, on décidait de lui donner la question et d'en attendre le résultat pour statuer sur le sort de ses co-inculpés. Le 11 mai, ceux-ci étaient tous relâchés sous caution, sauf Trouhet, dont le sort fut réglé le 15. Aux violents, à Belin, à Chaillot qui réclamaient la mort pour lèsemajesté ; à Chappuis qui voulait les galères, s'opposaient les indulgents, les tièdes, les antigranvellistes impénitents: Le Clerc, éternel temporisateur; Vauchard, Chifflet, Boisset, Sonnet, à qui dix ans d'exil et l'amende honorable paraissaient suffire. Finalement, une solution moyenne - celle de Colard, de Chuppin, du viceprésident Henri Colin - l'emporta. Le coupable, tête et pieds nus, en chemise, torche au poing, dut « crier mercy à Dieu, au Roy, à sa justice et à tous ceulx contre lesquelz il a escript lad. chanson », puis porter sa torche à Notre-Dame; cette humiliation subie, il avait dix jours pour quitter le Comté à tout jamais. Quant aux comparses, l'affaire traîna en longueur ; on les remit d'audience en audience ; l'un d'entre eux, Lardon, disparut de maladie; de réajournements en réajournements tout s'éteignit....

Un fait regrettable était venu d'ailleurs édifier la cour sur la partialité de la première enquête. Le 15 décembre 1568, un tisserand de Salins, Estevenin Mathieu, en appelait à elle d'une sentence de mort portée contre lui par le lieutenant de Salins, Pierre Marceret. L'accusé, aux termes du jugement, aurait tenu divers propos scandaleux en matière de foi. Il s'en défendait énergiquement, accusant les témoins de mensonge et le substitut, Simon Vigoureux, de partialité : il lui aurait, disait-on, porté haine à cause d'une femme. De fait, la cour convainquit deux des témoins de mensonge et les fit pendre et étrangler ; quant aux officiers, le lieutenant fut condamné à 200 livres d'amende et le substitut à 100. Haines locales, passions et rancunes personnelles : c'était toujours le règne des « envies de Bourgogne ». Le Parlement restait profondément divisé. Sans doute, le passage du duc d'Albe, l'enquête confiée à F. de Lannoy avaient réchauffé un peu son zèle catholique. Le 16 mars 1568, il avait condamné à mort un hérétique de Pesmes, coupable d'être allé vivre en pays réformé, d'y avoir assisté aux prêches, pris part à la 
Cène et mal parlé des prêtres et des sacrements. La police des livres se faisait sévèrement ; non moins sévèrement, celle des moeurs et des pratiques religieuses. En 1568, en 1569, c'est toute une série d'inculpations et de condamnations : contre un carme fugitif de Clairvaux ; contre deux paysans de Vernierfontaine, deux violents qui brutalisaient leur curé, l'appelaient « asne, diable de prebstre » et lui mettaient sur la tête, d'un geste inélégant, "des cornetz de papier en forme d'oreilles »; contre le curé de Champagney-lez-Pesmes, hantant les hugenots d'Auxonne et chantant la grand'messe " après avoir desjeuné »; contre deux prêtres encore, les frères Claude et Didier Payen de Jussey, dénoncés par des ennemis personnels comme entretenant avec les gueux des relations criminelles. Pareillement, on surveillait de près les suspects de Saint-Amour, sur la frontière lyonnaise, ceux de Rupt, de Luxeuil, sur la frontière lorraine, ceux de Saint-Claude aussi, proches de Genève. Des prêches se tenaient toujours à Fontenoy, et Belin ne dormait des méfaits, jusqu'alors impunis, d'un nommé Jean Muretel, de Jonvelle, un orangiste décidé qu'il ne pouvait parvenir à prendre. Mais cette activité, cette vigilance ne satisfaisait pas les catholiques les plus fanatiques, les «granvellistes » les plus convaincus. Si l'on faisait bonne garde aux frontières, si l'on arrêtait les étrangers, les passagers, on n'enquêtait guère sur les sédentaires, les habitants des villes et des bourgs. Surtout, les poursuites entreprises ne rendaient pas crédit à la Cour de Dole. Son prestige, des événements de mars 1568, avait reçu une atteinte irréparable. Et c'était chose grave que cette diminution.

\section{VII}

A cette époque d'ailleurs, Belin n'était plus aux Pays-Bas. Il s'y déplaisait trop - et il y déplaisait. Pas assez de souplesse, de docilité, d'obéissance. Au début, il gardait encore ses illusions sur la présidence. Mais il avait bien vite déplu au duc d'Albe. Dès juin 1568, il était jugé impossible au Conseil des Troubles et son collègue Hessele, neveu par alliance du président Viglius, l'informait qu'on entendait le pourvoir soit « d'un estat de conseiller au Privé Conseil, ou bien de l'estat de conseiller au Parlement de Dole », comme il lui conviendrait le mieux. Belin demanda à en référer à son grand protecteur, le cardinal. Celui-ci lui conseilla vivement le Conseil privé. Sans doute tenait-il à garder sur les lieux un informateur, 
souvent maladroit, mais curieux ? Belin, du reste, ne tint pas compte de ses recommandations. Les Pays-Bas lui déplaisaient de plus en plus. Il y avait trop mal réussi vraiment. La Bourgogne, le petit monde familier du pays, et la vieille maison, et les vignes de Gy emportèrent tout. Il partit, laissant au passage à Paris l'un de ses fils chez les jésuites, " gens notoirement bons crestiens ». En août 1568, il était à Vesoul.

Immédiatement, il se remit en relations avec MM. de Vergy et de Lannoy et s'appliqua à l'étude des dossiers que le gouvernement lui fit tenir pendant les vacances. C'est ainsi notamment que les interrogatoires à faire subir aux Salinois prisonniers furent rédigés par lui. Du reste, son retour n'était pas demeuré inaperçu. En septembre 1568, un des inculpés de Salins, Claude Lardon, déclarait spontanément à l'instruction qu'ayant dîné, à la fin d'août 1568, chez Claude Alix de Salins, le frère de ce personnage, Jacques, lui avait raconté être allé au camp du prince d'Orange, près de Strasbourg, et y avoir appris que le prince enverrait « jusques à 60 personnages bien montez, qui se repartiront deux, trois à quatre pour rencontrer et tuer l'avocat Chasné, pour avoir faict et fulminé le procès du conte d'Eguemont ». L'avocat Chasné c'était Belin ; averti aussitôt par son beaufils, Prudent de Saint-Mauris, il s'abstint soigneusement de se mettre aux champs, resta à Vesoul trois mois durant sans en sortir, et n'apprit pas sans émotion qu'au début de décembre, un chanoine de Besançon avait été assassiné dans un bois par deux « galands lorrains » descendus à Vesoul au logis du Lion d'or, et munis chacun d'une « longue acquebouze ». Jacques Alix avait été vu avec eux : il fut arrêté, mis en prison et, sur appel, transféré à Dole. Belin, pourvu enfin de son état de conseiller, l'y suivit ; il prêta le serment d'usage le 8 décembre et, convaincu que les coups portés au chanoine lui étaient destinés, se mit avec passion à besogner, selon les conseils de Granvelle, « contre les sectaires » et les Salinois. Du reste, les occasions de satisfaire ses haines n'allaient pas lui manquer. 
PHILIPPE II ET LA FRANCHE-COMTÉ

Étude d’histoire politique, religieuse et sociale.

Troisième partie. La Comté et la révolution des Pays-Bas

\section{Chapitre XVIII}

\section{Le passage du Duc de Deux-Ponts}

$\underline{\text { Retour à la table des matières }}$

C'est une coalition disparate, une coalition, sinon de hasard, du moins de circonstances, qui, en 1567, s'était formée de tous les fidèles serviteurs du roi contre un Parlement suspect d'« orangisme », de tiédeur religieuse et de ménagements politiques. Elle avait agi ; elle ne pouvait durer.

En dépit de haines communes, trop d'intérêts contradictoires opposaient ses membres les uns aux autres. Nobles d'épée et bourgeois de robe - un Lannoy d'un côté, un Belin de l'autre, avaient pu, pour un temps, solidaires dans la rancune et la passion politique, collaborer à l'attaque de parlementaires «floches » et suspects ; Granvelle n'avait rien dit, heureux peut-être de voir infliger une leçon à d'ingrats protégés, et trop bon serviteur de l'absolutisme pour ne pas se réjouir d'une action énergique du ministre : une telle attitude ne pouvait se prolonger. Tandis que la noblesse d'épée, grisée de ses succès, forte de la faiblesse présente du Parlement, s'efforçait d'assurer sa revanche sur la robe humiliée - les bourgeois, d'autre part, gens de lettres et de justice, ceux-là mêmes qui, comme Belin, avaient collaboré le plus activement aux attaques dirigées contre la cour de Dole, se reprenaient maintenant et, la crise passée, les adversaires réduits à l'impuissance se retrouvaient, bourgeois et parlementaires avant tout, hostiles aux nobles par 
toute leur vie et tout leur être, décidés fermement à reformer contre eux un bloc compact de solidarités.

Ce fut à propos des affaires de guerre, de l'éternelle question des milices et de la défense provinciale, que la rupture se fit ou, du moins, s'annonça.

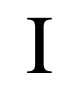

Lorsqu'en janvier 1568, 32 cornettes de reîtres et de lansquenets, soit 6000 cavaliers, et 4000 piétons, défilaient au long de la Comté, pour aller rejoindre l'armée de Condé, M. de Vergy et M. de Lannoy, avec 200 arquebusiers à cheval, les avaient suivis côte à côte « pour éviter une correrye », rompant ponts et passages, faisant retirer vivres dans les villes fortes et « otter tous les bateaux de la Sonne ». S'ils veulent fourrager, écrivait gaillardement Lannoy, « ils trouveront les boys farcis d'arquebusiers ; " s'ils veulent forcer le passage, « ce ne serrat sans que yl y en at par terre ». La tactique avait réussi ; les reîtres n'étaient pas entrés.

Plus tard, en février, quand les huguenots campaient aux environs de Langres, Lannoy, à nouveau, s'était tenu prêt, avec quatre cents arquebusiers, "pour aller donner par les boys ou vyllages sur cheus que eussent entreprins quelque malice sur le pays ». Qu'ils y viennent, écrivait-il à nouveau à Granvelle : "Nous leur montrerons que avons bon corrage, non seul de nous gharder mais de les aller assaillir entrant au pays ». L'éventualité ne s'était pas produite; mais l'humeur batailleuse de la noblesse comtoise s'était réveillée devant tous ces préparatifs ; espoirs de chevauchées et rêves de bataille l'avaient reprise ; la pacifique Comté redevenait un bon pays pour la gent militaire, dédaigneuse des ligues et des neutralités.

Au mois de mai enfin, lorsque Casimir, ses reîtres et ses gens de pied, traînant derrière eux un énorme train de «treize cens charyots tout chargé de butin, et byen mille et cinq cents bêtes à corne », se trouvaient à sept lieues de Gray, c'était à la tête d'une petite armée que Lannoy et Vergy surveillaient leur marche, « cottoiant ces diables » et veillant aux frontières. On avait proclamé « l'éminent péril », convoqué les ban et arrière-ban, ceulx du bailliage d'Aval à Pesmes, ceux du bailliage de Dole à Gray et ceux d'Amont à Vesoul ». Lannoy, sorti de Gray avec 
120 bons arquebusiers et 25 chevaux, était allé rejoindre d' « autres bons arquebusiers »; il avait charge de l'avant-garde. Vergy menait le gros, c'est-à-dire le ban et l'arrière-ban des bailliages de Dole et d'Aval, conduits par MM. d'Andelot et de Château-Roillaud ; les « mélyeurs vyeux soldatz » de Dole, sous les ordres de M. de Thoraise ; 300 arquebusiers à pied et deux compagnies d'arquebusiers à cheval, commandés par M. de Scey, gendre de M. de Thoraise ; 200 arquebusiers à M. de Montot ; 120 à M. d'Oiselay ; 60 à M. de Champvans ; en tout, 2000 arquebusiers et 400 chevaux, sans compter, prêt à la rescousse, le ban du bailliage d'Amont. C'était fête pour la noblesse comtoise.

Les amis de Granvelle ne s'étaient pas oubliés : Lannoy, son beau-frère, menait la bande ; M. de Champagney, le plus jeune frère du cardinal, lui était venu servir comme d'aide de camp, « avecq bone troppe de gentishommes »; M. d'Andelot était le neveu par alliance du cardinal ; M. de Château-Roillaud, son neveu également ; M. de Thoraise (Jean d'Achey), son beau-frère ; M. de Montot (Claude de Beaujeu), son allié. Troupe joyeuse et gaillarde, heureuse de cette parade militaire, songeant aux beaux exploits, aux grades et aux pensions : rien d'intéressant, rien de passionné et d'allègre comme les lettres qu'en cette saison troublée, Ferdinand de Lannoy adresse au cardinal. Vraies lettres de reîtres, a-t-on dit, aux phrases courtes, saccadées, souvent incorrectes - et puis, tout d'un coup, de grandes poussées joyeuses, des détentes de colère, de plaisir, de passion : tout le roman de la guerre d'alors, guerre d'embuscades et de partisans, écrit en selle par un soldat de race, d'une longue écriture gauche, malhabile et hachée. Surprises au petit jour, après de longues chevauchées nocturnes ; embuscades dressées au coin d'un bois, au long d'un de ces passages « sans boys ne brussaylle » qui, de distance en distance, trouaient l'épaisse muraille forestière du Comté ; dialogues rapides avec les coureurs ennemis, aux portes d'une bicoque hasardeuse qu'il s'agit de défendre : «Ouvrés, ouvrés, dit l'ennemi. - Que volés-vous ? Volons entrer et volons vyvres et avoyne. - On leur dyt : retiré-vous ! - Un d'eus s'avance avec le pistolet - on le tirat d'une fenêtre, tombat mort et quatre autres et huit blessés. » Stratagème classique, un tambourin "tout seul, sonnant par les brussailles ", achève la déroute et les reîtres s'enfuient... Au dire de Lannoy, c'était d'ailleurs ce qu'ils faisaient de mieux. Il faut lire, dans une de ses lettres, le récit coloré qu'il nous donne de la défense d'un pont, près de Voisey : « $M$. le ghouverneur ettant retiré au pont, on y myt arcabusiers, et un de leur chef s'avança près du pont. M. 
de Champaygné, le capitaine, l'abatit net par terre et luy print le cheval au dépit d'eus. A la fin, demandarent à parlamenter, chose de gran vyllesse, s'ettant scaramussé. Ayant fait signe qu'il s'approchasse, dyt en bon françois : «Ôtté moi ces fleutes, ces longhes arcabuses, et je parleray ». L'ayant assuré, il parlat et dit: «Où est M. le ghouverneur? - Il est issi. - Il répondit: « Notre colonel m'a dit que il veut savoyre pourquoy on luy tue de ses gens, et porquoy on leur feit la gherre ». - On lui répondit : " Pour ce que vous venés à conté de Bourghogne brûler, saquager et tuer les sugectz de Sa Majesté, comment vous avez feit à Voysé... » - Y répondit : «Ce n'est pas nous, se sont cheus qui suyvent la troppe ». - On luy dit : « Porquoy vous accompaygné-vous de sy malheureuses gens ? Si vous entrés au pays de se conté, nous vous ferons partir dehors plus que de pas, et on tuerat tout se que on rencontrerat, car nous ne vous demandons ryen, sy ne ne feyssés ! - Il répondit : «Byen, byen, je feray le raport », et vire son cheval et s'en vat vers la troppe et tout s'en retorne sans autre chose »... Piètres soudards, conclut Lannoy, dédaigneux : « Se ne sont la plupart que serviteurs et canailles ».

Ainsi la noblesse comtoise moissonnait des lauriers faciles à cueillir. L'orgueil provincial s'exaltait. Les difficultés semblaient s'évanouir. Les louanges des Français flattaient agréablement les amours-propres locaux ; celles du duc d'Albe engendraient les belles espérances de fortune et de pouvoir. Lannoy surtout, le vrai chef du pays, ne connaissait plus d'obstacles : les reîtres reviennent ? « Il se faut mettre au frontières, lessant Gray et Dole bien forny et les faire enragé nuit et jour. Serroit mieux de i point venir, mais s'il i viennent, il i en arrat de par terre ! » - On dit, en septembre 1568, que le duc de Wurtemberg " s'en mêle » : que le roi saisisse donc Montbéliard et ce qu'il tient en Ferrette. L'entreprise serait facile: "Nous conoissons les Allemans : être bien payé et avoir forse vivres et peu combattre ». Quant aux huguenots, qu'ils passent la Saône s'il leur plaît : ils ne la repasseront pas ! - Bravades agressives ; Lannoy qui, dans ses chevauchées, était en train de gagner son gouvernement d'Artois, avait ses raisons sans doute pour s'y livrer. Mais en Comté beaucoup commençaient à dire tout bas ce que pensait la bourgeoisie : que la noblesse militaire allait un peu trop loin et dépassait la mesure. 


\section{II}

On le vit bien aux États de février 1569. Sans doute tout se passa très correctement, et lorsqu'on lit le compte rendu officiel des délibérations, aucune opposition n'apparaît entre noblesse et bourgeoisie. Les commissaires du roi : Vergy et le vice-président Henri Colin, après lecture de lettres royales remerciant la province du bon traitement accordé au camp du duc d'Albe, que S.M. savait bien « n'avoir esté sans grand coutange aud. pays », et de la résistance faite aux huguenots et aux reîtres « le coustoyant pour y entrer hostilement », réclamèrent le vote d'une somme de $100000 \mathrm{fr}$. applicable aux fortifications de Dole et de Gray. Les États, après discussion, votèrent 60000 fr. pour le roi et 20000 fr. pour les récompenses. Il fut décidé en plus qu'on garderait en réserve pour les cas graves « quelque épargne de deniers que l'on appelle surjets levés »; que les frais de perception et d'également du don gratuit seraient réduits sévèrement; enfin, qu'une commission revisant les comptes anciens ferait rendre gorge à tous ceux qui conservaient encore des deniers publics : l'argent rentré servirait à la défense du pays en cas d'incursion ou d'invasion. Sur les 20000 fr. des récompenses, 6000 furent de suite accordés à Vergy ; Lannoy toucha 4000 ; Henri Colin et le président Viglius, 800 chacun ; Bave et Courteville, 300 ; Belin, 500 ; enfin, parmi les gentilshommes qui avaient pris les armes, M. de la Villeneuve eut 500 fr.; M. de Thoraise, 800 ; M. de Château-Roillaud, 600 ; Bonet Jaquemet, ordinaire négociateur des affaires comtoises en Suisse, 500, et l'écuyer Franchet, son second, 300.

La noblesse, comme on voit, n'était pas oubliée. Pourtant elle n'eut pas lieu d'être entièrement satisfaite des débats. On le devine à vrai dire, plus qu'on ne le sait : les textes sont rares et elliptiques. Mais, d'une part, beaucoup de députés des villes arrivaient à Dole ulcérés des méfaits, des abus commis par les cavaliers comtois dans leurs chevauchées : tel, ce François Demongenet, procureur fiscal du bailliage d'Amont, dont l'attitude provoqua même un incident. De fait, les États décidèrent de faire instance au roi pour qu'il traite et arrête une ligne défensive réciproque et perpétuelle entre la Comté et les cantons suisses. L'idée n'était pas pour agréer aux nobles d'épée, tout fiers de leurs récents exploits, tout portés à croire désormais la Comté capable de «faire de soi » sous leur direction - sans 
qu'il fût besoin de ligues ou d'alliances. D'ailleurs, nous connaissons mal les incidents qui se produisirent alors, et nul parmi ceux qui assistèrent aux États ne nous a laissé à ce sujet de détails explicites. Ce que Lannoy signale surtout, c'est une reprise de la campagne jadis menée par les Rye contre le cardinal de Granvelle, dont on aurait surpris des lettres violentes à l'encontre de divers gentilshommes comtois : MM. de la Baume, de Saint-Claude, de Balançon, de la Villette, de Wateville, de Citey : le prudent diplomate aurait écrit d'eux qu'il serait bon de les faire prisonniers. Il s'en défendit fort et non sans apparence de raison. Mais il n'est pas moins intéressant de noter cette reprise d'hostilités à son endroit, au commencement de cette année 1569 qui, après la crise de 1568, allait voir se reconstituer en Comté, face à face et sous leur ancienne forme, le groupe nobiliaire et le groupe parlementaire. Cela, définitivement, à la suite du passage de Wolfgang de Deux-Ponts.

\section{III}

Le 25 février 1569 arrivaient à Dole des lettres « du comte Palatin se disant duc de Bavière, que l'on tient être le duc des Deux-Ponts ». Wolfgang de Bavière, car c'était lui, en effet, demandait à M. de Vergy et à la Cour « paissaige par led. pays avec son exercite en paiant raisonnablement ». L'émoi fut extrême parmi les conseillers, qui dépêchèrent en hâte vers le gouverneur. Tous les malheurs semblaient fondre sur la Comté : après les pestes, les inondations et les mauvaises récoltes; après les abus des munitionnaires, lors du passage du duc d'Albe, et les alarmes des Comtois lors des allées et venues de Casimir, les reîtres allemands du duc de Deux-Ponts venaient à la rescousse. Brusquement, une nouvelle grave vint faire mieux sentir encore le danger couru : on apprit, un matin, que le capitaine du château de Faucogney était passé à l'ennemi et, par Plancher-les-Mines, avait gagné l'Alsace.

Ce traître était un gentilhomme d'épée, Nicolas de Citey, dont le nom revient souvent dans les lettres de Belin et de Granvelle. C'est que, familier de MM. de Rye, membre influent du parti orangiste en Comté, il avait pris une part active à la fondation et au développement de la confrérie de Sainte-Barbe. En février 1567, 
c'était lui qui, à Bruxelles, avait reçu dans ses bras Claude-François de Rye, blessé à mort. Il s'était ensuite activement occupé d'enrôler des hommes pour le prince d'Orange, et pendant toute l'année 1567, n'avait cessé de voyager entre la Flandre, l'Allemagne et la Comté. En décembre, on se rappelle comment il avait suivi Belin se rendant à Bruxelles. Toutes ces démarches avaient finalement attiré l'attention sur lui et, en juin 1568, Morillon avertissait Granvelle qu'il était résolu de dépêcher mandatum capiendi contre Citey. Pour quelles raisons cette résolution ne fut-elle pas suivie d'effet ? Toujours est-il que le fougueux seigneur resta en liberté et put préparer à loisir la trahison qu'il méditait ; lorsqu'il partit à travers les Vosges pour aller rejoindre, vers Strasbourg, le camp orangiste, il laissa en effet, à un domestique, l'ordre de livrer aux Allemands les clefs du château de Faucogney.

Citey était capitaine de Faucogney depuis 1565 environ. C'était un poste important qu'on lui avait donné là, lorsqu'on l'avait appelé à y succéder à Jean Nicod. Le château, construit probablement au Xe siècle pour résister aux incursions des Normands et des Hongrois, dominait l'étroite vallée du Breuchin et barrait de son enceinte l'une des routes d'accès de la Lorraine en Comté. De plus, «la charge dépendante du château et capitainerie de Faucogney » était de quatre-vingts villages « joignans le duc de Lorraine et comté de Ferrette. Aussi, la trahison de Citey fit-elle dans la province un bruit considérable. Les détails furent vite connus; le lieutenant de Faucogney, Hugues Jacquemart, un ancien maître d'hôtel de M. de Rye, les révéla assez facilement, et tandis que la Cour donnait ordre d'appréhender au corps Jean du Prel, de Salins, et Pierre Bulle, de Pontarlier, tous deux serviteurs du capitaine fugitif ; tandis que les fiscaux faisaient saisir et confisquer par l'huissier Dangelon les biens du traître, le conseiller Chaillot s'acheminait luimême vers Faucogney pour enquête. Il découvrit d'abord de singulières accointances entre Citey et le frère de Simon Renard, Louis, trésorier de Vesoul, qui avait prêté de l'argent au fugitif et abrité dans sa maison, à Vesoul, partie du mobilier de Faucogney, distrait par ses soins. En outre, Chaillot recueillit des charges accablantes contre divers autres personnages de la région qui, imitant Nicolas de Citey, avaient, comme lui, passé à l'ennemi.

C'était d'abord André de Ville, baron et seigneur de Saint-Remy, le propre fils de Jean de Ville et de cette Nicole de Savigny qui suscita, en 1566, tant d'ennuis à l'archevêque de Besançon, Claude de la Baume - elle-même, à la fin de 1567, ajournée devant le Parlement pour transgression des édits sur la foi, et, après plu- 
sieurs défauts consécutifs, déclarée bannie à perpétuité. Puis venait le seigneur de Vellefin, Nicolas de Vienne, plus connu sous le nom de seigneur de Vauvillers ou de Clervans ; il était marié à Perrette de Geresmes, que la Cour devait également poursuivre pour la religion. A côté, des comparses : un certain capitaine Froid, un nommé Chardin, de Fontenoy. Pour finir, le sr de Mailleros, beau-frère du sr de Vellefin, et Nicolas de Vienne, son frère, qui, dès le 16 avril 1566, était reçu bourgeois de Genève avec son fils François, "gratuitement, attendu qu'il est grand seigneur qui pourroit beaucoup servir à l'avenir ». C'est lui qui avait recueilli à Metz l'érudit Boissard, forcé de quitter la Comté et la famille de Rye ; il lui confia l'éducation de son fils aîné. - Gentilshommes de frontière, tous ces inculpés ; leurs alliances, leurs relations, étaient pour la plupart en dehors du Comté. Le Parlement, contre eux, usa de rigueur ; le 18 mars, vu les informations, il décida qu'on les poursuivrait tous, et inscrivit d'office Louis Renard au « dernier rôle ». Le duc d'Albe, de son côté, faisait venir près de lui Jacquemart, pour mieux s'informer; il recommandait à Vergy de faire bonne garde et lui transmettait des renseignements sur l'ennemi.

\section{IV}

Renseignements opportuns : le 21 mars 1569, en effet, la neutralité comtoise était violée ; 8000 reîtres et 3000 Gascons, aux ordres de Wolfgang, envahissaient le bailliage d'Amont. Le duc établissait à Jussey son quartier général ; près de lui s'installaient Orange et son frère Louis ; aux environs, « du coustel de Cherlieu, Purgerot, Port-sur-Saône et Morey », s'épandaient les gendarmes, Allemands cupides et ivrognes, «rebelles françois, habillez de casacques blanches ». Citey, guide redoutable, marchait à leur tête.

Alors commença pour la province une des plus malheureuses périodes de son histoire. Plusieurs semaines durant, Wolfgang, attardé d'abord par la nouvelle de la défaite et de la mort de Condé, puis par la marche lente des piétons que, de Strasbourg, lui amenait son colonel, Jean-Jacques de Grandvillars, tint son camp à Jussey sans en vouloir sortir. Autour de lui, d'incessants mouvements de troupe : détachements de cavalerie allant vers Montbéliard, au-devant des fantassins ; ren- 
forts arrivant de Belfort ou de Bâle ; groupes de déserteurs ou de transfuges huguenots venant du camp français au camp allemand : c'était une animation extrême et continue ; tout le nord du Comté était occupé par l'ennemi ; toute la marche frontière du bailliage d'Amont, dévastée et pillée par de sauvages ennemis n'écoutant pas leurs chefs, ne songeant qu'au profit et, comme l'écrivait Vergy au duc d'Albe, « faisant plusieurs pillaiges et saccaigemens tant d'églises, chasteaux, villes et villaiges ; bruslans abbayes, aussi églises, villes et villaiges ; tuans prestres et religieulx et aultres personnes; prenant prisonniers les aultres qu'ils tailloient à rançon, et rendans par ce moyen le povre peuple tellement éperdu que c'est chose pitoyable ».

Pour connaître tout ce que la Comté eut alors à souffrir, il faut lire la longue liste des «abbayes, églises, priorez, villes, villages et granges brulées, pillées et saccagées » par les soudards féroces qui, pendant plus d'un mois - du 21 mars au 30 avril - firent peser sur le pays la plus épouvantable tyrannie. Toutes les grandes abbayes d'Amont: Bitaine, Clairefontaine, Faverney, Cherlieu, Theuley, les prieurés de Saint-Marcel, de Dampierre, d'Enfonvelle, de Fleurey, de Fontaine furent détruites par le feu ou horriblement saccagées. A Bitaine, les forcenés tuèrent le prieur, un vieillard de soixante-douze ans, après lui avoir extorqué tout son argent. A Clairefontaine, ils volèrent toute l'orfèvrerie, les ornements d'église, les calices et en partant, dit le narrateur anonyme, « tuarent ung bon viez homme ». A Faverney, le curé et deux religieux furent massacrés, l'église paroissiale et la ville brûlées. A Cherlieu, ils découvrirent entièrement l'église pour voler le plomb de la toiture. Dès qu'arrivaient les casaques blanches, c'était une panique : les paysans fuyaient, cherchaient à se cacher, et au dire du conseiller Sonnet, «se laissaient tondre à la volunté de telz bouchiers ». Partout, les églises, les autels furent souillés : il fallut, la tourmente passée, adresser aux prêtres une instruction spéciale de Ecclesiis Pollutis ; plus de deux cents villages furent mis à sac, à moitié brûlés ou détruits. Au début, les coureurs prenaient seulement l'orge et l'avoine, vidaient les granges ; mais ils revenaient bientôt, prenaient le bétail, dépouillaient hommes et femmes de leurs vêtements, s'emparaient des meubles, des chevaux, des charrues, et même des verrières. L'un d'entre eux, fait prisonnier à Baulay près d'Amance, était accoutré, lorsqu'on s'en empara, « d'ung hault de chaulse de toille, sur lequel il avait cousu plusieurs pièces d'une chappe ou chasuble de satin ver brodé de fil d'or et les ymages des Saincts Pierre et Laurent fendues; et avoit une escharpe 
blanche qu'estoit d'ung aornement d'église ». D'autres, à Charmes-Saint-Valbert, apparaissaient vêtus de robes blanches de moines. Tous célébraient le culte «à la huguenote » : à Jussey, lorsqu'il y tenait son camp, le duc de Deux-Ponts avait fait ficher un poteau en terre, devant la porte de l'église, pour que nul n'y entre ; on faisait le prêche aux halles, en convoquant l'assemblée au son des trompettes.

Pendant que bourgeois et paysans fuyaient ; pendant qu'à Gray, c'était « grande pityé de veoir le nombre des villageois arrivans journellement à grand flot, avec leurs femmes, enffants et le peult de meubles qu'ilz peuvent retirer », le gouverneur était monté en selle avec quelques gentilshommes. Il n'avait eu d'abord que peu de monde à sa disposition. Manifestement, l'invasion l'avait pris au dépourvu. Les compagnies qui avaient fait merveille contre les reîtres de Casimir avaient été «cassées » en février 1569, comme l'écrivait Lannoy, et si leurs éléments restaient toujours à la disposition des chefs, il fallait du temps pour les reconstituer. Et puis cette fois, vraiment, la lutte n'était pas égale. L'ennemi était trop fort et trop audacieux. Sans doute, tout proches du Comté se trouvaient deux grands camps, deux armées levées pour surveiller Wolfgang : l'une, l'année française, l'armée royale des ducs d'Aumale et de Nemours, qui d'abord était venue prendre position vers Monthureux-sur-Saône et avait fait mine de vouloir défendre le passage de la Saône, mais qui s'était ensuite retirée vers Langres ; l'autre, l'armée de Mansfeld, qui avait reçu l'ordre de secourir la Comté en cas d'hostilité : une armée forte de huit à dix mille hommes, mais qui s'avançait avec la plus extrême lenteur et ne fut d'aucun secours aux malheureux Comtois.

C'était la présomption qui avait perdu Lannoy et Vergy. Il faut voir de quel ton, au début de mars, le premier se moquait de l'armée de Wolfgang : « Nous avons veu des armées, et savons se que on i fet », écrivait-il cavalièrement au cardinal. Quand l'ennemi fut là, ramassant quelques hommes, il partit du côté de Montbéliard pour rompre les passages : mais vivement poursuivi, il faillit par deux fois être enlevé et dut précipitamment «se retirer à Gray, à peu de chevaux ». Quant à Vergy, prenant sous ses ordres de soixante à soixante-dix chevaux, il commença de « côtoyer » l'ennemi sans « l'irriter », tentant par sa présence d'empêcher de trop lointaines excursions des reîtres. Le bon seigneur, du reste, était tout désemparé et ne savait auquel entendre. Il lui fallait à la fois, conscient de sa faiblesse, retenir les impatients et organiser la défense, mettre garnison dans les villes fortes, rassembler les compagnies comtoises, les diriger sur Gy où l'on 
formait un camp. L'incertitude aggravait encore la situation. Tandis que l'ennemi était abondamment renseigné par des nuées d'espions, les chefs comtois ignoraient tout des intentions réelles de Wolfgang. Les uns prétendaient qu'il voulait gagner Lyon par la montagne ; d'autres, qu'il longerait la Saône, passerait près de Gray et obliquerait de là vers le Duché ; d'autres encore, qu'il prendrait chemin vers Besançon et s'y installerait. De fait, il avait expédié un trompette au magistrat de la ville, porteur de lettres en date du 26 mars 1569, les assurant de l'affection que, prince d'Empire, il nourrissait naturellement pour une ville impériale ; il les exhortait à ne pas s'allier à ses ennemis, les Français, et à bien se rappeler « ce qu'estoit advenu à Toul, Mets et Verdun ». Il y avait là soucis nouveaux pour M. de Vergy, et comme il l'écrivait naïvement au Parlement, en le remerciant d'avoir envoyé à Gray plusieurs membres de la compagnie pour lui donner conseil et assistance, ce qui lui manquait en la saison, ce n'étaient pas au moins les affaires « sur les bras »...

Au reste, Vergy négociait activement avec Mansfeld, avec Nemours et d'Aumale, leur expédiant des officiers pour hâter la marche de l'un et connaître les desseins des autres. Le Parlement, de son côté, avait recouru à sa sauvegarde ordinaire et dépêché vers Messieurs des Ligues, pour obtenir lettres et ambassade de leur part au duc de Deux-Ponts. Il n'y eut d'ailleurs pas lieu à intervention. Le 24 avril, Wolfgang, après un long séjour, ayant promené son camp de Conflans à Jussey et de Jussey à Membrey, se décida enfin à partir pour Leffond. C'était un des villages de M. de Vergy : il le brûla et tira vers la France.

\section{V}

Le Comté évacué, on put connaître toute l'étendue du désastre. Sur le territoire occupé par l'ennemi, il ne subsistait que des ruines. A la vue des terres ravagées, des biens anéantis, des maisons ruinées, une violente colère saisit les bourgeois et les parlementaires. Avec une injustice évidente, ils rejetèrent les responsabilités sur la noblesse militaire. A quoi avaient servi les subsides votés ? A quoi les troupes levées, les chevauchées, les gendarmes ? N'aurait-on pas dû, plutôt que d'introduire « des façons nouvelles » de défendre le Comté, s'en tenir aux vieilles mé- 
thodes, recourir aux Suisses, et puisque des offres étaient venues de Wolfgang au début, conjurer à prix d'argent le malheur qui avait fondu sur la province ? Les cavaliers de Vergy et de Lannoy avaient-ils, en définitive, servi à autre chose qu'à «fouler le pauvre monde » et à accroître par leurs propres exigences la misère générale ? Les levées de soudards n'avaient-elles pas ramené les abus ordinaires, les exactions, les gains scandaleux des munitionnaires ? Rien de curieux comme de comparer à une lettre de Belin à Granvelle, du 30 décembre 1568 - avant l'invasion - une lettre de même au même, du 15 juin 1569. Dans la première, c'est un éloge sans réserve de Vergy, de son activité heureuse contre les reîtres de Casimir : « Je diray ce mot avec le commun, écrit le nouveau conseiller, que ce pais est bien heureux de, en ces tumultes de guerre, l'avoir pour directeur des négoces militaires contre les ennemis du pais ». Dans la seconde, tout est changé. Ce ne sont que doléances et récriminations. Vergy, sans doute, n'est pas nommé ; mais c'est sur lui que tombent les reproches des parlementaires, comme au dehors également ceux de Catherine de Médicis. Celle-ci, il est vrai, révélait la véritable cause de son dépit en constatant que Vergy n'avait « jamais voullu permectre à son cousin, le duc d'Aumale, d'entré en la Franche-Comté avec ses forces ». Mais ces accusations ne tenaient pas. La petite armée comtoise avait fait ce qu'elle avait pu. Elle avait réussi, un an auparavant, à empêcher 3000 Allemands de traverser le Comté et mérité alors des éloges unanimes. Contre la nouvelle et formidable armée des alliés, conduite par des gens du pays, des guides sûrs et hardis comme M. de Citey, elle s'était sentie impuissante ; on ne pouvait en justice le lui reprocher.

Dès le 29 avril 1569, cependant, le Parlement adressait à Vergy une lettre assez sèche. Le gouverneur ayant prié le trésorier Bonet Jaquemet de gagner incontinent la Suisse pour assister à la diète des Cantons, et lui ayant remis des instructions particulières - les conseillers s'excusaient d'abord de ne rien ajouter à ces instructions: "Comme la charge qu'il vous a pleu luy donner nous est incongneue... et ne sçavons bonnement à quel effect les précédens voiaiges par luy faiz aux Lighes... tendoient, ne luy avons peu envoier autres instructions, craidans qu'elle ne fussent en quelque choses contraires aux vôtres. » Ceci fait, « considérant l'estat où s'est retrevé ce pais pour estre pouvre et en deniers et en forces », ils priaient Vergy de faire assembler le plus tôt possible « les super-intendans et autres bons personnages du pais pour adviser meurement sur la deffense et seurté 
dud. pais... et se résoldre sur l'envoy du sr de Champaigney, ou aultre tel qu'il sera lors choisy, devers l'Excellence de M. le duc d'Alve ». La lettre se terminait ainsi : « Le pauvre populaire de ced. pais se retreuve en telle disette que l'on ne pourroit plus, selon que l'on nous rapporte de jour à autre. Et tenons pour asseuré que, remontrant de vive voix à S. E. la forme que du passé avons tenu en ced. pais ès dangers de guerre,... elle y pourveoira ». Vergy répondit qu'il se rendrait à Dole avec F. de Lannoy, et le 7 mai 1569, en effet, il venait au Conseil «pour obvier à ce que le duc de Deux-Ponts, qui est en France », ne repasse point par la Comté.

Or, le premier mot du premier opinant, le conseiller Le Clerc, fut : «Que surtout l'on doit conserver la paix et éviter la guerre ». Sans vergogne, il ajouta que si le duc voulait repasser par le pays, mieux vaudrait traiter avec lui, lui fournir même des vivres, que d'essayer une résistance vaine. D'ailleurs, il réclamait le recours aux Ligues et l'envoi au duc d'Albe de M. de Champagney. Ce fut l'avis de tous les parlementaires. D'aucuns même renchérirent, tel le conseiller Chifflet, et proposèrent d'aller, le cas échéant, au-devant du terrible Wolfgang, de lui verser quelque somme pour le détourner du pays. Finalement, on décida d'attendre le retour de Suisse du trésorier de Salins. Quant à dresser en Comté une gendarmerie régulière, il n'en fut pas question. Si l'on avait parlé de trouver quelques fonds, c'était simplement pour réparer les fortifications de Dole et de Gray.

La délibération était restée calme ; mais Vergy, et Lannoy qui l'accompagnaient, ne pouvaient guère se tromper sur les sentiments des bourgeois de Dole à leur égard. Eux-mêmes n'étaient pas d'humeur débonnaire : on peut penser, dès lors, quelle émotion saisit les conseillers de Dole lorsque, quelques jours après, le 18 mai, ils recevaient la nouvelle de l'arrestation brutale, par Vergy et Lannoy, d'un officier de bailliage : le procureur fiscal d'Amont François Demongenet.

\section{VI}

C'était un personnage que Belin n'aimait guère. Il en parle dans ses lettres assez souvent, en termes défavorables, car il le considérait comme un ami des Rye. Le 8 décembre 1567, il informait Granvelle que, d'après des lettres de M. de Vergy, Demongenet s'était, à cette époque, informé en Comté du revenu des gens 
d'église, des nobles et des communautés du pays - cela, prétendait-il, par ordre de la Chambre des Comptes et du Parlement, en réalité, insinuait Belin, " pour la part des huguenots français ». A nouveau, un an après, le 2 décembre 1568, Demongenet faisait parler de lui. Il avait été chargé, en sa qualité d'officier bailliager, de mener une enquête sur les excès de toutes sortes commis en Comté soit par les ennemis, soit par certains Comtois, lors du passage des reîtres de Casimir. Or, paraît-il, il avait mené cette enquête d'une manière insolite, et la Cour, après avoir examiné ses informations, constatait que « l'intendit n'était faict selon qu'en tel cas est accoustumé »; qu'il semblait « qu'il se voulait aider de lad. informacion aillieurs qu'en justice » et que, s'occupant de l'attitude de la noblesse comtoise « à la repulse des reistres », il paraissait le vouloir « toucher de non y avoir bien fait son devoir ». Aussi, la Cour lui avait-elle ordonné «que par après, il ne se rneslast d'instruire du fait de guerre sans l'ordonnance de ses supérieurs », ni de compromettre le gouverneur dans ses informations. Enfin, en février 1569, aux États, nous avons vu comment le même Demongenet avait à nouveau attiré sur lui l'attention peu sympathique du gouverneur et de Lannoy, en proposant de changer la façon accoutumée d'assembler les gens de guerre «pour éviter la foulle du povre peuple ». Il fut dénoncé comme «mutin » au duc d'Albe - et son arrestation fut évidemment la suite, la conséquence directe de cette dénonciation.

Saisi à Gray, traîné de là à Autrey, chez M. de Vergy, par des soudards de la garnison et jeté en prison, François Demongenet en appela à la cour, tandis que Vergy et Lannoy procédaient contre lui à un semblant d'instruction et dressaient en hâte un « besogné ». Le Parlement, fort ému, se réunit le 25 mai et la délibération commença. Des conseillers, les uns voulaient qu'on écrive au duc d'Albe ; les autres parlaient de faire « répondre de ses actes » le bailli d'Amont; tous furent unanimes à accepter l'appel. Lannoy, pendant ce temps, se réjouissait fort de sa capture. Le procureur, déclarait-il, «ne valait guère d'argent », et il ajoutait cavalièrement : «Il y en a trois ou quatre à la cour qui font grand bruit de sissi, disant que s'est contre les autoritez et franchises de ce comté : je crois que il y en a qui ont peur que quelque matyn, on fera le même à quelqu'un de eux ». Il se trompait d'ailleurs : ce n'étaient pas trois ou quatre conseillers, c'était toute la cour qui protestait : le granvelliste Chaillot s'était ému de l'affaire «pour la manutention des droits du pays », tout comme l'orangiste Sonnet ; l'excessif Belin, comme le prudent Boisset, Chifflet comme Colard. Le duc d'Albe, saisi de l'affaire, se montra 
moins radical que ses officiers. Après examen, il en renvoya la connaissance au Parlement, à charge de lui transmettre les résultats de l'instruction. Le Ier décembre 1569, Demongenet était transféré d'Autrey à Dole et mis en garde chez l'un des huissiers. MM. d'Arinthod et de Champvans étaient commis pour l'examiner. C'était un premier succès, ou, plus exactement, une première satisfaction pour la Cour. L'enquête fut longue d'ailleurs. Le 6 mars 1569-70, l'inculpé recevait copie de toute la procédure ; le 8 juin, le Parlement assemblé décidait « de rendre avis à S. E. de renvoyer absolument le Demongenet», de lui faire «rendre ses gaiges par ceulx qui les ont reçu », de le « remettre en son état » et finalement de poursuivre ses calomniateurs. Belin demanda même, dans la discussion, que l'on fît remontrance « que l'on ne doit suspendre les officiers de leurs estatz sans par devant informer ». Quelques mois après, le duc d'Albe renvoyait les pièces à nouveau au Parlement, cette fois pour jugement définitif. La délibération eut lieu le 13 février 1571 ; l'arrêt fut rendu le 15 ; il absolvait Demongenet de tous les griefs relevés contre lui, et notamment d'avoir « acheté son estat de procureur d'Amont à pris fait et l'avoir obtenu à la faveur des princes rebelles ; item, d'avoir fait information sur le revenu des biens, terres et seigneuries situez en ce pais, à la manière que ont cy-devant tenu les huguenots; item, d'avoir, aux derniers Estatz tenuz en ce piys, mis en avant plusieurs nouvelletez tendans à sédition et division entre lesd. Estatz ». L'arrêt, en outre, levait « la suspence à luy faite de l'exercice de sesd. estatz et office de procureur d'Amont et en la citée de Besançon, le remectant en la jouyssance d'iceulx, tout ainsi qu'il estoit auparavant..., déclarant que les gaiges ordinaires en deppendants, escheuz pendant sa détention, luy seront paiez ». Enfin, le procureur général recevait ordre, avec les fiscaux, de poursuivre les calomniateurs. Le Parlement l'emportait ; la robe était réhabilitée.

Malgré tout, son prestige n'était pas éclatant. La facilité avec laquelle ses droits étaient violés par un Vergy ou un Lannoy, qu'il s'agit de religion ou de guerre, le montrait bien. En dépit de ses efforts pour se relever, il restait suspect aux yeux du duc d'Albe. Il n'en était pas moins vrai que, devant les atteintes portées à ses prérogatives, un sentiment de solidarité corporative s'était à nouveau manifesté parmi tous ses membres. De même que le passage du duc d'Albe, en 1567, avait eu pour résultat principal en Comté d'unifier la noblesse, partagée jusqu'alors en deux groupes ; de même que désormais Vergy seul, assisté de Lannoy, avait pris la tête de la noblesse, et l'avait menée à la lutte contre la bourgeoi- 
sie parlementaire ; de même, le Parlement, un instant divisé et coupé en deux, retrouvait, devant le péril, son unité : granvellistes et orangistes se rejoignaient dans un égal souci des droits de la robe. 
PHILIPPE II ET LA FRANCHE-COMTÉ

Étude d'histoire politique, religieuse et sociale.

\section{Quatrième partie.}

\section{Les progrès de l'absolutisme \\ La Comté nouvelle}


PHILIPPE II ET LA FRANCHE-COMTÉ

Étude d'histoire politique, religieuse et sociale.

Quatrième partie. Le progrès de l’absolutisme.

\section{Chapitre XIX \\ Les réformes : L’Église}

$\underline{\text { Retour à la table des matières }}$

Cependant, le duc d'Albe avait accompli la première partie de son programme : il avait châtié les rebelles. Plus de gueux aux Pays-Bas : il le croyait du moins. A l'exception du prince d'Orange, en fuite et réduit à l'impuissance, les chefs du mouvement national de 1566 avaient trouvé la mort. La Comté pareillement semblait pacifiée. Les protagonistes, les promoteurs de la confrérie de Sainte-Barbe n'étaient plus ; crédit, biens, honneurs, les plus intrépides des « gueux » bourguignons : un Nicolas de Citey, un André de Ville avaient tout perdu dans la crise de 1569. C'était le moment pour le duc d'essayer la réalisation du programme concerté entre lui et Philippe à son départ d'Espagne.

Il avait pourvu : il fallait prévoir; il fallait rendre impossible le retour des événements qui s'étaient déroulés sous le gouvernement finissant de Marguerite ; il fallait, en achevant d'étouffer la Réforme, mettre, pesante et lourde, la main du roi sur les grands corps du pays - régler par-dessus tout, comme l'écrivait Philippe en de nombreuses missives, «le fait de la justice et celui des finances ». A cette tâche, le duc d'Albe s'appliqua en Comté. Passant en revue l'Église, l'Université et le Parlement de Dole, il porta à leurs privilèges des coups décisifs ; il fut par ses initiatives le propagandiste d'un esprit nouveau, fait de respect servile pour l'auto- 
rité, d'obéissance passive aux ordres royaux, d'observance stricte de la hiérarchie : un artisan passionné de centralisation et d'absolutisme.

\section{I}

Vingt ans d'essais avortés, de négociations vaines, d'encouragements sans fruit, avaient démontré l'incapacité du clergé comtois à porter lui-même le fer dans les abus. Il fallait que le salut vînt du dehors ; il fallait à l'Église le concours de l'État. Elle l'eut pleinement - mais elle dut le payer.

A vrai dire, et précisément au moment où le duc d'Albe prit le pouvoir, il put paraître un instant que le Saint-Siège réussirait là où les corps locaux comme les souverains avaient échoué. En 1566, au mois de janvier, Pie V recevait la tiare. Et tout de suite, l'énergique pontife manifestait sa volonté de voir, à la tête du diocèse de Besançon - diocèse frontière - un archevêque vraiment digne de ce nom. C'était le moment où Claude de la Baume, tombé dans les filets de Nicole de Savigny, se débattait éperdument et, de guerre lasse, cherchait à négocier son archevêché. L'évêque de Troyes, Claude de Bauffremont, attendait comme à l'affût et déjà pouvait croire son voeu réalisé : la résignation n'était-elle pas décidée en principe ? Il ne restait plus qu'à régler les détails d'exécution. C'est alors qu'intervint le nouveau pape. Il n'était pas d'humeur à assister, spectateur débonnaire, au trafic d'un archevêché - et nous savons comment, en avril 1566, « ung évesque Italyen, homme vieux », le dominicain Giulio Pavesi, envoyé par le pape comme nonce aux Pays-Bas, vint à Besançon aviser sur place à la situation. Il dut parler haut au jeune Claude de la Baume, car, le 7 juin 1566, une longue lettre arrivait d'Arbois au chapitre métropolitain : l'archevêque, avec de grandes protestations de dévouement, se déclarait touché par l'inspiration divine ; il renonçait à résigner son diocèse, et annonçait son intention de vivre désormais en ecclésiastique.

De fait, le 23 juillet, il était sous-diacre, et prêtre le 10 août. Grand changement d'existence : il avait peu touché les ouailles du pasteur repentant : trois mois après son ordination, le haut doyen François de Grammont semblait considérer encore le siège archiépiscopal comme vacant : n'annonçait-il pas à Granvelle que plusieurs chanoines, ne sachant si la résignation de Claude était admise ou non, 
réclamaient « que l'on deust procéder à quelque élection pour maintenir l'auctorité qu'a nostre église de pouvoir procéder à celle-ci quantes fois que l'archevêchée estoit vacante, comme elle est à présent ». Le pape fit mieux. Il convoqua à Rome Claude lui-même. Du reste, Nicole de Savigny avait déposé entre ses mains une plainte formelle contre le jeune prélat ; elle déclarait que celui-ci avait contracté mariage avec elle «per verba de futuro », et réclamait le bénéfice de cette union.

Le 8 février 1567, l'archevêque, accompagné du vicaire général Lulle, quittait son diocèse en accusé, passait les Alpes et gagnait Rome : il devait y rester plus de trois années. Première intervention du Saint-Siège dans les affaires comtoises. Elle ne devait pas être la seule ; le 8 juillet 1568, alors que le tribunal de Rote instruisait l'affaire du prélat, se place une tentative curieuse, d'ailleurs unique dans l'histoire religieuse de la Comté.

\section{II}

Depuis longtemps - dès 1247 - fonctionnait en Comté une inquisition diocésaine. Créée pour détruire l'hérésie vaudoise, elle avait subsisté à travers les âges et continuait à manifester au XVIe siècle, contre des suspects de "vaudoiserie » et de "guenaucherie », une activité d'ailleurs intermittente. Deux couvents de dominicains s'en disputaient l'exercice : celui de Besançon d'abord : n'était-ce pas au prieur de Rivotte qu'en 1247, Innocent IV avait adressé sa bulle d'institution ? En 1554, Fr. Thiébaut Reynaldi, docteur en théologie et prieur de ce même couvent, attestait que tout religieux élu au priorat de Besançon devenait par le fait inquisiteur, «a sede apostolica immediate institutus et delegatus ». Mais à diverses reprises, sinon des inquisiteurs, du moins des procureurs de la foi se rencontrent, qui appartiennent au couvent rival de Poligny : tel, Fr. Anthoine Barcaille en 1538, et, en 1551. 1552, 1562 et 1569, Fr. Simon Digny. A l'entendre, lui et son collègue Montot, les moines bisontins, au temps de Marguerite, s'acquittant mal de leur office, l'inquisition aurait été confiée à deux docteurs en théologie du couvent de Poligny, qui furent inquisiteurs généraux pendant trente-deux ans. Ensuite de quoi, à nouveau, les Bisontins se seraient, mais sans droit, « attribuez l'office de l'inquisition ». 
Office peu absorbant : la compétence de l'inquisiteur, en Comté, était mince. Elle se réduisait à l'hérésie, le sortilège étant laissé à la connaissance du juge laïque ; mais de l'hérésie, il convenait d'excepter tous les cas de contravention aux placards, c'est-à-dire tous les cas d'hérésie protestante. Restaient seules, dès lors, quelques affaires de «vaudoiserie » ou de sorcellerie, ces dernières réservées, en tant que telles, aux juges laïques: mais n'est-ce pas Boguet, le grand-juge de Saint-Claude, l'ennemi tristement célèbre des sorciers du Jura, qui le note quelque part : «Le crime de sorcellerie ne marche point sans l'hérésie, car renoncer à Dieu, sacrifier au diable, l'adorer, cela resent son hérésie manifeste ? »

D'autre part, rien de moins libre dans son action judiciaire que l'inquisiteur du diocèse bisontin. Un arrêt de 1539 l'obligeait à ne jamais agir que sous le double contrôle des officiers laïques et de l'officiel. Il ne devait « procéder à prendre aucuns des subjectz de S. M. en vertu de ses informations sans premier les communiquer aux officiers de la justice dont lesd. subjects estoient ressortissants ». Il devait mettre à même ces officiers de suivre dans son détail tout le procès criminel, ne donner la torture qu'en leur présence, n'emprisonner les inculpés que dans leurs prisons. Pareillement, en deux circonstances décisives, il était tenu d'en référer à l'officiel : pour torturer et pour prononcer la sentence, il devait prendre « l'avis et décret » du juge diocésain.

Ainsi, c'était une juridiction très secondaire, très subordonnée, que l'inquisition comtoise, telle qu'elle fonctionnait vers 1550. L'inquisiteur Reynaldi, en 1554, pouvait bien s'intituler : «Sacrosantae fidei nquisitor, a sece apostolica immediate institutus et delegatus »; dans la pratique, il faisait figure d'un subalterne de l'archevêque, très surveillé, très contrôlé par l'official et le Parlement. C'est ainsi qu'entre bien d'autres textes, cités et commentés ailleurs, nous le représentent d'importants documents de 1562 et 1563. En novembre 1562, à la rentrée, les officiers d'Amont demandèrent à la cour « de donner ung ordre et provision au regard des frais et despens que l'inquisiteur de la Foy et le procureur qui le suyt exige et preigne des villes et villaiges où par eulx les procès criminels se font contre sorciers et sorcières dévoyez de notre Sainte Foy ». Ainsi, ces officiers ne voyaient d'autre rôle pour l'inquisiteur que son intervention dans les affaires mixtes de sorcellerie et d'hérésie. Ils continuaient : « Puisque telle juridiction s'exerce soubz le nom et aultorité de Mgr le Très-Révérend Archevesque de Besançon, il 
est par droit debteur de lad. justice à ses frais, et non desd. villes et villaiges n'ayants faictz telz délictz ».

La cour, saisie, en écrivit à l'archevêque. Celui-ci transmit l'affaire à son conseil - et ses officiers élaborèrent un projet de taxe « pour les journées, vaccacions et despens tant du seigneur inquisiteur que procureur de la Saincte Foy ». Projet dans lequel l'officiel ne s'oubliait pas. Il s'allouait un écu sol pour ses peines de donner avis sur les procès. Par contre, il déniait tout salaire aux juges séculiers assistant l'inquisiteur, « attendu que cela deppend de leurs estatz et offices ». La cour mit d'accord les deux parties en les privant également de rétribution, puis alloua, comme frais, 35 sols tournois par jour à l'inquisiteur, 20 au procureur, 10 gros au greffier ; mais ce qu'il faut noter surtout, c'est combien alors l'inquisiteur paraissait être et se trouvait réellement dans la dépendance de l'archevêque : l'inquisition semblait, au plus juste, un rouage annexe de la juridiction archiépiscopale.

\section{III}

Cependant, depuis des années à Rome, par les soins de Caraffa, l'inquisition se relevait et se réorganisait. Depuis des années, la commission cardinalice du SaintOffice fonctionnait régulièrement, et pas plus que Paul IV ou que Pie IV, Pie V, l'homme de confiance de Caraffa, l'ancien commissaire général de l'inquisition, n'était disposé à laisser péricliter entre ses mains cette arme redoutable de contreréforme. On le vit bien en Comté.

Nous avons dit ailleurs en détail comment, le 8 juillet 1567, un bref pontifical adressé au haut doyen du chapitre métropolitain de Besançon (l'archevêque étant à Rome), à l'inquisiteur de la foi et au président du Parlement de Dole, leur avait dénoncé comme hérétique l'ancien secrétaire d'Érasme, Gilbert Cousin. Dénonciation singulière en vérité, sinon dans son fond, du moins dans sa forme. Le bref requérait simplement les juges laïques de poursuivre eux-mêmes l'hérétique - de le poursuivre, était-il dit textuellement, en vertu des placards : «Fuxta fotmam constitutionum istarum partium quas «placartos » vulgo appellannt ». Dès lors, que venait faire l'inquisiteur dans cette affaire ? le haut doyen, en l'absence de 
l'archevêque, était tout désigné pour recevoir le bref et le transmettre ; mais pourquoi lui adjoindre le juge attitré des sorciers et sorcières « dévoyés de la foi »? Était-ce, de la part du Saint-Siège, comme un dessein d'obtenir l'instruction du procès de Cousin par les juges ecclésiastiques agissant, comme dit des Lois, conjunctim ? Mais en Comté, c'était à l'official seul que, jusqu'alors, le Parlement avait toujours renvoyé, quand il n'en avait pas retenu l'instruction, les affaires d'hérésie concernant les ecclésiastiques ; et Cousin était prêtre, chanoine de Nozeroy. D'autre part, si tel était bien le dessein de Rome, pourquoi cette invitation aux juges laïques, de poursuivre Cousin en vertu des placards ? De toutes façons, la procédure suivie, le texte même du bref restent obscurs et difficiles à expliquer.

En fait, d'ailleurs, ce sont les parlementaires qui, se conformant au voeu impératif de Pie V, font arrêter Cousin et commencent - mollement - à instruire son procès. Dix mois se passent. Puis, brusquement, le 3 juin 1568, on voit venir à Dole l'inquisiteur Lancel, prieur des Frères Prêcheurs de Besançon. Au nom de l'archevêque ou du haut doyen son représentant? Nullement, mais du cardinal de Pise, inquisiteur général de la foi romaine. Il réclame Cousin «pour former son procès ». Et la cour, s'inclinant devant les volontés pontificales, décide que l'inculpé sera remis à Fr. Lancel « pour, en conformité de sa commission et puissance, procéder contre led. messire Gillebert Cousin, selon qu'il trouvera ou cas appartenir ». Deuxième épisode et fort intéressant. Motivé par le peu d'ardeur du Parlement à juger l'affaire ? En tout cas, cette fois, la démarche est nette. Il ne s'agit pas d'une demande du pape aux conseillers de faire arrêter et de poursuivre selon leurs lois propres, les placards, un hérétique qu'il leur signale - mais d'un véritable dessaisissement de la justice séculière au profit de Lancel, agissant sur les ordres directs de l'inquisition romaine et investi brusquement d'un rôle nouveau pour lui - d'un rôle contraire aux précédents et aux édits.

Comment ne pas rapprocher cette affaire, comment ne pas y voir la préface de la démarche, autrement explicite, que nous révèlent, à la date du 4 février 1569, les registres du Parlement de Dole ? Ce jour-là, les dominicains, Fr. Jean Montot, docteur en théologie, un Jurassien de Barretaine, et Fr. Simon Digny, tous deux religieux au couvent de Poligny, faisaient tenir requête à la cour. Pourvus de bulles apostoliques, l'une les instituant respectivement inquisiteur et procureur général de l'inquisition pour la Comté, l'autre leur assignant pension annuelle et perpétuelle sur les revenus de la mense archiépiscopale de Besançon, ils sollicitaient du 
souverain le placet nécessaire pour l'exécution de toutes bulles et provisions apostoliques dans la province. Le 4, les parlementaires réunis en Conseil examinaient la requête et en délibéraient.

Quel était le texte exact des bulles pontificales ? Nous connaissons la seconde ; Jean des Loix, successeur à Besançon, au début du XVIIe siècle, des Montot et des Simon Digny, l'a reproduite dans son Speculum Inquisitionis Bisuntinae. Elle était datée du 17 octobre 1568. Pie V, après avoir attesté son ardent désir de maintenir intacte la foi catholique dans la province, y déclarait que l'archevêque de Besançon, Claude de la Baume, s'engageait, pour lui et ses successeurs, à payer une pension annuelle et perpétuelle destinée à l'entretien en Comté d'un inquisiteur général, d'un procureur fiscal et de «ministres » de l'inquisition. Mais de la première bulle, ou plus exactement du bref qui instituait Jean Montot et Simon Digny, nous ne connaissons pas la teneur exacte. Quelques textes, sans doute : délibérations du Parlement ou requêtes des inquisiteurs, nous donnent, par allusions, des renseignements sur son contenu. A l'inquisiteur et au procureur qu'elle instituait tous deux, elle remettait le pouvoir entier et le pouvoir exclusif de poursuivre les hérétiques. Elle les armait du droit « de remettre pour la première fois » aux coupables dans certains cas; enfin, elle désignait le pape comme juge d'appel du tribunal d'inquisition. Telles sont les trois indications qui ressortent des textes avec quelque netteté. Il semble bien dès lors - sans que nous puissions l'affirmer complètement - que le bref de 1568 ait eu les plus grandes analogies avec la propre bulle d'institution, datée de 1623, que Jean des Loix nous a transcrite dans son Speculum.

De ces actes du moins, nous saisissons assez nettement la portée. D'abord mais le point de vue est secondaire - ils marquaient une victoire du couvent de Poligny sur celui de Besançon dans la lutte entreprise pour l'inquisition : au Bisontin Lancel succédait Fr. Montot. Surtout, ils attestent, de la part de Pie V ou de ses inspirateurs, un double effort pour affranchir l'inquisition de la tutelle archiépiscopale et du contrôle parlementaire. Les conseillers ne s'y trompèrent pas. Le 4 février, ils décidaient de communiquer requête, bref et bulle aux avocats fiscaux : énervement et affaiblissement de la répression contre les réformés ; négation brutale des droits de patronage appartenant aux laïques; ainsi ces officiers résumaient les conséquences des actes soumis à leur examen. La cour fit siens leurs arguments, dans un ample rapport au duc d'Albe. 
Réserver aux inquisiteurs les premiers bénéfices vacants, de quelque collation qu'ils puissent être et jusqu'à concurrence de 200 écus d'or, n'était-ce pas « porter intérêt aux collations et provisions appartenants tant à $S$. M. que aux prélatz vassaulx et subjectz de ce pays ? » Surtout, par la bulle d'institution, S.S. ne semblaitelle pas «tollir, tant à lad. court que aultres juges séculiers de S.M. en ce pais, cognoissance de la transgression des éditz et placards concernant nostre saincte foy ? » Et puis, remettre la connaissance des causes d'hérésie protestante à un seul juge d'Église, aventure périlleuse ; il y aurait risque « d'impunité quant aux délinquants et d'oppression à l'endroit des innocents, et la chose moins bien pesée par gens ignorans les drois civilz et canons et la pratique judiciayre ? " Le pape retient pour lui le recours d'appel : mais c'est « de trop grand circuyt, fraiz et labeur insupportables aux subjectz de $\mathrm{S}$. $\mathrm{M}$ en ce pays, singulièrement aux pauvres gens ». Non : les prédécesseurs du roi au Comté avaient été bien avisés de n'autoriser l'exercice de l'inquisition que «soubz l'auttorité et réformation par appel de la court, tant des sentences interlocutoires que diffinitives voyres leur procédure réduitte et limittée à la présence des officiers séculiers des lieux et avis du sr official du Rd archevesque de Besançon ». Là était la vérité ; il fallait s'y tenir et, rien ne justifiant un changement dans une province où la religion était si bien suivie et le Parlement si zélé, le devoir du duc d'Albe était d'écrire à S.S. «à ce que aud. Conté telle nouvelleté tant préjudiciable ne soit introduitte».

Ainsi plaidaient les conseillers de Dole. Ils faisaient mieux encore : ils expédiaient aux Pays-Bas un des leurs, Nicolas Fauche, chargé de présenter en personne ces remontrances au duc d'Albe et de remettre au Conseil privé les mémoires et instructions concernant l'affaire - non pour empêcher l'inquisition, disait modestement la cour, mais pour avoir interprétation et éclaircissement des difficultés qui en pourraient surgir. Granvelle, de son côté, était tenu au courant ; enfin Montot et Digny, ayant fait hardiment, en mai 1569, publier de leur autorité privée « aucuns articles contenans ordonnances » en Comté, ils furent mandés à Dole, interrogés et réprimandés. Les moines, d'ailleurs, ne se décourageaient pas : ils travaillaient activement aux Pays-Bas pour obtenir placet sur leurs bulles. Ils l'obtinrent finalement : le 5 mars 1570-71, ils les présentaient à la cour qui communiquait le tout aux fiscaux. C'était le triomphe des deux dominicains; mais un triomphe plus apparent que réel. 
Dans les registres postérieurs à 1569, qu'on examine, en effet, les documents concernant l'inquisition : rien ne paraît changé dans la pratique des choses. Après comme avant cette date, l'arrêt de 1539 reste en vigueur : il figure encore dans l'édition des Ordonnances que donne Pétremand en 1619. Après comme avant, la distinction de 1534, entre hérésie et sortilège, persiste : l'inquisiteur a l'une, le juge séculier l'autre. Après comme avant enfin, le Parlement reçoit les appels des Comtois poursuivis par les moines et veille à ce que ceux-ci ne commettent point d'abus. Au reste, l'activité inquisitoriale reste la même. Elle s'exerce spécialement contre les sorciers suspects d'hérésie - le Parlement maintenant toujours vigoureusement son droit de connaître de la sorcellerie pure. Bien plus : dans l'affaire Cousin, point de traces, une fois faite la démarche d'Antoine Lancel en 1560 - plus de traces d'une intervention quelconque de l'inquisition. Cousin, bien que réclamé, ne partit pas : on le trouve à Dole, en arrêt chez un huissier ou en prison à diverses reprises, en 1569 et 1570. Et lorsque, le 31 décembre 1571, il fut, sur lettres du duc d'Albe du 29 novembre, « réintruy » en prison pour être remis à l'archevêque de Besançon, « son juge ordinaire » - ce ne fut pas l'inquisiteur, ce fut le procureur général de l'officialité qui vint le saisir à Dole et le conduire à Besançon. Futce par ses soins seulement que fut instruit le procès de l'humaniste, décédé peu après " ès chartres de l'archevêque » ? Admettons même que l'inquisiteur y ait participé : l'affaire Cousin resterait la seule cause d'hérésie protestante qui, pendant tout le règne de Philippe II, aurait été instruite avec le concours de l'inquisition; constatation qui suffit à nous renseigner sur le succès réel de la tentative de Pie V.

Un point reste obscur. Dans quelle mesure le gouvernement du duc d'Albe avait-il été prévenu d'avance de la tentative de 1569 ? D'après une lettre de Belin à Granvelle du 28 mars 1568, on faisait, à cette date, courir en Comté le bruit « que le roy y veult mectre l'inquisition »; le correspondant du cardinal, alors en Flandre, au Conseil des troubles, protestait énergiquement contre de telles rumeurs. «Cela provient d'un malin esprit », déclarait-il, et si 1'auteur en était connu, il le faudrait saisir et châtier. Mais Belin, assez petit garçon aux Pays-Bas, n'était pas toujours dans le secret des puissants... Il est un fait : c'est que malgré les démarches du Parlement, Montot et Digny obtinrent du duc d'Albe le placet qu'ils sollicitaient. Il est notable, d'autre part, que les registres du Parlement ne nous aient conservé aucune trace d'une protestation, lorsque l'inquisiteur Lancel vint récla- 
mer Cousin pour «former son procès ». Cependant, si le gouvernement du duc avait prêté un appui vraiment efficace aux tentatives des inquisiteurs en 1569, leur rôle serait-il resté, après cette date, le rôle effacé que nous avons vu ? En tout cas, si des doutes sont permis, pour la très grosse affaire de la publication du Concile de Trente, il n'en est point de possibles : le Saint-Siège et le gouvernement de Philippe II s'entendirent d'avance et collaborèrent.

\section{IV}

Comment, par la mauvaise volonté intéressée de Claude de la Baume, avaient échoué les négociations entreprises dès 1564 , en vue de cette publication, nous l'avons dit ailleurs. Lorsque le prélat, mandé par Pie V, fut arrivé à Rome, une vaste enquête commença sur sa vie ; vie privée, vie publique : ses relations avec Nicole de Savigny, comme ses rapports avec les gueux. Dressant la liste de ses griefs contre cet archevêque par trop irrégulier, Pie V ne négligea pas, comme on pense, de l'interroger sur son peu de zèle à publier le Concile Claude, de son mieux, se défendit, tenta de rejeter la faute sur son chapitre métropolitain. Mais le Saint-Siège, sans doute, ne prit pas le change. Lorsque, après trois ans d'un dur séjour à Rome, Claude de la Baume fut, par le pape, renvoyé dans son diocèse ce fut au prix d'un engagement formel : celui de publier les décrets. Et comme Pie V restait méfiant, il pria le célèbre Père jésuite Possevin d'accompagner l'archevêque depuis Lyon, pour lui rappeler ses promesses ; il prévint, d'autre part, Philippe II et, par lui, le duc d'Albe.

Voilà comment, dès le 3 mai 1571, alors que Claude n'était pas encore rentré en Comté, des lettres pressantes lui étaient écrites par le gouverneur des Pays-Bas. Le duc priait l'archevêque, au nom du roi, « de présentement, sans nul délay, faire publier et mectre à exécution le Saint-Concile ». En même temps qu'à Claude, il écrivait au gouverneur et au Parlement. Il les chargeait de « tenir la bonne main » à ce que l'archevêque s'exécute promptement. Se montrerait-il à nouveau « défaillant ou négligent ? " Gouverneur et conseillers auraient à en avertir immédiatement les gouvernements de Bruxelles et de Madrid; le roi, alors, y pourvoirait « par tels moïens que Dieu a permis ». D'ailleurs, aucune innovation sous couleur 
du Concile ne devrait être tolérée relativement à la juridiction laïque sur les ecclésiastiques, aux droits de patronage des laïques, aux indults, droits de nomination, connaissance des causes en matière possessoire de bénéfices et dîmes possédées ou prétendues, administration par les laïques des hôpitaux et des fondations pieuses. Les instructions furent suivies à la lettre. Les 17 et 19 juin 1571, la cour les examinait et en référait à $M$. de Vergy. Le 23, Claude de Voisey, délégué du gouverneur, et le conseiller Boutechoux, délégué de sa compagnie, se transportaient à Arbois.

L'archevêque y était débarqué juste de l'avant-veille. Les deux envoyés le prièrent de procéder incontinent à la publication attendue, tout en mentionnant au nom du roi des réserves sur certains articles. Le prétendu de Nicole de Savigny dut penser qu'on lui laissait peu le temps de réfléchir. Mais non sans habileté, après s'être déclaré très humble serviteur du roi, avoir demandé copie des instructions du duc d'Albe et s'en être vu refuser le texte écrit, il requit un petit délai : le pape lui avait enjoint de publier les décrets purement et simplement ; le duc, par contre, exigeait des réserves sur certains d'entre eux ; le prélat, dans son embarras, entendait ne rien faire sans l'avis de Rome.

Tels étaient les scrupules qu'il exposa d'abord au Parlement le 11 juillet, puis, le 3 août, au duc d'Albe lui-même. Mais dans cette dernière lettre, assez maladroite, li marquait trop nettement son véritable but. Il s'étendait sur les dangers que ferait courir la publication à sa juridiction ecclésiastique : elle en serait «grandement endommagée, voire quasi éteinte »; il suppliait le duc d'avoir son église en recommandation, incriminait les intentions du Parlement qui, « diminuant l'authorité de l'Église..., veult accroistre celle que Sa Majesté lui a donnée »; il terminait enfin en annonçant qu'il en avait référé au pape et qu'il attendait sa réponse. Albe se fâcha. Le 28 août, il répondit avec vigueur que les réserves demandées par le roi n'étaient nullement pour empêcher de publier le Concile ; que la discussion en était affaire entre Philippe Il et Pie V et ne regardait en rien un simple archevêque. En même temps, il chargeait Parlement et gouverneur d'une nouvelle démarche auprès du prélat. Le 18 septembre, Claude de Beaujeu et l'avocat fiscal Pierre de Broissia se présentaient, en effet, à Arbois. L'archevêque, poussé dans ses derniers retranchements, s'inclinait et cédait. Le Ier octobre, il avertissait le duc d'Albe qu'il procéderait à la publication «le mercredy après la fête Saint-Luc prochaine », c'est-à-dire le 24 octobre. Il protestait de son dévouement au Roi Catholique 
et rappelait, avec les services des siens, sa « syncère et pure volonté » de toujours obéir aux ordres du souverain. - Le 21 octobre, le prélat faisait son entrée solennelle à Besançon ; il célébrait le 23 sa première messe archiépiscopale dans l'église métropolitaine de Saint-Jean, en présence des évêques suffragants de Bâle, Lausanne et Belley, des abbés du diocèse, de presque tout le clergé et de nombreux représentants de la noblesse. Le P. Possevin monta en chaire, expliqua la discipline établie à Trente, et la publication du Concile commença. Successivement, les évêques, le chapitre, les abbés et les ecclésiastiques présents le reconnurent et l'acceptèrent. Huit jours après la lecture des articles était terminée : le Concile était publié.

\section{$\mathrm{V}$}

Il était publié : il fallait l'appliquer. Ici encore, l'initiative vint du pouvoir séculier. Ce fut sous la pression constante, sous l'action persévérante de Philippe II, de ses représentants aux Pays-Bas, du Parlement enfin, que les résolutions conciliaires devinrent, de lettre morte, réalité vivante.

En même temps qu'ils l'avertissaient de la résolution finale de l'archevêque, les conseillers de Dole, le 31 octobre 1571, transmettaient au duc d'Albe un mémoire détaillé sur les mesures propres à assurer l'exécution du Concile en Comté ou, plus exactement, sur les réserves à formuler. Après un examen et un stage prolongés aux Pays-Bas, le mémoire fit retour dans son pays d'origine, sous forme de quatorze articles, datés de Nimègue, le 4 novembre 1572 : le roi les "prescrivait » au gouverneur et au Parlement, afin, était-il dit dans le préambule, que les décrets de Trente, accommodés "à la qualité et nature du pays », pussent être observés sans désordre, difficulté ni inconvénient. Articles intéressants, dont l'envoi marquait, dans l'histoire de la réception du Concile en Comté, une phase nouvelle et vraiment décisive.

Par les deux premiers, le gouverneur et le Parlement étaient institués les véritables gardiens du Concile dans la province. Ils étaient chargés de veiller à ce que les canons en soient solennellement annoncés et prêchés au peuple; ils étaient requis de prêter aide et assistance au clergé pour leur exécution ; ils recevaient 
l'ordre enfin, si les ecclésiastiques se montraient négligents, de prévenir le roi en toute diligence. Ceci dit, venaient toute une série d'articles relatifs aux bénéfices du Comté et à la sauvegarde des droits que pouvaient posséder sur eux, soit le roi, soit quelques-uns de ses sujets laïques. Explicitement, le roi réservait tous les droits de collation, d'institution, de patronage d'églises ou de bénéfices dont il se trouvait jouir dans la province (art. 4). Il spécifiait la nécessité de prendre son avis et d'obtenir son consentement, soit pour doter de pensions et prébendes sur les églises collégiales de son patronage ou de sa collation les nouveaux prédicateurs et professeurs d'Écriture sainte prévus par le Concile (art. 3). soit pour procéder à réparation, union, translation de bénéfices, dessertes, anniversaires et fondations, commutation et exécution de dernières volontés (art. 5). Il rappelait que les bénéfices de sa collation ou de son patronage devraient rester exempts de la juridiction des ordinaires diocésains comme par le passé (art. 6) ; que les visites d'hôpitaux, fabriques et confréries peu fortunées de la Comté devraient s'opérer sans frais ni dépens (art. 7) ; que les indults, privilèges apostoliques et droits issus du droit de régalie continueraient, après le concile, à sortir leur plein effet (art. II); que les dîmes enfin seraient, comme par le passé, payées au roi ou aux sujets laïques qui en auraient la propriété (art. 12).

Surtout, une série d'articles envisageaient les rapports de la justice séculière et de la justice ecclésiastique. Aux juges du roi se trouvait réservée la connaissance des usurpations de biens ecclésiastiques par les séculiers - dans l'intérêt même de l'Église : la justice laïque n'était-elle pas plus prompte et de plus grand effet que l'ecclésiastique ? De même, les contestations entre particuliers prétendant possession d'un même bénéfice; c'était affaire temporelle « et de fait hors de spiritualité ». Enfin, couronnant le tout, venait l'article capital, l'article 13, celui qui allait soulever toutes les résistances, celui qui dévoile la véritable attitude du Roi Catholique vis-à-vis de l'Église : le Concile ayant ordonné de n'user dorénavant de l'excommunication qu'en matière spirituelle, Sa Majesté ordonnait, par forme de provision et jusqu'à plus ample informé, que toutes les sentences au civil des juges ecclésiastiques du Comté fussent dorénavant mises à exécution par huissiers ou sergents commis par la Cour ou par les baillis, après mandement de cette Cour ou de ces baillis ; qu'au criminel, le concordat de 1559, entre l'archevêque et les officiers du roi, fût observé comme du passé ; enfin, qu'en ce qui concernait les exécutions dépendant d'obligations simples ou de contumaces, les officiers du roi 
accordassent mandement de debitis sur les obligations reçues sous le scel de l'archevêque, avec clause qu'en cas d'opposition, assignation serait donnée aux parties par-devant le lieutenant du bailliage dont elles ressortissaient; cet officier ordonnerait sur l'ultérieure exécution, réelle ou personnelle. En d'autres termes, au juge d'Église subsistait le droit de prononcer, en matière civile et d'obligation, toutes sentences comme par le passé ; mais le soin de mettre ces sentences à exécution était entièrement confié aux juges laïques.

Coup terrible pour cette officialité bisontine, dont nous avons dit ailleurs l'activité, les monstrueux abus et les profits. Elle n'était pas supprimée ? Sans doute. Sa compétence n'était en rien diminuée ou restreinte ? Sans doute encore ; mais qu'est-ce qu'une juridiction sans exécuteurs responsables envers qui l'exerce ? Et puis, supprimer cet emploi de l'excommunication qui faisait à lui seul tout le succès, toute la vogue de l'officialité bisontine - n'était-ce pas vraiment, à ne pas jouer sur les mots, supprimer l'officialité elle-même, c'est-à-dire la grande source de revenus de l'archevêque, de ses officiers et de tout le peuple immense de praticiens, courriers, avocats, procureurs, qui vivaient des abus et ne vivaient que d'eux ? Ainsi, c'était en vain que l'archevêque, secondé activement par le magistrat de Besançon, avait, depuis 1564, multiplié les démarches, les moyens dilatoires, les protestations ; en vain que, dans les premiers mois de 1572, il s'était astreint à siéger au Parlement, se rappelant qu'il y était, de droit, maître des requêtes. Tandis que, le 4 novembre 1572, les gouverneurs de Besançon réunis entendaient leur délégué Grillet, à son retour d'Espagne, leur rendre compte de ses négociations en cour et leur remettre des lettres de Philippe II promettant qu'il s'informerait de la matière, le prélat, de son côté, entouré de son vicaire, de son avocat fiscal et de divers officiers, se présentait encore devant le Parlement et se plaignait amèrement que, l'autorité et juridiction ecclésiastique ayant été cependant « plustot confermée et restablie que diminuée » par le Concile, et « combien qu'il n'appartinst à personne d'interpréter led. Saint Concile, synon à la Sainteté du Pape », le glaive d'excommunication, la grande arme de sa justice, lui était comme arraché des mains par un Parlement avide de conquêtes judiciaires. Il prenait mal son temps pour récriminer : deux jours après, le 24, la cour recevait les quatorze articles ; elle les exhibait triomphalement au prélat le 28, lui en refusait la copie écrite et, par la voix des fiscaux, le requérait sur l'heure de faire expliquer au peuple, dans les églises, les décrets conciliaires concernant « les articles de la foy; 
traditions et religieuses cérémonies et observances de notre mère Saincte Eglise »; il le sommait de pourvoir les cures et églises paroissiales de bons prêtres, " suffisans en meurs et sçavoir »; de contraindre les curés en charge à résider et à desservir personnellement leurs bénéfices ; de faire établir le séminaire diocésain prévu par le Concile ; d'instituer auprès des églises collégiales des prédicateurs et des professeurs de théologie, « afin que, à l'advenir, il n'y ayt deffault de personnes suffisantes pour estre entremises au ministère ecclésiastique et que les ténèbres d'ignorance, tant du peuple que des ecclésiastiques, soient par prédication, doctrines et instructions esclercies ». A toutes ces demandes précises, Claude ne put répondre que par l'affirmation résignée de sa bonne volonté : mais sa pensée était ailleurs sans doute ; il ne songeait, il ne pouvait songer qu'à la suppression de sa juridiction.

Tout de suite, du reste, les mesures d'application commencèrent. Un édit, rédigé par le Parlement, porta à la connaissance de tous la suppression des excommunications comme moyen de contrainte et de châtiment en matière civile. Déjà, depuis longtemps, des bruits couraient à ce propos, et Claude de la Baume, le 22 novembre 1572 - deux jours avant que les quatorze articles du 2 novembre ne fussent parvenus à la cour - se plaignait amèrement « que le glaive d'excommunication qu'est l'exécution de lad. jurisdiction, estoit venu à tel mespris que le commung peuple estoit en opinion que lad. excommunication fust du tout abolie ». Ce fut bien pis encore après l'édit - et bientôt, les praticiens de Besançon purent sentir les conséquences de la mesure prise. En vain, leur magistrat, en vain l'archevêque entreprirent-ils une lutte acharnée pour obtenir la suppression de l'édit ou du moins son adoucissement; en vain multiplièrent-ils les démarches, les requêtes, les ambassades aux Pays-Bas, en Espagne et jusqu'en cour d'Empire, au grand scandale de Granvelle qui ne se gênait pas pour écrire au prieur de Bellefontaine que si Claude de la Baume « conférait avec quelqu'un de ces Jésuites qui fust sçavant, pour sçavoir si avec bonne conscience il peut retenir le revenu que dois la détermination du Concile il a reçu, provenant desd. excommunications, il y trouverait du scrupule » - une décision provisionnelle de don Juan en 1578, un règlement royal de 1584, et divers édits des Archiducs en 1598, 1603 et 1618 purent bien faire à l'archevêque et aux Bisontins quelques concessions de forme : jamais l'officialité bisontine ne devait se relever d'un tel coup ; et il faut avouer que si, comme l'écrivaient vers 1575 des officiers bailliagers dans une sorte de rapport au 
Parlement, les Comtois étaient si heureux de la suppression des excommunications pour dettes qu'il leur semblait « estre à demy saulvez » maintenant et « avoir approcher paradis » - les conseillers de Dole et les lieutenants du bailliage avaient sujet de manifester une allégresse semblable devant la détresse et la ruine de leur vieille rivale : la juridiction de l'officialité.

Tel était en effet le double caractère de toutes ces mesures. Suppression des abus, redressement de l'Église et, dans la mesure où les abus avaient pu en favoriser les manifestations, coup porté à la Réforme protestante - c'était un de leurs aspects. Et, sans doute, du point de vue religieux, rien de plus justifié, rien de plus salutaire que la suppression des abominables pratiques dont étaient victimes les pauvres gens du Comté, meurtris dans leurs consciences de chrétiens par l'usage indiscret des excommunications. La publication du Concile, d'ailleurs, n'était que la préface de l'oeuvre de réforme qui allait se poursuivre des années durant, sous l'énergique impulsion du Parlement.

Mais, d'autre part, c'était une nouvelle conquête, un nouveau pas en avant de l'absolutisme monarchique que sanctionnaient les édits réformateurs du roi. Claude de la Baume avait pu apprendre à ses dépens qu'un archevêque devait être autre chose qu'un prince de l'Église : s'il avait des devoirs envers la papauté, il en avait aussi envers la royauté. N'est-il pas curieux de lire dans Gollut, bon interprète de la pensée des parlementaires comtois, l'intéressant passage où il signale le danger d'avoir, à la tête du diocèse, un étranger « non seulement de corps, mais de volonté et d'affection » ? Il propose finalement de remettre au maître du Comté le droit de choisir le prélat sur une liste de trois candidats dressée par le chapitre métropolitain - c'est-à-dire, simplement, d'assimiler aux conseillers du Parlement, aux officiers directs du souverain, celui qui tenait dans les assemblées des États un rôle prépondérant, qui possédait le droit d'entrer au Parlement comme maître des requêtes, qui n'avait pas seulement charge d'âmes, mais de sujets du roi, « commandait au clergé » et devait rester « l'oeil veillant sur le troupeau, afin que les loups ravisseurs hérétiques ne se ruent à travers le bercail ». Si dans son ardeur à réformer l'Église, à la vouloir respectée et « autorisée », Philippe II avait été tenté par impossible de lui céder quelque chose de ses droits - ou, plus exactement, de ne pas assez réduire les privilèges d'Église - ses sujets auraient su lui signaler sa faute. 
PHILIPPE II ET LA FRANCHE-COMTÉ

Étude d’histoire politique, religieuse et sociale.

Quatrième partie. Le progrès de l’absolutisme.

\section{Chapitre XX \\ Les réformes : L’Université de Dole}

$\underline{\text { Retour à la table des matières }}$

Détruire les abus les plus criants de l'institution ecclésiastique, et pour cela, préliminaire indispensable, faire publier le Concile de Trente en Comté : c'était une première mesure de contre-réforme qui, depuis longtemps, s'imposait. Surveiller les écoles et les universités, faire peser sur les régents, les professeurs et les étudiants le poids d'une censure étroite et rigoureuse - la tâche n'apparaissait pas moins urgente à Philippe II et à ses ministres. Ils savaient quels liens avaient uni à l'origine la Renaissance des études et la Réforme de la religion. Ils sentaient quelle force puisait le calvinisme dans sa solide organisation scolaire, dans la valeur et l'éclat d'une Académie comme celle de Genève. Ils se rendaient compte enfin de l'attrait que, souvent, exerçaient sur les jeunes gens la parole et la doctrine de maîtres célèbres, de juristes éminents, séduits et gagnés par les nouvelles doctrines. De là, un double effort : pour réorganiser les universités, d'une part ; de l'autre, pour empêcher le rayonnement des idées, des méthodes et de l'enseignement protestant en pays catholique. 


\section{I}

Dès novembre 1561, l'évêque et futur cardinal J.-Fr. Commendon demandait, au dire de Vargas, que Philippe Il interdît à tous ses sujets de sortir de ses États et d'aller à l'étranger s'infecter d'hérésie : il réclamait l'ouverture d'une université à Deventer, aux Pays-Bas. Or, la question préoccupait déjà Philippe. Le Ier août 1559, il avait obtenu de Paul IV un bref autorisant l'érection d'une université à Douai et réglant sa dotation; le 19 janvier 1562, il allait en signer les patentes d'établissement. Granvelle, de son côté, partageait ses idées. Il écrivait, le 15 octobre 1565, à Gonzalo Perez, que la fréquentation des écoles et des universités de France ou d'Allemagne par les jeunes sujets du roi était pernicieuse; qu'ils en revenaient imbus des pires doctrines; et il s'impatientait contre le Conseil privé qui refusait de rien faire, invoquant les libertés du pays.

Le duc d'Albe ne se laissa pas arrêter par de telles résistances. Philippe, au reste, lui avait rappelé, à diverses reprises, la nécessité d'agir. En mars 1570, une ordonnance assimilait, pour les sujets des Pays-Bas, le fait d'étudier dans une université étrangère au crime de rébellion, et le 8 mai I570, des lettres patentes, adressées au Parlement de Dole, interdisaient à tous les Comtois d' « étudier, enseigner ou apprendre ny tenir résidence en autres universiter, escolles généralles ou particulières, si ce n'est en iceulx noz pays ou d'autres royaulmes, pays et Estatz de nostre obéissance, excepté toutes fois la ville et université de Rome ». C'était pour l'avenir : pour le présent, ordre était donné à « tous ceulx que sont présentement en quelques universitez ou escolles publicques ou privées hors de noz pays et lieux susdicts » de s'en revenir au plus tôt « ou se transporter ès universitez nostres et permises, assavoir ceulx qui sont deça les monts en deans quatre mois, et les autres en deans six mois de la publication de cestes ». Le tout, à peine de confiscation et de bannissement perpétuel non seulement contre les contrevenants, mais contre leurs parents, tuteurs ou curateurs.

La mesure était radicale et violente : le Parlement sut bien le faire voir. Le 29 mai, il recevait communication de ces décisions ; aussitôt, il mettait en délibération s'il devait les publier ou non. L'embarras était grand pour les conseillers. La 
mesure atteignait nombre de familles, soit nobles, soit bourgeoises, qui avaient l'habitude d'envoyer leurs enfants aux « estudes » étrangères, soit pour apprendre les langues, soit pour entendre des juristes en renom. Et puis, le mandement soulevait des questions particulières : il y avait, à Paris, un collège fondé spécialement pour les étudiants comtois : le Collège de Bourgogne. Faudrait-il cesser d'y placer les jeunes gens ? De même, faudrait-il renoncer à envoyer les enfants à Paris chez les jésuites, où déjà des Comtois notables - entre autres le conseiller Belin - avaient pris l'habitude de mettre leurs fils ? D'ailleurs, où étudierait-on désormais avec profit les bonnes lettres, la médecine, la chirurgie et la théologie ? Point d'écoles suffisantes en Comté, où la Faculté des arts et celle de médecine, à Dole, ne furent jamais prospères et considérées. Les conseillers résolurent finalement de ne point publier le mandement avant d'en avoir plus mûrement délibéré. Rapport en fut fait au roi, qui consentit à ce qu'une enquête fût menée sur le Collège de Bourgogne par le Parlement. Elle fut toute en faveur de l'institution parisienne, préférable encore, disait la cour, aux écoles catholiques de Fribourg en Brisgau. Mais on voit par plusieurs demandes de particuliers conservées aux Archives du Doubs et tendant à obtenir exemption de l'obligation imposée en mai 1570, que la protestation de la cour resta vaine. Du moins, les plaintes du Parlement sur l'insuffisance de l'enseignement en Comté ne furent probablement pas sans influer sur les déterminations ultérieures du duc d'Albe.

\section{II}

C'était aux deux facultés de droit qu'allaient tous les encouragements, tous les soins du pouvoir. En 1540, Charles-Quint avait, sur la prière de son chancelier, Nicolas Perrenot, ancien élève des maîtres de Dole, accordé à l'université une allocation de $400 \mathrm{fr}$. pendant trois ans pour faire venir d'Italie ou de France quelqu'un de ces savants docteurs dont la présence assurait immédiatement la vogue à la faculté qui les appelait. C'est ainsi qu'en 1541 était arrivé de Casal à Dole le jurisconsulte Nicolas Belloni. Lui parti, en septembre 1547, et l'expérience ayant été bonne, la subvention fut continuée et même accrue ; après de longues démarches, en août 1551, Stratius, quittant Bourges, était venu s'installer dans la capitale commise ; il l'avait quittée en juin 1559, y était revenu à la fin d'octobre 1561 et 
finalement avait résigné ses fonctions professorales en novembre 1564. Un moment, on se le rappelle, Dumoulin avait professé à l'université, et François Alciat avait failli quitter, sur instances de Granvelle, sa chaire de Pavie pour la chaire doloise ; enfin, de 1566 à 1569 le Padouan Olziniani, de 1570 à 1572 le Romain Cynus se succèdent dans les fonctions extraordinaires qu'avait inaugurées Nicolas Belloni.

Ces étrangers de renom avaient attiré à Dole une masse d'étudiants assez considérable, et l'on avait même vu en 1562 - c'est le chiffre le plus fort qu'il nous soit donné de constater sur les matricules, de 1561 à 1601 - 268 étudiants inscrits dans les registres du recteur. Défalcation faite des Comtois et des Bisontins, dont le nombre reste pendant la seconde moitié du XVIe siècle à peu près constant, - il oscille entre vingt et trente - on voyait affluer à Dole de très riches et très nobles étrangers : des Allemands de toutes les parties de l'Empire, même des plus reculées ; des Poméraniens, des Saxons, des Bavarois ; des Flamands qui retrouvaient à Dole des professeurs de leur nation; des Anglais, des Français même, bien qu'en plus petit nombre. Ces hôtes, souvent fastueux, installés dans la ville avec un nombreux domestique, dépensant largement, constituaient un élément de richesse et de prospérité appréciable dans la cité. Seulement, les années n'amenaient pas toutes avec elles la même prospérité. De 268 en 1562, le chiffre des inscrits tombe à 78 en 1563, à 60 en 1564, à 38 même en 1565 ; et s'il se relève à 45 en 1566, et surtout à 78 en 1569, jamais la centaine n'est atteinte ni dépassée ; jamais elle ne le sera dans toute la fin du siècle. Il y avait à cette diminution des causes accidentelles - mais des causes profondes aussi, et permanentes. C'est que, réputée pour le droit, l'école doloise ne l'était ni pour la théologie, ni pour la philosophie, ni même pour la médecine; et - cause à la fois et conséquence de cet abandon relatif - les professeurs des trois facultés non juridiques et même les professeurs ordinaires des facultés juridiques étaient rémunérés très chichement. Belloni touchait 1000 fr. par an et Stratius 900 ; mais ses collègues étaient loin de semblables gages. Les Dolois, très émus du nombre décroissant des étudiants - surtout des étrangers - voyaient, non sans raison, dans la modicité des traitements magistraux une cause de déchéance pour leurs facultés. Dès 1569, le recteur s'occupait de faire représenter au duc d'Albe la situation réelle et sollicitait de lui quelque largesse ; en 1570, une ordonnance de Philippe accordait à l'université une augmen- 
tation de 3000 fr. par an ; pour en déterminer la répartition, le duc d'Albe, peu après, publia son règlement du 18 mai 1571.

\section{III}

D'abord, aux termes de cet acte important, les traitements des anciens maîtres se voyaient majorés de sommes importantes : 100 fr. étaient alloués en surplus aux deux théologiens ordinaires, à qui l'on promettait en outre une prébende à l'église de Dole ; 200 allaient à chacun des professeurs ordinaires de droit, et 600 à l'extraordinaire; 50 aux régents de philosophie, les moins bien partagés. En plus, le nombre des chaires était augmenté, la situation des maîtres régularisée, des enseignements nouveaux créés pour l'hébreu, les lettres latines, le grec. Les deux facultés de droit - toujours les préférées - compteraient jusqu'à huit professeurs titulaires : deux de droit canon, deux de droit civil, deux d'Institutes, un de droit criminel ; enfin, le professeur étranger, choisissant à sa guise le sujet de ses leçons : peu d'universités étaient aussi bien fournies de juristes. De bons professeurs de théologie seraient choisis : ils devraient être Comtois et anciens élèves de Dole, de Douai ou de Louvain. Ainsi, un effort vigoureux était tenté pour rendre Dole enviable aux maîtres et y attirer des compétences réelles.

Mais ces bonnes dispositions étaient bien compensées par les mesures d'ordre politique qui les accompagnaient. Dorénavant, les trois officiers ou distributeurs qui choisissaient les maîtres devraient consulter « les doyens et plus anciens de la faculté en laquelle la lection vaquera ». L'élection se ferait ensuite " soubz la superintendance du président ou du vice-président de la cour de parlement audit Dole », et ce magistrat se voyait investi d'un pouvoir énorme : s'il jugeait que le choix des distributeurs n'était pas bon, il pouvait «commander que, sans avoir reguard à lad. élection, l'on procède à une nouvelle ». Grave modification aux statuts anciens : le corps enseignant se trouvait ainsi placé sous le contrôle du président, c'est-à-dire, dans une certaine mesure, sous la main du roi. Mais l'ordonnance allait plus loin : jusque-là, le recteur était toujours choisi parmi les étudiants et élu par ses condisciples ; il ne devait être ni clerc, ni moine, ni Dolois, ni marié, ni professeur ; c'était un fils de bonne et riche famille, renommé pour son 
travail, son intelligence et sa libéralité. Or, il était armé de pouvoirs considérables : chef réel de l'Université - velut unius mystici corporis caput exsistens, disaient les statuts - son droit de juridiction s'étendait sur tous les membres de l'université, à de rares exceptions près, et embrassait le civil et le criminel. Lorsqu'un nouveau bailli de Dole, lorsqu'un nouveau lieutenant général du bailliage était institué, il devait, par-devant le recteur, jurer de respecter les libertés universitaires. Bref, l'élection faisait libre et indépendant le chef de l'université - un étranger souvent, non sujet du Roi Catholique. C'est ce que le duc d'Albe ne voulait pas. Par son ordonnance, il établit que le recteur serait pris désormais non parmi les simples étudiants, mais parmi les licenciés et les docteurs. Bien plus, par un appointement du 22 avril 1572, il fut résolu qu'il pourrait être professeur et Dolois : villatensis, et que, dorénavant, les régents seuls procéderaient à son élection, à l'exclusion de tous mandataires des étudiants. Cette mesure brutale provoqua des troubles et même, en 1575, une véritable émeute ; mais si le roi consentit, en 1578, à adoucir un peu la rigueur de ses décisions premières, il ne rendit pas cependant aux étudiants le droit de vote qu'il leur avait ôté.

\section{IV}

Quelle fut d'ailleurs la portée de cette réaction autoritaire ? Faut-il y voir la cause de ce que l'on nomme la décadence de l'université de Dole pendant la seconde moitié du XVIe siècle? Décadence réelle, sans doute : les nombreuses plaintes des Dolois l'attestent. Encore faut-il s'entendre à ce sujet. Des historiens, dont le travail sur les universités comtoises fait toujours loi, nous ont dépeint jadis la prospérité des Facultés doloises au temps de Charles-Quint, lorsque «Belloni, Stratius, Dumoulin, Olziniani, les Chifflet, Jean de Saint-Mauris attiraient un concours inusité d'étudiants épris de la science nouvelle du droit ». Alors, prétendent-ils, le nombre des immatriculés put s'élever jusqu'à 500 étudiants environ sans d'ailleurs jamais dépasser ce chiffre. Aussi considèrent-ils comme un total déjà très faible celui de 268 inscriptions que l'on constate, en 1563, sur les registres du recteur Besançon. 268 inscriptions! Mais c'est au contraire le chiffre maximum qu'il nous ait été donné de constater, entre 1540 et 1601, sur les listes annuelles dressées par les recteurs. Aux plus beaux temps des Belloni, des Stratius 
et des Dumoulin - c'est-à-dire entre 1540 et 1570 - la réalité était infiniment moins belle que ne le croyaient les historiographes des gloires doloises : on n'a, pour s'en rendre compte, qu'à parcourir le tableau que nous avons dressé ci-contre, à l'aide des registres rectoraux conservés. Et, sans doute, après l'année 1562, l'année du maximum - on ne revoit plus sur les listes ni les 112 inscrits de 1542 (l'année qui suivit l'arrivée de Belloni) - ni les 90 étudiants de 1553, les 133 de 1557 ou ]es 268 de 1562 qui se pressaient aux cours de Stratius lors de son premier ou de son second séjour en Comté. Les chiffres décroissent rapidement : de 1563 à 1601, ils se maintiennent en moyenne aux environs de la cinquantaine, oscillant entre les extrêmes constatés de 80, 78 et 75 d'une part, 38, 42 et 43 de l'autre. Mais, est-ce à la seule ordonnance du duc d'Albe qu'il convient de faire remonter la responsabilité de cette situation ? Tant d'autres causes contribuent à l'expliquer : les pestes, les guerres, l'état troublé de l'Europe, le moindre renom des professeurs extraordinaires de Dole, l'inobservance même des prescriptions de 1570 relatives au paiement des maîtres : sous la monarchie de Philippe II, on sait assez qu'en matière financière, les promesses et les réalités ne se confondaient pas.

Cependant, il est évident que les mesures prises par le duc d'Albe - plus encore, que sa politique universitaire et sa politique générale, jointes aux guerres du temps, - étaient faites non pour attirer, mais pour éloigner les étudiants étrangers : en particulier les Allemands, si faciles à suspecter d'hérésie. Ce ne sont à leur endroit que mesures de défiance, surveillance étroite de leurs actes, de leurs lectures, de leurs fréquentations. Et si, d'aventure, ils ne se plient pas aux moeurs catholiques du pays comtois - fussent-ils grands seigneurs, classés parmi les étudiants «d'illustre famille » et recommandés particulièrement par M. de Vergy - on les prie énergiquement ou de vider les lieux ou de vivre à la façon du pays : le marquis de Baden, en 1588, devait l'apprendre à ses dépens.

D'ailleurs, et de plus en plus, à mesure qu'on s'avance dans le siècle, toute spontanéité, toute joie, toute vie étaient, par ordre supérieur, bannies des moeurs universitaires. Dès 1555, Granvelle, préoccupé en face des progrès de la Réforme d'une transformation sévère des usages et des moeurs en pays catholique, donnait pour condition à l'octroi d'une dotation de 500 fr. faite à la ville de Dole pour entretenir Stratius, «que l'on face cesser l'abbaye qui ne sert d'autre chose que pour débaucher les escoliers ». C'était une joyeuse conspiration d'étudiants et d'écoliers qui, fidèles héritiers des Enfants Sans-Souci et des associations de la Basoche 
chères au XVe siècle, élisaient tous les ans un abbé et dépensaient en fêtes joyeuses, en banquets, en cavalcades leur belle humeur et leur entrain. Non sans abus évidemment : la jeunesse du temps avait parfois la gaieté un peu vive et brutale et comme les Dolois avaient eux aussi leurs sociétés joyeuses et leur Père fol, il s'ensuivait parfois des rixes, des batailles bruyantes entre les étrangers et leurs hôtes comtois. Malgré les arrêts d'ailleurs et les prohibitions, l'abbaye eut la vie dure et fit belle résistance. Après Granvelle, le Parlement dut encore intervenir et, le 18 octobre 1556, protester contre une compagnie « contraire à la bonne fame et renommée de l'Université et même contre les bonnes moeurs ». En 1570, le 4 juillet, il y revenait encore pour abolir expressément « les abbayes et pères folies ». Trois ans après, c'était le tour des Valentiniana. Les visites traditionnelles que nous décrit, en tout bien tout honneur, l'honnête Tyrolien Geizkofler, les longs tête-à-tête des étudiants étrangers et des aimables Doloises - échanges profitables de conversations - ne trouvèrent pas grâce devant les maîtres du temps. Ainsi la décence extérieure, la rigidité, l'hypocrite ennui remplaçaient peu à peu les moeurs du vieux temps.

Réforme de l'Église, réforme de l'Université : l'une rejoignait l'autre. Un même esprit les inspirait toutes deux, esprit d'absolutisme et de Contre-Réforme. 
Tableau dressé d'après les registres rectoraux conservés à la Bibliothèque de Besançon

\begin{tabular}{|c|c|c|c|c|c|c|c|}
\hline Année & $\begin{array}{c}\text { Nom } \\
\text { du recteur }\end{array}$ & $\begin{array}{c}\text { Total des } \\
\text { inscrits }\end{array}$ & $\begin{array}{c}\text { Étudiants } \\
\text { comtois }\end{array}$ & $\begin{array}{c}\text { Docteurs } \\
\text { créés (1) } \\
\text { id. }\end{array}$ & $\begin{array}{c}\text { Licenciés } \\
\text { créés (2) } \\
\text { id. }\end{array}$ & $\begin{array}{c}\text { Bache créés } \\
\text { (2) } \\
\text { id. }\end{array}$ & Maît. ès arts \\
\hline 1540 & Richard Receveur. & 51 & 14 & 2 & 1 & 3 & 2 \\
\hline 1541 & Pierre Mercier. & 56 & 18 & 4 & 1 & $"$ & $"$ \\
\hline 1542 & Rémond Chosal. & 112 & 78 & 4 & $"$ & 2 & 2 \\
\hline 1543 & Louis de Chavirey. & 32 & 16 & 4 & 3 & 6 & $"$ \\
\hline 1545 & Jean d'Eck. & 22 & 6 & 3 & 2 & 2 & $"$ \\
\hline 1546 & Guill. Maertenne. & 34 & 15 & 8 & $"$ & 4 & $"$ \\
\hline 1547 & Christ. Mellinger. & 62 & 12 & 7 & $"$ & 2 & 1 \\
\hline 1550 & Et. Mairot. & 51 & 15 & 6 & 4 & 1 & 1 \\
\hline 1552 & Jean Lallemand. & 41 & 23 & 2 & 10 & " & $"$ \\
\hline 1553 & Th. van der Karck. & 90 & 26 & 9 & 16 & 4 & $"$ \\
\hline 1554 & M. Stainberger. & 44 & 8 & 8 & 17 & 1 & $"$ \\
\hline 1557 & Jean de Marnix. & 133 & 15 & 16 & 16 & 1 & $"$ \\
\hline 1561 & Arnbr. de Goes. & 82 & 25 & 9 & 3 & 3 & $"$ \\
\hline 1562 & J. Besançon & 268 & 45 & 4 & 7 & 2 & $"$ \\
\hline 1563 & Laurent Holtman. & 78 & 24 & 13 & 6 & 7 & 1 \\
\hline 1564 & W. Quad a Lantzkron. & 60 & 23 & 9 & 3 & $"$ & $"$ \\
\hline 1565 & J. Marceret. & 38 & 24 & 16 & 4 & 1 & $"$ \\
\hline 1566 & CI. Guiot. & 45 & 28 & 7 & $"$ & 3 & $"$ \\
\hline
\end{tabular}




\begin{tabular}{|c|c|c|c|c|c|c|c|}
\hline Année & $\begin{array}{c}\text { Nom } \\
\text { du recteur }\end{array}$ & $\begin{array}{c}\text { Total des } \\
\text { inscrits }\end{array}$ & $\begin{array}{l}\text { Étudiants } \\
\text { comtois }\end{array}$ & $\begin{array}{l}\text { Docteurs } \\
\text { créés (1) } \\
\text { id. }\end{array}$ & $\begin{array}{l}\text { Licenciés } \\
\text { créés (2) } \\
\text { id. }\end{array}$ & $\begin{array}{c}\text { Bache créés } \\
\text { (2) } \\
\text { id. }\end{array}$ & Maît. ès arts \\
\hline 1569 & J.-G. Ganzhorn. & 78 & 23 & 11 & 6 & 1 & " \\
\hline 1577 & Christ. Eckius. & 80 & 17 & 17 & 4 & 1 & " \\
\hline 1580 & Claude Bavoux. & 62 & 29 & 11 & 4 & $"$ & $"$ \\
\hline 1581 & J. de Lamberg. & 59 & 16 & 12 & 5 & 1 & $"$ \\
\hline 1586 & Claude Javel. & 43 & 30 & 4 & 2 & $"$ & $"$ \\
\hline 1588 & Pierre Dardot. & 55 & 9 & & manque & & $"$ \\
\hline 1589 & Claude Gros. & 75 & 33 & 4 & 9 & $"$ & " \\
\hline 1592 & Philippe Broch. & 61 & 16 & 9 & 6 & $"$ & $"$ \\
\hline 1601 & Jean Froment & 42 & 26 & 4 & $"$ & $"$ & 3 \\
\hline
\end{tabular}

I. Y compris les Bisontins.

2. Un grand nombre de ces docteurs passent la licence la veille ou quelques jours avant de passer le doctorat. Nous ne les comptons naturellement pas parmi les licenciés créés. Même observation pour les bacheliers. 
PHILIPPE II ET LA FRANCHE-COMTÉ

Étude d’histoire politique, religieuse et sociale.

Quatrième partie. Le progrès de l’absolutisme.

\section{Chapitre XXI}

\section{Les réformes : Le Parlement}

$\underline{\text { Retour à la table des matières }}$

L'Église et l'université de Dole, tour à tour, avaient senti sur elles la main pesante du duc d'Albe. Le Parlement, le corps le plus important de la province, échapperait-il à ses prises ? Sans doute, lorsque Ferdinand de Lannoy, à Salins, s'était substitué à lui d'ordre du gouverneur, ou, plus récemment, lorsque François de Vergy avait incarcéré le procureur d'Amont, il avait subi de rudes assauts : mais il était à prévoir que le duc d'Albe ne s'en tiendrait point là.

C'est qu'il avait apporté les plus vifs sentiments de méfiance et d'hostilité visà-vis de tous les conseils locaux. Ce n'était pas en collaborateurs, mais en suspects que, dès l'origine, il avait traité les conseillers du Privé et du Grand Conseil. Or, le Parlement de Dole devait d'autant moins bénéficier d'une indulgence spéciale que, depuis fort longtemps, une réforme de la justice apparaissait nécessaire en Comté. Les Comtois eux-mêmes la réclamaient. En 1561, notamment, les États avaient demandé d'énergiques mesures, pour rendre plus prompte l'administration de la justice. Non sans raisons, si l'on songe, par exemple, qu'en 1579, les manants de Buffard pouvaient se plaindre qu'un procès relatif à un droit de taille de 37 livres se trouvait pendant au Parlement depuis le 20 décembre 1535 « sans que lesd. remonstrans en ayent sçeu obtenir vuydance, jaçoit que tousjours ilz l'ayent pour- 
suy ». Cas extrême, mais non unique. Or, très habilement, les parlementaires avaient répondu au voeu des États en proposant la réorganisation des justices subalternes ; mais quant aux abus propres de leur institution, ils n'avaient eu garde d'en parler. Par là-dessus, les années de troubles étaient venues. La mission de Moron avait peu touché aux questions judiciaires. Les conseillers avaient réussi à éviter la nomination projetée de nouveaux confrères et à maintenir avec le statu quo les abus. Là encore, il était réservé au due d'Albe sinon de les détruire, du moins de les attaquer.

Dès le début, en effet, il montra le dessein arrêté de faire exécuter les mesures déjà décidées, et d'en proposer de nouvelles. Sa première lettre à la cour, celle-là même où il notifie sa prise de possession du gouvernement, roule tout entière sur la gestion des salines : elle se termine par l'ordre de publier sur l'heure les nouvelles ordonnances de la Saunerie et d'instruire, en toute diligence, le procès pendant des quatre clercs des rôles.

La suite des événements ne démentit point ces débuts. Les ordonnances furent publiées : le duc veilla à ce qu'elles fussent observées. Le procès des clercs fut dressé : le duc, impitoyable, les déporta de leurs états. Un haussement du prix du sel, projeté par Marguerite en 1565, fut réalisé en 1571 et motivé par le renchérissement des denrées nécessaires à l'exploitation. Surtout, la confiscation du partage de Chalon donnant au roi les 5/6 de la Saunerie, dès 1568, par les soins du duc, des négociations s'engagèrent pour l'acquisition du sixte de Vignory, le dernier sixième. C'était M. de Vergy qui le détenait. Les négociations aboutirent en 1570 ; marché fut conclu, le 15 janvier de cette année, pour une somme de 138473 fr. Comme acompte, François de Vergy recevait pour vingt ans la seigneurie de Jussey, à réachat de 24567 fr. Ainsi s'achevait la concentration. Il est vrai que le duc d'Albe avait été moins heureux dans ses négociations pour racheter le Puits à Muire. Du moins, si elle ne devait être tranchée que plus tard, avait-il eu le mérite de poser la question avec vigueur. Pareillement - et le fait montre bien quel désir d'unification le possédait : contre les deux petites salines de Saunot et de Soulce, 
qui s'obstinaient à manifester une activité d'ailleurs bien précaire, le Parlement dut agir sur ses ordres et poursuivre une fois de plus - sans illusions probablement - la fin d'une concurrence pourtant peu inquiétante.

Même esprit, même activité, même surveillance minutieuse en ce qui concerne le domaine. Plus d'engagères nouvelles : si Jussey est pour vingt ans cédée à François de Vergy en 1570, ce n'est pas à titre de largesse ou de récompense, mais comme acompte. Par contre, en 1570, Jonvelle ; en 1571, Quingey, sont rachetés à leurs détenteurs. Une active surveillance pèse sur les gens des Comptes ; en revanche, leurs attributions sont précisées, élargies par le duc. Il les trouvait plus dociles, il les savait moins forts, moins capables de résistance que les parlementaires. De là, dans les conflits qui mettaient aux prises, à Dole, la jeune Chambre des Comptes et le vieux Parlement, sa tendance à prêter une oreille complaisante aux gens de finances, même lorsque leurs récriminations n'étaient guère fondées en raison. De là, surtout, ses efforts, que le succès devait couronner, pour leur conférer, au détriment du Parlement et en dépit de ses protestations, la connaissance des causes concernant le domaine.

\section{II}

Contre la cour de Dole, forte de ses privilèges, de son importance même, de cette perpétuité des grands corps constitués qui leur confère une telle puissance de résistance et d'inertie, les griefs ne manquaient certes pas : on les pouvait classer sous trois chefs. Griefs politiques et religieux d'abord : et l'on pense qu'ils n'apparaissaient pas dénués d'importance au duc d'Albe. - Griefs de moralité professionnelle ensuite. Il ne manquait pas de plaideurs malheureux en Comté pour incriminer de partialité tels ou tels de leurs juges ; fondées ou non, ces accusations fréquentes n'étaient pas pour « autoriser » beaucoup la justice. Surtout, à côté des manquements individuels, les abus collectifs : de plus en plus, on reprochait aux conseillers une série de pratiques contraires aux règlements ; les nominations dégénéraient en marchandages; on respectait mal les prescriptions relatives aux liens de parenté ; une foule d'affaires fructueuses, mais sans rapport avec leurs charges, absorbaient le temps des conseillers ; on les voyait enfin, dans les ventes 
par décret, se porter acquéreurs de biens qu'ils convoitaient et user de leur situation pour se les faire délivrer à bon compte. Enfin venaient les griefs d'ordre administratif, et notamment le premier d'entre eux, cette infinie lenteur de la justice qu'on dénonçait depuis de longues années.

Or, dès janvier 1567-68, le duc d'Albe enjoignait au Parlement de lui envoyer copie de toutes les ordonnances et instructions le concernant, et de l'avertir spécialement «si icelles sont esté bien gardées et observées en tous leurs poinctz, ou esquelz non, si aucuns en y a ? la cause pourquoy, ensemble toutes les circonstances ? » le tout, avec injonction aux conseillers de se "ranger et conduire selon celles-ci ». S'exécutant, à la fin de février, les parlementaires adressèrent au duc " le livre des ordonnances, pièça publiées et imprimées », avec copie de l'institution et état de la cour. Ils protestèrent d'ailleurs qu'ils avaient toujours suivi ponctuellement les ordonnances, et « tellement veillé au service de Dieu, conservation de notre saincte et ancienne foy catholique et religion romaine, debvoir de fidélité envers S. M. et administration de bonne et droicturière justice que, Dieu grâce, ce pays et conté de Bourgoingne estoit demeuré du tout tranquille au contentement de sad. Majesté ». Ils terminaient en suppliant le duc « de maintenir et conserver tousjours l'auctorité de cestedicte court » : conclusion qui témoignait nettement de leur inquiétude.

Pendant deux ans pourtant, on ne parla pas de réforme. La cour, simplement, dut faire face à de rudes et multiples assauts, défendre de son mieux ses prérogatives, témoigner entre temps d'un zèle religieux propre à racheter ses erreurs passées. Étrangers porteurs de livres défendus ; Comtois rentrés au village natal après quelque séjour en pays suspect; mangeurs de viande en carême, insulteurs de prêtres, colporteurs trop hardis : tous, nous l'avons vu, avaient, en 1568, senti le poids d'une justice que la crainte dépouillait de clémence. Même vigilance, mêmes arrêts en 1569 et 1570. Banni, en juin 1570, un Toulousain porteur de mauvais livres ; bannis, en février 1571, deux menuisiers champenois, trouvés munis d'un traité hérétique ; confisqué, en février 1572, le contenu de « deux grands tonneaulx de sapin plains de livres, la plupart des oeuvres de Calvin et aultres suspectz », que véhiculaient à Pontarlier deux charretiers de Vauvillers. Pareillement, en décembre 1570, ce Jean Muretet de Jonvelle, propagandiste infatigable, qui, depuis si longtemps, déployait aux frontières de Lorraine, à Fontenoy-en-Vôge, une activité haïssable à Belin, saisi sur territoire comtois, expie sur l'échafaud son 
prosélytisme. Surtout, une lutte énergique est entreprise contre les mal mariés, les Comtois et Comtoises qui, «sans aulcung respect à leur salut, s'allient journellement.... avec ceulx qui tiennent les damnables sectes et erreurs régnants ». Dès juin 1569, Belin signalait au Parlement les dangers de telles unions. En juillet, la cour les prohibait et en avisait les officiers du ressort de Baume. Mesure rétroactive : devaient être poursuivis tous ceux qui, depuis dix ans, avaient contracté mariage en pays d'hérésie. - Pourtant, ce zèle ne désarmait pas les rancunes. Toujours des accusations se colportaient contre tels ou tels parlementaires : accusations de « connivence », de « huguenoterie » que la cour poursuivait avec une ardeur indignée et prudente. Malgré tous ses efforts, malgré son demi-succès dans l'affaire Demongenet, il restait visible que son prestige et son autorité avaient subi déjà les plus cruelles atteintes.

Au reste, elle n'était pas alors des mieux composée. Dans ses rangs, beaucoup d'hommes usés, fatigués, parvenus au terme de leur carrière et de leur existence. Point de chef : la présidence restait toujours vacante - depuis le 8 juin 1565 ! A la vice-présidence, un vieillard, le conseiller Colin, titulaire de son office depuis 1532 et qui allait disparaître, en 1572, après quarante ans de services parlementaires. A ses côtés, d'autres vieillards : le procureur général Marin Benoit, en fonctions depuis 1532 également; les deux chevaliers d'honneur, le vieux Jean d'Achey, beau-frère de Granvelle, et Antoine Mouchet de Château-Roillaud son allié ; le greffier Étienne Barnard, caduc et fatigué, tout entouré déjà d'une nuée de candidats « aboyant » à sa charge; des conseillers enfin : Vauchard, granvelliste dévoué, mais que le cardinal écartait, en 1566, pour sa mauvaise santé, du nombre des candidats possibles à la présidence ; Seguin surtout, si vieux, si usé qu'on ne mentionnait plus ses opinions au registre des délibérations.... C'étaient les plus âgés, les plus proches de leur fin; mais les autres? Médiocres caractères, ces Boutechoux, ces Chappuis, ces Sonnet, ces Le Clerc dont l'énergie semblait s'être usée toute, pendant la crise de 1566, à solliciter l'appui des maîtres du jour. De cette période de luttes et de compétitions acharnées, il ne leur restait que des désillusions, des rancunes, de l'amertume. Entre tous, l'aigre Belin, oubliant toute modération depuis qu'il était rentré sans gloire au pays, se distinguait par l'ingéniosité et la persévérance de ses haines. Il entraînait tous les siens dans le cercle étendu de ses passions vindicatives, et mettant à profit les relations qu'il avait gar- 
dées aux Pays-Bas, ne cessait d'y faire passer au duc d'Albe et à ses conseillers des dénonciations calomnieuses et des accusations plus ou moins précises.

\section{III}

Ni le duc ni les personnes de son entourage n'avaient d'ailleurs besoin de telles communications pour penser beaucoup de mal des conseillers dolois. En vain ceux-ci s'efforçaient de multiplier les preuves d'un zèle irréprochable. Lorsque, le 7 août 1570, ils eurent reçu des lettres de Son Excellence « pour la publication du pardon général de S. M. », ne les vit-on pas, trouvant l'occasion bonne de se montrer plus catholiques encore que le Roi Catholique, mettre en délibération s'il fallait ou non publier le pardon dans la province ? Ils conclurent que non : mais s'ils pensaient par de telles manifestations éviter l'inévitable enquête, ils se trompaient. Le 28 novembre 1570, on annonçait à Dole l'arrivée de messires Jean de Blasere et Polictonio Mesabarba, tous deux chargés de visite au Comté. C'était une répétition de ce qui s'était passé sous Marguerite, en 1564 et 1565. Seulement, cette fois, les enquêteurs étaient gens de robe longue, et lancés spécialement contre le Parlement.

Du second, un sénateur milanais, nous savons peu de chose; d'ailleurs, il semble n'avoir joué qu'un rôle d'assistant - ou de comparse. Mais le choix du premier était significatif. Ce Jean de Blasere, serviteur docile et zélé, avait commencé sa carrière comme avocat au conseil de Flandres. Charles-Quint, dans son dernier mandement à Josse Bave, l'avait nommé, le 22 octobre 1555, lieutenant civil du bailliage de Gand. Conseiller au conseil de Flandre en 1557, puis, en 1562, au grand conseil de Malines, il avait enfin été appelé au Conseil des Troubles ; il y avait siégé aux côtés d'Hessele, l'enquêteur de l'affaire Quiclet, et de Claude Belin qu'il appréciait assez. Tel était celui que le duc d'Albe envoyait inspecter et épurer le Parlement de Dole : c'était un représentant en mission du Conseil des Troubles.

La mesure aurait dû être prévue. Elle n'émut pas moins profondément les conseillers. Ils s'empressèrent de recevoir les enquêteurs, envoyèrent au-devant d'eux leurs confrères Sonnet et Belin - et même, les firent prier de passer à la cour, leur offrant d'avance un concours dévoué. Mais ces civilités accomplies, 
l'enquête commença. Elle fut sans ménagements comme sans délicatesse. D'abord, Blasere et Mesabarba firent afficher un placard « signifiant à tous.... que s'il auroit voulenté se plaindre de la court.... et autres ministres de justice en ce pays, ils le deussent faire et se pourveoir devers eulx deans 15 jours après lad. publication ». La publication, faite d'abord dans le bailliage de Dole, fut renouvelée successivement dans ceux d'Aval et, d'Amont avec pour chacun un délai analogue de quinze jours. Six semaines passèrent. Puis les commis, « passant à plus dangereux », firent publier un autre placard, « par lequel ilz promettaient impunité à ceulx qui révéleroient les malversations, abuz et excez d'aucuns, s'ilz estoient mesmes complices, culpables et punissables de droit ou par les ordonnances de $\mathrm{S}$. M. ». C'était un appel direct à la délation : il fut suivi d'effet puisque, le 27 mars 1570-71, le greffier Boullin, qui accompagnait Blasere et Mesabarba, se présentant de leur part en Chambre du Conseil, notifiait à la cour la suspension des conseillers Colard, Chifflet et Chappuis. Première fournée de victimes. D'autres allaient la suivre.

Quittant Dole, en effet, les commis, au printemps, se mirent à voyager à travers la Comté. Ils se déplacèrent de bailliage en bailliage : on les signale à Vesoul le 5 mai, à Salins le 30 Juin. Non seulement ils inspectaient les officiers royaux, les lieutenants, les substituts des procureurs fiscaux, les scribes et les greffiers, mais convoquant devers eux les «procureurs, scribes, maires, eschevins et proudhommes des lieux », se faisant exhiber les comptes des communautés, ils déployaient, au dire du Parlement, la plus minutieuse - et la plus indiscrète des curiosités.

Le résultat fut d'abord quelques mesures de rigueur isolées - notamment, le 30 juin 1571. l'arrestation du lieutenant d'Arbois Jacques Poly, décidée par la cour sur réquisition des enquêteurs ; puis, le 18 septembre 1571. une nouvelle visite du greffier Boullin au Parlement. Cette fois, il avait quatre écrits à notifier aux conseillers de la part de ses maîtres - le premier suspendait de son office leur collègue Sonnet, quatrième victime de la mission. Le second interdisait pareillement l'exercice de leur état à trois lieutenants de bailliage, tous trois du bailliage d'Aval : Mathieu le Jeune, de Poligny ; François du Tartre, de Montmorot ; Jacques Poly, d'Arbois : la cour, le 25, leur nomma des suppléants. Le troisième suspendait le clerc du procureur général, Guillaume Duchesne. Enfin, le quatrième concernait le procureur fiscal d'Amont François Demongenet, François Damedor 
et Louis Renard, trésorier de Vesoul : les enquêteurs priaient la cour d'intervenir " pour les faire contenir en bonne intelligence les ungs avec les autres ». Cinq suspensions d'office à joindre aux trois premières déjà décidées : c'était une vraie terreur judiciaire en Comté. Outre les suspendus, d'ailleurs, il y avait les suspects : un cinquième conseiller, le Clerc, s'il ne subit pas dès lors le sort de ses quatre collègues, fut du moins comme eux l'objet d'enquêtes et de rapports aux Pays-Bas.

On devine l'émoi du Parlement. Dès l'arrivée des commis, il en avait référé à Granvelle. Mais celui-ci, prudent à son ordinaire et désireux de ne point « s'enveloupper » dans le débat, les avait renvoyés simplement.... au duc d'Albe. Les conseillers alors s'étaient retournés vers la Flandre. Réunis une première fois le 31 juillet 1571, ils avaient décidé d'envoyer leur collègue, Louis de Boisset, aux Pays-Bas, « au fur de deux écus par jour », pour «faire remontrance à Sad. Excellence de plusieurs pointz contenuz en ses instructions ». Mais, le 6 août, le voyage avait été remis « à quelque autre meilleur saison ». Les commis partis, le 9 octobre 1571 la question fut reprise : on décida simplement l'envoi de lettres au duc d'Albe, à Viglius, à Tisnacq, à Hieronimo Olziniani, Courteville et Champagney, personnages influents en qui la cour se plaisait à voir des défenseurs. C'était prudemment faire, au reste : on ne voit pas bien quel accueil aurait trouvé aux PaysBas Louis de Boisset, ou tout autre de ses collègues, envoyé se plaindre et « faire remontrance » au sujet des visiteurs.

Ceux-ci avaient quitté la Comté dans les tout premiers jours d'octobre pour retourner chacun en son pays. Blasere, rentré en Flandre, s'était mis à rédiger ses notes, à compulser enquêtes et dossiers pour la rédaction d'un rapport définitif. Quelles charges pesaient au juste sur chacun des suspendus? On serait tenté d'abord, à ne considérer que leurs noms et leurs personnes, de songer à des représailles politiques et religieuses - à un épilogue judiciaire des événements de 1565 et 1566. Nous avons vu plus haut quelle part active Sonnet, l'ami et l'allié de Renard qu'il avait suppléé d'abord puis remplacé comme lieutenant d'Amont, avait prise à la campagne antigranvelliste des seigneurs de Rye - et peut-être à la constitution de la Confrérie de Sainte-Barbe. Colard, pareillement, en dépit de tout ce qu'il devait au cardinal, s'était montré fervent « orangiste »; cet étranger d'origine, fils d'un conseiller au Parlement de Dijon, marié à une femme de cette maison bisontine d'Emskerque ou d'Anvers dont les deux chefs, en 1540, Denis et Louis d'Anvers, avaient mérité des poursuites pour hérésie, s'était cru un moment des 
titres sérieux à la présidence du Parlement de Dole. Mais Chappuis par contre ? Mais Laurent Chiflet ? C'étaient deux amis de Granvelle, et qui l'étaient toujours restés. En réalité, leur disgrâce à tous fut la suite d'accusations recueillies par les enquêteurs contre leur moralité professionnelle. Que l'attitude, que la conduite de quelques-uns d'entre eux à une époque troublée, ait prédisposé Blasere à la sévérité, la chose est plus que probable. Mais le plus compromis au point de vue politique, Sonnet, était en même temps un magistrat suspect. Dès le début de sa carrière, il courait sur son compte des bruits assez fâcheux pour que certains conseillers aient refusé, en 1556, de le porter candidat à une place vacante. Même chose pour Chappuis : il avait des ennemis qui, à tort ou à raison, l'accusaient de partialité et d'indélicatesse dans l'exercice de ses fonctions. Si nous ignorons les griefs allégués contre Colard et Chiflet, nous savons, par contre, que ce sont encore des accusations privées - celles d'un certain Claude Richardot - qui attirèrent l'attention des enquêteurs sur leur collègue Le Clerc. Ce personnage, dès 1562, n'était-il pas l'objet, aux Pays-Bas, d'une plainte en collusion et usage de faux ?

\section{IV}

Quoi qu'il en soit d'ailleurs, ce fut un beau tapage quand on connut à Dole les mesures prises. Tandis que les candidats au Parlement se réjouissaient d'une aubaine inespérée : quatre vacances soudaines, quatre places à pourvoir si la suspension se muait en révocation - les victimes de leur côté se mettaient en campagne et songeaient à la défense. Toutes possédaient en Comté et en Flandre de hautes relations : elles les utilisèrent. Chappuis et Chiflet se réclamaient de Granvelle trop même au gré du prudent Morillon, qui tremblait comme toujours de voir compromettre son ami. Sonnet avait trouvé un protecteur actif en don Francisco de Ibarra, le munitionnaire général des armées. Roda s'employait pour lui également et pour Le Clerc qu'il aurait voulu voir renvoyer avec ses collègues devant le Parlement. D'Assonleville, enfin, incriminait Blasere, l'accusant d'avoir outrepassé ses instructions en suspendant cinq conseillers sans leur donner de suppléants : la justice en souffrait ; c'était du moins ce que répétaient à l'envi les victimes de l'enquête, trouvant l'argument bon. Blasere laissait dire et travaillait toujours à son rapport : les ordres étaient tous venus du duc d'Albe, et s'il avait péché, c'était par 
excès de mansuétude : n'avait-il pas reçu l'ordre, non exécuté, de mettre Sonnet « en estroicte prison »? - Tous ces propos, ces démarches, cette effervescence de passions haineuses n'étaient guère faits, on le devine, pour rehausser le prestige du Parlement. Par surcroît, une nouvelle affaire, éclatant en 1572, vint accroître le trouble et les divisions.

Dans son enquête sur les lieutenants, Blasere avait recueilli au bailliage de Dole, contre le lieutenant d'Ornans, Quentin Roussel, de graves dénonciations. On l'accusait communément sinon d'être hérétique, du moins de favoriser ouvertement la propagande réformée dans son bailliage. Blasere n'avait cependant pas pris de mesures contre lui ; il voulait, sans doute, en référer aux Pays-Bas ; mais, avant son départ, il avait averti le procureur général des bruits qui couraient. Après réflexion, et probablement par prudence, la cour, malgré sa répugnance à paraître seconder l'oeuvre de Blasere, fit procéder, au printemps de 1572, à des informations générales sur les faits allégués. Elles confirmèrent pleinement les doutes des commis. On trouva, dans le ressort d'Ornans, la plus ample moisson d'hérétiques qui se fût vue en Comté depuis les enquêtes de Saint-Amour en 1567. Sur la frontière du pays de Neuchatel et de l'évêché de Bâle, les montagnons, en relations assidues avec leurs voisins réformés, se laissaient aller tranquillement à suivre leur exemple, à lire de mauvais livres, même à marier leurs filles en pays hérétique. D'autre part, dans la vallée de la Loue, à Vuillafans et à Ornans, une véritable petite communauté réformée se trouvait en formation, avec la complicité du lieutenant Roussel. Il était, en effet, l'ami de tous ses membres : Guillaume Vernier, Pierre Charmigney, Claude Gody d'Ornans ; Simon d'Anvers, Claude Mignot et Jean Joly de Vuillafans. Presque tous ces suspects étaient assez lettrés ; ils possédaient des livres. il y en avait chez Roussel lui-même, trouvé notamment saisi « d'ung livre intitulé Pantagruel », - trouvaille intéressante et qui confirme ce qu'on à noté aux Pays-Bas du goût des «mal sentants de la foi » pour les oeuvres de Rabelais. Il y en avait chez Simon d'Anvers, chargé d'avoir communiqué à Vernier « ung livre hérétique où estoient les pseaulmes en François » et même d'avoir « escript de soy mesme, en ryme françoise, certains vers mal sentants contre la religion catholicque, à couleur d'avoir ce prins et extraict sur aulcungs livres ». Il y en avait, enfin, chez Charmigney, où l'on signale un livre de Bèze, des psaumes suspects, le «Deffensoire de la Foy chrestienne », une Dominice precationis explanatio et surtout les Colloques d'Érasme. Quant à Claude Gody, 
licencié en droit et recteur des écoles municipales, il ne se contentait pas d'avoir gardé chez lui, contre toute prudence, l'Enchiridion militis Christiani d'Érasme et l'Eloge de la Folie, déclarant qu'en dépit des édits, il ne les brûlerait pas : voyant instruire le procès d'un homme de Réaumont, trouvé saisi d'une bible en français, il s'était épanché en libres propos : "Ne voilà pas une terrible chose, pour avoir Dieu en ses mains, que l'on prend ainsi les gens prisonniers ? Par Dieu, l'on fera venir les Suysses !» Et comme on lui répondait que de bonnes exécutions, comme en Flandre, sauraient y mettre ordre, il ajouta : "Nous sommes trop près des Suisses !» - Propos intéressants, qui montrent bien l'attraction exercée, sur certains esprits cultivés, par le libéralisme relatif de la Réforme en Suisse.

Que le lieutenant Roussel ait été l'ami de tous ces suspects, qu'il les ait fréquentés, qu'il ait dîné chez eux et peut-être sans grand souci de faire maigre en temps prescrit - le fait apparaît certain. Qu'il ait eu des paroles imprudentes, des opinions trop libres au gré de beaucoup, on peut le croire aussi. De là, sans doute, les accusations plus graves qu'on portait contre lui. D'abord, on l'incriminait d'avoir renvoyé absous, après leur avoir témoigné des égards insolites, Claude Mignot, Simon d'Anvers, Claude Joly, Pierre Thibault, Guyot Vuillemin, tous d'Ornans ou de Vuillafans à lui déférés comme suspects d'hérésie par le procureur fiscal d'Ornans. On l'incriminait ensuite de ne pas avoir hésité à prendre connaissance, dans cette même affaire, du cas de Pierre Charmigney, dont il avait cependant épousé la cousine. Enfin, on déclarait qu'il avait d'assidues relations avec un des principaux huguenots de Besançon, Fr. Buzon, et qu'avec trois autres suspects d'Ornans, il avait été, à Besançon même, faire la Cène chez ce personnage.

Ces affaires étaient graves. Par elles-mêmes d'abord : le Parlement ne pouvait rester indifférent à cette révélation que, sur la frontière neuchateloise, de nombreuses familles inclinaient tout doucement vers la Réforme. Cinquante procès, en avril, mai et juin 1572, furent aussitôt dressés contre les montagnons les plus compromis. Mais, surtout, le scandale d'Ornans était de grosse conséquence. Au moment où le Parlement était traité en suspect par le gouvernement des PaysBas ; au moment même où une enquête était dirigée contre lui - que l'enquêteur, que Blasere fût mis sur la piste d'une affaire semblable et conduit non seulement à inculper un lieutenant de bailliage, mais à incriminer à cette occasion le défaut de surveillance et d'activité répressive de la cour de Dole, rien de plus dangereux. Roussel, dès le 14 avril, cité à comparaître ainsi que Pierre Clément, substitut de 
l'avocat fiscal de Dole au siège d'Ornans, fut mis en arrêt dans son logis, interrogé par deux conseillers, et le 28 seulement relâché sous caution. Il partit aux PaysBas se justifier ; mais son inculpation donnait beau jeu aux médisants, aux ennemis-nés du Parlement et des gens de robe ; d'autre part, les «partialitez » et les envies de Bourgogne trouvaient dans cette affaire un nouvel aliment.

Tout pourtant finit par s'apaiser. Les procès des montagnons se terminèrent par un certain nombre de sentences de bannissement avec confiscation de biens prononcée par défaut - et par un nombre au moins égal de sentences absolutoires, prononcées pour la plupart en 1575. Des inculpés d'Ornans et de Vuillafans, deux furent acquittés purement et simplement : Claude Gody, le recteur des écoles, et Jean Joly de Vuillafans ; un troisième, Guillaume Vernier, mourut en prison dès le début du procès, en 1572 ; deux autres n'eurent que des peines légères : Claude Mignot, 200 livres d'amende et l'amende honorable à la grand'messe pour avoir mal parlé du De profundis ; Pierre Charmigney, 200 livres d'amende également pour avoir gardé en mains les Colloques d'Érasme. Simon d'Anvers seul, le plus compromis, fut assez durement traité. Au premier bruit de poursuites, il s'était enfui. Il s'engagea aux Pays-Bas au service du roi, et combattit vaillamment devant Mons. Zèle intéressé : condamné, en effet, une première fois par défaut, à Dole, au bannissement perpétuel avec confiscation de biens, il obtint, arguant de ses bons services militaires, des lettres de purge de S. M. Il revint alors se constituer prisonnier devant la cour, et réussit à faire transformer en exil de dix ans son bannissement perpétuel. Peine encore sévère. Elle atteste bien que les griefs portés contre lui apparaissaient sérieux à la cour.

Celle-ci, en effet, était aussi peu disposée que possible à grossir de tels événements. Elle l'avait montré, du reste, dans sa conduite vis-à-vis de Roussel. Renvoyé devant elle, le lieutenant une première fois, en septembre 1572, s'était vu absoudre de tous les griefs relevés contre lui, sauf de deux : ceux qui concernaient sa conduite indulgente à l'endroit de deux suspects : Guyot Guillemin et Pierre Charmigney, son allié. Pour le premier, les pièces, disait l'arrêt, étaient égarées momentanément ; pour le second, elles avaient été emportées aux Pays-Bas par Blasere. Du reste, l'affaire devait revenir en 1573 et se terminer sur ces deux chefs également par une nouvelle absolution. Clémence justifiée ? Il faut, sans doute, faire la part des "envies de Bourgogne", et si tous les accusateurs de Roussel ressemblaient à Belin qui, après l'avoir chargé sans ménagements, décla- 
rait, paraît-il, à Morillon n'avoir trouvé « en tout le Comté de Bourgoigne homme plus net que led. Lieutenant », l'acquittement était justifié. Mais il faut aussi tenir compte des relations de Roussel, des efforts qui furent faits en sa faveur par Granvelle, par Morillon, par M, de Champagney, par son intime ami Froissard. Chez le cardinal, très évidemment, il y avait le désir de ne pas envenimer une situation qu'il sentait grave, d'apaiser et d'adoucir les conflits, de ménager la robe et le Parlement. Quant à ce dernier, n'était-il pas l'accusé, au moins autant que Roussel ? Et n'était-ce pas Blasere qui avait introduit l'affaire ?

Ainsi, des diffamations, des calomnies, des haines et des rigueurs individuelles : tel était le fruit de la mission d'enquête. Rigueurs fondées ? Étaient-ce vraiment des hommes tarés et de mauvais catholiques que les Sonnet, les Le Clerc, les Colard, les Chappuis ? Il convient, avec le cardinal lui-même, de ne pas « asseurer pour certain ce que demeure secret en la poitrine des hommes ». Mais ce qu'il y a de sûr, c'est que l'enquête judiciaire avait porté le dernier coup à l'autorité, au prestige du Parlement de Dole. Les divisions, les rivalités, les faiblesses de ses membres, une fois de plus, avaient été exposées en pleine lumière. On les avait vus, les juges souverains du Comté, à la merci d'un Flamand et d'un Italien, suspendus de leur office et courant aux Pays-Bas pour se défendre ; on les avait vus implorant l'appui des grands, des puissants du jour et cherchant le salut par des voies obliques. On devine dès lors quels commentaires, quels récits, quelles insinuations dans cette Comté ou, si l'on voulait juger, comme l'écrivait Granvelle, par « les soupçons et envies » des habitants, il aurait aisément semblé « qu'en tout le pays, il n'y eût pas un homme de bien ». Le cardinal, d'ailleurs, tenu au courant par ses correspondants, jugeait nettement les événements : " J'apperçois bien, écrivait-il à Bellefontaine le 18 janvier 1573, qu'on cherche de diminuer l'autorité de la cour, et si vois bien aussi clairement que cela ne convient nullement... Si la justice n'est autorisée, les grands mangeront les moindres. » Le 17 août, il revenait encore sur la question, avertissait Morillon que « la court perdoit de plus en plus l'auctorité ». C'était la conséquence directe de ses erreurs, sans doute, individuelles ou collectives - mais aussi de la politique du duc d'Albe et de ses coups de force ; c'était le premier résultat de la mission Blasere. 


\section{V}

Elle devait, d'ailleurs, en avoir un second. Mission d'enquête répressive ; mission de réorganisation également. Pendant son séjour en Comté, Blasere avait étudié, avec la minutie de son esprit flamand, le fonctionnement des institutions judiciaires comtoises ; il avait relevé les erreurs commises, les pratiques vicieuses, les défaillances coutumières ; bref, il avait ramené de Bourgogne un plein chariot d'informations : documents qui, étudiés, utilisés, revus par le Conseil privé, devaient fournir la base d'un travail législatif nouveau.

Seulement, une telle entreprise rendait singulièrement plus urgente la nomination d'un président de Bourgogne - ou mieux, soulignait plus nettement tout ce qu'avait d'absurde l'irrésolution du roi. Depuis six ans, le président Desbarres était mort. Depuis six ans, Marguerite de Parme, le duc d'Albe et Philippe II lui-même n'avaient pas laissé passer de mois sans se répéter dans leurs lettres combien la vacance était fâcheuse ; - mais la question n'avait pas fait un pas. Il y a vraiment quelque chose de comique dans ces communications multipliées, toutes pareilles et, d'ailleurs, toutes de même effet... Philippe et son ministre étaient si persuadés de l'importance d'un bon choix qu'ils n'osaient se décider, hésitaient, recommençaient leurs enquêtes, semblaient même parfois chercher des prétextes pour ne point trancher une question si grave. Les jours, les mois passaient ; le successeur de Tisnacq, Hopperus, malgré les exhortations de Viglius, ajoutait encore à celle du maître son insupportable lenteur - et le sentiment de sa responsabilité s'accroissant pour Philippe II avec le temps, l'espoir d'une solution reculait chaque jour.

Pourtant, las d'hésiter entre les Comtois, le roi, en novembre 1569, sembla incliner vers une solution neuve : ne pourrait-on choisir un Italien, quelque bon serviteur du Milanais, et l'envoyer régenter les Bourguignons ? Il en écrivit au duc d'Albe et à Granvelle - et c'est à cette idée peut-être qu'il faut rattacher l'envoi en Comté, comme second de Blasere, du sénateur milanais Mesabarba. Blasere, de son côté, s'occupa de la question - et, naturellement, écartant les Comtois, préconisa des Flamands. Il n'aurait tenu qu'à lui de se faire nommer : dans une lettre à Granvelle, Morillon l'indique : « Je ne pense point, écrit-il, que Blasere ou d'As- 
sonville voudroient accepter le parti, et eulx avec leur mesnaige transporter si loing ; chascung d'eulx, ad ce que je pense, ha l'oeil pour estre avancé en sa patrie ». Il ajoutait : "Seroit mieulx le cas de Mesabarba ou del Rio, ne fust que je les tiens tous deux subjectz à la pince et le dernier fort léger ». Texte bien intéressant et qui montre en quel discrédit les Comtois étaient alors plongés. Ainsi, pour désigner un président de Bourgogne, c'était à des Flamands, à des Espagnols, à des Italiens même que l'on songeait - et Morillon, dépourvu d'antipathie pour les Comtois ; Morillon, le confident favori de Granvelle, notait le fait sans étonnement, sans scandale, sans protestation. Mais Granvelle lui-même, lorsque Philippe II avait parlé d'un président italien, n'avait-il pas accepté l'idée - et même rappelé au roi un précédent : celui de Gattinara ? En fait, ce ne fut point à Mesabarba, ce fut à un Flamand, Guillaume de Pamele, conseiller au grand Conseil de Malines, que la présidence fut offerte et donnée : il dut recevoir sa commission dans le courant de mai 1573 ; pour la première fois depuis des années, un des privilèges les plus chers des Comtois était ainsi brutalement violé par leurs maîtres.

Heureusement pour eux, l'intérêt personnel rendit Pamele plus clairvoyant que Philippe II et le duc d'Albe : à peine nommé, cet homme jeune encore refusa la charge : il songeait, sans doute, à ses biens qu'il lui faudrait quitter - mais plus encore aux rudes combats qu'il aurait à livrer pour s'imposer en pays étranger à une compagnie hostile et irritée. Étudiant à Dole en 1553, il avait pu connaître les humeurs du pays : nul ne fut étonné lorsqu'il eut rendu son refus définitif.

A défaut d'étrangers, il fallut bien en revenir aux Comtois. Le duc d'Albe le fit avec une rapidité insolite - et sitôt Pamele récusé, on se mit aux Pays-Bas à lui chercher un successeur. Blasere, malgré les réserves que ne pouvait manquer de susciter le caractère partial et brouillon de Belin, se sentait pourtant une certaine tendresse pour ce violent, prompt à crier au crime, au scandale, à l'hérésie, et qui, dans son besoin jaloux de pureté politique et religieuse, faisait volontiers bon marché de ses contemporains. Granvelle par contre, fixé depuis longtemps sur le compte de son ancien protégé, faisait campagne doucement, mais activement, pour un homme jeune encore, depuis peu avocat fiscal au Parlement, et qu'il avait employé avec profit en diverses circonstances: Pierre Froissard, seigneur de Broissia, fils aîné d'Anatoile, mort président d'Orange, et d'une Bourguignonne du Duché, Madeleine Le Goux. Malgré l'opposition de certains qui le prétendaient suspect tout au moins de tolérance religieuse, Froissard triompha. Blasere qui, 
cependant, ne l'aimait pas, constatait dès mars 1572 que si le choix du président était laissé au Parlement lui-même, il ne se porterait sur nul autre que sur lui. Lorsqu'à la fin de juillet 1572, en remplacement de Pamele, une liste de trois candidats fut dressée aux Pays-Bas pour être soumise à Philippe II -Froissard y fut inscrit le premier, Richardot le second et Belin le troisième. Ordre que respecta Philippe Il : à une date et sous une forme que nous ignorons, il agréa le choix de Pierre Froissard.

Tout s'était fait fort vite. Dès le 21 juillet 1573, Viglius annonçait à Hopperus que le nouveau président, appelé par le duc aux Pays-Bas, venait d'y arriver : il y avait fait d'ailleurs bonne impression. Blasere aussitôt avait été convoqué, ainsi que les conseillers commis à examiner les papiers de la visite; tous, redoublant d'ardeur, se mirent avec Froissard à terminer une tâche dès longtemps commencée. Pendant deux mois, ce fut un travail opiniâtre : il ne s'agissait pas moins que de dresser tout un corps d'ordonnances réformatrices - sans parler d'instructions spéciales et secrètes pour le Parlement et son président. Celui-ci séduisait tout le monde par sa netteté d'esprit et sa décision : il gagna dans les conseils et l'entourage du duc d'Albe, avec des sympathies précieuses, le renom d'un homme « duquel S.M. et le public pourraient recevoir bon service en lieu plus important ».

Dès le début de septembre, tout était prêt, les ordonnances et les instructions rédigées : on n'attendait plus que l'approbation du duc d'Albe et sa signature. Viglius, dans ses lettres à Hopperus, s'effrayait de cette formalité, prévoyait des longueurs, des semaines, des mois peut-être de nouveau retard: contre ses prévisions, tout alla fort vite ; le 3 octobre, le président constatait joyeusement la vanité de ses craintes : le duc avait tout signé, tout expédié. Sans doute, une petite difficulté avait surgi : au moment de délivrer à Froissard sa commission, on s'était aperçu qu'il n'avait pas été créé chevalier : impossible, dès lors, de lui donner ce titre, que tous ses prédécesseurs à la présidence avaient cependant porté. Viglius, pour trancher la difficulté, avait alors proposé une solution dont il ne prévoyait point les inconvénients : elle consistait à faire délivrer par le roi lui-même, en cour d'Espagne, une commission qui contiendrait mandement à quelque chevalier comtois - Vergy, Antoine de Canoz, François de Vautravers ou autre - de donner à Froissard, en son nom, la chevalerie ; cet avis avait mis tout le monde d'accord. En même temps, il avait été décidé que Blasere repartirait en Comté pour achever sa visite et prêter mainforte au nouveau président. Celui-ci, muni de ses instruc- 
tions et de ses ordonnances, assuré d'être confirmé par le maître et soutenu par le gouvernement des Pays-Bas, quitta la Flandre à la fin de l'automne. Au début de novembre, il était en Comté ; le 11, il prenait possession de son état au Parlement ; le 12, jour de rentrée, il faisait lire et publier en présence de la cour assemblée, des officiers convoqués et « de plusieurs notables personnages, tant ecclésiastiques, gentilshommes, avocats, procureurs, marchans, bourgeois que autres de tous estats, illec assistants en grand nombre », ces fameuses ordonnances de 1573 qui allaient provoquer une des crises les plus violentes de l'histoire comtoise au cours du XVIe siècle.

\section{VI}

Que contenaient donc les textes importants rédigés aux Pays-Bas par cette collaboration d'enquêteurs et de conseillers flamands, assistés à la fin d'un seul Franc-Comtois ? Il faut analyser de près le mince volume qui, par les soins de Froissard, sortit des presses de Pierre Roussin, à Lyon, en 1574.

Après protestation du « soin singulier » que le roi avait toujours eu de son Comté - soin qu'attestait encore la récente visite - le recueil s'ouvrait par l'établissement d'une formalité nouvelle et vraiment caractéristique. Avant toute entremise, président, conseillers, fiscaux, baillis, lieutenants, châtelains, prévôts, en un mot tout ce qui exerçait la justice en Comté, recevait l'ordre le plus strict, le plus impératif d'avoir à prêter serment solennel d'observer les édits et de les faire observer. Mesure dont nul - pas même Froissard - n'était exempté ; mesure qui s'accompagnait d'anormales prescriptions : tant qu'ils n'auraient point juré, l'exercice de leurs charges était interdit aux officiers ; mesure, enfin, qui, s'appliquant non pas à de nouveaux juges, à des débutants, mais à des magistrats déjà en fonctions, prenait le caractère d'un reproche, d'un blâme, d'une censure : de l'institution d'un tel serment, dans de telles conditions, n'était-il point logique de conclure, en effet, à la négligence ordinaire, aux habituels manquements, jusqu'à la forfaiture des officiers de justice?

Première impression que venaient confirmer deux articles : l'article II, qui, rappelant aux lieutenants leur obligation de veiller sur les juges inférieurs, les 
menaçait, en cas de négligence, d'être rendus responsables « non seulement de leurs transgressions particulières, mais aussi de la négligence, connivence et dissimulation des autres rière leurs ressorts et juridictions »; - l'article VI qui, donnant pour cause au « désordre reconnu » de la justice comtoise « la malice, ignorance, insuffisance et négligence de ceux qu'ont été commis aux magistrats, offices et charges publiques » du pays - portrait peu flatteur, sans doute, pour ceux qui, en 1573, possédaient ces offices - précisait pour l'avenir les formalités rigoureuses des nominations... Ceci dit, les nouvelles ordonnances entraient dans le détail des faits, et, s'occupant d'abord du Parlement, s'attaquaient à son vice capital : la lenteur. Pour gagner du temps, abréger les délais, permettre la prompte liquidation des milliers d'affaires en souffrance, deux séries de mesures étaient adoptées : les unes, d'ordre matériel ; les autres, d'ordre personnel.

Énumérons rapidement les premières. D'abord [art. VII], les vacances étaient réduites. La cour ne rentrerait plus en novembre, le lendemain de la Saint-Martin, mais le 19 octobre, lendemain de la Saint-Luc. C'étaient près de quatre semaines acquises au travail. Puis venaient [art. XIII, XIV, XV] des mesures diverses destinées à empêcher la cour d'être dorénavant « distraite de sa charge par présentation d'infinies requestes et par procédures sur ce meües ». D'autres suivaient, pour restreindre «l'usage indiscret des évocations » [art. XVIII] ; pour « rejeter preuves superflues et le moins qu'il se pourra distraire... conseillers et juges de leurs charges ordinaires » [art. XIX]; pour réduire à un maximum de dix le nombre des témoins à examiner sur un fait [art. XX] ; enfin, pour simplifier et abréger la forme des arrêts et sentences, leur exécution, les adjudications de fruits et intérêts, les liquidations de fruits et compensation de dépens, les appellations d'interlocutoires, etc. - Mais les mesures personnelles étaient d'autre portée. Pour que tout leur temps puisse être consacré aux devoirs de leur charge, les conseillers et autres officiers du roi se voyaient interdire, par l'article VIII, de s'empêcher dorénavant de l'également du don gratuit, ou de l'audition des comptes en procédant - cela, à peine de privation de leurs offices. L'article IX leur interdisait toute participation à « l'administration, conduite et direction du Puys à Muyre du Bourg-Dessoubs et Chauderette de Salins ny des affaires ce concernans, ny aussi de ceux de communauté ». L'article $\mathrm{X}$, tout aussi rigoureux, interdisait de prendre ou recevoir, sous aucun prétexte, dons, récompenses ou pensions des États, du Puits, de la Chauderette ou des communautés. L'article XI prohibait toute participation au régime ou 
gouvernement de bénéfices vacants ou réduits sous la main du roi, biens litigieux, deniers confisqués, séquestres ou mainmises de bien. L'article XII défendait formellement de s'entremettre d'affaires particulières pour les manier ou les solliciter; d'en accepter la superintendance; d'en prendre charge quelconque, gratuite ou payée. L'article XXV enfin, plus général, interdisait aux officiers, sous peine de privation d'office, l'acceptation de tous « présents d'or, d'argent, bagues, joyaux ny victuailles, denrées, ypocras, épices, sucre ou autres choses quelconques, quelles qu'elles soyent ».

Cette fois, le souci d'interdire aux officiers royaux des occupations trop absorbantes et propres à les détourner de leurs devoirs professionnels ne pouvait être allégué par les rédacteurs de l'article : la préoccupation de moralité professionnelle passait au premier rang. Et c'était elle encore qui dictait l'article LX sur les frais de déplacement, ou encore l'article LXVIII, décidant qu'à l'avenir, les officiers de justice ne pourraient ni juger ni aider à juger les causes de prélats, collateurs ou seigneurs dont eux, leurs enfants ou leurs frères, directement ou indirectement, auraient obtenu quelque bénéfice. Toutes ces prohibitions non seulement frappaient durement les conseillers dans leurs intérêts matériels les plus évidents : elles les atteignaient encore dans leur amour-propre; elles leur infligeaient une sorte de flétrissure publique - et l'on imagine aisément quelles pensées, quels sentiments roulaient en eux conseillers et lieutenants, lorsque, le 12 novembre 1573, dans la séance solennelle de rentrée, en présence d'une si nombreuse affluence, le greffier Delesmes lisait tous ces articles qui prenaient une allure de réquisitoires.

Après la cour, d'ailleurs, les bailliages. Point de ménagements là non plus. Dès le début, l'article LXIX proclamait tout crûment que « les désordres recogneus ès justices des bailliages » procédaient de ce que les lieutenants n'avaient été cidevant commis « tels ni comme il convenoit, ains la pluspart inexpérimentez et insuffisans » - cela, parce que leur charge ne leur avait point été donnée par les baillis « pour leurs vertuz ou doctrines, ains pour sommes de deniers ou récompence de service ». Aussi l'article LXX stipulait-il que, dans les deux mois suivant la publication des ordonnances - et, dorénavant - à chaque vacance nouvelle - les baillis, «appellez avec eux les fiscaux du ressort », choisiraient et nommeraient comme lieutenants, hors de toute affection, recommandation et faveur, les candidats les plus dignes et les plus capables, « sur quoy ilz presteront tous préalablement le serment pertinent aux Sainctz Évangilles de Dieu ». Acte de leur décision 
dressé et transmis à Dole, le candidat choisi se présenterait devant la cour ; celleci ou bien confirmerait la nomination, et son président recevrait alors le serment du lieutenant ; ou bien la repousserait, et le bailli alors devrait procéder à une seconde désignation.

C'était un nouveau pas vers la régularisation de l'institution bailliagère en Comté. Ainsi nommés, sous le contrôle assuré du Parlement, les lieutenants cesseraient complètement d'être ce qu'ils étaient restés, même après la réforme de 1565 : les simples commis des baillis ; l'article LXXI spécifiait qu'ils ne seraient dorénavant « sujects à déport et descharge de l'estat à la simple volonté des baillifs ; ains seront à mesme respect que nos autres officiers ». D'autre part, il leur était permis par l'article XCIV de prendre sportules de toutes sentences tant définitives que provisionnelles qui se rendraient par leurs soins. Sportules raisonnables et dont le montant serait soigneusement vérifié chaque année par le procureur général et au besoin par la cour elle-même : elles constitueraient dorénavant pour les lieutenants le plus clair de leurs ressources.

Réforme analogue, réforme parallèle en ce qui concernait les avocats et procureurs fiscaux des bailliages. Dorénavant, chaque ressort aurait son procureur et son avocat, munis de gages fixes, payables sur la recette des exploits du ressort. Leur service, d'ailleurs, devrait les prendre tout entiers : ils seraient astreints à la résidence, ne pourraient recevoir pensions, offices, gages ou traitements d'autres que du roi, ne devraient assister ou postuler en jugement en d'autres causes qu'en causes royales. Pareillement, étant pourvus de salaire compétent et régulier, ils ne toucheraient plus rien dorénavant sur les amendes et, pas plus que les lieutenants, ne seraient admis à rien prendre des parties.

Ainsi s'achevait l'évolution dès longtemps commencée qui, de serviteurs, d'employés sans traitement et sans garantie des baillis, transformait les lieutenants en officiers royaux. Sans doute, tous les pouvoirs du bailli n'étaient pas détruits. Il conservait un certain droit de nomination, de présentation des lieutenants : mais si restreint, si assujetti à contrôle, qu'on est vraiment surpris lorsque, dans l'article LXXIII, on voit les rédacteurs de l'ordonnance prendre encore la peine de rappeler les baillis - ces autorités administratives et judiciaires défuntes - au respect des anciennes prescriptions concernant la visite de leurs ressorts. Il est vrai que la mention est de pur style: pratiquement et sous leur nom, c'est aux lieutenants seuls que l'article s'adresse. En fait, la multiplication de ces derniers n'entraînait- 
elle pas nécessairement l'élimination des baillis ? Ce n'était plus trois, mais douze bailliages que reconnaissait en Comté la nouvelle ordonnance. Ce qui jadis ne se trouvait qu'à Dole, à Vesoul et à Montmorot, dans les trois chefs-lieux : la réunion d'un lieutenant général, d'un procureur et d'un avocat fiscal - se rencontrait maintenant dans tous les sièges secondaires. Plus de lieutenants généraux, plus de fiscaux ambulants, à compétence étendue, et ne possédant, en la personne des lieutenants locaux ou des substituts, que des commis leurs subordonnés : des officiers stables, fixes, à compétence égale et nettement définie. Un dernier article, d'ailleurs, l'article CXII, précisait encore et pour ainsi dire achevait le sens de la réforme : il supprimait, purement et simplement, comme inutiles désormais et « frustratoires », les tenues d'assises - ces derniers vestiges d'une justice ambulante.

Centralisation, régularisation - simplification aussi : l'article LXXII dénonçait vivement la multiplicité dispendieuse des ressorts de bailliage. Et il décidait, en principe, la réduction à deux des trois sièges du bailliage de Dole et, sinon à trois, du moins à quatre, des six sièges du bailliage d'Aval. Mesure brutale, qui ne devait s'accompagner pour les personnes lésées d'aucune compensation, d'aucun dédommagement. L'article LXXV signalait pareillement le nombre excessif et l'insuffisance des sergents et huissiers de bailliage : il les faudrait réduire après choix des meilleurs. Même chose pour les notaires, pullulant en Comté ; pour les procureurs postulants des bailliages, astreints dorénavant à enquête préalable et à examen par les lieutenants en présence des fiscaux; pour les greffiers, enfin, et pour leurs clercs, en nombre limité et, comme les procureurs, assujettis désormais à inquisition et à examen : c'était du haut en bas, des lieutenants aux sergents, des juges aux scribes, toute une refonte, toute une réorganisation judicieuse, logique, bien conçue et bien cohérente, de l'institution bailliagère en Comté. L'ordonnance ne s'en tenait pas là. Relatifs aux justices inférieures et à celles des vassaux, sept ou huit articles terminaux complétaient l'ensemble de ses prescriptions. Un même esprit de réforme hardie, vigoureuse et claire les animait. L'article 173 dénonçait « les infinies concussions et rançonnemens » auxquels donnaient lieu les prévôtés fermières, interdisait à l'avenir «toutes telles fermes d'offices de judicature, ensemble les fermes d'exploits et amendes de justice », et en abolissait l'usage " tant ès justices royales qu'ès justices de vassaux ». Tout aussi radical, l'article CLVVIV décrétait suppression des sièges de prévôté partout où ils coexistaient 
avec un siège de bailliage ou de châtellenie : ils seraient réunis purement et simplement à ce siège. Enfin, l'article BLXXV, abolissant d'un trait de plume des abus séculaires, portait courageusement qu'en chaque seigneurie, soit du domaine, soit des vassaux, il ne devrait y avoir à l'avenir qu'un seul siège de justice : bailliage, châtellenie ou prévôté.

\section{VII}

Telle était dans ses dispositions essentielles l'ordonnance de 1573. A n'examiner que le fond de ses dispositions, c'était une oeuvre remarquable de législation administrative et de réforme. Aux institutions judiciaires comtoises, de caractère très archaïque encore et très particulariste, les articles élaborés en Flandre, sous le contrôle de Viglius, par Blasere et ses collègues, faisaient faire un pas décisif dans la voie de la centralisation monarchique et de la régularisation administrative. Sur les lieutenants de bailliage, sur les fiscaux, sur les procureurs postulants, les greffiers, sur les féodaux eux-mêmes, si jaloux cependant de leurs droits judiciaires, la main du roi étendait, appesantissait sa prise. La royauté, se faisant centre de plus en plus, ramenait tout à elle - pénétrait sur tous les domaines, sur toutes les terres, pour faire sentir universellement son action. Mais ses progrès en même temps étaient ceux de la logique, de la clarté, de la simplicité - autant du moins que le comportaient l'esprit, les habitudes, les besoins du moment. Tant de dispositions neuves, développement logique de vieilles situations antérieures ; tant de réformes hardies étaient de nature sans doute à justifier sinon aux yeux des victimes, à ceux du moins des justiciables comtois, les empiètements nouveaux du pouvoir royal.

Mais ce n'était qu'un aspect de ces ordonnances. Elles en avaient un autre. La visite de Blasere terminée, le mal dénoncé et les sanctions prises, la brutalité n'était, ne devait plus être de mise vis-à-vis du Parlement. Les conseillers suspendus et leurs confrères humiliés avaient assez expié leurs manquements passés. Plus de danger qu'ils tentent de s'émanciper. Toute violence dès lors, toute brimade, tout brutalité contre eux devenait inutile à la fois et dangereuse. Elle ne pouvait se justifier que par un parti pris, un dessein arrêté de détruire entièrement l'autorité de la cour au profit de la noblesse d'épée: parti pris, dessein que 
n'avaient ni Philippe ni son ministre. N'était-elle donc pas souverainement maladroite, la rédaction de ces articles de réforme, si durs en eux-mêmes pour les intérêts des conseillers - plus durs coenre pour leur amour-propre ? Régler soigneusement le mode de nomination des officiers bailliagers; prendre de vigoureuses mesures pour que lieutenants, avocats, procureurs, fussent dorénavant hommes de moralité et d'intelligence éprouvée ; assurer sur eux le contrôle efficace des parlementaires - rien de mieux ; mais pour justifier de semblables réformes, était-il nécessaire d'accuser de «malice, d'ignorance, d'insuffisance et de négligence » tous les juges du Comté, grands ou petits - cela, dans des textes dépourvus de tout caractère confidentiel et faits, au contraire, pour être répandus dans toute la province ?

D'autant que, vigoureusement cinglés par cette mercuriale publique, les conseillers n'échappaient point aux sévérités de remontrances secrètes. Cinquantneuf articles avaient été rédigés pour être lus et publiés « en Chambre du Conseil seulement », puis enregistrés « ès registres secretz, pour perpétuelle mémoire et observance ». Or, avec plus de netteté encore, avec moins de ménagements, ils reprenaient, contre les conseillers et les lieutenants, les griefs de Blasere et de ses inspirateurs. Nécessité de veiller sur la religion, « sans faveur, dissimulation, interprétation, modération ny altération quelconque »; obligation de vider au plus tôt les procès pendants « en matière d'hérésie ou contravention de placardz »; de toujours faire en pareil cas «adjudication des biens des condampnez »; de ne jamais modifier ou interpréter les édits sans l'avis du souverain et son consentement - les premiers articles rappelaient tour à tour aux conseillers leurs devoirs contre les hérétiques. Plus désagréables, plus durs, l'article VI et les suivants : «Estans les ministres de lad. cour appellez au degré qu'ils sont en icelle pour les vertus, sçavoir et bonne réputation esquelles ils excelloyent par dessus tous aultres », le roi, successivement, édictait à leur usage une série de prohibitions à la fois très fâcheuses pour leurs intérêts et très blessantes pour leur amour-propre. Qu'ils n'abusent plus de leurs privilèges. Qu'ils ne se fassent plus presser pour le paiement « des décimes, censes, redebvances et aultres prestations réelles » qu'ils doivent acquitter. Qu'ils n'en prétendent exemption, ni eux ni les officiers au bailliage, « soubz ombre ou à cause de leurs estatz ». -Pareillement, quant aux nominations à venir, qu'ils y procèdent « à haultes et vives voix, sans user à l'abvenir de balottemens », après serment spécial de choisir en conscience et en motivant 
oralement leur vote. Nommer des frères, des cousins germains, des neveux de conseillers, "soit en consanguinité ou affinité » - interdit ; interdit également de donner sa voix à ses parents ou à des proches jusqu'au quatrième degré inclusivement, les degrés pris selon le droit canon. Le président devra, mieux que du passé, être respecté et obéi. Tout ce qu'apprendront les conseillers intéressant « le général » ou la cour, ils devront le révéler à leur chef, «afin de non laisser renaistre moyens de désordre » - allusion directe aux événements de 1566 et aux pratiques des confrères de Sainte-Barbe. Après la cour, du reste, les bailliages, la gruerie, la Saunerie, tout le vaste peuple des gens de justice. «Pour ce que, disait l'article XLI, par les commis à la visitte a esté faict rapport d'infinies concussions, rançonnements, malversations et désordres ès sièges de noz gruyeries, chastellainie de Braccon, prévostez et justices inférieures de nous et de noz vassaulx et aultres, n'ayans lesd. visitateurs heu le temps d'en informer particulièrement ", la cour à leur défaut devait agir sans retard et faire par les fiscaux dresser poursuites convenables. Mission de confiance sans doute, mais peu agréable et tout entourée de suspicion.

Un dernier texte enfin achève de révéler la pensée et les intentions du gouvernement de par deçà : l'instruction particulière délivrée à Froissard de ce qu'il aurait à faire « incontinent son retour aud. Bourgoingne » pour l'exercice de sa charge nouvelle. Venaient d'abord les recommandations coutumières, de veiller à la religion, de faire appliquer les décrets de Trente, instituer « de bons pasteurs, prédicateurs, magistrats, percepteurs et bonnes escolles ». Mais la méfiance vis-à-vis du Parlement se manifestait à chaque ligne. C'était, à l'article Il, l'ordre au président de faire exécuter les édits sans faveur ni dissimulation ni altération quelconque ; à l'article III, la charge à lui donnée d'avertir S.M. ou le gouverneur des pays d'Embas, «de temps à autre », de la conduite «de ceulx de lad. court ou suppostz d'icelle et de tous les juges inférieurs et subalternes »; à l'article VI, de nouveau - insistance bien significative - l'ordre « de tenir principal soing et regard à ce que, en toutes poursuites qui se feront en lad. court pour contraventions concernants nostre Ste Foy et ancienne religion, il y soit procédé sincèrement, et iceulx édictz vivement exécutez, sans aucune faveur, dissimulation, altérations ou connivence »; à l'article VII, enfin, celui de faire observer toutes les ordonnances et, en cas de manquement, « de procéder jointement avec lad. court à toutes corrections contre ceulx des ministres en icelle qui se treuveront la mériter ». Par là, 
le nouveau président ne devait plus être l'homme du Parlement, le représentant de ses confrères vis-à-vis du roi et du gouverneur ; on entendait qu'il fût, au contraire, l'homme du roi, placé en face et au-dessus des conseillers pour les maintenir dans le droit chemin, les surveiller de près et, s'il y avait lieu, réprimer leurs écarts.

Ainsi se précisait peu à peu le caractère de l'oeuvre poursuivie, en Comté, par le duc d'Albe et ses hommes de confiance. 
PHILIPPE II ET LA FRANCHE-COMTÉ

Étude d’histoire politique, religieuse et sociale.

Quatrième partie. Le progrès de l’absolutisme.

\section{Chapitre XXII}

\section{L'affaire des ordonnances et les États de 1574}

$\underline{\text { Retour à la table des matières }}$

Les ordonnances avaient été publiées : restait à les appliquer. Tâche urgente, s'il est vrai que ne cessaient point en Comté les doléances, les protestations contre la lenteur et la partialité des juges ; tâche délicate, plus encore : ne faudrait-il pas un dur combat pour imposer les réformes aux bénéficiaires des abus ? Sur Pierre Froissard allait retomber tout le poids d'une semblable besogne.

Sans doute, c'était en connaissance de cause qu'il avait accepté la présidence. Parlementaire, fils et frère de juristes ou d'officiers royaux, il n'ignorait rien des affaires comtoises, de cette décadence des justices qui appelait, justifiait d'énergiques remèdes. Comme il était jeune, ambitieux d'arriver, il s'était de toute son ardeur associé à l'oeuvre de réforme entreprise - et cela, d'autant plus volontiers qu'un parlementaire, soucieux des intérêts de sa classe, de sa caste, pouvait, devait trouver cette oeuvre salutaire. Ne savait-il pas les défauts, les vices des justices locales ? Justices lentes; il les fallait rendre plus expéditives. Justices compliquées ; il fallait supprimer, tailler, élaguer dans la forêt des offices. Justices partiales, enfin, boiteuses souvent, discutées toujours ; il fallait à force d'énergique sé- 
vérité les « réauctoriser », les maintenir désormais à l'abri du soupçon. Ainsi, la robe reprendrait son prestige dans un pays apaisé et soumis. Grande oeuvre : grâce aux ordonnances, le nouveau président rêvait de la mener à bien.

\section{I}

Malheureusement, avec beaucoup de qualités, Froissard possédait quelques lourds défauts. Promu à quarante ans au poste le plus élevé qu'il pût ambitionner ; « bien voulu » du duc d'Albe, de Granvelle, des membres influents des Conseils ; un peu grisé peut-être par les éloges que son activité, son ardeur au travail, son intelligence lui valaient, il était orgueilleux, hautain, méprisant. De ses fonctions nouvelles, il concevait la plus grande, la plus haute idée ; et comme il savait que, pendant des années, la place qu'il occupait était restée vacante ; comme il soupçonnait chez ses collègues, déshabitués depuis longtemps d'obéir, le ferme propos d'incliner le moins possible leurs volontés ombrageuses devant sa jeune autorité un sentiment très fort de responsabilité, le désir de remplir ses fonctions dans leur plénitude renforçait, redoublait son plaisir naturel de commander et de parler en maître. Dispositions personnelles qui ne facilitaient pas une tâche difficile.

Qu'en définitive, les ordonnances dussent relever le prestige et l'autorité des parlementaires - la chose était possible, probable même. Mais il était humain que les conseillers en charge et les officiers de justice, atteints par les dispositions nouvelles, se souciassent davantage du présent que de l'avenir. Or, prenons quelques exemples : l'article VII leur interdisait toute participation à « l'esgalement du don gratuit » et à l'audition de ses comptes. Reportons-nous aux recès des trois tenues d'États immédiatement antérieures à 1573. Sur les neuf membres de la commission d'également figurent : en 1561, deux conseillers et un lieutenant ; en 1564, un fiscal, un conseiller, un chevalier d'honneur ; en 1569, deux conseillers. Semblablement parmi les neuf de la commission de clôture, on trouve, en 1561, un procureur d'Amont et un fiscal ; en 1564, un procureur d'Amont et un conseiller; en 1569, un fiscal. Or, de ces charges, le profit était bon. Non seulement les commis étaient rémunérés, grassement ; mais ils gardaient aux mains bonne part des deniers levés dans la province et ne se privaient point de les faire «travail- 
ler ». C'était à chaque tenue des difficultés renaissantes pour faire rendre gorge à ces singuliers dépositaires ; et il faut lire le procès-verbal des séances de la commission extraordinaire nommée par les États de 1569 pour le recouvrement des sommes dues « dez le trépas de l'Empereur Maximilien jusques à présent », si l'on veut se rendre compte de l'extraordinaire confusion qu'entretenaient clercs, nobles et bourgeois entre l'argent du public et leurs propres deniers. Il n'y eut pas de prétexte, pas de moyen dilatoire qui ne parût bon alors aux Jean de la Tour, aux Colard, aux Boutechoux, pour prolonger le plus longtemps possible, contre tout droit et tout patriotisme, le séjour dans leurs caisses des deniers publics. Il serait facile de montrer pareillement quelle part prenaient parlementaires et officiers royaux à l'administration du Puits à Muire ; quelles charges ils assumaient souvent de veiller aux biens ou aux procès des grands seigneurs ; surtout, quel coup leur portait l'interdiction, si nettement formulée par l'article CLVI, d'acheter dans les décrets terres ou seigneuries. Nécessairement, dès lors, le président, le nouveau chef qui devait appliquer les réformes, devait leur apparaître comme un ennemi - plus, comme un transfuge, comme un traître.

Froissard, cependant, se mit avec ardeur à l'ouvrage. Dès la fin de 1573, les divers articles des ordonnances réformées recevaient un commencement d'exécution. Les baillis prêtaient leur serment au président et recevaient celui des officiers de leur circonscription, préalablement confirmés par eux en présence des fiscaux. Les candidats aux lieutenances étaient rigoureusement examinés selon les prescriptions de l'article LXX ; une fois nommés, ils durent visiter régulièrement leurs ressorts et exercer sur les juges inférieurs une surveillance rigoureuse. En même temps, le nouveau président s'occupait, dès février 1574, de dresser une liste de candidats propres à être institués avocats et procureurs fiscaux des bailliages dans les divers ressorts; il faisait appliquer sans délai les dispositions concernant les notaires, les procureurs, les sergents ; enfin, il tenait la main aux diverses mesures d'économie et de simplification judiciaires qu'avaient sanctionnées les nouvelles ordonnances : notamment, il décidait de faire porter sur les trois sièges d'Arbois, d'Orgelet et de Quingey les suppressions réclamées par l'article 72. - Mesures normales : le 4 mars 1573-74, rédigeant à l'intention de Philippe II un intéressant « Discours de l'estat du conté de Bourgoigne et de ce qu'il y reste à remédier pour la seureté d'iceluy », Pierre Froissard croyait pouvoir, dans un préambule d'une modestie un peu cherchée, annoncer au roi que ses subordonnés, « comme de tout 
temps très fidelles et très obéissans ", commençaient à s'accommoder aux réformes : «Et veulx espérer, ajoutait-il, qu'ilz continueront, nonobstant la contradiction d'aulcungs, laquelle j'impute à ce que advient ordinairement en toutes nouvelles et si généralles réformations, où l'habitude formée par la tolérance trop longue du désordre passé résiste - mais non avec durée ». Paroles confiantes. Froissard, cependant, ne pouvait taire au roi les résistances que soulevaient les textes de réforme - et tout son Discours semblait à la fois une justification de sa conduite et un appel discret à l'appui royal. C'est que, presque dès le début, dès le lendemain de son arrivée en Comté, une vive opposition s'était organisée contre le metteur en oeuvre des nouvelles ordonnances. Officiers et parlementaires; notaires, huissiers, procureurs "réséqués " au chiffre prescrit ; surtout, habitants des petites villes d'Orgelet, d'Arbois et de Quingey, ruinés par la perte de leur bailliage, tous poussaient des clameurs, protestaient à l'envi.

Or, les circonstances étaient mauvaises pour Pierre Froissard. C'est le 12 novembre 1573 qu'il avait publié les textes litigieux : c'est le 30 du même mois qu'une lettre officielle, adressée à la cour, venait lui apprendre la prise de possession par M. de Requesens du gouvernement général des Pays-Bas. Du duc d'Albe, instigateur de la réforme, promoteur de la mission d'enquête dont tant de dispositions nouvelles étaient sorties directement, le nouveau président était en droit d'espérer un appui sans réserve, un soutien efficace. Mais du Grand Commandeur ? Envoyé brusquement et contre son gré de Naples aux Pays-Bas; ignorant tout des affaires comtoises; différant d'ailleurs d'idées et de sentiments avec le duc d'Albe sur la conduite à tenir vis-à-vis des sujets - pourrait-il, saurait-il soutenir Froissard ; déploierait-il, pour faire appliquer les réformes, la même autorité décisive, la même volonté brutale qu'on était en droit d'attendre du duc d'Albe ? Auprès de lui, personne ou presque pour le documenter, le guider, l'informer. Point de conseiller bourguignon aux Pays-Bas, dans le Conseil privé, depuis la retraite et la mort de Grandjean ; point même de Comtois en mesure de donner, à l'occasion, un renseignement utile, un avis, un conseil. Pareille situation, d'ailleurs, en Espagne. C'était Hopperus maintenant qui s'y trouvait chargé des affaires comtoises, en sa qualité nouvelle de garde des sceaux pour les pays d'Embas. Mais, archiviste patient, commis de bureau irréprochable, ce gros et lourd Flamand manquait de vivacité et d'influence ; il ne savait rien de la Comté ; enfin, il portait en tout sa lenteur légendaire, qui aggravait encore la lenteur du maître. Or, 
de lui, de son concours, Froissard aurait eu besoin. Nous avons vu comment, nommé à la présidence et envoyé en possession par le duc d'Albe sur le simple consentement de Philippe II, mais sans confirmation expresse de celui-ci, Froissard avait vu Viglius, à propos d'une difficulté particulière, réclamer pour lui un titre de chevalerie et une reconnaissance spéciale : formalités indispensables pour faire du nouveau chef du Parlement l'égal en dignité de ses prédécesseurs. L'affaire n'avait point été oubliée. A plusieurs reprises, dans les mois qui suivent la nomination, on voit Viglius rappeler à Hopperus la nécessité d'une confirmation du président. Dans son Discours, Froissard à son tour exprimait au roi l'espérance que, « de briefz », il lui plairait de lui faire par la confirmation des ordonnances " plus ouverte déclaration » de ses desseins et de son entremise en la présidence, « à ce que, disait-il, avec plus d'auctorité je puisse faire recognoistre à ung chacun le fruit et bon effect de tant saincte et salutaire réformation ». Vainement. Rien ne venait. Philippe II gardait un silence obstiné - et les ennemis de Froissard et des ordonnances avaient beau jeu dès lors pour déclarer que le maître désapprouvait en son for intérieur et les réformes et le réformateur.

Pareille lenteur, du reste, s'observait en tout. Il avait été décidé aux Pays-Bas, lorsque Froissard y avait été mandé, que Blasere retournerait à la fin de 1573 en Comté, pour y parachever ses diverses enquêtes. Rien n'aurait été plus opportun qu'un tel retour. L'énergique missionnaire qu'était Blasere aurait pu, lors des débuts du nouveau président, lui prêter sur place un appui précieux. Mais la détresse financière s'était trouvée telle que, pendant des mois, on n'avait pu trouver les fonds nécessaires pour subvenir aux frais de la mission d'enquête. Ce fut plus d'un an seulement après la publication des ordonnances que Blasere, en décembre 1574, arriva en Comté avec le greffier Boulin, son second : à cette époque, il pouvait bien terminer sa visite - mais il ne devait être d'aucune utilité, d'aucun secours à Froissard. Ainsi, le gouvernement des Pays-Bas comme celui de Madrid semblait prendre à plaisir de paralyser lui-même la bonne volonté et les efforts du nouveau président. Et celui-ci, parfois, pouvait se demander si on ne l'avait nommé que pour l'abandonner.

De ces lenteurs, de ces maladresses, de ces irrésolutions, les adversaires des réformes triomphaient bruyamment et tiraient grand parti. Pour exciter Hopperus à quelque activité, Viglius, dès le 19 avril 1574, lui signalait l'intensité des plaintes bourguignonnes contre les ordonnances. Il y avait longtemps, à cette date, que 
Granvelle, de son côté, mis au courant de la situation, s'employait à prêcher le calme et la modération aux parlementaires, ses amis. Sans doute, écrivait-il, il y avait dans les textes compilés aux Pays-Bas des choses fâcheuses pour la cour. Il était visible qu'on se méfiait d'elle, qu'on suspectait même ses bonnes intentions : mais, à qui la faute ? Si les ordonnances jadis faites à Madrid avec le concours du président Marmier avaient été fidèlement observées, « l'on n'eust donné cause à S. M. d'envoyer par delà visitateurs ", ni d'en rédiger tout un corps de nouvelles. Ne valait-il pas mieux, au lieu de se bander contre le président, le seconder dans ses efforts pour remettre la justice sur pied, et, tout en lui remontrant doucement ses erreurs s'il y avait lieu, s'allier avec tous les honnêtes gens pour le relèvement du pays et le rétablissement de la cour dans son autorité première ? Paroles sages, paroles vaines : Jacques de Saint-Mauris, le prieur de Bellefontaine, à qui le cardinal prodiguait tant de conseils raisonnables, était précisément l'un des plus passionnés, l'un des plus violents adversaires de Froissard. A ses côtés, Duchamp, un nouveau venu au Parlement, et le vieux Belin se signalaient également par leur violence ; chez le dernier peut-être, candidat évincé à la présidence, quelque rancune secrète se mêlait à ses protestations. Tous, d'ailleurs, s'accordaient pour mêler Granvelle à toutes ces questions - au grand désespoir du prudent cardinal. Les uns prétendaient que le coup venait de lui et qu'il était l'inspirateur des ordonnances ; les autres, qu'il les désapprouvait ; mais tous souhaitaient qu'il fût saisi de l'affaire par la cour, et qu'on cherchât à utiliser pour la cause commune l'influence que, depuis sa disgrâce, il avait su lentement reconquérir sur Philippe IL Le 26 août notamment, les parlementaires, réunis en conseil, décidèrent une démarche auprès du cardinal. Les termes de la lettre furent longuement débattus, quelques conseillers proposant qu'on prît texte de la "généralité » des plaintes comtoises contre les ordonnances; les autres protestant que la cour n'avait pas à s'occuper « de la plainte et doléance du général », mais simplement de ce qui la concernait. Le président assistait à cette délibération : dans quelles dispositions, on peut le deviner. Il opina, son tour venu, que l'on pouvait prier le cardinal « d'estre nostre intercesseur et tenir main que la court puisse, en ce mesme que la concerne particulièrement ou les suppoz d'icelle, estre par S. M. ouyz à temps sur les nouvelles ordonnances »; mais il s'éleva contre ceux qui voulaient « faire mention de plaintes universelles, attendu qu'elles n'y sont, et que la court ne les a reçeu ». Situation singulièrement difficile que la sienne. L'abandon où le laissaient ses chefs et son 
maître, les attaques perpétuelles dont il était l'objet, rien n'était fait pour adoucir les aspérités de son caractère et le disposer à une souple indulgence.

Avec le temps toutefois, au prix de quelques modifications, de quelques transactions, l'affaire se serait peut-être arrangée si, d'une part, Philippe II avait fait le geste que Viglius et que Froissard lui-même attendaient avec impatience - surtout si, vers le milieu de 1574, une grave nouvelle ne s'était répandue en Comté : celle de la convocation prochaine des États du pays.

\section{II}

La dernière tenue des États de Franche-Comté remontait au mois de février 1569. Rien d'étonnant dès lors à ce que, au milieu de 1574, Requesens ait songé à réclamer des Comtois une contribution pécuniaire qui serait la bienvenue en ce temps de détresse. Mais, à cette réunion normale et naturelle, les circonstances allaient donner une portée singulière.

Pour quelles raisons précises ? A première vue, et si l'on s'attachait seulement à l'étude de la situation créée en Comté par la publication des ordonnances et par l'opposition des parlementaires, on risquerait de ne le point saisir nettement. Des mesures prises par les rédacteurs des nouveaux textes, la plupart en effet avaient été réclamées, à diverses reprises, par les États. La réforme de la justice n'avait point de partisans plus décidés qu'eux. Négligeons les tenues antérieures : examinons seulement le recès des États de 1569. Qu'y voit-on ? D'abord, une protestation contre l'abus des commissions, aussi fructueuses pour eux que dommageables au public. Inversement, la demande que les lieutenants soient dotés de gages annuels, ou autorisés à prendre sportules; le voeu que la cour soit accrue de six conseillers et partagée en deux chambres ; enfin, l'indication de mesures propres à assurer un meilleur fonctionnement des scriberies bailliagères, ou une conservation plus assurée des protocoles notariaux. Reportons-nous aux articles de 1573 : ici et là, mêmes questions, et sinon toujours mêmes solutions de détail, du moins mêmes tendances, même esprit. Dans leur ensemble, les réformes élaborées aux Pays-Bas et rapportées en Comté par Froissard répondaient bien aux voeux des États du pays. 
Sans doute, les nouvelles ordonnances lésaient des intérêts, mais c'étaient des intérêts bourgeois et parlementaires. Or, les gens de justice - et parmi eux les plus éminents : les conseillers -avaient su conquérir une place enviable dans les États ; mais ils ne les composaient pas à eux tout seuls. Certes, on pouvait prévoir que toute la Chambre des villes, en 1574, formerait bloc contre les réformes. Mais cette Chambre ne constituait que le tiers de la délégation provinciale aux États. Sans l'appui du clergé, sans l'appui de la noblesse, elle ne pouvait rien. Aurait-elle cet appui ?

Celui du clergé, oui. Par raison de circonstances, non de principe. L'interdiction, en décembre 1572, d'excommunier, comme jadis, les débiteurs récalcitrants, avait provoqué chez les hauts dignitaires de l'Église une agitation très vive. Claude de la Baume, appuyé par le magistrat de Besançon, multipliait ses démarches aux Pays-Bas et en Espagne pour obtenir le retrait ou l'adoucissement des mesures prises. Au reste, le clergé subissait toujours, dans les tenues d'États, l'influence des deux ordres voisins, qui contribuaient tous deux à son recrutement. Dans les circonstances présentes, il devait se réjouir de la convocation annoncée ; elle lui permettrait sans doute de faire entendre sa voix dans cette question de la justice qui lui tenait si fort au coeur - et peut-être, par d'habiles négociations, en prêtant son appui à la bourgeoisie parlementaire, d'obtenir d'elle quelques concessions.

Restait la noblesse. On sait avec quel plaisir elle accueillait toujours la nouvelle d'une tenue d'États. Elle y voyait la promesse d'un « surjet » - l'annonce d'une distribution de récompenses pécuniaires enviables - la possibilité de poser, une fois de plus, la question de l'organisation militaire du Comté. D'autre part, c'était dans les États seulement, et par eux, qu'elle pouvait jouer un rôle politique, si minime fût-il - le Parlement lui étant fermé, les offices restant aux mains de la bourgeoisie et le gouverneur n'ayant pas, en sa qualité de représentant du roi dans la province, toute sa liberté d'action ni d'allures. Les États, c'était, pour la noblesse, l'assemblée rivale du Parlement de Dole. Mais précisément pour cette raison, la noblesse allait-elle prendre parti contre les ordonnances ? Celles-ci atteignaient, frappaient les parlementaires, les robins, ses adversaires déclarés et résolus ; ne devait-elle pas, dès lors, heureuse d'une telle attaque, rester à l'écart et se borner simplement à marquer les coups ? Elle avait pour cela de trop puissantes raisons d'intervenir. 
Raisons matérielles ? En tout cas, elles étaient faibles. Une seule série d'articles des nouvelles ordonnances touchait directement à ses intérêts ; encore n'atteignait-elle les nobles qu'en leur qualité de possesseurs de seigneuries. Les articles CLXXIII à CLXXIX, comportant réorganisation des justices inférieures, spécifiaient, entre autres, que dorénavant les offices de judicature, non plus que les amendes, ne pourraient être donnés à ferme. Ils décidaient que, dans chaque seigneurie, n'existerait plus désormais qu'un seul siège de justice : bailliage, châtellenie ou prévôté - au choix du seigneur ; enfin, que dans les seigneuries originellement uniques, mais actuellement partagées entre plusieurs maîtres, ceux-ci se réuniraient et s'entendraient pour n'établir qu'une seule justice commune à toutes les portions ; dépenses et recettes seraient réparties entre eux, au prorata du nombre de leurs sujets. Évidemment, c'était là une intrusion hardie du pouvoir royal dans un domaine que, volontiers, la noblesse considérait comme réservé. Encore, aucun texte ne nous fait-il apparaître d'un préjudice pécuniaire causé aux possesseurs de seigneuries par cette mesure de simplification et, semble-t-il même, d'économie.

Donc, les raisons matérielles pesaient peu. Mais, de la crise des nouvelles ordonnances, le Parlement n'allait-il pas sortir plus fort, plus puissant, rajeuni et restauré dans son ancien prestige ? Que tel fût le but dernier des ordonnances, que tel dût être leur résultat, beaucoup de nobles le sentaient - non pas confusément, mais nettement, distinctement, et l'énonçaient ; un des correspondants de Granvelle, Bonet Jaquemet, le constate en propres termes dans une lettre au cardinal du 4 août 1574 : « La noblesse, écrit-il, est très opposée aux nouvelles ordonnances ;.... elles sont odieuses aux méchants pour faire cheminer la justice droite. » De plus, Froissard n'était pas, ne devait pas être agréable et sympathique à la noblesse ; il pouvait bien momentanément entrer en lutte avec ses collègues; il pouvait bien leur apparaître, à eux, comme un adversaire et comme un transfuge, il n'en était pas moins le chef, la tête de leur grand corps si longtemps décapité - le représentant de ces conseillers qui, par leurs idées, par leurs sentiments comme par leurs fonctions mêmes, s'opposaient si résolument aux gentilshommes d'épée.

Or, de ceux-ci, le gouvernement du duc d'Albe avait ranimé les espérances. N'avaient-ils pas vu, à deux ou trois reprises, les parlementaires humiliés par les leurs : un Vergy, un Lannoy? Ne les avaient-ils pas vus, tremblants et confus devant les enquêteurs? Ne savaient-ils pas en quelle maigre estime le duc avait 
tenu ces robins orgueilleux et prévaricateurs, qu'un homme de robe comme eux avait pu confondre et déporter de leurs états ? Quelle plus belle occasion, dès lors, pour les féodaux, de chercher, dans un effort décisif, à transférer du Parlement aux États la puissance politique ? Ils avaient cette double chance : d'une part, que le Parlement chancelait; que les mesures de rigueur prises contre lui par le duc d'Albe avaient affaibli son pouvoir, ruiné son prestige, détruit même, paralysé sa confiance en lui-même ; - de l'autre, que les parlementaires, au lieu de combattre les États, au lieu de voir, comme jadis, dans leur réunion, une menace pour eux ; au lieu d'attendre sur la réserve, avec méfiance et soupçon, la tenue projetée, la désiraient au contraire, la souhaitaient, voyaient en elle le moyen de faire entendre plus haut leur voix intéressée contre les réformes, contre les ordonnances de 1573, contre le nouveau président qui les voulait commander, réformer et conduire à sa guise. L'occasion était belle ; il la fallait saisir avec d'autant plus d'empressement que par les États peut-être, se réaliseraient enfin ces perpétuelles espérances de commandement militaire, d'organisation d'une milice en Comté, que ne cessait de nourrir la noblesse d'épée - espérances exaltées encore et rendues plus vives par les événements récents. Les temps étaient durs, par ces années de misère, de peste, de mauvaises récoltes, de hausse exorbitante des prix, pour tous ceux qui tiraient des seigneuries leurs revenus; nouvelle excitation, nouvel encouragement pour eux à mettre la main, s'ils le pouvaient, sur les États, à les entraîner à leur suite là où ils voulaient aller - à en faire le vrai corps politique, le porte-parole de toute la province.

Et d'ailleurs, autour d'eux, dans les pays voisins, un grand courant d'idées, un grand mouvement d'opinion ne se produisait-il pas alors en faveur des États contre l'absolutisme monarchique et les Parlements ? Certes, ce n'étaient point des révoltés que les nobles Comtois de 1573-1574; ce n'étaient ni des adversaires de l'autorité monarchique, ni des rebelles, prêts à se soulever contre Philippe IL Mais c'étaient des Comtois - fiers comme tels de leurs vieux privilèges, de leur « franchise ». et que, peut-être, avaient inquiétés bien des mesures hardies, bien des projets du duc d'Albe, portant en Bourgogne le même esprit qu'aux Pays-Bas hostile, ici comme là, aux hommes et aux institutions indigènes, aux traditions particularistes, aux garanties traditionnelles. Or, de ces garanties, des privilèges du pays, les États n'étaient-ils pas les gardiens attitrés ? N'était-ce pas eux, et eux seuls, qui détenaient la première, la plus précieuse des libertés comtoises, celle 
même qui valait son nom à la province : la liberté de consentir l'impôt ? Le bruit ne s'était-il pas répandus, quelque temps avant son retour en Espagne, que le duc d'Albe songeait à violer la franchise du pays - à établir en Comté ce dixième abhorré, que repoussaient les Flamands de toute leur énergie ? C'étaient de dures têtes et de mauvaises langues, les grands seigneurs comtois, prompts à la main, orgueilleux entre tous les nobles de leur époque, libres de leurs actions et de leurs propos: quelques-uns d'entre eux l'avaient bien montré au temps des Gueux. Mais, si un Claude-François ou un Marc de Rye n'était plus, il restait encore à foison des raisonneurs, des frondeurs: tel ce J.-B. d'Andelot, le fils du grand écuyer de Charles-Quint, le frère du décapité de 1568, qui, au dire de Granvelle, son beau-frère, était « libre à dire, quelques foys, plus qu'il ne luy convenoit ». Ils entretenaient, ces seigneurs, d'actives relations avec les Pays-Bas, savaient ce qui se passait, aussi bien chez les rebelles que chez leurs adversaires, suivaient également les affaires de France. Or, c'était un fait que, le duc d'Albe parti, un grand désir d'apaisement, par réaction contre ses violences et ses abus d'autorité, s'était saisi de tous les esprits. C'était un fait qu'aux Pays-Bas, deux Comtois de marque, qui occupaient tous deux de hautes situations, qui tous deux avaient gardé en Comté des terres, des relations, des amitiés fidèles: Champagney, le frère de Granvelle, et le comte de la Roche, son beau-frère, manifestaient alors, avec la même décision sinon toujours avec la même énergie, leur réprobation des horreurs de la guerre, leur haine des abus et des excès d'une soldatesque espagnole qui venait de chasser le premier d'Anvers et qui, sous les yeux du second et malgré ses efforts, avait manqué d'incendier Utrecht. -C'était un fait, enfin, que la SaintBarthélemy avait provoqué en France, aux Pays-Bas, à Genève, l'éclosion de toute une littérature politique favorable aux États, hostile aux Parlements et à l'absolutisme sans frein des royautés. Selon la forte parole de du Plessis-Mornay, il semblait que, depuis le 24 août 1572, l'État se fût « crevassé et ébranlé ». 1573 : c'est la publication à Genève, par Hotman, du texte latin de la Franco-Gallia. Et n'estce pas dans ce vigoureux ouvrage de théorie libérale que se lit un portrait si sévère de cette « ne sçay quelle manière de gens qui a la vogue par toute la France, que les uns appellent gens de justice, les autres praticiens, lesquels depuis trois cens ans ença ou environ, ont si bien sçeu jouer leur personnage et ont fait tant de bons tours d'habileté et de soupplesse qu'ils ont non seulement mis sous leurs pieds et supplanté toute l'autorité du concile des États, mais aussi.... contraint tous les princes du Royaume, voire mesmes la Majesté du Roy, de passer sous leur main 
et de s'humilier sous leur grandeur ? » N'est-ce pas là que se trouvent ces remarques sur les parlementaires qui, une fois reçus à la cour, « quoy qu'ils soyent issus de petit lieu ». en moins de quatre ou cinq ans « amassent tant de biens et tant de richesses qu'ils deviennent comme de petits roys ? " N'est-ce pas là enfin qu'est formulée cette théorie de l'excellence d'un État « où quelque nombre de gens de bien et d'honneur » exercerait le gouvernement, « lequel, à raison de la noblesse de race conjointe avec la suffisance et expérience aux affaires approche de la dignité royale - mais aussi, pour autant qu'il est un degré plus bas à cause de la sujétion qui luy est commune avec le peuple, n'est pas fort éloigné de l'état populaire ». - Qu'on nous entende bien : nous ne songeons nullement à établir une influence précise de la France-Gaule - ou d'aucun autre écrit politique du temps sur les événements de 1573 et de 1574 en Comté. Mais nous avons le droit de retenir ces textes pour constater qu'un grand courant d'opinion favorable à la noblesse, au droit des aristocraties, à l'action politique des États, se dessinait alors dans l'Europe occidentale.

Que parlons-nous de textes, d'ailleurs ? Les événements des Pays-Bas ne comptaient-ils point, eux aussi ? N'est-ce pas le 7 juin 1574, cinq mois avant la réunion des États de Franche-Comté, que s'ouvrent à Bruxelles, sur convocation de Requesens, les États généraux ? On connut en Comté leurs remontrances sobres mais énergiques, et dont tant d'articles pouvaient intéresser les Bourguignons : administration du pays par les indigènes, à l'exclusion des étrangers ; observation stricte de «tous les anchiens droictz, previlèges, usages et coutumes »; établissement en Espagne «d'ung conseil de personnaiges naturels des PaysBas » : programme très propre, notons-le en passant, à séduire tout particulièrement les parlementaires, à les intéresser à cette réunion prochaine des États que la noblesse attendait de son côté avec impatience - pour des raisons toutes différentes, sinon toutes opposées. Ainsi conspiraient l'esprit général du temps et les circonstances diverses des événements pour donner à la tenue projetée une gravité, une importance exceptionnelle. Ainsi, spectacle rare, les trois ordres, si souvent divisés, allaient se trouver unis pour une fois dans un commun désir, dans une commune opposition, sans que, d'ailleurs, aucun des motifs de leur antagonisme ait disparu - sans qu'ils soient guidés dans les mêmes actes ni par les mêmes causes ni par les mêmes désirs. C'est ce qui fait l'intérêt, c'est ce qui explique la por- 
tée de ces événements complexes de 1574, dont il nous reste maintenant à démêler la trame.

\section{III}

C'est le 8 novembre 1574 que les délégués se réunirent à Dole. Dans ses instructions à François de Vergy et à Pierre Froissard, chargés tous deux de présider la session, le roi s'était contenté de fixer la somme à réclamer des États : 100000 fr. - Mais le Grand Commandeur, dans une lettre du 27 septembre 1574, leur avait indiqué par surcroît la conduite à suivre en cas d'agitation et de murmures. Il faudrait tenir bon et « obvier aux practicques que aucuns irrequietz esperitz vouldroient par adventure susciter contre icelles ordonnances ». Aux mécontents, les commis du roi devraient répondre «que lesd. ordonnances sont esté faictes à grande et meure délibération du conseil pour le bien, repoz et tranquilité du pays et abbréviation de la justice, afin de remédier aux abuz » révélés par une visite faite « à leur réquisition ou du moings de plusieurs d'eulx ». Et s'ils mettaient en avant que, «paravant la publication d'icelles ordonnances, ilz et ceulx de lad. court de Parlement devoyent sur icelles estre ouys, leur direz qu'ilz n'ignorent que le prince ne doibt en estre ainsi astraint, ains qu'il fait ses édictz, placcartz et ordonnances de son propre mouvement ». Tel était le point de vue du gouvernement des Pays-Bas ; sa conclusion : inviter les esprits au calme ; ne pas s'opposer, d'ailleurs, à ce que Sa Majesté soit saisie de la question par les États - pourvu que ce soit en toute modestie.

Dernière condition qui ne devait point être réalisée.... Les États s'ouvrirent et ce furent, tout de suite, des clameurs violentes. Le trouble a été si grand, écrivait le 8 décembre au cardinal l'un de ses correspondants, Bonet Jaquemet, « que le commencement de la révolte des Gueux n'a pas été pire ». Comme d'habitude pourtant, les commis ouvrirent la séance en transmettant aux députés les remerciements du roi, ses protestations de service et de bonnes dispositions, ses demandes enfin. Alléguant la misère du pays, les mauvaises années, la cherté régnante en Comté « plus qu'en tous autres pays voisins », les États au lieu des $100000 \mathrm{fr}$. sollicités en votèrent 60 000, puis, l'affaire liquidée, s'occupèrent aussitôt des 
nouvelles ordonnances. Que se passa-t-il exactement dans les trois chambres? Quels furent les débats, quelles les négociations qui remplirent ces douze jours de laborieuse session? Nous ne le savons pas avec précision. Simplement, les relations nous montrent la noblesse, excitée et violente à son habitude, applaudissant aux déclarations véhémentes d'un Wateville, disant « qu'il falloit prendre le président et l'envoyer avec ses ordonnances en Espagne »; elles nous montrent des conseillers au Parlement, Belin notamment et Nicolas Duchamp, allumant les passions, jetant de l'huile sur le feu, poussant les féodaux à la révolte, tandis qu'en Chambre du clergé, leurs collègues les conseillers clercs : Jean de Saint-Mauris et François de Poitiers, joignaient leurs protestations véhémentes à celles de l'archevêque et du haut doyen. C'est à Claude de la Baume, en effet, que Bonet Jaquemet, dans une lettre à Granvelle du 31 décembre 1574, fait remonter l'origine d'une démarche qui émut beaucoup Froissard. Une de ses créatures, un Comtois du nom de du Tartre, alors résidant à la cour d'Espagne, avait présenté, à la fin d'août ou au début de septembre 1574, une requête au roi, directement. Requête émanant, à ce qu'il prétendait, « de la plus part et saine partie de la noblesse » : elle contenait de véhémentes protestations contre les nouvelles ordonnances et, en particulier, contre la suppression du siège d'Orgelet. Pendant les États, Vergy, qui de Flandre avait reçu copie de ce document, le communiqua à Froissard ; et, dans plusieurs lettres, gouverneur et président s'élevèrent tous deux avec vivacité contre le procédé et les allégations de du Tartre. Or, d'après Jaquemet, c'était sur demande de Claude de la Baume - toujours inconsolable de la suppression des excommunications - que du Tartre avait rédigé et présenté ses doléances au roi.

Au reste, les résolutions des États furent significatives. En premier lieu, deux délégations de trois membres chacune - un membre par ordre - furent constituées et chargées de gagner, l'une les Pays-Bas, l'autre l'Espagne, pour y porter au Grand Commandeur et au souverain en personne les doléances des États et leurs protestations contre les ordonnances. Mesure exceptionnelle, que n'avaient point connue les États antérieurs. Faut-il chercher un précédent flamand à la résolution des États franc-comtois ? Dans leur assemblée du 20 au 22 août 1571, les États de Hainaut, en pleine protestation contre le 10e et le 20e denier, que le duc d'Albe s'obstinait à vouloir introduire dans les provinces, avaient décidé l'envoi en Espagne, auprès du roi lui-même, de délégués des trois ordres. Ceux-ci étaient partis en effet, sans la permission du duc d'Albe. Le roi avait blâmé leur démarche, mais 
les avait reçus cependant, et même ne leur avait point fait un trop mauvais accueil. Précédent ou concordance : dans les deux cas, le fait est à noter. - Quoi qu'il en soit d'ailleurs, les deux délégations de Franche-Comté étaient brillamment composées. Pour l'Espagne devaient partir, s'il y avait lieu, avec l'archevêque Claude de la Baume, toujours heureux de quitter son diocèse et de s'offrir, sans qu'il lui coûtât rien, un voyage en cour, Henri de Vienne, baron de Chevreaux, un vaillant soldat, plus riche de bravoure que d'écus et qui, depuis des années, guerroyait sans trêve, tantôt dans le Levant, tantôt aux Pays-Bas - et le conseiller au Parlement Duchamp, orateur réputé, esprit lucide, mais caractère passionné et véhément. Pour la Flandre, les États désignèrent un haut prélat, l'abbé de Saint-Claude, Marc de Rye ; le bailli de Dole, Jean Baptiste d'Andelot ; enfin, l'avocat réputé Prudent de Saint-Mauris. Pour tous d'ailleurs, c'était une bonne aubaine : ils devaient être largement défrayés ; un crédit de 25000 fr. du surget fut affecté à leur seul entretien.

Mais plus grave encore était une autre résolution : celle qui donne leur exceptionnel intérêt aux États de 1574 et révèle avec le plus de netteté les desseins politiques des délégués. Une commission permanente de neuf membres, assistés d'un secrétaire, fut en effet constituée. Elle devait d'abord dresser les requêtes et compiler les mémoires que les députations présenteraient à Requesens et à Philippe II ; elle devait surtout, survivant aux États, rester en correspondance suivie avec ces députations ; les tenir au courant de tout ce qui se passerait en Comté ; aviser aux nécessités changeantes du moment ; bref, faire oeuvre politique au premier chef et assurer, pour la première fois en Comté, cette perpétuité, cette continuité des États d'une séance à l'autre qu'un Charles-Quint redoutait tant et s'était toujours efforcé d'interdire.

Comment se fit une telle création ? Laissons la parole sur ce point au procureur général et au premier avocat fiscal au Parlement. Le 24 novembre 1574, la session close, ils adressaient spontanément à Requesens, pour l'acquit de leurs charges, une relation de l'assemblée qui venait de se dissoudre. De tout temps, exposaient-ils, il y avait eu aux États de Franche-Comté trois chambres ; mais, «à ceste dernière assemblée, par vraysemblable direction d'aulcungs tendants à couvrir et tenir secret aux officiers de S.M. leurs desseings... fut et a esté excogittée et dressée une quatrième chambre de neufz, choisis et pris des aultres trois chambres ordinaires et d'une chacune d'icelles trois personnages pour, en appart et entre 
eulx, aviser et dresser articles que seront rapportez, reveuz et résolz par ceulx desd. estatz, pour la conservation des libertez de ced. pays, réformation et révocation des ordonnances ». Pourquoi cette opposition aux ordonnances ? Par désir de sauvegarder des intérêts privés ; par «forme de contradiction » aussi, par mauvais esprit de chicane comtoise ; mais surtout, par raison de principe, et parce que, au dire des protestataires, les ordonnances n'étaient point valables, ayant été « faittes et publiées sans la participation desd. Estatz et ceulx du pays ».

C'était bien en effet le point capital ; c'était bien la formule décisive qui pouvait grouper derrière elle, à la fois, les parlementaires proclamant leur droit de participer à toute oeuvre législative concernant la province - et les partisans des États réclamant pour leur assemblée, représentation directe du pays, un droit de contrôle effectif en matière politique et administrative comme en matière financière. Ainsi, d'après le témoignage des fiscaux, à la thèse absolutiste, que le souverain seul légifère, s'opposait la thèse libérale, la thèse défendue pratiquement aux Pays-Bas par les Flamands en lutte contre le roi d'Espagne et contre ses lieutenants ; la thèse soutenue théoriquement en France par tant d'auteurs de pamphlets, de libelles, de dissertations : celle du Réveille-Matin, celle de la FranceGaule. Et c'étaient des parlementaires, c'étaient les Belin et les Duchamp qui, par une véritable trahison envers leur compagnie, travaillaient, de toute la passion qui les aveuglait, à la grandeur des États rivaux du Parlement.

Les fiscaux protestèrent. Ils ne pouvaient laisser dire tout haut « que S. M. n'avoit l'auctorité de, sans participation desd. estatz et ceulx du peys, establir loix et ordonnances à ses vassaulx et subjectz ». Forts des précédents, alléguant les événements de 1538, ils firent aux États « certaines remontrances pour demonoir et admonester les bien-affectionnez... de non attenter aucune chose aux haulteurs de Sad. Majesté ». Mal leur en prit. Les Neuf, reprenant une vieille querelle - déjà soulevée précisément en 1538 - leur répondirent que les discussions des États n'étaient point de leur ressort, et qu'au surplus ils n'avaient même pas droit d'entrée en la Chambre des villes ; «n'eust esté, constatent les fiscaux, la bonne assistance des comte de Champlytte et président de Bourgogne, ilz ne se fussent contenté de proposer hardiement que, comme suspectz, ne devions être admis ny receuz ausd. Estatz ; croyons que, sans l'intervention et auctorité desd. srs commis, nous eussions peu estre excluz ». D'ailleurs, les fiscaux ne pénétrèrent point dans la Chambre des Neuf. Ceux-ci dressèrent à leur guise des articles secrets, ne 
les soumirent pas au vote des États, et comme le procureur général, lassé des récriminations qu'il entendait contre certains articles des ordonnances, s'était avisé "d'informer desd. plainctes... en aucungs endroitz du pays », ils protestèrent énergiquement contre son initiative, prétendant qu'il dépassait ses droits et ne devait pas agir motu proprio.

Le résultat de tant de conciliabules et de séances secrètes fut une longue doléance au roi contre l'oeuvre législative nouvelle. Par les ordonnances, les trois États du pays étaient diffamés et se voyaient la risée des circonvoisins ; par elles, les justices et juridictions de l'Église et des seigneurs étaient altérées et changées, les styles judiciaires rendus plus compliqués et plus dispendieux, plus longues les causes des veuves, celles des pupilles, des orphelins, des serviteurs du roi, des écoliers et généralement des privilégiés ; surtout, une multitude de bons sujets se voyaient privés de leur état, contraints de « mandier leurs vies » et de laisser leurs fils sans science ni doctrine... Ainsi se lamentaient longuement, copieusement, les trois ordres. La conclusion était que le roi devait abolir les ordonnances - d'abord ; mais qu'il devait ensuite, au plus tôt, « rétablir le nombre des sieurs superintendans aux affaires du pays, et tellement accroître leur autorité qu'ils puissent, avec le sr gouverneur, pourvoir en cas d'emport requérant prompte provision et mesure ». Ces superintendants, les États prenaient soin de les désigner au roi. Ce n'étaient pas les «bons personnages » d'autrefois, choisis, nommés par le souverain : c'étaient les neuf délégués de la commission permanente...

Proposition habile et singulièrement dangereuse : le plan des meneurs était cohérent. Il tendait tout entier au partage de l'autorité entre le roi et les représentants élus de la province - et au transfert à une commission permanente des États des attributions politiques et de l'influence du Parlement de Dole. Projets anciens déjà, le second du moins. La rareté, l'intermittence et le peu de durée des tenues d'États en avaient jusque-là empêché toute réalisation. Contre la rareté, les députés ne pouvaient rien par eux-mêmes; du roi et du roi seul dépendait leur réunion. Mais contre l'intermittence, ils venaient de réagir. La commission permanente assurerait, d'une session à l'autre, la continuité des desseins et l'efficacité des mesures prises. La durée, déjà ils l'avaient prolongée. Jadis, trois jours suffisaient à tout régler ; les États de 1574 en vécurent dix. 


\section{IV}

Pendant toute la durée des débats, M. de Vergy était resté peu actif - visiblement désireux de ne pas se compromettre en prenant parti soit pour les ordonnances qu'il ne goûtait pas, soit contre le président, qui lui demeurait assez peu sympathique. Il louvoyait ; mais, de la commission des Neuf, Antoine d'Oiselay, son lieutenant, un de ses intimes, était membre ; membre aussi son neveu Henri de Vienne ; un de ses anciens secrétaires, Ant. Outenin, servait de greffier aux séances secrètes. Du reste, Vergy n'assista pas aux dernières délibérations ; il signa cependant, avec le président, une lettre à Requesens, où les deux commissaires se bornaient à constater - optimisme officiel - que tout s'était bien passé, et sans incidents, aux États. Lettre banale, cette lettre collective, et qu'il est intéressant de rapprocher de la lettre personnelle que le même Vergy, le même jour, adressait au même Requesens. Il le remerciait d'abord d'une grande grâce qui venait de lui être faite : l'érection en comté de sa terre de Champlitte. Et il continuait par un éloge bien suggestif de la noblesse comtoise, qui, aux États, « bien que la plupart composée de jeunes gens », s'était comportée « austant modestement et doulcement que l'on eust peu désirer ». Éloge auquel, sans doute, ni Bonet Jaquemet ni Froissard n'auraient souscrit sans réserve. On devrait bien, concluait le gouverneur, pour récompenser la noblesse d'une attitude si exemplaire, « advenant bonne occasion de pouvoir servir S. M. », l'y employer « selon le mérite de leurs bonnes affections ». D'ailleurs - et la fin de cette lettre démentait le début - Vergy, prudent et contraint, de par sa situation, à certaine réserve, croyait utile de faire savoir à Requesens que son neveu le baron de Chevreaux, ayant été désigné pour faire partie de la délégation d'Espagne, avait déclaré « qu'il n'entendoit en accepter la charge, sinon après avoir veu les instructions que sur ce ilz entendoient leur dresser et reconneu qu'en icelles il n'y eust choses dont S. M. ou V. E. en puisse

prendre tant peu soit-il de mescontantement ». C'était se ménager, à tout hasard, une porte de sortie...

Quant à Froissard, il était sorti des États ulcéré. Il avait dû assister, impuissant, résigné, aux attaques dirigées contre son oeuvre, son autorité, contre sa personne même, par la noblesse et par la bourgeoisie. Et sans doute, ce n'étaient pas 
les calomnies, les accusations brutales colportées contre lui, qui l'affectaient le plus ; - mais des séances comme celle du 15 novembre 1574, à la Cour, où sous sa présidence s'était débattue la question du congé à accorder au conseiller Duchamp, désigné par les États pour aller en Espagne, vers Sa Majesté ; c'étaient les complots, les ententes sournoises des conseillers entre eux pour les nominations, les présentations de candidats agréables à Vergy, déplaisant à Froissard; plus que tout, l'abandon persistant où le roi laissait un de ses serviteurs les plus fidèles - le roi et Hopperus également qui, le 28 novembre 1574, écrivait à son maître qu'il n'avait pu encore "récrire » les ordonnances pour les lui soumettre, «à cause qu'elles sont sy très grandes et beaucoup en nombre... »Duchamp, Bellefontaine et leurs amis continuaient leur campagne obstinée contre lui ; - et deux ou trois fois, au dire de Jaquemet, le président, désespéré, se vit sur le point d'abandonner sa charge et de démissionner. Du reste, dans toutes ces luttes, son orgueil blessé s'exaspérait ; Morillon, dans une lettre à Granvelle du 21 décembre 1574, note sa " grandeur », cette humeur hautaine qu'encourageaient en lui de sots conseillers et que sa femme, maladroitement, manifestait aussi. Maigres satisfactions d'amourpropre, cherchées comme une revanche par un homme débile, calomnié, abandonné de tous, mais gardant la conscience de sa haute valeur ; elles ne pansaient pas les blessures profondes. Déjà malade à la fin de 1574, les attaques redoublées qui suivirent les États achevèrent le président. En vain Blasere, enfin muni d'argent, quitta les Pays-Bas et parvint à Dole dans les premiers jours de décembre. Il était trop tard. Malgré le secours qui lui venait ainsi, Froissard, épuisé par ces mois de lutte et d'incessant travail, dut s'aliter ; en quelques jours, il fut perdu ; il rendit le dernier soupir dans la nuit du 28 au 29 janvier ; il n'avait encore que quarante-deux ans.

Grosse perte en un tel moment. Il est permis de penser, avec Granvelle, que « s'il eust vescu », bien des choses, peut-être, se seraient redressées « par sa dextérité et bon cerveaul ». Mais sa disparition laissait aux ennemis le champ libre. Une crise nouvelle s'ouvrait. De l'oeuvre tentée par Froissard, du grand travail de centralisation absolutiste dont il s'était fait l'artisan, qu'allait-il demeurer ? Et quels fruits porterait en Comté le mouvement libéral qu'inauguraient les nobles ? 
PHILIPPE II ET LA FRANCHE-COMTÉ

Étude d'histoire politique, religieuse et sociale.

Quatrième partie. Le progrès de l’absolutisme.

\section{Chapitre XXIII}

\section{Le gouvernement de Don Juan d'Autriche}

\section{$\underline{\text { Retour à la table des matières }}$}

Cependant, tout un plan d'action avait été conçu par les États : il s'agissait de l'exécuter. Sitôt la session close, la commission des Neuf et les membres désignés des deux délégations s'y employèrent avec activité.

\section{I}

Ce fut la délégation des Pays-Bas qui partit la première, dès le 14 janvier 1575 ; on ne voit pas d'ailleurs que Requesens ait cherché à interdire son départ. Au début de février, elle était à Bruxelles, mais incomplète ; le représentant du clergé, Marc de Rye, ayant pris les fièvres, avait dû s'arrêter en chemin. En l'attendant, ses collègues parlaient haut, se répandaient en propos violents ; Viglius, effrayé, en informait Hopperus : les Comtois, écrivait-il, semblent plutôt poursuivre la ruine du pouvoir royal que la révocation des nouvelles ordonnances - et il dénonçait comme auteurs du mal les parlementaires, cherchant dans une agitation 
politique une diversion aux poursuites que méritaient leurs manquements professionnels.

En mars, le retardataire arrivé, Requesens put donner audience aux Comtois à Anvers. Audience mouvementée sans doute: au gouverneur qui cherchait un moyen terme, des mesures conciliatrices, les députés opposèrent une intransigeance irréductible. Ce n'était pas des modifications qu'ils réclamaient, mais l'abrogation pure et simple des ordonnances. Requesens, ému sans doute par leur attitude et qui déjà avait demandé à Vergy des explications sur la conduite du conseiller Duchamp et sur l'autorisation à lui accordée d'aller en Espagne, saisit alors de la question une commission mixte de conseillers du Conseil privé et du grand Conseil de Malines. Elle aboutit, après quelques jours de travail, à un projet transactionnel : remaniées sur presque tous les points litigieux conformément au voeu des États, les ordonnances devaient dès lors, dans leur pensée et dans celle de Requesens, être acceptées et exécutées sans murmure dans la province. Vaine illusion : les Comtois, loin de savoir gré à Requesens de ses concessions, n'en prirent que plus d'arrogance. Ils en référèrent aux Neuf : ceux-ci, précipitamment assemblés à Besançon, dépêchèrent en toute diligence un des leurs, le docteur Perrot, en Flandre ; il portait l'ordre aux trois envoyés de persister dans leur attitude intransigeante et de réclamer non le remaniement mais la suppression pure et simple des ordonnances. Les délégués obéirent et, prenant congé du Grand Commandeur, déclarèrent que, malgré ses concessions, l'ambassade d'Espagne irait trouver le roi.

De fait, lorsque le 23 juillet 1575 les articles remaniés par Requesens à la date du 9 parvinrent à Dole, ils n'apaisèrent nullement les esprits. Pourtant, sur tous les points, le gouverneur avait donné satisfaction aux réclamations des États. Il n'en avait réservé que deux et priait Vergy et le Parlement de lui fournir au plus tôt leur avis motivé sur la suppression des trois sièges condamnés, la réunion des prévôtés aux bailliages et aux châtellenies et l'unification des justices seigneuriales. D'autre part, il avait adressé aux conseillers une réponse spéciale. Reprenant un à un les articles de l'ordonnance secrète qui les avaient le plus vivement émus, il s'efforçait d'en adoucir le sens, d'en atténuer la rigueur. Il se contentait de recommander vivement à tous le plus grand respect pour le président et terminait aimablement par une promesse d'augmentation prochaine des gages de la cour. 
Vaine séduction. Les concessions de Requesens furent aussi mal reçues par le Parlement que par les États. Réunis le 23 août 1575, les conseillers commencèrent par refuser tout net de publier les articles amendés - prétextant que mieux vaudrait reviser d'ensemble anciennes et récentes ordonnances, et en dresser un recueil que compileraient avec la cour les plus avisés des officiers bailliagers. En même temps, ils décidèrent à leur tour d'user d'ambassades auprès de leurs maîtres, et reprenant le vieux projet déjà mis en avant au temps du duc d'Albe, désignèrent, comme alors, leur confrère Boisset pour aller porter en Flandre des doléances rédigées par quatre d'entre eux. En vain Blasere protesta-t-il aigrement, le 8 septembre, non contre ce projet, mais contre la non-publication des articles réformés. La cour persista - et, le 21 octobre 1575, Boisset annonçait d'Anvers, à ses collègues, l'heureux succès de son voyage d'aller.

Épisode intéressant : l'envoi de Boisset en Flandre, c'est la première fissure dans le bloc temporaire que conseillers de Dole et partisans des États avaient constitué singulièrement à la fin de 1574. Fissure légère sans doute : lorsqu'il avait quitté la Comté, Boisset avait passé par Flagy. Il y avait rencontré M. de Vergy, lui avait lu ses instructions, et le gouverneur les avait fort approuvées. De fait, elles avaient trait partiellement à une question qui intéressait en lui, de très près, l'homme d'épée. Dans leurs articles 13 et 14 . les parlementaires exaltaient à leur habitude l'alliance avec Messieurs des Ligues comme le seul moyen de préserver efficacement la Comté des coups de main et des entreprises hostiles. Mais ils réclamaient un " éclaircissement » des termes traditionnels de cette alliance et qu'au lieu de la clause équivoque du Léal Regard, le traité portât désormais obligation aux Suisses d'assister militairement leurs voisins de Bourgogne s'ils étaient attaqués ou menacés. Or, sur ce point, ils pouvaient se rencontrer avec M. de Vergy. Sans doute, ils ne précisaient pas les moyens : mais comment proposer la substitution d'un traité formel d'alliance défensive à la promesse, un peu vague, de bons offices que comportait la clause du Léal Regard, si cette alliance devait rester sans profit pour l'une des deux parties contractantes ? Les Suisses accepteraient-ils une modification qui accroîtrait leurs charges sans avantage pour eux ? N'était-il pas nécessaire que la Comté, si elle voulait promettre son appui aux Ligues, devienne ce que les Ligues étaient et ce qu'elle n'était pas : une puissance militaire ? C'était dès lors toute la question de la milice, l'éternelle question de l'entretien en Comté de troupes permanentes qui pouvait être ainsi posée à nou- 
veau - et cette fois, d'une façon fort spécieuse, et propre sans doute à embarrasser dans leurs résistances ces parlementaires qui, toujours, s'étaient montrés les adversaires acharnés de telles créations ? Illusion, sans doute, de croire à la possibilité de telles négociations, avec des politiques aussi positifs que Messieurs de Berne, par exemple, ou Messieurs de Bâle. Mais cette illusion, l'attitude de certains cantons catholiques à cette époque pouvait l'entretenir - et de fait, les graves parlementaires ne semblaient-ils pas la partager alors avec les plus folles têtes de la noblesse comtoise?

Par contre, une deuxième question était longuement débattue dans les remontrances que portait Boisset au Grand Commandeur : celle de l'autorité et des droits politiques du Parlement. Sur ce terrain, l'accord était sans doute moins facile avec M. de Vergy. Ainsi s'explique que Boisset, ayant de Flagy gagné Gray et rencontré Blasere, ait obtenu de celui-ci, pareillement, l'approbation sinon de sa démarche, du moins de la partie de ses instructions qui concernait le prestige nécessaire de la robe.

Longuement, en effet, les rédacteurs des remontrances s'étaient étendus sur le passé glorieux du Parlement, sur ses droits et sur ses privilèges, sur le partage d'autorité que toujours les souverains avaient établi entre la cour, d'une part, et le gouverneur particulier de l'autre. Ils rappelaient nettement, dans l'article 9, que leur compagnie avait toujours eu « soin et regard de contenir la noblesse ès obéissance de S. M. »; ils rappelaient, dans l'article 6, que leur justice était souveraine et que les princes avaient voulu, « par l'institution du gouverneur particulier, qu'il fût appelable à lad. cour »; ils se targuaient enfin, dans l'article 4 - c'était leur grand argument contre les prétentions rivales des États - de représenter à la fois « le prince souverain et les trois estats du pays ». Suivaient les doléances : contre le Pardessus de la Saunerie et le capitaine de Dole, qui, munis de prescriptions du duc d'Albe, prétendaient troubler la juridiction traditionnelle du Parlement ; contre le gouverneur lui-même, $M$. de Vergy, dont le Grand Commandeur avait récemment étendu, et de manière abusive, la juridiction sur les militaires ; contre la visite du Comté, qui, ayant eu pour résultat la suspension de plusieurs conseillers, laissait vacants leur siège dans l'attente d'une solution définitive ; enfin, contre les nouvelles ordonnances : l'article 39 en réclamait nettement la suspension. Il se basait sur l'intérêt du roi qui, du seul fait de la suppression des prévôtés, allait perdre plus de 10000 fr. La solution proposée était simple : confier au Parlement 
le soin de dresser un volume contenant les meilleurs articles des anciennes et des nouvelles ordonnances; ainsi les conseillers affirmeraient dans la pratique leur droit de participer au travail législatif ; ainsi ils réduiraient à néant les prétentions rivales des États.

Ces remontrances, Boisset réussit difficilement à les présenter à Requesens, alors fort occupé par le siège de Zierikzée. Il y parvint cependant, à Anvers, le 27 novembre 1575. L'accueil du Grand Commandeur fut aimable, comme l'avait été celui des conseillers influents qui l'entouraient: Roda, d'Assonleville, del Rio, pour ne point parler de Viglius, de plus en plus «floche »au dire de Morillon, et soucieux uniquement «de tirer ses gaiges». Mais Boisset ne remporta que de bonnes paroles vagues, ainsi qu'une belle lettre de d'Assonleville au Parlement, pleine de maximes sur la vérité qui « peult pâtir, mais non être vaincue ». D'engagements précis, point. En rentrant d'ailleurs, Boisset devait trouver à Dole un nouveau président. Par extraordinaire, la vacance ouverte par la mort de Froissard avait été comblée presque immédiatement. Un candidat s'était trouvé, à la fois très sympathique à Vergy qui le comptait parmi ses clients les plus respectueux et les plus dociles - et aux amis de Froissard, aux granvellistes partisans des nouvelles ordonnances comme B. Jaquemet : Claude Boutechoux, qui d'avocat fiscal était devenu, en 1570, conseiller au Parlement. Déjà, en 1572, son nom avait été prononcé pour la présidence. D'origine grayloise, il était très soutenu par les Vergy ; d'autre part, il avait épousé la fille du chroniqueur Jean de Vandenesse, et son beau-père d'abord, son beau-frère Jacques ensuite, lui avaient ménagé leur appui à la cour. Il est vrai que des bruits peu favorables avaient un instant circulé sur son honorabilité professionnelle. Lorsqu'il était reparti pour une seconde mission, Blasere avait même reçu des instructions spéciales à son sujet. Mais le roi - laissé dans l'ignorance ou circonvenu - passa outre : Boutechoux reçut, en octobre, sa nomination, et tout le monde s'inclina. 


\section{II}

Cependant, le temps coulait. L'agitation des esprits, en Comté, semblait se calmer peu à peu, la crise s'apaiser. Peut-être les solutions intermédiaires - celles de Requesens - seraient-elles parvenues à s'imposer si, brusquement, au début de mars 1576, la mort du Grand Commandeur, la prise du pouvoir par le Conseil d'État, les difficultés presque inextricables avec lesquelles ses membres durent bientôt lutter - toute cette série d'événements qui agitèrent si profondément alors les Pays-Bas, n'étaient venus ranimer en Comté passions et colères. Plus de gouverneur général. Un pouvoir divisé, se débattant au milieu d'embarras sans cesse accrus. Des mesures d'apaisement qui pouvaient s'interpréter comme des indices sinon d'affaiblissement, du moins de relâchement de l'autorité. Enfin, toute une succession dramatique d'événements : la mutinerie des soldats espagnols ; la retraite de Roda dans la citadelle d'Anvers; l'arrestation des membres du Conseil d'État, et, le 4 novembre, cette Furie d'Anvers que le Comtois Charnpagney essaie vainement de prévenir et d'empêcher : faits tragiques, rapidement enchaînés l'un à l'autre, que les Comtois suivent avec passion ; communications officielles, dépêches du gouverneur et du Parlement, correspondances privées et conversations, brochures enfin : ces plaquettes imprimées en tel nombre aux Pays-Bas et qui se retrouvent abondantes dans les bibliothèques comtoises - ils ont tout pour connaître cette histoire des Flandres à laquelle tant des leurs prennent part. Dans le désarroi des provinces, comment ne le constateraient-ils pas ? une force tous les jours grandit : celle des États généraux. Rien d'étonnant dès lors à ce que les États du Comté - les Neuf du moins, qui les représentaient - se soient résolus à ce voyage d'Espagne que Requesens s'efforçait de prévenir et d'empêcher.

En juin 1576, l'archevêque Claude de la Baume, le baron de Chevreaux et le conseiller Duchamp prenaient, d'un commun accord, leur chemin vers Madrid. Le 12 juillet, ils arrivaient à destination. Vingt-quatre jours durant, ils attendirent audience. C'était l'époque où les soldats espagnols venaient de prendre Alost et couraient la campagne en bandits sanguinaires. Influence d'événements si tragiques ? Désir de ménager l'opinion du Comté ? Toujours est-il que le roi, lorsque le 6 août il admit enfin à l'Escurial les trois délégués des États, les reçut aimable- 
ment, approuva la harangue de Duchamp qui, une demi-heure durant, réclama de sa justice et de sa charité la suppression des ordonnances « avec telle substance, éloquence et action que $S$. $M$. et tous les assistants restèrent satisfaitz et contens »; enfin, déclara dans une réponse conçue en termes généraux "qu'il estoit fort ayse de veoir » les députés, et renvoya le tout aux bons soins d'Hopperus. Le garde des sceaux devenait l'arbitre de la situation. Il fallait le gagner. Les députés y consacrèrent mille écus que le Frison accepta sans difficulté... il n'en était pas à son coup d'essai. - Pourtant, il recula devant une mesure trop radicale ou, peut-être, Philippe refusa-t-il de l'accepter ? Le 24 novembre 1576, ce qu'il remit aux Comtois, c'était non la révocation, mais la suspension provisoire des ordonnances.

Succès modeste, en somme, puisque l'avenir était réservé. Notons, en outre, que Duchamp s'était soigneusement abstenu de parler au roi des revendications politiques et des ambitions de cette ardente noblesse qui, en novembre 1574, réclamait si énergiquement pour les États le droit de participer à l'œuvre législative. Même, si le compte rendu de la collection Chiflet est exact, Duchamp, dans sa vive harangue, s'exprima moins en délégué des États qu'en représentant du Parlement. S'il protesta contre les ordonnances, ce fut parce qu'elles avaient été rédigées et publiées au nom du roi, "à son insceu » et "sans l'advis de ses principaulx ministres en son Conté de Bourgoigne » - termes qui, malaisément, s'appliquaient aux députés des trois États. En somme, son ambassade en Espagne ne faisait guère que doubler la mission de Boisset auprès de Requesens ; et lorsque son confrère, à une objection de Roda, avait répondu, un an auparavant, que son envoi à Madrid, loin de lui nuire, profiterait à l'autorité royale - il avait dit plus vrai qu'il ne croyait peut-être.

Longtemps, les formalités du lent Hopperus retinrent en Espagne les trois députés. Pendant qu'ils y négociaient à la fois leurs affaires propres et celles du Comté - les Neuf ne perdaient pas de temps. Ils semblent bien s'être mis, alors, en relations directes avec les États généraux des Pays-Bas. C'est, du moins, ce qui, à défaut d'autres textes plus objectifs et plus explicites, paraît résulter d'une lettre de Morillon à Granvelle. Le 26 octobre 1576, le prévôt écrivait au cardinal : « J'entendz que les Estatz du Conté de Bourgoingne ont escript pour sçavoir s'ilz donneront passage aux gens de guerre que vouldroient venir par là, et qu'ilz doibvent de brief envoier leurs députez par deçà pour entretenir avec les Estatz-Généraulx ». 
D'autre part, la mission de M. de Potelles en Comté, dans les dernières semaines de 1576, témoigne assez, sinon d'une entente, du moins d'un espoir d'entente entre Flamands et Comtois. Malheureusement, les documents sont extrêmement rares sur les négociations qu'il dut entreprendre en Comté. Quant à ses relations avec les Neuf, nous ignorons tout. Nous savons simplement qu'il se mit en rapport avec le Parlement et lui apporta des lettres des États généraux. Le 13 novembre, la cour décidait qu'on ne lui ferait aultre réponse « que verbale et gracieuse » et qu'on lui déclarerait « que lorsque les Estatz de ce païs seront assemblez par ordonnance de S. M., que l'on leur fera plus ample réponse ». - De fait, les registres constatent qu'à la date du 4 décembre 1576, M. de Potelles fut introduit en chambre du conseil ; on lui apprit simplement qu'on avait averti Sa Majesté des lettres des États de par deçà envoyées à la cour - et que don Juan avait rejoint son poste ; nouvelles qui, sans doute, n'avaient pas de quoi l'intéresser beaucoup.

D'ailleurs, à la même époque - s'il faut toujours en croire Morillon - certains Comtois préconisaient une rupture, une séparation politique et administrative de leurs provinces et des Pays-Bas. Sans doute, l'affaire des nouvelles ordonnances, compilées à Bruxelles au lendemain de la visite de Blasere, en réveillant le vieil esprit d'hostilité des Bourguignons à l'égard des Flamands, avait-elle donné lieu à de tels projets ? Ils n'étaient pas pour déplaire à M. de Vergy ; débarrassé du contrôle et de l'autorité des lieutenants généraux de par-deçà, ne serait-il pas devenu le vrai maître du Comté, sous l'autorité lointaine d'un roi mal informé et d'Espagnols incompétents ? Ces démarches, d'ailleurs, n'eurent pas de succès ; les faits confirment l'indication de Morillon: " J'entendz, écrit-il au cardinal le 22 avril 1577, que les nouvelles ordonnances de Bourgogne sont révocquées et que S. M. ne veult souffrir qu'elle soit séparée de ces pays ». De fait, nous n'avons pas trouvé trace de négociations ultérieures à ce sujet - non plus, d'ailleurs, que de rapports politiques directs entre Flamands et Comtois.

Il n'en reste pas moins que, pendant toute la durée du gouvernement du Conseil d'État, la situation politique était restée, en Comté, incertaine et troublée. Personne pour y remédier, pour s'efforcer de maintenir dans la province le bon ordre et l'ancienne discipline. Granvelle, relevé brutalement depuis peu de son gouvernement de Naples, méditait tristement à Rome sur les vicissitudes de sa fortune et sur l'ingratitude chronique de son maître. Le désordre était partout et 
l'agitation ; le gouvernement de don Juan n'allait pas améliorer une situation aussi trouble et confuse.

\section{III}

Lorsque la cour, le 15 novembre 1576, reçut avis officiel que le frère du roi, le nouveau gouverneur, était arrivé à Luxembourg, elle décida d'envoyer un de ses membres le congratuler. Jacques de Saint-Mauris partit et, se joignant au jeune baron d'Autrey que son père, $M$. de Vergy, dépêchait de son côté au vainqueur de Lépante, il remplit sa mission avec exactitude. Chargé de recommander à don Juan « le bien de la justice », il en obtint l'assurance que la cour de Dole serait maintenue dans ses prérogatives et qu'aucune mesure ne serait prise contre elle sans qu'elle n'ait été d'abord entendue. Jamais promesse ne devait être plus mal tenue.

C'est que rien, ni dans son caractère ni dans son passé, ne prédisposait don Juan à favoriser les gens de robe et les corps de justice - tout au contraire. Granvelle, qui ne l'aimait guère, le peignait tout entier avec clairvoyance lorsqu'il écrivait à Marguerite de Parme : «Le seigneur don Joan est jeusne, et verd, et amy des armes, et désireux d'honneur ; et se vouldra vanger et ruyner tout. » Bouillant et emporté, prompt à tirer l'épée, facile à donner toute licence au soldat - il l'avait prouvé lors du siège de Tunis ; - ambitieux d'ailleurs, et rempli de projets lointains, le vainqueur de Lépante, l'homme qui avait rêvé d'un royaume de Tunis ressuscitant, après des siècles de mort, l'antique splendeur carthaginoise, et qui, acceptant d'aller aux Pays-Bas, espérait y gagner la couronne d'Angleterre - cet homme n'était ni un diplomate ni un politique, mais un soldat amoureux de gloire et passionné d'honneur.

Pour le guider, d'ailleurs - mais pouvait-on le guider ? - pour le retenir, du moins, et l'éclairer, personne. De la Comté, notamment, il était condamné à ne rien savoir. Pas de conseiller bourguignon par deçà. En Espagne, ni Comtois ni Flamands ; Hopperus meurt le 15 décembre 1576, et trois ans s'écoulent avant qu'un successeur, Fonck, ne reprenne sa place. Long intérim, durant lequel agissent des Espagnols « qui ne sçaivent, écrivait Granvelle, non plus de l'estat des 
Pays d'Embas que moy du Royaulme du Sophy ». Aux Pays-Bas même, nulle compétence. Inerte et désabusé depuis longtemps, le vieux Viglius disparait le 8 mai 1577. Blasere ? C'est un personnage de second rang; mais d'ailleurs, il n'a plus de crédit. "Il me pèse jusques aux entrailles, écrit Morillon au début de 1577, que Blasere est en si maulvaise opinion vers le maistre, après y avoir consumé son milleur eaige. » Il faudra le retour de Marguerite pour qu'il reprenne faveur, à l'aide du Cardinal. Richardot, le futur président d'Artois, n'est encore que simple conseiller au grand Conseil ; d'ailleurs, il n'a jamais manié les affaires de son pays, et son attachement à la cause de Matthias le privera, sous don Juan, de toute influence. Restent Champagney et Granvelle lui-même ; mais le premier, si Requesens se serait contenté de l'exiler, don Juan, dans sa haine violente, songe à l'assassiner. Et le second, il le hait pareillement. Ne sait-il pas qu'en toute occasion, le cardinal se déclare auprès du souverain l'ennemi des militaires et de la force armée ? Rien qui dise plus net les sentiments de don Juan pour son prédécesseur que cette lettre passionnée du 2 février 1577, où il dénonce le cardinal au roi comme un fauteur de troubles, l'assimile à Champagney et l'accuse de trahir, en Italie, la cause espagnole. Ce n'était pas de Granvelle, certes, qu'il recevrait jamais des inspirations.

Aussi, point de conseillers. Point de ces robes longues qui, seules, au dire du cardinal, savent négocier « les affaires d'emport ». Don Juan, parfois, semble s'en plaindre. Il se lamente dans ses lettres au roi sur son isolement ; mais, en réalité, ce qu'il déplore, ce n'est pas l'absence d'hommes d'État flamands, capables et laborieux ; c'est, dans sa haine pour tous ceux qui l'entourent, l'éloignement de ces familiers italiens ou espagnols dont il réclame si souvent la venue à son frère. D'ailleurs, même mieux entouré et plus disposé à prendre des avis, don Juan aurait-il pu tirer profit de tels avantages ? Granvelle ne le pensait pas : avec raison. Il est équitable, pour juger l'homme et son gouvernement, de se rappeler dans quel trouble, dans quel désarroi il passe tout son temps aux Pays-Bas. Errant de ville en ville - de Luxembourg à Bastogne, de Bastogne à Marche, de Marche à Huy, de Huy à Marche et à Namur, de Namur à Louvain, de Louvain à Bruxelles, de Bruxelles à Malines, de Malines à Namur, de Namur à Bastogne, de Bastogne à Luxembourg : voilà pour la seule année 1577 ; et les déplacements sont plus fréquents encore, plus hâtifs en 1578 - don Juan mène la vie, non d'un chef de gouvernement, mais d'un chef de bande à demi nomade. 
Tout ainsi semblait favoriser en Comté de furieuses attaques contre le Parlement. Les gens de robe sont tenus à l'écart. Auprès du nouveau gouverneur, ils n'ont ni amis, ni représentants, ni avocats. Du reste, le plus souvent, don Juan n'a pas le temps de faire de l'administration régulière. Pour donner des ordres, dans la hâte fébrile de ses courses, il s'adresse à ceux qui l'entourent, aux hommes d'action qu'il trouve à ses côtés. Peu de lettres : s'il faut en écrire, plutôt qu'au Parlement, c'est à François de Vergy, homme de main et d'épée, qu'il préfère s'adresser. Surtout, il gouverne avec des aides de camp - des jeunes gens qui le suivent à l'armée, l'escortent, commandent des compagnies de lances ou de chevau-légers. Tels, pour ne citer que les Comtois, MM. de Gatey et de Moissey, tous deux fils de l'ancien président Hugues Marmier ; Marc de Rye, d'abbé de Saint-Claude devenu M. de Varambon, ou Gaspard d'Andelot ( $\mathrm{M}$. de Chemilly), le demi-frère de Jean-Baptiste et de l'archevêque Claude de la Baume. Ces cavaliers, naturellement, ont leur crédit : ils s'en servent pour eux d'abord, puis pour leurs parents, leurs amis : les nobles de Bourgogne. Il se forme ainsi autour de don Juan toute une petite cour - une coterie plutôt - que Granvelle, bien souvent, incrimine et dénonce. Quelques gens de robe : un Boutechoux, un Charreton, les aident et les servent ; soutiens d'une même cause : ils sont les clients tout dévoués de Vergy. A eux vont les faveurs et par eux elles s'obtiennent. Car don Juan est généreux ; trop même au gré du roi et de Granvelle : c'est un reproche qu'ils lui adressent souvent, de faire largesse de ce qui n'est point à lui.

\section{IV}

Hommes et événements, tout semblait ainsi conspirer la ruine du Parlement. De fait, dès 1576, c'est un assaut furieux : en tête des assaillants, M. de Vergy. Profitant hardiment des circonstances, le représentant au pouvoir de la noblesse d'épée poursuit sans se lasser son double but : dépossession du Parlement des affaires d'État ; constitution en Comté d'une milice permanente. Dès 1575, Morillon alarmé signale à Granvelle ses visées ambitieuses, et qu'il voudrait mener à sa guise les destinées comtoises. Ne réclame-t-il pas, non sans habileté, la reconstitution de cet ancien conseil des bons personnages qui avait disparu en fait, sans jamais avoir été supprimé ? Démarche astucieuse : elle n'était pas de nature à effa- 
roucher ceux qui, comme Granvelle, ne voyaient le salut que dans un retour au passé ; et, si elle réussissait, quelle victoire pour le gouverneur ? Impossible de le taxer d'ambition, puisqu'il réclamait spontanément qu'on lui adjoigne un conseil. Mais ce conseil, comme il le dispenserait, à l'avenir, de prendre avis du Parlement de Dole ? Deux ou trois seigneurs le composeraient, animés des mêmes passions, des mêmes désirs que Fr. de Vergy ; le président Boutechoux, tout à sa dévotion, y représenterait - y trahirait par sa seule présence - le Parlement. Et celui-ci, doucement, sans violences inutiles et dangereuses, serait chassé bien loin du domaine politique....

A côté du gouverneur, les États - ou plutôt les Neuf, encouragés par le demisuccès du voyage d'Espagne, par la suspension provisoire des ordonnances. Avec obstination ils poussent leur pointe ; l'ignorance de don Juan leur rend la tâche facile - et c'est ainsi que, le 8 mai 1577 la cour réunie apprenait avec émoi que l'un des Neuf, le grand gruyer Philibert de Montmartin, avait adressé une lettre à don Juan, pour réclamer que « doiresenavant, toutes choses d'import soient traictées par les Estatz de ce pais et superintendans en iceulx ». Ce fut une grande colère et tous les conseillers - sauf Duchamp - furent d'avis que l'on devait écrire à Son Altesse au nom du gouverneur et de la cour, lui demander de ne rien décider sans enquête préalable et lui rappeler enfin les précédents, tous défavorables à la demande des Neuf. Le 16 juillet, nouvelles alarmes, nouvelles résolutions, lettres à Granvelle, au président Sasbout, à Richardot et à Champagney. Chose étrange, qu'une requête des États de Franche-Comté fût accueillie avec tant de bienveillance par don Juan, le grand adversaire des États ? C'est qu'elle était présentée, soutenue, appuyée par des nobles d'épée, hostiles au Parlement ; c'est que le Parlement, dans sa résolution du 8 mai, pouvait bien feindre que Vergy s'accordait avec lui pour repousser les prétentions des Neuf : en réalité, c'étaient les mêmes idées, les mêmes rancunes qui guidaient les deux beaux-frères, un François de Vergy, un Philibert de Montmartin. Au premier, qui réclamait les lumières d'un conseil autre que le Parlement, le second proposait celles des Neuf ; Vergy, volontiers, aurait accepté l'offre, et, en attendant, ne perdait pas une occasion de réclamer la convocation des États, dispensateurs du surget, des récompenses et des crédits de guerre. Ainsi faisait bloc toute la noblesse contre l'ennemi commun : le parlementaire.

Noblesse turbulente d'ailleurs, et de jour en jour plus audacieuse. La guerre des Pays-Bas continuait de réveiller son humeur batailleuse. Les jeunes gens, tour 
à tour, partant pour les Flandres avec deux ou trois chevaux - les plus riches à la tête d'une compagnie - revenaient au pays avec les mœurs violentes, les allures brutales du parfait soudard. En Comté d'ailleurs, ils retrouvaient sinon la guerre, du moins son décor. Qu'on dépouille Pour 1575, Pour 1576, les comptes de garnison, de fortification, de confiscation : c'est toute une mobilisation en Comté, provoquée par la surprise de Besançon (21 juin 1575) et par les mouvements de Condé aux frontières. La noblesse est sur pied ; l'argent ne manque pas : Requesens, le Ier août 1575, a donné ordre au receveur général Marchant de fournir à Vergy, sur simple réquisition, tout ce qu'il lui réclamerait de deniers disponibles ; peu après, en octobre, des envoyés spéciaux ont ramené en Comté un mandement de 14000 fr. pour les fortifications de Dole et de Gray. Aussi, toute la province est en armes, l'éminent péril déclaré, les « retrahants »astreints aux corvées de guerre, les bourgeois aux aguets derrière leurs murailles. Dans les villes fortes : Dole, Gray, Besançon ; dans les châteaux tenables : Sainte-Anne, Joux, Arguel, Châtillon-sous-Maîche, les gouverneurs sont à leurs postes et des soldats « d'accrue » renforcent les garnisons ordinaires : six à Arguel, six à Sainte-Anne en 1575, 150 à Dole, 105 à Gray, 270 à Besançon à la même époque. Tout cela coûte, tout cela dépense et réclame sa paie. Et ce sont, en plus, les achats de munitions : salpêtre, plomb, poudre ; les réparations aux murailles, aux ponts-levis, aux bastions : un âge d'or pour les capitaines, les lieutenants, les gardes de l'artillerie et des munitions, les châtelains, les receveurs, contrôleurs et distributeurs de deniers, les entrepreneurs enfin, les maîtres maçons et jusqu'aux chirurgiens empressés à guérir les accidents de travail....

\section{V}

Nouvelles alertes, nouvelles alarmes en 1576. C'est Jean-Casimir qui, s'étant décidé à se joindre à Condé, prend en janvier le même chemin que, jadis, le duc de Deux-Ponts. " Il est venu à trois lieues du Comté où l'on at heu peur, écrit Morillon le 6 février 1576 ; et avait-on député quelcung vers les Suisses pour demander leur adsistance, qu'est bien la plus seure deffense que le pays polroit faire. » Les Suisses, d'ailleurs, n'eurent pas à intervenir ; mais, dès le 6 mai, le roi signait la paix avec les confédérés : Condé, Jean-Casimir, Turenne et François d'Alençon. 
Et dès le 19, Vergy avertissait le Conseil d'État que Casimir, sans doute, repasserait par Langres avec ses Allemands. Qui sait si ceux-ci, excités par les huguenots français, ne feraient pas quelques courses dans le bailliage d'Amont? Nouvel envoi d'un négociateur en Suisse; nouvelles alarmes, savamment entretenues par le gouverneur. On mobilise en Comté ; Vergy assigne à Gray, pour le 18 juin, le ban et l"arrière-ban du bailliage d'Amont, le tient dans la ville pendant deux jours, puis le renvoie. En même temps, avec des arquebusiers à cheval, il surveille les passages de la Savoie - tandis qu'à Dole on renouvelle les édits sur les étudiants étrangers. L'ennemi approche toujours ; de Châtillon-sur-Seine, le 21 juin 1576, François d'Alençon écrit à Vergy pour lui recommander les bannis de Besançon lettres qu'il renouvelle le 8 juillet. Casimir, à son tour, écrit à Vergy, le 11 juillet, de Sombernon. Le 19, il lui recommande ses colonels et capitaines suisses qui vont traverser la Comté pour rentrer chez eux. Le 21, d'Is-sur-Tille, il le remercie d'un envoi de venaison et l'assure de sa bonne volonté. Des ambassadeurs suisses, d'ailleurs, sont venus le trouver ; il leur a promis par écrit de ne pas endommager la Comté, à moins « qu'il ne fust d'ailleurs forcé d'y prendre léger passage ». Restriction peut-être menaçante ? Et Vergy de se livrer à une longue dissertation sur les deux méthodes : la pacifique, donner à l'envahisseur des vivres aux étapes; la militaire, l'empêcher d'entrer : son choix est tout fait. D'ailleurs, il n'est bruit que de surprises, à Gray, à Besançon, par les huguenots français et les bannis....

L'année 1577 fut plus tranquille : à peine Graylois et Dolois connurent-ils quelques alarmes, quelques craintes de coups de main. Mais la Comté reste en armes, les garnisons renforcées, la noblesse en éveil. D'ailleurs, la guerre reprend aux Pays-Bas. Dès le 8 janvier 1577, don Juan, faisant le compte des troupes qui lui seraient nécessaires pour une offensive sérieuse, prévoyait la levée d'un régiment de 3000 fantassins bourguignons et wallons : bonnes troupes, écrivait-il au roi. De fait, le 15, il demandait au baron de Chevreaux de lui lever 2000 Comtois. C'était de quoi satisfaire et apaiser déjà bien des désirs d'activité. Or, l'année suivante, au début de 1578, ce sont de nouvelles levées - de chevau-légers cette fois. Dès la fin de mars, les cavaliers vont par le pays, vivant sur le bonhomme, faisant de petites étapes d'une demi-lieue par jour, pressurant le paysan et le violentant. Le 27 mars, le 7 avril, le 17, le Parlement se plaint, proteste, menace de recourir à Son Altesse, dépeint en termes émouvants la misère du peuple. Rien n'y fait. Quelques compagnies partent assez rapidement ; mais d'autres s'attardent et, dans 
les villages, commettent les pires excès. Insolents et brutaux, les petits nobles enrôlés pour partir en Flandre se font héberger plantureusement par les communautés, commandent en maîtres dans les auberges, donnent du froment pur à leur chevaux ou du vin avec de l'avoine - puis, quand les pauvres paysans lassés font mine de se plaindre, arrivent « boutez, esperonnez et montez sur leurs chevaulx », assurent leur lance ou tirent leur épée, injurient, battent, blessent, écrasent les manants....

En mai, ils partent enfin : Granvelle s'en félicite dans ses lettres à Vergy. Mais des bruits d'invasion se répandent aussitôt. Casimir lève des troupes en Allemagne ; Alençon, fuyant de nouveau la cour, se trouve à Landrecies avec ses partisans. Entrevues à Dole entre gouverneur, Parlement et bons personnages; ordre aux gens du plat pays d'avoir à retirer aux villes leurs meubles les plus précieux et de convoyer leurs grains dans les enceintes; mobilisation des élus franc-comtois tandis qu'un grand seigneur, M. de Varambon, lève par les Pays-Bas un nouveau régiment. Et quels excès! De nombreuses enquêtes nous montrent à l'oeuvre les élus. Sitôt revêtus d'un morion, affublés d'un buffle et ornés d'une pique, ces paysans comtois devenaient « pires que des diables » et tournaient leur fureur sur leurs compatriotes. Parfois, ce sont de vraies batailles rangées dans les villages, des fuites éperdues de manants pillés et rossés courant chercher, au plus prochain bailliage, les officiers royaux. Il faut lire, dans les registres du Parlement, les chefs d'accusation relevés, en 1580, contre un Claude de Saint-Mauris, écuyer, « capitaine d'une enseigne et compagnie de trois cents hommes de pied et d'environ 25 chevaulx soubz messire Jehan de Baufremont, chevalier, sr de Clerevaulx, bailly d'Aval, coronel au bailliage de Dole de 10 enseignes et 200 chevaulx ». Chargé en juillet, août, septembre et novembre 1578 de passer en montre et revue les élus d'au moins cinquante villages de la montagne, aux quartiers d'Ornans et de Vuillafans - au lieu de 300 hommes, il en levait 900, « pour puis après en tirer argent et proffit » en congédiant, contre clairs deniers sonnants, les 600 paysans enrôlés indûment. Aux communautés, pour ce beau travail, il réclamait des frais de séjour exorbitants, des indemnités en argent ou même en nature ; puis c'étaient encore des amendes arbitraires infligées aux élus, des sommes extorquées pour les dispenser de fournir, tel un corcelet, tel une arquebuse ou un cheval, - parfois même, pour les «trasser» des rôles. Et Claude de Saint-Mauris n'était pas le seul ; son porte-enseigne, Simon d'Anvers, de Vuillafans ; son sergent de bande et 
caporal Pierre Darc, son caporal Vernerey, l'assistaient de leur mieux ; pareillement s'enrichissaient par pareils moyens son frère Henri, sr de Certémery, « capitaine de l'enseigne et compagnie des esleuz et gens de pied levez au siège et ressort d'Arbois »; Marc Cussemenet, sr de Dornon, son porte-enseigne ; l'écuyer Jean de Montrond ; Claude de Groson, sr de Chevigney, capitaine des 300 piétons et des 25 chevaux de Vercel, Vennes, Chatelneuf-en-Vennes, Réaumont et Naisey ; son lieutenant Jean de Foucherans ; son porte-enseigne Christophe Malarmey ; le fourrier Literet d'Aiglepierre ; Claude Laille, secrétaire du prévôt des maréchaux - tout un peuple. La malheureuse Comté souffrait mille maux et n'en apercevait pas la fin, car Vergy était infatigable à semer les alarmes, à donner ordre aux capitaines de faire bonne garde, à signaler des tentatives dangereuses sur Besançon, cette « grande villasse », sur Lons, sur Sainte-Anne, sur Dole. La moindre picorée de cavaliers bourguignons mettait en émoi toutes les places frontières : vite on vérifiait les murs, on visitait les chemins de ronde, on réparait les brèches, on envoyait chercher du salpêtre à Moirans.... Et les soldats oisifs, s'éternisant au pays, « le mangeaient jusqu'à l'os ».

Le résultat ? Tous ceux qui observent et connaissent la Comté le signalent à l'envi - et tous dans les mêmes termes : c'est une recrudescence de violence militaire, un retour agressif de féodalité turbulente et dangereuse. Le vieil Hopperus, quelques jours avant sa mort, s'en effrayait ; il se plaignait que la noblesse comtoise se « débordât » contre la justice, « dont passé douze ans est encommenché le mal des Pays-Bas », - et il proclamait énergiquement la nécessité que la cour de Dole « soit absolument gardée en son autorité ancienne ». Même note chez Granvelle : dans toutes ses lettres à Bellefontaine, à Marguerite, à Philippe, il reprend et développe la formule énergique que, dix ans auparavant, il envoyait déjà à Viglius : sans le Parlement, de par la noblesse - cette misérable et insolente noblesse bourguignonne, comme il dit quelque part, - tout le pays comtois ne serait qu'une « brigandaille ». Même note, enfin, chez d'Assonleville lui-même : continuer le vieux chemin, donner crédit aux militaires, rabaisser la cour en toute occasion, « c'est évidemment perdre le tout et y planter (je ne dis en peu d'années, mais devant peu de mois, et, par aventure, de semaines) une rébellion et désobéissance aussi manifeste et dangereuse que en ces Païs-Bas - et les fondements en sont jà jectez ». La cause ? Il la dénonçait sans équivoque : « Si est une bonne partie de la noblesse tant endebtée et accoustumée aux armes et à force, comme sont aussi 
plusieurs roturiers. » C'étaient les fruits de la guerre - un retour offensif de l'esprit féodal.

\section{VI}

Ce qui rendait plus grave encore la situation, c'est que le Parlement se montrait incapable de défense sérieuse. Granvelle y revient souvent : Je l'aiderai fort volontiers, écrit-il un jour à Bellefontaine, «s'il s'aide.... » Condition bien difficile à remplir pour une cour divisée en coteries rivales et dépourvue d'ailleurs de caractères. Le président Boutechoux était un honnête homme, mais faible, et dévoué corps et âme à Fr. de Vergy. Sous ce chef débonnaire - que l'exemple de Pierre Froissard ne devait pas pousser à déployer une énergie trop grande, les conseillers tiraient chacun de leur côté. Beaucoup, surtout parmi les derniers nommés, dépendaient de Vergy, étroitement : tels, le conseiller Huot, un Graylois « de médiocre sçavoir », et les deux fiscaux : Oudot Pierre, un Graylois également, nommé par le crédit du gouverneur - et Grivelet, gendre de son secrétaire Otenin. Le Clerc et Chappuis, les deux suspendus, réintégrés, l'un en novembre 1576, l'autre en novembre 1577, à peine remis d'alarmes aussi chaudes, ne songeaient plus maintenant qu'à couler en paix le restant de leurs jours. Les vieux : Belin, en passe de devenir sourd ; Boisset, consciencieux mais terne magistrat ; Chaillot, enfin, manquaient d'énergie ou d'autorité, tandis que Duchamp et Jacques de Saint-Mauris continuaient d'exercer leurs « partialitez », odieuses au cardinal.

Aussi, point d'action commune, point de résistance énergique aux empiétements, aux atteintes quotidiennes, quelles qu'elles fussent. En novembre 1576, le Conseil d'État crée sans nomination le lieutenant Cécile conseiller à la cour. En cas pareil, au temps de Marguerite d'Autriche, on avait vu les conseillers refuser d'installer, malgré les ordres et menaces, un procureur général créé sans leur participation - et finalement triompher de leur souveraine. Plus tard encore, quand Boisset, en 1566, avait été envoyé à Dole en surnombre, ses futurs confrères avaient refusé de l'admettre d'abord et n'avaient cédé qu'à de longues démarches. Cette fois, on ajourna seulement Pierre Cécile - et quelle confusion, quelle timidité dans la discussion. Tous les opinants n'ont qu'un souci : savoir ce que pensera 
M. de Vergy : il ne faut point mécontenter un homme si puissant, et qui déjà ne les aime guère. Pareillement, il ne faut pas irriter le Conseil d'État qui a nommé Cécile ; ni Philippe II qui a donné plein pouvoir au Conseil d'État, ni personne de puissant ou d'influent. - Même attitude vis-à-vis des nobles turbulents, des seigneurs indisciplinés et méprisants qui s'agitent en Comté et menacent la cour. Un Wateville, violent entre les violents, injurie, en 1577, Granvelle à la fois et le Parlement : ce dernier ne s'émeut pas. Quand Jacques de Saint-Mauris, le 8 mai 1577, dénonce formellement ses "propoz insolens », les conseillers esquissent un geste d'énergie, donnent l'ordre d'informer au procureur. Mais lassés sans doute d'un tel effort, ils s'abstiennent de poursuivre. Rien d'étonnant, dès lors, écrit le cardinal, que leur autorité « voise par terre » - et il ajoute, avec une pointe de dépit : « Ilz se sont bien montrez plus chaudz contre les ordonnances »...

Par moment, cependant, il semble qu'un peu de vigueur rentre en eux. Poussés à bout, en 1578, à la fin de l'année, ils se décident à envoyer un des leurs aux Pays-Bas, près de don Juan. Mais, d'abord, leur choix n'est pas heureux. Une fois encore, ils désignent Boisset - Boisset, «orator parum vehemens, homme de bien et de bon zèele, mais peu civil et peu duyt à telles choses ». Le vieux conseiller se prépare cependant. En septembre, il est prêt. Mais avant de partir, il tient, comme à son voyage précédent, à passer par Gray et à voir Vergy. Il s'achemine vers la ville, et d'abord va trouver le président Boutechoux et ses confrères Huot et Oudot Pierre : on était en vacances. Prié de l'accompagner chez le gouverneur - le président Boutechoux refuse, sous un mauvais prétexte: véritable trahison envers le Parlement. Accompagné de Huot et de Pierre, Boisset va cependant au logis du gouverneur, lui présente ses instructions et le prie de bien vouloir « escripre deux motz de lettres à S. A. pour plus facilement obtenir l'effect du contenu ». Refus de Vergy : les instructions de Boisset, «il ne les vouloit veoir, pour de longtemps avoir entendu ce qu'elles contenoient ». Le conseiller insiste, allègue « que S. A. ne prendroit de bonne part le peu d'intelligence que par ce elle recognoistroit estre entre luy et lad. cour ». - Le gouverneur alors lui exhibe une lettre de don Juan, « contenant en effect et substance que S. A. estoit advertie du peu de respect que lad. court ou les conseillers d'icelle pourtoient aud. sr Conte, qu'elle entendoit y donner ordre de sorte que led. sr gouverneur en prendroit contentement ». La révélation de ces mépris, témoignés par la cour au gouverneur, avait de quoi étonner et confondre Boisset. Elle plongea la cour « en très grand esbéhissement », - et 
séance tenante le conseiller Cécile fut député auprès de Vergy - pour protester contre son attitude ? Nullement - mais pour lui faire entendre « la vraye et sincère bonne affection » que lui portait la cour. C'était le Parlement qui s'excusait et demandait pardon d'être maltraité : il méritait pleinement sa déchéance.

Les circonstances pourtant allaient apporter d'elles-mêmes quelque remède à la misérable situation de la cour. Lorsque Boisset arriva aux Pays-Bas, il n'y trouva plus don Juan, mais le prince de Parme. Changement notable pour la Comté comme pour les Pays-Bas - et ce n'était pas seulement le changement d'une personne. Sans doute, le politique qu'était Alexandre Farnèse - l'homme jeune encore, mais calme, réfléchi, pondéré, excellent général, meilleur diplomate, qui allait faire sortir les Pays-Bas d'une situation plus que désespérée - cet homme n'avait avec don Juan que bien peu de traits communs. Mais ce qui importait surtout aux affaires comtoises, c'est que l'avènement au pouvoir du fils de Marguerite allait rendre à Granvelle une influence prépondérante. 
PHILIPPE II ET LA FRANCHE-COMTÉ

Étude d'histoire politique, religieuse et sociale.

Quatrième partie. Le progrès de l’absolutisme.

\section{Chapitre XXIV}

\section{La rentrée de Granvelle}

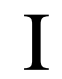

$\underline{\text { Retour à la table des matières }}$

Que pensaient réciproquement, de leurs personnes et de leurs idées, don Juan et Granvelle - nous l'avons vu. En fait, tant que le frère du roi fut au pouvoir, le cardinal s'appliqua à critiquer son attitude et ses résolutions. Critiques générales, en ce qui concernait les Pays-Bas ; elles eurent tant de poids sur l'esprit de Philippe II, qu'un instant celui-ci, en octobre 1577, demanda à Granvelle de reprendre avec Marguerite de Parme le chemin de Bruxelles. Mais critiques particulières aussi, en ce qui concernait la Comté ; critiques monotones, du reste, toujours les mêmes : pas de « nouvelletez »; l'idéal est de « suivre l'ancien pied », d'appliquer strictement les principes politiques de Charles-Quint, de tenir balance égale entre les pouvoirs rivaux du gouverneur et du Parlement, de ne recourir aux États qu'avec précaution, à longs intervalles, et dans le ferme dessein de ne leur demander que des contributions.

Pas de gendarmes en Comté, d'autre part. Contre les « corne-guerre », contre tous ceux qui exploitent - tels, Vergy et ses amis - les mouvements des troupes protestantes pour maintenir en armes des garnisons nombreuses, dépenser les deniers de la province en soldes, en murailles, en canons, le cardinal, dans ses lettres 
privées, n'a pas assez de malédictions. De toute son influence, il cherche à peser sur ces brouillons, à les contrarier dans leur jeu, vainement d'ailleurs. Son crédit près du roi reste trop incertain; près de don Juan, il est nul. Chez le maître, ce sont des oscillations continuelles, de perpétuels revirements de faveur et de discrédit. Si, le 7 septembre 1577, l'ancien vice-roi de Naples, brusquement privé jadis de son gouvernement, obtient du souverain cette belle pension de $4000 \mathrm{du}-$ cats, qui réjouit tellement son ami Morillon; si, à la même époque, ses vues conciliatrices semblent triompher à Madrid, en novembre don Juan et le parti de la violence militaire l'emportent ; la guerre recommence et Granvelle, sans doute, ne cesse pas ses critiques, ni auprès du roi, ni surtout de Marguerite; mais, sur le gouvernement des Pays-Bas, il n'a point de prise ni d'autorité. D'ailleurs, l'attitude de son frère Champagney n'était pas faite pour faciliter sa tâche en Comté.

Le 12 novembre 1577, on avait lu à Dole, à la séance de rentrée du Parlement, des lettres de don Juan ordonnant saisie des biens meubles et immeubles appartenant « aux srs d'Aurech, Champagney, Vers, Myon, et de tous autres qui sont au service des États des Pays-Bas ». Ces lettres furent commentées très vivement en Comté, et beaucoup, cherchant à lier les causes de Granvelle et de son frère, voulurent voir, dans la rébellion de l'un, motif de disgrâce pour l'autre. Le cardinal déclara ne pas plus se soucier «de ces disées de Bourgoingne » que «d'une prune »; en réalité, l'affaire lui tint plus à coeur qu'il ne le voulut dire. Pendant toute l'année 1577, pendant tout le début de 1578, il se trouva réduit au rôle ingrat de censeur, de critique pessimiste, d'annonciateur de calamités, voyant le mal, connaissant le remède, mais sans pouvoir aucun pour l'appliquer.

Peu à peu cependant, il reprit le dessus. A les lire, on sent dans ses lettres, non plus de fermeté, mais plus de confiance dans l'avenir. C'est qu'en mars 1578, Escovedo a été assassiné par les soins d'Antonio Perez; qu'un découragement profond s'empare de don Juan ; que le roi, s'abstenant systématiquement de répondre aux questions, aux dépêches de son frère, semble prendre à tâche de le désespérer. Disgrâce lente, mais qui s'annonce certaine. Aussi, dans ses lettres, Granvelle pousse sa pointe, parle plus librement et plus longuement. On n'a pas voulu le croire. On n'a pas voulu, en temps utile, suivre ses avis. Le roi peut voir maintenant les résultats de la politique de violence et de guerre. Et, sans doute, tout va bien encore pour les amis, les familiers de don Juan, les militaires et les « corneguerre » ; mais, dès juillet, le cardinal est assez sûr de lui pour écrire à Bellefon- 
taine ces mots significatifs : "Ceulx qui s'aident du temps et en reçoipvent les mercédes et faveurs sunt filii hujus seculi. Bien pour eulx s'il dure; mais je me doubte que le temps ne sera pas tousjours tel; et ce n'est pas tout d'avoir crédit : le poinct est de le sçavoir maintenir. »

Bientôt d'ailleurs - nouvelle circonstance favorable pour Granvelle - un successeur était donné à Hopperus, dans la personne du prévôt Fonck. Dès le milieu de 1578, la nomination est décidée en principe ; et Granvelle aussitôt d'entrer en correspondance active avec le prévôt, de lui prodiguer à la fois les témoignages d'une amitié sans réserve et les conseils d'une expérience consommée. Comme Fonck, en juin, est envoyé à Besançon pour procéder à une enquête sur les relations réciproques du chapitre et du magistrat, Granvelle lui adresse de longues lettres, lui expose tout au long ses idées sur les choses et les gens de son pays natal, le prie de s'en informer diligemment. C'est un dessein évident, un propos délibéré de séduire le successeur d'Hopperus, de se l'attacher par des paroles flatteuses, d'en faire un ami personnel et le soutien docile d'une politique. Ainsi le cardinal prenait patience en préparant l'avenir.

La mort de don Juan, le 2 octobre 1578, ne le prit donc pas au dépourvu. Invité par le roi et par Marguerite à tenir correspondance avec son successeur, Granvelle le fit aussitôt et sans se faire prier. Dès le Ier décembre, il adressait à Farnèse une lettre courte, mais pleine, sur la situation et la conduite à tenir vis-à-vis des provinces. Lettre remplie de vues ingénieuses que son destinataire allait faire siennes ; elle marque le début d'une correspondance régulière qui, d'abord consacrée aux seuls événements des Pays-Bas, bientôt se remplit de conseils et d'indications sur les affaires comtoises.

Dès janvier 1579, Granvelle commence l'attaque. Il s'élève avec vivacité contre les gens de guerre, le séjour dans la province de compagnies qui y mangent leur solde sans utilité, surtout, les prétentions d'une noblesse acharnée à réclamer la convocation lucrative des États. Fonck de son côté, stylé par le cardinal, se déclare ému de l'attitude de Vergy, du sans-gêne dont il use vis-à-vis de la cour, de son empressement à répondre aux dépêches en son nom personnel, sans jamais s'entendre avec le Parlement. Il s'en plaint à Farnèse qui, dans une lettre du 10 janvier, prenant à son compte les griefs de Fonck, invite Vergy à communiquer dorénavant avec les conseillers pour toutes les affaires politiques importantes. Il y avait longtemps que pareil ordre n'était parvenu à Autrey. 
Seulement, ce n'étaient que débuts, ce n'étaient que promesses. D'Assonleville, dans une curieuse lettre à Granvelle, notait, dès le 23 novembre, qu'en dépit de ses excellentes dispositions, et bien qu'il eût « les bonnes pars que l'on peult désirer d'ung tel seigneur », Farnèse avait trop à faire à l'armée, trop à entendre « aux affaires de l'exercice » pour vaquer tout entier "à ce qui est de la paix ». Et il s'accordait avec le cardinal pour désirer auprès du prince sa mère Marguerite dont l'expérience des affaires intérieures et des hommes politiques du pays ferait merveille. De fait, la guerre absorbait trop Farnèse, les militaires gardaient trop d'influence encore, trop de part à la conduite des événements pour que les vieux errements pussent être sur l'heure abandonnés, les hommes d'épée remis en bonne place, la robe restituée en son honneur ancien.

En Comté même, les événements contrariaient l'effort pacificateur du cardinal. Le 12 septembre 1578 - don Juan vivait encore -, un parti de Français, commandé par Claude de la Chambre, seigneur de Montfort, et le sr de Savigny, son frère, était entré hostilement en Comté, du côté de Courlaoux. Sans perdre de temps, les envahisseurs, surprenant « le bourg Saint-Aignes et le chatel de Saint-Laurent et depuis celui de Présilli, celui de l'Estoille, la Tour de Montfleur », pillaient Arlay et le plat pays, «leur aiant donné les clefz de leur ville ceulx de Saint-Amour, et s'estant défendu contre eulx les villes d'Orgelet et de Lyon-le-Saulnier ». Ce fut un bel émoi dans la province, une mobilisation tumultueuse et redoutable sinon pour l'ennemi, du moins pour les paysans. Il faut lire, dans le gros cahier que conserve la Bibliothèque nationale, les dépositions des échevins des villages et des villes envahis : c'est une impression de désarroi total, de trouble et de violence sans répit. A Lons, au début de septembre, sur ordre de Vergy, on fait d'abord entrer une première compagnie : la compagnie Charreton, 200 hommes de pied, Comtois et Suisses mêlés. L'invasion faite, les Français rôdant par la campagne, incendiant les fermes, pillant les greniers, nouveau renfort. D'abord, la compagnie du sr de Villette, conduite par le maître d'hôtel du marquis de Varambon ; le lendemain, la compagnie du sieur de Tremblay, 120 hommes environ; plus tard, la compagnie Bradefert, la compagnie de Saint-Mauris et ses 100 chevaux ; la compagnie Raincourt, 100 chevaux également; les compagnies de Balançon et de Belchemin ; le rière-ban du bailliage, sous M. d'Oiselay ; d'autres encore : cohue sans nom de militaires aguerris ou improvisés, mais tous aussi hardis à picorer, à brûler les villages, à voler poules, brebis, draps, meubles et deniers - au besoin 
même, à « couper la garguiotte » des pauvres diables qui osaient protester. Du reste, «gens assez mal façonnez pour la guerre par leur yvrognerie et pauvre conduite » ; ils le montrèrent surabondamment. Comme une centaine de Français s'étaient jetés dans le château de l'Étoile, deux capitaines comtois, MM. de Maillot et de Tremblay, réunissant leurs forces, vinrent les assiéger. Dans ce pays vignoble, les caves étaient bien garnies. Plus attentifs a les épuiser qu'à surveiller l'ennemi, les Comtois se firent battre honteusement. Mésaventure dont Granvelle n'attendit pas longtemps pour tirer la conséquence ; ne montrait-elle pas que les Comtois n'étaient pas nés pour guerroyer de leur chef « et que le plus sheur est de s'appuyer aux dits des Ligues »; n'étaient-ce pas ceux-ci, en effet, qui avaient dissuadé Alençon d'entrer à son tour dans la province et délivré le pays de ses envahisseurs, - de ceux, du moins, qui y venaient en ennemis ; car longtemps les villages du nord durent défrayer les reîtres d'Annibal d'Altaemps établis dans la terre de Luxeuil sous le prétexte de la protéger.

\section{II}

Ainsi, bien que Farnèse, par une mesure applaudie de Granvelle, eût rappelé en Flandre, au mois de janvier 1579, les cavaliers bourguignons qui infestaient le pays, - de beaux jours encore luisaient pour les gendarmes dans le gouvernement de François de Vergy. Ils n'y rencontraient point la gloire - mais, du moins, le profit. Et les efforts de Granvelle pour faire réduire leur rôle demeuraient infructueux. Pareillement, le cardinal devait être impuissant à empêcher, en mars 1579, la convocation des États du pays, et même à obtenir qu'elle fût faite sur lettres signées du roi, dans les formes usitées jadis par Charles-Quint.

États bien paisibles, d'ailleurs, et bien modestes, si on les compare à ceux de 1574. Au lendemain de l'invasion française, leur objet, strictement défini, était, comme le déclara le conseiller au Conseil privé Hugues Boutechoux, de «communiquer, conférer, discourir et aviser par ensemble les moyens plus duysants par lesquels soit promptement pourvu à la tuition, deffense et seureté dud. pays ». Aucun don gratuit ne fut voté. Tout au contraire, les États demandèrent avec insistance le remboursement des sommes énormes dépensées lors des passages ou des 
séjours de troupes en Comté ; ils s'émurent des abus grandissants des gendarmes, nommèrent pour les poursuivre une commission de neuf membres, s'élevèrent contre l'exportation des deniers provenant des confiscations, demandèrent enfin la conduite de négociations sérieuses pour «l'ampliation » et éclaircissement de la Ligue héréditaire. Et sans doute, il y eut dans les délibérations, on trouve dans le recès, quelques allusions au passé récent de 1574 ; sans doute, les États entendirent avec satisfaction le sr de Saint-Ylie déposant sur le bureau de chaque chambre, au nom de la commission des Neuf et des deux délégations d'Espagne et de Flandre, "les instructions, pièces et mémoires concernant leur négociation »; sans doute encore, alléguant l'incommodité du recueil en usage des ordonnances, les trois ordres constituèrent une commission de neuf membres chargée de compiler un recueil mieux disposé « et aussy de dresser articles à l'effect de l'abréviation de justice et l'instruction des procès et vuydange d'iceux »; reprise déguisée et timide des prétentions législatives de 1574. Mais ce qui frappe surtout, lorsqu'on lit le recès, ce qui importe vraiment dans la session, c'est l'opposition, la distinction très nette de la classe bourgeoise et des deux classes privilégiées; c'est le vieil antagonisme, masqué en 1574 par une coalition temporaire et disparate, mais reparaissant, en 1579, dans toute sa netteté : antagonisme d'intérêts et de conceptions.

Si noblesse et clergé, trouvant profitables les longs voyages en Espagne ou en Flandre, réclament à nouveau l'envoi d'une délégation au gouverneur et au roi, chargée de leur porter les doléances des États, d'insister même pour la révocation des ordonnances simplement suspendues - Messieurs des villes protestent, refusent leur consentement " pour éviter frais ». Si pareillement les deux ordres privilégiés, d'accord avec M. de Vergy, toujours à l'affût de ce qui peut diminuer le Parlement, demandent que, pour négocier en Suisse «l'éclaircissement» de la Ligue héréditaire, trois commis des États soient adjoints aux personnages que le roi chargera de cette lourde mission -Messieurs des villes protestent à nouveau et refusent leur participation " pour éviter frais ». Encore, si les deux ordres privilégiés, reprenant une fois de plus leurs vieux griefs, émettent le voeu que soient supprimées les calandres humiliantes qui courbaient la tête des puissants devant la majesté des robins - le vieil esprit parlementaire, le vieil esprit bourgeois se réveille : Messieurs des villes refusent de s'associer à ce voeu. Enfin sur un dernier point - et capital - le désaccord s'affirme entre nobles et bourgeois, soutenus cette 
fois par le clergé. Les deux ordres, en effet, se retrouvent pleinement d'accord pour repousser ces projets de milice formulés par Vergy avec une audace, une énergie croissante: projets ruineux, dangereux pour l'ordre public, inefficaces surtout : les précédents récents ne le montraient-ils pas ?

Qu'importe, dès lors, que les États aient reconstitué, aux gages de 50 fr., une commission des Neuf chargée de dresser les instructions et de maintenir la correspondance avec les trois commis désignés, malgré l'opposition des villes, pour aller au nom des États en Flandre et en Espagne ? L'accord était bien rompu, qui avait fait toute l'importance, toute la force des États de 1574 ; et il est frappant de constater l'élimination presque complète cette fois, l'abstention presque totale de ces parlementaires qui, à la session précédente, avaient joué un tel rôle, mené un tel fracas. C'est un plein divorce de l'épée et de la robe ; parlementaires et gentilshommes dans leur chambre s'opposent et se contredisent, tandis qu'à la porte des États, dans la rue, leurs pages et leurs clercs se provoquent, s'injurient et en viennent aux mains.

Du reste, les Neuf, cette fois, n'eurent point d'action. Ils se réunirent, tinrent des assemblées; en septembre 1580, dans une lettre à Marguerite de Parme, Granvelle s'en indigne même et réclame sinon des poursuites, du moins une information contre cette nouvelleté ». Mais, en même temps, il note leur impuissance et les rivalités, les discordes qui les partagent. Quant à l'ambassade en Espagne, elle n'eut pas lieu. Farnèse y mit ordre, approuvé d'ailleurs énergiquement par le roi. Les trois commis : l'abbé de Saint-Claude, Joachim de Rye; le grand gruyer Philibert de Montmartin et le docteur Perrot durent se contenter d'un voyage en Flandre ; ils soumirent leurs doléances au gouverneur, qui longtemps après en signa les apostilles à Mons, le 8 mars 1581; obtinrent la nomination d'une commission mixte de Flamands et de Comtois pour enquêter sur les abus des munitionnaires et, sur demande spéciale du clergé et de la bourgeoisie, l'assurance qu'aucune milice permanente ne serait dressée en Comté : maigre résultat pour la noblesse, comme on voit - et même pour les États ; il ne valait certes pas les 22 000 fr. que coûta au pays épuisé le voyage des trois délégués. 


\section{III}

Au reste, à la même époque, le Parlement n'était guère plus favorisé du pouvoir royal. En 1579, en 1580, sous Farnèse, il se voit presque aussi méprisé et vexé qu'en 1577 et en 1578 sous don juan. Non par la volonté expresse du gouverneur, sans doute, ni par un dessein systématique d'abaisser la robe pour exalter l'épée : Farnèse reste en bonne correspondance avec Granvelle, reçoit de lui des avis fréquents, en tient compte ; le cardinal, de jour en jour, jouit d'une plus grande autorité ; le 30 mars 1579, une lettre pressante et cordiale du roi l'a mandé de Rome à la cour d'Espagne : réparation tardive, mais éclatante, de disgrâces répétées. Il est parti en mai, bien décidé sans doute à ne pas « s'envelopper » dans les « partialitez » et les haines de Bourgogne - plus décidé encore à employer son crédit reconquis pour le plus grand bien de son pays natal. Sitôt en route, il a écrit à Philippe II pour qu'il hâte la venue en Espagne de Fonck. Surtout, il a repris, accentué sa campagne pour qu'un partage d'autorité fût établi entre Farnèse et Marguerite - le fils prenant charge des affaires militaires et diplomatiques, la mère, de l'administration et du gouvernement intérieur. Le 16 mars 1580, en effet, Marguerite se mettait en route pour les Flandres. Elle traversait la Comté, y séjournait longuement, inspectait le pays et recueillait sur sa situation les avis des hommes compétents. Une active correspondance la tenait en communication avec le cardinal, et, sur les points importants, leurs vues étaient semblables - mais, malgré tant de circonstances favorables, la cour se débat misérablement au milieu d'affronts, de menaces répétées.

En mai 1579, première affaire. Un lieutenant de bailliage, celui de Montmorot, chargé d'enquêter sur les abus d'un capitaine, Guillaume Charreton, qui gouvernait le château de Saint-Laurent-de-la-Roche, se voit outrager gravement par lui. La cour s'émeut, et, le 29 mai 1579, décerne mandement contre le délinquant, qui est enfermé dans les prisons de Dole. Mais, aux Pays-Bas, il a des protecteurs - et d'abord, le trésorier de l'Épargne et des Confiscations Benoît Charreton. Aussi, le 19 juin, ordre de Farnèse de relâcher le prisonnier et de laisser là son affaire, évoquée d'office aux Pays-Bas. Grave atteinte aux droits des conseillers : n'étaitce pas un recommencement de l'affaire Demongenet, jadis, sous le duc d'Albe? 
En novembre, nouvelle alarme, nouvelle atteinte. Un ordre arrive, d'avoir à installer comme conseiller surnuméraire François Grandjean, fils de l'ancien conseiller au Conseil privé. Stupeur, indignation des parlementaires : non seulement leur droit de nomination est violé ainsi par le gouverneur ; mais François Grandjean se trouve être plus qu'un médiocre : un incapable. Certes, il y eut de belles clameurs et l'amour-propre du surnuméraire fut soumis à dure épreuve. Le procureur général et les conseillers Grivelet et Galyot, « s'estans levez », déclarèrent qu'une enquête sommaire «sur les suffisance et expérience dud. sr Grantjan et les moyens qu'il avoit tenus pour obtenir led. estat de conseiller supernuméraire » leur avait démontré jusqu'à l'évidence « que led. Sr Grantjan n'avoit en luy les qualitez requises pour la desserte dud. estat, n'ayant jamais fait acte pour faire paraistre de sa suffisance »; d'ailleurs, « qu'il constoit par ung bruict commung qu'il avoit acheté led. estat de conseiller et en avoit payé notable somme de deniers à aucungs estans après la personne de S. E. ». Pareillement, le vieux Belin, malade, mais visité par un clerc du greffe, opina catégoriquement que François Grandjean n'avait « ny le sçavoir et jurisprudence, ny l'expérience nécessaire au personnaige qui veult estre conseiller en lad. court »; interrogé non sur les difficultés du droit, mais « sur choses bien vulgaires », il resterait coi. Vaines doléances. La cour n'eut pas le courage de repousser nettement le surnuméraire. On le reçut sans gages, en lui donnant rang au-dessous des fiscaux. Il est vrai que, quelque temps après, le conseiller Huot étant mort et Grandjean demandant à prendre sa place, les parlementaires refusèrent d'accéder à sa demande et procédèrent à nomination de trois candidats pour remplacer le défunt. Protestations platoniques : Grandjean fut nommé par Farnèse et, le 3 novembre 1580, installé à son rang par le président.

Granvelle s'était élevé énergiquement contre une nomination aussi scandaleuse ; mais le discrédit de la cour semblait aussi fort qu'au temps de don Juan. La Chambre des Comptes se moquait de son autorité. Vergy ni Farnèse ne la consultaient plus sur les affaires d'État. Et toujours de Flandre venaient de nouvelles atteintes à son prestige. C'était, en janvier 1580, un certain docteur Landry, qui obtenait des lettres de faveur pour éviter une calange de procureur et échapper à un emprisonnement. C'était, en novembre de la même année, toute une série de surséances à des arrêts motivés de la cour. C'était, quelques semaines après, une nouvelle nomination arbitraire, moins scandaleuse au fond, mais tout aussi préju- 
diciable dans la forme que celle de Grandjean : Philippe Merceret, jadis lieutenant suspect de partialité au siège de Salins, était adjoint d'office au Parlement. D'où venaient tous ces coups, et pourquoi Granvelle, malgré ses efforts, ne parvenait-il pas à les détourner ?

C'est d'abord que, sur Farnèse, la petite cour comtoise de don Juan avait conservé toute son influence. Elle l'entourait, le circonvenait habilement, lui faisait contresigner sous des prétextes ingénieux les mesures les plus contestables. Le désordre qui régnait aux Pays-Bas, le trouble des bureaux où tout s'égarait; le désarroi général d'une administration profondément bouleversée facilitait singulièrement la tâche d'intrigants subtils et dénués de scrupules. Granvelle, à diverses reprises, dénonce leurs agissements, soit à Marguerite, soit à son fils même : mais ils restaient sur place et ne lâchaient point prise.

D'autre part, le cardinal, outre qu'il n'était en rien chargé officiellement des affaires comtoises, n'avait pas aux Pays-Bas, dans l'administration, de correspondant direct - d'homme de confiance. Tout son effort allait à s'en procurer un. Il y réussit, mais tardivement : c'est seulement en juillet 1582 que, nommé en avril, le lieutenant de la gruerie Jean Froissard de Broissia, frère du défunt président du Parlement, alla prendre possession d'un poste de conseiller au Conseil privé, longtemps sollicité pour lui par le cardinal et par Marguerite.

Surtout, aider le Parlement ne servait de rien, s'il ne s'aidait lui-même. Or, c'était là son moindre souci. Granvelle le constate amèrement à plusieurs reprises, et notamment le 3 mars 1579, dans une de ses lettres à Bellefontaine : «Le païs est fort pauvre de telz personnages dont je l'aie vu ci-devant riche, que tenaient sans passion ni partialité soin du bien de celui-ci et qui savaient, pouvaient et voulaient faire les offices tels que pour le bien du païs convenait ». Un chef mou, débonnaire, tremblant à l'idée de déplaire aux puissants et toujours à genoux devant François de Vergy; des conseillers vieillis, sourds comme Belin, plus que fatigués comme Boisset, uniquement soucieux d'assurer à un fils, à un frère leur succession prochaine; des jeunes incapables ou avides, prêts à tous les abus : n'était-il pas question, en novembre 1580, d'une nouvelle visite, et Granvelle, si Comtois au fond du coeur, si conscient des mérites de ses compatriotes, n'inclinait-il pas parfois à l'idée que, pour régénérer le grand corps affaibli, conduire dans le droit chemin tant de petits caractères, des étrangers, des Flamands ne seraient pas inutiles? 


\section{IV}

Pourtant, avec lenteur mais continuité, toute une réforme des institutions comtoises se préparait. Réforme singulièrement nécessaire : lorsque le duc d'Albe, en 1573, l'avait tentée à l'aide des ordonnances du président Froissard, n'était-elle pas réclamée comme urgente depuis de longues années ? Ces ordonnances, le roi, en 1576, les avait suspendues : suspendu, non révoqué ; et jamais, par sa décision, il n'avait entendu condamner en Comté toutes les tentatives réformatrices. Aussi, en 1579, en 1580, coïncidant avec le retour de faveur du cardinal, rares d'abord, puis nombreuses et pressantes, des demandes d'avis et d'éclaircissements affluent au Parlement depuis les Pays-Bas sur tous les points intéressants de l'organisation et de la vie comtoise.

Le voyage de Marguerite en 1580 ; son séjour assez long en Franche-Comté ne fut, à vrai dire, qu'une sorte d'inspection générale du pays. Endoctrinée d'avance par le cardinal, elle suivit ses voies, docilement nota, au jour le jour ses réflexions, rédigea finalement à l'usage du roi un Discours sur les affaires comtoises. De semaines en semaines, Granvelle s'enquiert de ses progrès. Enfin, le 18 novembre 1580, le mémoire est prêt: Marguerite l'annonce. Prêt - c'est-à-dire rédigé. Mais il fallait encore qu'il soit examiné et doublement : en Espagne et aux Pays-Bas. Or, la situation de Marguerite était mal définie. Pendant toute la fin de 1580 et le début de 1581, ce sont des difficultés, des contestations au sujet d'un partage d'autorité que Farnèse repoussait et qu'il savait mauvais gré à Granvelle de désirer : ce fut seulement en juillet 1581 que les observations recueillies par la duchesse furent envoyées au roi. Là, nouveau stage, nouveaux délais - interminables. En vain, Marguerite s'informe ; en vain, Granvelle s'efforce de presser le roi ; le 5 octobre 1582, la duchesse n'avait pas encore reçu réponse du roi.

Il est vrai qu'à cette date, et depuis plusieurs mois, Fonck s'était attelé aux affaires de Bourgogne. Dès le 29 janvier 1582, il avertissait Granvelle qu'on examinait trois questions importantes : la ligue avec les Suisses, les censures ecclésiastiques, la gardienneté de Besançon. Restait à pourvoir au plus important : aux désordres de la justice, de la police, du domaine et à la sûreté du pays. Grosses 
questions, qu'il était nécessaire d'étudier prudemment. Mais, d'une manière générale, Fonck partageait le sentiment du cardinal : il fallait en revenir à l'ancien état de choses, à cette vieille constitution des pays bourguignons où la monarchie, l'aristocratie et la démocratie « avoient leur part et portion et estoient tous trois si parfaitement proportionnées et mêlées l'un parmi l'aultre qu'on ne savoit souhaiter davantage ». Belles paroles, qu'approuvait le cardinal. Et pareillement, il s'accordait avec Fonck sur la marche à suivre : pour les affaires de justice, en saisir le Conseil privé renforcé, s'il y avait lieu, de conseillers comtois et des présidents Blasere et Richardot, puis soumettre le travail au roi et le publier incontinent en Comté ; quant au reste, renvoyer les questions diverses au Conseil des finances et au Conseil d'État.

Bientôt d'ailleurs, Froissard, aux Pays-Bas, vint aider de son activité la réforme. Le 14 décembre 1582, Granvelle lui accusait réception d'un mémoire composé par lui pour le prince de Parme, et il en approuvait les conclusions. La tâche première était bien celle qu'indiquait Froissard : «faire les ordonnances ». Que d'ailleurs l'on prît, si l'on voulait, l'avis du gouverneur, du Parlement et même du cardinal de la Baume sur le redressement de la justice, Granvelle n'y voyait pas d'inconvénient ; mais à une condition : c'est qu'une fois les ordonnances rédigées, envoyées en Espagne et confirmées par le roi, elles soient mises à exécution sans ménagement, hésitation ni timidité. Point de réclamations admissibles : les sujets « ne sçauroient jamais monstrer previlèges que brydent en ce le Prince». Point d'opposition: au premier bruit que quelqu'un, «spécialement des nobles du pays », mènerait «sinistres pratiques pour faire treuver maulvaises lesd. ordonnances », qu'on l'arrête, qu'on le saisisse sans aucune indulgence. « Et je vouldrois veoir, s'écrie le cardinal avec un ton d'autorité et de menace qui ne lui est point coutumier, je vouldrois veoir celluy qui se feroit chef au pays pour y vouloir contredire ».

De fait, pendant toute l'année 1583, Granvelle garde la même attitude, la même ardeur. Contre la théorie des États, formulée en 1574 : que des ordonnances ne pouvaient être valables en Comté sans l'approbation et la participation des trois ordres ; contre la théorie du Parlement que son intervention était nécessaire pour toute oeuvre législative dans la province, le cardinal ne cesse de guerroyer et de protester avec véhémence. Les franchises du pays ? Quelles franchises ? «Je vouldroye, s'écrie-t-il, que ces seigneurs qui, à chaque pas, allèguent les libertés 
du pays et ses privilèges montrassent ces privilèges... Je confesse le pays estre franc, et pour ce s'appelle la Franche-Comté, et l'on n'y doit imposer contribution sinon de leur pure volonté ; mais en tant d'aultres choses où ilz allèguent ceste libertez, je ne sais imaginer sur quoy ilz se fondent... »

Ses avis prévalurent, et jusque dans le détail. Pendant des mois, une avalanche de consultations, de demandes, d'observations de toute nature s'abat sur la Comté. Les lettres se suivent avec une rapidité sans précédent - lettres d'interrogation, lettres de rappel : que pense la cour du calendrier et de sa réforme ? d'un renouvellement général des reprises de fief ? de la monnaie ? des bois ? de la garde des archives ? de l'aide aux quatre cas ? de l'unification des poids et mesures ? des successions de bâtards? du tarif des vacations judiciaires? Mille questions se pressent, s'enchevêtrent, se succèdent avec une hâte fébrile. Le Parlement, stimulé, répond, enquête, expédie « les plus portatifz » de ses membres dans les bois, aux essarts, sur les frontières - pas assez vite, d'ailleurs, pour éviter les rappels à l'ordre, les réprimandes sur sa lenteur, les demandes d'explication motivées sur telle ou telle de ses résolutions. Aux Pays-Bas, Froissard et ses collègues du Conseil privé reçoivent les réponses, dépouillent les lettres, construisent leurs projets ; le 19 septembre 1583, la tâche est prête - et le Conseil privé avertit Farnèse que Froissard lui portera au camp les résolutions prises sur la justice, la police et le domaine du Comté.

Peu après, en effet, le travail du Conseil était transmis au souverain. Granvelle, en novembre, signale que Fonck, aidé de Richardot alors en Espagne, l'examinait de près. D'ailleurs, il approuve tout ce qui s'est fait, « oyres que, en aulcuns pointz, il eust désiré plus de sévérité ». Il semblait, dès lors, que l'on touchât au port ; les lenteurs de Philippe II retardèrent de deux ans la solution. Ce fut seulement au début de 1586 que le roi transmit l'ordre au président Boutechoux d'avoir à publier les nouvelles ordonnances. Des instructions secrètes accompagnaient cet ordre ; elles étaient calquées sur celles que, jadis, le duc d'Albe avait données au président Froissard ; on s'était contenté de supprimer plusieurs articles et d'adoucir notablement le ton de quelques autres : la défiance à l'encontre des conseillers s'y montrait moins crûment ; mais le fond restait le même. D'ailleurs, dans une lettre particulière, le roi enjoignait spécialement au président de refuser toutes remises « si aulcuns l'on mectoit en avant... pour retarder lad. publication ». Souvenir évident de 1574. 
En fait, lorsque Philippe II écrivait cette lettre, il savait, à n'en pas douter, que l'opposition comtoise était morte. Le 7 mars 1585, les États de la province avaient été convoqués par lettres datées de Saragosse et signées, cette fois, du roi luimême : Granvelle, sans doute, avait veillé à cette formalité. Le 28 juin 1585, ils s'étaient réunis, comme d'habitude, à Dole, au collège de Morteau. Les deux commis, Fr. de Vergy et CI. Boutechoux, leur avaient lu une longue lettre du souverain réclamant un don gratuit de 150000 fr. pour l'achèvement des fortifications de Dole et Gray et l'entretien des garnisons requises ; surtout, ils leur avaient transmis le désir du roi, que tous eussent en respect ses « ministres » et « surtout, que cette assemblée d'États passât en toute modestie et avec le respect à elle deu et qu'il n'y fût traité que de choses concernant son service et bénéfice du pays ». Il en fut ainsi fait. Point de questions d'ordre politique. Point d'allusions même à la réforme du pays. Alors que leur rappel semblait s'imposer, point de reprise des vieilles revendications sur les droits législatifs des États. Surtout, nulle entente entre les ordres. L'accord des bourgeois parlementaires et des nobles d'épée, réalisé une seule fois par les événements de 1574, brisé déjà et rompu en 1579, se montre impossible à nouveau et à jamais. S'agit-il de l'aide aux quatre cas, de sa réglementation en Comté ? Sur les droits du père usufruitier et légitime administrateur du bien de ses enfants - de la femme douairière et usufruitière - du mari agissant au nom de sa femme - du seigneur engagiste d'une seigneurie tenue en haute justice - si les deux ordres privilégiés s'entendent et s'accordent, le tiers s'oppose à eux et combat leur avis. Antagonisme pareillement sur la question des successions mainmortables; de l'unification des aunes, poids et mesures repoussée par la noblesse, réclamée par les villes ; de la diversité des habits et passements ; du droit de porter arquebuses à rouet en dehors des grands chemins et de les employer comme armes de chasse : sur tous ces points qui touchent aux sources mêmes de leur fortune, les conceptions des ordres rivaux se heurtent, les solutions s'affrontent.

D'ailleurs, un louable effort est tenté pour remédier aux abus les plus criants des États. Le roi, dans sa lettre, insistait fortement sur la nécessité de « retrancher » les gages des députés nommés aux diverses commissions et ceux des receveurs du don gratuit. En fait, l'assemblée prit des résolutions pour éviter les brigues et les poursuites secrètes lorsqu'il faudrait nommer à ces commissions. Même, le règlement des gages dus aux commis et aux receveurs de 1574 ne se fit pas 
sans observations. Il est vrai que l'octroi de larges récompenses : $10000 \mathrm{fr}$. à Vergy, 4000 à Boutechoux, 2000 à l'abbé de Saint-Oyan et au chevalier d'honneur Antoine d'Oiselay, 1000 aux présidents Pamele et Fonck - sans compter diverses menues sommes à plusieurs comparses - sembla démentir ces principes d'économie plus rigides qu'à l'ordinaire. Mais Fr. de Vergy et le président Boutechoux, touchés sans doute par l'état misérable du pays, montrèrent en abandonnant pour les nécessités de la province, l'un 4 000, l'autre 2000 fr. sur leurs récompenses, un désintéressement d'autant plus notable qu'il fut moins imité.

Au reste, plus de Neuf ; plus d'ambassade coûteuse en Flandre ou en Espagne. Les États terminés, alors que les gens des villes et les ecclésiastiques se dispersaient déjà, seuls les nobles réunis dans leur chambre décidèrent d'envoyer Nicolas de Montfort remercier Son Altesse en Flandre et, s'il y avait lieu, Sa Majesté à Madrid. Pour le reste, il avait suffi que Granvelle montrât les dents et que Philippe II parlât haut et clair.

Aussi, en 1586, nul trouble, nulle émotion lorsque Claude Boutechoux publia les ordonnances. Tout le monde s'inclina sans protestations. Et sans doute, c'étaient des ordonnances cette fois et non des mercuriales ; mais la forme écartée, n'était-ce pas, en 1586 comme en 1573, les mêmes prohibitions gênantes, faites aux conseillers, de s'entremettre dans l'également ou la perception du don gratuit (art. VI) - d'accepter la présidence du Conseil des rentiers du Puits à Muire et de la Chauderette de Salins ou de siéger même à ce conseil (art. VII) - de prendre ou recevoir dons, récompenses ou pensions des États, des rentiers ou de quelque autre société que ce fût (art. VIII) - d'accepter présents des parties « sauf des dragées, épices, sucres, ypocras ou choses semblables» (art. IX et X), - enfin, de directement ou par personnes interposées « faire acheter les biens qui se discutent publiquement et par licitation » - les biens « vendus par exécution d'arrêt collocatoire rendu par icelle court » ou les biens de ceux ayant cause criminelle, fiscale ou civile importante devant la cour ou pouvant y être dévolue par appel (art. XI, XII et XIII) ? Qu'on compare ces articles avec ceux de 1573 : la modération n'est que dans la forme; les rédacteurs ont supprimé les préambules comminatoires qui, en 1573, justifiaient chaque article : concession de style, mais non de doctrine. 


\section{V}

Date importante, celle du 14 avril 1586. Administrativement d'abord, parce qu'elle marque la consécration définitive, la terminaison finale de cette oeuvre de régularisation, de perfectionnement des institutions judiciaires et financières qu'avait projetée déjà et préparée Marguerite - et qu'une première fois le duc d'Albe, en 1573, avait réalisée. Politiquement ensuite. La publication, sans opposition ni trouble, des ordonnances réformées de 1586 ; leur publication dans une Comté redevenue docile et pleinement soumise, annonce bien la fin d'une période, le dénouement d'une crise.

Sinon à ce jour en effet, du moins dans les mois qui virent la mise en train du nouveau régime se clôt définitivement le dernier épisode de l'histoire complexe que nous avons entrepris de retracer : le réveil d'activité des États, l'effort par eux tenté pour usurper sur le Parlement - au début, avec la complicité des parlementaires eux-mêmes - une autorité politique et un rôle directeur qu'ils n'avaient jamais pu jusqu'alors assumer. Épisode intéressant, mais de courte durée. C'est qu'à la différence de ce qui se passe alors aux Pays-Bas, la noblesse et la bourgeoisie comtoise ne se trouvaient pas unies, rapprochées d'une manière durable par une haine commune et vigoureuse - par le lien de sentiments communs et profonds. Il fallut tout un jeu de circonstances propices : la faiblesse du Conseil d'État succédant à Requesens et les défauts particuliers d'un don Juan, pour que la tentative de 1574 n'avortât pas plus vite et plus complètement encore qu'elle ne le fit. Mais cet avortement est un fait décisif. Avec lui et par lui s'achève l'évolution politique que nous avons vue commencer au temps de Marguerite et dont nous avons décrit la courbe sous les gouvernements successifs d'Albe, de Requesens, du Conseil d'État, de don Juan, de Farnèse enfin. Nous sommes partis du régime de CharlesQuint - régime d'équilibre entre les divers pouvoirs du pays ; nous l'avons vu s'altérer, se modifier peu à peu sous l'effort des hommes et des événements, sous la double poussée des forces économiques et des faits politiques. Après toute une série de vicissitudes, nous voici revenus, en apparence du moins, à notre point de départ. L'homme dont l'influence est prépondérante en 1585 sur les affaires comtoises - sans qu'il en ait d'ailleurs la charge spéciale - c'est le même qui veillait, en 
1560, à leur bonne marche ; c'est l'ancien collaborateur de cette Marguerite de Parme qui, après avoir si longtemps gouverné le Comté, après avoir assisté aux débuts de la crise violente qui le secoue pendant plus de quinze années, revenait le visiter en 1582, l'étudiait et l'inspectait de près pour porter remède à sa situation.

Or, de remède, pour Marguerite comme pour Granvelle, il n'y en avait qu'un : le retour en arrière, le rétablissement pur et simple des institutions comtoises, telles qu'elles fonctionnaient en 1560. Programme qui, après bien des vicissitudes, semblait s'être réalisé. Le gouverneur n'était plus soutenu de parti pris dans toutes ses tentatives contre le Parlement. Celui-ci n'était plus systématiquement humilié et condamné. Les États, convoqués comme au temps de Charles-Quint, n'osaient plus empiéter sur le terrain politique et se bornaient comme jadis, en votant le don gratuit, à proposer au roi des changements de détail. Une grande réforme administrative venait de se préparer et de s'accomplir par les soins du pouvoir royal, avec simple consultation du Parlement et du gouverneur, sans participation aucune des États. Était-ce donc, purement et simplement, le retour au passé ? L'histoire comtoise repliait-elle sa courbe en anneau, revenait-elle à son point de départ après des tentatives capricieuses d'innovation ? Une analyse de détail, une étude attentive de la situation politique et nationale de la Comté seule nous permettra de répondre - et de conclure.

Mais notons-le encore. C'est à cette époque même, c'est dans les années qui précèdent ou suivent immédiatement 1586 que disparaît à jamais la génération dont nous avons suivi l'histoire. Après le duc d'Albe, mort à Lisbonne le 11 décembre 1582, c'est Guillaume d'Orange qui, le 10 juillet 1584, succombe aux coups de Balthazar Gérard. Trois jours après, le 14, dans son prieuré d'Arbois, Claude de la Baume s'éteint, couvert de dettes, « ensepveli en une paouvre et trouée nappe de cuisine au lieu d'un linceux, une mitre de papier, huict torches et six petites chandelles ». En Comté, aux Pays-Bas, en Espagne, rien que des noms nouveaux: François de Vergy durera jusqu'en 1591; le vieux Belin jusqu'en 1592 ; Boisset, prodige de longévité, jusqu'en 1598 ; mais autour d'eux, dans le Parlement, dans les bailliages, à la Saunerie, à la gruerie, dans toutes les administrations comtoises, les représentants d'une nouvelle génération accèdent aux honneurs et s'y installent. Surtout, en 1586, tous deux : Granvelle et Marguerite, disparaissent. Déjà fatigué lorsque, la soixantaine passée, il avait quitté Rome en 1579, les soucis du pouvoir, les labeurs d'une existence trop active finirent par 
triompher, chez le cardinal, d'une merveilleuse robustesse d'esprit et de corps. Une dernière satisfaction lui était venue, peu avant, de son pays natal. Ses compatriotes avaient réalisé le voeu le plus cher de Nicole Bonvalot : à la mort du cardinal Claude de la Baume, le chapitre, tout d'une voix, l'avait postulé comme archevêque ; et tout proche de sa fin, Granvelle s'était laissé faire ; il avait accepté un diocèse qui lui était cher mais qu'il ne devait pas diriger longtemps. Sans répit, en effet, la mort faisait des victimes autour de lui. Quelques semaines avant de s'attaquer à lui, elle le privait de son " compère », du plus familier, du plus libre, du plus assidu de ses correspondants : Morillon. Lorsqu'à son tour elle le terrassa, il ne put l'accuser d'une hâte excessive : elle ne l'enlevait qu'une fois toute sa tâche finie - son destin accompli. 
PHILIPPE II ET LA FRANCHE-COMTÉ

Étude d'histoire politique, religieuse et sociale.

Quatrième partie. Le progrès de l’absolutisme.

\section{Chapitre XXV}

\section{Conclusion :}

\section{La Comté exploitée et sacrifiée}

\section{$\underline{\text { Retour à la table des matières }}$}

En 1550, en 1556 même, nous l'avons noté, une illusion restait possible aux Comtois. Confiants dans le passé, ils pouvaient croire que leur pays gardait pour ses maîtres une valeur propre. Cette illusion, tout concourait à l'entretenir : l'attitude bienveillante de Charles-Quint envers les Comtois, sa grande attention à respecter leurs usages, leurs traditions, les formes mêmes de leur gouvernement ; le rôle joué à sa cour et dans ses conseils par les seigneurs et les légistes bourguignons ; enfin, l'importance longtemps persistante de la question du Duché.

En 1580, par contre, le plus confiant, le moins perspicace des Comtois doit se l'avouer : la Comté vit, travaille et souffre pour les besoins de la politique espagnole aux Pays-Bas. Elle est une route où passent les troupes à destination de par deçà ; un réservoir d'hommes propres à combattre les rebelles flamands ; un coffre à deniers, bien maigrement rempli, mais qu'en cas d'urgence on vide sans merci et jusqu'au dernier liard. 


\section{I}

Une grande route, le trait d'union nécessaire entre Savoie et Lorraine, dès 1567, avec le passage d'Albe, la Comté le devient. Au début cependant, les mouvements de troupes sont rares. Il est vrai qu'en diagonale des pistes traversent la province et que par elles, à diverses reprises, des soldats suisses s'acheminent vers la Bourgogne : telles, en mars 1570, ces compagnies qu'il faut guider dans la neige épaisse, de Pontarlier à Levier, Salins, Chamblay, Souvans, Rahon, Annoire, Grand et Petit-Noir. Un an après, en mars 1571, ce sont des troupes venues des Pays-Bas qui, du nord au sud, parcourent la Comté : dix compagnies de cavalerie italienne, renvoyées dans leur pays d'origine ; elles firent grand'peur aux Bisontins, grand dommage aux Comtois. Deux ans s'écoulent dans la tranquillité ; mais, en mai 1573, nouveau passage. Toute une armée - 7000 fantassins espagnols et 1 500 chevaux, - défile de Chavannes à Saint-Loup, par Gigny, Lons, Brainans, Germigney, Montbarrey, Rans, Fraisans, Marnay, Fretigney, Gy, Port-sur-Saône, Faverney. Il faut la nourrir, la payer, la munir de chariots et de guides pour les bagages. A Lons, le receveur général de Bourgogne, Philippe Marchant, doit « la secourir de nouvel argent » ; il verse, sur les fonds de sa recette, « postposant toutes autres assignations », 335991.7 s. 6 d. t. A chaque étape, accumulation formidable de victuailles : à Fretigney, le 28 mai, s'amassent 20480 livres de pain, 26 boeufs, 232 moutons et agneaux, 31 veaux, 37 queues de vin, 41 bichots 9 mesures d'avoine, du foin pour 84 fr. ; au total, près de 4000 fr. de denrées. Et presque tout est consommé sur place : 12870 livres de pain, 5942 livres de boeuf, 2 580 livres de veau et de mouton, 29 queues 2/3 de vin, 4914 picotins d'avoine, tout le foin. Même dépense à Port, à Faverney : en deux jours, les Espagnols absorbent 30000 oeufs, 8000 livres de fromage, 1300 de beurre ; on leur distribue pour 3,175 fr. de blé, $3034 \mathrm{fr}$. de vin, 757 fr. d'avoine, 883 fr. de boeuf, 346 fr. de veau et de mouton, $643 \mathrm{fr}$. de poisson, d'oeufs, de fromage et de beurre, $116 \mathrm{fr}$. de foin et paille ; au total, 8872 fr. de produits en nature. Et à Marnay, on ne réquisitionne pas moins de 140 chariots pour traîner les bagages jusqu'aux frontières lorraines. 
On devine ce que représentait de sacrifices, pour les paysans, l'abandon de semblables quantités de victuailles, à une époque de protectionnisme étroit, de circulation difficile, de récoltes le plus souvent manquées. C'était pour longtemps les greniers, les granges, les étables vides. Or, sitôt partis les 7000 Espagnols, voici qu'arrive, avec 1500 chevaux, le successeur du duc d'Albe, Requesens. Voici, cinq ou six semaines après, le duc d'Albe lui-même, avec 600 chevaux. La Comté semblait si épuisée, que le Parlement pria le duc d'éviter le plat pays, d'entrer «par la montagne et commencer doiz Luxeul à Rougemont, à Baulme et conséquemment le long de lad. montaigne jusques à Arinthod». Vainement, du reste : Albe passa par Gray, Pesmes et le bas pays. Trois compagnies de chevaulégers l'escortèrent jusqu'en Savoie, puis revinrent au printemps de 1574.

Nouvelles charges bientôt : en mai, 4500 Suisses, levés par Requesens, passent par Luxeuil et Villersexel. En août, ordre vient de tout disposer pour le prochain passage du roi de Pologne gagnant son royaume de France, et le duc d'Arscot arrive à 20 chevaux pour saluer le souverain. Voici don Juan : les allées et venues se multiplient. Juin 1577 : c'est le défilé des Espagnols renvoyés des PaysBas ; 20,000 bouches, écrit Morillon, «dont les VlIm sont pour combattre, avec IIm mouchachoz assez promptz pour manier les armes ; le surplus sont femmes et enffantz et garssons ». En juin, tout ce monde dévore la Comté ; en juillet, il pénètre dans la Lombardie, mais, dès septembre, repart ; en octobre, traverse la Savoie ; en novembre, à nouveau, la Comté : 17 compagnies de chevaux, 27 d'infanterie entrent par Arinthod, gîtent à Orgelet, Blye, Vers, Levier, Saint-Gorgon, Valdahon, Saint-Jean d'Adam, Mésandans, Les Esnans et Luxeuil. Frais énormes : 320 fr. pour les barques à passer l'Ain ; 3614 pour l'étape d'Arinthod, 2 888, 2 728, 2 792, 3 051, 3 665, 3 350, 3 407, 2 801, 2 925, 3261 pour les suivantes : au total, $35000 \mathrm{fr}$., en chiffres ronds, sans compter les frais extraordinaires....

Et la série continue. En février 1578, nouveau passage, nouvelle armée : vingt-deux - enseignes d'infanterie, 400 aventuriers, 5000 bouches au total et 1400 chevaux sous don Lope de Figueroa. Ils passent «à la défilade » par groupes de deux compagnies qui se concentrent partiellement à Vevy et forment définitivement trois corps, l'un de 2 000, le second de 1300 , le dernier de 1800 bouches. A chaque étape - Arinthod, Orgelet, Vevy, Poligny, Port-Lesny, Saint-Vit, Voray, Fondremand, Fleurey, Bouligney - ils consomment 10000 livres de pain, deux milliers de carpes, quatre à cinq tonnes de harengs, 3000 livres de beurre et 
de fromage, des centaines d'oeufs. Et pas de fin, pas de trêve. Après don Lope de Figueroa, Gabrio de Cerbelloni en juin : le tercio de Sicile, partie de l'infanterie espagnole du Milanais et des chevau-légers. Rien en 1579; mais, le 17 mai, le traité d'Arras est signé. Philippe s'engage à éloigner des Pays-Bas « les gens de guerre espaignolz, italiens, albanais, bourguignons et aultres estrangiers ». Nouveau calvaire pour le paysan comtois. En avril 1580, les compagnies d'Octavio Gonzaga, 12000 bouches, 7000 chevaux, entrant par Saint-Loup, continuent par Amance, Rosay, Gy, Marnay, Ranchot, Germigney, Toulouse, Lons-le-Saunier et Arinthod. La guerre reprend ? Les Espagnols repassent. En juin 1582, 800 chevaux, 13000 bouches ; en mai 1584, 2500 chevaux, 10000 bouches ; en novembre 1586, les Espagnols de don Antonio Manrique de Lara ; en août 1587, les Napolitains du tercio de Carlo Spinelli ; en septembre et octobre, le tercio de don Antonio de Çuniga ; le tercio de Biazio Capicuca : une multitude de compagnies italiennes, véritables troupes de brigands, saccageant, pillant, brûlant, violant partout....

Cette fois, ils passèrent les bornes. Parlement et gouverneur s'émurent, sous la pression du peuple surexcité. Au conseil du 14 novembre 1587, le vieux Boisset opina le premier qu'il fallait « suplier S. M. de cy-après faire passer les Espagnols par mer et les Italiens par Suisse », et Galyot, menaçant, proposa de remettre « aux subjectz le payement du don gratuit pour le prochain terme ». Mais quoi ? On dressa des articles. On montra les compagnies italiennes, très mal disciplinées, n'observans les estappes que l'on leur avait donné, ny se réglans aux rations que l'on avait convenu », exerçant les pires actes de cruauté, pillant les églises, ravissant les femmes, brûlant les villages, bref, faisant « les actes que l'ennemy, voire le plus barbare, n'eust voulu faire, comme d'applier les povres subgects aux chariotz pour s'en servir comme de bestes bruttes, et, y estants appliez nudz, les oultragier de fouetz qu'ilz avoient propres à ce ; oster l'enffant de la mamelle de la mère, le mectre sur le charbon ardent pour avoir assovissement de leurs desbordées volontez », - toute une énumération de sauvageries et de crimes. Mais quels pauvres remèdes, ensuite, pour de tels maux ? Pourtant, le document l'avoue : le peuple était à bout. Les communautés avaient dû fournir plus de 80000 écus dans l'année. Plus de 500 chariots prêtés aux soldats avaient été perdus, brisés, égarés ou vendus; de même, plus de 200 chevaux; et la misère guettait les pauvres 
paysans, la famine implacable, « lorsque seront mangez les grains que l'on a cuilly, qui sera bien avant la moisson »....

\section{II}

Le pire, c'est que les soudards n'étaient pas seuls à rançonner, exploiter, ruiner les paysans. Des Comtois, des munitionnaires rapaces et prévaricateurs, édifiaient sans vergogne leurs fortunes insolentes sur la misère générale. Mêmes plaintes à chaque passage, et mêmes agissements. La tentation était trop forte ; limpunité presque acquise. Du premier coup, en 1567, ces habiles négociants atteignent la perfection : les Sansonnet, les Hugon, les Colotte, les Agnus, les Noirot, gagnent plus de 100000 écus au passage du duc d'Albe. Graylois de marque : d'autres, aussi riches déjà, aussi puissants, reprennent leur tradition : tel Benoît Charreton, le futur trésorier de l'Épargne et des Confiscations - fort suspect d'indélicatesse dans ses « entremises ». A plus forte raison, tout un peuple de bouchers, de marchands, de sous-traitants, s'engraisse dans les fournitures. En 1580, un des trois adjudicataires des munitions pour les 12000 Espagnols et les 7000 chevaux d'Octavio de Gonzague, Louis Choleret de Champlitte, s'acquitta si bien de son entreprise, que « les subjectz de S. M., des lieux et villaiges où lesd. compaignies passèrent, furent contrainctz de les nourrir de leurs propres biens à leur grande foule et jacture ». Et l'acte d'accusation dressé contre lui, en 1589, révèle une ingéniosité, une habileté vraiment admirables à tirer grain de tout. Suivons-le à l'oeuvre : d'abord, il se fait verser d'abusives redevances par les communautés. Puis, trois semaines durant, il fait champoyer leurs champs, gratuitement, par un énorme troupeau de boeufs « que disoit estre pour lad. munition », mais, en réalité, qu'il se réservait. Les soldats arrivés, il ne leur fournit rien. A Vantoux, pour dix compagnies de gendarmes qui séjournent quatre jours, il livre tout juste une demi-queue de piquette et soixante bottes de foin ; les habitants doivent donner tout le reste gratuitement ; mais Choleret présente la note.... Pour de tels méfaits, vingt fois répétés, 400 livres d'amende ; la punition n'était pas trop rigoureuse.

Elle ne fit pas peur, du reste, aux munitionnaires de 1587 : ils furent plus cyniques encore que leurs devanciers ; le récit de leurs méfaits n'occupe pas moins 
de 124 pages in-folio dans le registre des arrêts de 1591. Voici l'un des accusés, Nicolas Broch, de Vesoul. Les habitants de Thiénans doivent lui apporter, pour l'étape de Gouhelans, 500 livres de pain. Ils les fabriquent, les pèsent, les amènent. La balance de Broch accuse 351 livres. Et les manants, confus, doivent livrer sur l'heure les 249 livres «manquantes ». - Ceux de Maussans apportent 300 livres de pain. Broch les prend pour 192. Ceux de la Barre conduisent 36 quartes d'avoine ; elles se changent en 32 à Gouhelans. Ceux de Roche doivent fournir pour l'étape de Port 50 livres de beurre et 50 de fromage. Ils s'exécutent; mais Broch déclare le fromage mauvais, exige du bon « vachelin ». Les manants obéissent, achètent des vachelins de dix livres chaque, à deux gros la livre. Broch prend le vachelin, garde le fromage qu'il sert aux soldats, et s'établit ensuite marchand de vachelin...

Il avait d'autres tours. Le vin qu'il faisait livrer par les communautés était de beau et bon vin ; il le gardait pour lui ; en place, aux soldats, il servait une piquette de verjus et de cidre. D'autres fois, il spéculait sur les différences des mesures, recevait à la mesure de Port, qui était grande, les quantités fixées de vin, d'avoine, de blé, et les distribuait en rations à la mesure de Dole, qui était petite. Tel maître, tels valets. Les habitants de Moncey doivent fournir deux boeufs pour l'étape de Port. Jean Girard, un des associés de Broch, les examine : trop petits ! Et il les contraint d'en acheter sur l'heure deux autres à son compère Nicolas Broch - qui les avait par vol et les vend $60 \mathrm{fr}$. Analogues, des milliers de menus faits; ils attestent non la sottise du paysan, qu'on voit trompé, exploité, volé aussi crûment mais son impuissance totale à se défendre, sa misère, sa faiblesse vis-à-vis de ces rapaces. Il a le couteau sur la gorge : il faut bien qu'il cède. Plus tard, dans son village, il se ressaisit un peu, se plaint, et peut-être, si la cour consent à l'entendre, provoque une enquête, une condamnation. Maigre satisfaction ; le paie-t-elle jamais du mal subi ? empêche-t-elle les exploiteurs de recommencer sans fin ?

Qu'on ajoute les transports incessants d'armes, de marchandises diverses, les convois d'argent avec leurs escortes ; les convois de poudre et de salpêtre formés en Savoie ou en Comté même ; surtout, les courses vagabondes et les méfaits de tout ce peuple de déserteurs, d'éclopés, de pillards, défilant par troupes de quinze ou vingt - humbles ou violents tour à tour, mendiant ou menaçant, terrorisant partout les femmes dans les villages : à nier qu'elle fût une route et qu'elle ne fût qu'une route - la Comté vraiment aurait eu mauvaise grâce. 


\section{III}

Rôle passif - si l'on peut dire. Les gouverneurs des Pays-Bas lui en réservaient un autre. Dans les moments d'extrême détresse, ils se rappelaient l'ancien renom de richesse, la forte réputation militaire de la province. Et, le plus possible, ils s'efforçaient d'en tirer des hommes ou de l'argent.

Des hommes d'abord. Première levée en 1567, lorsque le duc d'Albe entreprend son voyage. Quatre compagnies de chevau-légers comtois : les compagnies de Clairvaux, de Chevreaux, de Vergy et de Ray, équipées par les plus grands seigneurs du pays, se rassemblent en juin et, se joignant aux troupes espagnoles et italiennes du duc, vont servir en Flandre jusqu'à l'extrême fin de 1569. Deuxième levée en 1573 : 1000 arquebusiers, répartis en cinq compagnies de 200 hommes chacune, sont formés en régiment sous le commandement d'Henri de Vienne - $\mathrm{M}$. de Chevreaux - qui les mène aux Pays-Bas et les conduit brillamment jusqu'à la fin de l'année. Troisième levée en 1577 : au mois de janvier, don Juan, désireux de reprendre la guerre, confie au même seigneur le soin de lever 2000 Bourguignons. Nouvelles levées, enfin, en 1578 : M. d'Achey, M. de Montmartin, d'autres encore, constituent lentement des compagnies de chevau-légers, qui s'acheminent au début de l'été vers les Pays-Bas. Elles en reviennent à l'automne, lors de la surprise du château de l'Étoile, puis repartent, du moins en partie, au début de 1579. Mais le 30 janvier 1580, Farnèse les licencie, en exécution du traité d'Arras. Elles regagnent la Comté. Pas pour longtemps. Quand la guerre reprend en 1582, cavaliers et fantassins repartent : quatre cornettes de lances et un régiment de piétons sous M. de Varambon arrivent dans les provinces en juillet 1582. Soldats hardis et courageux, mais aussi pillards et violents que les Espagnols et les Italiens. Pour les troupes mal payées du Roi Catholique, la guerre n'était qu'une école de brutalité et de sauvagerie - et bien souvent, ceux qui s'intéressent à la Comté signalent en termes vifs le péril qu'offrait pour la province l'endurcissement au meurtre et à la violence, chaque année, des centaines d'hommes recrutés sur son sol.

Plus que ces hommes pourtant, c'était son argent que pouvait regretter la Comté : le pauvre argent de ses paysans, emporté lui aussi vers les Pays-Bas pour les 
besoins de la guerre royale. Non que les fonds du don gratuit ou les revenus de l'ancien domaine se trouvassent entièrement détournés de leur affectation et ne continuassent, comme par le passé, à alimenter des oeuvres strictement comtoises. Mais les confiscations, en 1567, en 1568, avaient créé au roi un nouveau domaine, aussi étendu que l'ancien ; les seigneuries de Chalon en formaient l'essentiel. De l'argent qu'elles rapportaient chaque année au souverain, que devait faire celui-ci ? Évidemment, répondaient les Comtois, le dépenser en Comté et pour la Comté ! Les gouverneurs généraux ne l'entendaient pas ainsi. Et, dès le début, ils prirent l'habitude d'attirer à eux, pour les besoins de leur politique flamande, les deniers profitables des confiscations bourguignonnes.

Sort peu digne d'envie, celui du receveur général du Comté. En 1569, le 14 août, il a reçu commission de receveur général des confiscations. Entre ses mains vient désormais se concentrer, outre l'argent des dons gratuits, du domaine ancien et du partage de Chatelbelin, le produit des seigneuries et des rentes confisquées. Mais, périodiquement, des lettres comminatoires troublent à Salins sa quiétude : on a besoin d'argent aux Pays-Bas ; vite, qu'il vide sa caisse. Le malheureux proteste ; son intérêt, naturellement, est de garder entre les mains, le plus longtemps possible, les deniers publics qu'il fait « travailler » à son profit. Confondant volontairement ses comptes divers, embrouillant leurs chapitres à plaisir, il se débat, argumente, déclare ses mains vides et sa caisse à sec. C'est une lutte alors, une lutte de ruses qui s'établit entre lui et le gouvernement des Pays-Bas. En 1573, en décembre, Antonio del Rio, tout récemment nommé par le duc d'Albe receveur général des confiscations, dépêche en Comté un agent de confiance, Dierick de Hombre, avec mission de saigner à blanc le receveur général.

Rien d'intéressant, de significatif comme les instructions qu'il donne à l'envoyé. « En courant la poste de jour et de nuict, si faire se peult », Dierick gagnera Dole. Déjà le duc d'Albe est parti, laissant la place à Requesens. Il le rejoindra en route, le devancera, courra, aussitôt arrivé chez le président du Parlement, puis chez Messieurs des Comptes. Là, il remettra aux maîtres une lettre du duc, datée du temps qu'il était encore en charge - lettre révoquant toutes les ordonnances précédemment données tant sur Marchant que sur les receveurs particuliers, et commandant à ceux-ci que, « du jour en avant de la insinuation de la lettre, ilz payent au trésorier général Anthonio del Rio.... tous les deniers de leurs recepte » : en outre, que dans les trois jours, ils fournissent à la Chambre « la spécifica- 
tion de ce qu'ilz peuvent avoir furny et payé sur les ordonnances passées et de ce que encoires reste à payer des ordonnances ». Ceci fait, Dierick tirera de son pourpoint une seconde lettre - de Requesens celle-là, ordonnant à la Chambre de reconnaître del Rio pour trésorier général des confiscations et d'ordonner à tous les receveurs de ne plus rien verser à d'autres qu'à lui. Enfin, il requerra les maîtres de lui fournir sur l'heure une lettre pour Marchant, lui enjoignant d'obéir strictement aux prescriptions nouvelles ci-dessus énumérées.

Premier acte. Le second devait se dérouler à Salins, où Marchant demeurait. Muni de ses lettres, Dierick devait s'y rendre, et prendre dans ses coffres ce qu'ils pourraient contenir : soit, supposait-on, près de quarante mille francs. Entreprise difficile. Aussi, le financier emportait des lettres de recommandation pour plusieurs notables salinois; et si, entre temps, le duc d'Albe et Vargas arrivaient à Dole, il devait recourir à leur influence pour faire sur Marchant le plus de pression possible. L'opération achevée, nouvelle péripétie. Dierick reviendra à Dole. Et alors, mais alors seulement (il ne fallait pas trop brusquer, trop effaroucher Marchant dès l'abord), il «semondra " ceux des Comptes de mander sur l'heure le receveur dépouillé et de lui faire rendre ses comptes en souffrance de 1572 et 1573. Dierick en «verra l'estat de clôture » et tiendra bonne note des sommes à valoir. Mêmes formalités en ce qui concerne les trois receveurs particuliers des confiscations : P. Patornay, receveur de Dole ; Bonet Jaquemet, de la Saunerie ; Louis Renard, de Vesoul. Lorsqu'ils auront vidé leur caisse, signé toutes les obligations possibles, Dierick alors versera l'argent reçu au banquier génois Doria, de Besançon : celui-ci l'emploiera conformément aux ordres d'Antonio del Rio.

Analyse un peu longue : mais ce document ne résume-t-il pas admirablement toute une situation et toute une politique ? Ces ruses du pouvoir ; cette tentative à la fois brutale et cauteleuse pour dépouiller un pays au profit d'un autre ; ces résistances prévues de la Chambre des Comptes et des trésoriers, inspirées à la fois par l'intérêt privé et le particularisme bourguignon - quelle lumière jetée par de tels faits sur les relations du pouvoir central et de ses agents - du gouvernement d'Embas et de la Franche-Comté ? D'autant qu'ils ne sont pas isolés. Plus d'un an avant le voyage de Dierick, le 12 juin 1572, le Parlement ne recevait-il pas des lettres du duc d'Albe, portant ordre aux baillis et à leurs lieutenants de délivrer aux trésoriers et receveurs de Sa Majesté les extraits de toutes les amendes par eux adjugées «sans aillieurs applicquer aucunes d'icelles» ? Ne fallait-il pas grossir le 
plus possible la caisse de ces officiers de finance, pour mieux pouvoir l'épuiser ensuite ? Un an après, le 14 septembre 1575, l'ordre venait d'Anvers aux gens des Comptes d'avoir à vendre et engager des parties du domaine, jusqu'à la somme de deux cent mille francs - " pour furnyr aux très grands et excessifs frais et despens.... de ceste présente guerre civile et intestyne ». Cette fois, le vieux domaine lui-même se voyait entamer pour les besoins d'une politique lointaine. Mais c'était l'argent des confiscations qui restait, malgré tout, pour les gouverneurs des PaysBas, le grand objet de convoitise. Non seulement les trésoriers de l'Épargne, périodiquement, s'occupent, comme dit Vergy, « à relever les deniers procédans des confiscations de par deçà pour les porter par delà » - mais lorsque, le 16 janvier 1581, le receveur Marchant meurt à Salins, ce n'est pas son successeur à la recette générale de l'ancien domaine, du don gratuit et de Chatelbelin, François de Grutère, qui lui succède - mais l'écuyer Servel de Lons-le-Saunier, un simple commis du trésorier de l'Épargne Benoît Charreton. Ainsi, le départ s'établit plus net entre ce qui doit rester en Comté et ce qui est la part, le lot des Pays-Bas. En vain les États de 1579 protesteront avec énergie contre l'exode des deniers comtois ; nous avons vu quelle réponse cavalière leur fut faite par Farnèse sur ce point - et les comptes successifs de Benoît Charreton, conservés à Lille, montrent que chaque année, de 1579 à 1589, une vingtaine de mille francs sortirent régulièrement du Comté à destination des Pays-Bas.

\section{IV}

Pourtant, le roi lui-même et ses ministres n'avaient-ils pas créé à la province de nouvelles charges ? N'avaient-ils pas, par exemple, établi à Besançon une garnison qu'il fallait entretenir sur les fonds du pays ? N'aurait-il pas été juste dès lors de laisser aux Comtois pour des charges nouvelles de nouvelles recettes ? Juste : le mot est inexact ; c'est nécessaire qu'il convient de dire. Car les charges anciennes subsistant et demeurant plus que suffisantes pour absorber les recettes de l'ancien domaine et le produit des dons gratuits, où trouver les deniers pour payer les soldats ? C'étaient chaque année de quatre à cinq cents hommes à entretenir - près de 4000 fr. par mois à débourser. Toutes les fois qu'une échéance revenait - ou, plus exactement, toutes les fois que se faisaient plus vives les plaintes des malheu- 
reux soldats, laissés sans ressources par un temps de cherté croissante et au milieu d'une population fort peu sympathique - Vergy, le Parlement et la Chambre des Comptes connaissaient de nouvelles angoisses. Point d'argent, sauf dans la caisse des confiscations ; or cette caisse leur demeurait fermée.... Ils écrivaient, une fois de plus, aux Pays-Bas, représentaient leur malheureuse situation, montraient la garnison prête à se licencier d'elle-même. Vainement ; de don Juan ou de Farnèse, même réponse : il me déplaît fort, récrivaient-ils sur l'heure, que les deniers vous manquent ; mais je n'y puis rien « pour me trouver au même par deçà ».... Alors, furieusement, ils se retournaient vers les gens de finances : trésoriers ou receveur général. Des ordres comminatoires leur venaient des Pays-Bas : qu'ils payent sans délai.... Mais comment ? En février 1579, Philippe Marchant est mis en demeure d'avancer trois mois de solde à la garnison. Il refuse tout net, déclare ses coffres vides. Voilà François de Vergy au désespoir depuis cinq mois déjà, les soldats n'avaient rien touché : «J'en suis au bout de ma science, écrit-il à Farnèse, et de tant mesme que le lieutenant de lad. garnison s'est départy d'icelle et est de rechef venu vers moy, s'excusant d'y retourner pour les clameurs que luy font les hostes. » Et protestant une fois de plus contre l'exportation des deniers comtois, il s'enhardit jusqu'à déclarer au prince qu'il se permet, vu la nécessité, « de retenir par deçà lesd. deniers ». Peine perdue. Vandenesse, trésorier de l'Épargne, saisissait tout, jusqu'aux « grains et vins provenants des seigneuries confisquées » qu'il faisait vendre sur l'heure, avec clause de paiement dans le délai de quinze jours. Et c'était à nouveau un flot de lettres : de la Chambre des Comptes à Vergy ; des chef trésorier et commis des finances au Parlement; de Farnèse à la Chambre des Comptes, au Parlement, à Philippe Marchant : celui-ci, d'après le règlement des comptes de 1577, n'était-il pas redevable de plus de 73000 livres ? Erreur, répondait le receveur : cet argent, il ne l'avait pas en main ; les trésoriers le gardaient. Pourtant, à l'envoi d'un huissier, il cède. Il paiera trois mois de solde : il l'annonce à Vergy, mais malicieusement ajoute que, pour ce faire, il devra épuiser toutes ses réserves et suspendre, entre autres paiements, celui des gages du gouverneur et de ses pensions.... Trois mois du reste, c'était peu ; pourrait-on emprunter ? les banquiers génois « qui payent l'argent à S. E. » ne pourraient-ils avancer l'argent nécessaire pour liquider d'un coup tous les arriérés ? Espoir vite évanoui : « les seigneurs genevois » ne voulaient rien entendre " parce que, disaient-ils, le Roy ne paye en Espaigne, leur doigeant encore une partie de la paye de janvier et toute celle de février ». Enfin, Farnèse s'émouvait ; il envoyait à Vergy « une librance 
sur Josephe Judice, de la somme de 6000 escuz, pour en payer lad. garnison de leur solde de six mois ». Il était temps : Vergy, à la même heure, adressait aux soldats 1000 francs de sa poche pour leur permettre d'attendre. Mais à nouveau Marchant, chargé dans les trois mois de rembourser les 6000 écus fournis, arguait de sa pauvreté et refusait de s'engager. Triste comédie, qui se renouvelait sans cesse - tandis qu'aux abois, dépouillés « jusqu'à l'os », les Comtois se débattaient sans espérance....

Et comme par ironie, alors qu'ils ne pouvaient suffire aux dépenses de leur propre pays, on leur demandait de contribuer à celles de la guerre. Le 13 novembre 1577, en pleine disette, en pleine crise financière, M. de Vergy ne lisait-il pas à la cour assemblée des lettres de don Juan priant le Parlement, les bons personnages et la Chambre des Comptes de se concerter pour le secourir « de quelque bonne somme de deniers comme de cent mille escuz ». 100000 écus ? où se les procurer ? Pendant deux pleines séances, tout un après-midi et toute une matinée, les conseillers discutèrent : vendre le sel d'épargne ; vendre à réachat des fours, des moulins, des éminages, des dîmes dépendant du domaine royal ; faire la revision des accensements domaniaux et le procès de tous les usurpateurs ; surhausser le prix du sel; amodier les seigneuries de Chalon en demandant l'avance d'une année ou deux de cette amodiation ; affranchir les mainmortables de ces seigneuries : poussière d'expédients, proposés par les gens des Comptes, adoptés sans enthousiasme par les parlementaires : c'était la misère qui se mettait en peine de secourir la misère....

\section{V}

Misère créée par l'homme : sans doute ; mais à l'accroître, à la perpétuer, à la rendre plus lourde, la nature aussi travaillait activement. Ce sont de terribles années qui s'écoulent de 1570 à1575. A ce moment, où la population du Comté semble bien avoir atteint son maximum ; à ce moment, où la hausse des prix s'accentue, où les passages de troupes commencent à dévaster le pays comtois, tous les fléaux semblent fondre à la fois sur les cultivateurs et leurs récoltes. Inondations furieuses, pluies sans fin, gelées précoces, sécheresses implacables; nous 
avons vu plus haut quelles tragiques conséquences eurent ces calamités pour des centaines de familles paysannes. "Il y a cent ans, écrit Chavirey à Granvelle, le 23 décembre 1572, que la famine n'a régné si longuement, tant en pain que en vin ». Et suppliant le cardinal de faire quelques aumônes à ses sujets, «mesmes aux pouvres honteux » : plusieurs, ajoute-t-il, «meurent de faim et froidures ».

Même spectacle dans les villes. Les mendiants pullulent, -mendiants professionnels, dont les aumônes cérémonieuses du temps, si abondantes, si multiples, assuraient l'existence ; mendiants occasionnels, pauvres paysans déracinés par la misère, venus chercher asile et abri à la ville, troupeau minable de prolétaires semi-vagabonds. A Besançon, dans l'hiver de 1573, il y en a six cents d'officiellement reconnus, "tous nécessiteux extrêmes »; un texte nous les montre, "qui cryent ordinairement par les rues, mourants de faim et de froit »; il faut, pour les nourrir, passer marché spécial avec deux fourniers. A Gray, même situation. Tant de pauvres étrangers affluent vers la petite ville et veulent y pénétrer, qu'il faut entretenir à demeure un «chasse-coquin ». Destinée lamentable, de ces pauvres gens repoussés de partout, s'obstinant cependant à demeurer aux portes : à Dole, en 1574, le procureur général Henri Camu signale des troupes d'enfants, d'orphelins, établis sur les ponts, subsistant misérablement, grâce à quelques aumônes et à de maigres larcins, "vivants comme bestes brutes sans estre instruictz à la congnoissance de Dieu ny des traditions de nostre mère Saincte-Église » - si malheureux qu'on les fait recevoir à l'hôpital Notre-Dame hors les ponts, où ils seront catéchisés à la fois et nourris. - Du reste, tout augmente. Ce ne sont que doléances sur la cherté des vivres, réclamations de petites gens se déclarant incapables de subsister si leurs salaires ne sont pas augmentés, édits prohibitifs de toute exportation, taxes municipales du vin, de la viande, des hôtelleries, des salaires : une débauche de réglementation qui accroît le mal et en atteste la profondeur.

C'est dans cette Comté si éprouvée, si misérable, dévastée par la peste, remplie de vagabonds, de «mandiants valides que l'on appelle narquois » - c'est dans ce pays en plein état de crise que les soldats espagnols, italiens, suisses ou autres viennent s'abattre périodiquement. Et, sans doute, aux mauvaises années de meilleures succèdent. Les récoltes se relèvent. Longtemps cependant les campagnes gardent le lourd souvenir des années de disette; les souffrances se perpétuent chez les paysans ; et, en 1584, 1585, 1586, la peste, plus violente que jamais, re- 
vient visiter les villages et les villes, fait des morts par centaines - tandis que la famine, de son côté, aligne ses victimes.

Certes, tous ces maux, ces crises répétées n'interrompent pas brusquement la mise en valeur du pays et notamment ne font pas obstacle à cette puissante poussée industrielle que nous avons décrite. Moulins, foules, battoirs, fourneaux et forges à fer, papeteries, tuileries, continuent de s'édifier en grand nombre sur les rives des cours d'eau ; dans le haut Jura, avec moins de fièvre sans doute, mais plus de méthode, les colons défricheurs poursuivent leur tâche ; si elle souffre, la Comté, plus heureuse que les provinces flamandes, n'est pas, du moins, comme paralysée dans son développement ; les sources profondes de sa vie ne sont point taries. Mais les chiffres, ici, ne traduisent pas toute la réalité. Certains peuvent s'enrichir, tourner à leur profit les circonstances fâcheuses. Malgré tout, la Comté souffre. La masse n'est pas heureuse. Trop de misères, trop de vexations, trop d'abus ; disparu, ce sentiment d'allégresse, de confiance joyeuse dans l'avenir, dans la puissance du travail et de l'effort, qui animait les Comtois vers le milieu du siècle ; brisé par là même, ou du moins faussé, l'un des plus puissants ressorts de leur vie autonome.

\section{VI}

Il n'était point le seul. Toute la politique de Philippe II et de ses représentants n'avait-elle point tendu à détruire dans le pays les énergies particularistes, à diminuer le prestige et l'autorité des vieilles institutions, à abaisser le Parlement surtout - ce grand corps en qui s'incarnait vraiment l'esprit de la province. Dessein prémédité ? D'un certain biais, sans doute, tous les événements que nous avons retracés semblent avoir eu surtout des causes religieuses. N'est-ce pas la passion catholique du roi et de ses ministres ; n'est-ce pas leur désir de préserver la Comté de toute hérésie, de la garder fidèle à l'Église, qui explique, en maintes circonstances décisives, leur conduite et leur intervention ? C'est pour lutter contre la Réforme que Philippe et le duc d'Albe ont imposé à un Claude de la Baume la publication du Concile de Trente ; c'est pour entraver ses progrès qu'ils ont réformé l'université de Dole, porté à ses franchises et à ses libertés un coup presque 
mortel ; c'est parce qu'ils croyaient les gens de justice coupables d'indulgence pour les novateurs qu'ils ont pris appui sur la noblesse d'épée, recouru au procédé néfaste des missions d'enquête, humilié, sous la crainte et les menaces, des magistrats diminués et suspects. Oeuvre de contre-réforme, sans doute, et qui réussit, puisque la Comté resta catholique, obstinément. Mais oeuvre d'absolutisme aussi, de centralisation monarchique et de despotisme.

Certes, de 1556 à 1586, maints progrès matériels ont été réalisés. Successivement, les ordonnances réformatrices, en 1564, en 1573, en 1586, ont amélioré, simplifié, modernisé la justice et l'administration. Dans la société religieuse, par l'application de plus en plus stricte des décrets tridentins, - comme dans la société laïque, par la sévérité croissante des règlements, nombreux sont les abus qui ont dû reculer et céder la place. Mais ces progrès, la Comté, par ailleurs, n'en a-t-elle pas payé tout le prix ?

Dans sa constitution politique, rien de changé en apparence. Le Parlement reste au premier plan, avec son vaste rôle, ses attributions à la fois précises et innombrables, son vif souci de ses droits et de ses privilèges. En face, comme jadis, le gouverneur représente la noblesse de race, la force de l'épée. Autour de lui, de bons personnages l'aident, le conseillent, le soutiennent aux moments difficiles. Enfin, l'assemblée des États, comme par le passé, vote le don gratuit et soumet au roi ses doléances. Tous les rouages sont là, que nous avons décrits en 1556 ; mais leurs relations réciproques, ni leur structure interne, ne sont restées les mêmes.

D'abord, pour maintenir entre eux l'équilibre, pour veiller attentivement à ce que nul n'usurpe sur les autres la toute-puissance, plus d'arbitre. Ce rôle, que Charles-Quint excellait à remplir, Philippe II n'a pas su, pas pu le faire sien. Non par parti pris, semble-t-il, ni par calcul. Mais il est trop loin d'abord, cantonné toute sa vie en Espagne. On sait, d'autre part, sa lenteur précautionneuse, ses indécisions, ses perpétuels atermoiements. Il a, aux Pays-Bas, des représentants ; mais ils n'ont pas toute liberté d'action ; il leur faut compter avec le maître, lui communiquer d'avance les décisions vraiment importantes, attendre sa réponse et ses instructions ; bien vite, les événements leur ôtent tout loisir, toute sérénité, toute tranquillité d'esprit ; la guerre les invite, négligeant les vieilles formes et les lentes procédures, à agir directement, rapidement, à la mode militaire ; dans la vive 
tourmente où ils se débattent, c'est par à-coups, par décisions soudaines, par raisons de circonstances, qu'ils tranchent et décident des affaires comtoises.

Rien d'étonnant, dès lors, à ce que se soit faussé le délicat mécanisme des institutions comtoises. Tour à tour on a vu, sur le devant de la scène, s'avancer gouverneur, Parlement, États ; tour à tour on les a vus reculer, brusquement renvoyés dans l'ombre, au second plan, par quelque péripétie imprévue. Naturellement, de ces alternatives, le Parlement a surtout souffert. C'est de leurs fonctions et de leurs fonctions seules qu'à ses membres venait tout leur prestige. C'est l'autorité du prince dont ils étaient le glaive et le verbe souverain qui les « autorisait » euxmêmes en Comté. Leur force était d'apparaître comme ses porte-paroles authentiques, de l'incarner, pour ainsi dire, aux yeux de tous, d'être, sans contestation possible, les ministres, les exécuteurs de ses volontés, les organes de sa justice, - ses délégués dans la province lointaine où il régnait par eux. Mais si ce prince luimême semblait les suspecter, se méfier d'eux, désavouer leur action journalière, séparer de la leur sa personne, sa volonté, ses desseins, ses désirs ?

Le gouverneur, au contraire, ne tire pas du roi toute son autorité. Il le représente, lui aussi, sans doute. Il est, nominalement, à la tête du pays. Mais ce grand seigneur, un des plus riches, des plus puissants, des plus nobles du Comté, vaut par lui-même et par sa naissance. Et puis, il est libre, libre de son action, de sa personne et de ses initiatives. Trouve-t-on en Espagne, aux Pays-Bas, qu'il s'avance trop et vraiment qu'il empiète sur la cour de justice ? Les conseillers se plaignent-ils de son attitude ? Si, dans une dépêche, on l'invite discrètement à tenir compte de ces griefs, qui le sait ? Il n'est pas de ceux qu'on enquête bruyamment, ni qu'on dénonce, ni qu'on calomnie. Enfin, il représente des idées, des tendances, des sentiments simples, peu nombreux, bien définis; tout cela fait sa force en Comté, vis-à-vis de ce Parlement qui dresse en face du sien son pouvoir rival ; tout cela l'anime à la lutte, au duel : un duel sans risques pour lui, plein de péril, par contre, et pour son adversaire et pour la Comté même.

Car l'abaissement du Parlement profite-t-il au gouverneur ? A marquer son mépris à la cour, à l'écraser de son dédain, à provoquer contre lui des mesures vexatoires, il éprouve sans doute une jouissance profonde. Satisfaction d'amourpropre ; mais gain d'autorité ? Ni le duc d'Albe, ni Requesens, ni don Juan, aux moments même où ils usent de toute leur rigueur vis-à-vis des conseillers, ne songent un seul instant à diminuer leurs attributions, à en donner partie à François de 
Vergy. Politiquement parlant, ce dernier reste un assez mince personnage, dont les prises sont minimes sur la vie provinciale. Ainsi, tout ce que perdait de crédit et d'autorité la cour demeurait perdu sans profit pour personne. Et comme elle continuait à régler, à ordonner toute l'évolution politique et économique du pays, combattre cette cour, l'affaiblir, la diminuer, c'était en définitive combattre, affaiblir, diminuer le pays même.

Dans la Comté comme dans un champ clos se heurtaient donc, représentants de classes antagonistes, un gouverneur plein de prestige mais dénué de pouvoirs et un Parlement plein de pouvoirs, mais dénué de prestige. Tristes chefs pour la petite province, isolée et si souvent menacée du dehors. Pour assurer comme jadis sinon la bonne entente, du moins la collaboration, le travail en commun du grand seigneur et de la vieille compagnie, point d'efforts soutenus, suivis, attentifs du gouvernement des Pays-Bas. Au hasard des événements, des décisions improvisées et de soudaines injonctions. Rien qui rappelât les lettres d'autrefois, les lettres de l'Empereur, si souvent renouvelées, avec leurs recommandations patientes de coopération, d'action méthodique et concertée, de consultation des bons personnages. - Bons personnages : le mot existe toujours et même, semble-t-il, l'institution. Mais quel changement, là aussi. Au lieu de ce conseil d'État et de gouvernement qui se réunissait fréquemment, demandait parfois lui-même sa réunion, s'imposait pour ainsi dire au gouverneur, le prenait en tutelle et le guidait étroitement - quelques nobles d'épée, trois ou quatre, les parents, les amis, les familiers du gouverneur qui ne les réunit guère qu'en cas de mobilisation, d'éminent péril, pour leur distribuer quelques commandements militaires.... C'étaient des complices, non des conseillers, pour un François, puis un Claude de Vergy.

Restaient les États. Mais sur eux pesait le souvenir de leur tentative hardie - et manquée - de 1574. On savait maintenant, l'expérience faite, ce que l'on en pouvait attendre et que le pouvoir royal n'était pas d'humeur à les laisser faire campagne pour les «privilèges » du pays. N'était-ce pas Granvelle - peu suspect cependant d'animadversion, d'hostilité systématique pour les Comtois - qui écrivait à Bellefontaine, le 27 mars 1581, ce mot si parlant dans sa brièveté : «Monsieur mon cousin, nous voulons quelques fois être les protecteurs des privilèges du pays, que nous ne vismes oncques, et ne sçavons où ilz sont, comme quand, sur ce fondement, l'on contredit les ordonnances, prétendant brider en ce l'auctorité du maistre par celle de la court et des Estatz ». - Les Bisontins en trois mots parlaient 
plus net encore lorsque, dans la cour de leur maison de ville, ils gravaient sur la pierre : Fœlicitatis obedientia mater. C'était la devise des temps nouveaux.

Devise périlleuse. Obéir : mais à qui ? Trop loin, le gouvernement des PaysBas. Divisé, incertain, hésitant, le gouvernement local. Et l'ennemi, autour de la Comté, devient de plus en plus turbulent. Après les menaces et les alarmes, les invasions effectives, les entreprises directes vont commencer. Déjà le passage du duc de Deux-Ponts, le coup de main de 1578 sur l'Étoile, celui de 1579 sur le château de Saint-Remy, ont pu aux Comtois faire présager l'avenir. Les tentatives maintenant vont se multiplier. Entre 1585 et 1600, c'est de dépêches de guerre que s'emplissent les dossiers et les registres du Parlement de Dole. Invasion du marquis de Pont et du duc de Guise ; invasion des troupes du maréchal d'Aumont ; incessantes picorées des garnisons françaises ; passages de troupes étrangères allant guerroyer en France, au service des partis rivaux : Italiens, Suisses, reîtres et lansquenets - le tout pour arriver, en 1595, au coup de main d'Haussonville et de Tremblecourt, précédant de peu la campagne d'Henri IV. Où recourir, dans ces années de trouble et d'extrême péril ? Le roi, depuis l'Espagne ; ses représentants, depuis les Flandres, assurent les Comtois de leur bon vouloir : mais d'hommes, d'argent, point. Le gouverneur, en Comté, parle de milice ; le Parlement s'adresse aux Suisses; on redit une fois de plus les vieux arguments; on passe renouvellement de la Neutralité ; on remet sur le tapis les éternels projets d'ampliation de la Ligue héréditaire - et, en attendant, on se déchire âprement, on se fait une guerre sournoise pour des questions puériles de préséance ou d'étiquette. Nulle collaboration entre le chef de guerre, le comte de Champlitte, et les conseillers ; nulle entente entre les conseillers eux-mêmes; nul respect dans la province pour leur compagnie ; des injures, des querelles, des rivalités mesquines et sans cesse renaissantes. Peu d'hommes du reste. Souvent Granvelle, vers 1580, se plaint du manque d'individus, de la faiblesse et de l'abaissement des caractères : pénurie qui peut-être s'explique en partie par les premières conséquences de la contre-réforme, par le lourd régime de compression intellectuelle que le duc d'Albe avait institué en Comté, et dont maints documents attestent l'efficacité toute spéciale. - Ainsi les hommes à la fois et les institutions se dérobaient. Au moment où sa situation de province isolée, mais non libre, devenait de plus en plus paradoxale et périlleuse dans une Europe armée, toute ravagée de guerres, toute menacée de conflits, la Comté se voyait plus démunie que jamais de guides et de sou- 
tiens ; et ainsi, le résultat le plus important des années de lutte et de transformation que nous avons décrites, c'était - conséquence des succès de l'absolutisme et des progrès de la centralisation monarchique - l'énervement des forces vives d'un petit peuple, jusqu'alors vigoureux, résistant, plein du désir de vivre - c'était la conquête française rendue possible, facile et désirable. 
PHILIPPE II ET LA FRANCHE-COMTÉ

Étude d'histoire politique, religieuse et sociale.

\section{INDEX}

$\underline{\text { Retour à la table des matières }}$

Abbans

ACCENSEEMNTS DU JURA

ACCRUE, soldats d'.

Achey, François d'. Jean d', sr de Thoraise ; Jérôme

Adrisans, Srie

AFFRANCHISSEMENTS ; par désaveu.

Agnus, Oudot.

AIDE AUX QUATRE CAS

Albe, le duc d', (passage en Comté) ; (publication du concile de Trente) ; (réforme de l'Université) ; (réforme domaniale).

Alençon, Fr. d'.

Alix, CI.

ALLEMANDS en Comté.

ALLEUX.
Alsace.

Altaemps, Annibal d'.

Amance, Srie.

Amancey, Srie.

AMODITION des terres seigneuriales ; des seigneuries.

Amondans, Guy d'.

Amyot, Guill. ; Jean.

Andelot, Gaspard ; Georges ; Jean-Baptiste ; Pierre.

ANOBLISSEMENT

Anvers, famille bisontine d' ; Simon d'.

Apremont, Srie.

Arbois ; ses vins ; prieuré ; bailliage.

Archelange

ARCHEVÊQUE de Besançon

Arguel, Srieo château. 
Arinthod

ARMES des bourgeois

Assonleville

Asuel, CI. d'. Josse d'. Regnaud d'.

Augerans

Augsbourg, transaction d'.

Aumont, J. d' ; Pierre d'.

Aurech, M. d', v. à Croï, Ch. Ph. de.

Autoreille

Autrey

Autriche Antérieure

Avanne, Srie

Avignon, université

AVOCATS, 174 ; fiscaux des baillages ; id. du Parlement.

Babet, Hugues

Baden, le Mis de.

\section{BAILLIAGES}

BAILLIS

Baissey, Huguette de

Balançon

Balançon, M. de, v. à Rye, Gérard de.

Balanod, papeterie

Balay, Aimé de

Bâle

BAN et rière-ban.

Barbançon, P. de

Barcaille, Fr. Ant.

Barnard, Étienne
Barrillet, fam.

Barthoz, Mathieu

Basigny

Battefort, Louise de

BATTOIRS à chanvre

Bauffremont, J. de. Claude de.

Baume-les-Dames

Baume-les-Moines

Baume-Montrevel, fam. ; Claude, le maréchal ; Claude, l'archevêque (nomination) ; (rapports avec Pie V) ; (concile de Trente) ; (excommunications) ; François ; Françoise ; Peronne ; Pierre.

Baume-Perex, fam. (Aimé, Guill., Jean, Louis, Philib. de Corgenon dits de la B.).

Baume-Saint-Amour, Philibert de la.

Bave, Josse

Beaujeu, Srie

Beaujeu, Claude de

Belin, fam. salinoise

Belin, Charles ; Claude (portrait) ; (séjour aux Pays-Bas) ; (retour en Comté).

Bellefontaine, v. à Saint-Mauris, Jacques de.

Belloni, Nic.

Belmont

Belot, Bonne ; Jeanne.

Benoît Marin

Bergières, Jeannette de ; Robert de.

Berlaymont

Bernard, Nicolas 
Bernaud, Claude de ; Gérard de.

Berne, Bernois

Besançon, situation ; histoire, crise de 1552 ; maimorte ; banquiers italiens ; classes sociales ; clergé ; institutions ; débuts de la Réforme ; rapports avec les Suisses ; conflits avec le Parlement ; progrès de la Réforme ; passage du duc d'Albe ; mesures de défense.

Beure

BIBLIOTHÈQUES COMTOISES

BIJOUX

Binans, Claude de

Bithaine, abbaye

Blamont, Srie.

Blanchod, Claude ; Jean.

Blasere, J. de, première mission ; seconde mission.

Boguet, Claude

BOILLOT, Servois

Boigne, Jean de

Boissard, Jean

Boisset (de) Guillaume, procureur général ; Guillaume, grand juge de Saint-Claude ; Humbert ; Jean ; Louis ; Mercurin ; Philippe ; Pierrette.

Boissoneaul, Richard

Boitouset, chanoine

Bollwiller, Jean de ; Nicolas de.

Boni, Claude

Bonnal, forges

BONS PERSONNAGES
Bonvalot, famille ; François ; Nicole ; Pancras.

BORNES de Sries

\section{BOUCHERS}

Brevans

Boudier, fam., Jeanne

Boullin, AI.

Bouquet

Bourbon, le connétable de.

Bourguignon-les-Morey

Bourrelier de Malpas, Simon

Boutechoux, Claude ; Hugues (du Conseil privé) ; Jacques.

Bouverans

Bradefert, le capitaine

Branges, Philibert de

Brederode, Hélène de

Bresse

Bretin, Jean

Broch, Nicolas ; Philippe.

Bucey-les-Gy.

Butte, Claude de

By

Calvin

CALVINISTE (propagande)

Camu, Henri (le procureur); Jean, Pierre.

Canoz, Antoine de ; Marc de ; Pierre de.

Cantecroix, Srie

Cantons suisses

Capienca, Biazio 
CAPITAINES de Besançon ; de châteaux ; de Dole ; de Gray.

Carnavalet, Madame de, v. à Baume-Montrevel, Françoise de la.

CARTES géographiques

CARRIÈRES

Cécile, François ; Guyon ; Pierre.

Ceffia, forges

Celezot, Jeanne

CENSIVES

Cerbelloni, Gabrio de

Chabot-Charny, Catherine de ; Léonor ; Philippe de.

Chaillot, Christophe de ; Jean ; Jeanne ; Jeanne-Baptiste ; Luc.

Chailluz, forêt

Chalamont

Chalon, maison et domaine de.

Chambre, Claude de la ; Jean de la.

CHAMBRE DES COMPTES de Dole ; de Lille.

Champagney, v. Perrenot, Frédéric.

Champagnole

Champdivers

Champlitte

Champrougier

CHAPITRE DE BESANÇON (biens du).

Chappuis, Jean, consR.

\section{CHARBONNIERS}

Charles-Quint et la neutralité comtoise ; respecte l'œuvre de Marguerite ; favorise les bons personnages; ses precautions vis-à-vis des États ; ses acquisi- tions territoriales ; sa politique bisontine ; son abdication ; évolution de sa politique générale ; son affection pour les Perrenot ; s'entoure de Comtois.

Charles le Téméraire

Charmigey

Charmigey, Pierre

Charolais

Charreton ; Guillaume

Chassagne, Henri de ; Jehan de.

Chassault, Antoinette et Philibert de

Chassey, Philippe de

Chateaubelin (partage de)

Château-Lambert

CHATEAUX de Chalon

Chatelguyon (Chambre des comptes de)

Chatelneuf-de-Vuillafans

Chatelneuf-en-Vennes

Chatelot (le)

Chatelroillaud, Srie de.

Châtillon-sous-Courtine

Châtillon-sous-Maîche, Sie.

Chaussin

Chaux, forêt de

Chavannes

Chavirey, Claude de ; Louis de.

Chemilly, Antoinette de ; M. de, v. à Andelot, Gaspard d'.

Cheptel (bail à), v. à Commandise.

Cherlieu, abbaye

CHEVALIERS d'honneur 
Chevannay, famille

CHEVAUX

Chevreaux, le baron de, v. à Vienne, Henri de.

\section{CHÈVRES}

Chevry, srie.

Chifflet, Laurent

Choiseul, Jean de

Choisey

Choleret, Louis

Chupin, Nicolas

Cicon

Cicon, Claude de ; Guillaume de ; Jeanne-Baptiste de.

Cise, Jean de ; Louis de ; Thiébaud.

Citey, srie

Citey, Nicolas de

Civria, Jean de

Clairvaux, M. de, v. Bauffremont, J. de.

\section{Clairvaux}

Clément, Jacques, m. des comptes de Lille ; Pierre.

\section{Clémont}

Clereval, Claudine ; Marguerite.

Clermont, Thomas de

Clérou, Guy de

Cléron

Clerval

\section{CLOUTERIES}

Cointet, Louis de

Colard, Et., Jean.

Coligny
Coligny, l'amiral ; Philibert de.

Colin, Henri, vice-président du Parlement ; Henri, sr d'Arçon ; Hugues et Jérôme.

COLLÈGES de grammaire

Cologne, université

COMOURGEOISIES

COMMANDISES

COMMIS DES ÉTATS

COMTOIS AUX PAYS-BAS

Condé, le prince de. Conod, Louis.

CONSEIL D'ÉTAT

CONSEIL DES FINANCES

CONSEIL DE MALINES

Conseil privé

CONSEILLERS surnuméraires

Constantin, Oudot

CONSULTA

CONTREBANDE

Coquelin, Guillaume ; Louis.

Coquillard, Minime

Corbessain, Jeanne de

Corgenon, v. à Baume-Perex.

CORVÉES

Corvoisier, Jehan

COSTUME

Coue, Anne de

COURTISANES ITALIENNES

Courvoisier, Jean

Cousin, Gilbert ; Hugues.

Croï, Charles-Philippe de

CUIR ET PEAUX 
Cuniga, Antonio de

Curione

Cusance, srie

Cusance, Claude de

Cussemenet, famille salinoise

Cussey

Damas, Jean de

Dannemarie

Danou, Jean

Darc, Claude

DÉFRICHEMENT du Jura

Delivran, Françoise

Del Rio, Antonio

Demongenet, François ; Guillaume ; Jean-Guillaume ; Louis ; Marguerite ; Pierre

Desbarres, Pierre

Déservilliers

Deuilly, prêche

Digny, frère Simon

Dijon

Disse

Dole, site, accès ; distances ; Fortification, affaires de guerre ; Bouchers ; Écoles ; capitaine ; Monnaie ; Réforme ; Mairie ; Passage d'Albe ; Vie universitaire.

DOMAINE DE CHALON, V. à Chalon.

Dournon

Dramelay
Droz, Jeanne

Duchamp Nicolas

Du Chasne, Guillaume

Dumoulin

Du Pinet, Antoine

Du Prel, Jean

Du Tartre, François ; Jeanne ; Pierre.

Egmont, le comte d'.

ÉMANCIPATION

EMPHTTÉOSE

EMPRUNTS

Emskerque, v. à Anvers (fem.).

ENCLAVES

ENGAGÈRES

Epercy

Erasme

Escovedo

Essarts

Etalans

ETANGS

Êtoile, l', château de

Etrabonne

ÉTRANGERS en Comté ; v. Allemands, Flamands, Français, Genevois, Italiens, Lorrains en Comté.

\section{EXCOMMUNICATION}

Farel, Guillaume

Farnèse, Alexandre

Fauche, Étienne ; Jean ; Nicolas.

Faucogney 
Fauquier, Claude de ; Girard.

Faverney

Febvre, Pierre

Féret, Gilles

Ferrare, université

Ferrette,

Ferrières, Guillaume de

Fertans

Fétigny

FIEF (permis de tenir)

Figueroa, Lope de

Flagy

FLAMANDS EN COMTÉ

Flamisoul

Fleury

Florimond, Philippe

Foillet, Jacques

Fluriot, Pierre

FONCENIERS

Fonck, le prévôt

Fontaine-Française

Fontenoy-en-Vôge, 15

FORGES ET FOURNEAUX

Foucherans, Jean de

Fouchier, Claude de

Fourgs, les

Fraisans

Frais-Puits

FRANÇAIS EN COMTÉ

Franche-Montagne

Franchet, Guillaume

Francolin, Girard
Frasne

Fresne-Saint-Mamès

Fretigney

Fribourg en Brisgau

Fribourg en Suisse, Fribourgeois

Froissard de Broissia, Anatoile ; Jeanne ; Pierre.

FROMAGES

FRONTIÈRES du Comté

FUNÉRAILLES

GAGES des officiers royaux

Gaillard, Claude

Galyot

Ganne, Sébastien

Garapy, François-Nicolas

Garçon

Garnier, Françoise ; Perrenette.

Gâtey, voir à Marmier.

Gattinara

Gauthiot d'Ancier, Fernand

Jean ; Simon

Geizkofler, Luc

Gendrey

GENEVOIS en Comté

Genève

GENOIS, v. à Italiens.

Gérard, Balthazar

Geresmes, Perrette de

Gevigney, François de

Gevry

GIBIER 
Gigny

Gilley, Jean de ; Nicolas de.

Giponet, Claudine

Girard, Jean

Girardot, Guyenet et Étienne

Girod, Charles

GLANDÉE

Gody, Claude

Golu, Charles

Gonzaga, Ottavio

Gonzague, Fernand

Gorrevod, Antoine de ; Claude de ; François de ; Laurent de.

Grabusset, Guillaume

GRAINS, commerce des. Culture des. Exportation des.

Grammont, Antoine de ; François de ; Hugues de ; Marc de.

GRAND CONSEIL, $v$. à Conseil de Malines.

Grandjean, Charles ; François.

Grandmont, v. à Grammont.

Grandson

Grandvaux, Granvalliers

Grandvelle, sie

Grandvillars, Jean-Jacques de

GRANGES, Métairies

Granges, srie

Granvelle, v. à Perrenot.

Gray, situation ; Foires, commerce, marchands ; Population ; Fortifications, faits de guerre ; ECOLES ; Réforme ; Passage d'Albe ; Misère ; Divers.
Grenier, Antoinette

Grivelet, Anatole

Groson, Claude de

Grospain, famille, L'écuyer.

Gruères, Hélène de ; Jean de.

Grutère, François de

Guignoire, Antoine

Guillon, Jean

Guyon, Ferry de

Gy

Haraucourt, Élisabeth d' ; Humbert d', roi.

Haussonville, Nicole d'.

Hauré, le mis, d', v. à Croï, Charles-Philippe de.

Heberling, Horibald ; Quentin.

Heidelberg, Univ.

Héricourt

Hessele, Jacques

Hombre, Dierick de

Hopperus

HORLOGERIE

Hotelans

HOUILLE

Hugier

Hugon, Jean

Huissiers

Huot, Jean

Igny, Guillemette d'.

INONDATIONS

Isle-sur-le-Doubs 
ITALIENS en Comté

Jacquot, Léonard

Jacquelin, Bonadventure de

Jaquemet, Bonet

Jaquinot, famille ; Claude ; Nicolas.

Javel, Claude

Jeantet, Humbert

Jésuites

Joly, Jean

Jonvelle

Jougne

Joux

Juan, Don

Judice, Josephe

Julyot

JURÉE DES BÊTES

Kleberg, Diane de

Laille, Claude

LAINES de Sombernon, de Langres, de l'Auxois.

Lallemand, Charles ; Jean.

Lambelin

Lambert, François

Lancel, Frère Antoine

Landry, le dr

Lannoy, Ferdinand de

Lardon, Claude ; Étienne.

La Roche, comté
La Tour, Humbert de ; Jean de ; Louis de.

Laubespin, Antoine de ; Claude ; Claudine et Barbe.

Laubespine

Laval, Anthoine de ; Marguerite.

La Villette, Claude de.

Laviron, Jean

Le Blanc, Claude

Lebry, Catherin

Le Clerc, Étienne ; Léonore.

Leffond

Le Goux, Madeleine.

Le Jeune, Gilbert ; Mathieu.

Le Moine, Jean

Lépante

LETTRES, port des

Le Veau, Quentin

Lhermite, Jean

LIBRAIRES

Lods

Lods, Srie

Longin, le président

Longwy, Antoinette de ; Françoise ; Jeanne.

Lons-le-Saunier

Loulans, forges

Louvain, université

Loye, (la)

Loys, Claude

Lulier, Jeanne ; Nicolas.

Lulle, Antoine

Lure 
Luxeuil

Luyrieux, famille de

Lyon, Guyon de

Lyon

Maiche, srie

Maillot, M. de

Maire, Anne ; Richard ; Mathieu, de Jallerange.

MAIRIES (villes à.

Mairot, famille ; Claudine ; François ; Guyon.

Maisières, Christophe de, roi ; Simon de, roi.

MAISON COMTOISE

Maisonnettes

Malange

Malans-lez-Pesmes

Malarmey, François ; Christophe.

Mandeure, srie

Marceret, v. à Merceret.

MARCHANDISE

Marchant, fam. salinoise ; Philippe.

\section{MARÉCHAL DE BOURGOGNE}

Marenches, Constance de ; Jean ; Louis.

Mareschal, Antoine ; Jean.

Marguerite d'Autriche.

Marguerite de Parme ; ses débuts ; son attitude envers Renard; se tourne contre Granvelle ; organise la mission de Moron ; ses réformes de 1564 ; combat la Réforme à Besançon ; id., en Comté ; essaie de réformer
I'Église ; ses difficultés avec les Gueux ; sa rentrée en faveur ; son passage en Comté ; ses idées sur le pays ; sa mort.

MARIAGE dans la bourgeoisie ; dans la noblesse.

Marie de Hongrie

Marigny

Marmier, Hugues

Marnay

Marnix, Jean de, Philippe de.

Masson, Catherine

Matal, Antoinette

Mathey, Pooté de

Mathieu, Esterenin

Maublanc

Maufflans

Maussans

Maximilien I

Maximilien II

MENDIANTS

Merceret, François, Jean ; Pierre ; Philippe.

Mercier, Georges; Pierre.

Mervilliers, Guillaume de

Mesabarba, Polictonio

Mesmay, famille de

MESSAGERS

Messor, Jacques.

MichauIt, Regnaud

Michel, Jacques

Mièges

Miéry 
Mignot, Claude

Mignovillars

Mijoux

Millet

MINES DE PLOMB ARGENTIFÈRES ; Id. de fer.

MOBILIERS, ameublements

Moirans

Moncley, srie

Monnier, François

Montaigu

Montbéliard

Montbenoît

Montcourt, M. de, v. à Chaillot, Luc.

Montfleur

Montfort, Christophe de ; Claude de François de ; Jean ; Nicolas.

Monthureux-sur-Saône

Montjustin

Montmartin, Antoinette de ; Philibert.

Montmorot

Montoiche, Jeanne

Montot, Frère Jean

Montrichard, Claude de ; M. de.

Montrond, Guyon de ; Jean.

Montureux, Guy de

Monyet, Gaspard

Moor, Antonis

Morbier

Morel, Jacques

Morelot, Jacques

Morey
Morges

Moro, Anto. Cf. à Moor.

Moron, Guyon de

Morteau

Mouchet, Antoine, sr de

Myon ; Guyon, sr de Chateauroillaud ; Jean ; Pierre.

Moulins

Moultre

Mouthier

Mugnans, Claude et François de.

Mugnier, Simon

Murbach

Murier

Musy, Claude

Nardin

Nassau, Guillaume de, gouverneur du Comté ; rompt avec GrandVille ; ses relations avec Renard ; demande le renvoi de Grandville ; s'intéresse à Moron ; écrit aux États de 1564 ; patronne Stratius ; ses biens confisqués ; sa mort ; Henri de ; Louis de, René de.

NAVIGATION sur la Saône

Neublans, srie

Neuchatel

Neufchatel, maison de

NEUTRALITÉ

Nicod, Étienne ; Françoise ; Jean ; Louis.

Nobis, Jeanne.

NOBLESSE à Besançon. 
Noires

Noirot, Pierre

Nom (souci du)

Noroy-l'Archevêque

NOTAIRES

Noyelle, Marie de

Noyon, (paix de)

Nozeroy

Nycol, v. à Nicod

Nyon

Oisclay

Oisclay, Antoine d'.

Olziani

Orchamps-Vennes

ORFÈVRERIE

Orgelet

Orillard, François

Orléans-Longueville Louis d'.

Ormoy

Ornans

Outre-joux (terres comtoises d')

Padoue, université

Paget, Girard

PAIN

Pamele, Guillaume de

PAPETERIES

PARDESSUS de la Saunerie

PARTAGE DE LA COMTÉ (projets de)

Passavant

PATURE (vive et saine)
Pautrard

Pavie, bataille de

Payen, Claude et Didier

PÉAGES

PÉLERINAGES

Pelissonnier, Claude ; Pierre ; Simonne.

PENSIONS

Perrenin

Perrenot (hameau)

Perrenot, Antoine, card. de Granvelle ; débuts ; amitié avec Renard ; haï des Rye ; affaire Quiclet ; la Consulta ; attaqué par les nobles ; par Renard ; en obtient la disgrâce ; disgracié lui-même ; séjour en Comté ; Moron ; le ruine ; gagne Rome ; soutient Belin ; sans crédit en 1566 ; se détache de Belin ; Université de Dole ; mission Blasere ; pousse P. Froissard ; les ordonnances ; deuxième disgrâce ; combat don Juan ; id., les corne-guerre ; soutient le parlement ; les alternatives de 1577 ; consulté par Farnèse ; mais circonstances contraires ; États de 1574 ; restaure le prestige de la Cour ; travaille aux réformes ; ses idées politiques ; sa mort ; découragé vers 1580.

Perrenot, Frédéric de Champagney

Perrenot, Jérôme de Champagney

Laurence ; Marguerite I et II.

Perrenot, Nicolas, origine et carrière ; haï des Rye ; fortune territoriale ; Perronne ; Pierre ; Thomas, de Chantonnay. 
Perrot, Adrien ; Jacques ; Siméon.

Peschart, François-René

Pesmes

PESTE

Phénix, Pierre

Philibert-Emmanuel, duc de Savoie

Philippe II, roi d'Espagne, avènement ; peu aimé ; débuts en Comté ; Espagnol avant tout ; attitude envers Granvelle ; id., envers Renard ; néglige les nobles comtois ; réglemente les titres ; organise la Consulta ; pourvoit au gouvernement du Comté ; se méfie de Guillaume d'Orange ; appelle Renard en Espagne ; disgracie Granvelle ; reprend l'affaire Quiclet ; sa situation à Besançon ; combat la Réforme ; se méfie des parlementaires ; annonce sa venue par-deçà ; favorise l'Inquisition ; fait publier le Concile ; accroît son autorité sur l'Église ; réforme l'Université ; lent à choisir un président ; nomme Froissard ; reçoit les députés des États ; rend faveur àGranvelle ; ses lenteurs ; sa politique en Comté.

Pie V

Pierre, Oudot

Plumont

Poinson

Poinsot, famille ; Jean ; Thiébaut.

Poitiers, Dorothée de ; François de.

POIX

Ppligny

Poligny, Anne de ; Guy de.
Poly, Jacques

Pontailler, Blaise de ; Claudine ; Jeanne.

Pontarlier

Pont de Roide

PONTENAGES

PONTS

POPULATION DU COMTÉ

PORCS

PORTAILS, (bacs)

Port-Lesney

Port-sur-Saône

Portessain, Guillaume

Possevin, Antoine

POSTE AUX LETTRES

Postel, Guillaume

Potelles, M. de

Poupet, Guillaume de, abbé de Baume ; Jean, sr de la Chaux.

Poyet (le)

Precipiano, Ambroise

Prêts

Quiclet, Étienne

Quingey

Rabelais, François

Racle, Nicolas

Ragu, Jeanne

Rahon

Raincourt, M. de

Rans, Ranchot

Ray, Claude de ; Cleriadus de ; Jean-Baptiste de ; Renée de. 
Receveur, Richard

\section{RECEVEUR DE SEIGNEURIE}

Reculot, Marc de

\section{RELÈVEMENT DE NOM ET D'ARMES}

Renard, Jean ; Louis ; Simon, ses débuts ; relations avec Quiclet ; apparences de complicité ; ses ambitions ; impliqué dans la trahison ; ses cumuls ; sa fortune ; se lie avec les Gueux ; rappelé en Espagne ; doit partir ; sert les intérêts de Guillaume d'Orange ; mal accueilli en Espagne ; soutient Terrier.

RENTES CONSTITUÉS, en argent ; en nature ; sur la saunerie.

Requesens, don Luis de, sa nomination; ses instructions pour les États de 1574 ; reçoit leurs députés ; reçoit Boisset ; sa mort ; son itinéraire en Comté ; ses levées en Suisse.

RETENUE : (droit de)

\section{RETRAIT LIGNAGER}

Reymaldi, François Thibaud

Richardot, Claude ; François, évêque d'Arras ; Jean.

Richecourt, srie

Rigny

Rivière, la

Robinet, Philippe

Rochefort, srie

Rougemont

Roussel, Quentin

ROUTES

Rubilly, Prudent de
Ruffrey (Jura)

Rye, famille de ; Antoinette ; Claude-François ; Gérard, sr de Balançon ; Joachim, sr de Rye ; Louis ; Marc, sr de Dicey ; Marc, mis, de Varambon.

Philibert

Sachet, Aimé et Claudine ; Jean.

SAFRAN

Saint-Amour

Saint-Aubin, srie

Saint-Cergues

Saint-Claude

SAINT-EMPIRE

Saint-Gorgon

Saint-Hippolyte

Saint-Jean-d'Adam

Saint-Jean-de-Losne

Saint-Julien

Saint-Laurent-de-la-Roche, château

Saint-Loup

Saint-Mauris, Claude de ; Guillaume ; Henri ; Jacques, prieur de Bellefontaine ; Jean, le Président. Jeannette ; Louise ; Marguerite ; Luc ; Prudent.

Saint-Rémy

Saint-Vit

Sainte-Anne

SALAISONS

Saligney cf. La Tour (Jean de).

Salins ; écoles.

Salives, Adrien de 
SALPÊTRE

Santans

Saubief, Philippe de

Sauget, Jean ; Simon.

Saulnot

Saulx, Anne de ; Gaspard de.

Savigny, Nicole de

SAVOYENS

Scey-en-Varais

Scheyfve

SCIERIES

Seguin, Fernand ; Jean.

Semur, Claudine de

Sirod

Sombarde, famille

Sonnet, famille, Claude

SOUDARDS COMTOIS

Sources du Jura

SOUVENIRS BOURGUIGNONS

Soye

Stratius, Étienne

Surgect

Taillant de Monfort, Claude, Louis.

Tarlot, Jean

TERRES DE SURSÉANE

Terrier, Le docteur

Thevency, Louis

Thiébault, Pierre et Renobert

Thiénans

Thierry, Alonze ; François ; Pierre.

Thillot (le)
Thomassin, Adrien ; Jean ; Nicolas ; Philippe.

Thou, Thiébaud de

Thourière, Marguerite de la

Toulouse

Tour (famille de la) v. à la Tour.

Toumay, Jean de

Trois-Évêchés

Usier

USURE

Vaire

Valdahon

Valempoulières

Valimbert

Val d'Ain

Val Louais

Val de Morteau

Vandenesse, Jean de

Vantoux

Varey, Jeanne

Varondel, Claude

Vaucelles (trêve de)

Vauchard, Pierre

Vaud, Vaudois

Vaudrey, Anne de ; Jean ; Jeanne.

Le Foi ; Louis ; Pierre.

Vaulchier, Philippe

Vautravers, Philibert de

Vauvillers

Vennes, Sries 
Vercel

Vergy, Antoine de ; Antoinette ;

Chrétienne ; Claude I, le maréchal ; Claude II ; Cleriadus ; François ; Guillaume.

Vermot, Matthieu

Vernerey

Vernier, Guillaume

Vernierfontaine

VERRERIES

Verrières-de-Joux

Vers

Vésale, André

Vesoul

Vevy

Vienne, famille de, 236 ; Henri, baron de Chevreaux ; Nicolas ; Roberte.

Viglius

VIGNE

VIGNERON

Vigoureux, Quentin ; Simon.
VILLAGES (détruits)

Ville, André de ; Jean de.

Villelume, Hugues de

Villeneuve, M. de, v. à Oiselay, Ant. d'O.

Villers-sous-Chalamont

Villersexel

Villey, Christophe de

Vincart

Viron

Viry

Viry, Michel de

Vital, Laurent

Vôge, la

Voisey, Claude de

Vuillafans

Vy, Henri de

Wateville, Gérard de ; Nicolas.

Worms, partage de 
PHILIPPE II ET LA FRANCHE-COMTÉ

Étude d'histoire politique, religieuse et sociale.

\section{DOCUMENTS ET OUVRAGES UTILISÉS}

\section{NOTE PRÉLIMINAIRE}

Retour à la table des matières

Les pages qui suivent ne constituent pas la bibliographie complète et méthodique du sujet traité.

En premier lieu, il ne pouvait être question, sous peine d'une excessive surcharge, de dresser la liste des ouvrages intéressant l'Espagne, la France, l'Empire, les Pays-Bas, la Savoie, les Cantons - bref, les pays en relation avec la Comté du XVIe siècle - qui ont pu nous fournir des indications ou même des renseignements utiles. En particulier, une bibliographie complète devrait comporter l'énumération de nombreux ouvrages sur les Pays-Bas au temps de Charles-Quint et de Philippe II ; nous avons fait effort pour n'en retenir que le moins possible.

D'autre part, quelle que soit l'étendue de ses dépouillements, il est évident que l'historien d'une province à une période quelconque de sa vie moderne ne peut jamais utiliser qu'une faible partie des textes survivants, et nécessairement une liste de documents consultés pour une première et provisoire synthèse diffère singulièrement d'un répertoire complet des documents à consulter.

Enfin, quant aux ouvrages spécialement comtois ou relatifs à la Comté, nous avons éprouvé les hésitations que marque M. R. Reuss, en tête de sa belle monographie de l'Alsace au XVIIe siècle : nombreux, en effet, sont ceux qu'on ne vou- 
drait avoir l'air, en les citant, de recommander peu ou prou ; il faut résolument les ignorer. - Ainsi, notre effort est allé à réduire le plus possible la liste qui suit ; elle est strictement, elle entend être uniquement une liste des principaux livres et documents cités dans le corps du volume.

Tous les ouvrages retenus ont reçu un numéro d'ordre. Le rappel de ce numéro à la suite du nom de l'auteur nous permettra d'abréger sans inconvénient la rédaction de nos références. - Pour nos abréviations, nous avons adopté le plus souvent possible celles auxquelles le Répertoire méthodique de l'histoire moderne et contemporaine de la France a déjà accoutumé les travailleurs. - Nous n'avons mentionné qu'exceptionnellement les articles de revues et de recueils savants ; on trouvera au bas des pages l'indication de ceux que nous jugeons d'intérêt secondaire ; pour tous ces articles, sauf exception justifiée, nos références se rapporteront à la pagination des revues ou recueils, non à celle des tirages à part, généralement rares et introuvables en dehors de la province.

\section{DOCUMENTS MANUSCRITS}

\section{ARCHIVES DÉPARTEMENTALES DU DOUBS}

\section{Fonds de la Chambre des Comptes de Dole}

Fonds considérable (2686 art.), inventorié en trois volumes : Inventaire sommaire, série B, Chambre des comptes, par Gauthier (J.), 1883-95, 3 in-4 (CL, dans l'Introduction des vol. I et III, des indications sur l'histoire du fonds). Il serait difficile, et du reste sans intérêt, de transcrire ici la liste des pièces que nous avons eues en main. Nous mentionnerons simplement les documents les plus importants.

A. - D'abord, un certain nombre de registres, d'intérêt capital, qui fournissent la base solide de l'histoire économique et sociale du temps : 
B 563-65, Délibérations de la Chambre, 1565-1600 ; analyse (XVIIIe s.) des originaux disparus.

B 577-80, Chartes de concession des souverains, I531-1600.

B 635-43, Reprises de fief, 1532-1585 (ne contiennent que les procèsverbaux, sans dénombrements).

B 729-43, Minutes d'arrêts sur requêtes, 1561-1598.

B 2010-14, Accensement du domaine, 1530-1561.

B. - Ensuite, des comptes, encore nombreux malgré les destructions de 1790, mais rarement groupés en série. Ils sont de deux sortes : les comptes généraux, les comptes particuliers.

Les généraux, importants pour l'histoire budgétaire et financière du Comté, sont ceux de la Recette générale du Comté (B 1126, état sommaire pour 1589); de la Trésorerie de Dole (B 1085-86, souffrances et reliquats de 1561 à 1581 ; B 1087-96, comptes annuels de 1590 à 1598) ; de la Trésorerie de Vesoul (B 111116, comptes annuels pour I559-60-90-1600) ; de la Recette de Château-Belin (B 1384-87, comptes annuels pour 1549-60-90-99 et B 1736 sqq., B 1843 sqq., acquits pour 1555-78-82-86) ; de la Recette générale des confiscations (B 1824, état sommaire pour 1570 ; B 1825 sqq., comptes annuels et acquits pour 1569-74, 1580-87-89-90)

C. - Des comptes particuliers, nous avons dépouillé d'abord les comptes de seigneuries qui formaient série, soit :

B 1351-52-53, Comptes d'Arguel, série décennale de 1574 à1584.

B 1390-96, Comptes de Châtelneuf-de-Vuillafans pour 1563-66, 1577, 1586, 1596.

B 1399-140I-02-03-05-08, Comptes de Châtillon-sous-Maîche pour 1550-6070-80-90-1600.

B 1456-I460, Comptes de Faucogney (1555-64-65-74-85). 
B 1525-28-38-43, Comptes de Joux (1565-74-84-97).

En plus, des comptes isolés, d'intérêt divers : B 1347, Andelot (1577-78) ; B 1366, Chalamont (1584) ; B 1382, Châteauroillaud (1578) ; B 1419-20-26, Citey, comptes et acquits (1566-70); B 1430-33, Demangevelle (1568-72); B 1469, Faverney (1570-71) ; B 1481, Fertans (1594) ; B 1658-62, Saint-Remy (157275) ; B 1681, Toulouse (1584) ; B 1736-43, Château-Belin, acquits (1545-78).

Enfin, importants pour l'histoire militaire: B 1755-67, Gabelle de Gray, comptes (1570-82) ; B 1955-57, comptes de guerre (1573), etc.

D. - Quant aux liasses de titres locaux, elles sont surtout précieuses pour l'étude du régime domanial. Elles contiennent notamment :

Des dénombrements de seigneuries, presque tous datant de 1584, année d'une reprise générale des fiefs comtois (B 2230, Adrisans ; B 2288, Avanne et Avilley ; B 2345, Champdivers ; B 2375, Châtelneuf-en-Vennes; B 2376, Châteauroillaud ; B 2418, Seigneuries de J. de Bauffremont ; B 2451, Cugney ; B 2672, Marnay ; etc.).

Des rentiers et terriers (B 2296, Baume-les-Dames; B 2458, Fraisans; B 2798, Orgelet ; B 2884, Quingey).

Des registres de lods et contrats (B 2028, Scellés des Seigneuries de Chalon, 1569-1584; B 2273, Arguel; B 2374, Chatelblanc; B 2375, Chatelguion; B 3071, Vers-en-Montagne, etc.).

Des affranchissements et des inventaires de mainmortables (échutes); notamment les trois précieuses liasses des affran-chissements de Chalon en 1582 (B 2037-39).

Enfin, d'innombrables documents relatifs à l'industrie, aux mines et fourneaux (p. ex., B 1806-07, Mines de Saint-Bresson ; B 2368, id. de Château-Lambert ; B 2656, Forges de Loulans ; B 2957, Mines de Saint-Bresson, etc.), ou encore aux défrichements, au peuplement, aux mouvements de population (B 2626-27, Dé- 
nombrement des feux de la prévôté de Junny, 1593 ; B 2724, id., prévôte de Montjustin ; B 2811, id., ressort d'Ornans), etc.

\section{Fonds du Parlement de Dole}

Fonds considérable également, et d'importance primordiale. Classement provisoire, défectueux ; inventaire sommaire sur fiches, souvent erroné. On pourra consulter, pour le détail des séries, l'Introduction de nos Notes et Documents sur la Réforme et l'Inquisition en Franche-Comté, d'après les registres du Parlement de Dole on y trouvera notamment un tableau synoptique des registres et des liasses par nous dépouillés pour la période 1525-1575.

Le fonds comprend d'abord trois séries fondamentales de registres annuels, que nous avons dépouillés depuis l'origine jusqu'à 1600 :

\section{Registres Procureur}

Registres des causes où le procureur général était partie. Un registre par an, d'environ 300 feuillets in-folio. On y trouve, à côté des textes de procédure, des édits, des ordonnances, des requêtes, des propositions d'erreur de la plus haute importance pour l'histoire politique, économique et sociale ; surtout, une riche série de testaments - une centaine environ pour le XVIe siècle. Nous avons dépouillé les registres Procureur depuis le plus ancien (janvier 1525-66 - juillet 1526), égaré actuellement dans la série des Arrêts (cf. le Tableau synoptique cité plus haut), jusqu'à celui de 1598. La série est complète et régulière depuis 1530.

\section{Registres de délibérations}

Registres in-4, d'environ 200 feuillets. Les opinions exprimées par les conseillers dans les délibérations soit politiques (affaires d'État), soit judiciaires, s'y trouvent notées par le greffier. C'est également en tête de ces registres que sont ordi- 
nairement reliés les feuillets contenant les « articles de la Saint-Martin » ou remontrances faites à la cour, à la rentrée annuelle de la Saint-Martin, par les officiers du Comté. Ces remontrances étaient l'objet d'apostilles, généralement transcrites en marge. La série remonte à 1542 ; elle est double. En 1542, en effet, le Parlement se divisa en deux chambres. On distingue donc les registres de la Chambre du Conseil, ou Grande ou Ancienne Chambre ; et ceux de la Seconde ou Nouvelle ou Petite Chambre. Seuls, les premiers contiennent des affaires intéressantes et les délibérations politiques. Nous en avons dépouillé la série, à peu près complète, depuis l'origine (B 136, nov. 1542-sept. 1543) jusqu'à 1598.

Nous avons retrouvé en plus un certain nombre de registres isolés, non classés dans la série des registres de délibérations et intitulés les uns : « Registres de délibérations secrets et d'extraits », les autres « Registres de délibérations sur procès ». Ils sont cotés : B 024 (Extr. des délibérations de 1518 à 1567 ; reg. compilé vers 1585) ; B 1332 (Délib. de 1525-26) ; B 1331 (Délib. de nov.- déc. 1537 et de 1539-40) ; B 1330 (Délib. de 1540-41) ; B 1335 (id-, 1550-51) ; B 023 (1) (id., 1555-56) ; B 023(2) (table des lettres écrites au et par le Parlement, du lundi de Quasimodo 1571 au lundi de 1572) ; on trouvera des indications plus détaillées sur leur contenu dans l'Introduction de l'ouvrage déjà cité. - Dans la même catégorie doivent figurer les registres : B 1336 (Délib., 1575-76) ; B 023(3) (Aff. extraord., 1587-88) ; B 023, (Délib., 1587-88) ; B 1328 (1589-90) ; B 025(1) (159091) ; В 025(3) (1591-92) ; В 025(2) (1592-93) ; В 025(4) (1593-94) ; В 025(3) (1594-1595).

\section{Registres d'arrêts}

Reg. annuels, de 3 à 400 ff. in-fol. La série remonte à 1506 (B 1043) ; elle est très incomplète au début (5 reg. seulement pour la période 1506-1542 ; cf. le Tableau synoptique cité) ; nous avons dépouillé tous les registres existants (soit 52), de 1506 à 1598. - Les autres registres annuels sont d'intérêt uniquement procédurier ; nous avons eu à y conduire quelques recherches, mais nous n'avions pas à en entreprendre le dépouillement. 


\section{Correspondance du Parlement}

Ce sont non des registres mais des liasses contenant en minutes, originaux ou copies la correspondance de Charles-Quint, de Philippe Il, des gouverneurs généraux des Pays-Bas, etc., avec le Parlement de Dole et le gouverneur particulier du Comté. La première de ces liasses (B 45) concerne les années 1501-1539 ; la seconde, B 46, l'année 1540-41 ; la troisième, B 47, les années 1542-1559 ; quatorze liasses suivantes (B 48-B 61) renferment les documents de 1560 à 1598. Nous les avons intégralement dépouillées. - Nous avons vu en plus les registres de Lettres importantes B 010, B 013, B O14, compilés au XVIIIe s. En outre, sous la cote B 0495 figure un petit cahier intitulé : Inventaire des avis rendus par la cour à $S$. $M$. de 1564 à 1571, classé à tort avec les Avis sur requête; c'est une table des lettres écrites par la cour aux Pays-Bas et en Espagne pendant ces années ; à rapprocher du reg. B 023(2) cité plus haut, et qui présente le même intérêt pour les années 1511-73.

\section{Registres divers}

Des registres d'Édits, le premier a disparu ; le second (B 1307) contient les édits de 1591 à 1602. - La liasse B 0995, Anciens édits, contient les débris d'un recueil manuscrit, compilé en 1566 ; la seconde et la tierce partie (notaires, armes, voies de fait, brigands, etc.) subsistent seules.

Des registres d'Actes importants, les deux premiers ont disparu ; le troisième seul, B 1310, subsiste (1591-1602).

Des registres du Bullaire, le premier a disparu ; le second, B 1313, va de 1592 à 1605. B 1315 renferme des extraits des sept anciens registres du Bullaire (15821726).

Des Avis sur requête, une liasse (B 0495) intéresse le XVIe siècle. Elle est d'un vif intérêt pour l'histoire administrative et sociale. 
Liasses diverses

Elles comprennent :

Des minutes d'enquêtes sur procès et des informations criminelles. Nous avons dépouillé les liasses relatives au XVIe siècle (assez rares) ; elles sont cotées, pour les minutes d'enquête, B 1348 ; B 0893 ; B 0622 ; B 0680-81 ; B 0894 (1557-1600) ; pour les procès criminels à requête du procureur général, B 0762 ; B 0786 (procès Quiclet) ; B 0838 ; B 0951-52 ; B 0958 ; B 0996 ; B 0998 ; B 0109-1018 (I538-1600).

Des documents relatifs au Parlement lui-même, à son organisation, à celle de la justice en Comté : B 0990, Titres généraux, actes constitutifs du Parlement ; B 0991, ressorts de justice, bailliages secondaires.

Des documents relatifs aux affaires ecclésiastiques, cotés B 0107, Archevêché, abbayes ; 0108-1113, abbayes ; B 4245, Bénéfices séculiers ; B 4214 sqq., visites d'abbayes (ordre alphabétique des abbayes) ; B 0993, conflits de juridiction, Inquisition ; B 0974, id. ; B 0739, excommunications ; B 0759 affaire d'hérésie de G. Grosbois (1539).

Des documents relatifs aux affaires extérieures : B 0400-OI-02, accords avec la Suisse ; B 0405, délimitation avec Berne ; B 0406, copies des neutralités, 15221595 ; B 0408, délimitation avec Valangin, Neuchatel, Berne et Vaud ; B 0409 et B 0435) délimitation avec la Lorraine ; B 0439, B 0759, délimitation avec Besançon, etc.

Des comptes : B 0949, confiscation du domaine de Chalon, 1565-85, comptes de seigneuries (Montfaucon, Vaire, etc.) et correspondance ; B 01008, comptes des revenus du domaine à Dole, 1539 à 1543, et compte d'exploits du bailliage de Dole, 1547-48 ; etc.

Enfin, des documents relatifs à la vie économique du Comté ou importants pour l'histoire sociale: B 0892, visite des greniers du Comté, 1582 ; B 0992, chemins, ponts, digues, 1560 ; B 0994, industrie, commerce, agriculture ; B 01001-02, monnoies B 1346, travaux publics. - B 0876, Décrets (inventaires, 
etc.) ; B 0418, Testaments et inventaires après décès, 1533-1613 ; B 01138, Rièreban, XVIe siècle.

Fonds des États de Franche-Comté

Fonds prétendu classé ; Inventaire sommaire (séries C, D, E), par Babey, 1870, in-4. En réalité, classement et inventaire sont plus que défectueux ; à côté du fonds proprement dit, il existe un Supplément, plus volumineux que le fonds lui-même et formé, paraît-il, de documents négligés lors de la rédaction de l'inventaire. Aucun guide pour ce supplément; grâce à l'obligeance du personnel, nous avons pu examiner sur place ses nombreux cartons; extrêmement riches pour le XVIIe siècle, ils sont relativement pauvres pour le XVIe ; ils nous ont

Du fonds proprement dit, retenons les cotes suivantes :

C 212, Recès des États, reg. in-fol. de 457 feuillets (XVIIIe s.) qui semble avoir été la base de la publication de de Troyes, citée plus loin.

C 216, Délibérations des commis au cabinet des États de 1568 et suiv., jusqu'en novembre 1577.

C 243, Comptes du don gratuit de 1561, Amont; id., de 1568-69 ; id., de 1585, avec acquits.

C 263-64-65, Fournitures aux troupes de passage, comptes d'étapes.

C 273, Instructions du Souverain à ses représentants aux États.

C 278, contenant entre diverses pièces du XVIIe siècle un compte du don gratuit de 1561, inventorié sous le titre d'État des revenus du Comté en 1561 (!).

Du Supplément, les cartons suivants (cotes provisoires) renferment des documents utiles :

Carton 55, Comptes divers (notamment ceux des dons de 1542-44).

Carton 56, id. (notamment ceux du don de 1598).

Carton 57, id. (notamment ceux du don de 1564 ; des liasses d'acquits et de très précieuses requêtes en dégrèvement pour ce don ; des comptes et liasses analogues pour le don de 1568). 
Carton 77, Demandes de degrèvement du bailliage d'Aval pour le don de 1515 (précieux renseignements sur la misère générale).

Carton 87, Demandes analogues, même don, même bailliage ; documents divers sur les passages de troupes, comptes d'étapes, etc.

\section{Fonds de la maison de Chalon-Orange}

Débris d'un fonds considérable, disparu du dépôt sous la Restauration et devenu propriété privée des princes d'Aremberg. - Inv. somm. (séries C, D, E), par Babey, 1870, in-4.

Ce fonds nous a fourni notamment des comptes et des titres de seigneuries : E 1208 sqq., Seigneurie de Rougemont, 1546-1565 ; E 1291-92-93-94, Comptes de recettes et dépenses des seigneuries de Chalon, 1538-1588; E 1357, Comptes de Chavannes ; E 1359, Comptes de Châteaubelin (1575-1588) ; E 1361(3), 1361(3), belle série de comptes de la seigneurie de Montfleur (1541-1517); E 1363, Comptes divers de Saint-Laurent de la Roche.

Titres de famille

Nombreuses liasses, mais dont peu contiennent des titres du XVIe siècle. - Inventaire sommaire défectueux, par Babey (séries C, D, E, 1870, in-4).

Nous avons vu les liasses : E 1419-20-21-23-24-25, Famille Gauthiot d'Ancier ; E 1426, Inventaire des meubles de F. Gauthiot, 1596 ; E 1456, Famille Demongenet ; E 1460, Familles Jacquinot et Franchet ; E 1487, Famille Papay ; E 1493, Seigneurie d'Étrabonne.

\section{Notaires et tabellions}

Le dépôt contient d'importantes liasses de minutes notariales, presque toutes de provenance bisontine ; malheureusement, celles qui remontent au XVIe siècle 
sont fort rares. Les recherches sont facilitées par l'existence d'un Répertoire alphabétique manuscrit des notaires de Besançon, dont les minutes étaient conservées aux Archives des notaires de Besançon ; les divers actes y sont relevés avec leur date. Naturellement, le dépôt ne contient qu'une faible partie des minutes inventoriées dans le Répertoire.

Nous avons vu les minutes des notaires bisontins : Duchasne (deux liasses, 1567-1598) ; Bon Monnier (une liasse, 1564-1599) ; Alviset (un registre, 15801595). En plus, cotées E 1534, quelques minutes du notaire Perrenot, de Courchapon (1569-1600).

Fonds de l'Archevêché et du Chapitre métropolitain

Fonds inventoriés : Inv. somm., série G, t. I, par J. Gauthier ; Besançon, 1900, in-4. Celui de l'archevêché nous a fourni surtout des comptes de seigneuries : G 48, Compte d'Étalans pour 1560 ; G 56, de Gy pour 1561 ; G 60, de Mandeure pour 1559 ; G 65, de Noroy-l'Archevêque pour 1548-49. - Dans celui du chapitre, nous avons vu les registres des Délibérations capitulaires, G 195-199 (15461593).

\section{Abbayes et Prieurés}

Inventaires manuscrits anciens, au dépôt. Nous avons vu notamment divers cartons du fonds de Notre-Dame de Mont-benoît, intéressants pour la vie économique du haut jura (notamment les cartons 2 et 7); de même, le fonds du prieuré Saint-Simon de Mouthe nous a donné des accensements et des baux intéressants. 


\section{ARCHIVES GÉNÉRALES DU ROYAUME, À BRUXELLES}

CF, sur le dépôt en général, la notice de Laloire (E.) et Lefèvre (E.) : les Archives générales du Royaume à Bruxelles; Tableau synoptique des Archives; Renaix, 1903, in-8 (extr. de la Revue des Bibliothèques et des Archives de Belgique, t. I, fasc. I).

\section{Collection dite des Papiers d'État et de l'Audience}

Inventaire sommaire imprimé, par Edg. de Marneffe (dans : Arch. de l'Etat en Belgique. Inventaires sommaires des Archives des anciens gouvernements des Pays-Bas, conservés aux Arch. générales du royaume à Bruxelles ; t. I, Bruxelles, 1906, in-8).

Inventaire manuscrit, plus détaillé, au dépôt. Nous avons vu les documents suivants :

\section{Correspondances}

207. Billets de Tisnacq à Philippe II, avec les apostilles du roi, 1562-69.

239-40. Lettres de Tisnacq, Courteville et Hopperus à Marguerite de Parme et réciproquement, 1560-64.

241. Lettres de Marguerite de Parme à divers (1560-67).

249. Lettres de Viglius à Requesens, 1574-76.

414-75. Billets de Courteville à Viglius.

476. Correspondance de Tisnacq et de Viglius. 


\section{Conseil des Troubles}

Nous n'avons presque rien trouvé, dans les archives de ce Conseil, qui ait trait aux enquêtes menées en Comté, par ordre du duc d'Albe, sur les agissements de la Confrérie de Sainte-Barbe. Aucun document intéressant la Comté, en particulier, dans : 495, Sommaire des actes du Conseil ; 496, Registre aux patentes et commissions ; 499-500-501. Correspondances relatives aux personnes mêlées aux troubles ; 529, principaux seigneurs ; 530, Sentences. Seuls, les interrogatoires d'Egmont en espagnol et leur traduction en français (541-42) renferment quelques indications sur les Gueux de Franche-Comté ; mais les publications antérieures, notamment celle de Bavay, les avaient fait déjà connaître.

\section{Notules du Conseil d'Etat}

Nous avons dépouillé les Notules, cotées 778 (1559-63) ; 779 (1563-65) ; 780 (1566) ; 781 (1567-77). Lacunes très nombreuses et particulièrement regrettables pour la période 1568-1576.

\section{Commissions}

Nous avons vu les nos 785, Commissions des gouverneurs généraux ; 787, Ordonnances et instructions concernant le Conseil des finances et les Chambres des comptes ; 788, Commissions diverses pour le Grand Conseil, le Conseil privé, etc. ; 796 et 801, Instructions diverses pour missions ; 804. Commissions de gouverneurs ; 840, Registres-journaux de lettres patentes dépêchées à l'Audience ; 878, Patentes d'anoblissement ; 879, Requêtes pour anoblissement ; 880, Table des anoblissements depuis 1588 ; 883, Anoblissements sur requêtes. - En plus, pour les nominations ecclésiastiques, les reg. 935-38, contenant de très nombreuses pièces relatives à la Comté ; pour les patentes militaires, le reg. 973 ; pour l'Inquisition, l'original du fameux Registre sur le fait des hérésies (1177). Pour 
mémoire, sous la cote 1192, d'intéressants documents sur la surprise de Besançon en 1575.

La collection Cartulaires et manuscrits est la seule qui nous ait livré des documents relatifs à la Comté. Il ne paraît en exister aucun ni dans le fonds du Conseil privé, ni dans celui du Conseil des finances, malheureusement détruit en grande partie par l'incendie de 1731 (Inv. somm., par de Breyne, indiquant des documents sur le Parlement et la Chambre des Comptes de Dole, mais relatifs au XVIIe s.), ni dans celui du Conseil d'État (Inv. somm., par A. Gaillard ; même remarque); ni dans celui du Grand Conseil.

\section{IIl. ARCHIVES MUNICIPALES DE BESANÇON}

Nous n'avons pas ici à donner d'indications sur ce fonds -puisque nous n'avons pas écrit l'histoire de Besançon dans notre ouvrage. Mais cette histoire étant étroitement en rapport avec l'histoire du Comté, et les archives de la ville renfermant nombre de documents qui complètent ceux des archives du Parlement de Dole, il convient de noter que nous avons dépouillé les registres des Délibérations municipales pour la période qui nous occupe (cf., sur ces registres, l'ouvrage de Castan cité plus loin, no 302), sans compter l'importante série des Comptes municipaux (Inv. somm. mss., au dépôt, par Castan).

\section{BIBLIOTHÈQUE MUNICIPALE DE BESANÇON}

\section{Manuscrits}

Cf. Catalogue général des manuscrits des Bibliothèques publiques de France (départements), t. XXXII-XXXIII (I) XXXIII (2), Bibliothèque de Besançon, par Castan ; Paris, 1895-I9O2, 3 in-8. 


\section{Fonds général}

Nous laissons de côté, pour les raisons indiquées plus haut, tout ce qui concerne la ville de Besançon. - Nous retenons seulement les mss. Cotés :

395. Statuta curiae officialitatis Bisuntinae.

396. Juramenta notariorum practicancium.

397. Formulaire du notaire bisontin Borrey.

539. Steph. Bercin, Vesuntini, Paemata.

600. Gilb. Cognati Epistolœ (copies de Bâle, Ms. Bordier, 1884).

701. De vita ac gestis Claudii, nomine Secundi, archiepiscopi Bisunt., auctore CI. Jacquot.

916-919. Pièces diverses relatives aux États de Franche-Comté au XVIe siècle.

923. Négociations de Claude de Montfort relatives aux États de 1585.

1084. Compte quatrième de la Trésorerie de Dole, oct. 1584-sept. 1585.

1202. Premier registre du Parlement de Dole, concernant les lettres de noblesse, chevalerie, etc.

1204-1216. Recueils Boisot : originaux et copies d'actes importants en matière ecclésiastique et privée, généalogies, contrats, testaments, etc.

1296. Testaments de l'officialité de Besançon (quatre ou cinq seulement intéressent le XVIe Siècle).

\section{Collection Granvelle}

Les deux publications de Weiss et de Poullet-Piot (cf. plus loin, nos 397 et 399) n'ont pas épuisé le très riche fonds des Mss. Granvelle de Besançon. Notamment, une multitude de documents importants soit pour la connaissance parti- 
culière du cardinal, soit pour l'histoire de sa fortune, soit pour l'histoire politique du Comté au XVIe siècle, sont restés inédits. Nous avons dépouillé, pour prendre connaissance de ces documents, les volumes suivants :

III-XXXIII. Mémoires de ce qui s'est passé sous le ministère du chancelier et du cardinal de Granvelle (la plupart des pièces ont été publiées dans les recueils précités. Nous avons vu les inédits ; le catalogue facilite cette tâche puisqu'il indique exactement, à quelques erreurs ou omissions près, les pièces publiées).

XXXV. Démêlés de Claude de la Baume et de Fr. Bonvalot.

XXXVI. Lettres diverses au cardinal (généralement inédites et intéressantes).

XXXVIII. Correspondance du Parlement avec le gouverneur et réciproq. (1561-1600).

XXXIX. Id., du Parlement et de la Chambre des Comptes avec le gouverneur (1545-1594).

XL. Papiers d'affaires et divers de la famille Perrenot.

LXXVI-VII. Lettres de Joachim Hopperus (1567-76).

LXXXIII-V. Correspondance du cardinal et de Jacques de Saint-Mauris (1555-1601).

LXXXVII-IX. Correspondance de MM. de Vergy.

IC, C CI, CII. Supplément (1560-1584).

\section{Collection Chiflet}

De cette très riche collection, nous avons vu notamment les volumes suivants :

7-8. Démêlés de Fr. Bonvalot avec divers chanoines.

19. Chapitres, abbayes, prieurés de Franche-Comté (XVIe s.).

28. État de la Comté pendant la seconde moitié du XVIe siècle.

33. Second tome des recès et papiers des États ; 1561-1598.

39. Gouvernement de la Comté et négociations avec les Suisses. 
40. Formulaire d'Ét. Delesmes, 1554.

45-56. Tomes 4 et 6 des Papiers importants en matière civile.

54. Recueil relatif au Parlement.

127. Lettres d'Hopperus.

174. Lettres de P. Poutier à J. Chiflet (1589-1598).

\section{BIBLIOTHÈQUE NATIONALE}

\section{Manuscrits}

Cf. Ul. Robert, Catalogue des Mss. relatifs à la Franche-

Comté, conservés dans les Bibliothèques de Paris (M. Soc. Jura, 1876 et 1878 ; à part, Paris, 1878, in-8).

Les collections de la B.N. ne renferment que très peu de pièces originales relatives à la Comté ; elles contiennent surtout (notamment la Collection Moreau, de beaucoup la plus riche) des copies récentes de documents qui existent dans les dépôts bisontins à l'état soit d'originaux, soit de copies anciennes.

Retenons seulement les volumes suivants :

FONDS LATIN. - 9932. Mélanges relatifs à la Comté. - 10974.

Recueil de compliments et de vers adressés au Président Jean Froissard par les élèves du collège de Dole. - 9961 et suiv. Acta Rectoria Universitatis Parisiensis, 1519 et suiv. Nouv. Acq. LAT. - 189. Statuta curiae archiepiscopalis

Bisuntinœ. - 201. Lettres du Chapitre de Besançon en 1554. FONDS FRANÇAIS. - 5122. Pièces diverses sur la neutralité

(XVIe s.). - 7122-23-24. Copie de lettres de Granvelle à Bellefontaine (XVIIIe s.). - 11442-43. Notes historiques tirées de la correspondance de Granvelle (XVIIIe s.). - 11629-30. Documents relatifs aux Sauneries de Salins. - 22598. Limite des Duché et Comté de Bourgogne. - 23389. Neutralité (XVIIIe s.). 
NOUV. ACQ. FRANÇ. - 710. Enquêtes sur les méfaits des gens de guerre en 1518 dans le bailliage d'Aval (1578). - 771. Registre des actes du notaire comtois Séb. Bourgeois, 1537-57. -1034. Recueil relatif au Parlement de Dole ; lettres diverses. COLLECTION MOREAU. - 901. Copies de lettres écrites par les souverains au Parlement (1510-1667). - 914-15. Délimitation de la Comté avec la Lorraine et la Champagne (1610-11) - 924. Neutralité. - 935-36. Ordonnances du Parlement, de 1573 à1579. - 954. Lettres du Parlement aux souverains (15591672).

COLLECTION DUPUY. - 43. Limites du Comté. - 266. Procès GemelliLeblanc, 1562.

COLLECTION DE BOURGOGNE. - 112. Registre des délibérations des États de Comté de 1484 à 1606 (orig.). - 117. Actes originaux émanés des souverains. - 119. Documents (originaux et copies) sur les abbayes et prieurés du Comté.

COLLECTION DE LORRAINE. - 417-18. Limites du Comté.

\section{IMPRIMÉS}

\section{TABLE DES COLLECTIONS ET RECUEILS PÉRIODIQUES FRÉQUEMMENT CITÉS, AVEC LES ABRÉVIATIONS}

Recueils comtois

A. Fr.-Comtoises. - Annales Franc-Comtoises (Besançon).

An. Doubs. - Annuaire du département du Doubs.

An. Gray. - Annuaire de l'arrondissement de Gray.

An. Jura. - Annuaire du département du jura.

An. Haute-Saône. - Annuaire du département de la Haute-Saône. 
B. Acad. Besançon. - Académie des Sciences, Belles-Lettres et Arts de Besançon, Bulletin trimestriel.

B. Soc. Grayloise. - Bulletin de la Société Grayloise d'Émulation.

B. Soc. Haute-Saône. - Bulletin de la Société d'Agriculture, Sciences et Arts de la Haute-Saône (Vesoul).

B. Soc. Poligny. - Bulletin de la Société d'Agriculture, Sciences et Arts de Poligny.

Doc. Hist. Fr.-C. - Mémoires et Documents p. s. à l'histoire de FrancheComté, p. p. l'Académie de Besançon.

M. Acad. Besançon. - Académie... de Besançon. Procès-Verbaux et Mémoires.

M. Soc. Doubs. - Mémoires de la Société d'Émulation du Doubs (Besançon).

M. Soc. Jura. - Mémoires de la Société d'Émulation du Jura (Lons-le-Saunier).

M. Soc. Montbéliard. - Mémoires de la Société d'Émulation de Montbéliard.

Vieux Lons. - Le Vieux Lons.

\section{Autres recueils}

A. Soc. Vosges. - Annales de la Société d'Émulation des Vosges.

A. Soc. Ain. - Annales de la Société d'Émulation de l'Ain.

Arch. cur. - Archives curieuses de l'histoire de France (Cimber et Danjou).

Arch. ôsterreich. Gesch. - Archiv für österreichische Geschichte (Vienne).

B. Acad. Belgique. - Bulletin de l'Académie royale de Belgique (Classe des lettres).

B. Com. Arch. - Comité des Travaux historiques. Bulletin Archéologique.

B. Com. Géog. - Comité des Travaux historiques. Bulletin de géographie historique et descriptive. 
B. Com. Hist. - Comité des Travaux historiques. Bulletin historique et philologique.

B. Comm. Hist. belge. - Bulletin de la Commission royale d'histoire belge.

B. Com. Sc. éc.-soc. - Comité des Travaux historiques. Bulletin des Sciences économiques et sociales.

B. Éc. Chartes. - Bibliothèque de l'École des Chartes.

B. Éc. H.- É. - Bibliothèque de l'École des Hautes-Études.

B. Prot. Français. - Bulletin de la Société d'histoire du Protestantisme Français.

B. Soc. Arch. Lorraine. - Bulletin de la Société d'Archéologie lorraine.

Chron. belges. - Collection de Chroniques belges inédites, p. p. le gouvernement.

Doc. Hist. France. - Ministère de l'Instruction Publique et des Beaux-Arts. Collection de documents inédits sur l'histoire de France.

Doc. Hist. Espana. - Collection de documentos ineditos para la historia de Espana.

Doc. Hist. Suisse Rom. - Documents p. p. la Société d'histoire de la Suisse Romande.

J. Sav. - Journal des Savants.

M. Acad. Belgique. - Mémoires couronnés et autres Mémoires p. p. l'Académie Royale de Belgique.

M. Hist. belge. - Collection de Mémoires relatifs à l'histoire de Belgique (publ. de la Société de l'histoire de Belgique).

M. Soc. Arch. Lorraine. - Mémoires de la Société d'archéologie lorraine.

Mus. Neuchatel. - Musée neuchatelois.

Posit. Éc. Chartes. - École nationale des Chartes. Position des Thèses soutenues par les élèves.

R. Bibl. Belgique. - Revue des Bibliothèques et Archives de Belgique.

R. Bourguignonne. - Revue Bourguignonne d'Enseignement Supérieur. 
Réun. Soc. Beaux-Arts. - Réunion des Sociétés des Beaux-Arts des départements.

R. H. - Revue historique.

R. H. M. - Revue d'histoire moderne et contemporaine.

R. Q. H. - Revue des questions historiques.

R. S. - Revue de Synthèse historique.

R. Soc. Sav. - Revue des Sociétés Savantes.

\section{PRINCIPAUX OUVRAGES CONSULTÉS}

Bibliographie

I. FEBVRE (L.). Les régions de la France, IV, la FrancheComté ; Paris, 1905, in-8 et R. S., t. X, 1905, p. 176 et suiv. et 319 et suiv. ; t. XI, 1905, p. 64 et suiv.

2. HAUSER (H.). Les sources de l'histoire de France, XVIe siècle. Fascic. I et II ; Paris, 1905-1909, in-8.

3. PIRENNE (H.). Bibliographie de l'histoire de Belgique ; Bruxelles, 2e édit., 1902, in-8.

Histoires générales du Comté

4. CLERC (Ed.). Essai sur l'histoire de la Franche-Comté ; t. I, 2e édit., Besançon, 1810, in-8 ; t. Il, 1846, in-8.

5. DUNOD (F. I.). Histoire des Séquanois et de la province séquanoise, des Bourguignons et du premier royaume de Bourgogne, de l'Église de Besançon jusque dans le VIe siècle et des abbayes nobles du Comté ; Dijon, 1735, in-4.

6. - Mémoires p. s. à l'histoire du Comté de Bourgogne, contenant le nobiliaire du Comté ; Besançon, 1740, in-4 
7. - Histoire du second royaume de Bourgogne, etc., avec une description du Comté de Bourgogne et plusieurs généalogies ; Dijon, 1757, in-4.

8. GOLLUT (L.). Les Mémoires historiques de la République Séquanoise et des princes de la Franche-Comté de Bourgongne ; Dole, 1592, in-fol. - Édition moderne, avec notes et éclaircissements par Ch. Duvernoy et Emm. Bousson de Mairet ; Arbois, 1846, in-4 (nous citons d'après l'édition moderne, l'originale étant fort rare).

La Comté au XVe siècle : Cartes, Descriptions, Voyages, Itinéraires

9. COUSIN (G.). Brevis ac dilucida superioris Burgundiae, quae Comitatus nomine censetur, descriptio, per Gilbertum Cognatum Nozerenum ; Ire édit., Bâle, Oporin, 1552, in-8 (B. N., Lk2 743). - 2e édit., Bâle, 1562, avec modifications et additions, dans Opera Cognati (plus bas, $n^{\circ} 226$ ), t. I, p, 323 et suiv. - Traduction avec notes et réimpr. du texte de 1562 par A. Chéreau, Lons-le-Saunier, 1863, in8. - Traduction nouvelle, annotée et suivie du texte latin collat. sur les textes de 1552 et 1562, avec les variantes, par E. Monot : La Franche-Comté au milieu du XVIe siècle ou Description de la Haute-Bourgogne..., par G. Cousin ; Lons, 1907, in-8. Nous citons d'après cette édition.

10. - Brevis admodum totius Galliae descriptio ; Ire édit., Bâle, s. d. [1552], in-8, à la suite du précédent ; réimpr, en 1562, sans changement, dans les Opera Cognati, t. I, p. 370-80.

11. - Galliae populorum, urbium, fluminum et montium... locupletissimus index latino-gallicus. Fait suite au précédent, tant dans l'édit. de 1552 que dans les Opera, p, 393-99.

12. DA L'HERBA. Itinerario delle poste pet diverse parte del mondo ; Brescia, 1562, in-8.

13. Deliciarum Germaniae index, suivi de Deliciae Galliae ; Cologne, W. Lutzenkirchen, 1608, in-12.

14- ESTIENNE (Ch.). Le Guide des chemins de France ; Paris, 1552, in -12.

15. GAUTHIER (J.). Un voyageur allemand en Franche-Comté au XVIe s. ; M. Acad. Besançon, 1886, p. 46 et suiv. 
16.- Les cartes anciennes et modernes de Franche-Comté ; B. Com. Géog., 1895, p. 302 et suiv.

17. - Pèlerinage de Ph. de Vigneulles, bourgeois de Metz, jusqu'à SaintClaude en 1512 ; An. Doubs, 1898, p. 40 et suiv.

18. GEIZKOFLER (L.). Mémoires (1550-1620), traduits et édités par Ed. Fick ; Genève, 1892, in-8.

19. HYENNE (S. E.). De la corvée en France et en particulier dans l'ancienne province de Franche-Comté ; Paris-Besançon, 1863, in-8.

20. LALAING (A. DE). Relation du voyage de Philippe le Beau en Espagne en 1504 p. p. Gachard, Voyages des Souverains des Pays-Bas, t. I, Bruxelles, 1876, in-4 (Public. Comm. hist. belge).

21. MAYERNE-TURQUET (Th. DE ). Sommaire description de la France, Allemagne, Italie et Espagne, avec la Guide des Chemins et Postes ; Rouen, 1643, in-8.

22. MONTAIGNE (M. DE). Journal de Voyage, p. p. L. Lautrey ; Paris, 1906, in-8.

23. MUNSTER (Séb.) et BELLEFOREST (Fr. DE). La Cosmographie universelle de tout le monde ; auteur en partie Munster, mais beaucoup plus augmentée, ornée et enrichie par Fr. de Belleforest, Commingeois ; Paris, 1575, 2 Vol. en 3 t. in-fol.

24. ORTEL (Abr.). Theatrum Orbis Terrarum Abrahami Orteli Antverp., éd., Vintrius ; Anvers, 1603, in-fol.

25. PERRENET (G.). Itinéraire des députés suisses se rendant à la cour de Henri III ; A. Fr.-Comtoises, t. III, p. 167 et suiv.

26. PINET (A. Du). Plans, pourtraitz et descriptions de plusieurs villes et forteresses ; Lyon, 1564, in-fol. ; B. N., Inv., G 638, in-fol.

27. ROBERT (Ul.). Voyage de H. et R. de Nassau en Franche-Comté, 153334 ; M. Soc. Jura, 1898. 
Textes coutumiers et législatifs ; commentaires anciens

28. Ordonnances de la court de Parlement : et aultres officiers de l'empereur. En son côté de Bourgoingne, touchant la justice et administratio d'icelle; S. 1. n. d. [1539], pet. in-8, gothique. Coloph. : Imprimées pour Mongeot Danoux, marchand libraire demourant à Dole (Bibl. Munic. Besançon, 268.811).

29. Les Coustumes et ordonnances généralles du Conté de Bourgoingne, ausquelles sont adjoustez plusieurs Edictz et mandements de nouveau publiez ... ; Lyon, G. Regnault, 1540, 32 ff. in-4 (ibid., 64-458)

30. Ordonnances Impériales à la court souveraine de Parlement à Dole et aultres officiers du Conté de Bourgoingne, sur le fait de la justice et abréviation des procez ; Lyon, G. Regnault, 1540, 28 ff. in 4 (rééd. du n² 28, suivie d'édits du 20 mars 1539-40 ; ibid., 64-458).

31. Les ordonnances anciennes, observées en la court souveraine du Parlement de Dole et aux autres justices inférieures du Conté de Bourgoingne; Lyon, G. Regnault, 1540, 28 ff. in-4 (ibid., 64-458).

32. Ordonnances et édicts du pays et conté de Bourgongne, Charroloys, etc., faictes par l'Empereur et publiées en l'audience publique de la Court Souveraine de Parlement à Dole, 1545, Dijon ; J. des Planches, 1550, 32 p. pet. in-8 (ibid., 226-670 ; B. N., Inv. Rés., F 1516).

33. Les Ordonnances impériales à la court souveraine de Parlement et autres officiers du Conté de Bourgongne : sur le faict de la justice et abreviatio des procès ; on les vend à Dole par Mongeot Danot ; Dijon, J. des Planches, 1552, 160 p. pet. in-8 (Bibl. Besançon, 226.670 ; B. N., Inv. Rés., F 1516 ; texte des ordonnances de 1539 , comme dans les $n^{\circ}$ s 28 et 30 ; en plus, mandements sur les bulles apostoliques et les péages). -2e édit., identique, Dijon, J. des Planches, 1553 (Bibl. Bes., 226.671).

34. Les Coutumes générales du Conté de Bourgogne ; Dijon, J. des Planches, 1552, 64 p. in-8 ; cf. plus haut, $\mathrm{n}^{\circ} 29$; en plus, divers mandements et édits, paginés de I à 157, sans titre distinct (Bibl. Bes., 226.671 ; ibid., 226.670 et B. N., Inv. Rés., F 1516). 
35. Les Ordonnances anciennes du Conté de Bourgogne ; Dijon, J. des Planches, pour Mongeot Danot demeurant à Dole, 1552, 159 p. pet. in-8 (cf. plus haut, n 31 ; Bibl. Besançon, 226.670 ; B. N., Inv. Rés., F 1516). - 2e édit., identique, Dijon, J. des Planches, 1553 (Bibl. Besançon, 226.671).

36. Ordonnances et édits du pais et Conté de Bourgogne, Charroloys, etc. ; Dijon, J. des Planches, 1553, 30 p. pet. in-8 (p. 30 : A Dijon, de l'imprimerie de Jean des Planches, 1552) ; Cf. plus haut, nº 32 ; Bibl. Besançon, 226.671.

37. Ordonnances de très haut, etc... prince Charles... publiées en sa cour souveraine de Parlement à Dole; reveües et augmentées de nouveau de plusieurs autres choses...; on les vend à Dole, en la boutique de J. Droz, librairie; Lyon, P. Roussin, 1570, 4 + 8 ff. + 175 p. num., in-fol. ; Bibl. des Arch. dép. du Doubs, ${ }^{\circ}$ 262 [Recueil contenant, outre les ordonnances de 1539 (p. 1-113), Celles du duc Jean sur la guerre (p. 113) ; celles de 1564 (p. 117) ; les coutumes (p. 133) ; les coutumes déclarées notoires (p. 148); le taux des frais de justice de 1553 ; l'arrêt d'union de la terre de Saint-Claude, 1537 ; le concordat de 1559 avec l'archevêque de Besançon et l'édit d'institution de la Chambre des comptes].

38. Recueil d'aucuns édicts, statuts et mandements publiez et observez au conté de Bourgoingne; divisé en unze parties; ausquels sont adjoustez deux mandemens du Roy, publiez depuis led. recueil faict, contre les recelateurs des biens des rebelles, leurs fauteurs et assistans ; on les vend à Dole en la boutique de J. Droz, libraire ; Lyon, P. Roussin, 1570, 8 ff. + 250 p. num., in-fol. (Ce recueil est l'oeuvre du greffier CI. Delesmes ; ibid., ${ }^{\circ} 262$.)

39. Ordonnances de très haut, etc., prince Philippe, par la grâce de Dieu Roy des Espaignes, Conte de Bourgongne ; publiées en sa court de Parlement à Dole, le douzième jour du mois de novembre 1573. On les vend à Dole, en la boutique de J. Cotard, libraire ; Lyon, P. Roussin, 1574 ; 50 p. in-fol. (ibid., n 262 ; ex. unique ?).

40. Ordonnances de très haut, etc., prince Philippe..., publiées en sa court de Parlement à Dole, le quatorzième d'avril 1586 ; on les vend à Dole, en la boutique de Guill. Delivrand, libraire juré de l'Université ; Lyon, J. d'Ogerolles, 1586 ; 194 p. in-4 (Bibl. Besançon, 226.673 et 267.311 ; B. N., Rés., F 1292).

41. Ordonnances, déclarations et interprétations faictes par S. M. TrèsCatholique sur les articles à elle présentez par les gens des trois estatz de sa Fran- 
che-Comté de Bourgongne ; publiées en sa court souveraine de Parlement à Dole le second jour du mois de mars l'an 1587 ; à Dole, par J. Poyvre et J. Ravoillot, 1587, 42 p. in-4 (suivies, p. 29 sqq., du mandement au fait des placet sur les provisions de bénéfices par les ordinaires ; p. 34, de l'édit sur la peste ; p. 36, de l'édit sur la nourriture des pauvres).

42. Mandement de S. M., du taxe des fraitz de justice en son conté de Bourgogne ; à Dole, par Ant. Dominique, imprimeur ; 1588, 20 p. in-4 (Bibl. Besançon, 226.672). - 2e édit., 1592, in-4 ; B. N., Rés., F 1294

43. PÉTREMAND (J.). Recueil des ordonnances et édictz de la FrancheConté de Bourgongne ; Dole, 1619, in-fol.

44. BOGUET (H.). In consuetudines generales Comitatus Burgundiae observationes ; Lyon, 1604, in-8 ; Besançon, 1725, in-8 (cit. d'après la 2e édit.).

45. DUNOD (F.-I.). Observations sur les titres des droits de justice, des fiefs, des cens, des gens mariés et des successions de la coutume du Comté de Bourgogne, avec des traités... sur les institutions contractuelles, la puissance paternelle, les sociétés tacites, les baux à cheptel et une dissertation sur les incendies ; Besançon, 1756, in-4

46. GRIVEL (J.). Decisioncs celeberrimi Senatus Dolani ; Anvers, 1618 ; Genève, 1622 et 1660 ; Dijon, 1731, in-fol. (cit. d'après cette dernière édit., plus correcte).

47. SAINT-MAURIS (Prudent DE). La Practique et stil judiciaire observé tant ès cours de Parlement que tribunaux de justice au conté de Bourgoingne. On les vend à Dole, en la boutique de J. Tarlot, libraire ; Lyon, P. Roussin, 1577, 12 ff. + 96 p. num. +22 ff. in-4.

Histoire administrative, Institutions

48. CLERC (E.). Histoire des États généraux et des libertés publiques en Franche-Comté ; Besançon, 1882, 2 in-8.

49. DROZ (F.). Essai sur l'histoire des bourgeoisies du roi, des seigneurs et des villes ; Besançon, 1760, in-8. 
50. DUBOIS DE JANCIGNY (A.). Recueil de chartes et autres documents p. s. à l'histoire de la Franche-Comté sous les princes de la maison d'Autriche ; Vesoul, 1869, in-8.

51. DUPONT-FERRIER (G.). Les officiers royaux des bailliages et sénéchaussées et les institutions monarchiques locales en France à la fin du moyen âge (B. Ec. Htes-Et., fasc. 145) ; Paris, 1902, in-8.

52. LURION (R. DE). Notice sur la Chambre des comptes de Dole, suivie d'un armorial de ses officiers. Besançon, 1892, in-8.

53. PERRECIOT. Dissertation sur l'origine, la forme et les pouvoirs des États de Franche-Comté, 1765 ; p. avec notes et pièces justificatives dans Doc. hist. Fr.C., t. VII, 1876, p. 97.

54. THIBOUDET (A.). Trois recès inédits des États de Franche-Comté, 1498, 1507, 1538 (M. Soc. Jura, 1873)

55. TROYES (A. DE). La Franche-Comté de Bourgogne sous les princes espagnols de la maison d'Autriche. Première partie : les Recez des Etats ; Paris, 1847,4 in-8.

56. TUETEY (A.). Étude sur le droit municipal au XIIIe et au XIVe s. en Franche-Comté et particulièrement à Montbéliard ; Montbéliard, 1864, in-8

\section{Condition des personnes et des terres}

57. DEY (A.). Étude sur la condition des personnes, des biens et des communes au comté de Bourgogne pendant le moyen âge (B. Soc. Hre-Saône, 18691874 ; à part, Paris, 1870-72, in-8).

58. DUNOD (F.-I.). Traité de la mainmorte et des retraits ; Epinal, 1761, in-4.

59. FINOT (J.). Affranchissements inédits de la mainmorte dans le bailliage d'Amont, 1260-1790 (B. Soc. Hte-Saône, 1879).

60. - Études sur la mainmorte dans le bailliage d'Amont aux XIIIe, XIVe et XVe siècles, d'après des documents inédits (B. Soc. Hte-Saône, 1881). 
61. GÉRARD (L.). De la condition des mainmortables dans la coutume de Franche-Comté ; Paris, 1895, in-8 (thèse de droit).

62. PERRECIOT. De l'état civil des personnes et de la condition des terres dans les Gaules dès les temps celtiques jusqu'à la rédaction des coutumes ; Besançon, 1786, 2 in-4.

63. SÉE (H.). Les classes rurales et le régime domanial en France au moyen âge ; Paris, 1901, in-8.

64. - Les classes rurales en Bretagne du XVIe siècle à la Révolution ; Paris, 1906, in-8.

Agriculture, Industrie, Commerce, Monnaies, Mesures

65. AGRICOLA (G.). De Re Metallica libri XII ; Bâle, Froben, 1561, in-fol.

66. BÉCHET (J.-B.). Notions faciles et indispensables sur les nouveaux poids et mesures, avec des tables de comparaison ; Lons-le-Saunier, an IX, in-8.

67. BONZON. La banque à Lyon aux XVIe, XVIIe et XVIIIe s. (R. d'histoire de Lyon, 1902, p. 433-46 ; 1903, p. 46-63).

68. BOREL (F.). Les foires de Genève au XVIe s. ; Genève-Paris, 1892, in-4.

69. COULON (A.). Les forêts en Franche-Comté, du Ier au XVIIe s. (Posit. Ec. Chartes, 1893).

70. FABIANO (R. P.). Tractatus de Cambiis... in melius reformatus ; Gênes, Belloni, 1568, in-4 (B. N., Inv., E 402).

71. FINOT (J.). La seigneurie de Ronchamp et l'origine de l'exploitation des houillères de cette localité, 1220-1789 (R. d'hist. nobiliaire et d'archéol. héraldique, 1882, p. 289-303 ; 385-397).

72. GAUTHIER (J.). L'industrie du papier dans les hautes vallées franccomtoises, du XVe au XVIIIe s. (M. Soc. Montbéliard, 1897).

73. GAUTHIER (L.). Les Lombards des Deux Bourgognes ; Paris, 1906, in-8 (B. Ec. Htes Et., fasc. 156). 
74. [GRAPPIN (dom)]. Recherches sur les anciennes monnaies du comté de Bourgogne, avec quelques observations sur les poids et mesures autrefois en usage dans la même province ; par un bénédictin de la congrégation de Saint-Vanne ; Paris-Besançon, 1782, in-8.

75. LEVASSEUR (É.). Histoire des classes ouvrières et de l'industrie en France avant 1789 ; 2e édit., Paris, 1903, 2 in-8.

76. - Mémoire sur les monnaies du règne de François Ier (Introd. au t. 1 du Recueil des ordonnances de François Ier, p. p. l'Académie des sciences morales ; Paris, 1902, in-4).

77. DEMOLE (E.). Histoire monétaire de Genève de 1535 à1792 ; ParisGenève, 1887, in-4.

78. HAUSER (H.). La controverse sur les monnaies de 1566 à1578 (B. Com. Sc. éc.-soc., 1905)

79. LONCHAY (H.). Recherches sur l'origine et la valeur des ducats et des écus espagnols (B. Acad. Belgique, 1906).

80. MERLE (A.). Les gîtes minéraux et métallifères et les eaux minérales du département du Doubs ; Besançon, 1905, in-8.

81. NICOLAY (N. DE). Description générale de la ville de Lyon et des anciennes provinces du Lyonnais et du Beaujolais, p. et annot. p. la Soc. de Topogr. hist. de Lyon ; Lyon, 1881, in-fol.

82. PLANTET (L.) et JEANNEZ (L.). Essai sur les monnaies du comté de Bourgogne, depuis l'époque gauloise jusqu'à la réunion ; Lons-le-Saunier, 1855, in-4.

83. PLANTET (D.). Liste des monnaies franc-comtoises (R. belge de numismatique, 1855, p. 87-103).

84. POEY D'AVANT (F.). Monnaies féodales de France, t. III, FrancheComté ; Paris, 1862, in-4

85. PRINET (M.). L'industrie du sel en Franche-Comté avant la conquête française (M. Soc. Doubs, 1996-97-98) ; à part, Besançon, 1900, in-8. 
86. PURICELLI. Recherches sur les anciennes monnaies du Comté de Bourgogne ; Besançon, 1761, in-4.

87. RIAT (G.). Étude historique et économique des moulins de la FrancheComté et du pays de Montbéliard, du Xe siècle à la Révolution (Posit. Ec. Chartes, 1895).

88. Tables de comparaison entre les mesures anciennes en usage dans le département du Doubs et celles qui les remplacent dans le nouveau système métrique ; Besançon, an X, in-4.

89. Traité politique et économique des Chétels, par un ancien avocat du Parlement de Bourgogne ; Dijon, 1765, in-12.

90. VAISSIER (A.). La vigne et les vignerons à Besançon (M. Acad. Besançon, 1899).

91. VIGNE (M.). La banque à Lyon du XVe au XVIIIe s. ; Lyon-Paris, 1903, in-8.

Vie privée, familles, livres de raison

92. CASTAN (A.). Monographie du palais Granvelle (M. Soc. Doubs, 1866).

93. - La table sculptée de l'hôtel de ville de Besançon et le mobilier de la famille Gauthiot d'Ancier (ibid., 1879).

94. - Inventaire général des richesses d'art, Province, t. V, Musées de Besançon ; Paris, 1891, in-8.

95. FEUVRIER (J.). Feuillets de garde, les Mairot (M. Soc. Jura, 1901).

96. GAUTHIER (J.). Notes sur quelques livres de raison franc-comtois (M. Acad. Besançon, 1886).

97. - La vie d'un prélat franc-comtois au milieu du XVIe s. (ibid., 1890).

98. - Iconographie de Nicolas et d'Antoine Perrenot de Granvelle (Réun. Soc. B.-A., 1900). 
99. GUIGNARD (F.). Étude sur le testament au comté de Bourgogne, d'après les testaments de l'officialité de Besançon, 1265-1500 ; Paris, 1907, in-8 (thèse de droit).

100. Livre de raison de la famille Froissard de Broissia, 1532-1701 (M. Soc. jura, 1886).

101. LONGIN (E.). Le manuscrit de Jacques Cordelier de Clairvaux, 15701637 (M. Soc. Jura, 1898).

102. PIDOUX (A.-P.). Histoire du mariage et du droit des gens mariés en Franche-Comté, depuis la réduction des coutumes en 1459 jusqu'à la conquête de Louis XIV ; Dole, 1902, in-8.

103. PRINET (M.). Journal du poète Jean Vuillemin (M. Acad. Besançon, 1905).

104. PROST (B.). Inventaire mobilier d'une famille franc-comtoise en 1531 (B. Soc. Poligny, 1874).

105. - Extraits d'un livre journal tenu par une famille bourgeoise de Bletterans, 1542-1661 (ibid., 1877).

106. - Les choses mémorables ; chronique franc-comtoise de 1535 à 1559, par le sr Godard de Chevreaux (Mém. Soc. Jura, 1875).

107. - Annales de Franche-Comté, 1582-1789 (ibid., 1876).

108. QUIQUEREZ (A.). Les derniers sires d'Asuel et le mobilier de leurs résidences au XVIe siècle (M. Soc. Doubs, 1867).

109. ROBERT (U.). Les testaments de l'officialité de Besançon (1265-1500). Paris, t. I, 1902 ; t. II (p. p. Prinet), 1907, in-4 (Doc. Hist. France).

\section{Biographies et Généalogies}

110. BEAUSÉJOUR (E. DE). Quelques documents inédits relatifs à la terre, à la seigneurie et au nom de Grandvelle (B. Soc. Hte-Saône, 1899).

111. BERTIN (J.). Histoire généalogique de la maison de Beaujeu (B. Soc. Hte-Saône, 1901 et 1902). 
112. - Les Beaujeu de Franche-Comté dans le Duché de Bourgogne, l'Auxerrois, le Tonnerrois, la Champagne, etc. (M. Soc. bourguignonne géogr. et histoire, 1903).

113. BRANTS (V.). Un ministre belge au XVIIe s. : Jean Richardot, chefprésident du Conseil privé des Pays-Bas, 1597-1609 (B. Acad. Belgique, 1901).

114. BRANTS (V.). Jean Richardot, archevêque de Cambrai ; Louvain, 1902, in-8.

115. BRUNE (abbé). Une collection de portraits historiques : les Watteville en Franche-Comté (Réun. Soc. B.-A., 1900).

116. CASTAN (A.). La mort de François Ier et l'avènement de Henri Il, d'après les dépêches secrètes de Jean de Saint-Mauris (M. Soc. Doubs, 1878).

117. [CHIFLET, jules]. Traité de la maison de Rye ; s. 1. n. d. [1744], in-fol.

118. Du CHESNE (A.). Histoire généalogique de la maison de Vergy ; Paris, 1625, in-fol.

119. DUFLOT (L.). Un orateur du XVIe s., François Richardot, évêque d'Arras ; Arras-Paris, 1898, in-8.

120. [DUVERNOY, Ch]. Notice sur les maisons de Granvelle et de SaintMauris Montbarrey, Besançon, 1839, in-8.

121. FINOT (J.). Les anoblissements en Franche-Comté pendant la période espagnole (An. Jura, 1868, et R. nobiliaire, 1868).

122. GAUTHIER (J.). Les Gorrevod et leur sépulture dans l'église de Marnay (M. Soc. Doubs, 1869).

123. - Du degré de confiance que méritent les généalogies historiques : Jean Lallemand, de Dole (ibid., 1902).

124. - et SAINTE-AGATHE (J. DE). Obituaire du chapitre métropolitain de Besançon, XIe-XVIIe siècle, p. avec notes, éclaircissements et tables ; Besançon, 1901, in-8.

125. GERMAIN (L.). Jean de Ville, seigneur de Saint-Rémy (B. Soc. Arch. Lorraine, 1904). 
126. GUILLAUME (J.-B.). Histoire généalogique des sires de Salins au comté de Bourgogne, avec des notes historiques et généalogiques sur l'ancienne noblesse de cette province ; t. I, Besançon, 1757, in-4. - T. Il, Histoire de la ville de Salins avec une dissertation sur l'indépendance de la seigneurie de ce nom, le nobiliaire de cette ville, etc., Besançon, 1758, in-4.

127. LEVESQUE (dom P.). Mémoires p. s. à l'histoire du cardinal Granvelle ; Paris, 1753, 2 in-I2.

128. LORAY (Mis DE). La succession du cardinal de Granvelle (M. Acad. Besançon, 1887).

129. LURION (R. DE). Nobiliaire de Franche-Comté ; 2e édit., Besançon, 1894, in-8.

130, MARLET (A.). La vérité sur l'origine de la famille Perrenot de Grandvelle ; Dijon, 1859, in-8. CL en outre, id., Notes sur la généalogie des Perrenot (M. Soc. Doubs, 1865).

131. MONNIER (D.). Les Jurassiens recommandables; Lons-le-Saunier, 1828, in-8.

132. PERROD (M). Philibert de la Baume (M. Acad. Besançon, 1906).

133. RANCE DE GUISEUIL. Les chapelles de l'Église Notre-Dame de Dole ; Paris-Dole, 1902, in-8.

134. SAINT-MAURIS (C. E. P., Mis DE). Généalogie historique de la maison de Saint-Mauris, du comté de Bourgogne ; Vesoul, 1830, in-fol.

135. SIMONNET. Tables généalogiques de la maison de la BaumeMontrevel ; s. 1. n. d., in-fol. (Bibl. Sainte-Geneviève, fol. L 351(2)).

136. SUCHAUX (L.). Galerie biographique du département de la HauteSaône ; Vesoul, 1864, in-8.

137- TRIDON (M.). Simon Renard, ses ambassades, ses négociations, sa lutte avec le cardinal Granvelle, 1513-1573 (M. Soc. Doubs, 1881).

138. VIÉNOT (J.). Un apologiste de la Saint-Barthélemy, Pierre Charpentier (Séance de rentrée des cours de la Faculté de théologie protestante, 1902 ; Paris, 1903, in-8). 
139. WEISS (Ch.). Notice préliminaire sur la collection Granvelle et sur les principaux personnages qui y figurent (Papiers d'État du cardinal de Granvelle, t. I, p. I-LVII, Paris, 1841, in-4).

Histoire locale

140. LAURENS. Dictionnaire des communes du Doubs (An. Doubs, 1844 à 1848 ; 1853).

141. MARTIGNIER (D.) et CROUZAZ (A. DE). Dictionnaire historique, géographique et statistique du canton de Vaud (Publ. Soc. Hist. Suisse Romande) ; Lausanne, 1867, in-8.

142. ROUSSET (A.). Dictionnaire géographique, historique et statistique des communes de la Franche-Comté. Département du Jura. Lons-le-Saunier, 1857, 6 in-8.

143. SUCHAUX (L.). La Haute-Saône, Dictionnaire historique, topographique et statistique des communes du département. Vesoul, 1866, 2 in-8.

144. ABRY D'ARCIER. Histoire d'Arlay (M. Soc. Jura, 1881 et 1882).

145. BÉCHET (J.-B.). Recherches historiques sur la ville de Salins ; Besançon, 1828, 2 in- 12.

146. - Notice historique sur Cernans et ses environs (M. Soc. Jura, 1881).

147. BEURLIN (P. F.). Recherches historiques sur l'ancienne seigneurie du Chatelot (M. Soc. Montbéliard, 1887 et 1889).

148. BOUCHEY (abbé). Recherches historiques sur la ville, la principauté et la République de Mandeure ; Besançon, 1862, 2 in-8.

149. BOURGON. Recherches historiques sur la ville et l'arrondissement de Pontarlier ; t. I (seul paru), Pontarlier, 1840, in-8.

150. BOUSSON DE MAIRET (Emm.). Annales historiques et chronologiques d'Arbois... depuis son origine jusqu'en 1830 ; Arbois, 1856, in-8.

151. BRIFFAULT (abbé). Histoire de la seigneurie et ville de Champlitte ; Langres, 1869, in-8. 
152. BRUN (X.). Histoire de la seigneurie d'Andelot-lez-Coligny (Jura); M. Soc. Émulation Ain, 1904-08.

153. CHEVALIER (Fr.-F.). Mémoires historiques sur la ville et seigneurie de Poligny, avec des recherches relatives à l'histoire du Comté de Bourgogne et de ses anciens souverains, et une collection de chartes intéressantes; Lons-leSaunier, 1767-69, 2 in-4.

154. COUDRIET ET CHATELET (abbés). Histoire de la seigneurie de Jonvelle et de ses environs ; Besançon, 1864, in-8.

155. - Histoire de Jussey ; Besançon, 1876, in-8.

156. CRESTIN. Recherches historiques sur la ville de Gray ; Besançon, 1788, in-8.

157. DEY (A.). Mémoires p. s. à l'histoire de la ville de Luxeuil (M. Comm. Arch. Haute-Saône, t. III et IV, Vesoul, 1862-67, in-8).

158. DROZ. Mémoires p. s. à l'histoire de la ville de Pontarlier ; Besançon, I760, in-8.

159. FAVROT (J.). Histoire de Scey-en-Varais et du château Saint-Denis ; Besançon, 1890, in-8.

160. GATIN et BESSON (abbés). Histoire de la ville de Gray et de ses monuments. Nouvelle édition, revue et continuée par Ch. GODARD ; Gray, 1892, in-8. Cf. également GODARD (Ch.), Supplément à l'histoire de la ville de Gray et de ses monuments, Gray, 1909, in-8.

161. LOYE (C.-P.-A.). Souvenirs historiques suivis d'annales sur le village et la seigneurie de Rochejean ; Pontarlier, s. d., in-8.

162. LOYE (abbé L.). Histoire du comté de la Roche et de Saint-Hippolyte sa capitale ; Montbéliard, 1888, in-12.

163. - Histoire de la seigneurie de Neuchatel-Bourgogne ; Montbéliard, 1890, in-8.

164. LOYE (abbé, L.). Histoire de la baronnie de Belvoir ; Montbéliard, 1892, in-18. 
165. - Un coin des montagnes du Doubs : Laval et ses anciennes dépendances ; Montbéliard, 1894, in-18.

166. MEYNIER (J.). Essai historique sur Ornans (M. Soc. Doubs, 1889, p. 43107 ; 1890, p. 321-352 ; 1891, p. 273-344).

167. MONNIER. Histoire de la ville de Vesoul ; t. I, Besançon, 1909, in-8.

168. MOUTON (P.-D.). Histoire d'Autrey, de sa seigneurie et de ses dépendances ; Gray, 1868, in-8.

169. MUNIER (J.-B.). Recherches historiques sur les Foncines et le canton des Planches ; Salins, 1874, in-8.

170. NARBEY (abbé). Les hautes montagnes du Doubs.... depuis les temps celtiques ; Paris, 1868, in-8.

171. PERROD (M.). Lons-le-Saunier à travers les âges (M. Soc. Jura, 190304).

172. PERRON (Ch.). Broye-les-Pesmes (M. Soc. Doubs, 1888).

173. QUIQUEREZ (A.). Montjoie et les anciens châteaux du Clos du Doubs (M. Soc. Doubs, 1873).

174. RICHARD (abbé). Recherches historiques et statistiques sur l'ancienne seigneurie de Neuchatel au comté de Bourgogne ; Besançon, 1840, in-8.

175. - Monographie du bourg et de la terre de Maîche, suivie de notices historiques sur les anciennes seigneuries de la Franche-Montagne ; Besançon, 1862, in-8.

176. SAINT-MARC (C.). Tablettes historiques, biographiques et statistiques de la ville de Saint-Amour (M. Soc. Jura, 1868 , in-8).

177. THURIET (Ch.). Étude historique sur le bourg de Rougemont (M. Soc. Doubs, 1876).

178. TISSOT (J.). Les Fourgs, et accessoirement les environs. Les événements. Besançon, 1870, in-8. 
Abbayes, couvents, prieurés

179. BARTHELET (A.). Recherches historiques sur l'abbaye de Mont-SainteMarie et ses possessions et sur les prieurés de Romain-Mouthier ou de Vaux et de Saint-Point ; Pontarlier, 1858, in-12.

180. BARTHELET (A.). Histoire de l'abbaye de Montbenoît, du val du Saugeois et des anciennes seigneuries d'Arçon et de Lièvremont ; Besançon, 1853, in12.

181. BAUMONT (H.). Étude historique sur l'abbaye de Luxeuil ; Luxeuil, 1895, gr. in-8.

182. - De Luxoviensium abbatum potestate ; Nancy, 1894, in-8

183. BENOÎT (dom). Histoire de l'abbaye et de la terre de Saint-Claude; Montreuil-sur-Mer, 1890-92, 2 gr. in-8.

184. BERTHOD (dom). Dissertation sur l'origine et l'étendue des droits régaliens dans les abbayes de Saint-Claude, de Luxeuil et de Lure, 1761 (Doc. Hist. Fr.-C., t. VII, 1876).

185. BESSON (abbé). Mémoire sur l'abbaye de Baume ; Besançon, 1845, in8.

186. - Mémoire historique sur l'abbaye et la ville de Lure, suivi d'une note sur le prieuré de Saint-Antoine et les seigneuries de Lure et de Passavant ; Besançon, 1846, in-8.

187. - Mémoire historique sur l'abbaye de Cherlieu ; Besançon, 1847, in-8.

188. BLANCHOT (abbé). Histoire de Notre-Dame d'Acey ; Besançon, 1898, in-8.

189. [CHIFLET, Ph.]. Histoire du prieuré N.-D. de Bellefontaine au comté de Bourgogne ; Anvers, 1631, in-4.

190. FODÉRÉ (J.). Narration historique et topographique des couvents de l'ordre de Saint-François en la province de Saint-Bonaventure ; Lyon, 1619, in-4 
191. GATRIO (A.). Die Abtei Murbach im Elsass, nach den Quellen gearbeitet ; Strasbourg, 1894, 2 gr. in-8.

192. GAUTHIER (J.). Le prieuré de Marast (Hte-S.) et les dalles funéraires de sa chapelle (M. Acad. Besançon, 1876-77).

193. - Tombes et inscriptions de l'église abbatiale de Theuley (M. Soc. HteSaône, 1882).

194. - Les monuments de l'abbaye de Rosières (Jura) (M. Acad. Besançon, 1879-1880).

195. - L'église et les monuments de l'abbaye cistercienne d'Acey (ibid., 1896).

196. GINGINS-LA-SARRA (F. DE). Annales de l'abbaye du lac de Joux, depuis sa fondation jusqu'à sa suppression en 1530 (Doc. hist. Suisse Rom., t. I 3e livraison) ; Lausanne, 1842, in-8.

197. [GRAPPIN, dom]. Mémoires sur l'abbaye de Faverney qui contiennent en abrégé l'histoire de la ville, par un bénédictin de la congrégation de SaintVanne et de Saint-Hidulphe. Besançon, 1771, in-8.

198. PROST (B.). Notice historique sur l'abbaye de Rosières (Jura), de l'ordre de Cîteaux (B. Soc. Poligny, 1869).

199. Recueil historique sur l'origine de la vallée du lac de Joux, l'établissement de ses premiers habitants... avec un récit abrégé de quelques événements arrivés dans ce pays (Doc. hist. Suisse Rom., t. I, 2e livraison) ; Lausanne, 1840, in-8.

200. RICHARD (abbé). Histoire de l'abbaye de la Grâce-Dieu. Besançon, 1857, in-8.

201. SUCHET (J.-M.) et GAUTHIER (J.). L'abbaye du Mont-Sainte-Marie et ses monuments (M. Acad. Besançon, 1883)

202. TERRIER DE LORAY (Mis DE). L'abbaye de Migette (ibid.,1888). 


\section{Histoire ecclésiastique}

203. Acta synodi provincialis per continuationem in civitate bisuntina celebratœ, anno Domini 1572 ; Lyon, Fr. Dutelle, 1572, in-8.

204. BABEY. Intronisation de l'archevêque Claude de la Baume et publication du concile de Trente à Besançon (A. fr.-comtoises, 1866).

205. CASTAN (A.). Les évêques auxiliaires du siège de Besançon (M. Soc. Doubs, 1876).

206. - La première entrée des archevêques de Besançon, sous l'ancien régime (ibid., 1875)

207. DUNOD (F.-I.). Histoire de l'église, ville et diocèse de Besançon, qui comprend la suite des prélats de cette métropole depuis la fin du IIe siècle, leur vie et le gouvernement civil de Besançon ; Besançon, 1750, 2 in-4

208. FEBVRE (L.). L'application du Concile de Trente et l'excommunication pour dettes en Franche-Comté (R. H., t. CIII, p. 225-246 ; t. CIV, p. I-39, année 1910).

209. FLEURY-BERGIER. Les familiarités paroissiales en Franche-Comté avant 1789 (M. Acad. Besançon, 1888).

210. GAUTHIER (J.). Le Saint-Suaire de Besançon et ses pèlerins (M. Soc. Doubs, 1902).

211. Notes iconographiques sur les pèlerinages franc-comtois (M. Acad. Besançon, 1889).

212. HAURÉAU. Gallia Christiana in provincias ecclesiasticas distributa ; t. XV, Provincia Vesuntionensis ; Paris, 1860, in-fol.

213. JACQUENET. Histoire du séminaire de Besançon; t. I (seul paru), Reims, 1864, in-8.

214. LE PLAT (J.). Monumentorum ad historiam Concilii Tridentini potissimum illustrandam spectantium amplissima collectio. T. VII, pars prior, complec- 
tens monumenta Concilii in Belgio et Gallia admissionem et publicationem spectantia ; Louvain, 1787, in-4.

215. LOYE (abbé L.). Histoire de l'Église de Besançon ; t. I, II et III ; Besançon, 1901-1902, in-8.

216. MOREY (abbé). Notice historique sur les curés de campagne en Franche-Comté ; Besançon, in-8.

217. PERROD (M.). L'ancienne confrérie laïque de la Croix, d'Arbois (M. Soc. Jura, 1899).

218. RICHARD (abbé). Histoire des diocèses de Besançon et de SaintClaude ; t. I, II et III, Besançon, 1847-1851, in-8.

219. Statuta synodalia Ecclesiae Bisuntinae, cum brevibus quibusdam praeceptis doctrinae catholicae ad singulos titulos singulasque materias pro ratione argumentorum. adjunctis, ad simplicium clericorum institutionem; Lyon, G. Rouille, 1560, in-8 (Bibl. Besançon, 235861).

220. Statuta synodalia Bisuntinae Ecclesiae, metropol., cum. tractatibus summariis rerum quœ ad statuta ipsa pertinent ; Lyon, G. Rouille, 1575, in-8 (ibid., 235862).

221. SUCHET (J.-M.). Le pape et les chanoines de Besançon (A. Fr.Comtoises, 1870).

Réforme, hérésie, sorcellerie

222. BOGUET (H.). Discours des sorciers. Lyon, 1610, in-8.

223. CRESPIN (J.). Histoire des martyrs. Toulouse, 1889, 3 in-4.

224. CHENOT (Ch.). Notice historique sur l'introduction de la Réforme religieuse dans les trois seigneuries souveraines d'Héricourt, de Clémont, du Chatelot (M. Soc. Montbéliard, 1881).

225. COUSIN (G.). Epistolarum laconicarum atque selectarum farragines duae. Bâle, Oporin, 1554, in-16.

226. - Opera multifarii argumenti ; Bâle, Henri Petri, 1562, 3 t. en I vol. in-fol. 
227. DEY (A.). Histoire de la sorcellerie au comté de Bourgogne (M. Comm. Arch. Hse-Saône, t. II, Vesoul, s. d. [1860-61], in-8).

228. DUPARCHY. La justice criminelle dans la terre de Saint-Oyan de Joux, aujourd'hui Saint-Claude (M. Soc. Jura, 1891).

229. FEBVRE (L.). Un secrétaire d'Érasme : Gilbert Cousin et la Réforme en Franche-Comté (B. Soc. Hist. Protestantisme français, 1907).

230. - Notes et Documents sur la Réforme et l'Inquisition en Franche-Comté ; extraits des archives du Parlement de Dole ; Paris, 1911, in-8.

231. HAAG (Eug. et Em.). La France Protestante, Paris, 1847-1859, 10 vol. in-8. - Nouv. édit., p. p. H. Bordier, Paris, 1877-92, in-8 (inach.).

232. HERMINJARD. Correspondance des réformateurs dans les pays de langue française, Genève et Paris, 1866-1897, 9 vol. in-8.

233. LEA (H. Ch.). A history of the Inquisition of Spain ; New York, 190607,4 in-8.

234 - The inquisition in the Spanish dependencies ; ibid., 1908, in-8.

235. LOIX (J. DES). Speculum inquisitionis bisuntinae, ejus vicariis et officiariis exhibitum. Dole, Binart, 1628, in-8.

236. PROST (A.). Les sciences et les arts occultes au XVIe siècle : Corneille Agrippa, sa vie et ses oeuvres ; Paris, 1881-82, 2 in-8.

237. REUSCH (F.). Der Index des Verbotener Bûcher ; Bonn, 1883-85, 2 in8.

238. TISSOT (J.). Notice sur l'établissement et les statuts de l'inquisition en Franche-Comté (R. Soc. Sav., 1866).

239. VIÉNOT (J.). Histoire de la Réforme dans les pays de Montbéliard (M. Soc. Montbéliard, t. 27 et 28 ; Paris, 1901, 2 in-8). 
Histoire intellectuelle

A. - Ouvrages d'auteurs du XVIe siècle, Comtois ou ayant trait à la Comté

240. BOISSARD (J.-J.). Poemata ; Metz, 1589, in-8.

241. - Parnassus biceps, cum imaginibus Musarum ; Francfort, 1627, in-fol. (B. N., Inv. Rés., J 864).

242. CHASSIGNET (J.-B.). Le mespris de la vie et consolation contre la mort ; Besançon, N. de Moingesse, 1593, in-12.

243. CHIFLET (CI.). Claudi Chifletii, J. C. Sequani, eorum quaee de jure pars prior ; Lyon, J. J. Giunta, 1584, in-8 (Bibl. Besançon, 226 955).

244. CHIFLET (J.). Joannis Chiffletii... singulares ex curationibus quam cadaverum sectionibus observationes ; Paris, J. Richer, 1612, in-8.

245. Du MONIN (J. E.). Nouvelles oeuvres de Jean-Édouard du Monin (dédicace à Fr. de Vergy) ; Paris, J. Parant, s. d. [1581], in-12 (B. N., Inv. Rés., Ye 2053).

246. Du MOULIN. Opera, Paris, 1612, 3 in-fol.

247. FLORY (J.). Elégies ou déplorations sur le trespas de Monsieur Philibert de Rye, prince et evesque de Genève, et de très illustre seigneur René de Chalon..., avec celle du trespas de très vertueuse dame Antoyne de Montmartin ... ; Lyon, Zachée Quadier, 1556, in-8 (Bibl. Besançon, Cat. B.-L., 2948).

248. GILLEY (J. DE). In laudem Hannibalis e Livio expressam... commentariolus ; Bâle, Oporin, 1550, in-8 (B. N., Inv., J 14509).

249. G0LLUT (L.). Paroles mémorables de quelques grands personnages, entre lesquels sont plusieurs mots joyeux et rustiques ; Dole, Ant. Dominique, 1589, in-12 (Bibl. Besançon, Inv., 246512).

250. GUIOT (G.). Georgii Guioti Nozereni Ovantes odae ad cardinalem Granvellanum ; Lovanii, M. Verhasselt, 1562, in-4 (Bibl. Besançon, Inv., 1165). 
251. HERVET (G.). Gentiani Herveti Aurelii quaedam opuscula ; Lyon, Ét. Dolet, 1541, in-8 (Bibl. Besançon, cat. B. L. 5987).

252. JULYOT (F.). Les élégies de la belle fille lamentant sa virginité perdue ; Bâle, 1557, in-8.

253. LHERMITE (J.). Le passetemps, p. d'après le ms. original, t. 1, par Ch. Ruelens ; t. II, par E. Ouverleaux et J. Petit (Uitgaven der Antwerpsche Bibliophilen, XVII, XX). Anvers, 1890-96, 2 in-8.

254. LULLE (Ant.). Antoriii Lulli Balearis Progymnasmata rhetorica; Lyon, G. Rouille, 1572, in-8 (B. N., Inv., X. 17.887).

255. MONET (Ph.). Lubia, apud Burgundiones Sequanos fons mirabilis, s. 1. n. d. (cf. Bibl. de la Cie de Jésus, éd. Sommervogel, t. V, Col. 1207-1212) ; B. N., L,k 4162.

256. MORELOT (J.). Discours de M. Jean Morelot, docteur ès loix, juge en la régalie, aux excellents et magnifiques seigneurs les gouverneurs de la cité impériale de Besançon ; Besançon, J. Foillet, 1588, in-8 (Bibl. Besançon, Cat. BellesLettres, 2009).

257. - Jo. Moreloti Vesontini, J. C., Carmina ; Besançon, J. Exertier, 1589, in8 (id., ibid.).

258. MORISOT (J.). Colloquiorum libri IV ; Bâle, Oporin, 1550, in-8.

259. PONTOUX (CI. DE). Les œuvres de Claude de Pontoux, gentilhomme chalonnois, docteur en médecine ; Lyon, B. Rigaud, 1579, in-16 (B. N., Inv. Rés., Ye 1845).

260. POISSENOT (B.). Nouvelles histoires tragiques de Benigne Poissenot, licencié aux loix, ensemble une lettre à un ami contenant la description d'une merveille appelée la Froidière, veue par l'auteur en la Franche-Comté de Bourgogne ; Paris, G. Richon, 1586, in-8.

261. POISSENOT (Ph.). Belli sacri historia, libris XXIII comprehensa, primun... in lucem editum ; Bâle, N. Brylinger et J. Oporin, 1549, in-fol.

262. SAINT-MAURIS (J. DE). Utilissima simul ac doctissima repetitio legis unicae, c. quo loco mulier munera subire soleant ; Lyon, Seb. Gryphe, 1538, in-8 (Bibl. Besançon, 226878). 
263- - Restitutionis in integrum materia ad amussim excussa ; Paris, Poncet le Preux, 1548, in-4 (ibid., 226878).

264. - Sylvae quas vario carminum genere primani scholastici collegii Dolani, S. J., ... obtulerunt nobilissimo... D. de Vergy ; Dole, Ant. Dominique, 1592, petin-4 (ibid., cat. B. L. 1945).

265. WILLEMIN (J.). Discours sur le trespas de très ault et très illustre seigneur, feu messire Fr. de Vergy ; Dole, Ant. Dominique, 1592, pet. in-4.

B. - Écrivains et humanistes ; notices biographiques et bibliographiques

266. CASTAN (A.). Notice sur J. J. Boissard (Arch. histor., artist. et littér., t. I, Paris, 1889-90, in-8).

267. - Catalogue des incunables de la bibliothèque de Besançon ; Besançon, 1893, in-8.

268. CLERC (É.). Louis Gollut (M. Acad. Besançon, 1872-73).

269. DANTÈS. La Franche-Comté littéraire, scientifique et artistique ; Paris, 1879, in-12.

270. [GIROD, de Novillars]. Essai historique sur quelques gens de lettres nés dans le Comté de Bourgogne, avec une notice de leurs écrits ; Besançon, 1806, in8.

271. PICOT (É). Les Français italianisants au XVIe siècle ; t. I et Il, Paris, Champion, 1906-07, in-8.

272. SCHWARZ. Commentatio de vita G. Cognati Nozereni ; Altorfii, 1715, in-4 (B. N., Ln (27) 5077).

C. - Universités et Écoles 
273. BRUGI (B.) et ANDRICH (A.). Rotulus et matricula DD. Juristarum et Artistarum Gymnasii Patavini, annis 1592-93 ; Padoue, 1892, in-fol. (B. N., R 231).

274. BEAUNE (H.) et D'ARBAUMONT (J.). Les Universités de FrancheComté ; Dijon-Besançon, 1870, in-8.

275. BEAUNE (H.). Les écoliers et les professeurs à l'Université de Dole (A. Fr.-Comtoises, t. XIII).

276. CARDON (G.). La fondation de l'Université de Douai, Paris, 1892, in-8.

277. CASTAN (A.). Sully et le collège de Bourgogne à Paris (M. Soc. Doubs, 1869).

278. FEUVRIER (J.). Le collège de l'Arc à Dole (Dole, 1887, in-8).

279. - Un collège franc-comtois au XVIe siècle. - Étude historique et pédagogique ; Dole, 1889, in-8.

280. - Les collèges de Poligny avant la Révolution (M. Soc. Jura, 1898).

281. - L'ancien collège d'Arbois (M. Soc. Jura, 1899).

282. GODARD (Ch.). Histoire de l'ancien collège de Gray (1557-1792) ; Gray, 1887, in-8.

283. LABBEY DE BILLY (N. A.). Histoire de l'Université du Comté de Bourgogne et des différens sujets qui l'ont honorée ; t. I et II, Besançon, 1814, in4.

284. PERROD (M.). Écoles et collèges de Salins jusqu'en 1820 (A. Fr.Comtoises, 1899, in-8).

285. PIALAT (P.). Dumoulin à l'Université de Dole (1555-56) ; Dole, 1844, in-12.

286. PICOT (E.). Les matricules de l'Université de Ferrare (J. des S., 1902).

287. PIDOUX (P. A.). Notice historique sur le collège des orphelins de Broissia à Dole (M. Soc. Jura, 1903-04).

288. SAINT-MARC (C.). Notice sur l'histoire de l'instruction publique en Franche-Comté et plus particulièrement dans le Jura, depuis les temps les plus reculés (M. Soc. Jura, 1864). 
289. SUCHET (chanoine). Le collège de Granvelle à Besançon (M. Acad. Besançon, 1898).

290. DE TEULE (E.). Chronologie des docteurs en droit civil de l'Université d'Avignon, 1303-I79I ; Paris, 1887, in-8.

291. TOEPKE (G.). Die Matrikel der Universität Heidelberg von 1386 bis 1662 ; t. I, II et III, Heidelberg, 1884-93, in-8.

292. VILLEQUEZ. Les Écoles de droit en Franche-Comté et en Bourgogne (R. de législation, 1872-74).

Besançon

293. CADIX (M.). Essai historique sur la réforme à Besançon au XXIe s. ; Moutauban, 1905, in-8.

294. CASTAN (A.). Origines de la Commune de Besançon (M. Soc. Doubs, 1858).

295. - Les variations du régime municipal à Besançon (ibid., 1866).

296. - Charles-Quint et sa statue à Besançon (ibid., 1867)

297. - Les sceaux de la commune, l'hôtel de ville et le palais de justice de Besançon (ibid., 1870-71).

298. - Granvelle et le petit empereur de Besançon (R. H., t. I, 1876 ; M. Soc. Doubs, 1905, vol. 9).

299. - Consultation de Cujas sur l'organisation de l'enseignement du droit à Besançon en 1580 (M. Soc. Doubs, 1877).

300. - L'architecteur Hugues Sambin (ibid., 1890).

301. - La rivalité des familles de Rye et de Granvelle au sujet de l'archevêché de Besançon (ibid., 1891).

302. - Notes sur l'histoire municipale de Besançon ; Besançon, 1898, in-8.

303. - Besançon et ses environs ; nouvelle édition, complétée et mise à jour par L. Pingaud ; Besançon, 1901, in-8. 
304. CHIFLET (J.-J.). Vesontio, civitas imperialis libera Sequanorum metropolis, illustres. Lyon, 1618, in-4.

305. Chroniques bisontines du XVIe siècle, p. dans le t. VII des Doc. Hist. Fr.-C.

306, GROSRENAUD (F.). La corporation ouvrière à Besançon, XVIe-XVIIe s. (Coll. d'études sur l'histoire du droit et des institutions de la Bourgogne) ; Dijon, 1907, in-8.

307. MOLINES (E.). La juridiction des gouverneurs de Lyon (id.) ; Dijon, 1907 , in-8.

308. ORIVAL (Cl. Fr. D'). Commentaires sur les usages et coutumes de Besançon ; Besançon, 1721, in-4.

309. PINET (A. Du). Conformité des églises réformées de France et de l'église primitive ; Lyon, 1564, in-12.

310. ROBERT (U.). L'enseignement à Besançon jusqu'à la fin du - XVIe siècle ; Besançon, 1899, in-8.

311. TOURNIER (abbé). La crise huguenote à Besançon au XVIe siècle ; Besançon, 1909, in-8.

312. VIÉNOT (J.). Origine de la Réforme à Besançon, 1520-1534 (Et. de théologie et d'histoire p. p. les professeurs de la Faculté de théologie protestante de Paris) ; Paris, 1901, in-8.

Histoire diplomatique et militaire ; relations avec les pays voisins

313. Amtliche Sammlung der ä1tern Eidgenossischen Abschiede, hgg. auf Anordnung der Bundesbehôrden ; t. II, 1421-1477, Lucerne, 1863, in-4 ; t. III, Ire partie, 1478-1499, Zurich, 1858, in-4 ; t. III, 2e partie, 1500-1520, Lucerne, 1869, in-4.

314. Catalogue des Actes de François Ier, p. p. l'Académie des Sciences morales ; Paris, 1887-1908, 10 vol. in-4. 
315. [CHIFLET, J.-J.]. Recueil des traittez de paix, trêves et neutralité entre les couronnes d'Espagne et de France depuis le traité de Madrid en 1526 jusqu'en 1611 ; Anvers, 3e édition, 1644, in-8.

316. Du MONT. Corps universel diplomatique du droit des gens ; Amsterdam et La Haye, 1726-1731, 8 vol. in-fol.

317. AUMALE (duc D'). Histoire des princes de Condé pendant les XVIe et XVIIe siècles, t. I et II, Paris, 1863-64, 2 Vol. in-8.

318. DELABORDE (J.). Gaspard de Coligny ; Paris, 1882, 3 in-8.

319. DUTRUY (P.). Études sur les contestations de limites et les traités de neutralité entre la Franche-Comté et les terres françaises de Champagne et de Bourgogne, jusqu'aux abords de 1612-1614 (Posit. Éc. Chartes, 1907).

320. DUVERNOY (Ch.). Esquisse des relations qui ont existé entre le Comté de Bourgogne et l'Helvétie, du XIe au XIIe s .; Neuchatel, 1841, in-8.

321. FINOT (J.). Étude de géographie historique sur la Saône, ses principaux affluents et le rôle qu'elle a joué comme frontière dans l'antiquité et au moyen âge (B. Soc. Haute-Saône, 1877).

322. - La Saône considérée comme frontière naturelle (M. Soc. Doubs, 1877).

323. FLEURY. Franc-Comtois et Suisses ; Besançon, 1841, in-8.

324. GAUTHIER (J.) et FEUVRIER (J.). Les fortifications de Dole (C. R. du 58e Congrès archéologique de France ; Caen, 1894, in-8).

325. GINGINS-LA-SARRA (F. DE). Recherches historiques sur les acquisitions des sires de Montfaucon et de la maison de Chalon dans le pays de Vaud (Doc. hist. Suisse Rom., t. XIV ; Lausanne, 1857, in-8.)

326. GRAPPIN (dom). Mémoires historiques sur les guerres du XVIe s. dans le comté de Bourgogne ; Besançon, 1788, in-8.

327. GUICHENON (S.). Histoire de Bresse et de Bugey ; Lyon, 1650, in-fol.

328. HEYD (W.). Ulrich, Herzog zu Wüttemberg. Tubingen, 1841-43, 3 in-8

329. LINOTTE (A.). La Franche-Comté et ses voisins, XVIe-XVIIIe s. (B. Soc. Grayloise, 1900). 
330. MAAG (R.). Die Freigrafschaft Burgund und ihre Beziehungen zu der schweizerischen Eidgenossenschaft, vorn Tode Karls des Kühnen bis zum Frieden von Nymwegen, 1477-1678 (Université de Zürich ; Dissertat. inaugurale) ; Zurich, 1891, in-8.

331. MANDROT (B. DE). Relations de Charles VII et Louis XI avec les Cantons suisses, 1444-1493 (Jahrbuch für Schweiz. Geschichte, t. V et VI) ; ParisZurich, 1881, in-8.

332. [PALLUD DE MONTMIREY]. Conspiration contre Dole... en 1543 par les Français... p. p. un paléographe dolois ; Dole, 1850, in-8.

333. PIÉPAPE (L. DE). Histoire de la réunion de la Franche-Comté à la France ; événements diplomatiques et militaires (1279-1678) ; Paris, 1881, 2 in-8.

334. PFULB (Fr. J.). Bollwiller et ses seigneurs (R. Catholique d'Alsace, t. XIX, 1900, in-8).

335. PINGAUD (L.). Les Saulx-Tavanes ; études sur l'ancienne société française ; Paris, 1876, in-8.

336. PLANCHER (dom). Histoire générale et particulière de Bourgogne ; Dijon, 1739-1781, 4 in-fol.

337. PRINET (M.). François Ier et le comté de Bourgogne (B. Acad. Besançon, 1908).

338. QUIQUEREZ (A.). Histoire des comtes de Ferrette ; Montbéliard, 1863, in-8.

339. ROTT (E.). Histoire de la représentation diplomatique de la France auprès des Cantons Suisses, de leurs alliés et de leurs confédérés ; t. I, 1430-1559 ; t. II, 1559-1610 ; Berne-Paris, 1900-02, 2 in-4.

340. STOUFF (L.). Le pouvoir temporel et le régime municipal dans un évêché de l'Empire germanique jusqu'à la Réforme ; Paris, 1896, 2 in-8.

341. - Les possessions bourguignonnes dans la vallée du Rhin sous Charles le Téméraire (Annales de l'Est, 1904).

342. - Les origines de l'annexion de la Haute-Alsace à la Bourgogne en 1469 (R. Bourguignonne, 1900). 
343. SCHWEIZER (P.). Geschichte der schweizerischen Neutralität ; Erster Halbband, Frauenfeld, 1893, in-8.

344. TISSOT (J.). Mémoire sur une question de frontière entre la FrancheComté et la Suisse (Com. Trav. Hist., Mém. lus à la Sorbonne, 1867).

345. TUEFFERD (P. E.). Histoire des comtes souverains de Montbéliard d'après les documents authentiques ; Montbéliard, 1877, in-8.

346. WITTE (H.). Zur Geschichte der Enstehung der Burgunder Kriege ; Herzog Sigismunds Beziehungen zu den Eidgenossen und zu Karl dem Kühnen ; Haguenau, 1885, in-4.

La Comté, l'Espagne et les Pays-Bas

A. - Ouvrages généraux

347. ALEXANDRE (P.). Histoire du Conseil privé dans les anciens Pays-Bas (M. Acad. Belgique, t. LII ; Bruxelles, 1895, in-8).

348. Biographie nationale belge, p. p. l'Académie Royale... de Belgique; Bruxelles, 1866 et suiv., in-8.

349. GACHARD (L. P.). Rapport à M. le ministre de l'Intérieur sur différentes séries de documents concernant l'histoire de la Belgique, qui sont conservées dans les Archives de l'ancienne Chambre des Comptes à Lille. Bruxelles, 1841, in-8.

350. - Rapport à M. le ministre de l'Intérieur sur les documents concernant l'histoire de la Belgique qui existent dans les dépôts littéraires de Paris et de Dijon ; première partie, Archives de Dijon. Bruxelles, 1843, in-8.

351. - Relations des ambassadeurs vénitiens sous Charles-Quint et Philippe II ; Bruxelles, 1855, in-8.

352. - Les bibliothèques de Madrid et de l'Escurial ; notices et extraits des manuscrits qui concernent l'histoire de Belgique. Bruxelles, 1875, in-4.

353. - La Bibliothèque Nationale à Paris ; notices et extraits des manuscrits qui concernent l'histoire de Belgique. Bruxelles, t. I et Il, 1875-77, 2 in-4. 
354. HUBERT (E.). Étude sur la condition des protestants en Belgique depuis Charles-Quint jusqu'à Joseph Il ; Bruxelles, 1882, in-8 (Université de Liège, dissertat. inaugurale).

355. PIRENNE (H.). Histoire de Belgique ; t. Il et III, Bruxelles, 1905-07, in8.

356. RACHFAHL (F.). Die Trennung der Niederlanden vom Deutschen Reiche (Westdeutsche Zeitschrift, 1900).

357. Recueil des Ordonnances des Pays-Bas. Deuxième série. T. I, 1506-19, p. Ch. Laurent, Bruxelles, 1893 ; t. II, 1519-29, p. Ch.-L. et J. Lameere, 1898 ; t. III, I529-36, p. J. L., 1902 ; t. IV, 1536-43, p. J. L. et H. Simont, 1907 ; 4 in-fol.

358. TURBA (G.). Geschichte des Thronfolgerechtes in allen habsburgischen Ländern ; Vienne, 1903, in-8.

359. WALTHER (A.). Die burgundischen Zentralbehôrden unter Maximilian I und Karl V ; Leipzig, 1909, in-8.

B. - Ouvrages relatifs à une période. -

Première période : Maximilien, Marguerite d'Autriche, Charles-Quint

a) Documents

360. CHARLES-QUINT. Correspondance de - et d'Adrien VI, p. p. Gachard ; Bruxelles, 1859, in-8.

361. FRANÇOIS II. Négociations, lettres et papiers divers, relatifs au règne de -, tirés du portefeuille de Séb. de Laubespine par L. Paris ; Paris, 1841, in-8.

362. MARGUERITE D'AUTRICHE. Correspondance sur les affaires des Pays-Bas, p. p. Ph. Van den Bergh ; Leyde, 1845-47, 2 in-8.

363. MAXIMILIEN. Correspondance de l'Empereur - et de Marguerite d'Autriche, I507-15I9, p. p. Le Glay (Public. Soc. Hist. France) ; t. I et II, Paris, 1839, in-8. 
364. - Lettres inédites sur les affaires des Pays-Bas, p. p. Gachard (B. Comm. Hist. belge). Bruxelles, 1851-52, 2 in-8.

365. Négociations diplomatiques entre la France et l'Autriche durant les trente premières années du XVIe siècle, p. p. Le Glay (Doc. Hist. France) ; t. I et II, Paris, 1845, 2 in-4.

366. VANDENESSE (J. DE). Journal des voyages de Charles-Quint de 1514 à 1551, p. p. Gachard, dans Collection des Voyages des souverains des Pays-Bas, t. II ; Bruxelles (Chron. belges), 1874, in-4.

361. VITAL (L.). Relation du premier voyage de Charles-Quint en Espagne, p. p. Gachard et Piot ; ibid., t. III, Bruxelles, 1881, in-4.

\section{b) OUVRAGES}

368. BUCHOLTZ (F. B. VON). Geschichte der Regierung Ferdinand des Ersten ; Vienne, 1831-1838, 9 in-8.

369. CASTAN (A.). La conquête de Tunis en 1535, racontée par deux écrivains franc-comtois, Ant. Perrenin et Guill. de Montoiche (M. Soc. Doubs, 1890).

370. GACHARD (L. P.). Retraite et mort de Charles-Quint au monastère de Yuste; Introduction, t. I et t. II, Bruxelles, 1854-55, 3 in-8 (publ. Comm. roy. Hist. belge).

371. GOSSART (E.). Charles-Quint et Philippe II (Mém. couronnés et autres mém. p. p. l'Acad. royale de Belgique, t. LIV ; Bruxelles, 1896, in-8).

372. - Notes p. s. à l'histoire du règne de Charles-Quint (ibid., t. LV ; Bruxelles, 1897).

373. - Charles-Quint roi d'Espagne ; Bruxelles, 1910, in-8.

374. HENNE (A.). Histoire du règne de Charles-Quint en Belgique ; Bruxelles-Leipzig, 1858-60, 10 in-8.

375. JUSTE (Th.). Histoire de Marie de Hongrie ; Bruxelles, 1855, in-8.

376. - Charles-Quint et Marguerite d'Autriche (Mém. couronnés et autres mém. p. p. l'Acad. royale de Belgique, Bruxelles, 1858, in-8). 
377. KOOPERBERG (L. M. G.). Margaretha van Oostenrijk, Landvoogdes der Nederlanden, tot den vrede van Kamerijk (1508) ; Amsterdam, 1908, in-8.

378. KREITEN (H.). Untersuchungen über den Briefwechsel Kaiser Maximilians I mit seiner Tochter Margareta ; Vienne, 1907, in-8 [c. r. crit. de A. Walther, Gottingische gel. Anzeiger, 1908, n 4. p. 253-286].

379. MÜNCH (E.). Maria von Burgund ; Leipzig, 1832, 2 in-8.

380. QUINSONAS (E. DE). Matériaux p. s. à l'histoire de Marguerite d'Autriche ; Paris, 1860, 3 in-8.

381. RAUSCH (K.). Die Burgundische Heirat Maximilians I ; Vienne, 1880, in-8.

382. ROBERT (U.). Philibert de Chalon, prince d'Orange, vice-roi de Naples (1502-1530) ; Paris, t. I et II, 1902, in-8.

383. SANDRET (L.). Philibert de Chalon, prince d'Orange ; Paris, 1889, in-8.

C. - Première période : Philippe II

\section{a) DOCUMENTS}

384. Actes des États généraux des Pays-Bas, 1576-1585, p. p. Gachard. T. I, 1576-78 ; t. II, 1578-80 ; Bruxelles, 1861-66, 2 in-8.

385. CATHERINE DE MÉDICIS. Lettres de -, p. p. H. de la Ferrière ; t. I-IV, Paris, 1880-91, in-4 (Doc. Hist. France).

386. DEL RIO (M. A.). Mémoires sur les troubles des Pays-Bas durant l'administration de don Juan d'Autriche ; éd. Delvigne, Bruxelles, 1869-71, 3 in-8.

387- GUILLAUME DE NASSAU. Correspondance de -, p. p. Gachard ; Bruxelles, 1847-1866, 6 in-8.

388. GUYON (F. DE). Mémoires, p. p. A. P. L. de Robaulx de Soumoy; Bruxelles, 1858, n-8 (M. Hist. belge). 
389. HOPPERUS. Epistolœ ad Viglium, p. p. M. de Nélis ; Utrecht, 1802, in4.

390. - Recueil et Mémorial des troubles des Pays-Bas, 1559-1566 ; éd. par Alph. Wauters dans : Mémoires de Viglius et d'Hopperus, Bruxelles, 1858, in-8 (M. Hist. belge). - Continuation par R. Fruin, dans : Bijdragen en Mededeelingen van het hist. genootschap te Utrecht, t. XIII, 1891.

391. JEAN-CASIMIR. Briefe des Pfalzgrafen Johann-Casimir, mit verwandten Schriftsstücken, p. p. Fr. von Bezold. T. I, 1576-82 ; t. II, 1582-86 ; t. III, 1587-92 ; Münich, 1882-84-1903, 3 in-8.

392. LA HUGUERIE (M. DE). Mémoires, p. p. A. de Ruble ; t. I, II et III, Paris, 1877-78-80, in-8 (Public. Soc. Hist. France).

393. MARGUERITE D'AUTRICHE, duchesse de Parme. Correspondance de - avec Philippe II, suivie des interrogatoires du comte d'Egmont, p. p. le baron de Reiffenberg ; Bruxelles, 1842, gr. in-8 (Public. Soc. Bibliophiles de Belgique).

394. - Correspondance de - avec Philippe II, 1559-1565, p. p. Gachard; Bruxelles, 1867-1881. 3 in-4.

395. ORANGE-NASSAU. Archives ou Correspondance inédite de la maison d'-, p. p. Groen van Prinsterer ; première série, 1552-1581, t. I-VIII, Leyde, 18351847, in-8.

396. PONTUS-PAYEN. Mémoires de -, p. p. Al. Henne ; Bruxelles, 1860-6I, 2 in-8.

397. PERRENOT (ANTOINE, Cardinal de Granvelle). Papiers d'État, p. p. Ch. Weiss ; Paris, 1841-1852, 9 in-4

398. - Lettres inédites (1582-83), p. p. Junca (M. Soc. Jura, 1864).

399. - Correspondance, p. p. E. Poullet et Ch. Piot ; Bruxelles (Chron. belges), 1877-1888, I0 in-4.

400. - Lettere di Antonio Perrenot di Granuela, vescovo d'Arras e poi Cardinale, al duca di Savoia Emanuele-Filiberto, p. da E. Ricotti ; Turin, 1880, in-8 (extr. de Miscellanea di Storia Italiana, série II, t. IV).

401. PERRENOT (FRÉDÉRIC, de Champagney). Recueils d'Arétophile, contenans par quels moyens les gens de guerre espaignols, ammenez ès Pays-Bas 
par le duc d'Alve s'estans mutinez... entrèrent en Anvers le XXVI d'avril XVe LXXIIII ... ; Lyon, Nie. Guérin, 1578, pet. in-4.

402. - Mémoires, 1513-1590, p. p. A. L. P. de Robaulx de Soumoy ; Bruxelles, 1860, in-8 (M. Hist. Belg.).

403. PHILIPPE IL Correspondance sur les affaires des Pays-Bas, p. p. Gachard ; Bruxelles-Gand-Leipzig, 1848-1879, 5 in-4.

404. - Correspondance avec le duc d'Albe relative aux Pays-Bas (Documentos relativos a los Paises Bajos, 17 avril 1567-26 décembre 1569) p. dans Doc. Hist. Espana, t. XXXVII et XXXVIII, Madrid, 1860-61, 2 in-8.

405. - Correspondencia con los hermanos don Luis de Requesens y don Juan de Zùniga ; Doc. Hist. Espana, t. CII, Madrid, 1892, in-8 ; cont. dans Nueva Collection de Doc. Hist. Espana, p. p. don Fr. de Zabàlburu y don José Sancho Rayon, t. I-V, Madrid, 1892-95, in-8.

406. RACHFAHL (F.). Le registre de Franciscus Linaldius, trésorier général de l'armée espagnole aux Pays-Bas (1567-1576) ; Bruxelles, 1902, in-8.

407. Résolutions des États généraux des Pays-Bas, p. p. de Jonge (J. C.) ; t. I et II, La Haye, 1827-31, 2 in-4.

408. SAULX-TAVANES. Correspondance des - au XVIe siècle, p. p. L. Pingaud ; Paris, Champion, 1877, in-8.

409. Sommier discours des justes causes et raison qu'ont constrainct les Estats généraulx des Païs-Bas de pourveoir à leur deffence contre le seigneur don Jehan d'Austrice ; Anvers, Guill. Sylvius, 1577, in-8.

410. Subtilz Moyens (les), par le cardinal de Granvelle avec ses complices inventez pour instituer l'Inquisition ; p. p. Ch. Rahlenbeck; Bruxelles, 1866, in-8 (M. Hist. Belg.).

411. VANDENESSE (J. DE). Journal des Voyages de Philippe Il de 1554 à 1569, p. p. Gachard, et suivi de correspondances diplomatiques et d'actes officiels concernant le mariage entre Philippe, prince d'Espagne, et Marie, reine d'Angleterre (Coll. Voyages des Souverains des Pays-Bas, t. IV, Bruxelles, 1882, in-4.)

412. VARAMON (Mis DE). Mémoires sur le -, p. p. J. Borgnet ; Bruxelles, 1873, in-8 (M. Hist. Belg.). 
413. Viglius. Vita Viglii ab ipso scripta, p. p. C. P. Hoynck Van Papendrecht, dans Analecta Belgica, t. I, pars I ; La Haye, 1743, in-4.

414. - Epistolœ politicae et historicae ad Joachimum Hopperum. (id., ibid., t. I, p. II).

415. - Epistolœ selectœ ad diversos (id., ibid., t. II, p. 1).

416. - Discours sur le règne de Philippe II, suivi de : La source et commencement des troubles suscitez aux Pays-Bas (1563-1573) p. p. Wauters (Alph.), dans Mémoires de Viglius et d'Hopperus ; Bruxelles, 1858, in-8 (M. Hist. belge).

\section{b) OUVRAGES}

417. BARADO Y FONT (Fr.). Don Luis de Requesens y la politica espanola en los Paises Bajos ; Madrid, 1906, in-4.

418. GACHARD (L. P.). Notice sur le Conseil des troubles (B. Acad. Belg., t. $\mathrm{XVI})$.

419. - Emmanuel-Philibert ; Bruxelles, 1855, in-8 (à la suite de : Relations des ambassadeurs vénitiens, $n^{\circ} 351$ )

420. - Inventaire des papiers laissés par le cardinal de Granvelle à Madrid en 1586 et inventaire des archives trouvées au Palais de Granvelle à Besançon en 1607 ; Bruxelles, 1862, in-8 (B. Comm. Hist. belge, 3e série, t. IV, 1863)

421. GOSSART (E.). Projets d'érection des Pays-Bas en royaume sous Philippe II ; Bruxelles, 1900, in-8 (B. Acad. Belg., nouv. série, t. II).

422. - Espagnols et Flamands au XVIe siècle ; l'Établissement du régime espagnol dans les Pays-Bas et l'insurrection ; Bruxelles, 1905, in-8.

423. - Id. La Domination espagnole dans les Pays-Bas à la fin du règne de Philippe Il ; Bruxelles, 1906, in-8.

424. HOLTZMANN (R.). Kaiser Maximilian II, bis zu seiner Thronbesteigung, 1527-1564 ; Berlin, 1903, in-8.

425. LONCHAY (H.). Étude sur les emprunts des souverains belges au XVIe et au XVIIe s. ; Bruxelles, 1907, in-8. 
426. MARX (E.). Studien zur Geschichte des Niederlândischen Aufstandes ; Leipzig, 1902, in-8 (Leipziger Studien aus dem Gebiet der Geschichte, hgg. von G. Buchholz, K. Lamprecht, E. Marcks, G. Seeliger ; III Bd., 2 Heft).

427. PHILIPPSON (M.). Philipp II von Spanien und das Papstthum (Histor. Ztschr., hgg. von H. von Sybel, 2e série, t. III, Munich, 1878, in-8).

428. - Ein Ministerium unter Philipp II ; Berlin, 1895, in-8.

429. RACHFAHL (F.). Margaretha von Parma ; Munich, 1898, in-8.

430. - Wilhelm von Oranien und der niederlândische Aufstand ; t. I et Il, Halle, 1906-07-08, 3 in-8.

431. TURBA (G.). Beiträge zur Gesch. der Habsburger, I-III, Vienne, 18981901 (Extr. de l'Archiv für ôsterreichische Geschichte, t. 86 et 90).

\section{NOTE RELATIVE AUX DATES}

Dans les textes comtois du XVIe s., jusqu'en 1575, l'année se prend généralement à partir de Pâques. C'est le 2o décembre 1574 que le Parlement de Dole, sur remontrances faites par les États « des contentions, difficultez, ambiguitez et inconvéniens qu'amenait l'usage de compter le miliaire en aucuns lieux dèz le Ier de janvier, en aultres dèz la Nativité et plus fréquentement dèz le jour de Fête Résurrection N. S., qu'est mobile », ordonna que «dioresenavant, le commencement de l'année se prendra et comptera par tout ced. pais et en tous cas et actes... à chacun Ier jour de janvier » (Parlem., B 1075, Arrêts, fol. $16 v^{\circ}$ ). - Dans nos citations de textes antérieurs à 1575, nous avons toujours indiqué, pour éviter les causes d'erreur, la date corrigée à côté de la date relevée.

\section{Fin du texte}

